
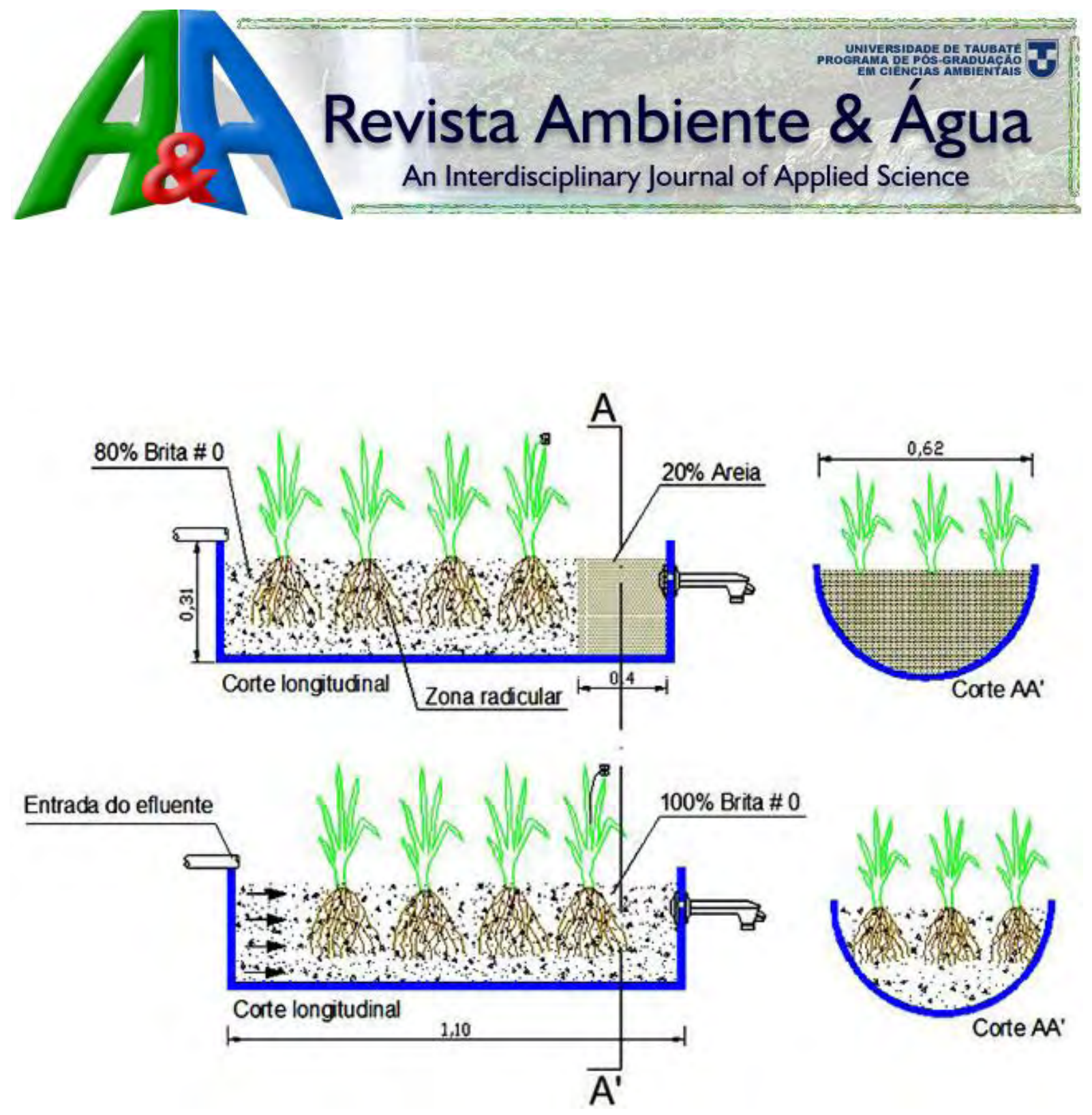

ISSN = 1980-993X (Online)

www.ambi-agua.net

Edição 19 da Revista Ambiente \& Água - An Interdisciplinary Journal of Applied Science, Taubaté, v. 7, n. 2, p. 1-290, Agosto 2012. (doi:10.4136/ambi-agua.v7.n2) 


\section{EDITORIAL BOARD}

\section{Editor}

\section{Getulio Teixeira Batista}

Instituto de Pesquisas Ambientais em Bacias Hidrográficas (IPABHi), Brasil

\section{Associate Editors}

Amaury Paulo de Souza

Universidade Federal de Viçosa (UFV), Brasil

\section{Antonio Evaldo Klar}

Universidade Estadual Paulista Júlio de Mesquita Filho, UNESP, Brasil

Dar Roberts

Universityof Califórnia at Santa Barbara, US

Hans Raj Gheyi

Universidade Federal de Campina Grande (UFCG), Brasil

\section{Hélio Nóbile Diniz}

Instituto Geológico, Secretaria do Meio Ambiente do Estado de São Paulo (IG/SMA), Brasil

\section{João Vianei Soares}

Instituto Nacional de Pesquisas Espaciais (INPE), Brasil

\section{Editorial Section}

Portuguese Text Editor

Text (EN e ES) Editors

Reference Editor

Layout Editors

Technical Support
Luis A. Bartolucci

Florida International University (FIU), EUA

Marcelo dos Santos Targa

Universidade de Taubaté (UNITAU), Brasil

Nelson Wellausen Dias

Universidade de Taubaté (UNITAU), Brasil

Paul W. Mausel

Indiana State University (ISU), EUA

Paulo Renato Schneider

Universidade Federal de Santa Maria (UFSM), Brasil

\section{Sebastião do Amaral Machado}

Universidade Federal do Paraná (UFPR), Brasil

Silvio Jorge Coelho Simões

Universidade Estadual Paulista Júlio de Mesquita Filho (UNESP), Brasil

Yosio Edemir Shimabukuro

Instituto Nacional de Pesquisas Espaciais (INPE), Brasil

Nelson Wellausen Dias, PPGCA, UNITAU, IBGE, BR

Maria de Jesus Ferreira Aires, GELP, UNITAU, BR

Getulio T. Batista, UNITAU \& Nelson W. Dias IBGE, BR

Liliane Castro, Biblioteca ECA/Civil, UNITAU, BR

Vera L. F. Batista, IPABHi \& Getulio T. Batista, UNITAU, BR

Tiago dos Santos Agostinho, LAGEO, UNITAU, BR

Library catalog entry by

SIBi - Sistema Integrado de Bibliotecas / UNITAU

Revista Ambiente \& Água - An Interdisciplinary Journal of

Applied Science / Instituto de Pesquisas Ambientais em

Bacias Hidrográficas. Taubaté. v. 7, n. 2 (2006)-

Taubaté: IPABHi, 2012.

Quadrimestral

ISSN 1980-993X.

1. Ciências ambientais. 2. Recursos hídricos. I. Instituto de Pesquisas Ambientais em Bacias Hidrográficas. III. Título.

$$
\begin{aligned}
& \text { CDD - 333.705 } \\
& \text { CDU - (03)556.18 }
\end{aligned}
$$




\section{ÍNDICE}

\section{CAPA}

Planta da configuração dos SAC(s) em "bombonas" de PEAD, utilizados na pesquisa (unidades em m).

Fonte: MENDONÇA, H. V.; RIBEIRO, C. B. M.; BORGES, A. C.; BASTOS, R. R. Remoção de nitrogênio e fósforo de águas residuárias de laticínios por sistemas alagados construídos operando em bateladas. AmbiAgua, Taubaté, v. 7, n. 2, p. 75-87, 2012. (http://dx.doi.org/10.4136/ambi-agua.805)

\section{EDITORIAL}

Editorial of the nineteenth edition of Ambiente \& Água - An Interdisciplinary Journal of Applied Science (http://dx.doi.org/10.4136/ambi-agua.952)

Getulio Teixeira Batista

\section{ARTIGOS}

Climate change scenarios and their impact on the water balance of sugarcane production areas in the State of São Paulo, Brazil (http://dx.doi.org/10.4136/ambi-agua.907)

Dayana L. dos Santos; Paulo C. Sentelhas

Effect of the bentonite application on the cadmium mobility in an Argisol (http://dx.doi.org/10.4136/ambi-agua.901)

Gilvanise Alves Tito; Lúcia Helena Garófalo Chaves; Hugo Orlando Carvallo Guerra

Antimicrobial resistance profiles of diarrheagenic Escherichia coli strains isolated from bathing waters of the Lajeado reservoir in Tocantins, Brazil

(http://dx.doi.org/10.4136/ambi-agua.756)

Kleverson Wessel de Oliveira; Fátima de Cássia Oliveira Gomes; Guilherme Benko; Raphael

Sanzio Pimenta; Paula Prazeres Magalhães; Edilberto Nogueira Mendes; Paula Benevides de

Morais

Microbiological analysis of drinking water quality of Ananthanar channel of Kanyakumari district, Tamil Nadu, India (http://dx.doi.org/10.4136/ambi-agua.881)

Raju Mary Antony; Ferdinand Brisca Renuga

Atributos microbianos do solo fertilizado com composto de lodo de esgoto (http://dx.doi.org/10.4136/ambi-agua.915)

Ericléia Büerg Suszek; Paulo Fortes Neto; Nara Lúcia Perondi Fortes; Eliana Maria de Araújo

Mariano da Silva; Fabiana Brambatti; Claudio Roberto Silva; Dimas Donizeti Patrocinio

Desempenho de sistema decanto-digestor com filtro biológico seguido por alagado construído e reator solar no tratamento de esgoto doméstico (http://dx.doi.org/10.4136/ambiagua.723)

Glícia Pinto Barra Reinaldo; Rafael Oliveira Batista; Paulo Cesar Moura da Silva; Luis

Cesar de Aquino Lemos Filho; Miguel Ferreira Neto; Delfran Batista dos Santos

Remoção de nitrogênio e fósforo de águas residuárias de laticínios por sistemas alagados construídos operando em bateladas (http://dx.doi.org/10.4136/ambi-agua.805)

Henrique Vieira de Mendonça; Celso Bandeira de Melo Ribeiro; Alisson Carraro Borges; Ronaldo Rocha Bastos

Variáveis no processo de coagulação /floculação/decantação de lixiviados de aterros sanitários urbanos (http://dx.doi.org/10.4136/ambi-agua.861)

Victor Fernandes Bezerra Mello; Juliana Prazeres da Gama Abreu; Joelma Morais Ferreira; José Fernando Thomé Jucá; Maurício A. da Motta Sobrinho 
Influência da temperatura na remoção de fosfato por microalgas em biorreatores heterotróficos (http://dx.doi.org/10.4136/ambi-agua.856)

Juliana Guerra Vieira; Eduardo Jacob-Lopes; Adriana Gonçalves da Silva Manetti; Maria Isabel

$101-109$ Queiroz

Avaliação da poluição doméstica fluvial na zona urbana do município de Piracicaba, SP, Brasil (http://dx.doi.org/10.4136/ambi-agua.846)

Jefferson Mortatti; Diego Vendramini; Helder de Oliveira

Urbanização e escoamento superficial na bacia hidrográfica do Igarapé Tucunduba, Belém, PA, Brasil (http://dx.doi.org/10.4136/ambi-agua.905)

Marcelo dos Santos Targa; Getulio Teixeira Batista; Hélio Nóbile Diniz Nelson Wellausen Dias; Fernando Cardoso de Matos

Caracterização hidrogeológica e hidroquímica do aquífero livre localizado no manto de alteração da Formação Serra Geral, na bacia hidrográfica Taquari-Antas, região nordeste do estado do Rio Grande do Sul (http://dx.doi.org/10.4136/ambi-agua.903)

Pedro Antonio Roehe Reginato; Siclério Ahlert; Karoline Chiaradia Gilioli; Gisele Cemin

Modelagem do fluxo de contaminantes em aquífero freático na área do cemitério Bom Jardim, Fortaleza, CE, Brasil (http://dx.doi.org/10.4136/ambi-agua.917)

Mauro César de Brito Sousa Marco Aurélio Holanda de Castro; David Lopes de Castro; Mariano da Franca Alencar Neto; Bruno Leonardy Sousa Lopes

Interpolação geoespacial da evapotranspiração de referência (ETo) em regiões com escassez de dados: estudo de caso no Sul de Minas Gerais, Brasil (http://dx.doi.org/10.4136/ambiagua.763)

Mateus Ricardo Nogueira Vilanova; Silvio J. C. Simões; Isabel C. B. Trannin

Modelagem para integração de dados sobre macrobentos em Infraestrutura de Dados Espaciais (http://dx.doi.org/10.4136/ambi-agua.774)

Gabriel Niero de Carvalho; Mariana Abrantes Giannotti; Silvia Sartor; José Alberto Quintanilha

Ictiofauna de igarapés de pequenas bacias de drenagem em área agrícola do Nordeste Paraense, Amazônia Oriental (http://dx.doi.org/10.4136/ambi-agua.739)

Jean Michel Corrêa; Pedro Gerhard; Ricardo de Oliveira Figueiredo

Adequação e avaliação da aplicabilidade de um Protocolo de Avaliação Rápida na bacia do rio Gualaxo do Norte, Leste-Sudeste do Quadrilátero Ferrífero, MG, Brasil (http://dx.doi.org/10.4136/ambi-agua.872)

Aline Sueli de Lima Rodrigues; Guilherme Malafaia; Adivane Terezinha Costa; Hermínio Arias Nalini Júnior

Qualidade da água de uma represa localizada em área agrícola (Campo Verde, MT, Brasil) (http://dx.doi.org/10.4136/ambi-agua.904)

Carolina Hortêncio Malheiros; Edna Lopes Hardoim; Zoraidy Marques de Lima; Ricardo Santos

Silva Amorim

Pantanal de Cáceres: composição granulométrica dos sedimentos de fundo no rio Paraguai entre a foz do rio Cabaçal e a cidade de Cáceres, Mato Grosso, Brasil (http://dx.doi.org/10.4136/ambi-agua.876)

Gustavo Roberto dos Santos Leandro, Célia Alves de Souza

Vulnerabilidade natural e ambiental do município de Ponta Porã, Mato Grosso do Sul, Brasil (http://dx.doi.org/10.4136/ambi-agua.786)

Thalita Beatriz Antunes Klais; Fabrício Bau Dalmas; Renata Porto Morais; Gabriela Atique; 


ISSN $=$ 1980-993X - doi:10.4136/1980-993X
www.agro.unitau.br/ambi-agua
E-mail: ambi-agua@@agro.unitau.br
Phone: +55 (12) 3625-4212

\title{
Editorial of the nineteenth edition of Ambiente \& Água - An Interdisciplinary Journal of Applied Science
}

\author{
(http://dx.doi.org/10.4136/ambi-agua.952)
}

\author{
Getulio Teixeira Batista \\ Professor of the Master Degree Program in Environmental Sciences of the University of Taubaté \\ e-mail: ambi-agua@agro.unitau.br
}

\begin{abstract}
We are publishing the nineteenth edition since the first issue published in August, 2006. Since then, all issues were published on time as schedule in December 31, April 30 and August 31 of every year. Hopefully, this encourages potential authors to submit their manuscripts to our journal. This $19^{\text {th }}$ edition contains 20 articles that were peer reviewed and selected for publication among 126 submitted in this period. The last three issues had also 20 articles published. These numbers meet one of the SciELO's criteria to consider the indexation of a journal. We continue to practice the complete open access policy and fostering the visibility, securing data storage, and working to increase the scientific impact of the journal.
\end{abstract}

Keywords: Ambi-Agua, environment, water resources, Google Analytics, Redalyc, Sumários.org.

\section{Editorial da décima nona edição da revista Ambiente \& Água - An Interdisciplinary Journal of Applied Science}

\section{RESUMO}

Estamos publicando a décima nona edição desde a primeira edição publicada em agosto de 2006. Desde então, todos os números foram publicados em dia conforme a programação: 31 de dezembro, 30 de abril e 31 de agosto de cada ano. Esperamos que esse fato encoraje potenciais autores submeterem seus trabalhos à nossa revista. Esta $19^{\text {a }}$ edição contém 20 artigos que foram revisados e selecionados para publicação entre 126 submetidos neste período. As últimas três edições também tiveram 20 artigos publicados. Esses números satisfazem um dos critérios da SciELO para uma revista ser considerada para indexação. Continuamos a praticar a política de acesso aberto completo e a promover a visibilidade, garantir diversos meios de armazenamento dos artigos publicados, e a trabalhar para aumentar o impacto científico da revista.

Palavras-chave: Ambi-Agua; meio ambiente; recursos hídricos, Google Analytics, Redalyc, Sumários.org.

\section{INTRODUCTION}

We continue to monitor the access and download of articles. Figure 1 shows the number of visits that the journal site had this year of 2012 up to August 18. One can observe that the accesses are pretty much constant, except just after an issue publication as can been seen in 
May and that they decrease during weekends. It is worth mentioning that we had access every single day and that the site was up during the entire period.

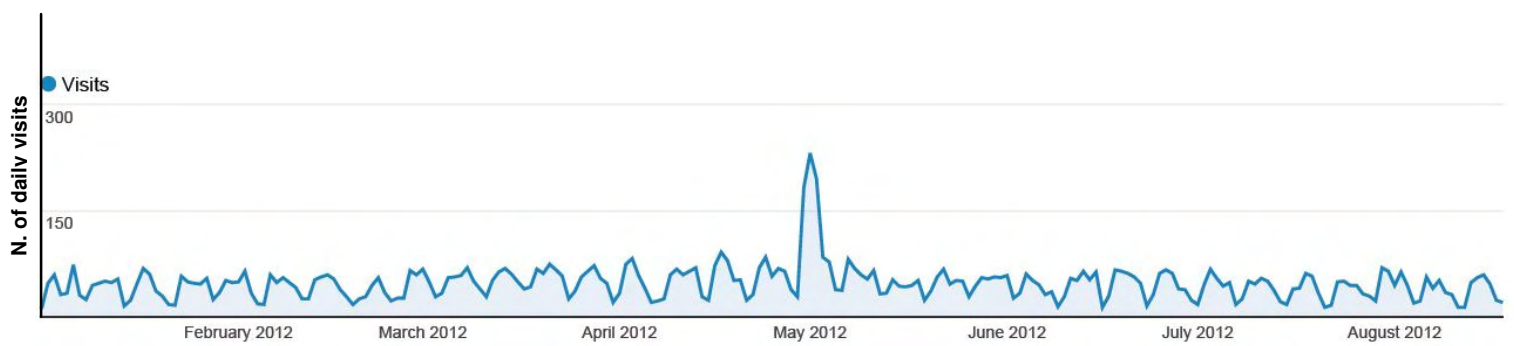

Figure 1. A total of 6,381 people visited Ambiente \& Agua Journal site from January 1st, 2012 to August $18^{\text {th }}, 2012$, completing 10,927 visits in this period and $74.6 \%$ of these visits have come from Brazil, 3.2\% from Mexico, 2.4\% from USA, 2.4\% from India, and 1.2\% from the United Kingdom, the remaining $16.2 \%$ from 112 other countries.

Source: Google Analytics (2012). <https://www.google.com/analytics >. Access August 18, 2012.

To guarantee data preservation, in addition to register the doi ${ }^{\mathrm{TM}}$ of all published articles, we made agreements with several other data basis to capture metadata and to store articles' full texts. In this issue, we show that Ambiente \& Agua articles are also stored in Redalyc and Sumários.org server (Figures 2 and 3) and they can be downloaded directly from their data basis.

Note that since Redalyc began to support Ambiente \& Agua Journal the number of downloads increased with a decrease in 2011. This drop coincided with the Natural and Social Sciences decrease in the number of downloads for that period.

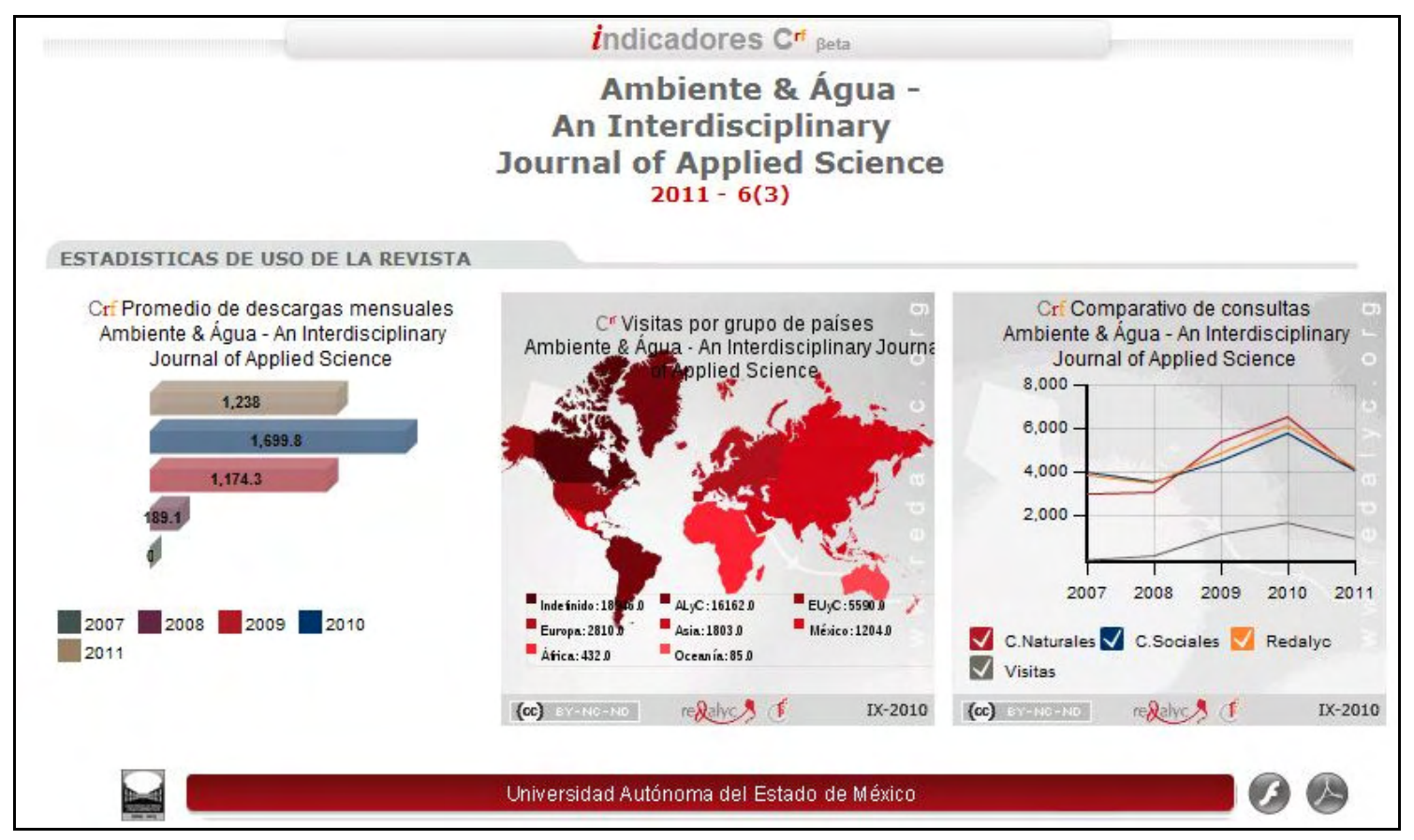

Figure 2. Page extracted from the Redalyc site that shows the number of yearly downloads of articles from their server.

Source: Red de Revistas Científicas de América Latina y el Caribe, España y Portugal Sistema de Información Científica (Redalyc). http://redalyc.uaemex.mx/src/inicio/HomRevRed.jsp?iCveEntRev=928. Acess August 20th, 2012). 
Figure 3 shows that all volumes and issues can also be accessed from the Sumários.org site.

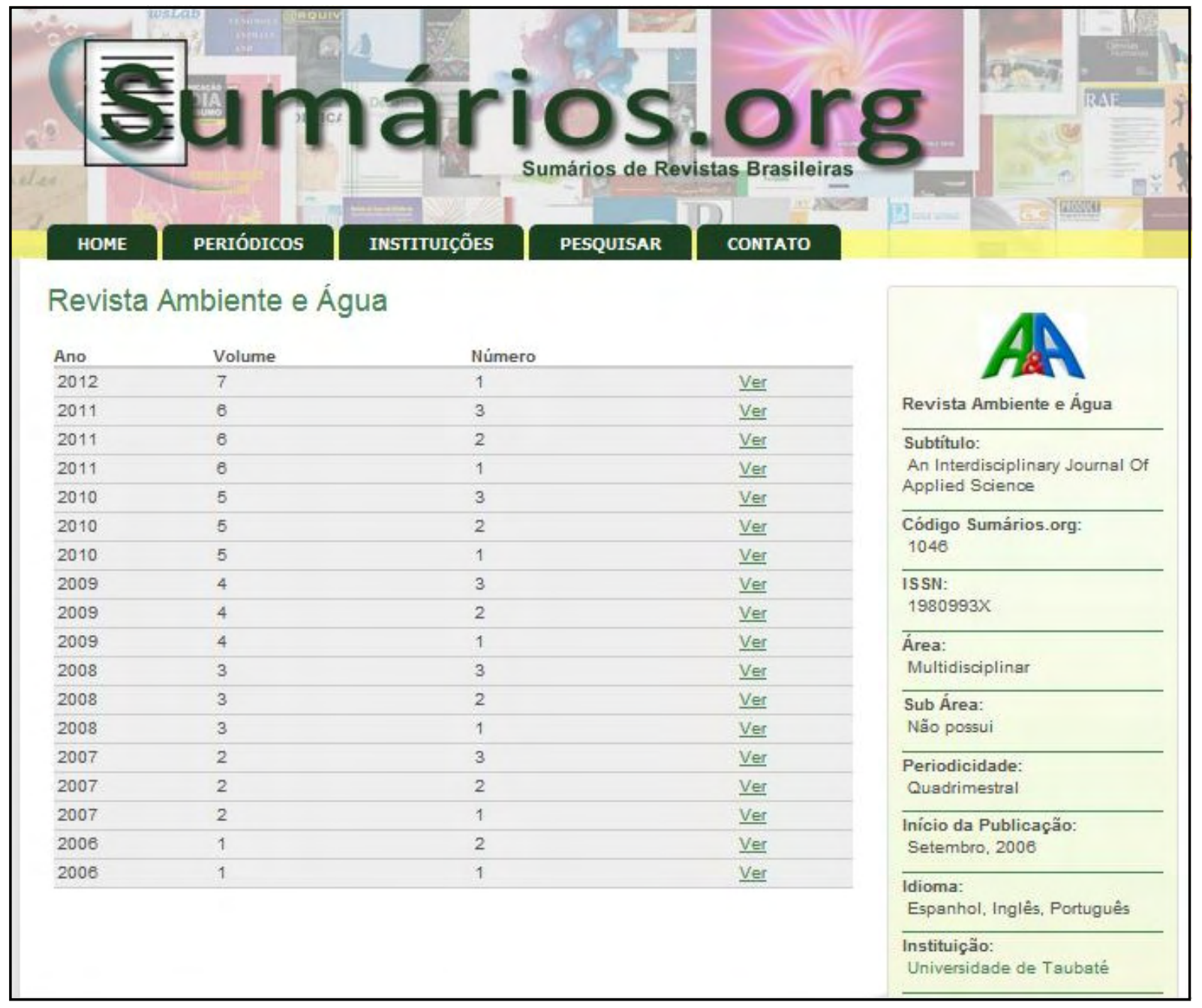

Figure 3. Page extracted from Sumários.org site the published issues of Ambiente \& Agua that can be downloaded directly from their server.

Source: Sumários de Revistas Brasileiras (Sumários.org): http://sumarios.org/revistas/revista-ambiente-e\%C3\%A1gua-interdisciplinary-journal-applied-science. Acess August 20, 2012).

\section{FINAL REMARKS}

Ambi-Agua welcomes good quality submissions that effectively increases the scientific knowledge in the great interdisciplinary scientific thematic area related to Environmental Sciences and Water Resources. Thematic areas include Hydrology, Hydrogeology, Environmental and Sanitation Engineering, Forest Engineering and Forest Resources, Ecology, Aqüiculture, Oceanology and Fishing Resources, Agronomy, Agrometeorology and Agricultural Engineering, Global Change, Fishing Engineering, Environmental Zootechny, Geography and Geology, as well as Remote Sensing, Geoinformation, and Spatial Analysis However, these broad areas have to focus on water or environmental sciences issues for the submission be considered.

Ambi-Agua continues with the complete Open Access Policy: no fee to publish and no fee to access articles and is committed to register doi ${ }^{\mathrm{TM}}$ for all published articles. 


ISSN = 1980-993X - doi:10.4136/1980-993X
www.ambi-agua.net
E-mail: ambi-agua@agro.unitau.br
Tel.: (12) 3625-4212

\title{
Climate change scenarios and their impact on the water balance of sugarcane production areas in the State of São Paulo, Brazil
}

\author{
(http://dx.doi.org/10.4136/ambi-agua.907)
}

\author{
Dayana L. dos Santos ${ }^{1}$; Paulo C. Sentelhas ${ }^{2}$ \\ ${ }^{1}$ Agricultural Systems Engineering Graduate Program, ESALQ, \\ University of São Paulo, Piracicaba, SP, Brazil. e-mail: dayana.santos@usp.br, \\ ${ }^{2}$ Biosystems Engineering Department, ESALQ, \\ University of São Paulo, Piracicaba, SP, Brazil.e-mail: pcsentel.esalq@usp.br
}

\begin{abstract}
The evidence of climate changes has increased the demand for biofuel such as the ethanol from sugarcane, which has major comparative advantages in economic and environmental terms in relation to other biofuel sources. The sugarcane production in the State of São Paulo is highly influenced by the soil water availability, which is the main factor causing inter-annual yield variability. With the expected climate change, the crop water balance in the sugarcane production regions may be affected, which will also bring consequences for crop production. Based on that, the objective of this study was to assess the impacts of different climate changes scenarios on potential (ETP) and actual (ETA) evapotranspiration, as well as on water deficit (WD) and water surplus (WS) for four sugarcane production regions in the state of São Paulo, Brazil. For that, twelve climate changes scenarios, with increasing temperatures and rainfall variation, were considered for the years of 2030, 2060 and 2090, based on 2007 IPCC's report. The results indicated that ETP will increase substantially as a function of higher air temperatures projected for the future scenarios. However, for ETA the elevation will not be so intense due to the variations projected for the rainfall scenarios. In general, the expectation is the reduction of the soil water availability in all locations by 2090, with substantial increase in the WD, around 550, 650,530 e $720 \mathrm{~mm}$ for the worst scenario in relation to the present conditions, respectively for Araçatuba, Assis, Jaboticabal and Piracicaba.
\end{abstract}

Keywords: Global warming, climatological water balance, evapotranspiration, water deficit.

\section{Cenários de Mudanças Climáticas e seus Impactos no Balanço Hídrico de Regiões Canavieiras do Estado de São Paulo, Brasil}

\section{RESUMO}

Os indícios de mudanças climáticas tem elevado a demanda por álcool proveniente da cana-de-açúcar que apresenta grandes vantagens comparativas em termos econômicos e ambientais em relação a outros biocombustíveis. A produção da cana-de-açúcar no Estado de São Paulo é altamente influenciada pela disponibilidade de água no solo, sendo este o principal fator responsável pela variabilidade interanual da sua produtividade. Sendo assim, as mudanças climáticas deverão impactar o balanço hídrico das regiões produtoras e, consequentemente, a produção da cana-de-açúcar. Desse modo, o objetivo deste estudo foi avaliar os impactos dos cenários projetados de mudanças climáticas na evapotranspiração potencial (ETP) e real (ETA), no déficit hídrico (WD) e no excedente hídrico (WS) de quatro 
SANTOS, D. L.; SENTELHAS, P. C. Climate Change Scenarios and Their Impact on the Water Balance of Sugarcane Production Areas in the State of São Paulo, Brazil. Ambi-Agua, Taubaté, v. 7, n. 2, p. 7-17, 2012. (http://dx.doi.org/10.4136/ambi-agua.907)

regiões produtoras de cana-de-açúcar no Estado de São Paulo. Para tanto, foram considerados doze cenários de mudanças climáticas para os anos de 2030, 2060 e 2090, baseados no relatório do IPCC de 2007. Os resultados indicam aumentos acentuados da ETP em função do aumento da temperatura do ar nos diferentes cenários. No entanto, para a ETA esses aumentos não serão tão acentuados devido à variação no regime hídrico. Espera-se uma redução na disponibilidade hídrica em todas as localidades para o ano de 2090, com aumento significativo do WD, da ordem de 550, 650, 530 e $720 \mathrm{~mm}$ para o pior cenário em relação à condição atual, respectivamente para Araçatuba, Assis, Jaboticabal e Piracicaba.

Palavras-chave: Aquecimento global, balanço hídrico climatológico, evapotranspiração, deficiência hídrica.

\section{INTRODUCTION}

The projections of global climate change promoted by the anthropic action, having as consequence the increasing greenhouse effect, is becoming more and more accepted by the scientific and agricultural communities around the world (Marengo, 2008). As a consequence of that, there is an special concern by creating new sources of renewable energy which has increasing the demand by biofuels, including the sugarcane ethanol, which has several advantages in relation to other sources.

In this context, Brazil has a competitive advantage in relation to other countries, since it is the most traditional sugarcane producer in the world, with more than 8 million of hectares planted and a production of 571.5 million of tons during the 2011/12 growing season, with 287.6 million of tons for producing 22.9 billion liters of ethanol (CONAB, 2011). The state of São Paulo is the main sugarcane producer in the country, counting with more than 200 mills. In this state, the sugarcane is produced in different environments with diverse climatic conditions which affect the cane yield (Teramoto, 2003), as well as all the activities related to the production, transport and storage (Pereira et al., 2002).

In the state of São Paulo, the rainfall inter-annual variability is the main cause of sugarcane yield fluctuation, since it affects the soil water balance and, consequently, the water availability for plants. So, any change in the water balance variables, mainly rainfall and/or evapotranspiration, will promote changes in the plant water consumption. Based on the results of Marks et al. (1993), Medeiros (2003) and Villani et al. (2011), an increase in air temperature will lead to a higher evapotranspiration which in a non-changing rainfall regime or in a scenario of less rainfall will promote an increase in the water deficit for plants and, as consequence, a decrease in crop yield by a reduced evapotranspiration. Also, any change in the rainfall regime, with an increase or a decrease in the precipitation amount will result in changes in the water balance (Horikoshi and Fisch, 2007), with positive or negative impacts on agriculture. Results from the study carried out by Liberato and Brito (2010) showed that the climate changes projected for Occidental Amazon will result in a drier climate, with reduction in the soil water availability. In agriculture, such reduction associated with temperature changes will affect plant phenology, crops geographic distribution (crop zoning) and crop yield (Crimmins et al., 2011; Li et al., 2011; Pérez and Sierra, 2012).

As agriculture is among the economic activities the most vulnerable to climatic conditions, the climate change will have a strong impact on crop zoning, yield, and quality. Based on that, the assessment of the factors of environmental vulnerability for sugarcane production is of high importance, mainly considering that this crop is the most efficient for sugar and ethanol production (Zullo Jr. et al., 2008). So, the objective of this study was to evaluate the impact of different climate change scenarios on the water balance of four sugarcane production regions in the state of São Paulo, in order to subsidize the strategies to 
SANTOS, D. L.; SENTELHAS, P. C. Climate Change Scenarios and Their Impact on the Water Balance of Sugarcane Production Areas in the State of São Paulo, Brazil. Ambi-Agua, Taubaté, v. 7, n. 2, p. 7-17, 2012. (http://dx.doi.org/10.4136/ambi-agua.907)

be adopted by the authorities, growers and sugar mills to face the challenges of sugarcane production in the future climatic conditions.

\section{MATERIAL AND METHODS}

The present study was developed for four sugarcane regions in the state of São Paulo,

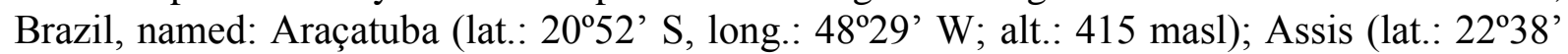
S, long.: 50²4' W, alt.: 560 masl); Jaboticabal (lat.: $21^{\circ} 15^{\prime}$ ' S; long.: 48 $19^{\circ}$ ' W; alt.: 595 masl)

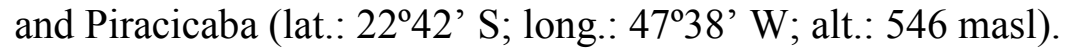

The weather data of the locations listed above were obtained from different sources. Tenday period data of air temperature were estimated with multiple linear models proposed by Pedro Jr. et al. (1991), based on the normal data from the Brazilian Meteorological Service (INMET) and Agronomic Institute of Campinas (IAC), as a function of latitude, longitude and altitude. The daily average sunshine hours data for each 10-day period were also estimated by multiple linear models, as proposed by Monteiro (2012). Sunshine hours were used to estimate global solar radiation ( Rg) by the Angstron-Prescott's method (Pereira et al., 2002). The daily rainfall data of a 30-year period, from 1979 to 2008, was obtained from the Brazilian Water Agency (ANA), for each location, and transformed in the same 10-day time scale. For the description of the present conditions, the monthly climate data was considered, whereas for the comparisons among the present and future scenarios the annual time scale was analyzed.

Twelve future scenarios were created for the years of 2030, 2060 and 2090 by combining changes in temperature and rainfall for the four regions. A combination of the three A1 scenarios was used (IPCC, 2007). These scenarios (A1T, A1B and A1Fl) were adopted because they present a full range of variations for air temperature, from 1.4 to $6.4^{\circ} \mathrm{C}$. Based on that, the actual temperature data base was increased by 2,4 and $6^{\circ} \mathrm{C}$. For rainfall, as the projections for the state of São Paulo have a great uncertainty associated to, the future scenarios were based on the percentages in relation to the present scenario $(-10,-5,+5$ and $+10 \%)$ suggested by the 2007 IPCC's report for all this region of Brazil. The changes for rainfall were applied for each rainfall event of the 30-year series in order to evaluate the interannual variability of this variable as well as of water balance variables. Table 1 presents all the combinations of the proposed future scenarios, having as reference the average data from 1979 to 2008 , mentioned as scenario C0, which refers to the normal data obtained in the end of 2008 .

Air temperature data, from $\mathrm{C} 0$ to $\mathrm{C} 12$ scenarios, were used to estimate potential evapotranspiration (ETP) considering the method of Thornthwaite (1948) adjusted by Camargo et al. (1999). Such method uses the effective temperature (Tef) which is calculated as a function of daily extreme temperatures. This ETP method was chosen among several others for using only air temperature and photoperiod as variables, and for presenting accurate estimates for the state of São Paulo, as presented by Camargo et al. (1999).

ETP, rainfall and soil water holding capacity (SWHC) for each location and scenario were used for estimating the 10-day serial water balance by the method of Thornthwaite and Mather (1955), which was programmed in an Excel spreadsheet by Rolim et al. (1998). The outputs of the water balance are: soil water content; actual evapotranspiration (ETA); water deficit (WD); and water surplus (WS).

The water balance simulations were conducted annually for the actual 30-year database and considering this data with the possible changes presented by the 2007 IPCC's report. The SWHC for each location was estimated according to the predominant soil in the region, since the water retention by the soils is a function of their physical characteristics (Prado et al., 
2008). Based on that and considering a root depth of $100 \mathrm{~cm}$ for sugarcane crop, the SWHC ranged from 70 to $120 \mathrm{~mm}$, as presented in Table 2 .

Table 1. Present (C0) and future scenarios of climate change (C1 up to $\mathrm{C} 12)$ considering the combinations of increase in temperature $(\Delta \mathrm{T})$ and variation in rainfall $(\Delta \mathrm{P})$.

\begin{tabular}{c|l|l|r}
\hline Scenarios & Year & $\begin{array}{c}\Delta \mathbf{T} \\
\left({ }^{\circ} \mathbf{C}\right)\end{array}$ & $\begin{array}{r}\Delta \mathbf{P} \\
(\boldsymbol{\%})\end{array}$ \\
\hline C0 & 2008 & 0 & 0 \\
C1 & 2030 & +2 & -10 \\
C2 & 2030 & +2 & -5 \\
C3 & 2030 & +2 & +5 \\
C4 & 2030 & +2 & +10 \\
C5 & 2060 & +4 & -10 \\
C6 & 2060 & +4 & -5 \\
C7 & 2060 & +4 & +5 \\
C8 & 2060 & +4 & +10 \\
C9 & 2090 & +6 & -10 \\
C10 & 2090 & +6 & -5 \\
C11 & 2090 & +6 & +5 \\
C12 & 2090 & +6 & +10 \\
\hline
\end{tabular}

Table 2. Soil types for each location and their respective water holding capacity (SWHC) in the studied regions.

\begin{tabular}{l|l|l}
\hline \multicolumn{1}{c|}{ Location } & \multicolumn{1}{|c}{ Soil Type } & \multicolumn{1}{c}{$\begin{array}{c}\text { SWHC } \\
(\mathbf{m m})\end{array}$} \\
\hline Araçatuba, SP & Sandy-Loam & 70 \\
Assis, SP & Loam & 90 \\
Jaboticabal, SP & Clay-Loam & 120 \\
Piracicaba, SP & Loam & 90 \\
\hline
\end{tabular}

The results were analyzed by comparing the changes promoted by the future scenarios in relation to the present one, considered as 2008.

\section{RESULTS AND DISCUSSION}

\subsection{Climate characteristics of the studied areas: present conditions}

Table 3 presents the seasonal variation of air temperature in the four studied areas, regarding the average extreme (Tmax - maximum and Tmin - minimum temperature) and the daily average temperature (Tavg) values. As all the locations are in the tropical region, with latitudes between 21 and $23^{\circ}$ South, the seasonal variation is low, with Tavg ranging between 18 and $26^{\circ} \mathrm{C}$ along the year. The hottest region is in the West of the state of São Paulo, Araçatuba, where altitude is lower and the continentality effect is more evident. Annual Tavg is $23.8^{\circ} \mathrm{C}$. In Assis and Piracicaba, temperatures are very similar, being Piracicaba a little bit cooler than Assis. In terms of annual average temperature the differences are of only $0.2^{\circ} \mathrm{C}$. 
SANTOS, D. L.; SENTELHAS, P. C. Climate Change Scenarios and Their Impact on the Water Balance of Sugarcane Production Areas in the State of São Paulo, Brazil. Ambi-Agua, Taubaté, v. 7, n. 2, p. 7-17, 2012. (http://dx.doi.org/10.4136/ambi-agua.907)

Jaboticabal has temperature between the conditions presented for Araçatuba and Assis/Piracicaba, with an annual average temperature of $22.5^{\circ} \mathrm{C}$.

Regarding the solar energy variables (Table 4), it is clear that there are no much differences among the four locations studied. The seasonal variation of sunshine hours follows the rainfall regime, having an inverse relationship between them. This variable ranges from $6.4 \mathrm{~h}$ in the rainy season (summer) to $8.2 \mathrm{~h}$ in the dry season (winter). Photoperiod or maximum sunshine hours is an astronomical variable and consequently is influenced by latitude. As latitude is very similar among the four locations, ranging from 21 to $23^{\circ}$, there is no much variation in photoperiod for them, ranging seasonally from 10.6 to $13.4 \mathrm{~h}$ in average. Finally, for global solar radiation the values follow basically the photoperiod variation, but are also modulated by the sunshine hours. The $\mathrm{Rg}$ variation along the year is, in average, from 13.1 $\mathrm{MJm}^{-2} \mathrm{day}^{-1}$ in June to $22.6 \mathrm{MJm}^{-2}$ day $^{-1}$ in November.

Table 3. Estimated normal maximum (Tmax), minimum (Tmin) and average (Tavg) air temperature, in ${ }^{\circ} \mathrm{C}$, for Araçatuba, Assis, Jaboticabal and Piracicaba, in the state of São Paulo, Brazil.

\begin{tabular}{l|c|ccccccccccccc}
\hline Location & Variable & Jan & Feb & Mar & Apr & May & Jun & Jul & Aug & Sep & Oct & Nov & Dec & Annual \\
\hline \multirow{4}{*}{ Araçatuba } & Tmax & 31.7 & 31.9 & 31.7 & 30.5 & 28.6 & 27.6 & 27.9 & 30.5 & 31.5 & 31.7 & 31.8 & 31.4 & 30.6 \\
& Tmin & 20.1 & 20.3 & 19.6 & 17.1 & 14.5 & 13.2 & 12.6 & 14.3 & 16.4 & 18.0 & 18.6 & 19.7 & 17.0 \\
& Tavg & 25.9 & 26.1 & 25.7 & 23.8 & 21.6 & 20.4 & 20.3 & 22.4 & 24.0 & 24.9 & 25.2 & 25.6 & 23.8 \\
\hline \multirow{4}{*}{ Assis } & Tmax & 30.2 & 30.3 & 29.9 & 28.2 & 26.2 & 25.0 & 25.3 & 27.4 & 28.3 & 28.9 & 29.5 & 29.4 & 28.2 \\
& Tmin & 18.8 & 19.0 & 18.3 & 15.6 & 12.9 & 11.4 & 10.9 & 12.3 & 14.3 & 15.9 & 16.8 & 18.1 & 15.4 \\
& Tavg & 24.5 & 24.7 & 24.1 & 21.9 & 19.6 & 18.2 & 18.1 & 19.9 & 21.3 & 22.4 & 23.2 & 23.8 & 21.8 \\
\hline \multirow{5}{*}{ Jaboticabal } & Tmax & 30.3 & 30.4 & 30.2 & 29.0 & 27.3 & 26.2 & 26.6 & 29.0 & 30.2 & 30.3 & 30.3 & 30.0 & 29.1 \\
& Tmin & 19.0 & 19.2 & 18.5 & 16.0 & 13.4 & 12.1 & 11.5 & 13.1 & 15.2 & 16,9 & 17.5 & 18.5 & 15.9 \\
& Tavg & 24.7 & 24.8 & 24.4 & 22.5 & 20.4 & 19.2 & 19.1 & 21.1 & 22.7 & 23.6 & 23.9 & 24.3 & 22.5 \\
\hline \multirow{5}{*}{ Piracicaba } & Tmax & 30.0 & 30.1 & 29.7 & 28.0 & 26.0 & 24.9 & 25.1 & 27.2 & 28.2 & 28.7 & 29.3 & 29.3 & 28.0 \\
& Tmin & 18.7 & 18.9 & 18.1 & 15.5 & 12.8 & 11.3 & 10.7 & 12.1 & 14.1 & 15.8 & 16.7 & 18.0 & 15.2 \\
& Tavg & 24.4 & 24.5 & 23.9 & 21.8 & 19.4 & 18.1 & 17.9 & 19.7 & 21.2 & 22.3 & 23.0 & 23.7 & 21.6 \\
\hline
\end{tabular}

Table 4. Estimated normal sunshine hours (n), maximum sunshine hours $(\mathrm{N})$ and global solar radiation $\left(\mathrm{Rg}, \mathrm{MJm}^{-2} \mathrm{day}^{-1}\right)$ for Araçatuba, Assis, Jaboticabal and Piracicaba, in the state of São Paulo, Brazil.

\begin{tabular}{l|c|ccccccccccccc}
\hline Location & Variable & Jan & Feb & Mar & Apr & May & Jun & Jul & Aug & Sep & Oct & Nov & Dec & Annual \\
\hline \multirow{4}{*}{ Araçatuba } & $\mathrm{n}$ & 6.9 & 6.7 & 6.6 & 7.0 & 7.0 & 6.9 & 7.4 & 8.1 & 8.0 & 7.7 & 7.7 & 7.0 & 6.9 \\
& $\mathrm{~N}$ & 13.1 & 12.7 & 12.1 & 11.5 & 11.0 & 10.8 & 10.9 & 11.3 & 11.9 & 12.5 & 13.0 & 13.2 & 12.0 \\
& $\mathrm{Rg}$ & 21.5 & 20.5 & 19.2 & 17.2 & 15.0 & 13.7 & 14.6 & 17.5 & 20.0 & 21.5 & 22.6 & 21.7 & 18.3 \\
\hline \multirow{3}{*}{ Assis } & $\mathrm{n}$ & 6.8 & 6.5 & 6.4 & 6.6 & 6.6 & 6.6 & 7 & 7.6 & 7.5 & 7.3 & 7.4 & 6.8 & 7.2 \\
& $\mathrm{~N}$ & 13.1 & 12.7 & 12.1 & 11.5 & 11.0 & 10.8 & 10.9 & 11.3 & 11.9 & 12.5 & 13.0 & 13.2 & 12.0 \\
& $\mathrm{Rg}$ & 21.3 & 20.3 & 18.7 & 16.7 & 14.5 & 13.3 & 14.2 & 16.9 & 19.3 & 20.9 & 22.1 & 21.3 & 18.8 \\
\hline \multirow{4}{*}{ Jaboticabal } & $\mathrm{n}$ & 6.8 & 6.5 & 6.5 & 6.8 & 6.9 & 6.8 & 7.3 & 8 & 8 & 7.6 & 7.6 & 7.0 & 7.1 \\
& $\mathrm{~N}$ & 13.2 & 12.7 & 12.1 & 11.5 & 11.0 & 10.7 & 10.8 & 11.3 & 11.9 & 12.5 & 13.0 & 13.3 & 12.0 \\
& $\mathrm{Rg}$ & 21.4 & 20.2 & 18.8 & 16.8 & 14.6 & 13.3 & 14.3 & 17.1 & 19.9 & 21.3 & 22.4 & 21.7 & 18.5 \\
\hline \multirow{5}{*}{ Piracicaba } & $\mathrm{n}$ & 6.7 & 6.6 & 6.6 & 6.8 & 6.9 & 7.0 & 7.6 & 8.2 & 7.9 & 7.6 & 7.7 & 7.0 & 7.2 \\
& $\mathrm{~N}$ & 13.3 & 12.8 & 12.2 & 11.5 & 10.9 & 10.6 & 10.7 & 11.2 & 11.9 & 12.5 & 13.1 & 13.4 & 12.0 \\
& $\mathrm{Rg}$ & 21.3 & 20.4 & 18.8 & 16.6 & 14.3 & 13.1 & 14.2 & 17.0 & 19.5 & 21.3 & 22.6 & 21.9 & 18.4 \\
\hline
\end{tabular}

Different from solar energy variables, rainfall varies significantly among the four regions. The annual rainfall in Assis and Jaboticabal normally is higher than $1400 \mathrm{~mm}$, whereas in Piracicaba it is around $1240 \mathrm{~mm}$ and in Araçatuba it remains below $1180 \mathrm{~mm}$. The 
SANTOS, D. L.; SENTELHAS, P. C. Climate Change Scenarios and Their Impact on the Water Balance of Sugarcane Production Areas in the State of São Paulo, Brazil. Ambi-Agua, Taubaté, v. 7, n. 2, p. 7-17, 2012. (http://dx.doi.org/10.4136/ambi-agua.907)

seasonal variation is similar among locations, with a rainy summer, with the total rainfall from October to March representing around $75 \%$ of the annual total, and a dry winter. The rainfall regime is mainly caused by convective rains, during the summer, and the influence of high pressure at central Brazil, during the winter, which inhibit the rainfall. The only few rain events during the winter is due to the penetration of cold fronts from south of Brazil.

When the water balance was determined for each location using the 30-year series (19792008), the average water surplus and average water deficit were determined for each one of the 36 ten-day periods of the year. These data are presented in Figures 1 to 4 and show the current water availability regime along the year for these locations.

Table 5. Normal monthly $\left(\mathrm{mm}\right.$ month $\left.^{-1}\right)$ and annual $\left(\mathrm{mm} \mathrm{year}^{-1}\right)$ rainfall for Araçatuba, Assis, Jaboticabal and Piracicaba, in the state of São Paulo, Brazil, from 1979 to 2008. Source: Brazilian Water Agency.

\begin{tabular}{c|ccccccccccccc}
\hline Location & Jan & Feb & Mar & Apr & May & Jun & Jul & Aug & Sep & Oct & Nov & Dec & Annual \\
\hline Araçatuba & 224 & 174 & 132 & 61 & 39 & 39 & 24 & 15 & 49 & 124 & 118 & 173 & 1172 \\
Assis & 231 & 173 & 147 & 96 & 97 & 64 & 40 & 36 & 88 & 118 & 142 & 180 & 1412 \\
Jaboticabal & 286 & 205 & 148 & 73 & 61 & 26 & 23 & 22 & 59 & 109 & 153 & 238 & 1403 \\
Piracicaba & 207 & 188 & 143 & 79 & 73 & 51 & 29 & 27 & 54 & 99 & 124 & 167 & 1239 \\
\hline
\end{tabular}
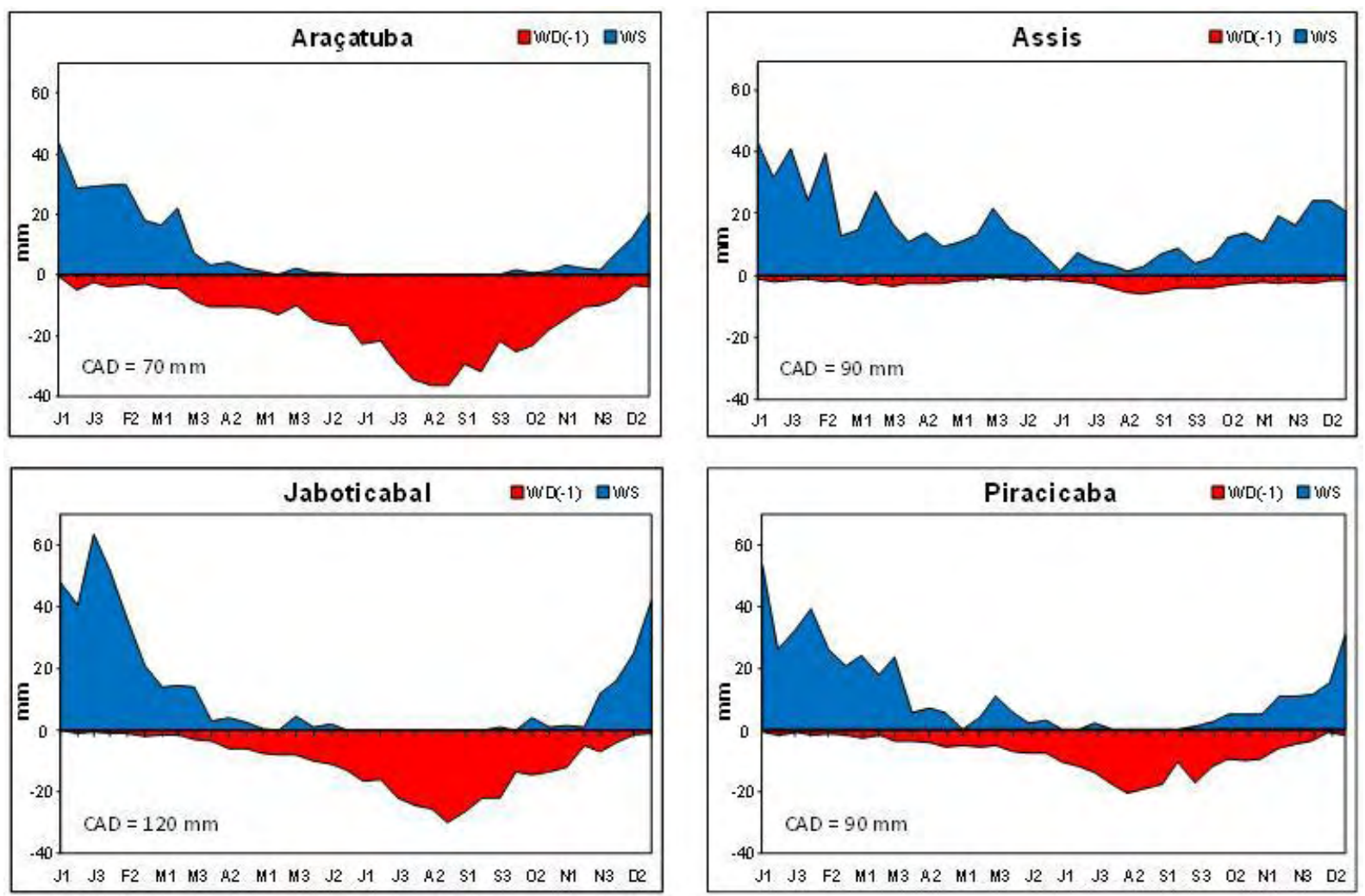

Figure 1. Average water balance $($ Water Deficit $=$ WD; Water Surplus = WS) for Araçatuba, Assis, Jaboticabal and Piracicaba, state of São Paulo, Brazil, for the 10-day time scale, considering the soil water holding capacity of 70, 90, 120 e $90 \mathrm{~mm}$, respectively. WD was multiplied by -1 just to make the graphic representation. The symbols in the $\mathrm{X}$-axis correspond to the 10-day period considered in a sequence from the first 10-day period of January (J1) to the last one in December (D3 - not shown). 
SANTOS, D. L.; SENTELHAS, P. C. Climate Change Scenarios and Their Impact on the Water Balance of Sugarcane Production Areas in the State of São Paulo, Brazil. Ambi-Agua, Taubaté, v. 7, n. 2, p. 7-17, 2012. (http://dx.doi.org/10.4136/ambi-agua.907)

Figure 1 shows the great difference observed among the four locations, with Assis presenting a predominance of water surplus along the year, with very low water deficiency, even during the winter, when there is the dry season and the monthly rainfall decreases substantially. In Araçatuba, the water deficit is the most intense, showing its highest values during August. Water deficit also can be observed, with less intensity, during the rainy season, showing that there is a higher possibility of dry spells, which are local named as veranicos, than the other locations. Jaboticabal and Piracicaba are in a transition between the wetter climate of Assis and the drier climate of Araçatuba, with Jaboticabal a little bit drier during the winter than Piracicaba, but with very similar water surplus conditions during the summer.

The wet season in Araçatuba, Jaboticabal and Piracicaba, in average, lasts from November to March, with the water surplus totaling, respectively, 209, 288 and $181 \mathrm{~mm}$. In Assis the water surplus is better distributed along the year, totaling $244 \mathrm{~mm}$. For water deficit, the predominance is from April to October, except for Assis, which has very few water deficits, but occurring all year long. In average, the annual water deficit is around $480 \mathrm{~mm}$ in Araçatuba, $248 \mathrm{~mm}$ in Jaboticabal and $146 \mathrm{~mm}$ in Piracicaba. In Assis, however, the annual water deficit is less than 1/5 of what happen in Araçatuba, which means only $61 \mathrm{~mm}$ per year.

\subsection{Climate characteristics of the studied areas: future scenarios}

Based on the future temperature and rainfall scenarios, the potential (ETP) and actual (ETA) evapotranspiration were estimated, as well as the water balance for each one of the locations studied (Tables 6 and 7). Based on these results, there is an expectation of very high values of ETP in the future scenarios, in accordance to the higher temperature, with increases, in relation to the present conditions, ranging from 19 to $41 \%$ in Araçatuba, from 24 to $62 \%$ in Assis, from 23 to $53 \%$ in Jaboticabal, and from 24 to $63 \%$ in Piracicaba (Table 6). Similar results were reported by Marks et al. (1993) and Horikoshi and Fisch (2007), working respectively in a basin and municipality scales.

Even considering that ETA is influenced by ETP, the changes in this variable in the future scenarios demonstrated that it will be also influenced by the magnitude of the changes in the rainfall regime. For Araçatuba and Piracicaba, the minimum changes in ETA were obtained in the scenario $\mathrm{C} 9$ (2090: $\Delta \mathrm{T}=+6^{\circ} \mathrm{C} ; \Delta \mathrm{P}=-10 \%$ ), whereas in Assis and Jaboticabal this happened in the scenario $\mathrm{C} 1\left(2030: \Delta \mathrm{T}=+2^{\circ} \mathrm{C} ; \Delta \mathrm{P}=-10 \%\right)$. For the highest values of ETA, all locations will have them under the scenario $\mathrm{C} 12$ (2090: $\Delta \mathrm{T}=+6^{\circ} \mathrm{C} ; \Delta \mathrm{P}=+10 \%$ ), which combine the increase of ETP, caused by temperature increase, with the higher rainfall amount, resulting in a higher ETA.

For the water deficit and water surplus (Table 7), the changes will be very similar for all scenarios, since WD will increase and WS will decrease. However, the magnitude of such changes will vary according to the macroclimate conditions of each region. For Araçatuba, WD will increase from $13.5 \%$ in the scenario $\mathrm{C} 4\left(2030: \Delta \mathrm{T}=+2^{\circ} \mathrm{C} ; \Delta \mathrm{P}=+10 \%\right)$ to $115.2 \%$ in the worst scenario, $\mathrm{C} 9$ (2090: $\left.\Delta \mathrm{T}=+6^{\circ} \mathrm{C} ; \Delta \mathrm{P}=-10 \%\right)$. As Araçatuba is the driest region among those studied, the change in WD will be the smallest. However, it will be the most affected in relation to the water surplus; it can become zero if the following scenarios happen: $\mathrm{C} 1, \mathrm{C} 2$, C5, C6, C9, C10 and C11. In Assis, there will be the greatest change in WD. As this region has very small WD in the present scenario, any change will promote a considerable percentage of variation. Because of that, the WD changes will vary between $94.5 \%$ in scenario C4 to more than $1160 \%$ in scenario C9. In relation to the WS, the scenarios $\mathrm{C} 5, \mathrm{C} 6$, C7, C9 and C10 will not have excess of water in order to recharge the water table. Similar condition for both WD and WS will be occurring in Piracicaba, where WD will increase between 73.4 and $589.8 \%$ and no WS will be observed in the scenarios C5, C6, C9, C10 and 
SANTOS, D. L.; SENTELHAS, P. C. Climate Change Scenarios and Their Impact on the Water Balance of Sugarcane Production Areas in the State of São Paulo, Brazil. Ambi-Agua, Taubaté, v. 7, n. 2, p. 7-17, 2012. (http://dx.doi.org/10.4136/ambi-agua.907)

C11. Finally, in Jaboticabal, the changes in WD will be between what will happen in the other locations, with WD increase ranging between $51 \%$ in $\mathrm{C} 4$ and $314 \%$ in $\mathrm{C} 9$. On the other hand, Jaboticabal will be the only location with WS $=0$ just in one scenario (C9).

Based on the results of Table 7, a reduction in the water availability (WD increase and WS decrease) is expected for all the scenarios of climate change, even when a rainfall increase is projected. The worst scenario, $\mathrm{C} 9\left(2090: \Delta \mathrm{T}=+6^{\circ} \mathrm{C} ; \Delta \mathrm{P}=-10 \%\right)$ will result in an increase of 553, 652, 529 and $717 \mathrm{~mm}$ for WD in relation to C0, respectively for Araçatuba, Assis, Jaboticabal and Piracicaba. WS will decrease abruptly, reaching zero in several scenarios, which means decreases of 209, 244, 288 and $181 \mathrm{~mm}$ for the same locations.

The results obtained with the present study is in accordance to other ones conducted in different parts of the world, as in Columbia river basin, in USA (Marks et al., 1993), in northern Jalisco, México (Ibarra-Montoya et al., 2011), in La Pampa province, Argentina (Pérez and Sierra, 2012), in Louess Plateau of China (Li et al., 2011), and in Brazil, like in Taubaté, in the Paraíba Valley (Horikoshi and Fisch, 2007), in the Occidental Amazon (Liberato and Brito, 2010), and in the Northeast semi-arid region (Medeiros, 2003). However, the results presented in this study is much more drastic then presented by these authors, which is related to the fact that the climate change scenarios were applied in all the historical series of rainfall data (from 1979 to 2008) in a 10-day time scale and not only in the monthly normal data. The results presented in this study in terms of WD and WS are the average of the results from the water balance processed for each year of the data series, representing a more comprehensive way to determine the actual average of these variables, as also considered by Gouvêa et al. (2009). The use of normal data can induce to an underestimation of the water balance parameters, giving an unreal vision of the expected water availability conditions for the future, which means much less impact.

Table 6. Annual potential (ETP) and actual (ETA) evapotranspiration in mm year ${ }^{-1}$, obtained by the serial climatological water balance, for the present condition $(\mathrm{C} 0)$ and future scenarios of climate change $(\mathrm{C} 1$ to C12), in the locations of Araçatuba, Assis, Jaboticabal and Piracicaba, state of São Paulo, Brazil.

\begin{tabular}{c|cc|cc|cc|cc}
\hline \multirow{2}{*}{$\begin{array}{c}\text { Climate } \\
\text { Scenarios }\end{array}$} & \multicolumn{2}{|c|}{ Araçatuba } & \multicolumn{2}{c|}{ Assis } & \multicolumn{2}{c|}{ Jaboticabal } & \multicolumn{2}{c}{ Piracicaba } \\
\cline { 2 - 8 } & ETP & ETA & ETP & ETA & ETP & ETA & ETP & ETA \\
\hline C0 & 1504 & 1024 & 1227 & 1166 & 1338 & 1090 & 1212 & 1066 \\
C1 & 1785 & 1097 & 1526 & 1274 & 1649 & 1178 & 1505 & 1130 \\
C2 & 1785 & 1160 & 1526 & 1312 & 1649 & 1204 & 1505 & 1168 \\
C3 & 1785 & 1217 & 1526 & 1379 & 1649 & 1252 & 1505 & 1229 \\
C4 & 1785 & 1241 & 1526 & 1407 & 1649 & 1274 & 1505 & 1251 \\
C5 & 1979 & 1090 & 1792 & 1290 & 1886 & 1235 & 1774 & 1124 \\
C6 & 1979 & 1154 & 1792 & 1367 & 1886 & 1270 & 1774 & 1192 \\
C7 & 1979 & 1270 & 1792 & 1441 & 1886 & 1328 & 1774 & 1294 \\
C8 & 1979 & 1299 & 1792 & 1496 & 1886 & 1353 & 1774 & 1330 \\
C9 & 2119 & 1087 & 1992 & 1279 & 2049 & 1272 & 1981 & 1118 \\
C10 & 2119 & 1149 & 1992 & 1355 & 2049 & 1311 & 1981 & 1183 \\
C11 & 2119 & 1277 & 1992 & 1498 & 2049 & 1380 & 1981 & 1317 \\
C12 & 2119 & 1337 & 1992 & 1545 & 2049 & 1409 & 1981 & 1367 \\
\hline
\end{tabular}

The findings of this study are important information to provide a better understanding of the susceptibility of the environment to the climate change, even considering the uncertainties related to the climate scenarios projected to the future (Dessai and Van Der Sluijs, 2007). The global warming seems to be the worst impact, since, even with an increase in rainfall, the higher evapotranspiration will increase the water deficit, making the conditions for rainfed sugarcane crop critical, since the plants will face a drier winter with extremely low water availability in the soil. For irrigated sugarcane crops, the lower water availability in the rivers and reservoirs will be also a problem to be addressed, since it will be hard to apply enough 
water for sugarcane plants demand. This drastic scenario should be focused by authorities, scientists, sugarcane growers and sugar mills to prepare themselves for finding the best solutions of preparedness to deal with shortage of water in a world which is demanding each day more food (sugar) and energy (ethanol). The best solutions in this case would be the use of biotechnology to make available new water deficit resistant varieties and anti-transpirants that when applied on plants could reduce their transpiration (Fletcher and Nath, 1984).

Table 7. Annual water deficit (WD) and water surplus (WS) in $\mathrm{mm}_{\text {year }}{ }^{-1}$, obtained by the serial climatological water balance, for the present conditions $(\mathrm{C} 0)$ and future scenarios of climate change $(\mathrm{C} 1$ to C12), in the locations of Araçatuba, Assis, Jaboticabal and Piracicaba, state of São Paulo, Brazil.

\begin{tabular}{c|rr|rr|rr|rr}
\hline \multirow{2}{*}{$\begin{array}{c}\text { Climate } \\
\text { Scenarios }\end{array}$} & \multicolumn{2}{|c|}{ Araçatuba } & \multicolumn{2}{c|}{ Assis } & \multicolumn{2}{c|}{ Jaboticabal } & \multicolumn{2}{c}{ Piracicaba } \\
\cline { 2 - 8 } WD & \multicolumn{1}{|c|}{ WS } & WD & WS & WD & WS & WD & WS \\
\hline C0 & 480 & 209 & 61 & 244 & 248 & 288 & 146 & 181 \\
C1 & 689 & 0 & 252 & 39 & 472 & 89 & 375 & 16 \\
C2 & 625 & 0 & 214 & 68 & 445 & 122 & 337 & 50 \\
C3 & 569 & 53 & 147 & 129 & 397 & 188 & 276 & 108 \\
C4 & 544 & 83 & 119 & 161 & 375 & 228 & 254 & 137 \\
C5 & 890 & 0 & 502 & 0 & 651 & 37 & 650 & 0 \\
C6 & 826 & 0 & 425 & 0 & 617 & 65 & 582 & 0 \\
C7 & 709 & 7 & 352 & 0 & 559 & 126 & 480 & 37 \\
C8 & 681 & 34 & 297 & 87 & 533 & 159 & 444 & 63 \\
C9 & 1032 & 0 & 713 & 0 & 777 & 0 & 864 & 0 \\
C10 & 970 & 0 & 637 & 0 & 738 & 28 & 798 & 0 \\
C11 & 843 & 0 & 494 & 14 & 669 & 84 & 664 & 0 \\
C12 & 783 & 1 & 447 & 41 & 640 & 114 & 614 & 19 \\
\hline
\end{tabular}

\section{CONCLUSIONS}

From the results obtained in this study, we concluded that climate change, independently of the scenario considered, will impose an increase in potential and actual evapotranspirations, resulting in higher water deficits in all regions. This will be of great concern for sugarcane growers since it can reduce the yields of rainfed crops. On the other hand, water surplus will be reduced, which will have impact on groundwater and, consequently, on the water reservoirs levels, making irrigation very restrict and expansive. The changes in rainfall, positive $(+10 \%)$ or negative $(-10 \%)$, will have less influence on the water availability of the regions than the changes in temperature and, consequently, in evapotranspiration. In relation to the method of analysis, the use of historical data, year by year, allowed to identify that the impacts of climate change on water availability will be even worse than predicted by the studies which took into account only normal average data.

\section{REFERENCES}

CAMARGO, A. P; MARIN, F. R.; SENTELHAS, P. C.; PICINI, A. G. Ajuste da equação de Thornthwaite para estimar a evapotranspiração potencial em climas áridos e superúmidos, com base na amplitude térmica diária. Revista Brasileira de Agrometeorologia, Santa Maria, v. 7, n. 2, p. 251-257, 1999. 
SANTOS, D. L.; SENTELHAS, P. C. Climate Change Scenarios and Their Impact on the Water Balance of Sugarcane Production Areas in the State of São Paulo, Brazil. Ambi-Agua, Taubaté, v. 7, n. 2, p. 7-17, 2012. (http://dx.doi.org/10.4136/ambi-agua.907)

COMPANHIA NACIONAL DE ABASTECIMENTO - CONAB. Acompanhamento da safra brasileira: cana-de-açúcar, terceiro levantamento. Brasília, 2011. Disponível em: <http://www.conab.gov.br/OlalaCMS/uploads/arquivos/11_12_08_11_00_54_08.pdf>. Acesso em: 2 jan. 2012.

CRIMMINS, S. M.; DOBROWSKI, S. Z.; GREENBERG, J. A.; ABATZOGLOU, J. T.; MYNSBERGE, A. R. Changes in climatic water balance drive downhill shifts in plant species' optimum elevations. Science, v. 331, n. 6015, p. 324-327, 2011. http://dx.doi.org/10.1126/science.1199040

DESSAI, S.; VAN DER SLUIJS, J. Uncertainty and climate change adaptation - a scoping study. Utrecht: Copernicus Institute for Sustainable Development and Innovation, 2007. 95p.

FLETCHER, R. A.; NATH, V. Triadimefon reduces transpiration and increases yield in water stressed plants. Physiologia Plantarum, v. 62, n. 3, p. 422-426, 1984. http://dx.doi.org/10.1111/j.1399-3054.1984.tb04596.x

GOUVÊA, J. R. F.; SENTElHAS, P. C.; GAZZOLA, S. T.; SANTOS, M. C. Climate changes and technological advances: impacts on sugarcane productivity in tropical southern Brazil. Scientia Agricola, v. 66, n. 5, p. 593-605, 2009. http://dx.doi.org/10.1590/S0103-90162009000500003

HORIKOSHI, A. S.; FISCH, G. Balanço hídrico atual e simulações para cenários climáticos futuros no município de Taubaté, SP, Brasil. Revista Ambiente e Água, v. 2, n. 2, p. 33-46, 2007. http://dx.doi.org/10.4136/ambi-agua.26

IBARRA-MONTOYA, J. L.; ROMÁN, R.; GUTIÉRREZ, K.; GAXIOLA, J.; ARIAS, V.; BAUTISTA, M. Cambio em la cobertura y uso de suelo em el norte de Jalisco, México: um análisis del futuro, em um contexto de cambio climático. Revista Ambiente e Água, v. 6, n. 2, p. 111-128, 2011. http://dx.doi.org/10.4136/ambi-agua.189

INTERGOVERNMENTAL PANEL ON CLIMATE CHANGE - IPCC. Climate change 2007: the physical science basis. Summary for policymakers. Working Group I. Available in: <http://ipcc-wg1.ucar.edu/wg1Report/AR4WG1_Pub_SPM-v2.pdf>. Access in: 16 April 2009.

LI, Z.; LIU, W. Z.; ZHANG, X. C.; ZHENG, F. L. Assessing the site-specific impacts of climate change on hydrology, soil erosion and crop yields in the Loess Plateau of China. Climate Change, v. 105, n. 1/2, p. 223-242, 2011. http://dx.doi.org/10.1007/s10584010-9875-9

LIBERATO, A. M. L.; BRITO, J. I. B. Influência de mudanças climáticas no balanço hídrico da Amazônia Ocidental. Revista Brasileira de Geografia Física, v. 3, p. 170-180, 2010.

MARENGO, J. A. Água e mudanças climáticas. Estudos Avançados, v. 22, n. 63, p. 83-96, 2008. http://dx.doi.org/10.1590/S0103-40142008000200006

MARKS, D.; KING, G. A.; DOLPH, J. Implications of climate change for water balance of the Columbia river basin, USA. Climate Research, v. 2, p. 203-213, 1993.

MEDEIROS, Y. D. P. Análise dos impactos das mudanças climáticas em região semi-árida. Revista Brasileira de Recursos Hídricos, v. 8, n. 2, p. 127-136, 2003. 
MONTEIRO, L. A. Modelagem agrometeorológica como base para a definição de ambientes de produção para a cultura da cana-de-açúcar no Estado de São Paulo. 2012. 118f. Dissertação (Mestrado em Física do Ambiente Agrícola) - Escola Superior de Agricultura "Luiz de Queiroz", Universidade de São Paulo, Piracicaba, 2012.

PEDRO JÚNIOR, M. J.; MELlO, M. H. A.; ORTOLANI, A. A.; ALFONSI, R. R.; SENTELHAS, P. C. Estimativa das temperaturas médias mensais das máximas e das mínimas para o Estado de São Paulo. Campinas: Instituto Agronômico, 1991. 11p. (Boletim Técnico, 142).

PEREIRA, A. R.; ANGELOCCI, L. R.; SENTELHAS, P. C. Agrometeorologia: fundamentos e aplicações práticas. Guaíba: Agropecuária, 2002. 478 p.

PÉREZ, S.; SIERRA, E. Changes in rainfall patterns in the eastern area of La Pampa province, Argentina. Revista Ambiente e Água, v.7, n.1, p.24-35, 2012.

PRADO, H.; PÁDUA JUNIOR, A. L.; GARCIA, J. C.; MORAES, J. F. L.; CARVALHO, J. P.; DONZELI, P. L. Solos e ambientes de produção. In: DINARDO-MIRANDA, L. L. de; VASCONCELOS, A.C.M.; LANDELL, M.G.A. (Ed.). Cana-de-açúcar. Campinas: Instituto Agronômico, 2008. cap. 7, p. 179-204.

ROLIM, G. S.; SENTELHAS, P. C.; BARBIERI, V. Planilha no ambiente Excel ${ }^{\mathrm{TM}}$ para os cálculos de balanços hídricos: normal, seqüencial, de cultura e de produtividade real e potencial. Revista Brasileira de Agrometeorologia, v. 6, n. 1, p.133-137, 1998.

TERAMOTO, E. R. Avaliação e aplicação de modelos de estimativa de produção de canade-açúcar (Saccharum spp) baseados em parâmetros do solo e do clima. 2003. 86f. Tese (Doutorado em Agronomia) - Escola Superior de Agricultura "Luiz de Queiroz", Universidade de São Paulo, Piracicaba, 2003.

THORNTHWAITE, C. W.; MATHER, J. R. The water balance. New Jersey: Drexel Institute of Tecnology, 1955. 104p.

THORNTHWAITE, C. W. An approach toward a rational classification of climate. Geographical Review, Centeron, v. 38, n. 1, p. 55-94, 1948.

VILLANI, G.; TOMEI, F.; TOMOZEIU, R.; MARLETTO, V. Climatic scenarios and their impacts on irrigated agriculture in Emilia-Romagna, Italy. Italian Journal of Agrometeorology, v. 16, n. 1, p. 5-16, 2011.

ZULLO JUNIOR, J.; ASSAD, E. D.; PINTO, H.S. Alterações devem deslocar culturas agrícolas. Scientific American Brasil, São Paulo, v. 74, p. 72-77, 2008. 


ISSN = 1980-993X - doi:10.4136/1980-993X
www.ambi-agua.net
E-mail: ambi-agua@agro.unitau.br
Tel.: (12) 3625-4212

\title{
Effect of the bentonite application on the cadmium mobility in an Argisol
}

\author{
(http://dx.doi.org/10.4136/ambi-agua.901) \\ Gilvanise Alves Tito ${ }^{1}$ Lúcia Helena Garófalo Chaves²; \\ Hugo Orlando Carvallo Guerra ${ }^{3}$ \\ Departamento de Engenharia Agrícola, Universidade Federal de Campina Grande - PB \\ e-mails: ${ }^{2}$ gilvanisetito@yahoo.com.br, ${ }^{2}$ lhgarofalo@ hotmail.com, \\ ${ }^{3}$ hugo_carvallo@hotmail.com
}

\begin{abstract}
Aiming to evaluate the effect of doses of bentonite $\left(0,30\right.$ and $\left.60 \mathrm{t} \mathrm{ha}^{-1}\right)$ in the mobility of cadmium on an Argisol, tests of mobility in soil columns with different cadmium concentrations $\left(50,250\right.$ and $450 \mathrm{mg} \mathrm{kg}^{-1}$ of soil) and steady state flux, were conducted, determining its flux density and percolation velocity. The cadmium was dislocated by pulse, the solution containing the cadmium initially infiltrated into the soil for a given time period and afterwards the soil was lixiviated with distilled water. Leachates were collected every 10 minutes during 80 minutes of water percolation. The solutions percolated, expressed in pore volumes, were $6.33,2.28$ and 1.93 for the 0,30 and $60 \mathrm{t} \mathrm{ha}^{-1}$ of bentonite, respectively, being one pore volume equal to $1.22 \mathrm{~cm}^{3}$. The concentration of cadmium was measured by atomic absorption spectrophotometry. At the end of the experiment, the columns were dismounted and the concentrations of cadmium in the soil at different depths $(0-10,10-20,20-30$ e 30-40 $\mathrm{cm})$ were also determined. The results showed that the flux density and velocity of water percolation of the water solution were significantly reduced by the addition of bentonite to the soil. The levels of cadmium in the soil did not affect these mobility parameters. Increasing doses of bentonite favored the adsorption of cadmium in the soil.
\end{abstract}

Keywords: heavy metal, miscible displacement, clay mineral.

\section{Efeito da aplicação de bentonita na mobilidade de cádmio em Argissolo}

\section{RESUMO}

Objetivando-se avaliar o efeito da aplicação de doses de bentonita $\left(0,30\right.$ e $\left.60 \mathrm{t} \mathrm{ha}^{-1}\right)$ na mobilidade do cádmio num Argissolo, realizaram-se ensaios de mobilidade do referido metal em colunas de solo com diferentes concentrações de cádmio (50, 250 e $450 \mathrm{mg} \mathrm{de} \mathrm{kg}{ }^{-1} \mathrm{de}$ solo) submetidas a lixiviação num regime saturado, determinando-se a densidade do fluxo e a velocidade de fluxo. O cádmio foi deslocado por pulso, isto é, a solução contendo o cádmio inicialmente infiltrou no solo por um determinado tempo quando então a lixiviação foi continuada com água destilada. Lixiviados foram coletados a cada 10 minutos durante 80 minutos de percolação. As soluções percoladas, expressas em volume de poros, foram 6,33; 2,28 e 1,93 para os tratamentos de bentonita de 0,30 e $60 \mathrm{t} \mathrm{ha}^{-1}$ sendo um volume de poros igual a $1,22 \mathrm{~cm}^{3}$. As concentrações de cádmio determinadas por espectrofotometria de absorção atômica. Ao final dos ensaios, as colunas foram desmontadas e as concentrações de cádmio no solo a diferentes profundidades $(0-10,10-20,20-30$ e 30-40 cm), foram também 
TITO, G. A.; CHAVES, L. H. G.; GUERRA, H. O. C. Effect of the bentonite application on the cadmium mobility in an Argissol. Ambi-Agua, Taubaté, v. 7, n. 2, p. 18-29, 2012. (http://dx.doi.org/10.4136/ambiagua.901)

determinadas. Os resultados permitiram concluir que a densidade de fluxo e a velocidade de fluxo da solução foram reduzidas significativamente com a incorporação de bentonita ao solo. Os teores de cádmio do solo não afetaram a densidade de fluxo nem a velocidade de fluxo da solução. $\mathrm{O}$ aumento das doses de bentonita favoreceu a adsorção do cádmio pelo solo.

Palavras-chaves: metal pesado, deslocamento miscível, mineral de argila.

\section{INTRODUCTION}

In recent years, environmental pollution has reached alarming levels causing a great concern to the society, creating a conscience of environmental preservation. One of the problems that most affect the water environment is the organic or inorganic pollution resulting from residential and industrial effluents, in which the presence of heavy metals may occur. Cadmium $(\mathrm{Cd})$ is a highly toxic metal and has been described as the most dangerous of all the contaminants metals in the environment (Albertini et al., 2001; Guimarães et al., 2008). When added to soil it is absorbed rapidly increasing dramatically the accumulated level of the element (Paganini et al., 2004). According to Malavolta (1994) Cd available concentrations in the soil above $3 \mathrm{mg} \mathrm{kg}^{-1}$ are considered toxic, inadequate for the cultivation of human consumption plants.

The contaminant accumulation and transport processes in the soil depend of the soil type and the contaminant nature. The $\mathrm{pH}$, the organic matter, the cation exchange capacity, the specific surface and the ionic forces are soil attributes that correlate well with the adsorption of cadmium. The composition and the properties of the cadmium contaminant are significant factors on the development of the interactions with the soil subtract. The interactions between the soil and the cadmium determinate the fate and mobility of cadmium in the environment and they are the result of adsorption, complexation, dissolution, and precipitation reactions in the soil. However, although these processes occur simultaneously, the adsorption reactions are probably the one that more affect the availability of cadmium in the soil (Camargo, 2006).

The use of low quality irrigation water, the application of sewage sludge as source of nutrients for plants and the indiscriminate use of agrotoxics are dangerous sources of pollution, especially of heavy metals. According to Costa et al. (2007), the impact of heavy metal contamination should not be evaluated only by its soil total content, but by their bioavailability, which is a property related to its mobility in soil and uptake by plants.

One of the procedures proposed to reduce the mobility and bioavailability of metals, is the use of adsorbent materials, such as clay minerals (Rodrigues et al., 2004; Chui, 2005; Lacin et al., 2005). The sorption of cations can cause a real transfer of pollutants from the liquid to the solid phase. The mobility of solutes in soil is inversely related to the adsorption of the soil and the environmental conditions that favor chemical precipitation (Matos et al., 2001; Chaves et al., 2008).

The bentonite is a clay mineral constituted mainly of smectite, usually known as montmorillonite. Expansive and predominantly negative charged shows a high cation exchange capacity (CEC). In general, clay minerals are considered to be the active part of the soil, influencing the retention and movement of soil water, adsorption and ion exchange (Meurer, 2004), the latter being the most important mechanism for adsorption of inorganic pollutants such as heavy metals. Due to its sorbent properties, its low cost and feasibility to obtain it (the State of Paraiba is currently the largest bentonite producer in Brazil) studies have been conducted to evaluate the properties of the bentonite as a sorbent for heavy metals (Santos et al., 2002; Rodrigues et al., 2004; Lacin et al., 2005). Thus, the present study aimed to evaluate the effect of bentonite on the mobility of cadmium in soil columns, determining 
TITO, G. A.; CHAVES, L. H. G.; GUERRA, H. O. C. Effect of the bentonite application on the cadmium mobility in an Argissol. Ambi-Agua, Taubaté, v. 7, n. 2, p. 18-29, 2012. (http://dx.doi.org/10.4136/ambiagua.901)

the flux density and velocity of the solution, and the amount of $\mathrm{Cd}$ leached and remaining in the soil columns after application of different pore volumes of water.

\section{MATERIALS AND METHODS}

The experiment was conducted at the Agricultural Engineering Department in Campina Grande, Paraiba State, Brazil using a dystrophic Argisol. The bentonite clay used was collected at a deposit (Primavera) located in the city of Boa Vista, Paraiba, Brazil. The clay was analyzed by X-ray diffraction using the XRD 6000 equipment with a radiation of $\mathrm{K} \alpha \mathrm{Cu}$ $(40 \mathrm{kV} / 30 \mathrm{~mA})$. Figure 1 shows the $\mathrm{X}$-ray diffractogram of the bentonite showing characteristic peaks of the smectite clay mineral, the main component of the bentonite, as well as the presence, in minor amount, of silicon oxide peaks. The X-ray analysis was conducted at the Ceramics Laboratory of the Materials Engineering Department, Federal University of Campina Grande-PB.

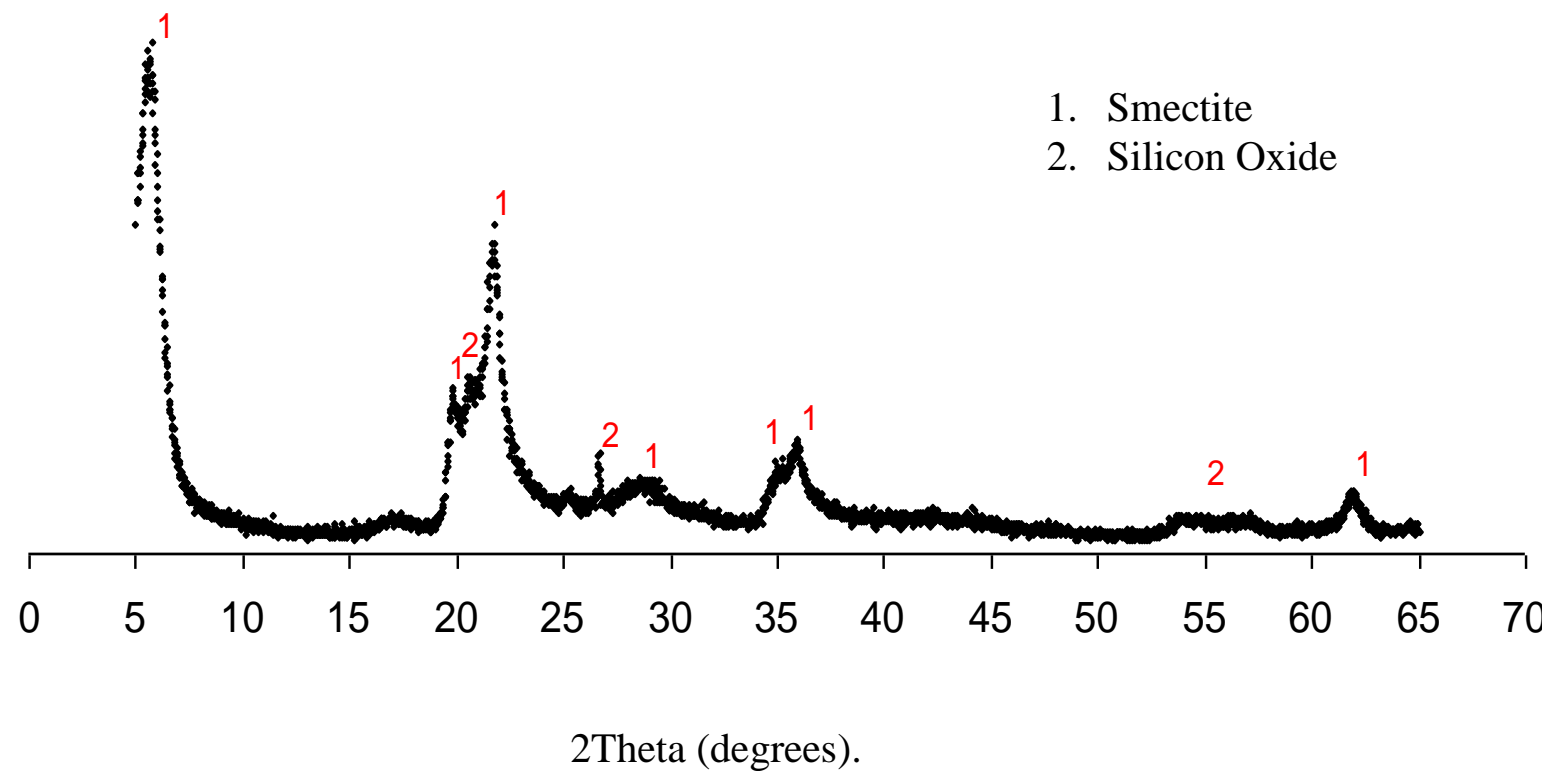

Figure 1. Diffractogram of bentonite obtained by X-ray diffraction.

X-ray fluorescent analysis of the clay were also conducted at the Ceramics Laboratory of the Materials Engineering Department, Federal University of Campina Grande-PB, with the EDX 720, being quantified: $\mathrm{SiO}_{2}=76.09 \% ; \mathrm{Al}_{2} \mathrm{O}_{2}=14.51 \% ; \mathrm{Fe}_{2} \mathrm{O}_{3}=5.21 \% ; \mathrm{MgO}=2.22 \%$; $\mathrm{CaO}=0.76 \% ; \mathrm{TiO}_{2}=0.55 \% ; \mathrm{BaO}=0.19 \% ; \mathrm{K}_{2} \mathrm{O}=0.18 \% ; \mathrm{MnO}=0.028 \% ;$ $\mathrm{Cr}_{2} \mathrm{O}_{3}=0.023 \% ; \mathrm{SrO}=0.008 \% ; \mathrm{ZnO}=0.004 \%$ and calcined residues $=0.23 \%$.

The soil sample was air dried, passed through a $2 \mathrm{~mm}$ mesh opening sieve and analyzed with respect to their physical and chemical characteristics (Table 1)

Four kilograms of soil were mixed with $0.00 ; 0.45$ and $0.90 \mathrm{~kg}$ of bentonite, corresponding to the doses of 0 (B0), 30 (B30) and 60 (B60) $\mathrm{t} \mathrm{ha}^{-1}$. These mixtures were left to rest during 30 days, allowing the reaction between soil and bentonite. After this period, the mixtures were again air dried and passed through a $2 \mathrm{~mm}$ sieve. A cadmium solution, prepared from $\mathrm{CdCl}_{2} . \mathrm{H}_{2} \mathrm{O}$, was added to the soil to obtain equivalent concentrations of 50 , 250 and $450 \mathrm{mg} \mathrm{kg}^{-1}$ of soil. 
TITO, G. A.; CHAVES, L. H. G.; GUERRA, H. O. C. Effect of the bentonite application on the cadmium mobility in an Argissol. Ambi-Agua, Taubaté, v. 7, n. 2, p. 18-29, 2012. (http://dx.doi.org/10.4136/ambiagua.901)

Table 1. Physical and Chemical characteristics of the Argisol used in the experiment.

\begin{tabular}{|c|c|}
\hline Characterístics & Value \\
\hline Sand $\left(\mathrm{g} \mathrm{kg}^{-1}\right)$ & 867.9 \\
\hline Silt $\left(\mathrm{g} \mathrm{kg}^{-1}\right)$ & 40.3 \\
\hline Clay $\left(\mathrm{g} \mathrm{kg}^{-1}\right)$ & 91.8 \\
\hline Textural class & sand \\
\hline Field Capacity (\%) & 24.42 \\
\hline Permanent Wilting Point (\%) & 3.88 \\
\hline Density & 1.56 \\
\hline Particle Density & 2.55 \\
\hline Total Porosity (\%) & 39.0 \\
\hline $\mathrm{pH}$ & 5.79 \\
\hline Electrical Conductivity $\left(\mathrm{dS} \mathrm{m}^{-1}\right)$ & 0.37 \\
\hline Phosphorus* (mg dm ${ }^{-3}$ ) & 18.3 \\
\hline Potassium** $\left(\mathrm{cmol}_{\mathrm{c}} \mathrm{kg}^{-1}\right)$ & 0.05 \\
\hline Sodium $* *\left(\mathrm{cmol}_{\mathrm{c}} \mathrm{kg}^{-1}\right)$ & 0.03 \\
\hline Calcium** $\left(\mathrm{cmol}_{\mathrm{c}} \mathrm{kg}^{-1}\right)$ & 2.61 \\
\hline Magnesium $* *\left(\mathrm{cmol}_{\mathrm{c}} \mathrm{kg}^{-1}\right)$ & 0.83 \\
\hline $\mathrm{H}^{+}+\mathrm{Al}^{2+}\left(\mathrm{cmol}_{\mathrm{c}} \mathrm{kg}^{-1}\right)$ & 1.48 \\
\hline Cation Exchange Capacity ${ }_{\text {pot }}\left(\mathrm{cmol}_{\mathrm{c}} \mathrm{kg}^{-1}\right)$ & 5.00 \\
\hline Organic Carbon \% & 0.94 \\
\hline Organic Matter g/kg & 16.2 \\
\hline Zinc* $\left(\mathrm{mg} \mathrm{kg}^{-1}\right)$ & 0.264 \\
\hline Copper* $\left(\mathrm{mg} \mathrm{kg}^{-1}\right)$ & 0.074 \\
\hline Cadmium* $\left(\mathrm{mg} \mathrm{kg}^{-1}\right)$ & 0.017 \\
\hline
\end{tabular}

The experimental design was a completely randomized in a $3 \times 3$ factorial arrangement (three doses of bentonite and three cadmium concentrations), with three replicates, totalizing 27 experimental units. Each experimental unit consisting of a PVC column, $500 \mathrm{~mm}$ height and $100 \mathrm{~mm}$ in diameter filled with $4 \mathrm{~kg}$ of soil plus bentonite. The columns were constructed of five rings $100 \mathrm{~mm}$ in height superimposed and joined with silicone glue. These rings facilitate the removal of samples of solid material at different depths at the end of experiment. At the bottom of the column was placed a cap with a PVC tube adapted in its center to drain 
TITO, G. A.; CHAVES, L. H. G.; GUERRA, H. O. C. Effect of the bentonite application on the cadmium mobility in an Argissol. Ambi-Agua, Taubaté, v. 7, n. 2, p. 18-29, 2012. (http://dx.doi.org/10.4136/ambiagua.901)

the percolated solution (Figure 2). Over the cap was placed an screen filter paper to support the solid material. The columns were filled with the soil bentonite mixture compacting with a socket each layer applied in order to provide uniformity in the density throughout the soil column. The columns were connected to a Mariotte bottle containing distilled water and saturated by capillary rise, then the columns were submitted to a constant flux maintaining a constant water level of $80 \mathrm{~mm}$ above the soil surface.

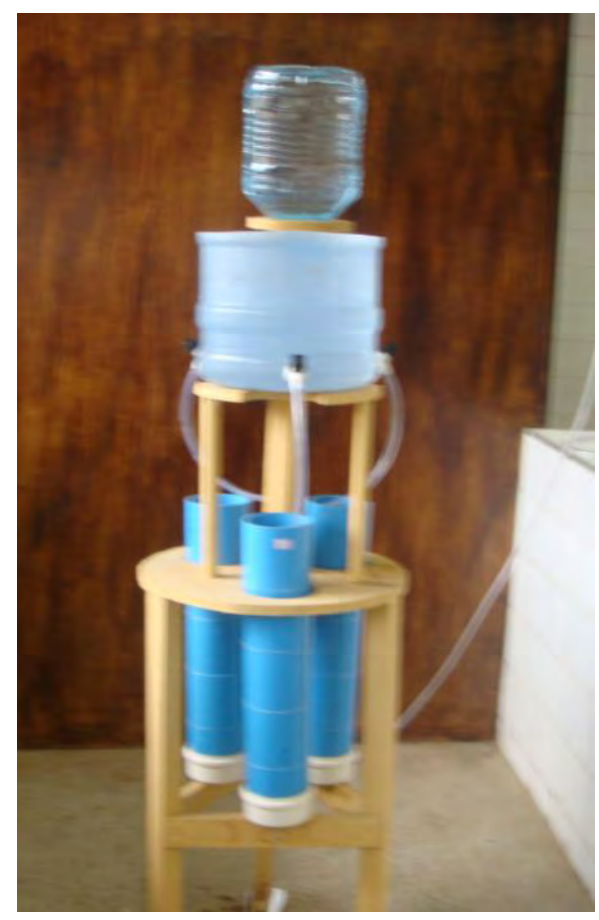

Figure 2. Set up utilized for mobility tests with three plastic columns filled with soil and bentonite.

After stabilization of the flow, the water supply at the top of each column was stopped and allowed to drain one pore volume of solution. At the end of the drainage, the bottom of the columns were closed and on top of them added a pore volume of metal solution equivalent to 50,250 and $450 \mathrm{mg} \mathrm{kg}^{-1}$ cadmium concentrations allowing to stand during 24 hours to facilitate the reactions among the soil mixture and the cadmium. After this period, the drains were opened again, and the supply of mineral water restarted and the percolation reinitiated, keeping the hydraulic charge of $80 \mathrm{~mm}$ of water. The percolation lasted 80 minutes removing leachates every 10 minutes. The solutions percolated, expressed in pore volumes, were 6.33, 2.28 and 1.93 for the 0,30 and $60 \mathrm{t} \mathrm{ha}^{-1}$ of bentonite.

The soil column pore volume was determined using the following equation:

$$
\mathrm{PV}=\pi \mathrm{r}^{2} \mathrm{~h}\left(1-\mathrm{ds} \mathrm{dp^{-1 } )}\right.
$$

where:

$\mathrm{PV}$ is the pore volume $\left(\mathrm{cm}^{3}\right), \mathrm{r}$ the column ratio $(\mathrm{cm}), \mathrm{h}$ the column length $(\mathrm{cm})$, and $\mathrm{ds} \mathrm{e}$ $\mathrm{dp}$ the soil density and particle density, respectively. The pore volume of the soil column was $1.22 \mathrm{~cm}^{-3}$.

To determine the cadmium content in the percolates, the solution samples collected were placed in polypropylene bottles, identified and stored in refrigerator until preparation for 
TITO, G. A.; CHAVES, L. H. G.; GUERRA, H. O. C. Effect of the bentonite application on the cadmium mobility in an Argissol. Ambi-Agua, Taubaté, v. 7, n. 2, p. 18-29, 2012. (http://dx.doi.org/10.4136/ambiagua.901)

quantification of the metal by atomic absorption spectrophotometry. At the end of the tests, the columns were dismounted separating the rings that composed it. The solid material contained in each ring was left to air dry, weighed and sieved to $2 \mathrm{~mm}$ mesh. The concentration of cadmium in the soil was determined using the normally used Mehlich extraction solution (Embrapa, 1997). The standard EPA procedures, very used in the laboratories, were not adopted; although the procedures of digestion and removal of metal are more efficient according with Silva et al. (2007) the EPA method has limitations to determine nickel and cadmium in the soil, because does not solubilizes the precipitated or occluded metals. For this, it would be necessary to conduct the extraction with fluorhidric acid, which is highly corrosive, of dangerous handling and responsible for damage to the instruments that conduct the analysis.

The mobility parameters of the cadmium in the soil (flux density and velocity) were determined using the DISP software developed at the Agricultural Engineering Department of the Federal University of Viçosa, by Borges Júnior and Ferreira (2006). The computational soft DISP calculates the parameters of soil solute transport equations, based on adjustment of theoretical models to observed data, as well as performs simulations for the space and temporary variations of the concentration and balance of the solute mass in the soil profile. The DISP uses the least-squares method to obtain the diffusion-dispersion coefficient and retardation factor parameters. Comparative tests between DISP and the program CXTFIT, relative to the calculations of the Peclet number and retardation factor parameters, pointed out equivalence between both programs, however the graphic interface in DISP makes its use more feasible in relation to CXTFIT. The CXTFIT 2.0 program provides a convenient way of solving direct and inverse problems for one-dimensional solute transport during steady water flow. PHREEQC and HYDRUS 1D, 2D, 3D models were not necessary to use. The input parameters for the DISP were the observed absolute cadmium concentrations $(\mathrm{C})$ for different pore volumes, soil water content (equal to saturation because the flux was under saturated conditions), soil density, column length, initial and final cadmium concentration.

The results obtained were subjected to analysis of variance, using the SISVAR program (Ferreira, 2003).

\section{RESULTS AND DISCUSSION}

The flux density and velocity of the solution were significantly influenced at the $1 \%$ probability level by the bentonite treatment. The increasing concentration of $\mathrm{Cd}$ and the interaction between $\mathrm{Cd}$ concentrations and doses of bentonite, were not significant (Table 2).

Applications of 30 and $60 \mathrm{t} \mathrm{ha}^{-1}$ bentonite compared to control $\left(0 \mathrm{t} \mathrm{ha}^{-1}\right)$ reduced the flux density in 72.62 and $78.63 \%$ and the percolation rate in 76.27 and $83.00 \%$, respectively. The beneficial effect of bentonite application can be attributed to the fact that this clay has a large quantity of micropores which difficult the passage of water and solutes through the soil, and also because its high specific surface favors cation exchange. Water moves more quickly through the large pores and spaces in a sandy soil, as the one used on this study, than it does through the small pores in a clayey soil; thus addition of bentonite clay to the soil favors the retention of water and pollutants. A low flow velocity and a high adsorption of the pollutant by the clay reduce risks of contamination by percolation.

According Jesus (2004), the migration and retention of pollutants in the soil is influenced, among other factors, by the mineralogy and cation exchange capacity of the soil. Because the reactions among the clay and pollutants are not instantaneous, if the flow velocity is relatively high, the cations do not have chance to be retained by the soil, being percolated and contaminating the subsoil waters (Freeze and Cherry, 1979). 
TITO, G. A.; CHAVES, L. H. G.; GUERRA, H. O. C. Effect of the bentonite application on the cadmium mobility in an Argissol. Ambi-Agua, Taubaté, v. 7, n. 2, p. 18-29, 2012. (http://dx.doi.org/10.4136/ambiagua.901)

Table 2. Summary of variance analysis and mean comparison test for the flow density and velocity as affected by cadmium and bentonite treatments.

\begin{tabular}{|c|c|c|c|}
\hline \multirow{2}{*}{$\begin{array}{c}\text { Sources of } \\
\text { variation }\end{array}$} & \multirow{2}{*}{$\begin{array}{c}\text { Degrees of } \\
\text { Freedom }\end{array}$} & \multicolumn{2}{|c|}{ Mean Square } \\
\hline & & Flux Density & Flow Velocity \\
\hline Cadmium (C) & 2 & $74.91 \mathrm{~ns}$ & $492.47 \mathrm{~ns}$ \\
\hline Bentonite (B) & 2 & $11742.6 * *$ & $77203.2 * *$ \\
\hline $\mathrm{C} \times \mathrm{B}$ & 4 & $132.46 \mathrm{~ns}$ & $870.83 \mathrm{~ns}$ \\
\hline Residue & 18 & 33.76 & 221.94 \\
\hline $\mathrm{CV}(\%)$ & & 14.00 & 14.09 \\
\hline \multicolumn{2}{|l|}{ Bentonite } & \multicolumn{2}{|c|}{ Mean $\left(\mathrm{cm} \mathrm{h}^{-1}\right)$} \\
\hline \multicolumn{2}{|l|}{$0 \mathrm{t} \mathrm{ha}^{-1}$} & 81.67 & 209.4 \\
\hline \multicolumn{2}{|l|}{$30 \mathrm{tha}^{-1}$} & 22.36 & 49.69 \\
\hline \multicolumn{2}{|l|}{$60 \mathrm{t} \mathrm{ha}^{-1}$} & 17.45 & 35.61 \\
\hline \multicolumn{2}{|c|}{ Linear Regression } & $\begin{array}{c}\mathrm{Y}=-30.3 \mathrm{X}+100.9 \\
\mathrm{R}^{2}=80.9 \%\end{array}$ & $\begin{array}{c}\mathrm{Y}=-77.6 \mathrm{X}+258.8 \\
\mathrm{R}^{2}=80.9 \%\end{array}$ \\
\hline \multicolumn{2}{|c|}{ Quadratic Regression } & $\begin{array}{c}\mathrm{Y}=25.5 \mathrm{X}^{2}-132.2 \mathrm{X}+ \\
185.9 \mathrm{R}^{2}=100 \%\end{array}$ & $\begin{array}{c}Y=65.4 X^{2}-339 X+476.8 \\
R^{2}=100 \%\end{array}$ \\
\hline \multicolumn{2}{|l|}{ Cadmium } & \multicolumn{2}{|c|}{ Mean $\left(\mathrm{cm} \mathrm{h}^{-1}\right)$} \\
\hline \multicolumn{2}{|l|}{$50 \mathrm{mg} \mathrm{kg}^{-1}$} & $38.85 \mathrm{a}$ & $99.62 \mathrm{a}$ \\
\hline \multicolumn{2}{|l|}{$250 \mathrm{mg} \mathrm{kg}^{-1}$} & $40.39 \mathrm{a}$ & $89.76 \mathrm{a}$ \\
\hline \multicolumn{2}{|l|}{$450 \mathrm{mg} \mathrm{kg}^{-1}$} & $44.44 \mathrm{a}$ & $90.69 \mathrm{a}$ \\
\hline
\end{tabular}

**, ns, Significant at $1 \%$ (F test) and no significant, respectively. Means followed by the same letter in column do not differ among themselves by Tukey test at $5 \%$ probability

In all the bentonite treatments it was not detected cadmium in the percolated solutions indicating that possibly the cadmium was transformed and retained by the soil in some chemical form, corroborating the results found by Amaral Sobrinho et al. (1999), Anjos and Mattiazzo (2000), Prado and Juliatti (2003), Dal Bosco et al. (2004) and Moreira et al. (2010). One explanation for this is the possible reactions of the cadmium with the oxides present in the soil and bentonite (mainly $\mathrm{Fe}$ and $\mathrm{Al}$ oxides) as shown by the fluorescent analysis described in the Materials and Methods. Wittbroadt and Palmer (1997) working with heavy metals in soil-humic acids also reported that the presence of oxides of $\mathrm{Fe}$ and $\mathrm{Al}$ in the soil has been used to explain the absence of heavy metals in leachates of soils treated with biosolids. Same fact was observed by Nascimento et al. (2010) studying the leaching of lead and zinc in soils treated with steel waste. Another explanation for not detecting $\mathrm{Cd}$ in soil solution in the present study maybe because the $\mathrm{Cd}$ concentrations were below the limit of detection of the instrument used, in this case the atomic absorption spectrometry $\left(0.034 \mathrm{mg} \mathrm{kg}^{-1}\right)$.

Figure 3 shows the distribution curves of cadmium at the 0-10, 10-20, 20-30 and 30-40 $\mathrm{cm}$ soil layers at the end of the experiment and after sectioning the columns. 
TITO, G. A.; CHAVES, L. H. G.; GUERRA, H. O. C. Effect of the bentonite application on the cadmium mobility in an Argissol. Ambi-Agua, Taubaté, v. 7, n. 2, p. 18-29, 2012. (http://dx.doi.org/10.4136/ambiagua.901)
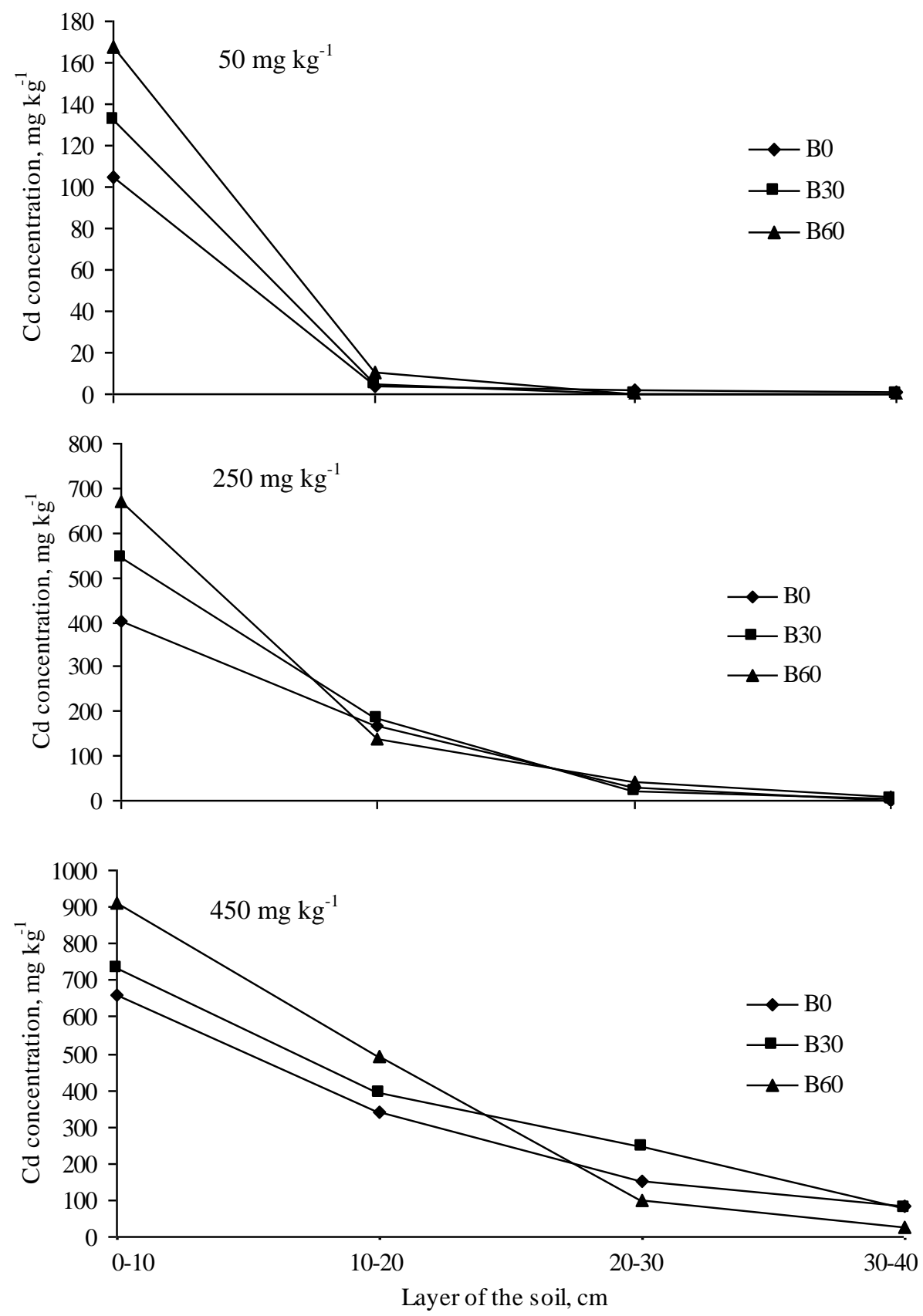

Figure 3. Distribution of the available cadmium in the 0-10, 10-20, 20-30 and $30-40 \mathrm{~cm}$ soil layers of the column after the lixiviation with 7 pore volumes of distilled water, for the different cadmium levels $(50 ; 250$ and $\left.450 \mathrm{mg} \mathrm{kg}^{-1}\right)$ and doses of bentonite applied to the soil $\left(0 ; 30\right.$ and $\left.60 \mathrm{tha}^{-1}\right)$.

It was observed that after the lixiviation with 7 pore volumes of distilled water, the highest levels of cadmium in the soil columns, regardless of bentonite concentrations, were found in the first layer of soil column $(0-10 \mathrm{~cm})$ decreasing significantly with depth. Messias et al. (2007) evaluating the mobility of micronutrients in soil treated with sewage sludge, also found that the $\mathrm{Cd}$ was retained most in the first layer of soil. Juliatti et al. (2002) studying the availability and mobility of $\mathrm{Cd}$ in a Red Oxisol observed that the higher concentrations of total $\mathrm{Cd}$ were restricted only to the surface layer of the soil not existing downward movement of the element into the soil. The high concentration of $\mathrm{Cd}$ at the soil surface characterize an strong interaction among the cadmium and the soil, probably a high 
TITO, G. A.; CHAVES, L. H. G.; GUERRA, H. O. C. Effect of the bentonite application on the cadmium mobility in an Argissol. Ambi-Agua, Taubaté, v. 7, n. 2, p. 18-29, 2012. (http://dx.doi.org/10.4136/ambiagua.901)

adsorption already at the surface layer, decreasing with depth to such extent that no Cadmium was detected in the percolated solution. The same was observed by Amaral Sobrinho et al. (1999) studying the lixiviation of $\mathrm{Pb}, \mathrm{Zn}, \mathrm{Cd}$ and $\mathrm{Ni}$ in a Yellow Red Podzolic soil.

With respect to the bentonite dose it can confirmed on Figure 3 that the Cd adsorption increased with the addition of bentonite. These results were expected since the bentonite is a 2:1 clay mineral with a high cation exchange and adsorption capacity. Figure 4 shows the total concentration of cadmium found in the soil column after the lixiviation with 7 pore volumes of distilled water for the different bentonite and cadmium treatments studied. Although $\mathrm{Cd}$ was not detected in the percolated solution, the total concentration for $\mathrm{Cd}$ determined in the soil after the dismantling of the columns, was lower than the total quantities of $\mathrm{Cd}$ applied to the soil at the beginning of the experiment. In the soil with $50 \mathrm{mg} \mathrm{kg}^{-1}$ of $\mathrm{Cd}$ were found only $55.68,68.85$ and $89.44 \%$ of the content initially applied to soil columns for the $0 ; 30$ and $60 \mathrm{t} \mathrm{ha}^{-1}$ bentonite treatments, respectively.

The high $\mathrm{Cd}$ concentrations found in the soil column after the lixiviation with 7 pore volumes of distilled water, when compared with the initially applied to the soil can be attributed to the fact that probably the extracting solution utilized by the Mehlich method did not extract the metal in all the forms found in the soil. According to Amaral Sobrinho et al. (2009), the different forms in which heavy metals in the soil may occur (soluble, exchangeable and adsorbed form; occluded in oxides of $\mathrm{Fe}, \mathrm{Al}$ and $\mathrm{Mn}$ form; retained in insoluble organic material form and precipitated forms) are only determined by specific extractors.
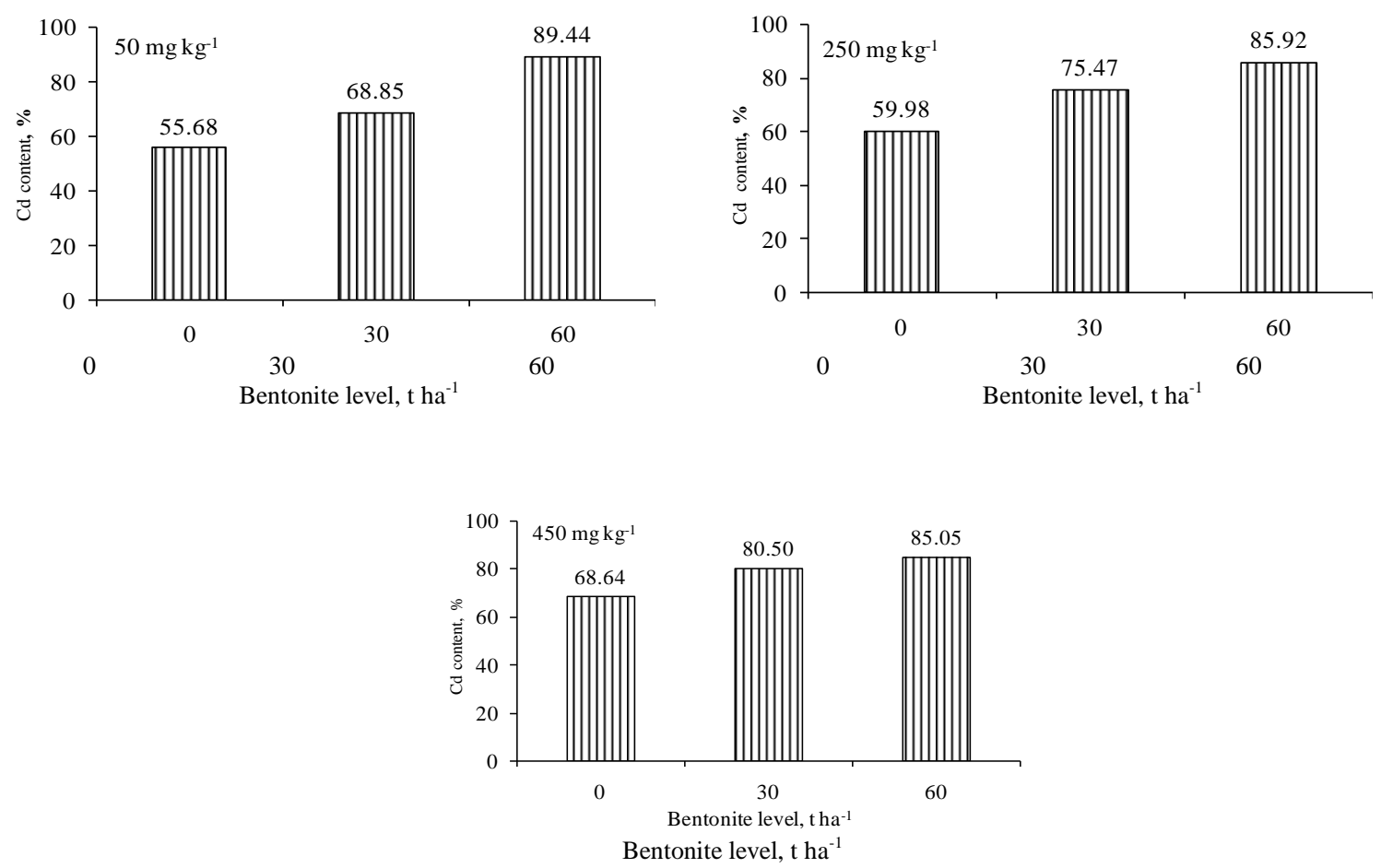

Figure 4. Cadmium content in the soil columns submitted to different cadmium $(50 ; 250$ and $\left.450 \mathrm{mg} \mathrm{kg}^{-1}\right)$ and bentonite $\left(0 ; 30\right.$ and $\left.60 \mathrm{t} \mathrm{ha}^{-1}\right)$ levels.

\section{CONCLUSIONS}

The mobility parameters flux density and percolation velocity of the solution were reduced significantly with the application of bentonite to the sandy soil used; 
TITO, G. A.; CHAVES, L. H. G.; GUERRA, H. O. C. Effect of the bentonite application on the cadmium mobility in an Argissol. Ambi-Agua, Taubaté, v. 7, n. 2, p. 18-29, 2012. (http://dx.doi.org/10.4136/ambiagua.901)

The cadmium content of the soil did not affect the flux density and the percolation rate of the solution;

Increasing doses of bentonite promoted the adsorption of cadmium into the soil.

Practically, there was not mobility of $\mathrm{Cd}$ in the soil column.

\section{ACKNOWLEDGMENTS}

Special thanks to the CNPq for granting the Ph.D. scholarship to the first author and to the Bentonite Union Industry and Commerce Ltda. for the donation of the bentonite.

\section{REFERENCES}

ALBERTINI, S.; CARMO. L. F.; PRADO FILHO, L. G. Isotermas de adsorção de cádmio por Saccharomyces cerevisiae. Ciência e Tecnologia de Alimentos, Campinas, v. 21, n. 2, p. 134-138, 2001. http://dx.doi.org/10.1590/S0101-20612001000200002

AMARAL SOBRINHO, N. M. B.; VELlOSO, A. C. X.; COSTA, L. M. Lixiviação de Pb, Zn, Cd e Ni em solos Podzólico Vermelho Amarelo tratado com resíduos siderúrgicos. Revista Floresta e Ambiente, Seropédica, v. 6, n. 1, p. 65-75, 1999.

AMARAL SOBRINHO, N. M. B.; BARRA, C. M.; LÃ, O. R. Químicas dos metais pesados no solo. In: MELO, V. F.; ALLEONI, L. R. F. (Eds.). Química e mineralogia do solo. Viçosa, MG: SBCS, 2009. v. 2. p. 249-312.

ANJOS, A. R. M.; MATTIAZZO, M. E. Lixiviação de íons inorgânicos em solos repetidamente tratados com biossólido. Revista Brasileira de Ciência do Solo, Viçosa, MG, v. 24, n. 4, p. 927-938, 2000. http://www.redalyc.org/src/inicio/ArtPdfRed. jsp?iCve $=253019677001$

BORGES JÚNIOR, J. F.; FERREIRA, P. A. Equações e programa computacional para cálculo do transporte de solutos do solo. Revista Brasileira de Engenharia Agrícola e Ambiental, Campina Grande, v. 10, n. 3, p. 604-611, 2006. http://dx.doi.org/10.1590/S1415-43662006000300010

CAMARGO, O. A. Reações e interações de micronutrientes no solo. 2006. Available in: <http://www.infobibos.com/Artigos/2006_3/micronutrientes/Index.htm>. Access in: 12 July 2012.

CHAVES, L. H. G.; SOUZA, R. S.; TITO, G. A. Adsorção de zinco em Argissolos do Estado da Paraíba: efeito do pH. Revista Ciência Agronômica, Fortaleza, v. 39, n. 4, p. 511516, 2008.

CHUI, Q. S. H. Uso da vermiculita massapé paulistana como adsorvedora de metais. Engenharia Sanitária e Ambiental, Rio de Janeiro, v. 10, n. 1, p. 58-63, 2005. http://dx.doi.org/10.1590/S1413-41522005000100007

COSTA, C. DAS N.; BISSANI, C. A.; TEDESCO, M. J. Fracionamento seqüencial de cádmio e chumbo em solos. Ciência Rural, Santa Maria, v. 37, n. 5, p. 1323-1328, 2007. http://dx.doi.org/10.1590/S0103-84782007000500016

DAL BOSCO, S. M.; JIMENEZ, R. S.; CARVALHO, W. A. Aplicação da zeólita natural escolecita na remoção de metais pesados de efluentes industriais: competição entre os cátions e processo de dessorção. Eclética Química, São Paulo, v. 29, n. 1, p. 47-56, 2004. http://dx.doi.org/10.1590/S0100-46702004000100006 
TITO, G. A.; CHAVES, L. H. G.; GUERRA, H. O. C. Effect of the bentonite application on the cadmium mobility in an Argissol. Ambi-Agua, Taubaté, v. 7, n. 2, p. 18-29, 2012. (http://dx.doi.org/10.4136/ambiagua.901)

EMPRESA BRASILEIRA DE PESQUISA AGROPECUÁRIA - EMBRAPA. Centro Nacional de Pesquisa de Solos. Manual de métodos de análise de solo. 2. ed. Rio de Janeiro: EMBRAPA Solos, 1997. 212 p.

FERREIRA, D. F. Sistema de análises estatísticas - SISVAR. Versão 4.6 (Build 60). Lavras: DEX/ UFLA, 2003.

FREEZE, R. A.; CHERRY, J. A. Groundwater. Englewood Cliffs: Prentice-Hall, 1979. $604 \mathrm{p}$.

GUIMARÃES, M. A.; SANTANA, T. A.; SILVA, E. V.; ZENZEN, I. L.; LOUREIRO, M. E. Toxidade e tolerância ao cádmio em plantas. Revista Trópica - Ciências Agrárias e Biológicas, Chapadinha, v. 1, n. 3, p. 58-68, 2008.

JESUS, S. C. Difusão de zinco em camada compactada de solo residual de gnaisse. 2004. 90f. Tese (Doutorado em Engenharia Civil) - Universidade Federal de Viçosa, Viçosa, MG, 2004.

JULIATTI, M. A.; PRADO, R. M.; BARRIQUELO, M. F.; LENZI, E. Cádmio em latossolo vermelho cultivado com milho em colunas: mobilidade e biodisponibilidade. Revista Brasileira de Ciência do Solo, Viçosa, MG, v. 26, p. 1075-1081, 2002. http://redalyc.uaemex.mx/src/inicio/ArtPdfRed.jsp?iCve=180218306026

LACIN, O.; BAYRAK, B.; KORKUT, O.; SAYAN, E. Modeling of adsorption and ultrasonic desorption of cadmium (II) and zinc (II) on local bentonite. Journal of Colloid and Interface Science, v. 292, n. 2, p. 330-335, 2005. http://dx.doi.org/10.1016/j.jcis. 2005.05.092

MALAVOLTA, E. Fertilizantes e seu impacto ambiental: micronutrientes e metais pesados, mitos, mistificação, e fatos. São Paulo: Produquímica, 1994. p. 4-121.

MATOS, A. T.; FONTES, M. P. F.; COSTA, L. M.; MARTINEZ, M. A. Mobility of heavy metals as related to soil chemical and mineralogical characteristics of Brazilian soils. Environmental Pollution, v. 111, n. 3, p. 429-435, 2001. http://dx.doi.org/10.1016/ S0269-7491 (00)00088-9

MESSIAS, A. S.; SILVA, H. A. E.; LIMA, V. N.; SOUZA, J. E. G. Avaliação da mobilidade de micronutrientes em solo tratado com lodo de esgoto. Revista Brasileira de Gestão e Desenvolvimento Regional, Taubaté, v. 3, p.193-211, 2007.

MEURER, E. J. Fundamentos de química de solo. 2. ed. Porto Alegre: Genesis, 2004. 290p.

MOREIRA, D. A.; MARTINEZ, M. A.; SOUZA, J. A. R.; MATOS, A. T.; REIS, C.; BARROS, F. M. Fatores de retardamento e coeficientes de dispersão-difusão de metais pesados em resíduos da construção civil e demolição. Revista Ambiente \& Água, Taubaté, v. 5, n. 2, p. 77-86, 2010. http://dx.doi.org/10.4136/ambi-agua.138

NASCIMENTO, R. S. MELO DO; CARVALHO, G. S.; PASSOS, L.; MARQUES, J. J. Lixiviação de chumbo e zinco em solos tratados com resíduos de siderurgia. Pesquisa Agropecuária Tropical, Goiânia, v. 40, n. 4, p. 497-509, 2010. http://www.redalyc.org/src/inicio/ArtPdfRed.jsp?iCve=253019677001

PAGANINI, W. S.; SOUZA, A.; BOCCHIGLIERI, M. M. Avaliação do comportamento de metais pesados no tratamento de esgotos por disposição no solo. Engenharia Sanitária e Ambiental, Rio de Janeiro, v. 9, n. 3, p. 225-239, 2004. http://dx.doi.org/10.1590/ S1413-41522004000300009 
TITO, G. A.; CHAVES, L. H. G.; GUERRA, H. O. C. Effect of the bentonite application on the cadmium mobility in an Argissol. Ambi-Agua, Taubaté, v. 7, n. 2, p. 18-29, 2012. (http://dx.doi.org/10.4136/ambiagua.901)

PRADO, R. M.; JULIATTI, M. A. Lixiviação de cádmio em profundidade em coluna com latossolo vermelho e nitossolo. Revista de Agricultura, Piracicaba, v. 78, n. 2, p. 219$228,2003$.

RODRIGUES, M. G. F.; SILVA, M. L. P.; SILVA, M. G. C. Caracterização da argila bentonítica para utilização na remoção de chumbo de efluentes sintéticos. Cerâmica, São Paulo, v. 50, n. 315, p. 190-196, 2004. http://dx.doi.org/10.1590/S036669132004000300004

SANTOS, C. P. F.; MELO, D. M. A.; MELO, M. A. F.; SOBRINHO, E. V. Caracterização e usos de argilas bentonitas e vermiculitas para adsorção de cobre (II) em solução. Cerâmica, São Paulo, v. 48, n. 308, p. 178-182, 2002. http://dx.doi.org/10.1590/S036669132002000400002

SILVA, F. C. DA; WEBER NETO, J.; ZANFELICI, M. R. Comparação metodológica para abertura de resíduos sólidos orgânicos urbanos na determinação dos teores totais de metais pesados. In: INTERNATIONAL CONFERENCE ON ENGINEERING AND COMPUTER EDUCATION, 2007, São Paulo. Proceedings... [S.1.]: Council of Researches in Education and Sciences, 2007, p. 501-504.

WITTBROADT, P. R.; PALMER, C. D. Reduction of Cr (IV) by soil humic acids. European Journal of Soil Science, v. 48, n. 1, p. 151-162, 1997. http://dx.doi.org/10.1111/j.13652389.1997.tb00194.x 


ISSN = 1980-993X - doi:10.4136/1980-993X
www.ambi-agua.net
E-mail: ambi-agua@agro.unitau.br
Tel.: (12) 3625-4212

\title{
Antimicrobial resistance profiles of diarrheagenic Escherichia coli strains isolated from bathing waters of the Lajeado reservoir in Tocantins, Brazil
}

(http://dx.doi.org/10.4136/ambi-agua.756)

\author{
Kleverson Wessel de Oliveira'; ${ }^{1}$ Fátima de Cássia Oliveira Gomes²; \\ Guilherme Benko² ${ }^{2}$ Raphael Sanzio Pimenta ${ }^{1}$; Paula Prazeres Magalhães ${ }^{3}$; \\ Edilberto Nogueira Mendes ${ }^{3}$; Paula Benevides de Morais ${ }^{1,4}$ \\ ${ }^{1}$ Laboratório de Microbiologia Ambiental e Biotecnologia, Universidade Federal do Tocantins, Palmas - TO, \\ ${ }^{2}$ Centro Federal de Educação Tecnológica de Minas Gerais CEFET-MG, \\ ${ }^{3}$ Universidade Federal de Minas Gerais-UFMG, \\ emails: oliwessil@uft.edu.br, fatimaog@dppg.cefetmg.br, benko@uft.edu.br, pimentars@uft.edu.br, \\ ppmagalhaes@icb.ufmg.br, enmendes@medicina.ufmg.br, moraispb@uft.edu.br
}

\begin{abstract}
The exposure to contaminated water constitutes an important mechanism for the transmission of gastrointestinal pathogens. Diarrheagenic Escherichia coli strains cause enteric infections in humans and include six different categories according to virulence factors. This paper aims at detecting the presence of diarrheagenic E. coli strains in bathing waters of seven beaches of Lajeado Reservoir, in the Tocantins River in Brazil, and to test the resistance to antimicrobial drugs to correlate with possible contamination of the water with human feces. Total coliform and E. coli counts were done by the Colilert ${ }^{\mathrm{TM}}$ chromogenic $^{-}$ substrate technique. Biochemical identification was accomplished by API20E and detection of virulence factors by PCR, employing specific primers for Shiga, LT, and ST and intimin genes. The susceptibility to 16 antibiotics was tested by disk-diffusion technique. Among one hundred and forty-nine strains of E. coli, two strains of EPEC and two of ETEC were detected in waters of beaches situated in urban areas, close to sewage discharge. These strains presented resistance to three to six antibiotics. Human origin is suggested based on the multiresistant profile of these strains.
\end{abstract}

Keywords: Diarrheagenic Escherichia coli, antimicrobial resistance, virulence factors, PCR and river beach waters.

\section{Perfis de resistência antimicrobiana de cepas de Escherichia coli diarreiogênicas isoladas de praias do Reservatório de Lajeado, em Tocantins, Brasil}

\section{RESUMO}

A exposição humana à água contaminada constitui um importante mecanismo para a transmissão de patógenos gastrointestinais. Cepas de Escherichia coli diarreiogênicas podem causar infecções entéricas em humanos e incluem seis categorias diferentes de acordo com fatores de virulência. Este trabalho tem por objetivos detectar a presença de cepas diarreiogênicas de E. coli nas águas de sete praias do reservatório de Lajeado, Tocantins, Brasil e testar a resistência a drogas antimicrobianas para correlacionar com a possível contaminação da água por fezes humanas. As contagens de coliformes totais e E. coli foram realizadas pela técnica do substrato cromogênico Colilert ${ }^{\mathrm{TM}}$. A identificação bioquímica foi realizada utilizando kit API20E e a detecção dos fatores de virulência por PCR, empregando 
primers específicos para Shiga, LT e ST e genes de intimina. A susceptibilidade a 16 antibióticos foi testada pela técnica de difusão em discos de papel impregnados com antibiótico. Entre as 149 cepas de E. coli testadas, duas cepas de EPEC e duas de ETEC foram detectadas em águas de praias situadas em áreas urbanas, perto de descarga de efluentes. Estas cepas apresentaram resistência de 3 a 6 antibióticos. A provável origem humana das cepas é sugerida devido ao perfil de multiresistentes apresentado.

Palavras-chave: Escherichia coli diarreiogênicas, resistência a antimicrobianos, fatores de virulência, PCR e praias fluviais.

\section{INTRODUCTION}

The presence of E. coli in food and water constitutes a major health concern. The dissemination of these bacteria in the aquatic environment may derive from the contact with human and animal excreta, and they may accumulate in the aquatic sediment (Haller et al., 2009). Epidemiological studies have depicted that high densities of E. coli in recreational waters is related to gastroenteritis in humans (Alm et al., 2006). Many E. coli strains are commensal; however there are strains that display the ability to cause enteric infections in mankind, named diarrheagenic E. coli (DEC), a group which includes emerging pathogens of public health importance (Vidal et al., 2005). The worldwide contamination of surface and potable waters by diarrheagenic $E$. coli due to addition of untreated sewerage has been demonstrated (Hamner et al., 2007; Higgins et al., 2005). DEC are described under six categories or pathotypes according to virulence factors: Enteropathogenic E. coli (EPEC), Enterotoxigenic E. coli (ETEC), Enterohemorrhagic E. coli (EHEC), Enteroinvasive E. coli (EIEC), Enteroaggregative E. coli (EAEC) and Diffusely adherent E. coli (DAEC) (Huang et al., 2006). The transmission of virulence factors among strains may contribute toward their pathogenicity and increases their diversity in the environment (Obi et al., 2004).

The Lajeado Reservoir was formed by the construction of the Luis Eduardo Magalhães Hydroelectric Dam in the Tocantins River and seven municipalities are situated in its area of influence, discharging effluents from sewage treatment plants (two municipalities, Palmas and Porto Nacional) or raw sewage (five municipalities), combined with intense land use for cattle raising of the surrounding area. The reservoir also displays bathing areas (beaches) that were created by the municipalities of Porto Nacional and Palmas cities or by the communities themselves. These beaches are considered touristic attractions being heavily used by bathers, increasing anthropic pressure on this resource especially during the dry season, from June to September annually.

This work aims to detect the occurrence of DEC strains in the waters of the main beaches of Lajeado Reservoir in order to discuss the possible human source of bacterial contamination in the reservoir waters and to describe their profile of antimicrobial drug resistance.

\section{MATERIALS AND METHODS}

\subsection{Characterization of the beaches}

The Lajeado Reservoir has a total area of $620 \mathrm{~km}^{2}$ and an extension of $172 \mathrm{~km}$ in Mid Tocantins River, between the municipalities of Lajeado and Ipueiras, in the State of Tocantins, Brazil, receiving direct influence from the municipalities of Brejinho de Nazaré, Ipueiras, Porto Nacional, Palmas, Lajeado, Miracema and Tocantínia, which constitute a total of 220.147 inhabitants. Permanent beaches have been built in the right margin of this reservoir in contrast to the seasonal river beaches typical of the Central-North region of Brazil 
that are created during the dry season and vanish under the river waters during annual floods from December to April. Among these six permanent beaches, five are located in urban centers ARNO, Prata and Graciosa beaches in Palmas, capital of Tocantins, and Porto Real beach in Porto Nacional city. The Caju and Buriti beaches in Palmas are distant from the urban centers, in rural areas occupied by cattle raising.

\subsection{Isolation and biochemical identification of Escherichia coli strains}

A total of sixty water samples, ten for each one of the six beaches of the reservoir were collected, being five samples between June and August, 2008 (dry season) and five between November 2008 and February 2009 (rainy season). The water samples were taken to the laboratory within two hours after collection, aseptically inoculated into Colilert ${ }^{\mathrm{TM}}$ (IDEXX ${ }^{\mathrm{TM}}$ ) QuantiTray of 98 wells, and incubated for $18 \mathrm{~h}$ at $35^{\circ} \mathrm{C}$, for determination of total coliforms and $E$. coli counts. The wells presenting typical fluorogenic reaction (E. coli presence) were inoculated using a bacteriological loop on Petri dishes containing Eosin Methylene Blue (EMB) Agar (Oxoid ${ }^{\mathrm{TM}}$ ), and then incubated at $37^{\circ} \mathrm{C}$ for 24 to $48 \mathrm{~h}$. Up to five typical $E$ coli colonies from each water sample were recovered from EMB plates, and all colonies were submitted to Gram staining and inoculated in $2 \mathrm{~mL}$ of Brain Heart Infusion (BHI) broth (Acumedia ${ }^{\mathrm{TM}}$ ) and incubated at $37^{\circ} \mathrm{C}$ for $24 \mathrm{~h}$ after which they were dispensed into cryogenic vials supplemented by $20 \%$ glycerol and placed at $-80^{\circ} \mathrm{C}$ freezer for further identification. Biochemical tests were performed by using API 20E strips (bioMerieux ${ }^{\mathrm{TM}}$ ).

\subsection{Detection of diarrheagenic Escherichia coli}

DNA was extracted from all strains identified as E. coli by a phenol-chloroform method. All PCR mixtures were cycled in an Eppendorf thermocycler. The following genetic virulence markers were investigated by employing specific primers previously described: eae (Reid et al., 1999), bfpA (Gunzburg et al., 1995), stxl (Vidal et al., 2004), stx2 (Vidal et al., 2004), elt (Aranda et al., 2004), and est (Aranda et al., 2004). PCR mixtures had final volumes of $20 \mu \mathrm{L}$ consisting of reaction buffer (Tris $\mathrm{HCl} 10 \mathrm{mM}-\mathrm{pH} 8.4, \mathrm{KCl} 25 \mathrm{mM}$ ), 1.0 to $1.5 \mathrm{mM} \mathrm{MgCl}_{2}$, $200 \mu \mathrm{M}$ each dNTP (Promega ${ }^{\mathrm{TM}}$ ), $0.5 \mu \mathrm{M}$ each primer (Integrated DNA Technologies), $1 \mathrm{U}$ Taq DNA polymerase (Phoneutria ${ }^{\mathrm{TM}}$ ), and $20 \mathrm{ng}$ DNA. Primers and thermocycling conditions are shown in Table 1. Amplicons were discriminated in $8 \%$ polyacrylamide gels $\left(\right.$ Sigma $\left.^{\mathrm{TM}}\right)$, stained with ethidium bromide $\left(\right.$ Sigma $\left.{ }^{\mathrm{TM}}\right)$, visualized under UV light (Cole-Parmer), and compared to a standard of $100 \mathrm{bp}$ (Fermentas $\left.{ }^{\mathrm{TM}}\right)$. Positive controls for eae, stxl, and stx2 (E. coli CDC EDL-933, INCQS 00171), bfpA (E. coli CDC O126, INCQS 000184), elt (E. coli 0761-2), and est (E. coli 0122-4), negative control (E coli ATCC 25922), and negative internal control (sterile Milli- ${ }^{\circledR}$ water; Millipore ${ }^{\mathrm{TM}}$ ) were included in each batch of reaction.

\subsection{Antimicrobial susceptibility test}

The investigation of antimicrobial susceptibility was carried out by the Kirby-Bauer disk diffusion method using the standard concentrations of ampicillin, amoxicillin + clavulanate, cefoxitin, gentamicin, amikacin, cefepime, cephalothin, cefuroxime, ceftriaxone, ceftazidime, ciprofloxacin, sulfamethoxazole+trimethoprim, cefotaxime, tetracycline, chloramphenicol, tobramycin and ticarcilin+ clavulanate (CLSI, 2009).

\subsection{Statistical analysis}

Geometric means of the counts of E. coli during dry and rainy seasons and among the six beaches were compared using t test. Significant value was set to $\mathrm{p}<0.05$. 
OLIVEIRA, K.W.; GOMES, F. C. O.; BENKO, G.; PIMENTA, R. S.; MAGALHÃES, P.P.; MENDES, E. N.; MORAIS, P. B. Antimicrobial resistance profiles of diarrheagenic Escherichia coli strains isolated from bathing waters of the Lajeado reservoir in Tocantins, Brazil. Ambi-Agua, Taubaté, v. 7, n. 2, p. 30-41, 2012. (http://dx.doi.org/10.4136/ambi-agua.756)

Table 1. PCR conditions employed for EPEC, EHEC, and ETEC identification.

\begin{tabular}{|c|c|c|c|c|}
\hline Gene & Primer & $\begin{array}{c}{\left[\mathrm{MgCl}_{2}\right]} \\
\mathrm{mM}\end{array}$ & Program & $\begin{array}{c}\text { Amplicon } \\
\text { (bp) }\end{array}$ \\
\hline Eae & $\begin{array}{l}\text { F:5' CTG AAC GGC GAT TAC } \\
\text { GCG AA 3' } \\
\text { R: 5' CCA GAC GAT ACG ATC } \\
\text { CAG 3' }\end{array}$ & 1.0 & $\begin{array}{l}95^{\circ} \mathrm{C} / 40 \mathrm{~s}, 53^{\circ} \mathrm{C} / 2 \mathrm{~min}, 60^{\circ} / 2 \\
\min -40 \mathrm{x}\end{array}$ & 917 \\
\hline$B f p A$ & $\begin{array}{l}\text { F:5' AAT GGT GCT TGC GCT } \\
\text { TGC TGC 3' } \\
\text { R:5' GCC GCT TTA TCC AAC } \\
\text { CTG GTA 3' }\end{array}$ & 1.0 & $\begin{array}{l}95^{\circ} \mathrm{C} / 40 \mathrm{~s}, 53^{\circ} \mathrm{C} / 2 \mathrm{~min}, 60^{\circ} \mathrm{C} / 2 \\
\mathrm{~min}-40 \mathrm{x}\end{array}$ & 326 \\
\hline stxl & $\begin{array}{l}\text { F:5' CAG TTA ATG TGG TGG } \\
\text { GGA AGG 3' } \\
\text { R:5' CCA CAG ACA ATG TAA } \\
\text { CCG CTG 3' }\end{array}$ & 1.0 & $\begin{array}{l}95^{\circ} \mathrm{C} / 20 \mathrm{~s}, 61^{\circ} \mathrm{C} / 40 \mathrm{~s}, \\
72^{\circ} \mathrm{C} / 90 \mathrm{~s}-30 \mathrm{x}\end{array}$ & 348 \\
\hline stx 2 & $\begin{array}{l}\text { F:5' ATC CTA TTC CCG GGA } \\
\text { GTT TACG 3' } \\
\text { R:5' GCG TCA TCG TAT ACA } \\
\text { CAG GACC 3' }\end{array}$ & 1.5 & $\begin{array}{l}95^{\circ} \mathrm{C} / 20 \mathrm{~s}, 61^{\circ} \mathrm{C} / 40 \mathrm{~s}, \\
72^{\circ} \mathrm{C} / 90 \mathrm{~s},-30 \mathrm{x}\end{array}$ & 584 \\
\hline Elt & $\begin{array}{l}\text { F:5' GGC GAG AGA TTA TAC } \\
\text { CGT GC 3' } \\
\text { R:5' CGG TCT CTA TAT TCC } \\
\text { CCT GTT 3' }\end{array}$ & 1.2 & $\begin{array}{l}95^{\circ} \mathrm{C} / 5 \mathrm{~min} ; 95^{\circ} \mathrm{C} / 45 \mathrm{~s}, \\
50^{\circ} \mathrm{C} / 1 \mathrm{~min}, 72^{\circ} \mathrm{C} / 1 \mathrm{~min}- \\
40 \mathrm{x} ; 72^{\circ} \mathrm{C} / 7 \mathrm{~min}\end{array}$ & 450 \\
\hline Est & $\begin{array}{l}\text { F:5’ AAA GGA GAG CTT CGT } \\
\text { CAC ATT TT 3' } \\
\text { R:5' AAT GTC CGT CCT GCT } \\
\text { TTA GGA C 3' }\end{array}$ & 1.2 & $\begin{array}{l}95^{\circ} \mathrm{C} / 5 \mathrm{~min} ; 95^{\circ} \mathrm{C} / 45 \mathrm{~s}, \\
50^{\circ} \mathrm{C} / 1 \mathrm{~min}, 72^{\circ} \mathrm{C} / 1 \mathrm{~min}- \\
40 \mathrm{x} ; 72^{\circ} \mathrm{C} / 7 \mathrm{~min}\end{array}$ & 190 \\
\hline
\end{tabular}

\section{RESULTS AND DISCUSSION}

All water samples were positive for the presence of $E$. coli both in the dry and rainy seasons (Figure 1). During the dry season, the highest counts of E. coli indicating high levels of fecal contamination were obtained at ARNO (133.2 Most Probable Numbers MPN/100mL), Prata (95.8 MPN/100mL) and Caju (93.5 MPN/100mL) beaches. In Porto Real beach, the counts were $5.6 \mathrm{MPN} / 100 \mathrm{~mL}$, the lowest during the dry season. In the rainy season Caju Beach presented the lowest values of of E. coli counts $(6.4 \mathrm{MNP} / 100 \mathrm{~mL})$. In Buriti and Porto Real beaches counts were lower in the dry season than in the rainy season, a different pattern to that found at other beaches. When E. coli counts detected in samples collected from each beach in dry and rainy seasons were compared using variance analysis significant difference was observed only for Caju Beach $(\mathrm{p}=0.0152)$. Similarly the analysis showed differences among beaches in the same season (Figure 2). In the dry season Porto Real and Buriti beaches showed similar low E. coli counts whereas in Caju, Prata and ARNO Beaches similar high counts were observed. Also in the rainy season similar low E. coli counts were found in Porto Real and Buriti beaches and high counts in Prata and ARNO. 
OLIVEIRA, K.W.; GOMES, F. C. O.; BENKO, G.; PIMENTA, R. S.; MAGALHÃES, P.P.; MENDES, E. N.; MORAIS, P. B. Antimicrobial resistance profiles of diarrheagenic Escherichia coli strains isolated from bathing waters of the Lajeado reservoir in Tocantins, Brazil. Ambi-Agua, Taubaté, v. 7, n. 2, p. 30-41, 2012. (http://dx.doi.org/10.4136/ambi-agua.756)

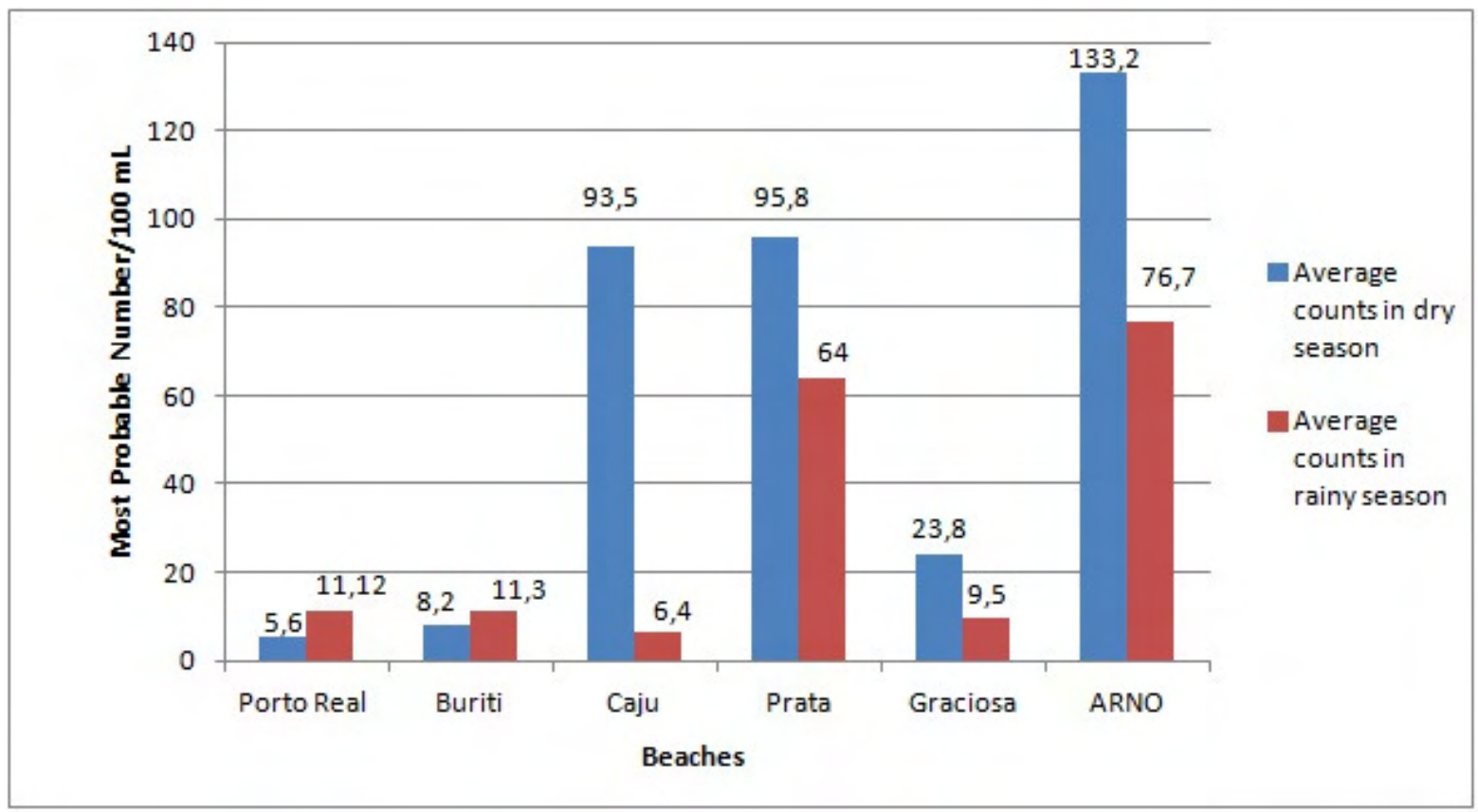

Figure 1. Variance analysis of the geometric media of $E$. coli counts in water samples from six beaches in the Lajeado Reservoir comparing data from the dry and rainy seasons of 2008/2009. Columns marked with the same letter are significantly similar according to $\mathrm{T}$ test with $5 \%$ of significance.
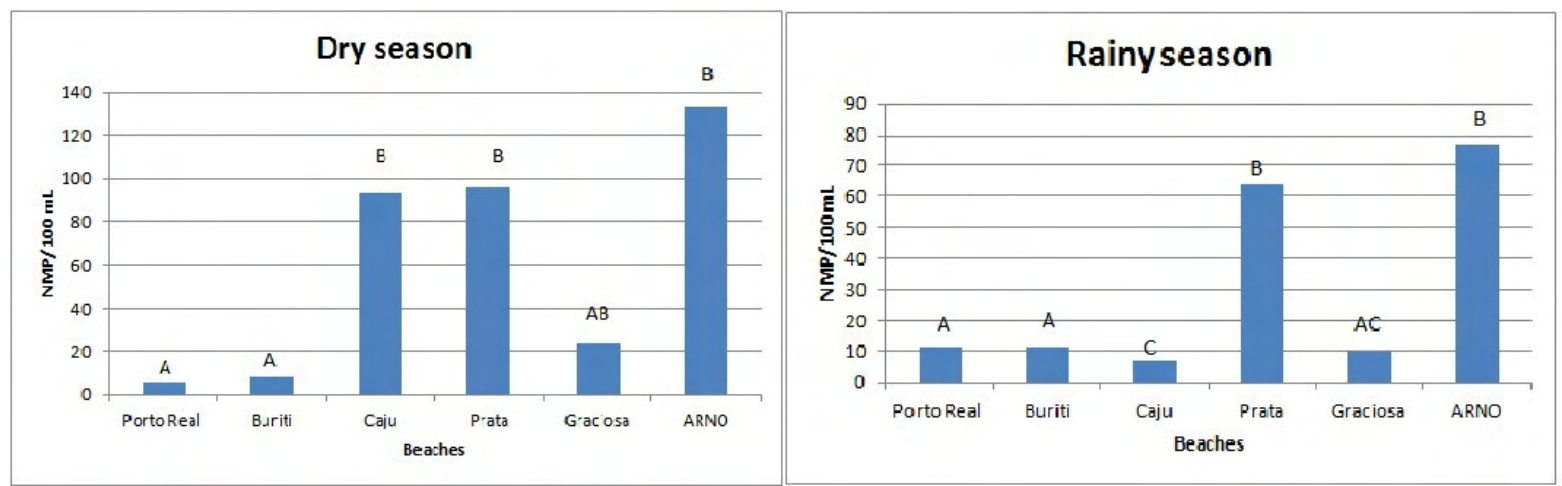

Figure 2. Variance analysis of the geometric media of $E$. coli counts in water samples from the Lajeado Reservoir comparing data from six different beaches in the dry (2.1) and rainy (2.2) seasons of 2008/2009. Columns marked with the same letter are significantly similar according to $t$ test with $5 \%$ of significance.

The investigation of water samples positive for $E$. coli in Colilert tests resulted in the isolation of 163 strains with typical E. coli lac+ profile from which $149(91.1 \%)$ were confirmed by the API20E (BioMerieux ${ }^{\mathrm{TM}}$ ). Among the other $8.9 \%$, seven were identified as Enterobacter cloacae, two as Citrobacter spp., two as Enterobacter intermedium and one each of Klebsiella pneumoniae, Serratia spp. and Escherichia vulneris.

Four out of the 149 E. coli strains were identified by PCR as DEC, two atypical EPEC (eae+, stx- and $b f p-)$ and two ETEC (elt positive) isolates. All of them were isolated from water samples of beaches located in urban areas: EPEC strains were recovered from one water sample obtained at Porto Real beach in Porto Nacional and ETEC strains were obtained from samples collected in ARNO beach in Palmas, in the dry season. 
EPEC isolates presented two multiresistance profiles, one strain resistant to sulfamethoxazole + trimethoprim, tetracycline, and cephalothin and the other strain resistant to sulfamethoxazole +trimethoprim, tetracycline, ampicillin, and chloramphenicol. In regard to ETEC one isolate was resistant to tetracycline and ampicillin and the other to sulfamethoxazole + trimethoprim, tetracycline, amoxicillin + clavulanate, ticarcillin +clavulanate, ampicillin and cephalothin.

According to Colilert testing, all the beaches fall in the category "Excellent for bathing" according to Brazilian regulations (Brasil, 2000), although DEC were isolated. Accidental water ingestion from the Lajeado Reservoir during bathing may constitute risks for human health, especially children. There was no significant difference in the E. coli counts between dry and rainy seasons, except for Caju Beach as shown in Figure 1. Porto Real, Buriti and Graciosa beaches presented low counts during both periods, and ARNO and Prata beaches presented high counts during both periods. This is probably due to the higher numbers of bathers that go to these latter two beaches, the most popular of Palmas, during the whole year. The Caju beach presented higher counts in the dry than in the rainy season, probably due to the higher frequency of bathers during the dry months of June to August.

The isolation of strains that belong to other enterobacterial species in Colilert wells is likely due to the simultaneous detection of both total coliforms and E. coli by this method. Besides E. coli, the total coliform group includes Citrobacter, Enterobacter, Klebsiella, Serratia and other species of Escherichia that may be found in feces and also in the environment (APHA et al., 2005). Several studies have shown that Colilert systems produce false positive results in the detection of coliform bacteria and also E. coli (e.g. Pisciotta et al., 2002). In a study of drinking water reservoirs, Kämpfer et al. (2008) identified $95 \%$ of bacterial isolates from Colilert-18 positive samples as coliforms of fecal origin, but some isolates were identified by the API 20E system as Enterobacter species of the Enterobacter cloacae complex, Serratia spp., Citrobacter spp. and Klebsiella spp. A more detailed identification resulted in the identification of Enterobacter nimipressuralis, E. amnigenus, E. asburiae, E. hormaechei, and Serratia fonticola as predominant coliforms. These species are often not of fecal origin and may interfere with the ability to accurately detect coliforms of fecal origin. Chao et al. (2004) isolated pure cultures from 240 yellow wells in Colilert-18 tests and 16 isolates out of 23 non-coliform bacteria were Erwinia carotovora. They showed that the false-positive rate for coliform detection was about $9.6 \%$.

ETEC strains were detected in samples from ARNO beach and may be originated from sewage effluents that arrive in the reservoir from the Água Fria sewage treatment plant in Palmas. ETEC is regarded as a major cause of $E$. coli mediated diarrhea worldwide in humans, affecting mainly children and travelers (Turner et al., 2006). In the developing world, an estimated 650 million cases of ETEC infections occur each year, resulting in $~ 800,000$ deaths, mostly in young children (WHO, 1999). A study of Singh et al. (2010) showed that aquatic vegetation and leafy vegetables cultivated in riverine systems could be important environmental reservoirs of ETEC in the Gangetic river system, in India. Other studies suggested that aquatic flora and leafy vegetables could serve as nonpoint sources of human bacterial pathogens (Bhanumathi et al., 2003; Brandl, 2008; Ishii et al., 2006). Nonetheless, there is no significant horticulture in the Lajeado Reservoir margins, and although aquatic macrophytes are common in the reservoir, they are absent from the beaches areas.

Two EPEC strains were found in a water sample from Porto Real beach and may have been introduced in the water by sewage directly disposed into the reservoir or through the São João stream, which receives sewage from Porto Nacional, an urban area of 46,722 inhabitants. EPEC are among the most important pathogens infecting children worldwide and are one of the main causes of persistent diarrhea in both developing and developed countries (Ochoa et 
al., 2008). A study of E. coli in water, sediment and plankton collected from two sampling sites in a freshwater lake extensively used by humans and animals in India showed that the lake is an important source of EPEC and other related DEC (Fei et al., 2003). Of the 150 strains which were characterized, $31(20.7 \%)$ were found to belong to the classic EPEC serogroups.

There are very few studies reporting DEC in waters in Brazil. Nascimento et al. (2007) reported the detection of five ETEC strains, three of them elt positive and two elt and est positive, in samples from sewerage of Porto Alegre, Brazil. Cardonha et al. (2004) detected two EPEC classical serogroups in Ponta Negra beach, Natal, near sewerage galleries. Sato et al. (1983) demonstrated the presence of ETEC in waters and sewage from São Paulo. Valentini et al. (1992) isolated EPEC, ETEC, and EIEC strains from recreational lakes, dams, mines, rivers, and wells, and from treated water (swimming pool) in São Paulo. Falcão et al. (1993) also isolated EPEC, ETEC and EIEC from fresh waters in Araraquara, Brazil.

Other studies detected enteropathogenic E. coli in water in different tropical (Begum et al., 2005; Bern et al., 1992; Qadri et al., 2005) and non-tropical regions (Bern et al., 1992; Obi et al., 2004). Obi et al. (2004) screened a total of 228 river samples in Africa, and recovered E. coli from $200(87.7 \%)$ and $135(67.5 \%)$ of water and sediment, respectively and genes coding for necrotoxigenic E. coli $(35.6 \%)$ and EPEC (34.1\%) were most frequently encountered. Hamelin et al. (2006) points to the potential public health threat of $E$. coli pathotypes originating from municipal wastewater sources. They showed a higher frequency $(48 \%)$ of $E$. coli isolates possessing virulence and antimicrobial resistance genes in an urban site located downstream of wastewater effluent outfalls than in other examined sites (average of $24 \%$ ), although they isolated mostly extraintestinal pathogenic E. coli, a few EAEC and some atypical EPEC.

The antimicrobial susceptibility profiles of DEC in Lajeado Reservoir waters indicated that both ETEC and EPEC isolates represent different strains since their multiresistant profiles were dissimilar. Multiple antibiotic resistance is common among EPEC (Donnenberg, 1995). Fei et al. (2003) showed that all clinical isolates of EPEC obtained from patients with diarrhea in a Malaysia hospital were resistant to furoxime, cephalothin and sulphamethoxazole. They argue that the high incidence of antibiotic-resistant isolates of EPEC may be due to the widespread use of antibiotics.

Recently, multiple antibiotic resistance for kanamycin, nalidixic acid, tetracycline and trimethoprim have been shown in fecal coliforms isolated from both stool samples from humans and treated drinking water in India (Pathak and Gopal, 2008). Similarly, high resistance levels to ampicillin, trimethoprim/sulfamethoxazole, gentamicin and tetracycline have been detected in E. coli isolates from drinking water sources in Jordan (Shehabi et al., 2006). Ozgumus et al. (2007) found that antibiotic-resistant coliforms were widespread in water samples from ten rivers in Northern Turkey.

It has been reported that in natural environments, resistant organisms can be indigenous or introduced by natural or anthropogenic causes (Hu et al., 2008). Numerous factors might be involved for the release of resistant strains in the environment. Insufficient sanitation facilities, indiscriminate use of antibiotics and lack of well-managed sewerage systems are important contributing factors (Ozgumus et al., 2008). Although there is no data available on the performance of sewerage treatment plants in the urban margins of Lajeado Reservoir, it is largely known that solely two of seven municipalities present collection and treatment of sewage in the area. 


\section{CONCLUSIONS}

Although coliform and E. coli counts in water samples collected from the Lajeado Reservoir did not exceed the standards for safety of bathers according to legal regulations, the presence of DEC strains in these waters may still represent a risk that would be neglected by standard water quality evaluation methods.

According to Singh et al. (2010) despite the potential public health threat from waterand foodborne ETEC, regulatory authorities in the developing world rely exclusively on "indicators" of fecal pollution (e.g., fecal coliform bacteria or generic E. coli) for determination of water quality. This fails to provide a clue on presence of pathogenic forms of E. coli viz., ETEC present in the contaminated source. Since detection of DEC is not part of the routine monitoring of fecal contamination in reservoir waters this study contributes to better knowledge of the occurrence of pathogenic E. coli in the Lajeado Reservoir and ultimately to help designing strategies for improving standards of freshwater safety in Brazil.

\section{ACKNOWLEDGEMENTS}

ETEC strains were kindly given by Dr. Tânia Aparecida Tardelli Gomes do Amaral, UNIFESP, Brazil. This research was sponsored by CT-Hidro/ CNPq Processo 5526902005-8.

\section{REFERENCES}

ALM, E. W.; BURKE, J.; HAGAN, E. Persistence and potential growth of the fecal indicator bacteria, Escherichia coli, in Shoreline Sand at Lake Huron. Journal of Great Lakes Research, Ann Arbor, v. 32, p. 401-405, 2006. http://dx.doi.org/10.3394/03801330(2006)32[401:PAPGOT]2.0.CO;2

AMERICAN PUBLIC HEALTH ASSOCIATION - APHA; AMERICAN WATER WORKS ASSOCIATION - AWWA; WATER ENVIRONMENT FEDERATION - WEF. Standard methods for the examination of water and wastewater. 21th ed. Washington DC, 2005.

ARANDA, K. R.; FAGUNDES-NETO, U.; SCALETSKY, I. C. A. Evaluation of multiplex PCRs for diagnosis of infection with diarrheagenic Escherichia coli and Shigella spp. Journal of Clinical Microbiology, Washington DC, v. 42, n. 12, p. 5849-5853, 2004. http://dx.doi.org/10.1128/JCM.42.12.5849-5853.2004

BEGUM, Y. A.; TALUKDER, K. A.; NAIR, G. B.; SVENNERHOLM, A. M.; SACK, R. B.; QADRI, F. Enterotoxigenic Escherichia coli isolated from surface water in urban and rural Bangladesh. Journal of Clinical Microbiology, Washington DC, v. 43, n. 7, p. 3582-3583, 2005. http://dx.doi.org/10.1128/JCM.43.7.3582-3583.2005

BERN, C.; MARTINES, J.; DE ZOYSA, I.; GLASS, R. I. The magnitude of the global problem of diarrhoeal disease: a ten-year update. Bull WHO, Geneva, v. 70, n. 6, p. 705-714, 1992.

BHANUMATHI, R.; SABEENA, F.; ISAC, S. R.; SHUKLA, B. N.; SINGH, D. V. Molecular characterization of Vibrio cholerae O139 Bengal isolated from water and the aquatic plant Eichhornia crassipes in the river Ganga, Varanasi, India. Applied and Environmental Microbiology, Washington DC, v. 69, n. 4, p. 2389-2394, 2003. http://dx.doi.org/10.1128/AEM.69.4.2389-2394.2003 
BRANDL, M. T. Plant lesions promote the rapid multiplication of Escherichia coli O157:H7 on postharvest lettuce. Applied and Environmental Microbiology, Washington DC, v. 74, n. 17, p. 5285-5289, 2008. http://dx.doi.org/10.1128/AEM.01073-08

BRASIL. Conselho Nacional do Meio Ambiente - CONAMA. Resolução n ${ }^{\circ} 274$ de 29 de novembro de 2000. Disponível em: <http://www.mma.gov.br/port/conama/res/res00/ res27400.html>. Acesso em: 02 de setembro de 2011.

CARDONHA, A. M. S.; VIEIRA, R. H. S. F.; RODRIGUES, D. P.; MACRAE, A.; PEIRANO, G.; TEOPHILO, G. N. D. Fecal pollution in water from storm sewers and adjacent seashores in Natal, Rio Grande do Norte, Brazil. International Microbiology, Barcelona, v. 7, n. 3, p. 213-218, 2004.

CHAO, K. K.; CHAO, C. C.; CHAO, W. L. Evaluation of Colilert-18 for detection of coliforms and Escherichia coli in subtropical freshwater. Applied and Environmental Microbiology, Washington DC, v. 70, n. 2, p. 1242-1244, 2004. http://dx.doi.org/10.1128/AEM.70.2.1242-1244.2004

CLINICAL AND LABORATORY STANDARDS INSTITUTE - CLSI. Performance standards for antimicrobial susceptibility testing. M 100-S 19. Villanova, 2009.

DONNENBERG, M. S. Enteropathogenic Escherichia coli. In: BLASER, M. J.; SMITH, P. D.; RAVDIN, J. I.; GREENBERG, H. B.; GUERRANT, R. L. (eds.). Infections of the gastrointestinal tract. New York: Raven Press, 1995. p. 709-726.

FALCÃO, D. P.; VALENTINI, S. R.; LEITE, C. Q. F. Pathogenic or potentially pathogenic bacteria as contaminants of fresh water from different sources in Araraquara, Brazil. Water Research, Delft, v. 27, n. 12, p. 1737-1741, 1993. http://dx.doi.org/10.1016/ 0043-1354(93)90111-T

FEI, W. K.; RADU, S.; CHEAH, Y. K.; BENJAMIN, P. G.; LING, C. M. W. V.; HON, S. F. et al. Antibiotic resistance, plasmid profile and RAPD-PCR analysis of enteropathogenic Escherichia coli (EPEC) clinical isolates Southeast Asia. Southeast Asian Journal of Tropical Medicine and Public Health, Bangkok , v. 34, n. 3, p. 620626, 2003.

GUNZBURG, S. T.; TORNIEPORTH, N. G.; RILEY, L. W. Identification of enteropathogenic Escherichia coli by PCR-based detection of the bundle-forming pilus gene. Journal of Clinical Microbiology, Washington DC, v. 33, n. 5, p.1375-1377, 1995.

HALLER, L.; AMEDEGNATO, E.; POTÉ, J.; WILDI, W. Influence of freshwater sediment characteristics on persistence of fecal indicator bacteria. Water, Air, \& Soil Pollution, Heidelberg, v. 203, n. 1/4, p.217-227, 2009. http://dx.doi.org/10.1007/s11270-0090005-0

HAMELIN, K.; BRUANT, G.; EL-SHAARAWI, A.; HILL, S.; EDGE, T. A.; BEKAL, S. et al. A virulence and antimicrobial resistance DNA microarray detects a high frequency of virulence genes in Escherichia coli isolates from Great Lakes recreational waters. Applied and Environmental Microbiology, Washington DC, v. 72, n. 6, p. 42004206, 2006. http://dx.doi.org/10.1128/AEM.00137-06 
HAMNER, S.; BROADAWAY, S. C.; MISHRA, V. B.; TRIPATHI, A.; MISHRA, R. K.; PULCINI, E. et al Isolation of potentially pathogenic Escherichia coli O157:H7 from the Ganges river. Applied and Environmental Microbiology, Washington DC, v. 73, n. 7, p. 2369-2372, 2007. http://dx.doi.org/10.1128/AEM.00141-07

HIGGINS, J. A.; BELT, K. T.; KARNS, J. S.; RUSSELL-ANELLI, J.; SHELTON, D. R. tirand $s t x$-positive Escherichia coli in stream waters in a metropolitan area. Applied and Environmental Microbiology, Washington DC, v. 71, n. 5, p. 2511- 2519, 2005. http://dx.doi.org/10.1128/AEM.71.5.2511-2519.2005

HU, J.; SHI, J.; CHANG, H.; LI, D.; YANG, M.; KAMAGATA, Y. Phenotyping and genotyping of antibiotic-resistant Escherichia coli isolated from a natural river basin. Environmental Science \& Technology, Washington DC, v. 42, n. 9, p. 3415-3420, 2008. http://dx.doi.org/10.1021/es7026746

HUANG, D. B.; MOHANTY, A.; DUPONT, H. L.; OKHUYSEN, P. C.; CHIANG, T. A review of an emerging enteric pathogen: enteroaggregative Escherichia coli. Journal of Medical Microbiology, Reading, v. 55, n. 10, p. 1303-1311, 2006. http://dx.doi.org/10.1099/jmm.0.46674-0

ISHII, S.; YAN, T.; SHIVELY, D. A.; BYAPPANAHALLI, M. N.; WHITMAN, R. L.; SADOWSKY, M. J. Cladophora (Chlorophyta) spp. harbor human bacterial pathogens in nearshore water of lake Michigan. Applied and Environmental Microbiology, Washington DC, v. 72, n. 7, p. 4545-4553, 2006. http://dx.doi.org/10.1128/ AEM.00131-06

KÄMPFER, P.; NIENHÜSER, A.; PACKROFF, G.; WERNICKE, F.; MEHLING, A.; NIXDORF, K. et al. Molecular identification of coliform bacteria isolated from drinking water reservoirs with traditional methods and the Colilert-18 system. International Journal of Hygiene and Environmental Health, Kusterdingen, v. 211, n. 3/4, p.374-384, 2008. http://dx.doi.org/10.1016/j.ijheh.2007.07.021

NASCIMENTO, A. M.; VAN DER SAND, S. T. O uso de PCR na deteç̧ão de Escherichia coli enterotoxigênica em amostras de água de esgoto. Acta Scientiae Veterinariae, Porto Alegre, v. 35, n. 2, p. 187-194, 2007.

OBI, C. L.; GREEN, E.; BESSONG, P. O.; VILLIERS, B.; HOOSEN, A. A.; IGUMBOR, E. O.; POTGIETER, N. Gene encoding virulence markers among Escherichia coli isolates from diarrhoeic stool samples and river sources in rural Venda communities of South Africa. Water SA, Gezina, v. 30, n. 1, p. 37-42, 2004.

OCHOA, T. J.; BARLETTA, F.; CONTRERAS, C.; MERCADO, E. New insights into the epidemiology of enteropathogenic Escherichia coli infection. Transactions of the Royal Society of Tropical Medicine and Hygiene, High Holborn, v. 102, n. 9, p.852856, 2008. http://dx.doi.org/10.1016/j.trstmh.2008.03.017

OZGUMUS, O. B.; CELIK-SEVIM, E.; ALPAY-KARAOGLU, S.; SANDALLI, C.; SEVIM, A. Molecular characterization of antibiotic resistant Escherichia coli strains isolated from tap and spring waters in a coastal region in Turkey. Journal of Microbiology, v. 45, n. 5, p.379-387, 2007. 
PATHAK, S. P.; GOPAL, K. Prevalence of bacterial contamination with antibiotic-resistant and enterotoxigenic fecal coliforms in treated drinking water. Journal of Toxicology and Environmental Health, Philadelphia, v. 71, n. 7, p. 427-433, 2008. http://dx.doi.org/10.1080/15287390701838796

PISCIOTTA, J. M.; RATH, D. F.; STANEK, P. A.; FLANERY, D. M.; HARWOOD, V. J. Marine bacteria cause false-positive results in the Colilert-18 Rapid Identification Test for Escherichia coli in Florida waters. Applied and Environmental Microbiology, Washington DC, v. 68, n. 2, p. 539-544, 2002. http://dx.doi.org/10.1128/ AEM.68.2.539-544.2002

QADRI, F.; SVENNERHOLM, A. M.; FARUQUE, A. S. G.; SACK, R. B. Enterotoxigenic Escherichia coli in developing countries: epidemiology, microbiology, clinical features, treatment, and prevention. Clinical Microbiology Reviews. Washington DC, v. 18, n. 3, p. 465-483, 2005. http://dx.doi.org/10.1128/CMR.18.3.465-483.2005

REID, S. D.; BETTING, D. J.; WHITTAM, T. S. Molecular detection and identification of intimin alleles in pathogenic Escherichia coli by multiplex PCR. Journal of Clinical Microbiology, Washington DC, v. 37, n. 8, p. 2719-2722, 1999.

SATO, M. I.; SANCHEZ, P. S.; MARTINS, M. T.; REIS, M. H.; TRABULSI, L. R. Isolation of enterotoxigenic Escherichia coli in water and sewage in São Paulo, Brazil. Revista de Microbiologia, São Paulo, v. 14, n. 4, p. 276-281, 1983.

SHEHABI, A. A.; ODEH, J. F.; FAYYAD, M. Characterization of antimicrobial resistance and class 1 integrons found in Escherichia coli isolates from human stools and drinking water sources in Jordan. Journal of Chemotherapy, Florence, v. 18, n. 5, p.468-472, 2006.

SINGH, G.; VAJPAYEE, P.; RAM, S.; SHANKER, R. Environmental Reservoirs for Enterotoxigenic Escherichia coli in South Asian Gangetic Riverine System. Environmental Science \& Technology, Washington DC, v. 44, n. 16, p. 6475-6480, 2010. http://dx.doi.org/10.1021/es1004208

TURNER, S. M.; SCOTT-TUCKER, A.; COOPER, L. M.; HENDERSON, I. R. Weapons of mass destruction: virulence factors of the global killer enterotoxigenic Escherichia coli. FEMS Microbiology Letters, Hoboken, v. 263, n. 1, p. 10-20, 2006. http://dx.doi.org/ 10.1111/j.1574-6968.2006.00401.x

VALENTINI, S.R.; GOMES, T.A.T.; FALCÃO, D.P. Lack of virulence factors in Escherichia coli strains of enteropathogenic serogroups isolated from water. Applied and Environmental Microbiology, Washington DC, v. 58, n. 1, p. 412-414, 1992.

VIDAL, R.; VIDAL, M.; LAGOS, R.; LEVINE, M.; PRADO, V. Multiplex PCR for diagnosis of enteric infections associated with diarrheagenic Escherichia coli. Journal of Clinical Microbiology, Washington DC, v. 42, n. 4, p. 1787-1789, 2004. http://dx.doi.org/10.1128/JCM.42.4.1787-1789.2004

VIDAL, M.; KRUGER, E.; DURÁN, C.; LAGOS, R.; LEVINE, M.; PRADO, V. et al. Single multiplex PCR assay to identify simultaneously the six categories of diarrheagenic Escherichia coli associated with enteric infections. Journal of Clinical Microbiology, Washington DC, v. 43, n. 10, p. 5362-5365, 2005. http://dx.doi.org/ 10.1128/JCM.43.10.5362-5365.2005 
OLIVEIRA, K.W.; GOMES, F. C. O.; BENKO, G.; PIMENTA, R. S.; MAGALHÃES, P.P.; MENDES, E. N.; MORAIS, P. B. Antimicrobial resistance profiles of diarrheagenic Escherichia coli strains isolated from bathing waters of the Lajeado reservoir in Tocantins, Brazil. Ambi-Agua, Taubaté, v. 7, n. 2, p. 30-41, 2012. (http://dx.doi.org/10.4136/ambi-agua.756)

WORLD HEALTH ORGANIZATION - WHO. The world health report: making a difference. Geneva, 1999. 


ISSN = 1980-993X - doi:10.4136/1980-993X
www.ambi-agua.net
E-mail: ambi-agua@agro.unitau.br
Tel.: (12) 3625-4212

\title{
Microbiological analysis of drinking water quality of Ananthanar channel of Kanyakumari district, Tamil Nadu, India
}

\author{
(http://dx.doi.org/10.4136/ambi-agua.881) \\ Raju Mary Antony; Ferdinand Brisca Renuga \\ Holy Cross College (Autonomous), Nagercoil, Kanyakumari District,Tamil Nadu, India. \\ Department of Zoology, e-mail: bristheo_cnr@yahoo.co.in
}

\begin{abstract}
Bacteriological analyses were carried out on Ananthanar channel water of Kanyakumari district, Tamil Nadu, India. The Ananthanar channel was selected in this study because this channel runs about nearly $28 \mathrm{~km}$ and supplies water for many villages for drinking and bathing purposes. Fecal and total coliform counts were performed using the standard membrane filtration technique and multiple tube technique. The results obtained were compared with reports of All India Institute of Medical Sciences Standards for Drinking and Recreational Water. Faecal coliform counts varied from 12 to $180 \mathrm{MPN} / 100 \mathrm{ml}$ while Escherichia coli counts ranged from 6 to $161 \mathrm{MPN} / 100 \mathrm{ml}$ for all the sampled sites. Among the total coliform Pseudomonas aeruginosa, Shewanella putrefaciens, Klebsiella pneumoniae, Citrobacter freundii and Proteus mirabilis are reported. The Faecal coliform and the E. coli counts exceeding acceptable limits are indicative of pollution from domestic wastes from several informal settlements located along the riverbank. Water uses in the area were determined and were found to be mainly domestic and recreational. The gross pollution of the river exposes the local people who depend on it for their primary water source to serious health risk.
\end{abstract}

Keywords: Escherichia coli, Pseudomonas aeruginosa, Shewanella putrefaciens, Klebsiella pneumoniae, Citrobacter freundii, Proteus mirabilis.

\section{Análise microbiológica da qualidade da água potável do canal Ananthanar do distrito Kanyakumari, Tamil Nadu, Índia}

\section{RESUMO}

Análises bacteriológicas foram realizadas nas águas do canal de Ananthanar, distrito de Kanyakumari, Tamil Nadu, na Índia. O canal Ananthanar foi selecionado para este estudo porque ele corre por cerca de $28 \mathrm{~km}$ e fornece água a muitas aldeias para consumo humano e para fins balneares. Contagens de coliformes totais e fecais foram realizadas utilizando a técnica da membrana de filtração padrão e técnica de tubos múltiplos. Os resultados obtidos foram comparados com os relatórios de All India Institute of Medical Sciences Standards for Drinking and Recreational Water. A quantidade de Coliformes fecais variou de 12-180 MPN/100 ml enquanto a contagem de Escherichia coli variou 6-161 MPN/100 ml para todos os locais amostrados. Entre todos coliformes Pseudomonas aeruginosa, Shewanella putrefaciens, Klebsiella pneumoniae, Citrobacter freundii e Proteus mirabilis estavam presentes. Coliformes fecais e a contagem de E. coli que excedem os limites aceitáveis são indicativos de poluição oriunda de resíduos domésticos de vários assentamentos informais localizados ao longo da margem do rio. Os usos da água predominantes na área foram 
ANTONY, R. M.; RENUGA, F. B. Microbiological analysis of drinking water quality of Ananthanar channel of Kanyakumari district, Tamil Nadu, India. Ambi-Agua, Taubaté, v. 7, n. 2, p. 42-48, 2012. (http://dx.doi.org/10.4136/ambi-agua.881)

principalmente domésticos e de lazer. A poluição do rio expõe as populações locais que dependem dele como sua fonte primária de água a um grave risco de saúde.

Palavras-chave: Escherichia coli, Pseudomonas aeruginosa, Shewanella putrefaciens, Klebsiella pneumoniae, Citrobacter freundii, Proteus mirabilis.

\section{INTRODUCTION}

India is rich in water resources, being endowed with a network of rivers and blessed with snow cover in the Himalayan range that can meet a variety of water requirements of the country (Bhardwaj, 2005). The rivers of India play an important role in the lives of the Indian people. Water resources are great significance for various activities such as drinking, irrigation, aquaculture and power generation. The importance of sustained hydrological studies on Indian waters is now recognized in water resource management due to exploitation of fresh water resources. Report of the scientists at All India Institute of Medical Sciences (AIIMS), New Delhi, finds an alarming prevalence of various diseases causing microbes in drinking water and recreational water. The use of this water may lead to several life threatening diseases. Different authors also reported that Indian River system is polluted mainly because of the human impact (Goel and Bhosale, 2001; Patil et al., 2003; Maity et al., 2004). Significance of water as a potent ecological factor can be appreciated only by studying its physico-chemical and microbial characteristics.

Major factors affecting microbiological quality of surface waters are discharges from sewage works and runoff from informal settlements. Indicator organisms are commonly used to assess the microbiological quality of surface waters and faecal coliforms (FC) are the most commonly used bacterial indicator of faecal pollution (South Africa, 1998). They are found in water that is contaminated with faecal wastes of human and animal origin. Total coliforms (TC) comprise bacterial species of faecal origin as well as other bacterial groups (e.g. bacteria commonly occurring in soil). The coliforms are indicative of the general hygienic quality of the water and potential risk of infectious diseases from water. High FC and TC counts in water are usually manifested in the form of diarrhoea and sometimes by fever and other secondary complications. Bathing and swimming in streams and river are also common among children and adults in the local community. The probability of ingesting infective dose of disease causing microorganism is very high considering the fact that water borne pathogens generally have low infective dose.

Kanyakumari District located in the extreme south of the Indian Peninsula is endowed with substantial number of rivers, rivulets and streams. Ananthanar channel is one among the rivulets of this district. Water from the major river Kodayar is diverted through this channel which takes off from Surlacode Headwork, running for a length of $24 \mathrm{~km}$ extended between $77^{\circ} 39^{\prime}$ and $77^{\circ} 47^{\prime}$ of east of longitudes and $8^{\circ} 07^{\prime}$ and $8^{\circ} 35^{\prime}$ north of latitudes. A study on the quality of water of this channel is one of the essential steps as rapid urbanization occurs along the course of this water.

The objective of this work is to evaluate the general bacteriological parameters of the Ananthanar channel of Kanyakumari District, source of water used for drinking and bathing purposes.

\section{MATERIAL AND METHODS}

\subsection{Sample collection}

Sample collection is a very important part of river study because conclusions drawn are based only on the testing of collected samples. The purpose of taking samples is to obtain 
ANTONY, R. M.; RENUGA, F. B. Microbiological analysis of drinking water quality of Ananthanar channel of Kanyakumari district, Tamil Nadu, India. Ambi-Agua, Taubaté, v. 7, n. 2, p. 42-48, 2012. (http://dx.doi.org/10.4136/ambi-agua.881)

information, which in some way typifies the aquatic system from which samples are drawn. Grab sampling procedure was adopted as recommended by Standard Method for microbiological analysis. Samples were collected during lean season, on monthly basis, for a period of five months from February 2007 to June 2007. Water samples from three sampling locations of Surlacode, Parvathipuram and Thengampudur and for every sampling date, were collected for this study. Water samples for microbiological examination, were collected in non-reactive borosilicate glass bottles of $500 \mathrm{ml}$ capacity each that had been cleansed and rinsed carefully, given a final rinse with distilled water and sterilized. Samples were taken from the river by holding the bottle near its base in the hand and plunging it, neck downward, below the surface. Then turning the bottle until neck points slightly upward and mouth is directed toward the current. The sampling bottle was not filled up to the brim and $20 \mathrm{~mm}$ to $30 \mathrm{~mm}$ space was left for effective shaking of the bottle (APHA, 1998). Microbiological analysis of water samples was started as soon as possible after collection to avoid unpredictable changes in the microbial population (Gaudy, 1998).

\subsection{Microbiological analysis}

Fecal and total coliform counts were performed using the standard membrane filtration technique. The $100 \mathrm{ml}$ water sample was filtered using $0.45 \mathrm{~mm}$ pore size, $47 \mathrm{~mm}$ diameter filter membrane as described by APHA (1998).

Multiple tube technique was used for the enumeration of Most Probable Number of coliform bacteria. Nutrient agar (NA) as a basal medium MacConkey agar as a differential medium and Blood agar as a special medium were used to determine enteric bacteria. Escherichia coli are isolated by inoculating the sample in Bismuth green bile broth. Enteric bacteria isolated on respective selective or differential media were identified on the basis of their colonial, morphological and Biochemical properties (Table 1) following Bergey's Manual of Determinative Bacteriology, 1994.

Table 1. Biochemical analysis.

\begin{tabular}{|c|c|c|c|}
\hline S. No. & Biochemical Testing & Inferences & Type of Bacteria \\
\hline 1 & $\begin{array}{l}\text { Kovacs' reagent: } \\
\text { (Paradimethyl amino bezaldehyde }+ \\
\text { Isoamyl alcohol }+ \text { Sulphuric acid) }\end{array}$ & Appearance of pink coloured ring & Presence of E.coli. \\
\hline 2 & Methyl red test: & $\begin{array}{l}\text { Appearance of pink coloured ring } \\
\text { in methyl red. }\end{array}$ & $\begin{array}{l}\text { Presence of E.coli and } \\
\text { Citrobacter freundii }\end{array}$ \\
\hline 3 & $\begin{array}{l}\text { Citrase utilization test: } \\
\text { (Simmon's citrate medium }+ \text { Bromo } \\
\text { thymol indicator }\end{array}$ & $\begin{array}{l}\text { Appearance of green colour or blue } \\
\text { colour in the medium Green- } \\
\text { Negative. Blue- Positive }\end{array}$ & $\begin{array}{l}\text { Absence or presence of } \\
\text { Citrobacter freundii. }\end{array}$ \\
\hline 4 & $\begin{array}{l}\text { Urease test: } \\
\text { (Urease is digested by urease } \\
\text { enzyme resulted in release of } \\
\text { ammonia) }\end{array}$ & $\begin{array}{l}\text { Appearance of yellow colour shows } \\
\text { negative. } \\
\text { Appearance of pink colour positive. }\end{array}$ & $\begin{array}{l}\text { Presence of Citrobacter } \\
\text { freundii. and Klebsiella } \\
\text { pneumoniae }\end{array}$ \\
\hline 5 & $\begin{array}{l}\text { Oxidase reaction: } \\
\text { (Tetra methyl parapholene diamine } \\
\text { dihydro chloride) }\end{array}$ & $\begin{array}{l}\text { Appearance of purple colour within } \\
30 \text { minutes. }\end{array}$ & $\begin{array}{l}\text { Presence of bacteria } \\
\text { contains cytochrome } \\
\text { oxidase like }\end{array}$ \\
\hline 6 & $\begin{array}{l}\text { Fermentation and gas production } \\
\text { test: } \\
\text { (Glucose, lactose, sucrose, mannose }\end{array}$ & $\begin{array}{l}\text { Change of colour from blue to } \\
\text { yellow. }\end{array}$ & $\begin{array}{l}\text { Presence of fermenting } \\
\text { and gas producing } \\
\text { bacteria. }\end{array}$ \\
\hline 7 & $\begin{array}{l}\text { Triple sugar iron test } \\
\text { (Glucose, lactose and sucrose } \\
\text { 1:10:10). }\end{array}$ & Black colour change in the media. & $\begin{array}{l}\text { Presence of hydrogen } \\
\text { sulphide gas producing } \\
\text { bacteria. }\end{array}$ \\
\hline
\end{tabular}


Escherichia coli were identified using MacConkey and Brilliant green blue broth as total coliform units in the samples. These two media types support growth of coliforms. Citrobacter freundii is capable of using citrate as carbon source for metabolic energy in the absence of fermentable glucose or lactose (Cappuccino and Sherman, 1996; Ashbolt, 2004; Hörman, 2005). Simmon's citrate medium does not have glucose or lactose therefore E. coli, which is citrate negative, does not grow on the medium. Citrobacter freundii has citrate permease, which facilitates transport of citrate in the cell hence could grow.

\section{RESULT AND DISCUSSION}

In the present microbial analysis total coliform count and $E$. coli count were analysed for 24 and 48 hours duration. Bacteriological quality of different water samples are shown in Figure 1. In Surlacode (Station I) the Faecal coliform and E. coli number is comparatively lesser than the other two stations namely Parvathipuram (Station II) and Thengampudur (Station III) (Figure 1). Different pathogenic coliform were identified in all sampled water (Table 2).

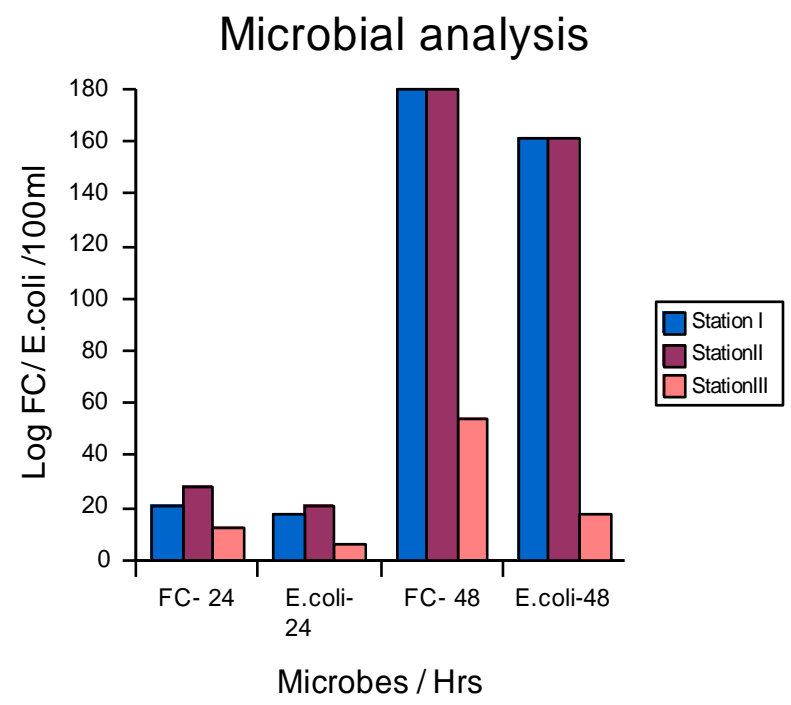

Figure 1. Number of coliform and E. coli bacteria in different stations.

Note: FC- Faecal coliform; E. coli- Escherichia coli

Table 2. Microbial Isolates from Water Samples

\begin{tabular}{|c|c|c|c|c|}
\hline S.No. & $\begin{array}{c}\text { Name of the } \\
\text { bacteria }\end{array}$ & Station I & Station II & Station III \\
\hline 1 & $\begin{array}{c}\text { Pseudomonas } \\
\text { aeruginosa }\end{array}$ & + & + & + \\
\hline 2 & $\begin{array}{c}\text { Shewanella } \\
\text { putrefaciens }\end{array}$ & + & + & + \\
\hline 3 & $\begin{array}{c}\text { Klebsiella } \\
\text { pneumonia }\end{array}$ & + & + & + \\
\hline 4 & $\begin{array}{c}\text { Citrobacter } \\
\text { freundii }\end{array}$ & + & + & + \\
\hline 5 & Proteus mirabilis & + & + & + \\
\hline
\end{tabular}


The bacteriological analysis of water determines the potability of water. According to Indian standard (BIS, 1981) throughout the year 95\% of samples should not contain any coliform organisms or should not be detectable in $100 \mathrm{ml}$ of any two consecutive samples and no sample contains $E$. coli in $100 \mathrm{ml}$. The desirable limit of coliform in water is 10 MPN/100ml (ISI). The result shows that all the water samples in the above three places, i.e. Surlacode (Station I), Parvathipuram (Station II) and Thengampudur (Station III)) were contaminated with high amount of bacterial population than Indian acceptable limit. The reason for high number of bacterial colonies might be due to inadequate maintenance of water reservoirs and the mixing of sewage into the reservoirs or directly into the rivers. In the Station I the high total coliform count may be indicative of the presence of high organic compounds in the water. Because this place is very close to the place of origin and there are so many number of rubber processing industries in this area. In station II and III the primary sources of these bacteria in water are animal and human wastes. These sources of bacterial contamination include surface runoff, pasture, and other land areas where animal wastes are deposited. Additional sources include seepage or discharge from septic tanks, sewage treatment facilities and natural soil /plant bacteria (EPA, 2003). The same results of the high number of total coliforms were observed by different authors in different water bodies in India during pre-monsoon and post monsoon seasons (Rajurkar et al., 2003; Radha Krishnan et al., 2007).

From table 2, it was noted that the water samples had five different types of bacteria. Distinct colonies could be identified using biochemical analysis given in table 1 . The results of the bacteriological analysis of drinking water of Ananthanar channel showed that the three areas namely Surlacode, Parvathipuram and Thengampudur, water is contaminated with coliforms and pathogenic bacteria. The bacterial species identified were members of the Enterobacteriaceae family (Table 2). In Surlacode the number of bacterial counts lesser than other areas. One of the reasons may be due to less human intervention. But it is important to note that the limited presence may be due to that coliform bacteria which are widely found in nature and do not necessarily indicate faecal pollution (Binnie et al., 2002; Griffith et al., 2003).

\section{CONCLUSIONS}

The present study indicates the polluted condition of the water resource which will have serious effects.

Enteric pathogens cannot normally multiply in water hence water is not its mode of transmission to humans (WHO, 1996). However, the presence of enterobacteriae would be enough infective doses in people whose local or general natural defense mechanisms are impaired to significantly low. The people likely to be at risk would be the very old or the very young as well as patients undergoing immunosuppressive therapy. Other immunocompromised individuals suffering from AIDS would also be at risk. Also, water polluted by bacteria when permitted to contaminate food would lead to the multiplication of the pathogens to very large doses.

\section{REFERENCES}

AMERICAN PUBLIC HEALTH ASSOCIATION - APHA. Standards methods for the examination of water and wastewater. 20 ${ }^{\text {th }}$ edition. Washington DC, 1998. 
ANTONY, R. M.; RENUGA, F. B. Microbiological analysis of drinking water quality of Ananthanar channel of Kanyakumari district, Tamil Nadu, India. Ambi-Agua, Taubaté, v. 7, n. 2, p. 42-48, 2012. (http://dx.doi.org/10.4136/ambi-agua.881)

ASHBOLT, N. J. Risk analysis of drinking water microbial contamination versus disinfection by-products (DBPs). Toxicology, v. 198, n. 1/3, p. 255-262, 2004. http://dx.doi.org/10. 1016/j.tox.2004.01.034

BHARDWAJ, R. M. Water quality monitoring in India - achievements and constraints. In: INTERNATIONAL WORK SESSION ON WATER STATISTICS, Vienna, June 2022, 2005, Vienna. Available in: <http://unstats.un.org/unsd/environment/envpdf/pap wasess5a2india.pdf >. Access in: $16 \mathrm{Ag} .2012$.

BINNIE, C.; KIMBER, M.; SMETHURST, G. Basic water treatment, Cambridge: Royal Society of Chemistry, 2002.

BUREAU OF INDIAN STANDARDS - BIS. IS:1622: method of sampling and microbiological examination of Water. Edition 2.4. New Delhi, 1981. Reaffirmed 1996, 2003 to 2005.

CAPPUCCINO, J. G.; SHERMAN, N. A laboratory manual: standard qualitative analysis of water. $4^{\text {th }}$ edition. Boston: Addison-Wesely Longman, 1996. p. 299.

UNITED STATES ENVIRONMENTAL PROTECTION AGENCY - US.EPA. Safe drinking water act. Washington DC, 2003.

GAUDY, F. A. Microbiology for environmental scientists and engineers. London: McGraw Hill International Book Company, 1998.

GOEL, P. K.; BHOSALE, P. M. Studies on the river Panchganga at Kolhapur with special reference to human impact on water quality. In: TRIPATHY, G.; PANDEY, G. C. (Eds.). Current topics in environmental sciences. [S.1.]: ABD Publishers, 2001. p. 108-122.

GRIFFITH, J. F.; WEISBERG, B. S.; McGEE, D. C. Evaluation of microbial source tracking methods using mixed faecal sources in aqueous test samples. Journal of Water and Health, v. 1, n. 4, p. 141-151, 2003.

HÖRMAN, A. Assessment of the microbial safety of drinking water produced from surface water under field conditions. 2005. 68f. Dissertation (Ph. D) - Faculty of Veterinary Medicine, University of Helsinki, Helsinki, 2005.

MAITY, P. B.; SAHA, T.; GHOSH, P. B.; BANDOPADHYAY, T. S. Studies on pollution statua of Jalangi river around Krishnanagar city in West Bengal. Science and Culture, v. 70, n. 5/6, p. 191- 194, 2004.

PATIL, Y. S.; PATIL, S. K.; DHANDE, A. D.; PAWAR, N. S. Water quality of river Tapti at Bhusawal Town. Indian Journal of Environment Protection, v. 23, n. 6, p. 620- 623, 2003.

RADHA KRISHNAN, R.; DHARMARAJ, K.; RANJITHA KUMARI, B. D. A comparative study on the physicochemical and bacterial analysis of drinking, borewell and sewage water in the three different places of Sivakasi. Journal of Environmental biology, v. 28, n. 1, p. 105-108, 2007.

RAJURKAR, N. S.; NONGBRI, B.; PATWARDHAN, A. M. Physico-chemical and microbial analysis of Umian (Brapani) lake water. Indian Journal of Environmental Proceedings, v. 23, n. 6, p. 633- 639, 2003. 
ANTONY, R. M.; RENUGA, F. B. Microbiological analysis of drinking water quality of Ananthanar channel of Kanyakumari district, Tamil Nadu, India. Ambi-Agua, Taubaté, v. 7, n. 2, p. 42-48, 2012. (http://dx.doi.org/10.4136/ambi-agua.881)

SOUTH AFRICA. Department of Water Affairs and Forestry. Water Research Commission. Quality of domestic water supplies: volume 1: assessment guide. 2. ed. Pretoria, 1998.

WORLD HEALTH ORGANIZATION - WHO. Guidelines for drinking water quality: health criteria and other supporting information. , 1996. Vol. 2. 


ISSN = 1980-993X - doi:10.4136/1980-993X
www.ambi-agua.net
E-mail: ambi-agua@agro.unitau.br
Tel.: (12) 3625-4212

\title{
Atributos microbianos do solo fertilizado com composto de lodo de esgoto
}

(http://dx.doi.org/10.4136/ambi-agua.915)

\section{Ericléia Büerg Suszek'; Paulo Fortes Neto ${ }^{1}$; Nara Lúcia Perondi Fortes ${ }^{1}$; Eliana Maria de Araújo Mariano da Silva ${ }^{1}$; Fabiana Brambatti ${ }^{1}$; Claudio Roberto Silva ${ }^{2}$; Dimas Donizeti Patrocinio ${ }^{2}$}

\author{
1Universidade de Taubaté, Departamento de Ciências Agrárias, Taubaté, SP \\ e-mails: ericleiaagro@yahoo.com.br,paulofortes.neto@gmail.com,nara_fortes@uol.com.br, \\ emams.master@gmail.com, fabi_bram@hotmail.com \\ ${ }^{2}$ Fibria Celulose S/A. email: claudio.silva@fibria.com.br, dimas.patrocinio@ fibria.com.br
}

\section{RESUMO}

A aplicação do composto de lodo de esgoto em áreas agrícolas pode promover alterações nos atributos microbianos do solo. Assim, há necessidade de se avaliar o impacto da adição do composto sobre a atividade microbiana do solo. O presente trabalho objetivou avaliar a alteração nos atributos microbianos de um solo fertilizado com diferentes doses de composto de lodo por meio da medida de liberação de $\mathrm{CO}_{2}$ e a contagem de bactérias e fungos. $\mathrm{O}$ experimento foi realizado em condição de laboratório, com jarros respirométricos contendo em seu interior amostras de solo misturadas com composto nas doses de $0 ; 20 ; 40 ; 60$ e $80 \mathrm{Mg}$ ha ${ }^{-1}$. A liberação de $\mathrm{CO}_{2}$ do solo foi medida diariamente durante os 28 dias de incubação. Após a incubação, as amostras de solo foram retiradas dos jarros e submetidas à contagem de bactérias e fungos e à determinação da composição química do solo. Os tratamentos correspondentes às doses do composto foram dispostos em delineamento completamente casualizado com quatro repetições. A liberação de $\mathrm{CO}_{2}$ e o número de bactérias e fungos aumentaram significativamente com as doses do composto devido ao fornecimento de substrato energético e nutrientes proporcionados pelo composto. A medida de liberação de $\mathrm{CO}_{2}$ indicou que a doses de composto acima de $20 \mathrm{Mg} \mathrm{ha}^{-1}$ ocasionou impactos significativos sobre a atividade microbiana do solo.

Palavras-chave: atividade microbiana, bactérias, fungos.

\section{Soil microbial attributes treated with composting of sewage sludge}

\section{ABSTRACT}

The use of sludge composting in agricultural areas alters the microbial functions. In this context it is necessary to evaluate the impact of composting addition on microbial activities in the soil. This study evaluated the alteration of microbial attributes of a soil fertilized with sewage sludge compost by measuring the $\mathrm{CO}_{2}$ release rates and counting bacteria and fungi numbers. This experiment was conducted in laboratory using respirometric jars that contained samples of soil mixed with different doses of compost: $0 ; 20 ; 40 ; 60$ and $80 \mathrm{Mg} \mathrm{ha}^{-1}$, and $\mathrm{CO}_{2}$ release was quantified daily during the 28 days of incubation when the samples were removed from the jars and bacteria and fungi quantities were counted. The treatments corresponding to each dose of the composting were arranged in completely randomized design with four replications. The $\mathrm{CO}_{2}$ release and the quantity of bacteria and fungi increased with additional doses of the compound. This occurred as a result of supplying energetic substrate and 
SUSZEK, E. B.; FORTES NETO, P.; FORTES, N. L. P.; SILVA, E. M. A. M.; BRAMBATTI, F.; SILVA, C. R; PATROCINIO, D. D. Atributos microbianos do solo fertilizado com composto de lodo de esgoto Ambi-Agua, Taubaté, v. 7, n. 2, p. 49-61, 2012. (http://dx.doi.org/10.4136/ambi-agua.915).

nutrients from the compound. The $\mathrm{CO}_{2}$ released measurements indicated that compound above $20 \mathrm{Mg} \mathrm{ha}^{-1}$ has significant impact on soil microbial activity.

Keywords: microbial activity, bacterial, fungi.

\section{INTRODUÇÃO}

Os microrganismos possuem uma capacidade de dar respostas rápidas a mudanças nos atributos microbianos do solo, isto ocorre porque, as reações biológicas e bioquímicas são catalizadas pelos microrganismos (Brookes, 1995; Vieira et al., 2011). Essas reações são responsáveis pela decomposição de resíduos orgânicos, pela ciclagem biogeoquímica, incluindo a fixação de $\mathrm{N}_{2}$, pela formação de agregados do solo e pela taxa de decomposição de materiais orgânicos (Elsas et al., 1997). Devido a essas características, os microrganismos do solo são considerados como indicadores sensíveis para avaliar o impacto antropogênico sobre os processos biológicos do solo (Dick, 1994; Doran e Parkinson, 1994; Turco et al., 1994).

Os estudos referentes ao uso de medidas microbiológicas como indicadoras de poluição do solo e do ambiente têm sido desenvolvidos com o objetivo de verificar a ação dos elementos contaminantes, provenientes de fertilizantes, pesticidas, resíduos orgânicos e do manejo do solo, sobre a comunidade e a atividade microbiana do solo (Fortes Neto, 2000; Bettiol e Fernandes, 2004; Gil-Sotres et al., 2005; Sullivan et al., 2006; Vieira et al., 2011).

A utilização de medidas microbiológicas para indicar a qualidade do solo vem sendo pesquisada porque os microrganismos mantêm uma íntima relação com as propriedades químicas e físicas do solo e, também, porque são responsáveis por inúmeros processos biológicos e bioquímicos do solo; por isso, são sensíveis às alterações de origens naturais e antropogênicas que ocorrem nele. Entretanto, apesar dessa característica dos microrganismos, há vários critérios básicos para que uma propriedade microbiana possa ser considerada como indicadora ideal para avaliar as alterações resultantes do manejo dado ao solo (Brookes, 1995; Marchiori Júnior e Melo, 1999; Trasar-Cepeda et al., 2000; Silva et al. 2007; Santos et al., 2011).

De acordo com Brookes (1995), a propriedade microbiana deve apresentar as seguintes características: (1) ser mensurável de forma acurada; (2) ser testada em uma variedade de tipos e condições de solo; (3) ser sensível à ação do agente em estudo; e (4) apresentar validade científica confiável.

As propriedades microbianas sensíveis às variações provocadas no solo pelos elementos poluidores são divididas em três grupos. O primeiro é aquele que mede a atividade microbiana global; o segundo determina o tamanho da população de um organismo, de um grupo funcional, ou da comunidade; e o terceiro é a correlação da atividade com a comunidade microbiana predominante no solo (Brookes, 1995).

As análises microbiológicas são úteis na avaliação da qualidade do solo; porém, vários autores relataram a necessidade de se utilizarem diversas análises ao mesmo tempo, para se ter uma noção mais precisa das interferências ocasionadas pelos agentes poluentes no solo. (Turco et al., 1994; Brookes, 1995; Jahnel et al., 1999; Lisboa et al., 2012).

Nos estudos para determinar os efeitos dos agentes contaminantes e do manejo do solo sobre as atividades e a dinâmica das comunidades microbianas, as análises mais utilizadas como indicadoras são: liberação de $\mathrm{CO}_{2}$ pela respiração microbiana; mineralização de nitrogênio e carbono; fixação biológica de nitrogênio; atividades enzimáticas; contagem de grupos microbianos e biomassa microbiana de C, N, P e S (Marchiori Júnior e Melo, 1999; Paula et al., 2010; Zhong et al., 2010). 
Estudos integrados dessas atividades microbianas poderão fornecer dados importantes para a elaboração de índices de qualidade biológica de solos, necessárias para diagnosticar e monitorar impactos ambientais sobre a microbiota do solo (Turco et al., 1994; Brookes, 1995; Banerjee et al., 1997; Roscoe et al., 2006).

Com base no exposto, o presente trabalho teve como objetivo avaliar a alteração nos atributos microbianos do solo fertilizado com composto de lodo de esgoto, por meio de medidas microbiológicas de liberação de $\mathrm{CO}_{2}$ e de contagem de bactérias e fungos.

\section{MATERIAIS E MÉTODO}

No presente estudo foi utilizada amostra de um Latossolo Vermelho Amarelo distrófico (Embrapa, 1999) coletada na camada de $0-20 \mathrm{~cm}$ de profundidade em uma área de plantio comercial de eucalipto localizada no município de Guararema/SP. O solo apresentou as seguintes características químicas: $\mathrm{pH}\left(\mathrm{CaCl}_{2}\right)=4,0$; matéria orgânica $=23,6 \mathrm{~g} \mathrm{dm}^{-3}$; $\mathrm{P}=3,0 \mathrm{mg} \mathrm{dm} ; \mathrm{K}=0,4 \mathrm{mmol}_{\mathrm{c}} \mathrm{dm}^{-3} ; \mathrm{Ca}=2,0 \mathrm{mmol}_{\mathrm{c}} \mathrm{dm}^{-3} ; \mathrm{Mg}=1,0 \mathrm{mmol}_{\mathrm{c}} \mathrm{dm}^{-3}$; $\mathrm{Al}=14,3 \mathrm{mmol}_{\mathrm{c}} \mathrm{dm}^{-3} ; \mathrm{SB}=4,0 \mathrm{mmol}_{\mathrm{c}} \mathrm{dm}^{-3} ; \mathrm{T}=95,2 \mathrm{mmol}_{\mathrm{c}} \mathrm{dm}^{-3} \mathrm{e} \mathrm{V}=3 \%$.

O composto utilizado foi produzido a partir da mistura de lodo de esgoto com cavaco de madeira e cinza de caldeira gerada pela produção de celulose na unidade Fabril da empresa FIBRIA Celulose S/A, situada em Jacareí/SP. Os resíduos foram compostados durante um período de 120 dias, e a sua composição química e biológica, conforme especificada pela Resolução CONAMA n ${ }^{\circ} 375$ de 2006 (Brasil, 2006), está apresentada na Tabela 1.

Tabela 1. Características químicas e biológicas do composto resultante da mistura de lodo de esgoto com cavaco de madeira e cinza de caldeira.

\begin{tabular}{|c|c|}
\hline Atributo $^{(1)}$ & Valor ${ }^{(2)}$ \\
\hline $\mathrm{pH}$ & 6,5 \\
\hline Nitrogênio total $\left(\mathrm{g} \mathrm{kg}^{-1}\right)$ & 3,0 \\
\hline Carbono orgânico $\left(\mathrm{g} \mathrm{kg}^{-1}\right)$ & 88,0 \\
\hline Relação C/N & $29 / 1$ \\
\hline Cálcio $\left(\mathrm{g} \mathrm{kg}^{-1}\right)$ & 100 \\
\hline Sódio $\left(\mathrm{g} \mathrm{kg}^{-1}\right)$ & 4,8 \\
\hline Magnésio $\left(\mathrm{g} \mathrm{kg}^{-1}\right)$ & 8,3 \\
\hline Potássio $\left(\mathrm{g} \mathrm{kg}^{-1}\right)$ & 5,0 \\
\hline Fósforo $\left(\mathrm{g} \mathrm{kg}^{-1}\right)$ & 2,2 \\
\hline Arsênio $\left(\mathrm{mg} \mathrm{kg}^{-1}\right)$ & $<0,5$ \\
\hline Bário $\left(\mathrm{mg} \mathrm{kg}^{-1}\right)$ & 230 \\
\hline Cádmio $\left(\mathrm{mg} \mathrm{kg}^{-1}\right)$ & $<0,5$ \\
\hline Chumbo (mg kg-1 $)$ & 15 \\
\hline Cobre $\left(\mathrm{mg} \mathrm{kg}^{-1}\right)$ & 33 \\
\hline Cromo $\left(\mathrm{mg} \mathrm{kg}^{-1}\right)$ & 10,6 \\
\hline Mercúrio ( $\left.\mathrm{mg} \mathrm{kg}^{-1}\right)$ & $<0,03$ \\
\hline Molibdênio (mg kg$\left.{ }^{-1}\right)$ & $<0,5$ \\
\hline Níquel $\left(\mathrm{mg} \mathrm{kg}^{-1}\right)$ & 1,9 \\
\hline Selênio $\left(\mathrm{mg} \mathrm{kg}^{-1}\right)$ & $<0,5$ \\
\hline Zinco $\left(\mathrm{mg} \mathrm{kg}^{-1}\right)$ & 12 \\
\hline Coliformes termotolerantes $\left(\mathrm{NMPg}^{-1}\right.$ de ST) & $<1,8$ \\
\hline Ovos viáveis de helmintos (ovos $\mathrm{g}^{-1}$ de $\mathrm{ST}$ ) & 0,0 \\
\hline Salmonella spp $(10 \mathrm{~g}$ de ST $)$ & Ausente \\
\hline
\end{tabular}


SUSZEK, E. B.; FORTES NETO, P.; FORTES, N. L. P.; SILVA, E. M. A. M.; BRAMBATTI, F.; SILVA, C. R; PATROCINIO, D. D. Atributos microbianos do solo fertilizado com composto de lodo de esgoto Ambi-Agua, Taubaté, v. 7, n. 2, p. 49-61, 2012. (http://dx.doi.org/10.4136/ambi-agua.915).

O cálculo para definir a dosagem (DR) foi realizado tendo como base a concentração do nitrogênio no composto e a quantidade $\left(120 \mathrm{~kg} \mathrm{ha}^{-1}\right)$ de nitrogênio recomendada para a cultura do eucalipto, conforme a equação abaixo descrita por Ilhenfeld e Andreoli (1999).

$$
\mathrm{DR}\left(\mathrm{Mg} \mathrm{ha}^{-1}\right)=\text { recomendação de } \mathrm{N} \text { para o eucalipto } \div \text { concentração de } \mathrm{N}(\%) \text { x } 5
$$

Com base na dose recomendada de composto $\left(80 \mathrm{Mg} \mathrm{ha}^{-1}\right)$, efetuou-se o delineamento experimental em blocos casualizados com cinco tratamentos e quatro repetições. Os tratamentos foram distribuídos em cinco doses de composto (base seca): $\mathrm{T}_{1}=0 \mathrm{Mg} \mathrm{ha}^{-1}$; $\mathrm{T}_{2}=20 \mathrm{Mg} \mathrm{ha}^{-1} ; \mathrm{T} 3=40 \mathrm{Mg} \mathrm{ha}^{-1} ; \mathrm{T}_{4}=60 \mathrm{Mg} \mathrm{ha}^{-1} \mathrm{e} \mathrm{T}_{5}=80 \mathrm{Mg} \mathrm{ha}^{-1}$.

O composto, nas dosagens correspondentes aos tratamentos, foi misturado a 50 gramas de solo com teor de água ajustado para $80 \%$ da capacidade de campo e, depois, colocado dentro de um jarro de vidro ( $1,5 \mathrm{~L})$ fechado hermeticamente, contendo, em seu interior, um cadinho de vidro com $10 \mathrm{~mL}$ de $\mathrm{NaOH}\left(0,5 \mathrm{~mol}_{\mathrm{c}} \mathrm{L}^{-1}\right)$.

Os jarros de vidro, depois de fechados, foram levados para a incubação em uma sala climatizada à temperatura de $28^{\circ} \mathrm{C} \pm 2$, por um período de sete dias. Em intervalos de dois dias, foram realizadas as determinações do $\mathrm{CO}_{2}$ desprendido pelas amostras de solo que foi capturado pelo hidróxido de sódio contido nos cadinhos de vidro. Aos cadinhos, contendo o hidróxido de sódio, foram adicionados $1 \mathrm{~mL}$ de $\mathrm{BaCl}_{2}(50 \%)$ e três gotas do indicador fenolftaleína $(3 \%)$ e, depois, foi efetuada a titulação com $\mathrm{HCl}\left(0,5 \mathrm{~mol}_{\mathrm{c}} \mathrm{L}^{-1}\right)$, para quantificação da massa liberada de $\mathrm{CO}_{2}$ por amostra de solo $\left(\mathrm{mg} \mathrm{g}^{-1}\right)$, conforme a metodologia descrita por Stotzky (1965). O valor médio de $\mathrm{CO}_{2}$ liberado do solo em cada período de coleta foi o resultado do somatório da quantidade de $\mathrm{CO}_{2}$ determinado durante 28 dias de incubação das amostras de solo.

As amostras de solo para determinar a composição química e a quantificação de bactérias e fungos foram retiradas dos jarros de vidro 28 dias após a incorporação das doses do composto.

A contagem de bactérias e fungos no solo foi determinada 28 dias após a aplicação do composto, e o método utilizado foi o de Número Mais Provável (NMP) de microrganismos do solo, a técnica utilizada foi a de plaqueamento em gotas de meio de cultura agarizado sobre placa de Petri (Jahnel et al., 1999).

As diluições para determinar a contagem de bactérias e fungos foram realizadas em uma suspensão obtida a partir de $10 \mathrm{~g}$ de solo suspenso em $90 \mathrm{~mL}$ de solução salina a $0,85 \%$, contidas em frascos Erlenmeyer. Os frascos foram submetidos, por 10 minutos, à agitação circulante e, depois, realizou-se as diluições sucessivas até $10^{-2}$ para fungos e até $10^{-3}$ para bactérias. Essas diluições foram realizadas transferindo-se, com o auxílio de uma micropipeta, alíquotas de $0,1 \mathrm{~mL}$ dos tubos de ensaio contendo $0,9 \mathrm{~mL}$ de água esterilizada.

O plaqueamento do meio de cultura agarizado foi realizado em câmara de fluxo laminar, com a distribuição de gotas com volume de $0,04 \mathrm{~mL}$ na superfície de placas de Petri esterilizadas. As placas foram vedadas e incubadas em estufa para D.B.O (demanda bioquímica de oxigênio), sob temperatura de $28^{\circ} \mathrm{C} \pm 2$, por um período de 48 horas. Após o período de incubação, foi contado o número de colônias microbianas.

Para o crescimento de bactérias, o meio de cultura utilizado foi o Thorton, e para os fungos, o meio de Martin.

As amostras de solo, para a determinação química, foram colocadas para secar ao ar e depois de peneiradas em malhas de $2 \mathrm{~mm}$ foram realizadas as determinações de $\mathrm{pH}$, matéria orgânica, fósforo, cálcio, magnésio, potássio, alumínio + hidrogênio, capacidade de troca de cátions (T) e saturação por bases (V\%), conforme a metodologia descrita por Raij et al. (1987). 
Todas as determinações foram feitas em quadriplicatas e os resultados expressos com base no solo seco. Os dados foram submetidos à análise da variância e feitas comparações das médias pelo Teste de Tukey a 5\%.

\section{RESULTADOS E DISCUSSÃO}

\subsection{Caracterização química do solo}

Quanto às alterações nas características químicas do solo, proporcionadas pela incorporação de doses de composto de lodo, observa-se, na Tabela 2, que o pH, matéria orgânica, capacidade de troca de cátions, saturação por bases e os teores de fósforo, potássio e cálcio aumentam e que o alumínio + hidrogênio diminuem significativamente no solo, após a adição do composto de lodo. Esses resultados confirmam a observação de outros autores de que a prática de incorporação de composto orgânico resulta na elevação do $\mathrm{pH}$, nos aumentos dos valores da matéria orgânica, fósforo, potássio, cálcio, magnésio, na capacidade de troca de cátions (T), na saturação de bases (V\%) e redução do hidrogênio + alumínio no solo (Silva et al., 2001; Melo et al., 2001; Oliveira et al., 2002; Rocha et al., 2004; Viera et al., 2011).

Tabela 2. Composição química do solo 30 dias após a adição do composto de lodo de esgoto.

\begin{tabular}{c|ccccccccc}
\hline Doses do composto & $\mathbf{p H}$ & $\mathbf{M . O}$ & $\mathbf{P}$ & $\mathbf{K}$ & $\mathbf{C a}$ & $\mathbf{M g}$ & $\mathbf{H}+\mathbf{A L}$ & $\mathbf{T}$ & $\mathbf{V}$ \\
\hline$\left(\mathrm{Mg} \mathrm{ha}^{-1}\right)$ & $\left(\mathrm{CaCl}_{2}\right)$ & $\left(\mathrm{g} \mathrm{dm}^{-3}\right)$ & $\left(\mathrm{mg} \mathrm{dm}^{-3}\right)$ & $-------------\left(\mathrm{mmol}_{\mathrm{c}} \mathrm{dm}^{-3}\right)--------$ & & $(\%)$ \\
0 & $4,2 \mathrm{~d}^{(1)}$ & $23 \mathrm{c}$ & $4 \mathrm{e}$ & $1,5 \mathrm{c}$ & $3,2 \mathrm{c}$ & $1,1 \mathrm{~b}$ & $30 \mathrm{a}$ & $35,8 \mathrm{~b}$ & $16,2 \mathrm{~d}$ \\
20 & $4,7 \mathrm{c}$ & $29 \mathrm{c}$ & $52 \mathrm{~d}$ & $2,7 \mathrm{~b}$ & $20,5 \mathrm{~b}$ & $1,4 \mathrm{~b}$ & $22 \mathrm{~b}$ & $46,6 \mathrm{a}$ & $52,7 \mathrm{c}$ \\
40 & $5,4 \mathrm{~b}$ & $35 \mathrm{~b}$ & $70 \mathrm{c}$ & $3,4 \mathrm{~b}$ & $24,2 \mathrm{~b}$ & $1,6 \mathrm{~b}$ & $18 \mathrm{~b}$ & $47,2 \mathrm{a}$ & $61,8 \mathrm{bc}$ \\
60 & $5,6 \mathrm{~b}$ & $36 \mathrm{~b}$ & $115 \mathrm{~b}$ & $3,9 \mathrm{a}$ & $25,6 \mathrm{~b}$ & $2,1 \mathrm{a}$ & $15 \mathrm{bc}$ & $46,6 \mathrm{a}$ & $67,8 \mathrm{~b}$ \\
80 & $6,4 \mathrm{a}$ & $38 \mathrm{a}$ & $210 \mathrm{a}$ & $4,1 \mathrm{a}$ & $31,5 \mathrm{a}$ & $2,0 \mathrm{a}$ & $11 \mathrm{c}$ & $48,6 \mathrm{a}$ & $77,3 \mathrm{a}$ \\
\hline
\end{tabular}

${ }^{(\mathbf{1})}$ Médias seguidas por letras iguais, não diferem entre si, pelo teste de Tukey a 5\%.

\subsection{Liberação de $\mathrm{CO}_{2}$ no solo}

A Figura 1 apresenta a variação da emissão de $\mathrm{C}-\mathrm{CO}_{2}$ do solo em amostras coletadas ao $0^{\circ}, 7^{\circ}, 14^{\circ}$ e $28^{\circ}$ dias após a incorporação de doses $\left(0,20,40,60\right.$ e $\left.80 \mathrm{Mg} \mathrm{ha}^{-1}\right)$ de composto de lodo de esgoto no solo. Verifica-se que a liberação de $\mathrm{C}-\mathrm{CO}_{2}$, no $1^{\circ}$ dia, mantém-se estável entre os tratamentos e, depois do $7^{\circ}$ dia, com exceção da parcela com $20 \mathrm{Mg} \mathrm{ha}^{-1}$ de composto, a quantidade de C-CO $\mathrm{CO}_{2}$ apresenta uma elevação a partir da dose $40 \mathrm{Mg}$ ha $^{-1}$ até a dose de $80 \mathrm{Mg} \mathrm{ha}^{-1}$ de composto. Para o comportamento, observado na liberação de $\mathrm{C}-\mathrm{CO}_{2}$, entre o $0^{\circ}$ e $7^{\circ}$ dia, pode-se aventar duas hipóteses: na primeira, a causa seria a mudança no substrato energético, ou seja, a maioria dos microrganismos estabelecidos no solo não estava adaptada a decompor compostos orgânicos de baixa relação $\mathrm{C} / \mathrm{N}$ fornecidos pelo composto. A segunda está relacionada às alterações das condições do meio, proporcionadas pela liberação de nutrientes no solo. Esses fatores exigiram dos microrganismos um determinado tempo para adaptação das enzimas e ajustamento do metabolismo das células microbianas ao novo substrato orgânico e à nova condição química do solo (Cattelan e Vitor, 1990; Fortes Neto, 2000; Bettiol e Fernandes, 2004).

Já entre o $7^{\circ}$ e $28^{\circ}$ dia, verifica-se que a dose de $20 \mathrm{Mg} \mathrm{ha}^{-1}$ de composto não forneceu quantidades de substrato energético e nutrientes em proporções para ocasionar alterações significativas na atividade microbiana do solo. Por outro lado, observa-se, na Figura 1, que a produção de $\mathrm{C}_{-} \mathrm{CO}_{2}$ aumenta significativamente com as doses de 40 , 60 e $80 \mathrm{Mg} \mathrm{ha}^{-1}$ de composto. Esse aumento gradativo na quantidade de carbono respirado pela comunidade microbiana no solo com a incorporação de 40, 60 e $80 \mathrm{Mg} \mathrm{ha}^{-1}$ ocorreu, provavelmente, 
porque os microrganismos, após se adaptarem à nova condição do meio, proporcionada pela incorporação do composto, foram estimulados pela elevação do $\mathrm{pH}$, pelos aumentos nos teores de bases trocáveis, fósforo, nitrogênio e principalmente, pelo fornecimento de carbono orgânico (Sullivan et al., 2006; Paula et al., 2010; Zhong et al., 2010). Essa tendência fica mais evidente quando comparamos os valores de $\mathrm{C}-\mathrm{CO}_{2}$ com os resultados da composição química do solo das parcelas com 40, 60 e $80 \mathrm{Mg} \mathrm{ha}^{-1}$ de composto. A esse respeito, diversos autores também verificaram que a emissão de $\mathrm{C}-\mathrm{CO}_{2}$ apresenta uma estreita relação com as alterações químicas do solo (Araújo e Monteiro, 2006; Silva et al., 2007; Santos et al., 2011).

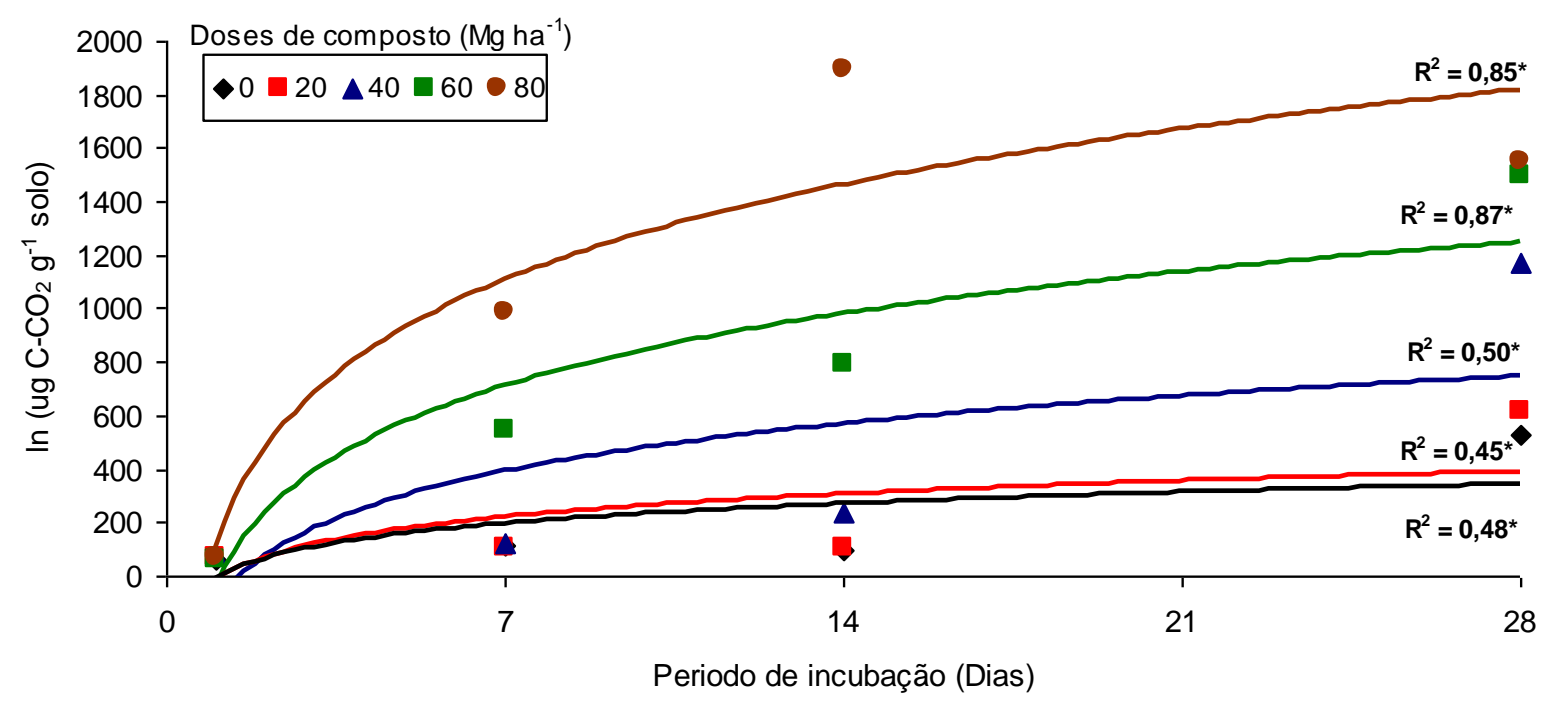

Figura 1. Variação da liberação do C- $\mathrm{CO}_{2}$ do solo incubado com doses de $0,20,40$, 60 e $80 \mathrm{Mg}$ $\mathrm{ha}^{-1}$ de composto de lodo de esgoto.

*significativo a $5 \%$.

A taxa acumulada da atividade respiratória dos microrganismos do solo foi expressa como $\mu \mathrm{g}$ de $\mathrm{C}-\mathrm{CO}_{2}$ liberado por grama de solo, 28 dias após a incorporação das doses de composto de lodo no solo (Figura 2). Os valores variaram significativamente com as doses aplicadas ao solo. Os valores de $\mathrm{C}-\mathrm{CO}_{2}$ acumulados variaram de $800 \mu \mathrm{g} \mathrm{g}^{-1}$ solo para a dose $0 \mathrm{Mg} \mathrm{ha}^{-1}$ a $4.500 \mu \mathrm{g} \mathrm{g}^{-1}$ para a dose de $80 \mathrm{Mg} \mathrm{ha}^{-1}$. Observa-se que os menores valores de C$\mathrm{CO}_{2}$ foram determinados nas parcelas com 0 e $20 \mathrm{Mg} \mathrm{ha}^{-1}$ de composto, e que os maiores valores nas amostras de solo foram provenientes das parcelas com 40, 60 e $80 \mathrm{Mg} \mathrm{ha}^{-1} \mathrm{de}$ composto. Isto ocorreu devido à maior atividade biológica que, por sua vez, foi estimulada pela quantidade de carbono orgânico proporcionada pelo aumento das doses do composto (Balota et al., 1998).

Analisando em conjunto os resultados das Figuras 2, 3 e 4, observa-se que a taxa acumulada de $\mathrm{C}-\mathrm{CO}_{2}$ liberado do solo reflete claramente o consumo de carbono orgânico pela comunidade de bactérias e fungos que se estabeleceram no solo com a aplicação de 40, 60 e $80 \mathrm{Mg} \mathrm{ha}^{-1}$ de composto de lodo de esgoto. Segundo Jahnel et al. (1999), esse fato ocorre devido ao crescimento de espécies microbianas tolerantes às mudanças proporcionadas pela incorporação do composto no solo. Também não se pode esquecer de que, juntamente com o composto, foi incorporado um grande número de células microbianas que não estava presente no solo (Fortes Neto, 2000). Deve-se ressaltar que, nesse caso, a alta taxa de $\mathrm{C}-\mathrm{CO}_{2}$ observada no solo com composto é considerada uma característica desejável porque, com a decomposição do composto, são liberados nutrientes para as plantas (Roscoe et al., 2006). 


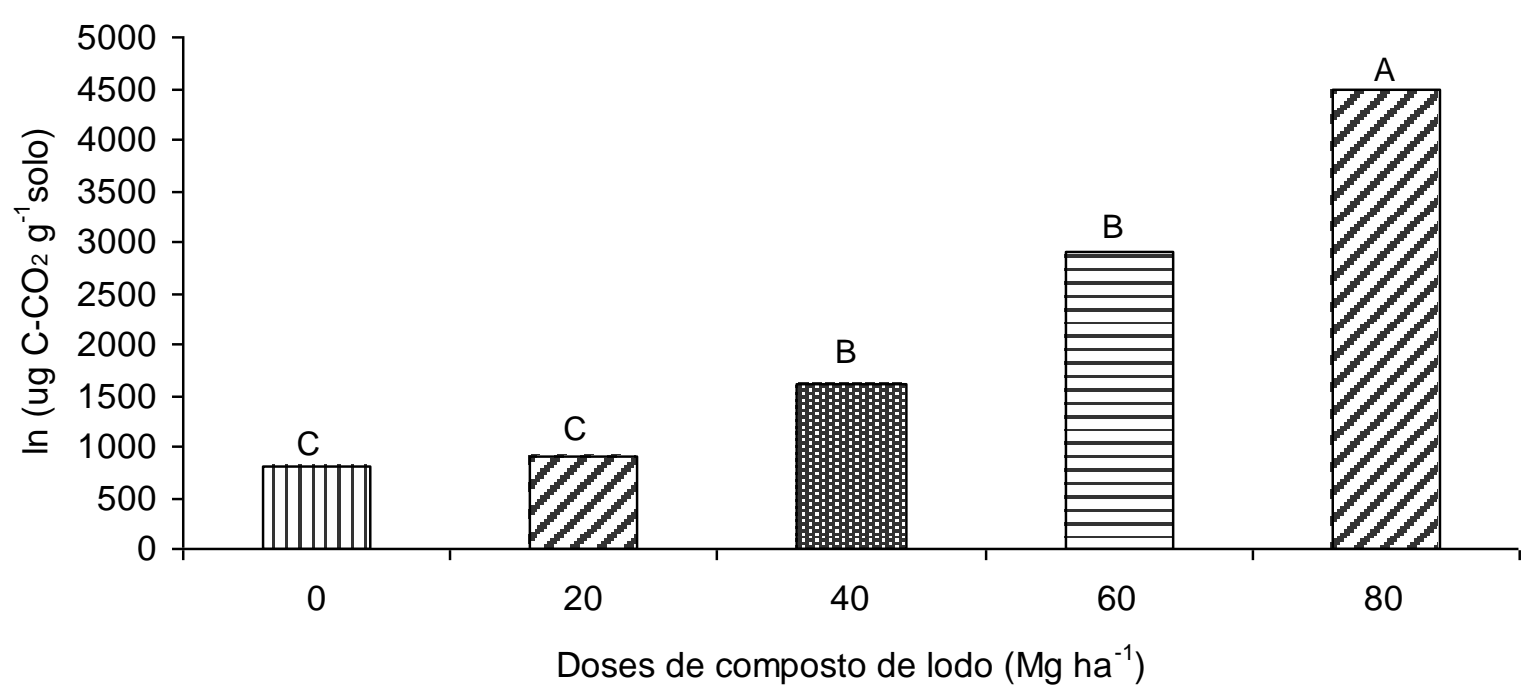

Figura 2. Taxa acumulada de $\mathrm{CO}_{2}$ liberado de amostras de solo coletadas nas parcelas com doses de $0,20,40,60$ e $80 \mathrm{Mg} \mathrm{ha}^{-1}$ de composto de lodo de esgoto.

Nota: Médias seguidas por letras maiúsculas iguais, não diferem entre si, pelo teste de Tukey a 5\%).

\subsection{Número de bactérias no solo}

A contagem do número mais provável (NMP) de bactérias, realizada 30 dias após a incorporação das doses de composto de lodo de esgoto, apresentou diferenças significativas entre os tratamentos, e os valores variaram entre 0,70 a 51,30 × $10^{5}$ por grama de solo (Figura $3)$. Esses resultados, quando comparados com os valores verificados em áreas com cultivos agrícolas, estão relativamente baixos, pois Silva Filho e Vidor (1984) e Catellan e Vidor (1990) constaram valores variando entre $10^{6}$ a $10^{7}$. No entanto, o número de bactérias determinado no presente estudo é similar aos valores observados nas pesquisas com aplicação de composto orgânico e lodo de esgoto (Fortes Neto, 2000; Bettiol e Fernandes, 2004).

Ainda na Figura 3, observa-se que o tratamento sem a adição do composto apresentou os menores números de bactérias. Por outro lado, nas parcelas com aplicação de doses de composto, constatou-se um aumento em consonância com o aumento da dose de composto. Esses aumentos na contagem de bactérias, verificados nos solos com a incorporação de composto, podem ter ocorrido devido à inoculação no solo de bactérias existentes no composto e, também, pelo fornecimento de substratos energéticos e nutrientes provenientes da decomposição do composto no solo, favorecendo, dessa maneira, a multiplicação das células bacterianas (Jahnel et al., 1999; Leite, 2009).

$\mathrm{Na}$ avaliação em conjunto dos resultados da composição química do solo (Tabela 2) e do número de bactérias (Figura 3), verifica-se que a comunidade de bactérias refletiu nas alterações ocasionadas pela liberação de nutrientes devido à decomposição do composto no solo. Provavelmente, o fósforo e o cálcio devem ter sido muito importantes para o aumento no número de bactérias no solo, pois os teores de fósforo e cálcio apresentaram aumentos significativos com a elevação na dose de composto incorporada no solo. Outro fator que pode ter contribuído para esse comportamento foi a elevação no $\mathrm{pH}$ do solo, que variou de 4,2 sem a adição de composto para 6,4 na parcela com $80 \mathrm{Mg} \mathrm{ha}^{-1}$ de composto. Essas condições do $\mathrm{pH}$, próximas da neutralidade favorecem o crescimento das células bacterianas que tendem a predominar no solo devido à redução da acidez e neutralização do alumínio. Esses resultados confirmam as observações de outros autores de que a melhoria na fertilidade do solo estimula o desenvolvimento das bactérias no solo (Mafra et al., 1998; Jahnel et al., 1999). 


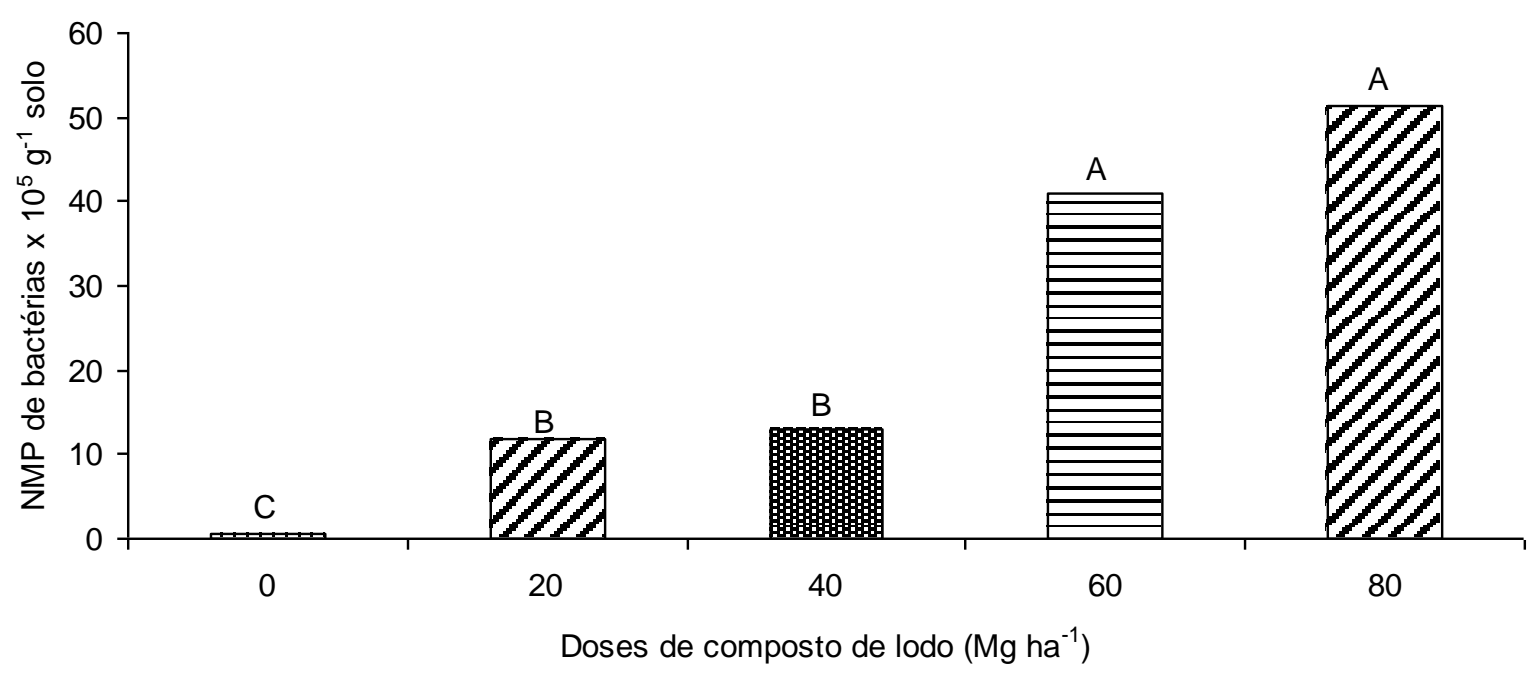

Figura 3. Número Mais Provável de bactérias $x 10^{5} \mathrm{~g}^{-1}$ de solo determinado na camada de $0-10$ $\mathrm{cm}$ de profundidade de solo tratado com doses de $0,10,20,30$ e $40 \mathrm{Mg} \mathrm{ha}^{-1}$ de composto de lodo de esgoto.

Nota: Médias seguidas por letras maiúsculas iguais, não diferem entre si, pelo teste de Tukey a 5\%).

Convêm destacar que o aumento no número de bactérias observado no presente estudo reflete o desenvolvimento de células bacterianas que foram estimuladas pela aplicação do composto no solo, ou seja, pela metodologia utilizada não é possível verificar se houve também aumento na diversidade de espécies bacteriana no solo. A esse respeito, Banerjee et al. (1997) constataram que a incorporação de lodo de esgoto reduziu a diversidade de espécie microbiana no solo, porém, para as espécies que permaneceram, o lodo não teve efeito negativo e até favoreceu o crescimento dos microrganismos.

\subsection{Número de fungos no solo}

O número mais provável (NMP) de fungos por grama de solo apresentou variação significativa entre os tratamentos (Figura 4). Observa-se que a comunidade de fungos aumenta no solo na medida em que se elevam as doses de composto incorporado ao solo, nota-se que os valores variaram entre $0,2 \mathrm{NMP} \times 10^{4} \mathrm{~g}^{-1}$ solo no tratamento sem composto a 4,8 NMP x $10^{4} \mathrm{~g}^{-1}$ solo no tratamento com $80 \mathrm{Mg} \mathrm{ha}^{-1}$ de composto. Esses valores estão no limite abaixo dos comumente encontrados para os fungos em áreas de solo com cultivos agrícolas, que variam entre $10^{4}$ a $10^{6}$, porém acima do limite de $10^{3}$ constatado em solos com adição de fertilizantes orgânicos produzidos a partir de resíduos urbanos e agroindustriais (Cattelan e Vidor, 1990; Jahnel et al., 1999; Bettiol e Fernandes, 2004; Silva Júnior e Pereira, 2007).

O aumento no número de fungos observado no solo com a adição de 20, 40, 60 e $80 \mathrm{Mg} \mathrm{ha}^{-1}$ de composto foi similar ao ocorrido com as bactérias (Figura 3). Isto ocorreu devido ao fornecimento de carbono orgânico e à disponibilidade de nutrientes liberados pela decomposição do composto, pois, no solo sem composto, foi determinado o menor valor no número de fungos (Jahnel et al., 1999; Marschner et al., 2003; Zhong et al., 2010).

A elevação no número de fungos pode estar relacionada ao crescimento de espécies adaptadas a composição química e física do composto, em outras palavras, o composto pode ter proporcionado um efeito seletivo sobre as espécies de fungos no solo (Silva et al., 2007). Estudos realizados por Leite (2009) constataram que a aplicação de lodo de esgoto reduziu a diversidade de espécies de fungos no solo e favoreceu o predomínio de colônias pertencentes aos gêneros Aspergillus sp e Penicillium SP, quando comparado com o solo sem aplicação de lodo. 


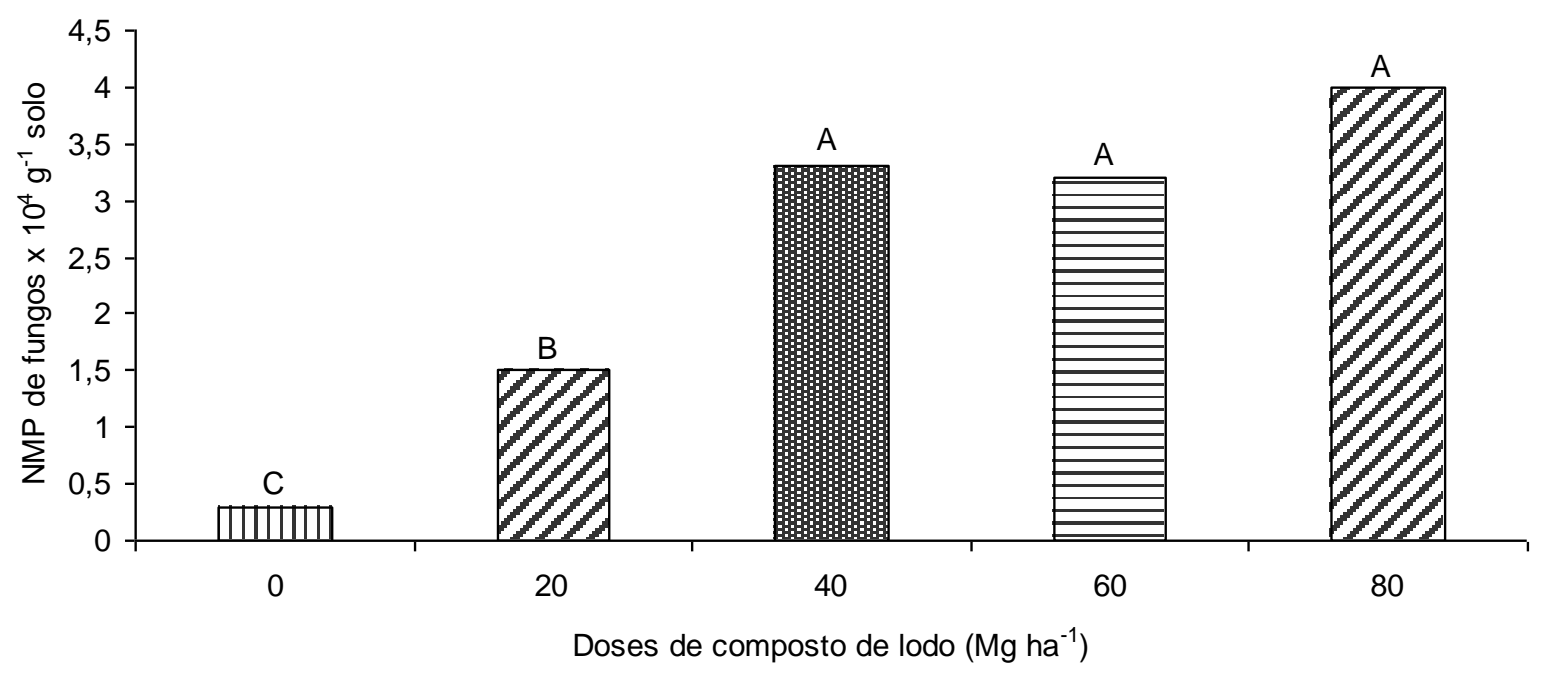

Figura 4. Unidade formadora de colônias de fungos $\mathrm{x} 10^{4} \mathrm{~g}^{-1}$ de solo determinadas na camada de 0-10 cm de profundidade de solo tratado com doses de 0,10, 20, 30 e $40 \mathrm{Mg} \mathrm{ha}^{-1}$ de composto de lodo de esgoto.

Nota: Médias: seguidas por letras maiúsculas iguais, não diferem entre si, pelo teste de Tukey a 5\%).

Analisando os resultados da Figura 4 e Tabela 2, constata-se que o crescimento da comunidade de fungos, assim como a de bactéria (Figura 3), foi também estimulado pela decomposição da matéria orgânica e a melhoria na fertilidade do solo proporcionada pela incorporação do composto de lodo de esgoto. A este respeito vários estudos têm verificado que as comunidades microbianas do solo tratado com resíduos orgânicos apresentam relação direta com a decomposição e liberação de nutrientes no solo (Fortes Neto, 2000; Marschner et al., 2003; Sullivan et al., 2006; Zhong et al., 2010).

\section{CONCLUSÃO}

A atividade microbiana do solo, medida pela liberação de $\mathrm{CO}_{2}$, e a contagem de bactérias e fungos foram sensíveis à incorporação das doses do composto de lodo.

$\mathrm{O}$ aumento no número de bactérias e fungos foi proporcional a elevação da liberação do $\mathrm{CO}_{2}$ no solo.

A adição do composto forneceu substrato energético e nutriente para os microrganismos do solo.

A medida de liberação de $\mathrm{CO}_{2}$ indicou que doses do composto acima de $20 \mathrm{Mg} \mathrm{ha}^{-1}$ ocasionou impactos significativos sobre a atividade microbiana do solo.

O composto de lodo de esgoto testado pode ser aplicado até a dose de $20 \mathrm{Mg} \mathrm{ha}^{-1}$.

\section{AGRADECIMENTOS}

Agradecemos à FIBRIA Celulose S/A pelo acesso à área de estudo ao CNPq por ter concedido uma bolsa de iniciação científica para a aluna Ericléia Bürg Suszek e a Profa. M.Sc. Ângela Popovici Berbare do Departamento de Ciências e Letras da Universidade de Taubaté. 


\section{REFERÊNCIAS}

ARAÚJO, A. S. F.; MONTEIRO, R. T. R. Microbial biomass and activity in a Brazilian soil amended with untreated and composted textile sludge. Chemosphere, Oxford, v. 64, n. 6, p. 1043-1046, 2006. http://dx.doi.org/10.1016/j.chemosphere.2006.01.040

BALOTA, E. L.; COLOZZI-FILHO, A.; ANDRADE, D. S.; HUNGRIA, M. Biomassa microbiana sua atividade em solos sob diferentes sistemas de preparo e sucessão de culturas. Revista Brasileira de Ciência do Solo, Campinas, v. 22, n. 4, p. 641-649, 1998.

BANERJEE, M. R.; BURTON, D. L.; DEPOE, S. Impact of sewage sludge application on soil biological characteristics. Agriculture, Ecosystems \& Enviroment, Oxford, v. 66, n. 3, p. 241-249. 1997. http://dx.doi.org/10.1016/S0167-8809(97)00129-1

BETTIOL,W.; FERNANDES, S. A. P. Efeito do lodo de esgoto na comunidade microbiana e atributos químicos do solo. Jaguariúna: Embrapa Meio Ambiente, 2004. (Comunicado Técnico).

BRASIL. Conselho Nacional do Meio Ambiente. Resolução CONAMA n 375/2006. Define critérios e procedimentos, para o uso agrícola de lodos de esgoto gerados em estações de tratamento de esgoto sanitário e seus produtos derivados, e dá outras providências. Disponível em: <http://www.mma.gov.br/CONAMA>. Acesso em: 12 jun 2012.

BROOKES, P. C. The use of microbial parameters in monitoring soil pollution by heavy metals. Biology and Fertility of Soils, Firenze, v, 19, n. 4, p. 269-279, 1995. http://dx.doi.org/10.1007/BF00336094

CATELLAN, A. J.; VIDOR, C. R. Flutuação da biomassa, atividade e população microbiana do solo. Revista Brasileira de Ciência do Solo, Viçosa, MG, v. 14, p. 133-142, 1990.

DICK, R. P. Soil enzyme assays as indicators of soil quality. In: DORAN, J. W. L.; COLEMAN, D. C.; BEZDICEK, D. F.; STEWART, B. A. (Eds.). Defining soil quality for a sustainable enviroment. Madison: Soil Science Society of America, 1994. p. 107-124.

DORAN, J. W; PARKINSON, T. B. Defining and assessing soil quality. In: DORAN, J. W. L.; COLEMAN, D. C.; BEZDICEK, D. F.; STEWART, B. A. (Eds.). Defining soil quality for a sustainable environment. Madison: Soil Science Society of America, 1994. p. 3-22.

EMPRESA BRASILEIRA DE PESQUISA AGROPECUÁRIA - EMBRAPA. Sistema brasileiro de classificação de solos. Brasília: Embrapa, 1999. 412p.

ELSAS, J. D. VAN; TREVORS, J. T.; WELLINGTON, E. M. H. Modern soil microbiology. New York: Marcel Dekker, 1997. 682p.

FORTES NETO, P. Degradação de biossólido incorporado ao solo avaliada através de medidas microbiológicas. 2000. 113f. Tese (Doutorado) - Escola Superior de Agricultura “Luiz de Queiroz", Universidade de São Paulo, Piracicaba, 2000.

GIL-SOTRES, F.; TRASAR-CEPEDA, C.; LEIRÓS, M. C.; SEOANE, S. Different approaches to evaluating soil quality using biochemical properties. Soil Biology and Biochemistry, Oxford, v. 37, n. 5, p. 877-887, 2005. http://dx.doi.org/10.1016/j.soilbio. 2004.10.003 
ILHENFELD, R. G. K.; ANDREOLI, C. V. Uso de lodo em áreas de produção. In: COMPANHIA DE SANEAMENTO DO PARANÁ; PROGRAMA DE PESQUISA EM SANEAMENTO BÁSICO. Uso e manejo do lodo de esgoto na agricultura. Curitiba, 1999. p. 62-73. Disponível em: <http://www.finep.gov.br/prosab/livros/ uso_ manejo_lodo_agricultura.pdf $>$. Acesso em: 17 ago. 2012.

JAHNEL, M. C.; CARDOSO, E. J. B. N.; DIAS, C. T. S. Determinação do número mais provável de microrganismos do solo pelo método de plaqueamento por gotas. Revista Brasileira de Ciência do Solo, Viçosa, MG, v. 23, n. 3, p. 553-559, 1999.

LEITE, M. V. Fungos filamentosos do lodo de esgoto: impacto na microbiota fúngica e potencial enzimático. 2009. 65f. Dissertação (Mestrado em Desenvolvimento de Processos Ambientais) - Universidade Católica de Pernambuco, Recife, 2009.

LISBOA, B. B.; VARGAS, L. K.; SILVEIRA, A. O.; MARTINS, A. F.; SELBACH, P. A. Indicadores microbianos de qualidade do solo em diferentes sistemas de manejo. Revista Brasileira de Ciência do Solo, Viçosa, MG, v. 36, n. 1, p. 45-55, 2012. http://dx.doi.org/10.1590/S0100-06832012000100004

MAFRA, A. L.; MIKLÓS, A. A. W.; VOCURCA, H. L.; HARKALY, A. H.; MENDOZA, E. Produção de fitomassa e atributos químicos do solo sob cultivo em aléias e sob vegetação nativa de cerrado. Revista Brasileira de Ciência do Solo, Viçosa, MG, v. 22, n. 1, p. 43-48, 1998.

MARCHIORI JÚNIOR, M.; MELO, W. J. Carbono da biomassa microbiana e atividade enzimática de um solo sob mata natural, pastagem e cultura do algodoeiro. Revista Brasileira de Ciência do Solo, Viçosa, MG, v. 23, n. 2, p. 257-263, 1999.

MARSCHNER, P.; KANDELER, E.; MARSCHNER, B. Structure and function of the soil microbial community in a long-term fertilizer experiment. Soil Biology and Biochemistry, Oxford, v. 35, n. 3, p. 453, 2003. http://dx.doi.org/10.1016/S00380717(02)00297-3

MELO, W. J. DE; MARQUES, O. M.; MELO, V. P. O uso agrí́cola do biossólido e as propriedades do solo. In: TSUTIYA, M. T.; COMPARINI, J. B.; ALEM SOBRINHO, P.; HESPANHOL, I. et al. (Eds.). Biossólidos na agricultura. São Paulo: SABESP, 2001. p. 289-363.

OLIVEIRA, F. C.; MATIAZZO, M. E.; MARCIANO, C. R.; ROSSETO, R. Efeitos de aplicações sucessivas de lodo de esgoto em Latossolo Amarelo distrófico cultivado com cana-de-açucar: carbono orgânico, condutividade elétrica, pH e CTC. Revista Brasileira de Ciência do Solo, Viçosa, MG, v. 26, n. 2, p. 505-519, 2002.

PAULA, A. M.; FONSECA, A. F.; CARDOSO, E. J. B. N.; MELFI, A. J. Microbial metabolic potential affected by surplus wastewater irrigation in tropical soil cultivated with Tifton 85 bermuda grass (Cynodon dactylon Pers. X. C. niemfuensis Vanderyst). Water, Air \& Soil Pollution, Oxford, v. 205, n. 1/4, p. 161-171, 2010. http://dx.doi.org/10.1007/s11270-009-0063-3

RAIJ, B. van; QUAGGIO, J. A; CANTARELLA, H. et al. Análise química do solo para fins de fertilidade. Campinas: Fundação Cargill, 1987. 170p. 
ROCHA, G. N.; GONÇALVES, J. L. M.; MOURA, I. M. Mudanças da fertilidade do solo e crescimento de um povoamento de Eucaliptus grandis fertilizado com biossólido. Revista Brasileira de Ciência do Solo, Viçosa, MG, v. 28, n. 4, p. 623-639, 2004. http://dx.doi.org/10.1590/S0100-06832004000400005

ROSCOE, R.; MERCANTE, F. M.; MENDES, I. C.; REIS JR., F. B.; SANTOS, J. C. F.; HUNGRIA, M. Biomassa microbiana do solo: fração mais ativa da matéria orgânica. In: ROSCOE, R.; MERCANTE, F. M.; SALTON, J. C. Dinâmica da matéria orgânica do solo em sistemas conservacionistas: modelagem matemática e métodos auxiliares. Dourados: Embrapa Agropecuária Oeste, 2006. p. 163-198.

SANTOS, J. A.; NUNES, L. A. P. L.; MELO, W. J.; ARAÚJO, A. S. F. Tannery sludge compost amendment rates on soil microbial biomass in two different soils. European Journal of Soil Biology, Braunschweig, v. 47, n. 2, p. 146-151, 2011. http://dx.doi.org/10.1016/j.ejsobi.2011.01.002

SIlVA, F. C.; BOARETto, A. E.; BERTON, R. S.; ZOTElli, H. B.; PEXE, C. A.; BERNARDES, E. M. Efeito de lodo de esgoto na fertilidade de um Argissolo Vermelho-Amarelo cultivado com cana-de-açúcar. Pesquisa Agropecuária Brasileira, Brasília, DF, v. 36, n. 5, p. 831-840, maio 2001. http://dx.doi.org/10.1590/S0100204X2001000500014

SILVA FILHO, G. N.; VIDOR, C. R. As práticas de manejo de solo na população microbiana. Revista Brasileira de Ciência do Solo, Viçosa, MG, v. 8, p. 291-296, 1984.

SILVA, E. E. da; AZEVEDO, P. H. S. de; DE-POLI, H. Determinação da respiração basal (RBS) e quociente metabólico do solo $\left(\mathbf{q} \mathbf{C O}_{2}\right)$. Seropédica: Embrapa Agrobiologia, 2007. 4p. (Comunicado Técnico, 99).

SILVA JÚNIOR, F. M. R.; PEREIRA, S. V. Ecologia e fisiologia de fungos filamentosos isolados de solo contaminado por metais pesados. Revista Brasileira de Biociências, Porto Alegre, v. 5, supl. 2, p. 903-905, 2007.

SUlliVAN, T. S.; STROMBERGER, M. E.; PASCHKE, M. W. , IPPOLITO, J. A. Longterm impacts of infrequent biosolids applications on chemical and microbial properties of a semi-arid rangeland soil. Biology and Fertility of Soils, Firenze, v. 42, n. 3, p. 258-266, 2006. http://dx.doi.org/10.1007/s00374-005-0023-z

STOTZKY, G. Microbial respiration. In: BLACK, C. A.; EVANS, D. D.; WHITE, J. L.; ENSMINGER, L. E.; CLARK, F. E. (Eds.). Methods of soil analysis. Madison: American Society Agronomy, 1965. p 1550-1570.

TRASAR-CEPEDA, C.; LEIRÓS, M. C.; SEONE, S.; GIL-SOTRES, F. Limitations of soil enzymes as indicators of soil pollution. Soil Biology and Biochemistry, Oxford, v. 32, n. 13, p. 1867-1875, 2000. http://dx.doi.org/10.1016/S0038-0717(00)00160-7

TURCO, F. R.; KENNEDY, A. C.; JAWSON, M. D. Microbial indicators of soil quality. In: DORAN, J. W. L.; COLEMAN, D. C.; BEZDICEK, D. F.; STEWART, B. A. (Eds.). Defining soil quality for a sustainable enviroment. Madison: Soil Science Society of America, 1994. p. 73-90. (Special Publication, n. 35). 
SUSZEK, E. B.; FORTES NETO, P.; FORTES, N. L. P.; SILVA, E. M. A. M.; BRAMBATTI, F.; SILVA, C. R; PATROCINIO, D. D. Atributos microbianos do solo fertilizado com composto de lodo de esgoto Ambi-Agua, Taubaté, v. 7, n. 2, p. 49-61, 2012. (http://dx.doi.org/10.4136/ambi-agua.915).

VIEIRA, G. A.; CASTILHOS, D. D.; CASTILHOS, R. M. V. Atributos do solo e crescimento do milho decorrentes da adição de lodo anaeróbio da estação de tratamento de efluentes da parboilização do arroz. Revista Brasileira de Ciência do Solo, Viçosa, MG, v. 35, n. 2, p. 535-542, 2011. http://dx.doi.org/10.1590/S010006832011000200022

ZHONG, W.; GU, T.; WANG, W.; ZHANG, B.; LIN, X.; HUANG, Q.; SHEN, W. The effects of mineral fertilizer and organic manure on soil microbial community and diversity. Plant and Soil, Dordrecht, v. 326, n. 1/2, p. 511-522, 2010. http://dx.doi.org/10.1007/s11104-009-9988-y 


ISSN = 1980-993X - doi:10.4136/1980-993X
www.ambi-agua.net
E-mail: ambi-agua@agro.unitau.br
Tel.: (12) 3625-4212

\title{
Desempenho de sistema decanto-digestor com filtro biológico seguido por alagado construído e reator solar no tratamento de esgoto doméstico
}

\author{
(http://dx.doi.org/10.4136/ambi-agua.723)
}

\author{
Glícia Pinto Barra Reinaldo $^{\mathbf{1}}$; Rafael Oliveira Batista ${ }^{\mathbf{1}}$; Paulo Cesar Moura da Silva ${ }^{\mathbf{1}}$; \\ Luis Cesar de Aquino Lemos Filho ${ }^{1}$; Miguel Ferreira Neto ${ }^{1}$; Delfran Batista dos Santos ${ }^{2}$ \\ ${ }^{1}$ Universidade Federal Rural do Semi-Árido - UFERSA, Mossoró-RN, \\ e-mails: gliciapinto@gmail.com, rafaelbatista@ufersa.edu.br, paulo.moura@ufersa.edu.br, \\ lcalfilho@ufersa.edu.br,miguel@ufersa.edu.br, \\ ${ }^{2}$ Instituto Federal de Educação, Ciência e Tecnologia Baiano, Senhor do Bonfim-BA, \\ e-mail: delfran.batista@gmail.com
}

\section{RESUMO}

O presente trabalho objetivou analisar o desempenho de sistema decanto-digestor com filtro biológico seguido por alagado construído e reator solar no tratamento de esgoto doméstico do assentamento rural Milagres em Apodi-RN. Nos meses de outubro e novembro de 2010 realizou-se o monitoramento do sistema 48 dias após o plantio do capim elefante (Pennisetum purpureum Schumach). Foram coletadas amostras do esgoto doméstico nas distintas etapas de tratamento, em quatro repetições no tempo, para determinação de características físico-químicas e microbiológicas referentes ao desempenho do sistema. Os resultados indicaram que houve remoção significativa de turbidez, Demanda Bioquímica de Oxigênio, Demanda Química de Oxigênio, sólidos totais, sólidos suspensos, fósforo e óleos e graxas com o uso sistema decanto-digestor com filtros biológicos seguidos de alagado construído e reator solar; a associação de radiação solar média de $28,73 \mathrm{MJ} \mathrm{m}^{-2} \mathrm{~d}^{-1}$, lâmina de 0,10 m de efluente no reator e tempo de exposição solar de 12 horas permitiu remoção de até 99,99\% dos coliformes termotolerantes no esgoto doméstico em Apodi-RN; e o efluente tratado apresenta padrão microbiológico satisfatório às diretrizes brasileiras para uso agrícola com restrição.

Palavras-chave: sustentabilidade, saneamento básico, água residuária.

\section{Performance of digester decant system with biological filter followed by constructed wetland and solar reactor in the treatment of domestic sewage}

\begin{abstract}
This study aimed to analyze the performance of digester decant system with biological filter followed by constructed wetland and solar reactor in the treatment of domestic sewage from Milagres rural community in Apodi-RN. The treatment system was monitored for the period of October and November 2010, 48 days after planting Pennisetum purpureum Schumach. Samples of domestic sewage were collected at different stages of treatment, in four replications on time, to determine physicochemical and microbiological characteristics about the system performance. The results indicated significant removal of turbidity, biochemical oxygen demand, chemical oxygen demand, total solids, suspended solids,
\end{abstract}


phosphorus and oil and grease using the set digester decant with biological filter, followed by constructed wetland and solar reactor; the association of average solar radiation of $28.73 \mathrm{MJ} \mathrm{m}^{-2} \mathrm{~d}^{-1}$, effluent depth of $0.10 \mathrm{~m}$ on reactor and time of sun exposure of 12 hours provided removal of fecal coliform up to $99.99 \%$ of domestic sewage in Apodi, RN, the treated effluent met microbiological standard of the Brazilian guidelines for agricultural use with restrictions.

Keywords: sustainability, sanitation, wastewater.

\section{INTRODUÇÃO}

A inadequação dos serviços de saneamento básico é a principal causa de doenças e de poluição ambiental no mundo. De acordo com o HDR (UNDP, 2006), cerca de 2,6 bilhões de habitantes moram em domicílio sem rede de esgoto. Em detrimento disso, anualmente, cerca de 1,7 milhões de crianças morrem em resultado direto de diarréia e de outras doenças provocadas por água contaminada e por más condições de saneamento.

Segundo a Pesquisa Nacional de Saneamento Básico de 2008, 44,8\% dos municípios brasileiros não possuíam rede coletora de esgoto. Enquanto, apenas $28,5 \%$ desses municípios dispõem de sistema para tratamento de esgoto (IBGE, 2010).

No que concerne às companhias de saneamento, o lançamento de esgoto doméstico bruto em corpos hídricos altera as características naturais da água, a partir do ponto de lançamento e compromete sua qualidade para consumo humano ou mesmo para uso em atividades agropecuárias e agroindustriais (Ribas e Fortes Neto, 2008).

Atualmente, as tecnologias utilizadas pelas companhias de saneamento tornam-se inviáveis para comunidades rurais de baixa renda de regiões semiáridas, tanto pelo alto custo de implantação e manutenção quanto pela grande dispersão populacional nas zonas rurais (Batista et al., 2011). Portanto, é necessário o desenvolvimento de tecnologias de baixo custo e de fácil operação para o tratamento de esgoto doméstico; e que possibilite aumento de renda pelo uso do efluente tratado na irrigação de cultivos agrícolas. Nesse sentido, destacam-se as seguintes tecnologias:

1. Tanque séptico: este dispositivo visa à retenção de sólidos flutuantes; decantação de sólidos sedimentáveis; alteração das características da fase líquida; deposição acúmulo e adensamento do lodo decantado em regime de decomposição anaeróbia; digestão parcial da escuma; redução sensível do número de bactérias patogênicas. Este é recomendado para o tratamento de esgotos gerados por até 300 pessoas, removendo em média 50\% da Demanda Bioquímica de Oxigênio (Matos, 2007).

2. Filtro anaeróbio: este dispositivo proporciona tratamento físico (filtração) e biológico (anaeróbio), complementar ao obtido no tanque séptico, removendo até $85 \%$ da Demanda Bioquímica de Oxigênio (Matos, 2007).

3. Sistema alagado construído (SACs): este dispositivo é construído em alvenaria ou com manta impermeabilizante preenchidos internamente com material poroso e inerte (cascalho, brita, tampa de garrafa pet e outros). Sobre o meio filtrante é cultivada espécies de plantas com grande capacidade de extração de poluentes presentes nos esgotos domésticos. Para evitar o surgimento de odores desagradáveis, insetos e animais peçonhentos, recomenda-se a utilização de fluxo subsuperficial do esgoto doméstico (Matos, 2007). Prochaska e Zoubouslis (2008) observaram remoções de 52, 60 e $96 \%$ nas concentrações de fósforo total, nitrato e Demanda Química de Oxigênio em SAC abastecido com esgoto doméstico, tendo o junco (phragmites australis) como planta extratora. Brasil et al. (2005) trabalharam com taboa (Typha sp) com dois diferentes tempos de residência hidráulica e quatro tipos de SACs no 
tratamento de efluente doméstico proveniente de tanque séptico, obtendo ao final dos ensaios experimentais redução média nos valores de Demanda Química de Oxigênio, sólidos suspensos, turbidez, nitrogênio total e fósforo total de 87, 91, 88, 33 e 35\%, respectivamente.

4. Reatores solares: são tanques construídos em alvenaria ou fibra de vidro que possibilitam o armazenamento de esgoto doméstico para exposição direta à radiação solar local, visando à inativação dos microrganismos patogênicos. A Região Nordeste se apresenta como a mais promissora para a aplicação desta tecnologia. Nos estados do Piauí e Maranhão, durante o ano todo, é preciso dois dias de exposição solar, em profundidade (até 0,20 m) da água residuária a ser tratada. Nas Regiões Sudeste e Centro Oeste, durante o inverno, são necessários menos de 2,5 dias; enquanto, no resto do ano serão necessários dois dias de exposição solar (Sanches-Ramon et al., 2007).

O presente trabalho objetivou avaliar o desempenho de sistema decanto-digestor com filtro biológico seguido por alagado construído e reator solar no tratamento de esgoto doméstico do assentamento rural Milagres em Apodi-RN.

\section{MATERIAIS E MÉTODO}

O presente trabalho foi realizado no Projeto de Assentamento Rural Milagres em ApodiRN, situado a $100 \mathrm{~km}$ de Mossoró-RN, sob as coordenadas geográficas 5 35 '22” de latitude sul e $37^{\circ} 54^{\prime} 09^{\prime \prime}$ de longitude oeste.

O assentamento Milagres possui 107 habitantes em 28 residências e dispõe de rede coletora de todo esgoto doméstico produzido, além de um decanto-digestor para tratamento preliminar e primário do esgoto doméstico bruto. Tal sistema possui um tanque séptico com duas câmaras, gradeamento e dois filtros anaeróbios de fluxo descendente. O decanto-digestor foi dimensionado para tratar uma vazão ate $20 \mathrm{~m}^{3} \mathrm{~d}^{-1}$ de esgoto doméstico com remoção do lodo a cada dois anos. No período experimental de setembro a dezembro de 2010 a vazão no sistema era de $12 \mathrm{~m}^{3} \mathrm{~d}^{-1}$, tendo em vista que apenas 60 pessoas estavam gerando esgoto doméstico.

Ao lado do decanto-digestor foi implantado um sistema alagado construído e um reator solar para tratamento secundário e terciário do esgoto doméstico. Na Figura 1 está apresentada a sequência do tratamento de esgoto no assentamento Milagres em Apodi-RN.

Decanto-digestor com filtros biológicos: objetiva a remoção de sólidos suspensos decantáveis, areia e óleos e graxas, efetuando o tratamento preliminar/primário. Este dispositivo foi construído em alvenaria de tijolos e reboco com impermeabilizante, nas dimensões de 4,0 $\mathrm{m}$ de largura por 8,0 $\mathrm{m}$ de comprimento por 1,80 $\mathrm{m}$ de profundidade (Figura 1b). No entanto, a profundidade útil do sistema foi de $1,30 \mathrm{~m}$, além de ser dividido da seguinte forma: a) um tanque séptico com duas câmaras, medindo de 2,0 m de largura por 7,6 $\mathrm{m}$ de comprimento por $1,30 \mathrm{~m}$ de profundidade útil, tempo de detenção hidráulica de 0,5 dia, frequência para remoção do lodo a cada dois anos, ocupando um volume de cerca de $21 \mathrm{~m} 3$; b) grade tipo fina para remoção de material particulado com tamanho de até 0,02 $\mathrm{m}$ nas dimensões de 1,0 m de largura por 2,0 m de comprimento, instalada a jusante do tanque séptico; e c) dois filtros anaeróbios de fluxo descendente, cada uma nas dimensões de 1,0 m de largura por 6,0 $\mathrm{m}$ de comprimento por $1,30 \mathrm{~m}$ de profundidade útil, ocupando os dois um volume de $16,0 \mathrm{~m} 3$. Os filtros anaeróbios foram preenchidos, internamente, com tijolos cerâmicos de oito furos para auxiliar na formação de biofilme para degradação de poluentes químicos e orgânicos presentes no efluente. O tempo de detenção hidráulica estimado para cada filtro é aproximadamente de duas horas. Foi dimensionamento conforme as recomendações da NBR 7229 (ABNT, 1993). 
REINALDO, G. P. B.; BATISTA, R. O.; SILVA, P. C. M.; LEMOS FILHO, L. C. A.; FERREIRA NETO, M. SANTOS, D. B. Desempenho de sistema decanto-digestor com filtro biológico seguido por alagado construído e reator solar no tratamento de esgoto doméstico. Ambi-Agua, Taubaté, v. 7, n. 2, p. 62-74, 2012. (http://dx.doi.org/10.4136/ambi-agua.723)

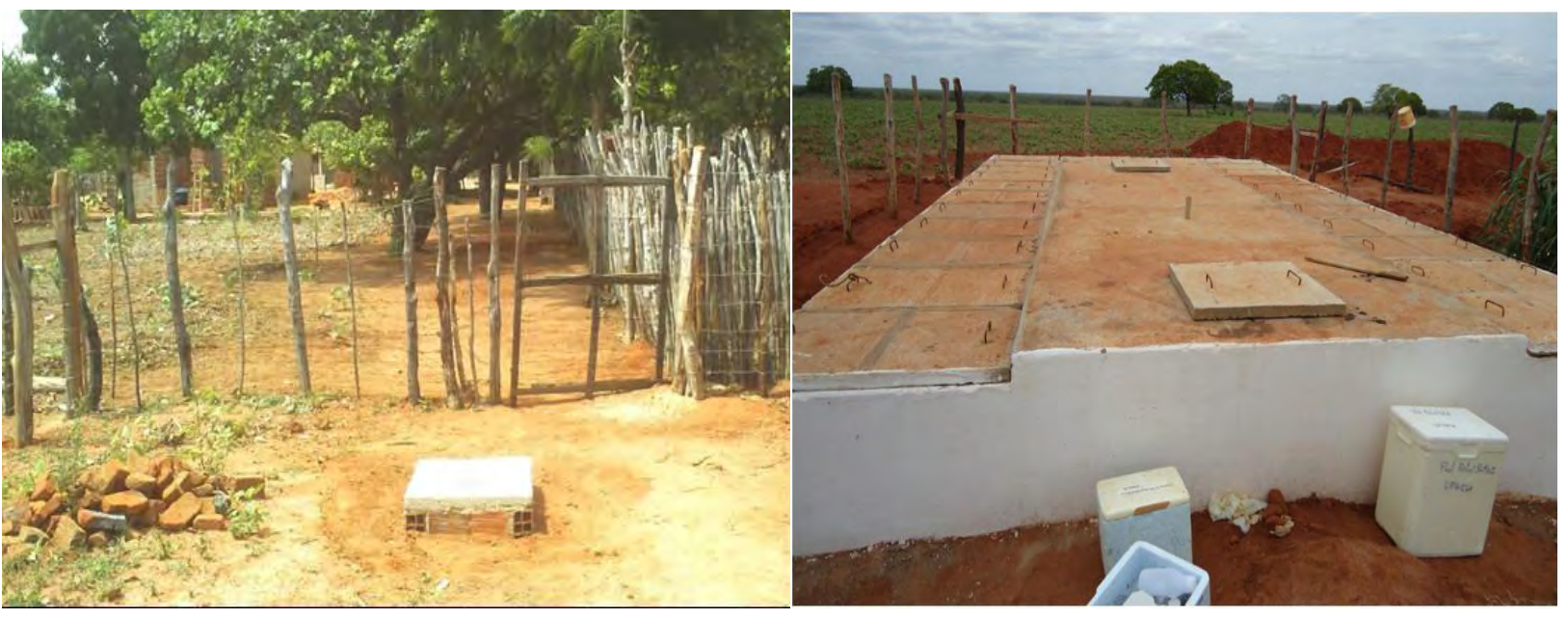

(a)

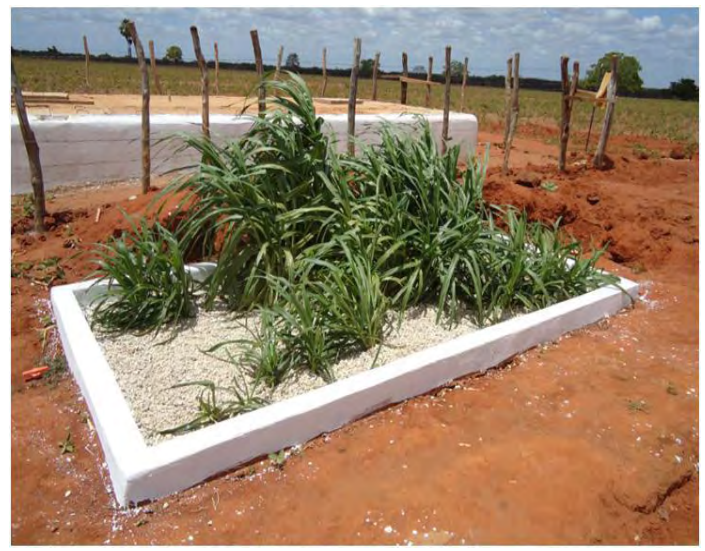

(c)

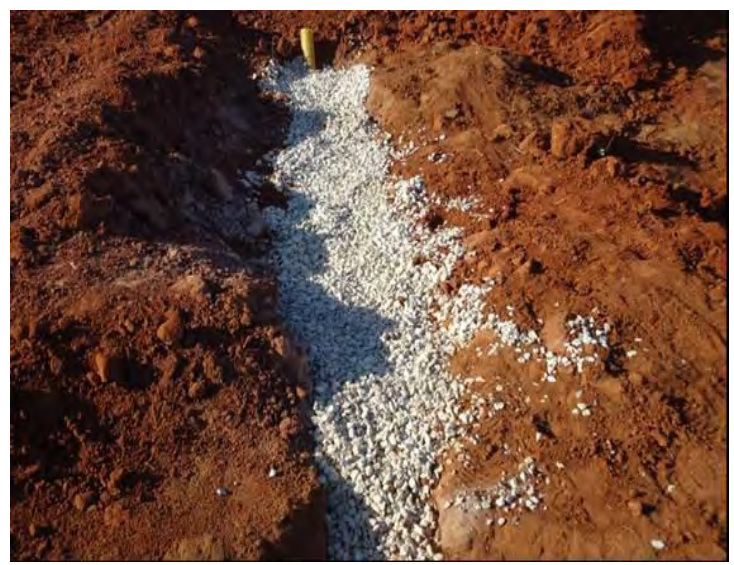

(e) (b)

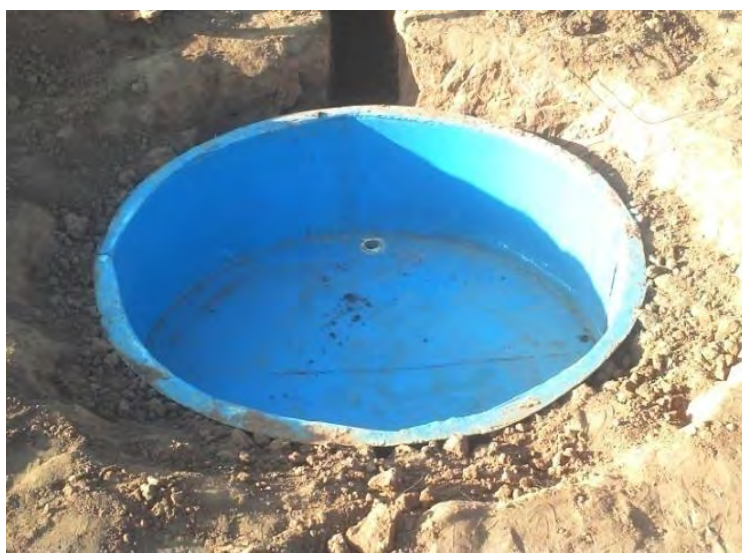

(d)

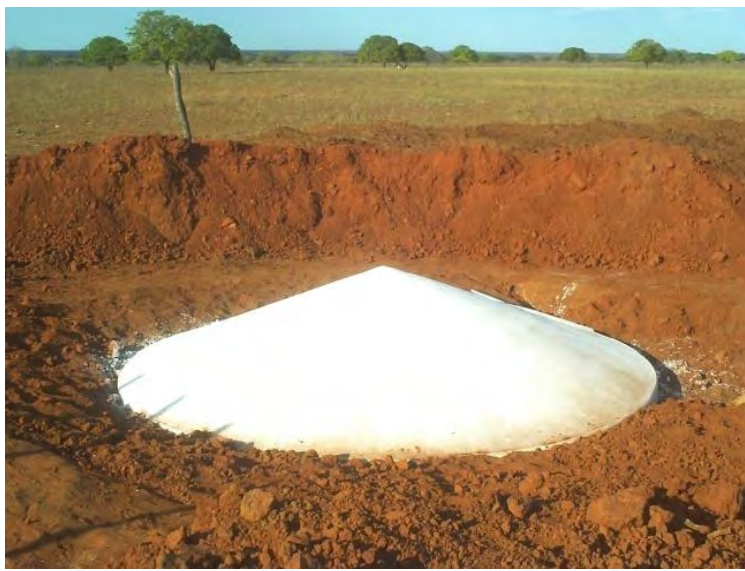

(f)

Figura 1. Sequência do sistema de tratamento e aproveitamento esgoto doméstico implantado no assentamento Milagres, área experimental da UFERSA, em Apodi-RN. Detalhe das caixas de passagem (a), decanto-digestor (b), mini-sistema alagado construído (c), reator solar (d), sumidouro (e) e reservatório para efluente tratado visando a irrigação (f). 
REINALDO, G. P. B.; BATISTA, R. O.; SILVA, P. C. M.; LEMOS FILHO, L. C. A.; FERREIRA NETO, M. SANTOS, D. B. Desempenho de sistema decanto-digestor com filtro biológico seguido por alagado construído e reator solar no tratamento de esgoto doméstico. Ambi-Agua, Taubaté, v. 7, n. 2, p. 62-74, 2012. (http://dx.doi.org/10.4136/ambi-agua.723)

Sistema alagado construído: composto por um leito com fluxo subsuperficial horizontal, para tratamento secundário/terciário do esgoto doméstico, construído em alvenaria nas dimensões de 2,0 $\mathrm{m}$ de largura por 4,0 $\mathrm{m}$ de comprimento por $0,50 \mathrm{~m}$ de profundidade, enterrado no solo. O meio suporte utilizado foi a brita 1 que possibilitará a formação do biofilme para o tratamento biológico do efluente (Figura 1c). No dia 23 de setembro de 2010 foram plantadas os colmos de capim elefante (Pennisetum purpureum Schumach) no sistema alagado construído no espaçamento de 0,60 m entre fileiras e 0,60 m entre centro de colmos. Tal espécie vegetal foi escolhida por capacidade de extração de nutrientes da água residuária e posterior conversão em biomassa (Oliveira et al., 2008) que pode, após exposição à radiação solar, servir como alimento para pequenas criações de animais no assentamento (bovinos, caprinos e ovinos). No dimensionamento do sistema alagado construído foi considerada uma vazão de $1,0 \mathrm{~m}^{3} \mathrm{~d}^{-1}$, taxa de aplicação de $400 \mathrm{~kg}$ de DBO ha ${ }^{-1} \mathrm{~d}^{-1}$ e concentração típica de DBO do esgoto doméstico de $300 \mathrm{mg} \mathrm{L}^{-1}$ seguindo as recomendações de Matos (2007).

Reator solar: este possibilita a redução do nível populacional dos coliformes termotolerantes, sendo denominado tratamento terciário. Tal dispositivo foi construído em fibra de vidro (3 mm), no formato cilíndrico, conforme as recomendações de Sanches-Roman et al. (2007) nas dimensões de $1,30 \mathrm{~m}$ de diâmetro e $0,40 \mathrm{~m}$ de profundidade, dotado de capacidade máxima armazenadora para $0,53 \mathrm{~m}^{3}$ (Figura 1d). No interior do reator foi fixada uma régua com precisão de um centímetro para o monitoramento da lâmina de efluente a ser tratado. Este dispositivo foi operado com uma lâmina de efluente de $0,10 \mathrm{~m}$ durante um período de exposição à radiação solar de 12 horas, de acordo com Moura et al. (2011).

Sumidouro: este dispositivo, também, permite o tratamento secundário e terciário do esgoto doméstico. O sumidouro só foi utilizado para infiltrar o volume de esgoto doméstico tratado no reator solar, ou seja, cerca de $0,13 \mathrm{~m}^{3}$ a cada ensaio realizado (Figura 1e). O restante do volume de esgoto doméstico tratado pelo sistema alagado construído era lançado em um reservatório para posterior aproveitamento na agricultura. Com um ensaio prévio de infiltração constatou-se que o coeficiente de infiltração do solo na área foi de $65 \mathrm{~L} \mathrm{~m}^{-2} \mathrm{~d}^{-1}$. No dimensionamento do sumidouro foram levadas em consideração as recomendações NBR 7229 (ABNT, 1982);

Reservatório: este dispositivo permite armazenar o efluente tratado no sistema alagado construído que não foi destinado ao sumidouro para a irrigação de cultivo agrícolas no Assentamento Milagres. Construído em concreto armado com capacidade armazenadora para $10 \mathrm{~m}^{3}$, tendo diâmetro de 3,5 $\mathrm{m}$ e profundidade de $1,0 \mathrm{~m}$ (Figura 1f).

No período de 20 de outubro a 10 de novembro de 2010 foram realizadas quatro amostragens de efluentes nos seguintes pontos do sistema: Ponto 1 - efluente coletado na entrada do decanto-digestor; Ponto 2 - efluente coletado na saída do decanto-digestor; Ponto 3 - efluente coletado à jusante do sistema alagado construído; e Ponto 4 - efluente coletado no reator solar.

Para caracterização físico-química dos efluentes, amostras foram coletadas nos pontos 1 , 2, 3 e 4 do sistema e preservadas em caixas isotérmicas com gelo à temperatura de $4^{\circ} \mathrm{C}$ até a entrada no laboratório, conforme recomendações do Standard methods for the examination of water and wastewater (APHA, 2005). Posteriormente, tais amostras foram encaminhadas para o Laboratório de Diagnóstico Físico-Químico da Universidade Estadual do Rio Grande do Norte (UERN) onde foram realizadas análises de: $\mathrm{pH}$ (método eletrométrico utilizando medidor de bancada), condutividade elétrica (condutivímetro de bancada), turbidez (turbidímetro de bancada), Demanda Química de Oxigênio (método oxidimétrico com refluxo), Demanda Bioquímica de Oxigênio (método iodométrico pelo processo Winkler), sólidos totais (método gravimétrico), sólidos suspensos (método gravimétrico com a utilização de membranas de fibra de vidro com $0,45 \mu \mathrm{m}$ de diâmetro de poro), nitrogênio total 
REINALDO, G. P. B.; BATISTA, R. O.; SILVA, P. C. M.; LEMOS FILHO, L. C. A.; FERREIRA NETO, M. SANTOS, D. B. Desempenho de sistema decanto-digestor com filtro biológico seguido por alagado construído e reator solar no tratamento de esgoto doméstico. Ambi-Agua, Taubaté, v. 7, n. 2, p. 62-74, 2012. (http://dx.doi.org/10.4136/ambi-agua.723)

(pelo método Kjeldhal), fósforo total (espectrofotometria), óleos e graxas (extrator Soxhlet) e nitrato (espectrofotometria), conforme recomendações do Standard methods for the examination of water and wastewater (APHA, 2005).

Para caracterização microbiológica dos efluentes, amostras foram coletadas em frasco esterilizados nos pontos 1 e 4 do sistema às 14:00 horas. Estas amostras foram preservadas em caixa isotérmica com gelo, foram encaminhadas para o Laboratório de Inspeção de Produtos de Origem Animal, localizado na Universidade Federal Rural do Semiárido (UFERSA) para identificação e quantificação dos níveis populacionais de coliformes totais e coliformes termotolerantes (método de tubos múltiplos), conforme recomendações do Standard methods for the examination of water and wastewater (APHA, 2005). Deve-se ressaltar que para avaliar estas características foi necessário o preparo do reator solar, um dia antes da amostragem, ou seja, às 14:00 horas do dia anterior armazenava-se uma lâmina de efluente no reator de cerca de $0,10 \mathrm{~m}$, para exposição à radiação solar local, e posterior coleta no dia seguinte.

No período de 11 a 17 de setembro de 2011, foi realizada a medição da vazão que estava passando pelo sistema alagado construído. Para tal, foi utilizado o método gravimétrico. $\mathrm{O}$ volume médio semanal de esgoto foi de 1932 L, resultando em uma vazão média de $80,51 \mathrm{~L} \mathrm{~h}^{-1}$.

Nos pontos 1 e 4 foram analisadas todas as variáveis, enquanto que nos pontos 2 e 3 foram analisados somente $\mathrm{pH}$, condutividade elétrica. turbidez, sólidos totais e sólidos suspensos. Os dados de radiação solar, por sua vez, foram obtidos junto ao Instituto Nacional de Meteorologia (INMET) para o período de avaliação da pesquisa. Deve-se ressaltar, também, que foi realizado um registro fotográfico do esgoto coletado nos pontos 1 e 4 para comparação visual do tratamento proporcionado.

O experimento foi montado no delineamento inteiramente casualizado (DIC) com quatro repetições no tempo. Como as variáveis são qualitativas, optou-se pela seguinte procedimento de análise estatística: a) os dados foram, inicialmente, submetidos a analise de variância, utilizando-se o teste $\mathrm{F}$ com significância de até 5\%; e b) as médias foram comparadas empregando-se o teste de Tukey com significância de até $5 \%$. O programa computacional SAEG 9.1 foi utilizado na análise estatística.

\section{RESULTADOS E DISCUSSÃO}

Na Tabela 1 estão apresentados os valores integralizados de radiação global no período de monitoramento do sistema de tratamento de esgoto. A radiação solar oscilou de 24,45 a $31,48 \mathrm{MJ} \mathrm{m}^{-2} \mathrm{~d}^{-1}$ no período experimental, tendo o valor médio de $28,73 \mathrm{MJ} \mathrm{m}^{-2} \mathrm{~d}^{-1}$.

$\mathrm{Na}$ Tabela 2 estão apresentados os resultados das análises físicas, químicas e microbiológicas dos efluentes coletados nos protótipos de tratamento de esgoto doméstico, no período de 20 de outubro a 10 de novembro de 2010, no Assentamento Milagres em Apodi$\mathrm{RN}$.

Tabela 1. Valores integralizados de radiação global no período de monitoramento do sistema de tratamento de esgoto.

\begin{tabular}{c|c}
\hline Data & Radiação acumulada $\left(\mathbf{M J ~ m}^{-\mathbf{2}} \mathbf{d}^{-\mathbf{1}}\right)$ \\
\hline 19/10 a 20/10 & 27,90 \\
26/10 a $27 / 10$ & 24,45 \\
02/10 a 03/11 & 31,48 \\
09/11 a 10/11 & 31,08 \\
\hline Média & $\mathbf{2 8 , 7 3}$ \\
\hline
\end{tabular}


REINALDO, G. P. B.; BATISTA, R. O.; SILVA, P. C. M.; LEMOS FILHO, L. C. A.; FERREIRA NETO, M. SANTOS, D. B. Desempenho de sistema decanto-digestor com filtro biológico seguido por alagado construído e reator solar no tratamento de esgoto doméstico. Ambi-Agua, Taubaté, v. 7, n. 2, p. 62-74, 2012. (http://dx.doi.org/10.4136/ambi-agua.723)

Tabela 2. Características físicas, químicas e microbiológicas dos efluentes coletados na mini-estação de tratamento de esgoto doméstico ao longo do período experimental.

\begin{tabular}{|c|c|c|c|c|c|c|c|c|c|c|c|c|c|}
\hline \multirow[t]{2}{*}{ Pontos } & pH & $\mathbf{C E}$ & TB & CT & CTe & DQO & DBO & ST & SS & $\mathbf{P}_{\text {total }}$ & $\mathbf{N}_{\text {total }}$ & OG & $\mathrm{NO}_{3}{ }^{-}$ \\
\hline & & $\mathrm{dS} \mathrm{m}^{-1}$ & UNT & NM & $\mathrm{mL}$ & \multicolumn{8}{|c|}{$\mathrm{mg} \mathrm{L}^{-1}$} \\
\hline
\end{tabular}

Amostragem de 20 de outubro de 2010

\begin{tabular}{|c|c|c|c|c|c|c|c|c|c|c|c|c|c|}
\hline Ponto 1 & 5,78 & 1,32 & 971,00 & $1,1 \times 10^{7}$ & $1,1 \times 10^{5}$ & 455,67 & 165,24 & 946 & 592 & 25,79 & 59,15 & 357,20 & 11,11 \\
\hline Ponto 2 & 6,02 & 1,31 & 189,00 & & & & & 618 & 234 & & & & \\
\hline Ponto 3 & 6,50 & 1,30 & 58,00 & & & & & 385 & 64 & & & & \\
\hline Ponto 4 & 6,56 & 1,29 & 45,00 & $3,0 \times 10^{2}$ & $3,0 \times 10^{1}$ & 121,15 & 71,40 & 372 & 68 & 14,26 & 55,31 & 1,02 & 5,86 \\
\hline $\mathbf{M}$ & 6,215 & 1,30 & 315,75 & $5,9 \times 10^{4 *}$ & $1,8 \times 10^{3 *}$ & 288,41 & 118,32 & 581 & 240 & 20,025 & 57,23 & 179,11 & 8,49 \\
\hline DP & 0,38 & $\mathbf{0 , 0 1}$ & 441,65 & $1,6 \times 10^{3 *}$ & $3,3 \times 10^{2^{*}}$ & 236,54 & 66,35 & 268,76 & 247,99 & 8,15 & 2,72 & 251,86 & 3,71 \\
\hline
\end{tabular}

Amostragem de 27 de outubro de 2010

\begin{tabular}{|c|c|c|c|c|c|c|c|c|c|c|c|c|c|}
\hline Ponto 1 & 6,12 & 0,97 & 556,50 & $6,0 \times 10^{8}$ & $5,4 \times 10^{6}$ & 500,20 & 180,40 & 934 & 390 & 25,70 & 49,16 & 169,50 & 23,18 \\
\hline Ponto 2 & 6,23 & 1,03 & 69,61 & & & & & 676 & 262 & & & & \\
\hline Ponto 3 & 6,55 & 1,05 & 8,98 & & & & & 646 & 40 & & & & \\
\hline Ponto 4 & 6,18 & 1,03 & 9,61 & $5,0 \times 10^{4}$ & $4,0 \times 10^{2}$ & 132,50 & 78,30 & 610 & 16 & 15,26 & 55,32 & 3,10 & 42,52 \\
\hline $\mathbf{M}$ & 6,27 & 1,02 & 161,175 & $5,5 \times 10^{6 *}$ & $5,7 \times 10^{4 *}$ & 316,35 & 129,35 & 717 & 177 & 20,48 & 52,24 & 86,30 & 32,85 \\
\hline DP & 0,19 & $\mathbf{0 , 0 3}$ & 265,08 & $7,3 \times 10^{2 *}$ & $8,3 \times 10^{2^{*}}$ & 260,00 & 72,20 & 147 & 180 & 7,38 & 4,36 & 117,66 & 13,68 \\
\hline
\end{tabular}

Amostragem de 03 de novembro de 2010

\begin{tabular}{|c|c|c|c|c|c|c|c|c|c|c|c|c|c|}
\hline Ponto 1 & 6,28 & 1,28 & 478,30 & $1,1 \times 10^{7}$ & $7,4 \times 10^{5}$ & 390,50 & 180,40 & 915 & 400 & 27,64 & 57,18 & 158,20 & 9,26 \\
\hline Ponto 2 & 7,22 & 1,33 & 100,30 & & & & & 804 & 264 & & & & \\
\hline Ponto 3 & 6,83 & 1,04 & 36,13 & & & & & 450 & 8 & & & & \\
\hline Ponto 4 & 6,91 & 1,05 & 31,48 & $7,0 \times 10^{4}$ & $6,7 \times 10^{2}$ & 140,30 & 68,90 & 366 & 6 & 16,29 & 51,39 & 2,10 & 28,54 \\
\hline $\mathbf{M}$ & 6,81 & 1,175 & 161,555 & $8,8 \times 10^{5^{*}}$ & $2,2 \times 10^{4 *}$ & 265,4 & 124,65 & 634 & 170 & 21,965 & 54,28 & 80,15 & 18,9 \\
\hline DP & 0,39 & 0,15 & 213,49 & $3,6 \times 10^{1 *}$ & $1,4 \times 10^{2^{*}}$ & 176,92 & 78,84 & 267 & 196 & 8,03 & 4,09 & 110,38 & 13,63 \\
\hline
\end{tabular}

Amostragem de 10 de novembro de 2010

\begin{tabular}{|c|c|c|c|c|c|c|c|c|c|c|c|c|c|}
\hline Ponto 1 & 6,50 & 1,35 & 300,20 & $3,0 \times 10^{8}$ & $3,1 \times 10^{6}$ & 490,40 & 200,20 & 895 & 310 & 17,40 & 58,28 & 148,20 & 10,60 \\
\hline Ponto 2 & 7,12 & 1,37 & 106,20 & & & & & 845 & 284 & & & & \\
\hline Ponto 3 & 6,72 & 1,39 & 45,30 & & & & & 470 & 11 & & & & \\
\hline Ponto 4 & 6,80 & 1,40 & 47,80 & $2,0 \times 10^{5}$ & $8,1 \times 10^{2}$ & 160,20 & 70,01 & 460 & 10 & 6,90 & 49,90 & 6,90 & 30,40 \\
\hline $\mathbf{M}$ & 6,785 & 1,38 & 124,85 & $7,8 \times 10^{6 *}$ & $5,0 \times 10^{4 *}$ & 325,30 & 135,10 & 667,5 & 154 & 12,15 & 54,09 & 77,55 & 20,5 \\
\hline DP & 0,26 & $\mathbf{0 , 0 2}$ & 120,22 & $1,8 \times 10^{2 *}$ & $3,4 \times 10^{2 *}$ & 233,49 & 92,06 & 234,5 & 166 & 7,42 & 5,93 & 99,91 & 14,00 \\
\hline
\end{tabular}

Nota: M - média; DP - desvio-padrão; Ponto 1: efluente coletado na entrada do decanto-digestor; Ponto 2: efluente coletado na saída do decanto-digestor; Ponto 3: efluente coletado à jusante do sistema alagado construído; e Ponto 4: efluente coletado no reator solar. $\mathrm{pH}$ - potencial hidrogeniônico; CE - condutividade elétrica; TB - turbidez; CT coliformes totais; CTe - coliformes termotolerantes; DQO - demanda química de oxigênio; DBO - demanda bioquímica de oxigênio; ST - sólidos totais; SS - sólidos suspensos; $\mathrm{P}_{\text {total }}$ - fósforo total; $\mathrm{N}_{\text {total }}$ - nitrogênio total; OG -

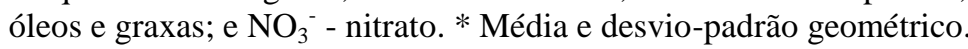


O tratamento proporcionado pelo sistema alterou as características físicas e químicas do esgoto doméstico. Constatou-se que, o valor de turbidez, Demanda Química de Oxigênio, Demanda Bioquímica de Oxigênio, sólidos suspensos, sólidos totais, fósforo e óleos e graxas reduziram a medida que o efluente passou pelas distintas etapas de tratamento. Enquanto, as características nitrogênio total e nitrato não foram removidas eficientemente, nesse período, pelo fato do capim elefante ainda estar na fase de desenvolvimento inicial (altura de 1,40 m) no sistema alagado construído. O ciclo do capim elefante é uma gramínea triploide com tempo de utilização de 110 dias fornecendo cortes da forragem a cada 50 dias. O sistema alagado construído melhorou muito a qualidade do esgoto no que se refere ao lançamento em corpo hídrico em função dos seguintes processos: a) remoção de nutrientes como nitrogênio, fósforo e nitrato pelo capim elefante; b) redução da Demanda Bioquímica de oxigênio e do nível populacional dos coliformes termotolerantes pelo biofilme formado no sistema; e c) remoção dos sólidos suspensos pela filtração do meio poroso e do sistema radicular do capim elefante. Os valores de $\mathrm{pH}$ e condutividade elétrica não apresentaram alterações, ao longo do período experimental (Tabela 2).

Estabelecendo comparação entre os valores de turbidez dos efluentes coletados nos pontos 1 e 4, nos quatro dias de amostragem, notaram-se remoções de 84 a $98 \%$. No ponto 4 , os valores de turbidez oscilaram de 45,0 a 47,8 UNT. Na Figura 2 está apresentada a variação encontrada na remoção de turbidez, ao longo do período experimental.

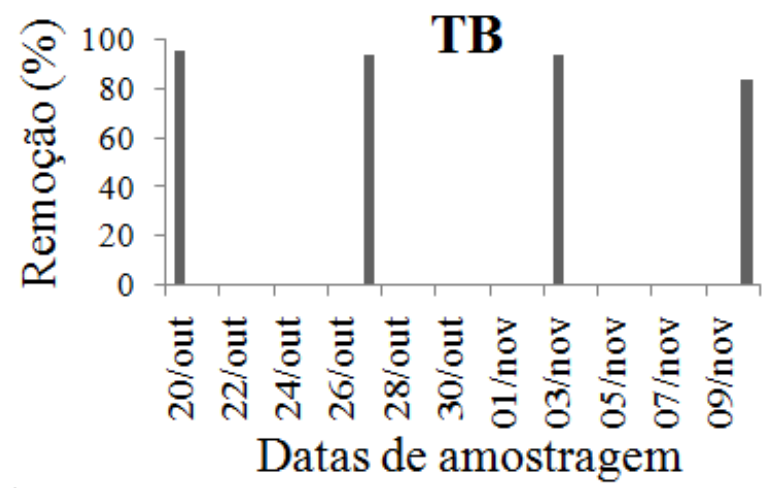

Figura 2. Remoção de turbidez (TB) do esgoto doméstico no sistema de tratamento, ao longo do período experimental.

Os valores de Demanda Química de Oxigênio (DQO) do efluente no reator solar (ponto 4) apresentaram variações de 121,15 a $160,20 \mathrm{mg} \mathrm{L}^{-1}$, nos quatro dias de amostragem. Constatou-se, ao longo do período experimental, que a DQO atendeu ao limite de $200 \mathrm{mg} \mathrm{L}^{-1}$ para lançamento direto de efluente tratado em corpo hídrico receptor (Ceará, 2002). As remoções de DQO, ao longo do período experimental, foram de 64 a 74\%.

Comparando os valores de Demanda Bioquímica de Oxigênio (DBO) dos efluentes coletados nos pontos 1 e 4, nos quatro dias de amostragem, verificou-se que as remoções desta característica oscilaram de 57 a $65 \%$. No entanto, os valores de DBO no ponto 4, obtidos ao longo do período experimental, foram inferiores ao limite máximo de $120 \mathrm{mg} \mathrm{L}^{-1}$ estabelecido pela Resolução CONAMA n. ${ }^{\circ} 430$ para lançamento de esgotos domésticos tratado em corpos hídricos (Brasil, 2011). Este limite somente poderá ser ultrapassado no caso de efluente de sistema de tratamento com eficiência de remoção mínima de $60 \%$ de DBO, ou mediante estudo de autodepuração do corpo hídrico que comprove atendimento às metas do enquadramento do corpo receptor, conforme especificado na Resolução CONAMA n ${ }^{\circ} 357$ (Brasil, 2005). A Figura 3 mostra essa remoção encontrada. 


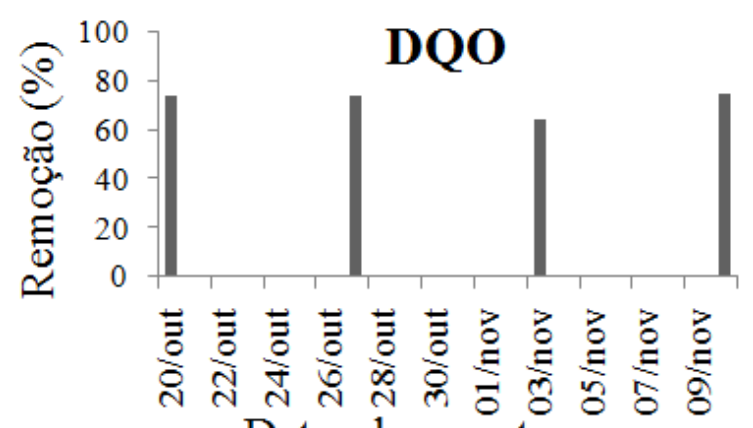

Datas de amostragem

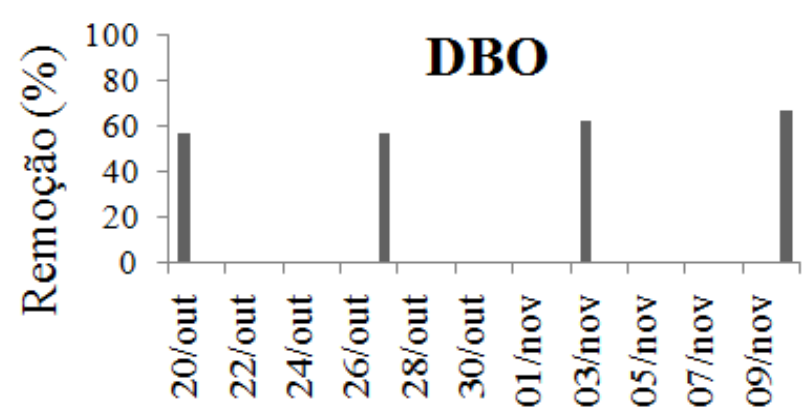

Datas de amostragem

Figura 3. Remoção da Demanda Química de Oxigênio (DQO) e Demanda Bioquímica de Oxigênio (DBO) do esgoto doméstico no sistema de tratamento, ao longo do período experimental.

Constatou-se que os valores de sólidos suspensos do efluente do reator solar (ponto 4) oscilaram de 6 a $68 \mathrm{mg} \mathrm{L}^{-1}$. Realizando comparações entre os valores de sólidos suspensos para os pontos 1 e 4 constataram-se remoções de 89 a $99 \%$. De acordo com a Portaria n. $^{\circ} 154$ do Estado do Ceará (Ceará, 2002), os resultados de sólidos suspensos foram inferiores ao limite de $50 \mathrm{mg} \mathrm{L}^{-1}$ estabelecido para lançamento de efluentes tratados em corpo hídrico, exceto no dia 20 de outubro de 2010.

Os valores de sólidos totais apresentaram variações de 366 a $610 \mathrm{mg} \mathrm{L}^{-1}$ para os efluentes coletados no reator solar (ponto 4). Notaram-se, também, remoções de sólidos totais variando de 35 a 61\%, ao longo do período experimental, conforme apresentado na Figura 4.
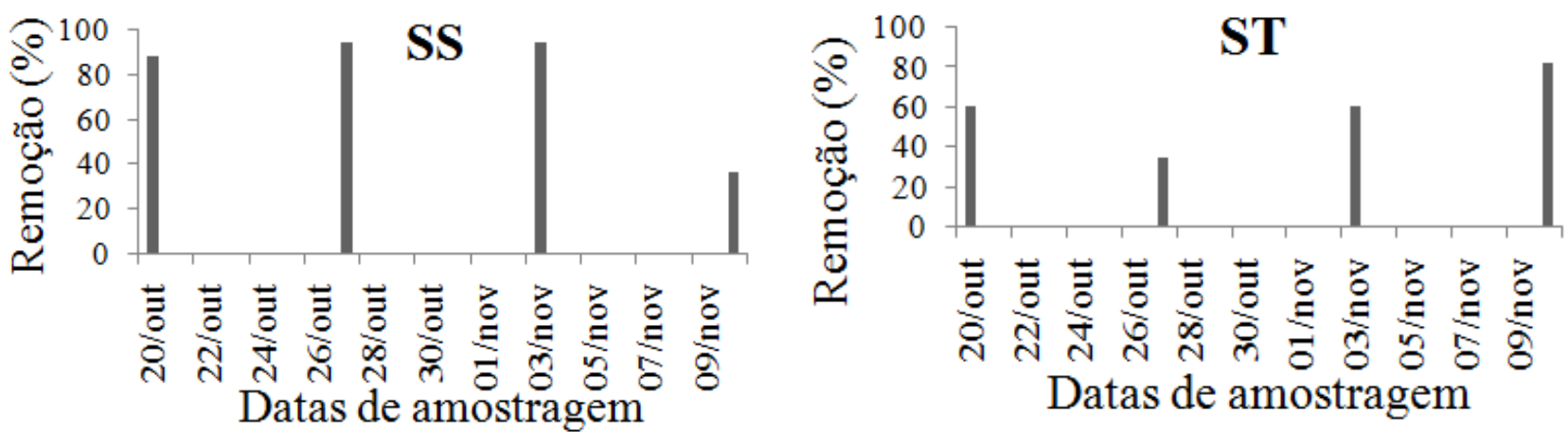

Figura 4. Remoção dos sólidos suspensos (SS) e sólidos totais (ST) do esgoto doméstico no sistema de tratamento, ao longo do período experimental.

As concentrações de fósforo nos efluentes coletados no ponto 4 oscilaram de 6,90 a $16,29 \mathrm{mg} \mathrm{L}^{-1}$. Verificou-se que as remoções de fósforo variaram de 41 a $60 \%$, ao longo do período experimental, como apresentado na Figura 5.

Os valores de óleos e graxas (substâncias solúveis em hexano) do efluente do reator solar (ponto 4) apresentaram variação de 1,20 a 6,90 $\mathrm{mg} \mathrm{L}^{-1}$. Os resultados obtidos em todo período experimental foram inferiores ao limite de $100 \mathrm{mg} \mathrm{L}^{-1}$ estabelecido pela Resolução CONAMA n. ${ }^{\circ} 430$ (Brasil, 2011) para lançamento de esgotos domésticos tratados em corpo hídrico receptor. As remoções de óleos e graxas variaram de 95 a 99,7\% ao longo do período experimental (Figura 5). 
REINALDO, G. P. B.; BATISTA, R. O.; SILVA, P. C. M.; LEMOS FILHO, L. C. A.; FERREIRA NETO, M. SANTOS, D. B. Desempenho de sistema decanto-digestor com filtro biológico seguido por alagado construído e reator solar no tratamento de esgoto doméstico. Ambi-Agua, Taubaté, v. 7, n. 2, p. 62-74, 2012. (http://dx.doi.org/10.4136/ambi-agua.723)

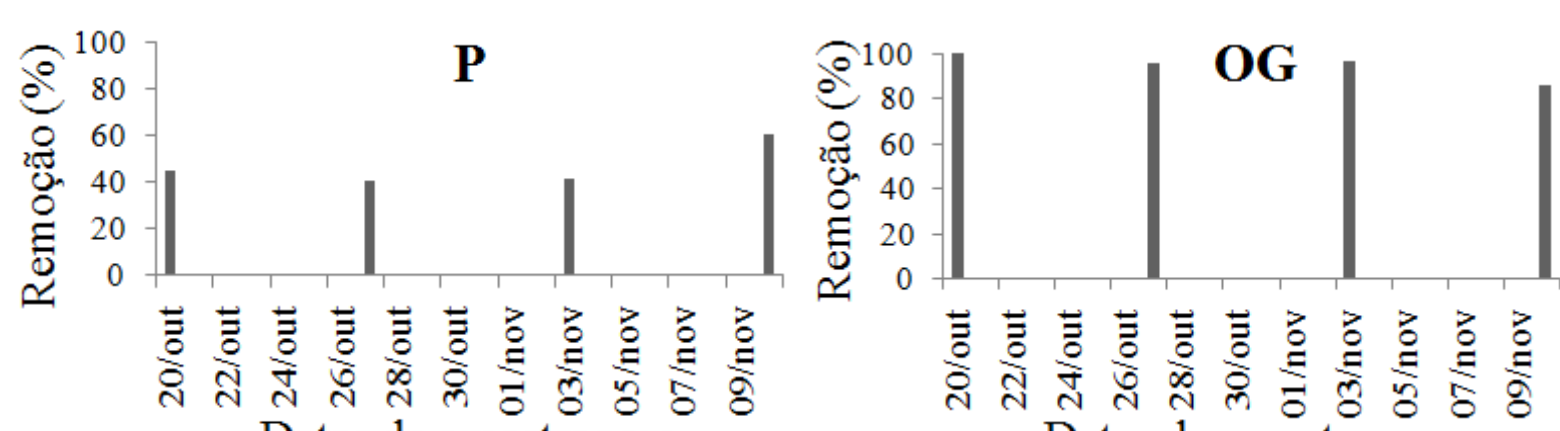

Datas de amostragem

Datas de amostragem

Figura 5. Remoção de fósforo total (P) e óleos e graxas (OG) do esgoto doméstico no sistema de tratamento, ao longo do período experimental.

Em relação às características microbiológicas, observou-se que houve redução no nível populacional de coliformes totais e termotolerantes quando se estabelece comparação entre os pontos 1 e 4, durante o período experimental.

As remoções de coliformes totais e termotolerantes oscilaram de 99,36 a 99,99 e de 99,91 a 99,99\%, respectivamente. De acordo com os limites estabelecidos pela Portaria ${ }^{\circ}{ }^{\circ}$ 154 do Estado do Ceará (Ceará, 2002), o efluente atende as recomendações para irrigação de culturas não consumidas cruas, onde o nível populacional de coliforme termotolerantes deva ser inferior a 5000 NMP $100 \mathrm{~mL}^{-1}$ (Número Mais Provável por $100 \mathrm{~mL}$ ).

Os níveis de remoção de coliformes totais e termotolerantes foram semelhantes aos obtidos por Moura et al. (2011) com o uso de reatores solares para a desinfecção de esgoto doméstico de filtro anaeróbio. Moura et al. (2011) verificaram que um tempo de exposição de 12 horas permitiu remoções de até 99,99 e $99,99 \%$ na população de coliforme total e coliforme fecal, respectivamente como mostrado na Figura 6.

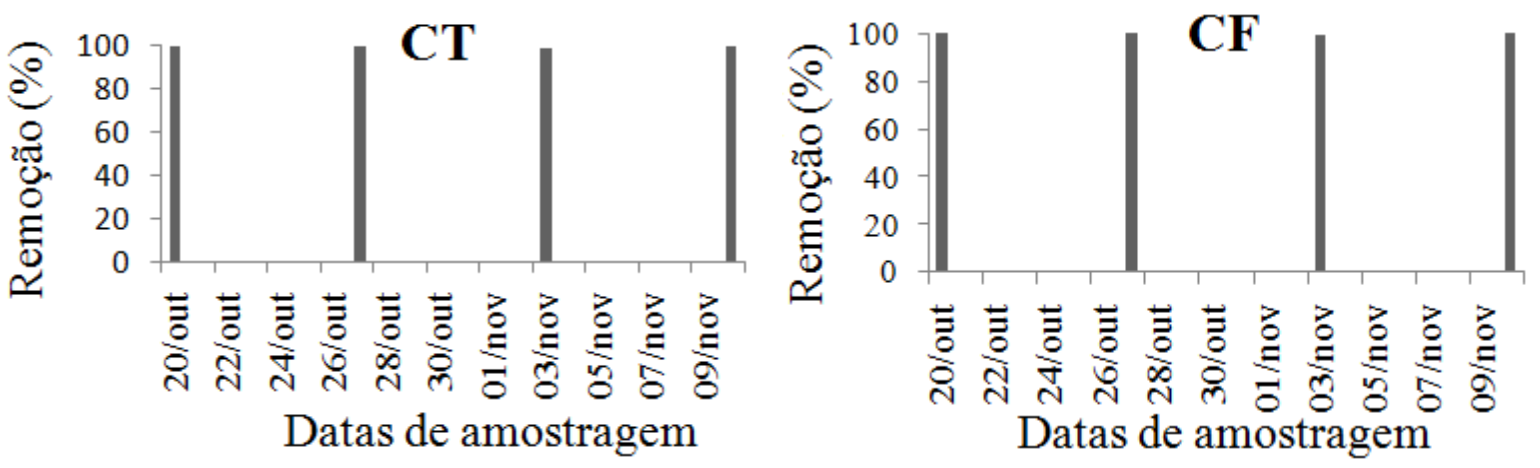

Figura 6. Remoção de coliformes totais (CT) e coliformes fecais (CF) do esgoto doméstico no sistema de tratamento, ao longo do período experimental.

Estão apresentados na Tabela 3 os valores médios e o resumo da análise estatística das características físicas, químicas e microbiológicas do esgoto doméstico nas etapas de tratamento referentes aos pontos 1, 2, 3 e 4 na fase inicial de desenvolvimento do capim elefante. 
REINALDO, G. P. B.; BATISTA, R. O.; SILVA, P. C. M.; LEMOS FILHO, L. C. A.; FERREIRA NETO, M. SANTOS, D. B. Desempenho de sistema decanto-digestor com filtro biológico seguido por alagado construído e reator solar no tratamento de esgoto doméstico. Ambi-Agua, Taubaté, v. 7, n. 2, p. 62-74, 2012. (http://dx.doi.org/10.4136/ambi-agua.723)

Tabela 3. Valores médios e o resumo dos testes estatísticos das características físicas e químicas do esgoto doméstico nos pontos de amostragem 1, 2, 3 e 4 dos protótipos de tratamento de esgoto doméstico.

\begin{tabular}{|c|c|c|c|c|c|}
\hline \multirow{2}{*}{ Característica } & \multirow{2}{*}{$\mathbf{F}$} & \multicolumn{4}{|c|}{ Amostragem } \\
\hline & & Ponto 1 & Ponto 2 & Ponto 3 & Ponto 4 \\
\hline $\mathrm{pH}$ & $3,99^{\mathrm{ns}}$ & 6,65 & 6,65 & 6,61 & 6,17 \\
\hline Condutividade elétrica $\left(\mathrm{dS} \mathrm{m}^{-1}\right)$ & $0,09^{\mathrm{ns}}$ & 1,26 & 1,23 & 1,2 & 1,19 \\
\hline Turbidez (UNT) & $6,22 *$ & $576,50 a$ & $116,28 b$ & $37,10 b$ & $33,47 b$ \\
\hline Coliformes totais (NMP $100 \mathrm{~mL}$ ) & $2,39^{\mathrm{ns}}$ & $6,8 \times 10^{7}$ & & & $4,7 \times 10^{5}$ \\
\hline Coliformes termotolerantes (NMP $100 \mathrm{~mL}$ ) & $50,75^{*}$ & $1,1 \times 10^{6} \mathrm{a}$ & & & $2,8 \times 10^{2} b$ \\
\hline Demanda Química de Oxigênio (DQO) & $150,51 *$ & $459,19 a$ & & & $138,54 b$ \\
\hline Demanda Bioquímica de Oxigênio $\left(\mathrm{DBO}_{5}\right)$ & $214,39 *$ & $181,56 a$ & & & $72,15 b$ \\
\hline Sólidos totais $\left(\mathrm{mg} \mathrm{L}^{-1}\right)$ & $65,88^{*}$ & $922,50 \mathrm{a}$ & $735,75 \mathrm{a}$ & $487,75 b$ & $452,00 \mathrm{~b}$ \\
\hline Sólidos suspensos (mg L $\left.{ }^{-1}\right)$ & $41,81^{*}$ & $423,00 \mathrm{a}$ & $261,00 \mathrm{a}$ & $30,75 b$ & $25,00 \mathrm{~b}$ \\
\hline Fósforo (mg L $\left.{ }^{-1}\right)$ & $12,26^{*}$ & $24,13 \mathrm{a}$ & & & $13,18 b$ \\
\hline Nitrogênio total (mg L $\left.{ }^{-1}\right)$ & $1,22^{\text {ns }}$ & 55,94 & & & 52,98 \\
\hline Óleos e graxas $\left(\mathrm{mg} \mathrm{L}^{-1}\right)$ & $16,91 *$ & $208,28 \mathrm{a}$ & & & $3,33 b$ \\
\hline Nitrato $\left(\mathrm{mg} \mathrm{L}^{-1}\right)$ & $2,56^{\mathrm{ns}}$ & 13,54 & & & 26,83 \\
\hline
\end{tabular}

Nota: Ponto 1: efluente coletado na entrada do decanto-digestor; Ponto 2: efluente coletado na saída do decanto-digestor; Ponto 3: efluente coletado à jusante do sistema alagado construído; e Ponto 4: efluente coletado no reator solar. * F significativo a $5 \%$ de probabilidade. ${ }^{\mathrm{ns}} \mathrm{F}$ não-significativo a $5 \%$ de probabilidade. Médias seguidas de pelo menos uma mesma letra nas linhas não diferem entre si, a 5\% de probabilidade, pelo teste de Tukey.

Pela análise de variância, verificou-se que as características $\mathrm{pH}$, condutividade elétrica, coliformes totais nitrogênio total e nitrato não foram significativas a 5\% de probabilidade pelo teste F. Enquanto, as características turbidez, coliformes termotolerantes, Demanda Química de Oxigênio, Demanda Bioquímica de Oxigênio, sólidos totais, sólidos suspensos, fósforo e óleos e graxas foram significativas a $5 \%$ de probabilidade pelo teste $\mathrm{F}$, o que permite a utilização do teste de Tukey para comparação das médias (Tabela 3).

Estabelecendo comparação entre os pontos 1 e 4, notou-se que as características turbidez, coliformes termotolerantes, Demanda Química de Oxigênio, Demanda Bioquímica de Oxigênio, sólidos totais, sólidos suspensos, fósforo e óleos e graxas diferem estatisticamente entre si à 5\% de probabilidade pelo teste de Tukey. Significa afirmar que o tratamento foi eficiente na remoção das características analisadas, o que tornar esta técnica valida e eficaz para o tratamento de esgoto domestico nestas condições ambientais.

Na Figura 7 está apresentado o indicador visual do nível de tratamento obtido no sistema implantado na Projeto de Assentamento Milagres, em Apodi-RN. Notou-se, nesta figura, que o sistema proporcionou ótima remoção de turbidez, sólidos e carga orgânica com tratamento preliminar/primário no decanto digestor e filtros anaeróbios, tratamento secundário/terciário no sistema alagado construído e tratamento terciário no reator solar. 


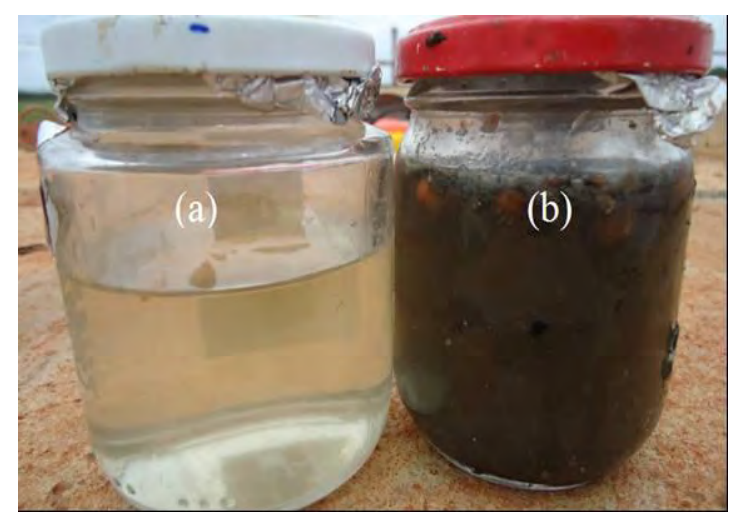

Figura 7. Indicador visual do nível de tratamento obtido na mini-estação. Efluente tratado (a) e efluente sem tratamento (b).

\section{CONCLUSÃO}

Diante dos resultados, conclui-se que: houve remoção significativa de turbidez, Demanda Bioquímica de Oxigênio, Demanda Química de Oxigênio, sólidos suspensos, fósforo nitrogênio total e óleos e graxas com o uso conjunto de decanto-digestor, sistema alagado construído e reator solar; os valores de óleos e graxas e Demanda Bioquímica de Oxigênio atendem as recomendações nacionais para lançamento de esgoto doméstico tratado em corpo hídrico; com um valor médio de radiação solar de $28,73 \mathrm{MJ} \mathrm{m}^{-2} \mathrm{~d}^{-1}$ com uso de uma lâmina de 0,10 m de efluente e tempo de exposição solar 12 horas em Apodi-RN permitiu remoção de até $99,99 \%$ dos coliformes termotolerantes; e o efluente tratado apresenta um padrão microbiológico que atende as diretrizes estaduais para irrigação de cultivos agrícolas não consumidos crus.

\section{AGRADECIMENTOS}

Agradecemos à FINEP e à Universidade Federal Rural do Semi-Árido pelo apoio financeiro.

\section{REFERÊNCIAS}

AMERICAN PUBLIC HEALTH ASSOCIATION - APHA. Standard methods for the examination of water and wastewater. 21th ed. Washington, DC,.2005.

ASSOCIAÇÃO BRASILEIRA DE NORMAS TÉCNICAS - ABNT. NBR 7229:1993: projeto, construção e operação de sistemas de tanques sépticos. Rio de Janeiro, 1993. $15 \mathrm{p}$.

ASSOCIAÇÃO BRASILEIRA DE NORMAS TÉCNICAS- ABNT. NBR 7229:1982: construção e instalação de fossas sépticas e disposição dos efluentes finais. Rio de Janeiro, 1982. 37p.

BATISTA, R. O.; SARTORI, M. A.; SOARES, A. A.; MOURA, F. N.; COSTA PAIVA, M. R. F. Potencial da remoção de poluentes bioquímicos em biofiltros operando com esgoto doméstico. Revista Ambiente \& Água, v. 6, n. 3, p. 152-164, 2011. http://dx.doi.org/10.4136/ambi-agua.625 
REINALDO, G. P. B.; BATISTA, R. O.; SILVA, P. C. M.; LEMOS FILHO, L. C. A.; FERREIRA NETO, M. SANTOS, D. B. Desempenho de sistema decanto-digestor com filtro biológico seguido por alagado construído e reator solar no tratamento de esgoto doméstico. Ambi-Agua, Taubaté, v. 7, n. 2, p. 62-74, 2012. (http://dx.doi.org/10.4136/ambi-agua.723)

BRASIL. Conselho Nacional do Meio Ambiente. Resolução no 430, de 13 de maio de 2011. Dispõe sobre as condições e padrões de lançamento de efluentes, complementa e altera a Resolução no 357, de 17 de março de 2005. Disponível em: <http://www.mma.gov.br/port/conama/res/res05/res35705.pdf>. Acesso em: 03 jun. 2012.

BRASIL. Conselho Nacional do Meio Ambiente. Resolução no 357, de 17 de março de 2005. Dispõe sobre a classificação dos corpos de água e diretrizes ambientais para o seu enquadramento, bem como estabelece as condições e padrões de lançamento de efluentes. Disponível em: <http://www.mma.gov.br/port/conama/res/res05/res35705. pdf>.Acesso em: 31 mai. 2012.

BRASIL, M. S.; MATOS, A. T.; SOARES, A. A.; FERREIRA, P. A. Qualidade do efluente de sistemas alagados construídos, utilizados no tratamento de esgoto doméstico. Revista Brasileira de Engenharia Agrícola e Ambiental, v. 9, p. 133-137, 2005. Suplemento.

CEARÁ. Portaria $\mathbf{n}^{\circ}$ 154, de 22 de julho de 2002. Dispõe sobre padrões e condições para lançamento de efluentes líquidos gerados por fontes poluidoras. Disponível em: $<$ http://antigo.semace.ce.gov.br/integracao/biblioteca/legislacao/conteudo_legislacao.as p?cd=95>. Acesso em: 25 mai. 2012.

INTITUTO BRASILEIRO DE GEOGRAFIA E ESTATÍCTICA - IBGE. Pesquisa nacional de saneamento básico 2008. Rio de Janeiro, 2010. 219p.

MATOS, A. T. Disposição de águas residuárias no solo. Viçosa, MG: AEAGRI, 2007. 140 p. (Caderno didático, n. 38).

MOURA, F. N.; BATISTA, R. O.; SILVA, J. B. A.; FEITOSA, A. P.; COSTA, M. S. Desempenho de sistema para tratamento e aproveitamento de esgoto doméstico em áreas rurais do semiárido brasileiro. Engenharia Ambiental, v. 8, n. 3, p. 264-276, 2011.

OLIVEIRA, D. Q. L.; CARVALHO, K. T. G.; BASTOS, A. R. R.; OLIVEIRA, L. C. A.; MARQUES, J. J. G. S. M.; NASCIMENTO, R. S. M. P. Utilização de resíduos da indústria de couro como fonte nitrogenada para o capim-elefante. Revista Brasileira de Ciência do Solo, v. 32, n. 1, 417-424, 2008. http://dx.doi.org/10.1590/S010006832008000100039

PROCHASKA, C. A.; ZOUBOUSLIS, A. I. Treatment performance variation at different depths within vertical subsurface-flow experimental wetlands fed with simulated domestic sewage. Desalination, Thessaloniki, v. 237, n. 1-3, p. 367-377, 2008. http://dx.doi.org/10.1016/j.desal.2008.01.028

RIBAS, T. B. C.; FORTES NETO, P. Disposição no solo de efluentes de esgoto tratado visando à redução de coliformes termotolerantes. Revista Ambiente \& Água, v. 3, n. 3, p. 81-94, 2008. http://dx.doi.org/10.4136/ambi-agua.63

SANCHES-RAMON, R.; SOARES, A. A.; MATOS, A. T; SEDIYAMA, G. C.; SOUZA, O.; MOUNTEER, H. A. Domestic wastewater disinfection using solar radiation for agricultural reuse. Transactions of the ASABE, v. 50, n.1, p. 65-71, 2007.

UNITED NATIONS DEVELOPMENT PROGRAMME - UNDP. Human development report 2006: power, poverty and the global water crisis. New York, 2006. 440p. 


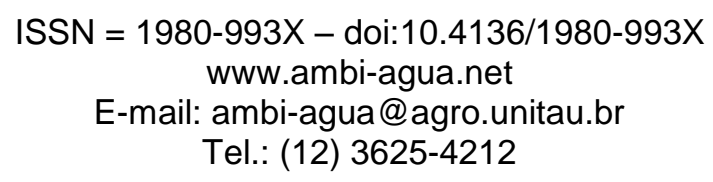

\title{
Remoção de nitrogênio e fósforo de águas residuárias de laticínios por sistemas alagados construídos operando em bateladas
}

\author{
(http://dx.doi.org/10.4136/ambi-agua.805)
}

\author{
Henrique Vieira de Mendonça ${ }^{1}$; Celso Bandeira de Melo Ribeiro² \\ Alisson Carraro Borges ${ }^{3}$; Ronaldo Rocha Bastos ${ }^{4}$ \\ ${ }^{1,2,4}$ Universidade Federal de Juiz de Fora, Juiz de Fora, MG, \\ ${ }^{3}$ Universidade Federal de Viçosa, Viçosa, MG, \\ e-mails: henriqueufv@gmail.com, celso.bandeira@ufjf.edu.br, \\ borges@ufv.br, ronaldo.bastos@ufjf.edu.br
}

\section{RESUMO}

Este trabalho apresenta os resultados de um estudo realizado durante 7 (sete) meses sobre a eficiência de sistemas alagados construídos, no tratamento de águas residuárias de laticínios, com ênfase na remoção de nitrogênio e fósforo. Os 6 (seis) sistemas experimentais foram construídos em tanques de PEAD com volume de 115 litros cada, com relação comprimento/largura na proporção de 2:1. Os materiais suporte utilizados foram brita 0 em três dos sistemas e brita 0 e areia em outros três, na proporção de $80 \%$ brita e $20 \%$ areia. Os sistemas foram operados em bateladas com ciclos de 48 horas, aplicando-se 7,5 litros do efluente por ciclo. Quatro das unidades experimentais foram cultivadas e duas mantidas como testemunhas. As espécies selecionadas foram as macrófitas Typha dominguensis e o Hedychium coronarium. A eficiência na remoção de compostos nitrogenados apresentou-se promissora com valores entre 29,4 a $73,4 \%$, a remoção de fósforo pelos leitos foi inferior, atingindo eficiências entre 18,61 a 34,3\%, valores promissores levando em conta a dificuldade da remoção destes elementos por sistemas convencionais.

Palavras-chave: nutrientes eutrofizantes, ecotecnologia, efluentes de laticínios.

\section{Removal of nitrogen and phosphorus from dairy wastewater using constructed wetlands systems operating in batch}

\section{ABSTRACT}

This work presents the results of a study conducted for a period of seven months on the effectiveness of constructed wetland systems for the treatment of dairy wastewater aiming at removing, nitrogen and phosphorus. Six experimental systems were assembled with a net volume of $115 \mathrm{~L}$ using HDPE tanks, with length/width ratio of 2:1. In three of the systems, gravel 0 was used as substrate, while gravel 0 and sand was used in the three others, in the percentage of $80 \%$ and $20 \%$, respectively. The systems were operated in batch cycles of 48 hours, applying $7.5 \mathrm{~L}$ of influent per cycle. Four of the experimental units were cultivated, and two kept as controls. The selected species chosen were the macrophytes, Typha domingensis and Hedychium coronarium. The removal efficiency concerning nitrogen compounds showed to be quite promising with values ranging from 29.4 to $73.4 \%$, while phosphorus removal from the beds was lower, reaching efficiencies between 18.61 and $34.3 \%$, considered good values, since the removal of these substances is quite difficult through conventional treatment.

Keywords: eutrophying nutrient, ecotechnology, dairy effluent. 


\section{INTRODUÇÃO}

As águas residuárias da indústria de laticínios (ARL) além de apresentarem alta carga orgânica, possuem concentrações relevantes de nutrientes eutrofizantes como nitrogênio e fósforo. A concentração destes nutrientes é potencializada quando os efluentes provenientes do processo de transformação e beneficiamento do leite são misturados com os efluentes sanitários gerados no próprio empreendimento. Segundo Von Sperling (2005), os efluentes sanitários apresentam em média uma concentração de $50 \mathrm{mg} / \mathrm{L}$ de nitrogênio e $8,1 \mathrm{mg} / \mathrm{L}$ de fósforo.

As águas brutas de laticínios, mesmo não havendo mistura prévia com os efluentes sanitários, apresentam teores de nutrientes semelhantes e por vezes superiores aos do esgoto doméstico. Como exemplo, uma indústria que produz leite UHT e doces de leite podem apresentar concentrações de 26,5 a 86,2 mg/L de nitrogênio e 4,5 a 14,2 mg/L de fósforo, (Wilson e Murphy, 1986; CETESB, 1990; Abrahão, 2006).

Segundo Von Sperling (2005), 50\% do fósforo presente nas águas residuárias pode ser atribuído ao uso de detergentes, produto largamente utilizado para limpeza de equipamentos do processamento do leite, limpeza de pisos e utensílios de refeitórios.

Nas últimas décadas as estações de tratamento de efluentes convencionais foram projetadas para remover primordialmente material orgânico biodegradável. Estas estações de tratamento são desprovidas de compartimentos onde possa ocorrer a remoção de nitrogênio por mecanismos microbiológicos como nitrificação seguida de desnitrificação. Em relação ao fósforo, as estações de tratamento convencionais também apresentam dificuldades para remover o elemento, pois não são dimensionadas com tal propósito.

Segundo Shutes (2001), na década de 40 teve inicio da utilização de sistemas alagados construídos para tratar diversos tipos de águas residuárias. Ao longo das décadas o uso deste sistema natural de tratamento mostrou que além de remover satisfatoriamente a matéria orgânica biodegradável dos efluentes, ainda possuía considerável capacidade de remover nutrientes como o nitrogênio e o fósforo.

Os mecanismos envolvidos no tratamento por estes sistemas são: filtração e degradação microbiana da matéria orgânica, absorção de nutrientes pelos rizomas das vegetações e microrganismos, adsorção e desorção. Diversos autores como Cooper (1998), Zanella (2008), Sezerino (2006), Mansor (1998) e U.S.EPA (2003), concluíram que os sistemas apresentam considerável capacidade de nitrificação e desnitrificação, devido à presença de sítios aeróbios proporcionados pela transferência de oxigênio da planta para o meio suporte anóxico, por meio dos rizomas das vegetações cultivadas. Na remoção de nitrogênio o mecanismo de oxidação anaeróbio da amônia (Anammox), também deve ser contabilizado. Neste processo biológico, em condições predominantemente anóxicas, ocorre à oxidação do íon amônio a nitrogênio gasoso (Van de Graaf et al., 1996), sendo este liberado para a atmosfera.

As formas de nitrogênio inorgânico de maior importância ao se estudar sistemas alagados são amônia $\left(\mathrm{NH}_{4}{ }^{+}\right)$, óxido nitroso $\left(\mathrm{N}_{2} \mathrm{O}\right)$, óxido nítrico $\left(\mathrm{NO}_{2}\right.$ ou $\left.\mathrm{N}_{2} \mathrm{O}_{4}\right)$, gás nitrogênio $\left(\mathrm{N}_{2}\right)$, nitrito $\left(\mathrm{NO}_{2}{ }^{-}\right)$e nitrato $\left(\mathrm{NO}_{3}{ }^{-}\right)$sendo que os quatros primeiros apresentam-se no estado gasoso dissolvido. As formas orgânicas de maior importância incluem produtos como aminoácidos, uréia, purinas e pirimidinas (APHA, 1995). Todas estas formas de nitrogênio são bioquimicamente convertíveis e são componentes do complexo ciclo de nitrogênio tanto em sistemas alagados naturais quanto construídos.

A remoção de fósforo dos efluentes dar-se-á de duas formas: o fósforo reativo solúvel é assimilado pelas plantas e é convertido a fósforo orgânico estrutural, sendo assim, armazenado na biomassa das vegetações. As frações de fósforo precipitadas e insolúveis são adsorvidas pelo meio suporte, principalmente por estruturas de rochas ricas em ferro e alumínio. 
A ocorrência de fósforo em águas naturais e em águas residuárias se dá quase que exclusivamente na forma de fosfato $\left(\mathrm{PO}_{4}\right)^{3-}$. Os fosfatos são classificados como ortofosfatos, fosfatos condensados (piro-, meta-, e outros polifosfatos), além de fosfatos ligados a compostos orgânicos (APHA, 1995).

Segundo a Wetland International (2003, citado por Eustáquio Jr. et al., 2010) a biomassa da planta cultivada nos sistemas alagados construídos, deve ser regularmente removida para assegurar elevada remoção de nutrientes do meio. Assim, quanto maior a produtividade da planta, maior a sua capacidade de remover poluentes das águas residuárias, por essa razão, a seleção da vegetação deve ser cuidadosa, de forma a se maximizar essas remoções.

No presente trabalho, adotou-se a sigla SAC para representar o sistema alagado construído, passando-se, a só se fazer referência a este sistema pela mesma.

Nos últimos anos, o uso de sistemas alagados construídos para o tratamento de águas residuárias de laticínios tem ganhado popularidade, devido a seu baixo custo de implantação e monitoramento em comparação aos demais sistemas convencionais. Nos Estados Unidos e Europa, o uso de $\mathrm{SAC}(\mathrm{s})$ vem sendo registrado em um grande número de indústrias de laticínios, apresentando resultados promissores (Healy e Cawley, 2002).

$\mathrm{Na}$ Irlanda, o método mais comum de tratamento da ARL era a disposição no solo. Atualmente este método vem sendo substituído pelos SAC(s), por estes fornecerem desempenho de tratamento eficaz, proporcionando também redução de espaço físico para implantação e aumento substancial das taxas de carga orgânica a serem aplicadas (Healy e Cawley, 2002).

Na província de Reggio Emilia, Itália, Mantovi et al. (2003), relataram o uso de um sistema alagado construído para tratar a ARL de uma queijaria. O sistema possuía um prétratamento composto por um decantador tipo Imhoff e dois $\mathrm{SAC}(\mathrm{s})$ de $72 \mathrm{~m}^{2}$, preenchidos com cascalho lavado e brita \# 3. Ambos os sistemas alagados foram cultivados com caniço d'água (Phragmites australis). Os resultados encontrados foram considerados promissores e os autores apontaram que esta ecotecnologia é apropriada para reduzir nutrientes contidos na ARL, com valores aceitáveis para sua descarga em corpos de águas superficiais. Os sistemas apresentaram remoções de 48,5 \% de NTK e 60,6\% de fósforo da água residuária.

$\mathrm{Na}$ Lituânia, Gasiunas et al. (2005), relataram o uso de um sistema de $100 \mathrm{~m}^{2} \mathrm{com}$ substrato composto por areia grossa e cultivados com Phragmites australis. Os autores obtiveram na pesquisa uma remoção de $71 \%$ de nitrogênio total e $58 \%$ de fósforo total do efluente bruto.

Kern e Brettar (2002) na Alemanha, utilizando uma unidade experimental de $10 \mathrm{~m}^{2}$ cultivados com Spartina pectinata, Phragmites australis e Acutiformis carex encontraram altas eficiências na remoção de nutrientes. Mesmo com altas concentrações de nitrogênio total (264 mg. $\mathrm{L}^{-1}$ ) no efluente bruto, foi detectada uma remoção de 85 a 90\% deste parâmetro.

Em uma pesquisa realizada na Universidade de Connecticut (EUA), Neafsey e Clausen (1994), utilizando três células em paralelo, ocupando uma área total de 0,037 ha, adotando um tempo de detenção hidráulica de 27 dias, cultivando as macrófitas Typha spp., Phragmites spp. e Scirpus americanus, conseguiram uma remoção de 55,3 a 99,6\% de NTK e 44,9 a 99,3\% de fósforo total.

No Reino Unido, Job (1992), operando dois sistemas em série obteve remoções de 90\% de compostos nitrogenados, mesmo verificando baixas taxas de nitrificação nos leitos devido a carência de oxigênio no substrato.

Em 2006, um estudo realizado na Universidade Federal de Viçosa por Abrahão, utilizando SAC(s) de escoamento subsuperficial cultivados com forrageiras (capim tifton-85 e napier), foi observado uma remoção média de 50 a $70 \%$ de nitrogênio total pelos leitos vegetados. 
Devido a carência de pesquisas sobre o tratamento de efluentes de laticínios, em condições de clima tropical, utilizando sistemas alagados construidos, com ênfase na remoção de nutrientes eutrofizantes, objetivou-se com esta pesquisa, avaliar o potencial destes sistemas para remover nitrogênio e fósforo, nas condições climáticas do municipio de Juiz de Fora MG.

\section{MATERIAIS E MÉTODOS}

O experimento foi conduzido nas instalações do Laticínio Flórida no município de Juiz de Fora - MG, com coordenadas geográficas $21^{\circ} 40^{\prime} 45^{\prime \prime}$ de latitude sul e $43^{\circ} 26^{\prime} 31^{\prime \prime}$ de longitude oeste. No laticínio são fabricados os seguintes subprodutos do leite: doce de leite em pasta e barra, leite condensado e leite empacotado tipo C.

Nesta pesquisa, a água residuária de laticínios (ARL) aplicada aos SAC(s) foi submetida apenas a tratamento preliminar, composto por grades finas em alumínio de 3/8" x 1 ", com espaçamento de $25 \mathrm{~mm}$, largura de $0,30 \mathrm{~m}$, comprimento $0,60 \mathrm{~m}$ e ângulo de inclinação de $60^{\circ}$, desarenador com $0,30 \mathrm{~m}$ de largura e $1,55 \mathrm{~m}$ de comprimento e uma caixa de gordura com 1,37 $\mathrm{m}$ de comprimento e $0,84 \mathrm{~m}$ de largura. O layout do sistema de tratamento e suas respectivas dimensões estão apresentados na Figura 1 a seguir.

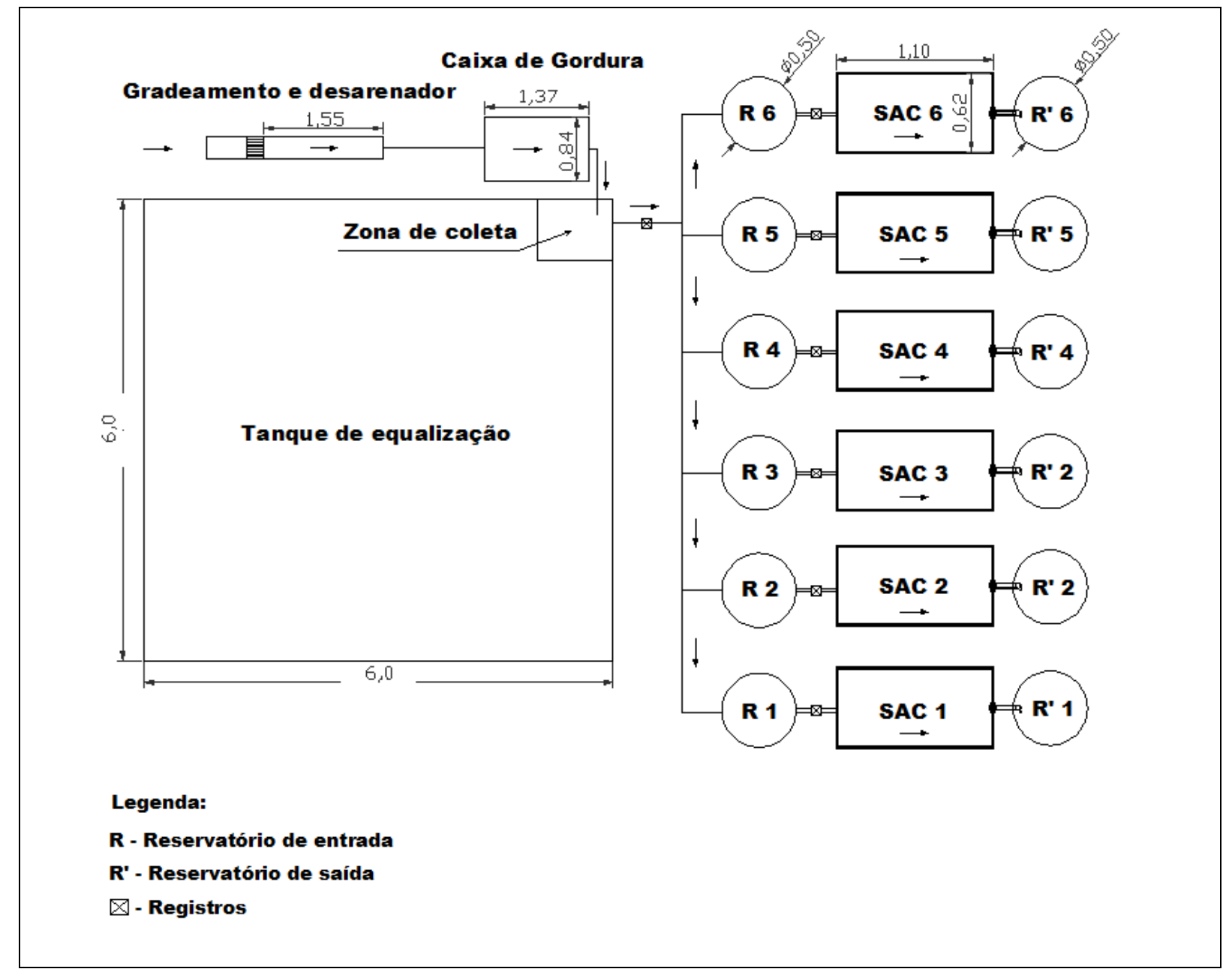

Figura 1. Layout completo do sistema de tratamento (unidades em m).

Os efluentes sanitários são misturados aos efluentes provindos da fábrica em um tanque de equalização a jusante da caixa de gordura. A água residuária aplicada aos SAC(s) foi 
coletada na zona de mistura do efluente sanitário com o efluente da fábrica, no interior do tanque de equalização.

As unidades experimentais foram constituídas por seis leitos horizontais em escala piloto instalados em paralelo. Os SAC(s) foram construídos a partir de bombonas de PEAD de 200 $\mathrm{L}$, serradas transversalmente ficando cada calha com o volume útil aproximado de $115 \mathrm{~L}$.

Cada unidade apresentava seção transversal semicircular com raio interno aproximado de $0,31 \mathrm{~m}$ e comprimento de 1,10 metros, com uma declividade média de $0,5 \%$ sobre o solo.

Como meio suporte foram utilizadas: brita \# 0 em três dos SAC(s) e brita e areia grossa em outros três, na proporção de $80 \%$ brita \# 0 e $20 \%$ de areia, como apresentado na Figura 2 a seguir.
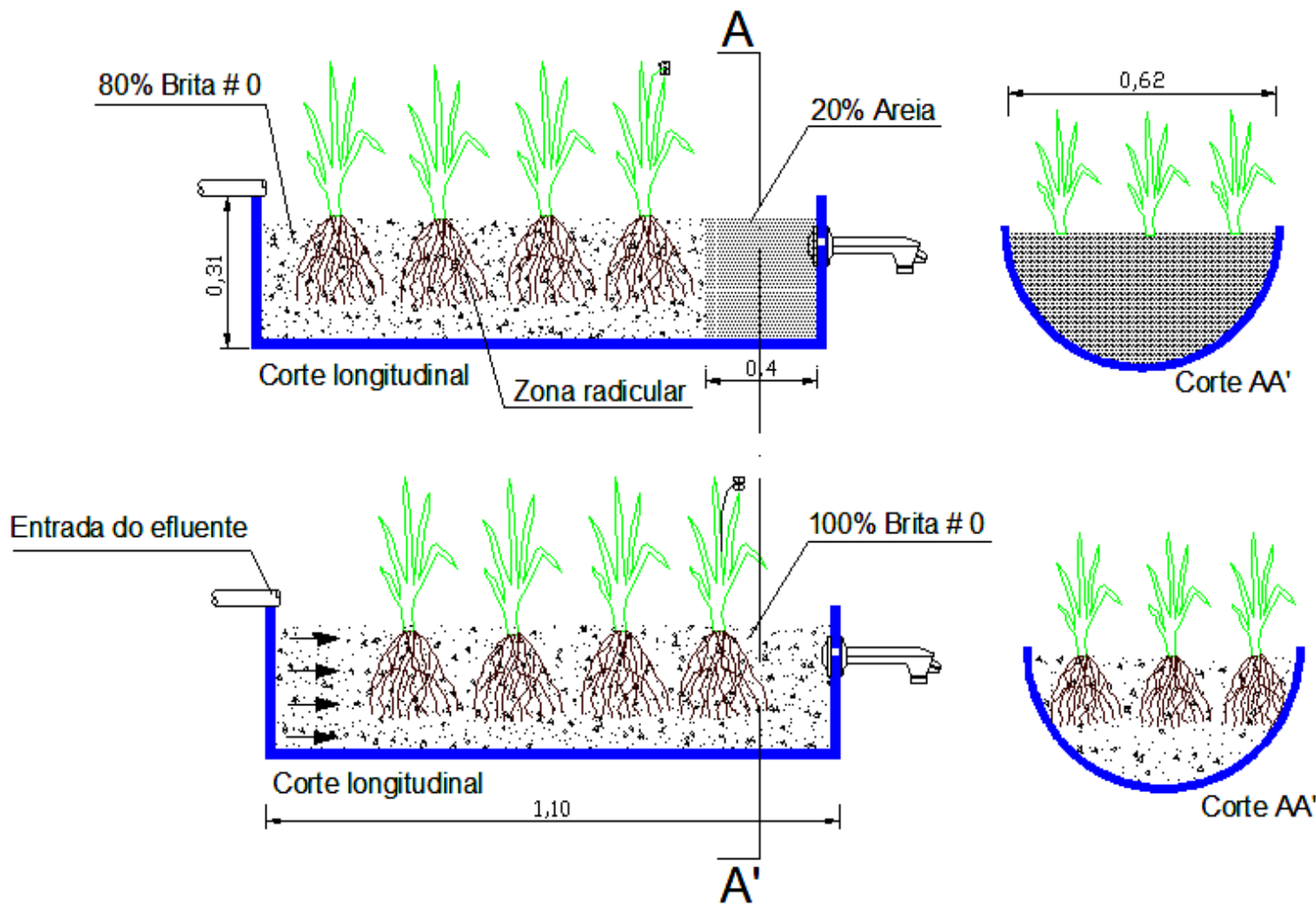

Figura 2. Planta da configuração dos $\mathrm{SAC}(\mathrm{s})$ em "bombonas" de PEAD, utilizados na pesquisa (unidades em $\mathrm{m}$ ).

As espécies vegetais selecionadas para o cultivo foram a Typha dominguensis (taboa) e a Hedychium coronarium (lírio do brejo), espécies inéditas no tratamento da ARL em SAC(s).

Quatro leitos foram plantados, sendo dois com cada espécie selecionada e dois sistemas foram mantidos sem vegetação, servindo como testemunhas.

O volume aplicado aos sistemas 7,5 L, foi empregado para manter a taxa de aplicação de carga orgânica em torno de $232 \mathrm{~kg}$ (ha.d) ${ }^{-1}$, levando em consideração uma DBO de 1.701 mg. $\mathrm{L}^{-1}$, valor médio da água residuária gerada pelo empreendimento. Abrahão (2006) fez uso em sua pesquisa no tratamento da ARL, de taxas de aplicação de carga orgânica entre 66 e $570 \mathrm{~kg}$ (ha.d) $)^{-1}$, sendo assim, neste trabalho procurou-se utilizar um valor intermediário da pesquisa supracitada.

O método empregado na operação dos SAC(s) foi realizado por meio de uma adaptação do método de fluxo intermitente ou bateladas, onde a ARL bruta ao ser aplicada na zona de entrada dos leitos, expulsava o efluente tratado para os reservatórios a jusante dos sistemas, sem haver esvaziamento das unidades experimentais. O tempo de ciclo (TC) adotado foi de 2,0 dias. 
A Tabela 1 sumariza a concepção das unidades experimentais de tratamento e na Tabela 2 são informadas as concentrações de nitrogênio total de Kjeldahl (NTK) e Fósforo total $\left(\mathrm{P}_{\mathrm{t}}\right)$ na ARL bruta.

Tabela 1. Concepções de tratamento adotadas no experimento.

\begin{tabular}{c|cccc}
\hline Sistema & Substrato* $^{\text {Vegetação }}$ & Volume & TC \\
\hline SAC1 & B e A & Taboa & $7,5 \mathrm{~L}$ & 2 dias \\
SAC2 & B e A & Lírio & $7,5 \mathrm{~L}$ & 2 dias \\
SAC3 & B & Taboa & $7,5 \mathrm{~L}$ & 2 dias \\
SAC4 & B & Lírio & $7,5 \mathrm{~L}$ & 2 dias \\
SAC5 & B & Testemunha & $7,5 \mathrm{~L}$ & 2 dias \\
SAC6 & B e A & Testemunha & $7,5 \mathrm{~L}$ & 2 dias \\
\hline
\end{tabular}

*B - Brita \# 0; A - Areia grossa; TC = Tempo de ciclo.

Tabela 2. Concentração em mg.L $\mathrm{L}^{-1}$ de NTK e P total na ARL bruta referente às análises de outubro 2009 até abril 2010.

\begin{tabular}{c|ccc}
\hline Variável & Unidade & Média & Desvio Padrão \\
\hline NTK & $\mathrm{mg} . \mathrm{L}^{-1}$ & 29,1 & $\pm 8,3$ \\
$\mathbf{P}_{\mathbf{t}}$ & $\mathrm{mg} \cdot \mathrm{L}^{-1}$ & 15,6 & $\pm 5,1$ \\
\hline
\end{tabular}

Visando a desobstrução dos poros do meio suporte, foi realizada a lavagem deste com água limpa por 15 dias. Posteriormente, por 30 dias fez-se saturação dos tanques diariamente, com o efluente bruto, objetivando-se o desenvolvimento de um biofilme adaptado às condições do ecossistema construído, antes de sua efetiva operação.

Em seguida, foram plantadas as vegetações por meio de propágulos vegetativos (rizoma + caule) com, aproximadamente, $25 \mathrm{~cm}$ de comprimento, no caso da taboa. O lírio do brejo foi inserido ao meio suporte, plantando-se mudas jovens entre 30 e $40 \mathrm{~cm}$.

Após o plantio das vegetações, foi iniciada a operação dos sistemas, com ciclos de 48 horas em regime de bateladas, durante 7 (sete) meses.

A regra operacional foi realizada da seguinte forma: a ARL foi coletada no tanque de equalização por meio de um balde com volume definido e posteriormente armazenada nos reservatórios indicados por (1) na Figura 3. Logo após abria-se lentamente os registros dos reservatórios, permitindo o escoamento do efluente pelas mangueiras (2) por gravidade até os SAC(s) indicados por (3). A ARL depois de ocupar o volume de vazios dos leitos, permanecia estática por dois dias em seu interior. Ao completar 48 horas iniciava-se um novo ciclo. $\mathrm{Na}$ medida em que a água bruta ia ocupando o interior dos leitos, gradativamente o efluente tratado deslocava-se para os reservatórios de coleta (4), onde se realizava as inspeções de qualidade da água residuária previamente tratada. Encerrando-se o processo a água tratada seguia para a rede coletora do empreendimento (5). 


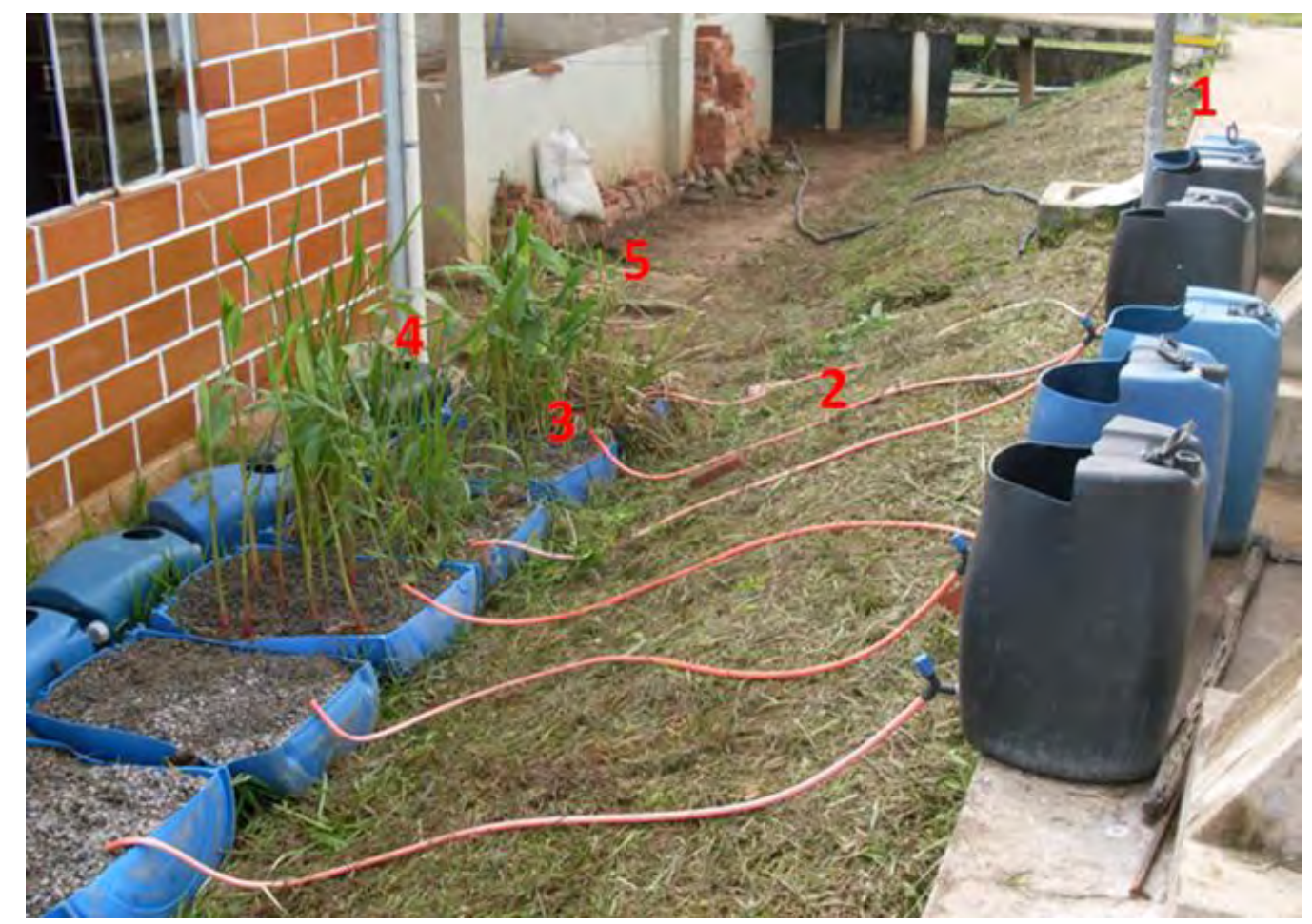

Figura 3. Regra operacional das unidades experimentais.

Para avaliar se houveram diferenças significativas entre as médias das eficiências dos tratamentos dos SAC(s) vegetados e não vegetados, fez-se uso de análise de variância ANOVA para medidas repetidas e os testes de Dunnett e Student-Newman-Keuls. As análises estatísticas foram realizadas com o auxílio do software PRIMER OF BIOSTATISTICS versão 3.0 (Stanton, 1992).

Neste estudo foram analisados 2 parâmetros, sendo eles, nitrogênio total Kjeldahl e fósforo total.

Foram realizadas 7 amostragens, uma para cada mês de operação, para quantificar a remoção de Nitrogênio (NTK) e Fósforo total $\left(\mathrm{P}_{\mathrm{t}}\right)$ pelos $\mathrm{SAC}(\mathrm{s})$, sendo o primeiro determinado pelo método de Kjeldahl, e a última quantificada por digestão nítrico-perclórica da amostra e quantificada em espectrofotômetro.

As análises laboratoriais foram realizadas em conformidade com as recomendações do Standard Methods for the Examination of Water and Wastewater (APHA, 1995).

\section{RESULTADOS E DISCUSSÃO}

Os resultados das eficiências de tratamento dos parâmetros analisados são apresentados a seguir.

\subsection{Remoção de nitrogênio (NTK) pelos SAC(s)}

A avaliação da eficiência dos leitos na remoção de NTK teve início no mês de outubro de 2009. A primeira análise apresentou elevada remoção de compostos nitrogenados com destaque para os SAC(s) cultivados. O SAC 1 cultivado com taboa e com meio suporte constituído por brita \#0 e areia, obteve a maior eficiência média na remoção de NTK com $53,47 \%$. A eficiência máxima encontrada ao longo do experimento foi de $73,40 \%$, também verificada no SAC 1. O SAC 3, cultivado com taboa tendo como meio suporte brita \#0 apresentou a segunda melhor eficiência com 52,91\%, seguido do SAC 2 (lírio do brejo, brita 
MENDONÇA, H. V.; RIBEIRO, C. B. M.; BORGES, A. C.; BASTOS, R. R. Remoção de nitrogênio e fósforo de águas residuárias de laticínios por sistemas alagados construídos operando em bateladas. Ambi-Agua, Taubaté, v. 7, n. 2, p. 75-87, 2012. (http://dx.doi.org/10.4136/ambi-agua.805)

\#0 e areia) com 51,0\%. O SAC 4 cultivado com lírio do brejo em brita \# 0 obteve a quarta melhor eficiência com 46,01\%. Os SAC(s) testemunhas obtiveram remoções de nitrogênio inferiores aos SAC(s) vegetados. O SAC 5, testemunha, cujo meio suporte foi composto somente por brita \# 0 teve eficiência média de $31,60 \%$. O SAC 6, testemunha, composto por brita \# 0 e areia apresentou o menor valor entre as médias com 29,40\%. Em todas as parcelas houve tendência de decaimento da eficiência em relação ao tempo de operação, que foi justificada pela estabilização do crescimento e desenvolvimento das vegetações cultivadas.

A análise de variância (ANOVA), assim como os testes de Dunnett e Student-NewmanKeuls, todos em nível de significância de 5\% mostraram que houve diferença significativa (P $<0,05)$ na remoção de NTK entre SAC(s) vegetados e testemunhas, confirmando que a presença das vegetações proporcionam maiores remoções deste parâmetro.

Na Tabela 3 a seguir são apresentados os valores de NTK do efluente bruto e tratado pelos SAC(s), e na Figura 4, a série temporal da remoção de NTK.

Tabela 3. Valores de nitrogênio total (NTK) do afluente bruto (entrada) e dos efluentes tratados (saída) pelas seis unidades experimentais.

\begin{tabular}{l|c|cccccc}
\hline Amostragens & Afluente* $^{*}$ & SAC 1* & SAC 2* & SAC 3* & SAC 4* & SAC 5* & SAC 6* \\
\hline $\mathbf{2 9 / 1 0 / 2 0 0 9}$ & 25,85 & 8,25 & 10,10 & 12,40 & 11,33 & 21,87 & 19,44 \\
$\mathbf{1 3 / 1 1 / 2 0 0 9}$ & 25,13 & 10,17 & 11,40 & 12,52 & 14,87 & 15,52 & 17,59 \\
$\mathbf{1 0 / 1 2 / 2 0 0 9}$ & 19,11 & 7,63 & 9,06 & 10,15 & 12,94 & 15,56 & 13,40 \\
$\mathbf{0 7 / 0 1 / 2 0 1 0}$ & 43,11 & 22,00 & 19,60 & 13,17 & 14,89 & 34,00 & 25,70 \\
$\mathbf{0 4 / 0 2 / 2 0 1 0}$ & 35,00 & 16,63 & 17,06 & 15,20 & 19,95 & 20,56 & 25,40 \\
$\mathbf{0 4 / 0 3 / 2 0 1 0}$ & 29,11 & 15,63 & 15,01 & 13,17 & 14,94 & 15,51 & 19,42 \\
$\mathbf{0 8 / 0 4 / 2 0 1 0}$ & 21,00 & 13,93 & 15,04 & 14,12 & 14,92 & 15,56 & 19,39 \\
\hline
\end{tabular}

*Valores em mg. $\mathrm{L}^{-1}$.

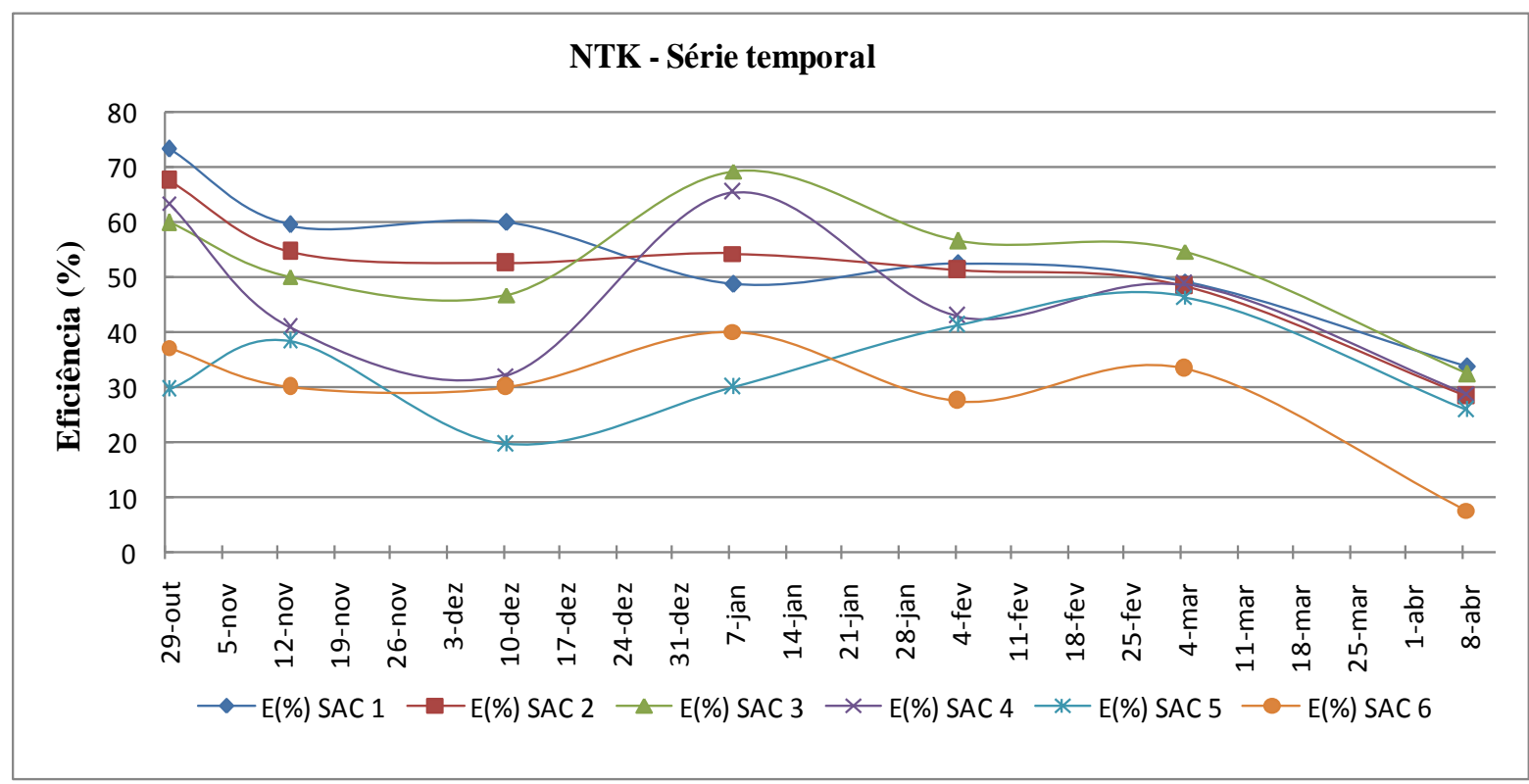

Figura 4. Série temporal da variação da eficiência de remoção de NTK pelos SAC(s). 
Em conformidade com os valores apresentados na Figura 4, pode-se aferir que inicialmente a remoção de NTK nos SAC(s) foi influenciada pelo desenvolvimento das vegetações, uma vez que estas fizeram uso metabólico deste elemento para seu brotamento e crescimento. Após o estabelecimento das vegetações, atingindo estas a maturidade a assimilação destes compostos foi reduzida. A mesma afirmação foi feita por (Mansor, 1998), onde o autor relata que ocorre maior absorção de compostos nitrogenados durante o período de crescimento das vegetações.

De forma geral, além da influência das vegetações cultivadas, supõe-se que a remoção de NTK nos leitos pode ter se dado por meio de processos microbiológicos, como a nitrificação autotrófica, ou mesmo a oxidação anaeróbia da amônia. Contudo, para que tal afirmação fosse validada, estudos envolvendo técnicas como extração de DNA teriam que ser realizadas.

Valores semelhantes aos desta pesquisa acerca da remoção de compostos nitrogenados da ARL foram relatados por Matos et al. (2008), os SAC(s) avaliados pelos autores atingiram eficiências de remoção de NTK entre 29,3 a 70,4 \%, fazendo uso de um tempo de detenção de 4,8 dias. Mantovi et al. (2003), cultivando a macrófita Phragmites australis, obteve uma remoção de 48,5\% de NTK da ARL em condições de clima frio na Itália. Em um laticínio na Alemanha, Kern e Brettar (2002), fazendo uso de consórcio entre as macrófitas Spartina pectinata, Phragmites australis e Acutiformis carex em SAC(s), atingiram uma eficiência de remoção entre 85 a $90 \%$ de compostos nitrogenados da ARL. Os valores superiores ao da presente pesquisa atingidos pelos autores foram atribuídos ao tempo de detenção de 25 dias empregado no tratamento da ARL, sendo assim os mecanismos de remoção foram intensificados.

Os resultados apresentados pelas diversas pesquisas citadas e também do presente estudo demonstram que a ecotecnologia é promissora na remoção de nitrogênio, a um baixo custo de implantação e monitoramento, sobretudo condizente ao cenário atual do saneamento no Brasil.

\subsection{Remoção de fósforo total $\left(P_{t}\right)$ pelos $S A C(s)$}

A maior eficiência média encontrada na remoção de $\mathrm{P}_{\mathrm{t}}$ foi de $34,3 \%$ no SAC 3 cultivado com taboa e com substrato composto por brita \# 0. O SAC 4 composto por brita \# 0 e cultivado com lírio do brejo, apresentou a segunda maior média com eficiência de 34,2\%, valor muito próximo do SAC 3. A maior eficiência encontrada no período experimental $48,2 \%$ oriunda do SAC 4. O SAC 1, composto por brita \# 0 e areia cultivado com taboa apresentou a terceira melhor média com 33,6\% seguido pelo SAC 2 cultivado com lírio do brejo e meio suporte idêntico ao SAC 1. Os SAC(s) não vegetados 5 e 6, (testemunhas) apresentaram valores percentuais de remoção de 18,81 e 18,61\%, respectivamente. Os valores de remoção de $\mathrm{P}_{\mathrm{t}}$ entre os $\mathrm{SAC}(\mathrm{s})$ não vegetados foram inferiores aos vegetados e foram detectadas diferenças significativas entre as médias pelos testes ANOVA, Dunnett e StudentNewman-Keuls, todos a nível de probabilidade de 5\% ( $\mathrm{P}<0,05)$, demonstrando que a presença das vegetações influenciou positivamente na remoção deste parâmetro.

A remoção encontrada ao longo do tempo neste trabalho apresentou comportamento desuniforme, sem haver desenvolvimento de uma tendência. $\mathrm{O}$ mesmo comportamento foi verificado por Fia (2008), utilizando os sistemas para tratamento de águas residuárias da lavagem/descartamento e despolpa dos frutos do cafeeiro (ARC). Na Tabela 4 a seguir são apresentados os valores de P-total $\left(\mathrm{P}_{\mathrm{t}}\right)$ do efluente bruto e tratado pelos $\mathrm{SAC}(\mathrm{s})$, e na Figura 5, a série temporal da remoção de $\mathrm{P}$-total pelas unidades experimentais. 
MENDONÇA, H. V.; RIBEIRO, C. B. M.; BORGES, A. C.; BASTOS, R. R. Remoção de nitrogênio e fósforo de águas residuárias de laticínios por sistemas alagados construídos operando em bateladas. Ambi-Agua, Taubaté, v. 7, n. 2, p. 75-87, 2012. (http://dx.doi.org/10.4136/ambi-agua.805)

Tabela 4. Valores de fósforo total (P-total) do afluente bruto (entrada) e dos efluentes tratados (saída) pelas seis unidades experimentais.

\begin{tabular}{c|c|cccccc}
\hline Amostragens & Afluente* & SAC 1* & SAC 2* & SAC 3* & SAC 4* & SAC 5* & SAC 6* \\
\hline $\mathbf{2 9 / 1 0 / 2 0 0 9}$ & 22,0 & 13,30 & 15,03 & 15,29 & 14,53 & 13,58 & 13,40 \\
$\mathbf{1 3 / 1 1 / 2 0 0 9}$ & 16,60 & 10,10 & 11,15 & 10,13 & 13,27 & 14,37 & 15,40 \\
$\mathbf{1 0 / 1 2 / 2 0 0 9}$ & 16,20 & 12,13 & 12,98 & 12,47 & 11,44 & 13,94 & 13,12 \\
$\mathbf{0 7 / 0 1 / 2 0 1 0}$ & 21,00 & 18,13 & 13,00 & 14,56 & 15,44 & 19,94 & 19,12 \\
$\mathbf{0 4 / 0 2 / 2 0 1 0}$ & 8,00 & 5,13 & 4,98 & 4,47 & 4,44 & 6,00 & 7,10 \\
$\mathbf{0 4 / 0 3 / 2 0 1 0}$ & 10,50 & 6,13 & 8,98 & 7,47 & 5,44 & 8,94 & 7,12 \\
$\mathbf{0 8 / 0 4 / 2 0 1 0}$ & 15,00 & 9,00 & 10,98 & 8,40 & 9,44 & 13,94 & 13,12 \\
\hline
\end{tabular}

*Valores em mg. $L^{-1}$.

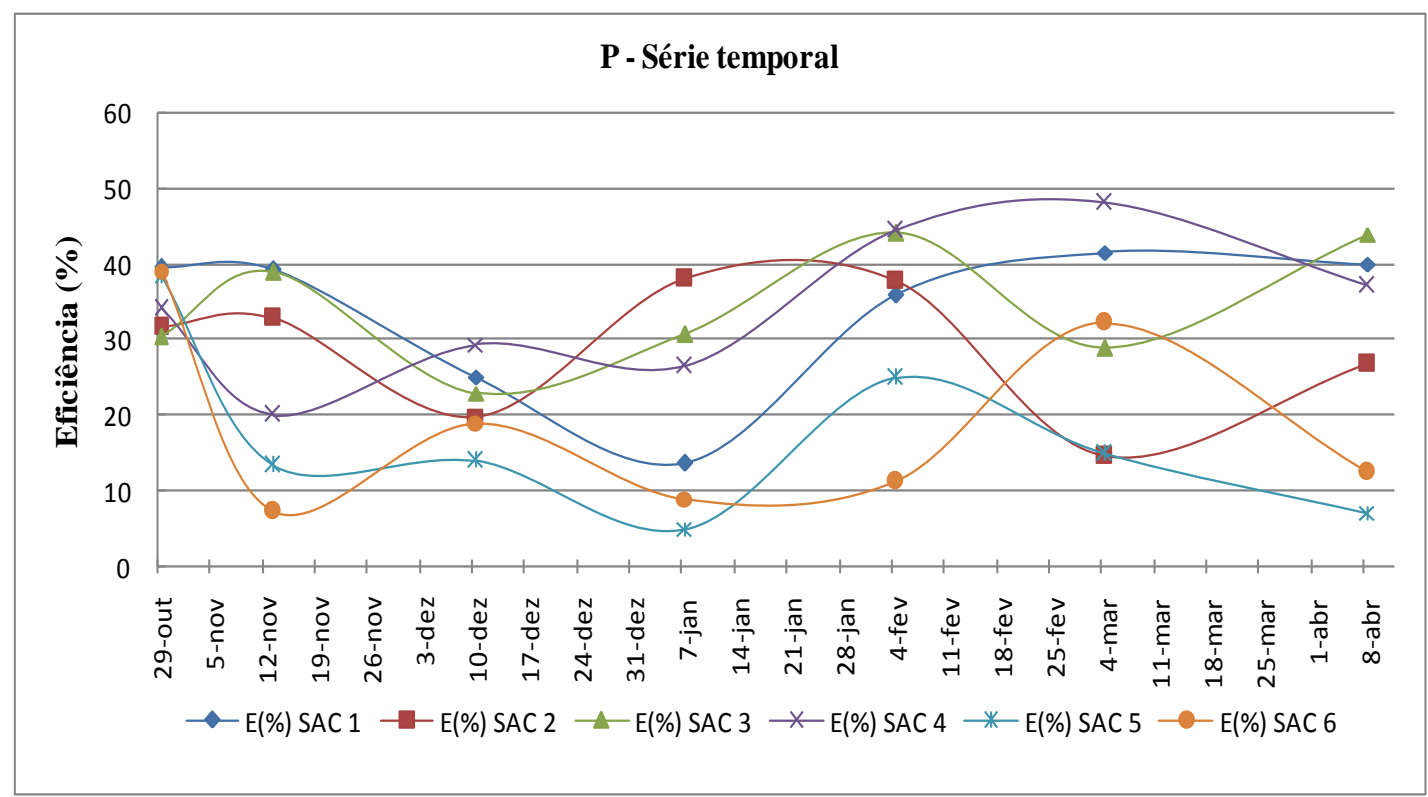

Figura 5. Série temporal da variação da eficiência de remoção de $P_{t}$ pelos $S A C(s)$.

A composição do meio suporte presente nos leitos foi crucial no que diz respeito a remoção de fósforo por processos de adsorção/dessorção, uma vez que íons fosfato $\left(\mathrm{PO}_{4}\right)^{3-}$ podem ser fixados por alumínio ou ferro. A brita utilizada nesta pesquisa foi retirada de jazidas de granito, rochas ígneas compostas basicamente por biotita e feldspato, minerais que possuem ferro e alumínio em sua estrutura molecular. Segundo Mansor (1998), este material possui composição química média de 11,50 a 13,75\% de óxido de alumínio e de 15,93 a 9,01\% de óxido de ferro. Sendo assim, pode-se aferir que a retenção de fósforo pelo substrato e remoção pelas vegetações são métodos potencias na redução deste parâmetro nos efluentes tratados em SAC(s). Abrahão (2006) ao tratar ARL em SAC(s) cultivados com forrageiras, relatou que a eficiência na remoção do fósforo foi bastante insatisfatória independente da presença ou não da vegetação. O mesmo autor encontrou em alguns sistemas valores da concentração do elemento maiores na saída (efluente tratado) do que na entrada (efluente bruto), alegando que os resultados deveriam ser ponderados, levando-se em consideração o efeito da concentração do líquido residente, proporcionado pela evapotranspiração.

A presente pesquisa obteve resultados próximos aos encontrados por Valentim (2003) e Brasil et al. (2005), que obtiveram eficiência média de remoção de fósforo total da ordem de 
23 a 36\% (tempo de detenção hidráulica entre 2 a 4 dias), 38\% (tempo de detenção hidráulica de 0,75 a 2,9 dias) e de 31 a $48 \%$ (tempo de 1,9 a 3,8 dias), respectivamente, em SAC(s) cultivados com taboa para o tratamento de esgoto doméstico. Freitas (2006) ao tratar águas residuárias da suinocultura em SAC(s) de fluxo subsuperficial, concluiu que a fração de fósforo orgânico foi removida pela imobilização microbiológica no meio suporte, tal como observado por Lee et al. (2004).

No método de operação por bateladas, o mecanismo de adsorção foi intensificado, aderindo os compostos fosfóricos ao substrato com maior sucesso em relação a sistemas operados por fluxo contínuo. Em todos os leitos, possivelmente, houve também volatilização da fosfina $\left(\mathrm{PH}_{3}\right)$ e assimilação pelos microrganismos presentes no meio suporte, fato relatado por Kadlec e Knight (1996).

Devido às dificuldades de remoção de fósforo entre diversos sistemas convencionais e naturais de tratamento, os resultados da pesquisa foram considerados satisfatórios.

\section{CONCLUSÕES}

Perante aos resultados obtidos, pode-se concluir que:

- As duas espécies cultivadas apresentaram boa adaptação nos SAC(s), porém a Typha dominguensis apresentou melhor desempenho em crescimento e desenvolvimento foliar, assim como maior eficiência de remoção de nitrogênio e fósforo.

- Os testes estatísticos evidenciaram que houve diferenças significativas na remoção de nitrogênio e fósforo pelos leitos vegetados em relação aos não vegetados (testemunhas).

- Os resultados deste experimento em operação por bateladas confirmam a conclusão de outras pesquisas acerca da maior eficiência de remoção de nutrientes, por sistemas vegetados, em especial nitrogênio e fósforo, principais causadores da eutrofização dos recursos hídricos.

- Em comparação com outras pesquisas utilizando SAC(s), as duas espécies removeram satisfatoriamente os nutrientes da água residuária.

- A utilização de brita somente ou brita com areia, não diferiram estatisticamente, em nível de 5\% de probabilidade na remoção de nutrientes, embora a biomassa aderida ao meio suporte contribuiu, com pequena influência, no tratamento.

- Possivelmente houve remoção de nitrogênio pela oxidação anaeróbia da amônia, porém a verificação deste processo biológico de remoção deverá ser melhor estudado por meio de testes de DNA bacteriano.

- Os resultados obtidos neste trabalho, embora preliminares, indicaram que os sistemas alagados construídos cultivados com Typha dominguensis e Hedychium coronarium podem ser utilizados para remover nitrogênio e fósforo de águas residuárias de laticínios. Porém existirá necessidade de um sistema complementar à jusante dos $\mathrm{SAC}(\mathrm{s})$, para potencializar a remoção de fósforo da água residuária.

\section{REFERÊNCIAS}

ABRAHÃO, S. S. Tratamento de água residuária de laticínios em sistemas alagados construídos cultivados com forrageiras. 2006. 110f. Dissertação (Mestrado em Engenharia Agrícola) - Universidade Federal de Viçosa, Viçosa, MG, 2006.

AMERICAN PUBLIC HEALTH ASSOCIATION - APHA. Standard methods for the examination of water and wastewater. 19. ed. Washington,DC, 1995. 
BRASIL, M. S.; MATOS, A. T.; SOARES, A. A.; FERREIRA, P. A. Qualidade do efluente de sistemas alagados construídos, utilizados no tratamento de esgoto doméstico. Revista Brasileira de Engenharia agrícola e ambiental, Campina Grande, v. 9, Suplemento, p. 133-137, 2005.

COMPANHIA DE TECNOLOGIA DE SANEAMENTO AMBIENTAL - CETESB. Nota técnica sobre tecnologia de controle - indústria de laticínios - NT-17. São Paulo, 1990. p. 20.

COOPER, P. A review of the design and performance of vertical-flow and hybrid reed bed treatment systems. In: INTERNATIONAL CONFERENCE ON WETLAND SYSTEMS FOR WATER POLLUTION CONTROL, 1., 27 set. a 02 out. 1998, Águas de São Pedro. Anais... Águas de São Pedro: CEA/UNESP;IAWQ, 1998. 1 CD-ROM.

EUSTÁQUiO JR., V.; MATOS, A. T.; CAMPOS, L. C.; BORGES, A. C. Desempenho agronômico da aveia-preta (Avena strigosa Schreb), cultivada em sistemas alagados construídos. Revista Ambi-Água, Taubaté, v. 5, n. 1, p. 68-78, 2010. http://dx.doi.org/10.4136/ambi-agua. 120

FIA, R. Desempenho de sistemas alagados construídos no tratamento de águas residuárias da lavagem e descascamento/despolpa dos frutos do cafeeiro. 2008. 181f. Tese (Doutorado em Engenharia Agrícola) - Universidade Federal de Viçosa, Viçosa, MG, 2008.

FREITAS, W. S. Desempenho de sistemas alagados construídos, cultivados com diferentes espécies vegetais, no tratamento de águas residuárias da suinocultura. 2006. 159f. Tese (Doutorado em Engenharia Agrícola) - Universidade Federal de Viçosa, Viçosa, MG, 2006.

GASIUNAS, V.; STRUSEVICIUS, Z.; STRUSEVICIÉNE, M. S. Pollutant removal by horizontal subsurface flow constructed wetlands in Lithuania, Journal of Environmental Science and Health, Philadelphia, v. 40, n. 6/7, p. 1467-1478, 2005. http://dx.doi.org/10.1081/ESE-200055889

HEALY, M. G.; CAWLEY, A. M. The nutrient processing capacity of a constructed wetland in western Ireland. Journal of Environmental Quality, New Jersey, v. 31, n. 5, p. 1739-1747, 2002. http://dx.doi.org/10.2134/jeq2002.1739

JOB, G. D. Treatment of medium strength industrial and agricultural effluents using reed bed treatment systems. 1992. 162f. Ph.D. thesis, University of Birmingham, Birmingham, 1992.

KADLEC, R. H.; KNIGHT, R. L. Treatment wetlands. Boca Raton: Lewis Publishers, 1996. $893 p$.

KERN, J.; BRETTAR, I. Nitrogen turnover in a subsurface constructed wetland receiving dairy farm wastewater. In: TREATMENT WETLANDS FOR WATER QUALITY IMPROVEMENT, 2., 15-21 oct. 2002, Ontario. Proceedings... Ontario: CH2M Hill, 2002. p. 15-21.

LEE, C. Y.; LEE, C. C.; LEE, F. Y.; TSENG, S. K.; LIAO, C. J. Performance of subsurface flow constructed wetlands taking pretreated swine effluent under heavy loads. Bioresource Technology, n. 92, n. 2, p. 173-179, 2004. http://dx.doi.org/10.1016/j. biortech.2003.08.012 
MANSOR, M. T. C. Uso de leitos de macrófitas no tratamento de águas residuárias. 1998. 106f. Dissertação (Mestrado em Engenharia Agrícola) - Universidade Estadual de Campinas, Campinas, 1998.

MANTOVI, P.; MARMIROLI, M.; MAESTRI, E.; TAGLIAVINI, S.; PICCININI, S.; MARMIROLI, N. Application of a horizontal subsurface flow constructed wetland on treatment of dairy parlor wastewater. Bioresource Technology, v. 88, n. 2, p. 85-94, 2003. http://dx.doi.org/10.1016/S0960-8524(02)00291-2

MATOS, A. T.; ABRAHÃO, S. S.; PEREIRA, O. G. Desempenho agronômico de capim tifton 85 (cynodon spp) cultivado em sistemas alagados construídos utilizados no tratamento de água residuária de laticínios. Revista Ambi-Água, Taubaté, v. 3, n. 1, p. 43-53, 2008. http://dx.doi.org/10.4136/ambi-agua.41

NEAFSEY, J. A.; CLAUSEN J. C. Constructed wetlands for treatment of milkroom wastewater. Internal report. [S.1.: s.n.], 1994. 122p.

SEZERINO, P. H. Potencialidade dos filtros plantados com macrófitas (constructed wetlands) no pós-tratamento de lagoas de estabilização sob condições de clima subtropical. 2006. 176f. Tese (Doutorado em Engenharia Ambiental) - Universidade Federal de Santa Catarina, Florianópolis, 2006.

SHUTES, R. B. E. Artificial wetlands and water quality improvement. Environment International, London, v. 26, n. 5/6, p. 441-447, 2001. http://dx.doi.org/10.1016/ S0160-4120(01)00025-3

STANTON, A. G. Software PRIMER biostatistics: the program. Versão 3.0. London, 1992.

VALENTIM, M. A. A. Desempenho de leitos cultivados ("Constructed Wetlands") para tratamento de esgoto: contribuições para concepção e operação. 233f. Tese (Doutorado em Engenharia Agrícola) - Universidade Estadual de Campinas, Campinas, 2003.

UNITED STATES. ENVIRONMENTAL PROTECTION AGENCY - U.S.EPA. A handbook of constructed wetlands. 2003. Disponível em: <http://www.epa.gov /owow/wetlands/pdf/hand.pdf>. Acesso em: 15 jul. 2003.

VAN DE GRAAF, A. A.; DE BRUIJN, P.; ROBERTSON, L. A.; JETTEN, M. S. M.; KUENEN, J. G. Autotrophic growth of anaerobic ammonium-oxidizing microorganisms in a fluidized bed reactor. Microbiology, v. 142, n. 8, p. 2187-2196, 1996. http://dx.doi.org/10.1099/13500872-142-8-2187

VON SPERLING, M. Princípios de tratamento biológico de águas residuárias: introdução à qualidade das águas e ao tratamento de esgotos. 3. ed. Belo Horizonte: DESA/UFMG, 2005. 425p.

WETLAND INTERNATIONAL. The use of constructed wetlands for wastewater treatment. Selangor, 2003. Disponível em: <http:// www.wetlands.org/pubs\&/ ConstructedWetlands.htm>. Acesso em: 19 dez. 2009.

WILSON, R. W.; MURPHY, K. L. Anaerobic treatment of dairy effluent: a report for Agropur, Granby. Quebec: [s.n], 1986.

ZANELLA, L. Plantas ornamentais no pós-tratamento de efluentes sanitários: wetlands construídos utilizando brita e bambu como suporte. 2008. 106f. Dissertação (Mestrado em Engenharia Civil) - Universidade Estadual de Campinas, Campinas, 2008. 


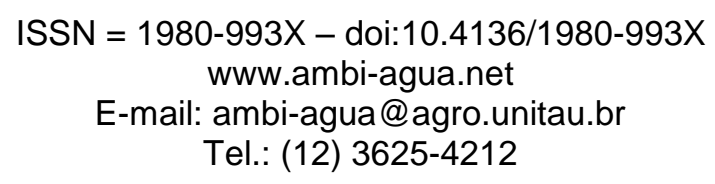

\title{
Variáveis no processo de coagulação/floculação/decantação de lixiviados de aterros sanitários urbanos
}

\author{
(http://dx.doi.org/10.4136/ambi-agua.861)
}

\section{Victor Fernandes Bezerra Mello; Juliana Prazeres da Gama Abreu; Joelma Morais Ferreira; José Fernando Thomé Jucá; Maurício A. da Motta Sobrinho}

\author{
Universidade Federal de Pernambuco, \\ Programa de Pós-Graduação em Engenharia Civil, Recife - PE \\ e-mails:vfbmello@yahoo.com.br,julliizinha@yahoo.com.br, \\ joelma@ufpe.br, jucah@ufpe.br, mottas@ufpe.br
}

\section{RESUMO}

A disposição desordenada de resíduos a céu aberto pode gerar impactos ambientais e sociais de grande porte. Para o tratamento de lixiviados de aterros sanitários, utilizam-se normalmente métodos biológicos e físico-químicos. A precipitação química utilizando hidróxido de cálcio vem sendo empregada com grande eficácia no tratamento de efluente com elevadas concentrações de compostos orgânicos e metais pesados. O lixiviado utilizado neste trabalho foi coletado na caixa de vazão do aterro de Muribeca, localizado na cidade de Jaboatão dos Guararapes - PE. Utilizou-se como coagulante hidróxido de cálcio comercial em solução aquosa. Foi montado um planejamento fatorial fracionário, seguido de um planejamento completo $2^{4}$. Pôde-se observar que os menores valores de turbidez e de cor são obtidos com velocidades de floculação no nível superior, todavia um tempo maior favoreceu a remoção da cor, o que não ocorre para a remoção de turbidez. Para o ponto ótimo, obteve-se redução da cor de $52 \%$ e uma turbidez NTU dentro dos padrões estabelecidos nas resoluções CONAMA 357/05 e 430/11.

Palavras-chave: Aterro Sanitário, Lixiviados, Coagulação, Floculação.

\section{Variables in the process of coagulation / flocculation / settling of leachate of municipal landfills}

\begin{abstract}
The careless disposal of waste may generate tremendous environmental and social impacts. For the treatment of landfill leachate, biological and physic-chemical treatments are routinely used. Chemical precipitation using calcium hydroxide has been used with great effectiveness in treating effluent with high concentrations of organic compounds and heavy metals. The leachate used in this study was collected from a flow box of the Muribeca landfill, located in the city of Jaboatão Guararapes, PE. Commercial calcium hydroxide was used as coagulant in aqueous solution. The experiment was implemented using a fractional factorial design, followed by a complete planning $2^{4}$. It was observed that the lowest turbidity and color were obtained at the highest flocculation speeds. Color removal was favored by long flocculation time whereas this did not occur for turbidity removal. For the optimal point, a reduction of $52 \%$ of the color and a NTU turbidity within the standards established in Brazilian Laws (CONAMA 357/05 and CONAMA 430/11) were obtained.
\end{abstract}

Keywords: sanitary landfill, leachate, coagulation, flocculation. 


\section{INTRODUÇÃO}

Todo resíduo gerado, precisa ser tratado ou disposto em algum local, e as formas de disposição final dos resíduos domésticos pode variar, sendo os mais empregados no Brasil os lixões e os aterros controlados e sanitários. Em 2009, foram coletadas aproximadamente $161.084 \mathrm{t} / \mathrm{dia}$ de resíduos sólidos urbanos, das quais cerca de 91.524 t foram depositados adequadamente em aterros sanitários e 69.560 t/dia tiveram disposição inadequada, sendo estimado 38.459 t/dia depositados em aterros controlados e $31.101 \mathrm{t} / \mathrm{d}$ em lixões (Alegria, 2010).

O chorume é uma substância líquida resultante do processo de putrefação de matérias orgânicas. É viscoso e possui um cheiro muito forte e desagradável enquanto o lixiviado é o resultado da percolação de água, que atravessa a massa de resíduos, acompanhada de extração de materiais dissolvidos ou em suspensão, na maior parte das vezes forma-se a partir de água com origem em fontes externas, tais como a chuva, escoamentos superficiais, águas subterrâneas ou águas de nascente e da decomposição dos resíduos (Mello, 2011; Bidone, 2007).

Para tratar o lixiviado, podem-se utilizar os métodos biológicos e físico-químicos. $\mathrm{O}$ tratamento físico-químico é normalmente utilizado como um pré-tratamento, aumentando a biodegradabilidade da matriz ou polimento final, por meio de remediação de parâmetros que não são alcançados pelos tratamentos biológicos (Morais, 2005; Gomes, 2009). O método físico-químico visa proporcionar um pré-tratamento ou a diminuição dos parâmetros, como por exemplo cor e turbidez, que são objeto de estudo deste trabalho.

Os perigos dos lixiviados são devidos às altas concentrações de poluentes orgânicos e nitrogênio amoniacal. Agentes patogênicos e substâncias químicas tóxicas podem estar presentes (Silva, 2011).

Dentre os métodos físico-químicos, um processo simples e de baixo custo que vem sendo utilizado é a precipitação química a partir do hidróxido de cálcio diluído em várias concentrações. Este método vem apresentando grande eficácia no tratamento de efluentes com elevadas concentrações de compostos orgânicos e metais pesados.

No tratamento do lixiviado de aterros sanitários antigos, estes processos têm se mostrado eficientes. Têm sido largamente utilizados no pré-tratamento, obtendo melhores resultados que nos tratamentos biológicos ou por osmose reversa. Ainda podem ser utilizados como um polimento final ao pré-tratamento para remoção da matéria orgânica não biodegradável (Renou et al., 2008a).

Os processos de Coagulação-floculação desestabilizam as partículas coloidais pela adição do coagulante. Para aumentar o tamanho da partícula, o processo da coagulação é seguido normalmente pela floculação das partículas instáveis, onde há formação de flocos volumosos por agruparem-se mais facilmente. Essa técnica facilita a remoção de sólidos suspensos e partículas coloidais da solução (Kurniawan et al., 2006).

Amokrane et al. (1997) utilizaram sais de ferro e de alumínio no tratamento de lixiviados com baixa relação $\mathrm{DBO}_{5} / \mathrm{DQO}$, obtendo eficiências de até $65 \%$ na redução DQO e de carbono orgânico total.

Bila (2000), tratando lixiviados por coagulação com $\mathrm{Al}_{2}\left(\mathrm{SO}_{4}\right)_{3}, \mathrm{FeCl}_{3}$, Tanfloc SG, Cloralfloc 18 alcançou eficiências de 40\%, 43\%, 37\% e 26\%, respectivamente, na redução de DQO. Já Trebouet et al. (2001), na França, utilizaram a nanofiltração seguida de coagulação química, e obtiveram uma remoção de DQO entre 70 a $80 \%$, enquadrando o lixiviado tratado nos padrões de lançamento da França.

A eficiência do processo de coagulação/floculação depende de fatores como: natureza e dose do coagulante, idade do lixiviado, uso do processo como etapa de pré ou pós-tratamento e pH (Renou et al., 2008a). 
Vários autores (Thornton e Blanc, 1973; Ho et al., 1974; Keenan et al., 1983; Slater et al., 1983; Millot, 1986) afirmam que a cal é o reagente mais utilizado na precipitação química, requerendo, geralmente, entre 1 a $15 \mathrm{~g} / \mathrm{L}$ de cal no tratamento de lixiviado de aterros. As principais vantagens da aplicação de hidróxido de cálcio (cal hidratada) na precipitação química incluem: disponibilidade do reagente em muitos países; não contribui para o aumento da salinidade, como é o caso quando se emprega sais de alumínio ou ferro; baixo custo e simplicidade do método.

Renou et al. (2008b) afirmaram que o tratamento com cal age preferencialmente em compostos orgânicos de alto peso molecular, essencialmente ácido-húmicos contidos nos lixiviados estabilizados.

Segundo Renou et al. (2009), o tratamento de lixiviado por precipitação química com cal elimina a maioria das macromoléculas orgânicas nos primeiros momentos da reação. Eles citam que quase $91 \%$ da remoção total da matéria orgânica ocorre durante os primeiros 30 segundos e mais de $99 \%$ foram eliminados no final da mistura rápida (5 min).

Giordano (2003) afirma que a redução da concentração de matéria orgânica está relacionada à precipitação de sais orgânicos e, em menor proporção, à desestabilização de colóides. Este fato é corroborado por com Hong e Elimelech (1997), ao afirmarem que ao contrário dos cátions monovalentes, cátions divalentes interagem especificamente com a matéria orgânica e formam complexos de metais húmicos. Giordano (2003) cita ainda que nesses casos o que acontece é um aumento do peso molecular, que praticamente dobra e o novo composto perde a capacidade de dissolução pois os sítios ativos ficam ocupados pelo cátion divalente.

O presente trabalho objetivou otimizar o processo de coagulação /floculação/decantação de lixiviados de aterros sanitários urbanos com uso da ferramenta planejamento fatorial fracionado, seguido de um planejamento fatorial completo $2^{4}$.

\section{MATERIAIS E MÉTODO}

Para os ensaios de coagulação foi utilizado o lixiviado proveniente do aterro da Muribeca (Jaboatão dos Guararapes, PE). O aterro controlado da Muribeca, que até 2009 recebeu todo lixo das cidades de Recife e Jaboatão dos Guararapes possui uma área de 64 ha e localiza-se a $16 \mathrm{~km}$ da Cidade do Recife. Foi o maior aterro em operação na Região Metropolitana do Recife de 1985 até meados de 2009, estando atualmente fechado, teve seu processo de recuperação iniciado em 1994 com a construção de nove células revestidas por uma camada de solo impermeabilizante, sobre a qual é depositado e compactado o lixo (Braga et al., 2010).

A coleta do lixiviado foi realizada na caixa de vazão localizada entre a lagoa de decantação e lagoa anaeróbia da Estação de tratamento de Lixiviados da Muribeca. O lixiviado coletado em bombonas de polietileno, com capacidade de volume de 20 litros, e foi conservado sob refrigeração até a sua utilização.

Para as análises de caracterização do lixiviado foi seguida a metodologia Standard Methods for Examination of Water and Wastewater (APHA et al., 2012). Na Tabela 1 são apresentadas as referências dos métodos utilizados. Para medição de DBO e DQO foi utilizado um bloco digestor modelo FTC 90 da VELP.

O tratamento do lixiviado foi realizado, utilizando como coagulante hidróxido de cálcio diluído com água destilada em diversas concentrações, recebendo denominação de "leite de cal". 
MELLO, V. F. B.; ABREU, J. P. G.; FERREIRA, J. M.; JUCÁ, J. F. T.; MOTTA SOBRINHO, M. A. Variáveis no processo de coagulação /floculação/decantação de lixiviados de aterros sanitários urbanos. Ambi-Agua, Taubaté, v. 7, n. 2, p. 88-100, 2012. (http://dx.doi.org/10.4136/ambi-agua.861)

Tabela 1. Análises realizadas para caracterização do lixiviado.

\begin{tabular}{|c|c|c|}
\hline Parâmetro & Método & Observação \\
\hline pH & $\begin{array}{l}\text { Método eletrométrico - } \\
\text { SMEWW } 4500 \text { B }\end{array}$ & $\begin{array}{l}\text { Potenciômetro modelo DM } 22 \\
\text { (Digimed) }\end{array}$ \\
\hline $\begin{array}{l}\text { Condutividade } \\
(\mu \mathrm{S} / \mathrm{cm})\end{array}$ & $\begin{array}{l}\text { Condutância elétrica SMEWW } \\
2510 \text { B }\end{array}$ & $\begin{array}{l}\text { Condutivímetro modelo DM } \\
32 \text { (Digimed) }\end{array}$ \\
\hline Turbidez (NTU) & Nefelométrico SMEWW 2130 B & $\begin{array}{l}\text { Turbidímetro modelo } \\
\text { turbiquant } 1000 \text { IR (MERCK } \\
\text { KGa A). }\end{array}$ \\
\hline Sólidos Totais $(\mathrm{mg} / \mathrm{L})$ & & \\
\hline $\begin{array}{l}\text { Sólidos Suspensos } \\
\text { Totais (mg/L); } \\
\text { Sólidos Dissolvidos } \\
\text { Totais (mg/L); }\end{array}$ & $\begin{array}{l}\text { Gravimétrico } \\
\text { Adapatado do SMEWW } 2540 \text { - } \\
\text { B, } 2540 \text { C, } 2540 \text { D. }\end{array}$ & \\
\hline $\mathrm{DQO}(\mathrm{mg} \mathrm{O} / \mathrm{L})$ & $\begin{array}{l}\text { Titulométrico (Digestão } \\
\text { com K2Cr2O7) - SMEWW } \\
5220 \text { C }\end{array}$ & $\begin{array}{l}\text { Reator de DQO compacto, } \\
\text { banho seco para } 8 \text { tubos, } \\
\text { modelo ECO } 8 \text { thermoreactor, } \\
\text { (Velp scientifica) }\end{array}$ \\
\hline $\mathrm{DBO}\left(\mathrm{mg} \mathrm{O} \mathrm{O}_{2} / \mathrm{L}\right)$ & $\begin{array}{l}\text { Manométrico Adapatado do } \\
\text { SMEWW } 5210\end{array}$ & \\
\hline
\end{tabular}

As soluções de cal (leite de cal) foram preparadas dissolvendo 50, 125 e $200 \mathrm{~g}$ de cal em $1000 \mathrm{~mL}$ de água destilada $(\mathrm{C}=50 \mathrm{~g} / \mathrm{L}$ ou $5 \% ; 125 \mathrm{~g} / \mathrm{L}$ ou $12,5 \%$ e $200 \mathrm{~g} / \mathrm{L}$ ou $20 \%)$. Em seguida foram adicionados $50 \mathrm{~mL}$ do leite de cal em $450 \mathrm{~mL}$ do lixiviado, compreendendo um volume final de $500 \mathrm{~mL}$ no Jar Test. Tem-se para cada litro de lixiviado massas de 5,5; 13,75 e 22,22 g de cal/L de lixiviado para as concentrações de leite de cal de 50, 125 e $200 \mathrm{~g} / \mathrm{L}$ respectivamente.

O leite de cal utilizado foi preparado a partir da cal comercial $\left(\right.$ Qualical ${ }^{\circledR}$ ) que de acordo com LINS (2011), é a cal mais apropriada ao pré-tratamento dos lixiviados, pelo seu alto grau de pureza e um baixo custo (cerca de $\mathrm{R} \$ 0,40 / \mathrm{kg}$ ).

O hidróxido de cal utilizado foi analisado no NEG LABISE /UFPE (Núcleo de Análises Geoquímicas do curso de geologia da Univ. Federal de Pernambuco). As análises foram realizadas pulverizando-se a cal a partir de mortar de ágata, seguindo para estufa a $110{ }^{\circ} \mathrm{C}$ para eliminar umidade e posteriormente foi levada à mufla a $1000^{\circ} \mathrm{C} / 2 \mathrm{~h}$ para determinação da perda ao fogo. A amostra seca foi prensada numa prensa hidráulica à pressão de 25 toneladas, formando pastilhas. Para análise química foi utilizado um espectrofotômetro de fluorescência de raio X Rigaku modelo R1X 3000, equipado com tubo de Rh.

\subsection{Planejamentos Experimentais}

Para se avaliar a influencia das variáveis experimentais controláveis no processo de coagulação-floculação, foram definidas como variáveis de entrada para o primeiro planejamento o tempo e a velocidade de coagulação e de floculação, tempo de decantação e concentração do leite de cal sobre as variáveis dependentes turbidez e cor.

Devido ao grande número de fatores a ser analisados (6), tornou-se inviável, a utilização de um planejamento fatorial experimental completo, portanto uma das soluções para suprir esta limitação, foi construir e planejar experimentos utilizando-se a técnica de confundimento ou as técnicas de experimentos fatoriais fracionados $2^{\mathrm{n}-\mathrm{p}}$. 
Realizando-se um planejamento fatorial fracionado é possível analisar os efeitos sobre uma resposta de interesse, realizando-se apenas uma parte dos ensaios experimentais sem comprometer significativamente a precisão das conclusões decorrentes da análise de resultados. Simultaneamente, os custos e o tempo de duração dos ensaios são significativamente reduzidos (Calado e Montgomery, 2003). As variáveis selecionadas e seus respectivos níveis estão descritos na Tabela 2.

Tabela 2. Níveis das variáveis do planejamento fatorial experimental fracionário $2^{6}$.

\begin{tabular}{c|cccccc}
\hline $\begin{array}{c}\text { Variáveis/ } \\
\text { Níveis }\end{array}$ & $\begin{array}{c}\text { Tc } \\
(\mathbf{s e g})\end{array}$ & $\begin{array}{c}\text { Vc } \\
(\mathbf{r p m})\end{array}$ & $\begin{array}{c}\text { Tf } \\
(\mathbf{m i n})\end{array}$ & $\begin{array}{c}\text { Vf } \\
(\mathbf{r p m})\end{array}$ & $\begin{array}{c}\text { Leite de } \\
\text { Cal (g/L) }\end{array}$ & $\begin{array}{c}\text { Td } \\
(\mathbf{m i n})\end{array}$ \\
\hline-1 & 10 & 80 & 2 & 20 & 50 & 30 \\
0 & 30 & 95 & 4 & 40 & 125 & 60 \\
+1 & 50 & 110 & 6 & 60 & 200 & 120 \\
\hline
\end{tabular}

Nota: Tc: Tempo de coagulação; Vc: Velocidade de coagulação; Tf: tempo de floculação; Vf: velocidade de floculação; Td: tempo de decantação.

Baseado nos resultados obtidos no primeiro planejamento procedeu-se a otimização do processo de coagulação/floculação/decantação empregando-se na segunda etapa a metodologia experimental fatorial completo $2^{\mathrm{k}}$. Neste caso foram utilizadas apenas as quatro variáveis selecionadas. e as quais foram positivamente significantes no primeiro estudo.

Os valores das variáveis nos três níveis foram mantidos e para as demais foram tomados os valores máximos.

Os ensaios de otimização da dosagem de leite de cal foram realizados em Jar Test modelo JT- 203 (Figura 1). Foram utilizados, no equipamento, seis béqueres com capacidade de um litro, como reatores.

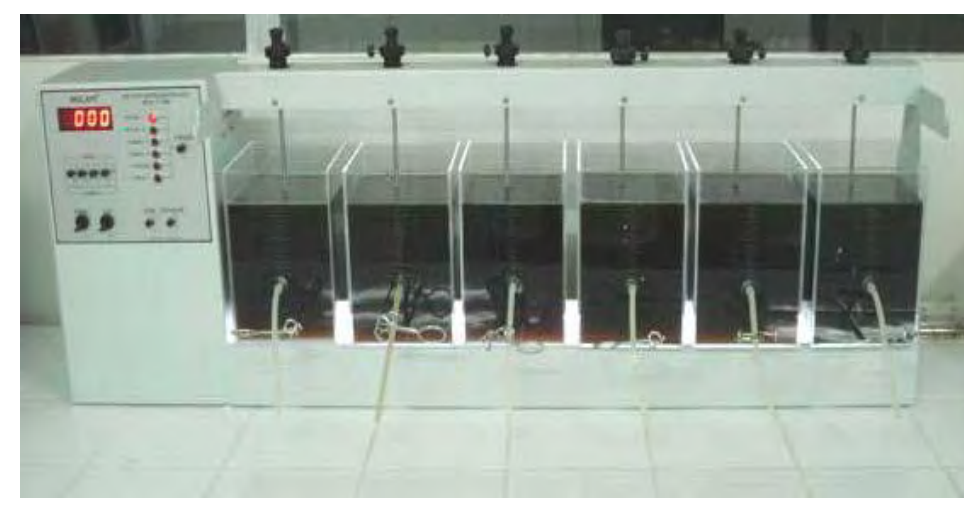

Figura 1. Equipamento Jar Test utilizado nos ensaios de otimização para precipitação química.

O objetivo da utilização do Jar Test nos ensaios foi simular, em escala de laboratório, as condições físicas de precipitação química que mais se aproxime da realidade. Em cada béquer (reator) foi adicionado lixiviado numa escala de 1:10 em relação ao leite de cal, ou seja utilizou-se $450 \mathrm{~mL}$ de lixiviado para $50 \mathrm{~mL}$ de leite de cal.

Decorridos os tempos de coagulação e floculação de cada ensaio, as amostras foram postas em repouso para decantação pelo tempo determinado no planejamento experimental. Os dados foram analisados no software Statistica versão 6.0. 
A turbidez foi determinada na unidade NTU utilizando para isso, turbidímetro Turbiquant 1000 IR da Merk. A determinação da cor foi realizada utilizando-se o colorímetro MERK spectroquant modelo Nova 60.

\section{RESULTADOS E DISCUSSÃO}

Do lixiviado utilizado, coletado na entrada da Estação de Tratamento de Chorume (ETC) do aterro controlado da Muribeca no dia 20 de setembro de 2010, foi analisado diversos parâmetros, a fim de caracterizar a sua composição. Os resultados obtidos podem ser observados na Tabela 3.

Tabela 3. Caracterização do lixiviado utilizado nos ensaios.

\begin{tabular}{|c|c|c|c|}
\hline Parâmetros & $\begin{array}{c}\text { Setembro } \\
2010 \\
\end{array}$ & Parâmetros & $\begin{array}{c}\text { Setembro } \\
2010 \\
\end{array}$ \\
\hline $\mathrm{DBO}(\mathrm{mg} / \mathrm{L})$ & 1510 & Cor (Hazen)* & 5505 \\
\hline $\mathrm{DQO}(\mathrm{mg} / \mathrm{L})^{*}$ & 2822 & Cloretos $(\mathrm{mg} / \mathrm{L})$ & 670 \\
\hline DBO/DQO (mg/L) & 0,410 & Sulfetos (mg/L) & 0,200 \\
\hline Sólidos Totais $(\mathrm{ST})(\mathrm{mg} / \mathrm{L})^{*}$ & 8784 & Fósforo Total (mg/L) & 10,75 \\
\hline Sólidos Totais Voláteis (STV) $(\mathrm{mg} / \mathrm{L})^{*}$ & 2070 & Turbidez (NTU)* & 33,07 \\
\hline $\mathrm{STV} / \mathrm{ST}(\mathrm{mg} / \mathrm{L})^{*}$ & 0,235 & Alcalinidade Total $\left(\mathrm{mg} / \mathrm{L} \mathrm{CaCO}_{3}\right)^{*}$ & 8558 \\
\hline Sólidos Dissolvidos Totais (STD) (mg/L) * & 8116 & Condutividade $(\mathrm{mS} / \mathrm{cm})$ & 22,63 \\
\hline Sólidos Dissolvidos Voláteis (SDV) $(\mathrm{mg} / \mathrm{L})^{*}$ & 1608 & Nitrogênio Amoniacal (MG/L)* & 2365 \\
\hline SDV/SDT $(\mathrm{mg} / \mathrm{L})^{*}$ & 0,198 & Ferro $(\mathrm{mg} / \mathrm{L})$ & 7,320 \\
\hline Sólidos Suspensos Totais (SST) (mg/L)* & 668 & Manganês (mg/L) & 3,575 \\
\hline Sólidos Suspensos Voláteis (SSV) (mg/L)* & 462 & Cromo (mg/L) & 0,575 \\
\hline SSV/SST (mg/L)* & 0,692 & Zinco (mg/L) & 4,625 \\
\hline $\mathrm{pH}^{*}$ & 8,340 & & \\
\hline
\end{tabular}

*valores médios das medições realizadas em duplicata.

Como pode ser observado pela Tabela 3, o lixiviado apresenta uma característica de baixa DQO, e boa degradabilidade (relação DBO/DQO de 0,4). Em relação aos sólidos verifica-se, pela relação STV/ST que cerca de $76 \%$ são de origem inorgânica (Sólidos fixos). Ele apresenta uma elevado concentração de nitrogênio amoniacal e um pH ligeiramente alcalino. Dentre os metais consta-se alta concentração de ferro e magnésio oriundo, possivelmente, do solo que tem alta concentração destes metais.

Após a caracterização do lixiviado, foi realizada análise da cal utilizada na pesquisa. A Tabela 4 apresenta os resultados de sua caracterização.

A NBR 6473 (2003) especifica que a cal hidratada deve conter um mínimo de $67 \%$ de $\mathrm{CaO}$ e no máximo $3 \%$ de $\mathrm{MgO}$, estando portanto a cal fornecida pela Qualical dentro dos padrões estabelecidos pela norma. As analises demonstraram que esta cal apresenta teor de impurezas de aproximadamente $0,66 \%$.

Tabela 4. Caracterização da cal utilizada na pesquisa.

\begin{tabular}{c|c|c|c}
\hline Parâmetro & \% & Parâmetro & \% \\
\hline $\mathrm{CaO}$ & 75,02 & $\mathrm{Al}_{2} \mathrm{O}_{3}$ & 0,05 \\
$\mathrm{~K}_{2} \mathrm{O}$ & 0,05 & $\mathrm{SrO}$ & 0,34 \\
$\mathrm{SiO}_{2}$ & 0,23 & $\mathrm{MnO}$ & 0,02 \\
$\mathrm{P}_{2} \mathrm{O}_{5}$ & 0,2 & $\mathrm{PF}$ & 23,91 \\
$\mathrm{Fe}_{2} \mathrm{Or}$ & 0,18 & Total & 100,00 \\
\hline
\end{tabular}

Fonte: Lins (2011). 


\subsection{Planejamento experimental fracionário}

Para a análise estatística dos resultados obtidos nesse trabalho considerando-se um nível de significância $(\alpha)$ igual a 5\%, sendo, portanto, a confiabilidade dos resultados de $95 \%$.

A partir da análise estatística foi inicialmente plotado o gráfico de Pareto (Figura 2) para as variáveis de resposta turdibez e cor. Quase todas as variáveis isoladas apresentaram influencia estatisticamente significativa, ao nível de $95 \%$ de confiança, de valores significativos no processo, conforme pode ser observada na Figura 2 para os parâmetros que se localizam à direita da linha tracejada $(\mathrm{p}=0,05)$. A única exceção foi a concentração de cal para resposta turbidez (Figura 2A).

Para resposta cor (Figura $2 \mathrm{~B}$ ), a interação entre os fatores tempo de coagulação $\left(\mathrm{T}_{\mathrm{c}}\right)$, e velocidade de floculação $\left(\mathrm{V}_{\mathrm{f}}\right)$, representado no gráfico de Pareto como 1 by 4 , foi o que apresentou maior efeito significativo seguido da concentração de cal $\left(\mathrm{C}_{\text {cal }}\right)$, que foi a segunda mais representativa, enquanto que a velocidade de coagulação não apresentou efeito significativo para esta resposta e dentro dos níveis estudados.
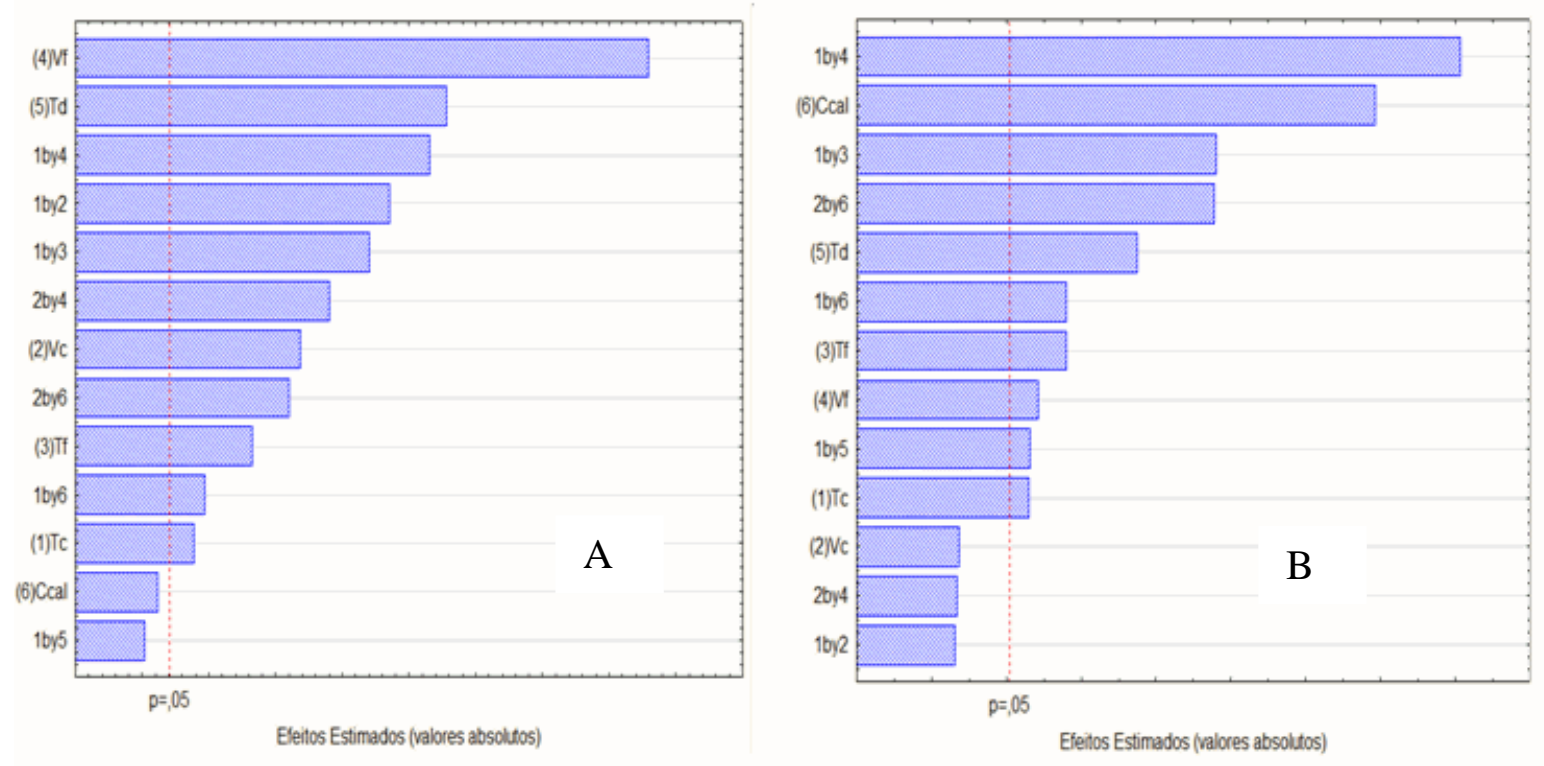

Figura 2. Avaliação da significância dos efeitos das variáveis independentes estudadas no processo de otimização do planejamento fracionado por meio do gráfico de Pareto para a turbidez (A) e cor (B). Em que: tempo de coagulação -Tc (1); velocidade de coagulação- Vc (2); tempo de floculação -Tf (3); velocidade de floculação - Vf (4); tempo de decantação -Td (5) e concentração de cal Ccal (6).

Após realizar uma triagem dos fatores com efeito significativo, foram construídas as superfícies de resposta. Os níveis dos fatores escolhidos foram ajustados, baseados nos experimentos do planejamento fracionado descritos acima. As informações obtidas após a construção de superfícies de resposta também foram utilizadas na interpretação dos resultados.

Ao se analisar as superfícies de resposta, representadas pela Figura 3, é possível observar graficamente as interações das variáveis $\mathrm{C}_{\mathrm{cal}}$ e $\mathrm{V}_{\mathrm{c}}$ sobre a turbidez e a cor.

A região de menor valor de cor foi alcançada para níveis superiores da variável independente $\mathrm{C}_{\text {cal }}$ e com pouca significância da velocidade de coagulação. No caso da turbidez houve discreta influência para menores valores de $C_{c a l}$ e valores maiores de $V_{c}$. Portanto, utilizou-se $\mathrm{C}_{\text {cal }} 200 \mathrm{~g} / \mathrm{L} \mathrm{e} \mathrm{V}_{\mathrm{c}} 110 \mathrm{rpm}$. 

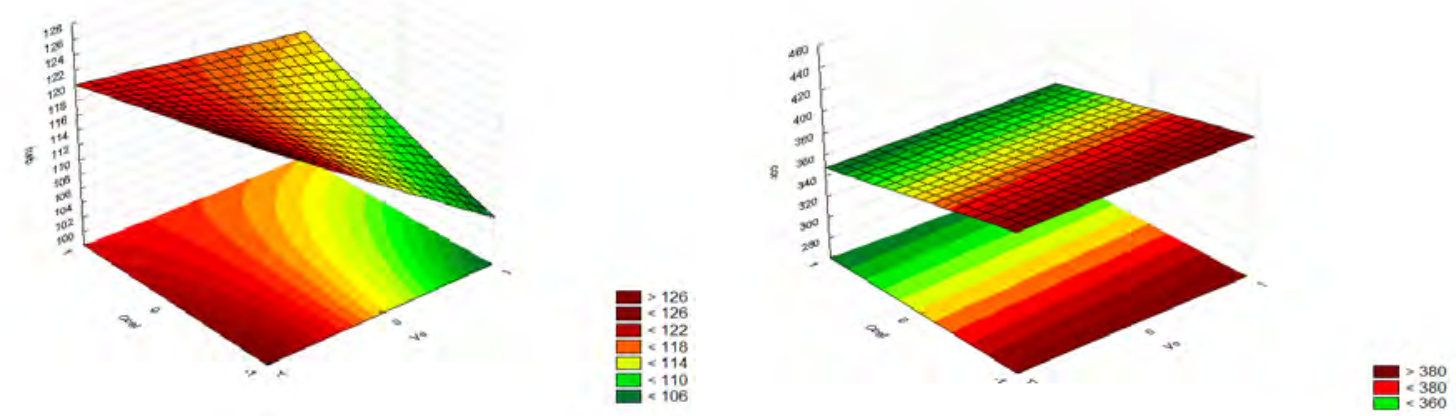

Figura 3. Efeito do leite de cal e da velocidade de floculação sobre a turbidez (A) e sobre a cor $(\mathrm{x} 10)(\mathrm{B})$.

Com base no planejamento fatorial fracionado foi possível identificar a velocidade de floculação e os tempos de decantação, coagulação e floculação como as variáveis mais importantes do modelo, nos níveis estudados, de modo a reduzir o espaço de busca da etapa de otimização.

\subsection{Planejamento experimental fatorial $2^{4}$}

Considerando as informações da análise estatística realizada na primeira etapa (planejamento fracionado), identificou-se 4 das 6 variáveis de entrada que tiveram um nítido efeito sobre as variáveis respostas, portanto um novo experimento foi planejado. Nessa fase foi utilizada a técnica de planejamento fatorial completo $2^{4}$ acrescido de 3 pontos centrais.

Com os resultados obtidos nesta segunda etapa foi plotado um novo gráfico de Pareto (Figura 4) para as variáveis respostas turbidez e cor. Analisando-se esta figura, verificou-se que a variável velocidade de floculação (Vf) foi o fator que apresentou maior importância significativa sobre as respostas turbidez (Figura 4A) e cor (Figura 4B) . O valor negativo do seu coeficiente (teste t-student) significou que menores faixas de turbidez e remoção de cor foram encontradas para valores elevados de velocidade de floculação.
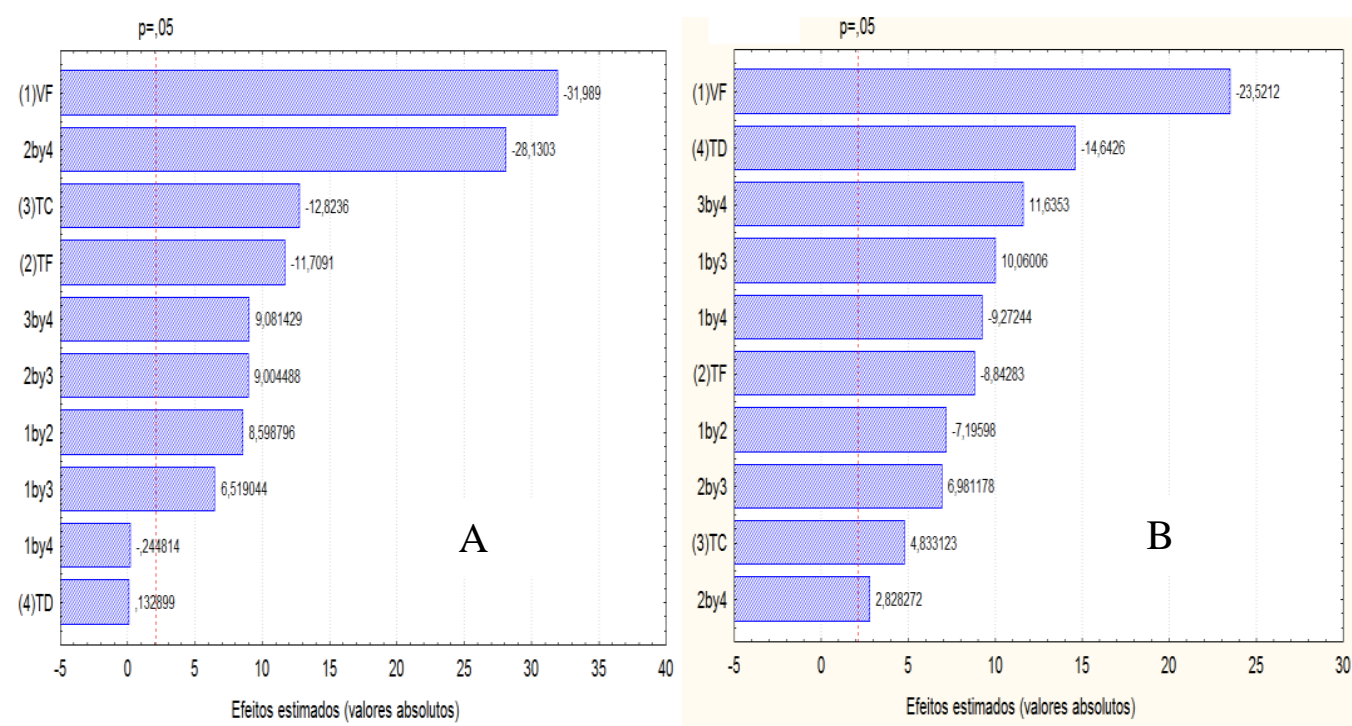

Figura 4. Avaliação da significância dos efeitos das variáveis independentes estudadas no processo de otimização do planejamento fatorial 24 por meio do gráfico de Pareto para a turbidez (A) e cor (B). Em que: velocidade de floculação - Vf (1); tempo de floculação -Tf (2); tempo de coagulação -Tc (3) e tempo de decantação $\operatorname{Td}(4)$. 
Observa-se também pela Figura 4B que os efeitos principais de todas variáveis independentes e as interações entre elas apresentaram efeitos estatisticamente significativos tendo como resposta a variável cor.

Observou-se influência estatisticamente significativa ao nível de 95\% de confiança da variável velocidade de floculação, tempo de coagulação e tempo de floculação, bem como a interação entre as variáveis tempo de floculação e tempo de decantação, sendo os efeitos mais representativos para a resposta turbidez.

Observando-se a Figura 5 (superfícies de resposta) pode-se verificar que os menores valores de turbidez e de cor são obtidos com velocidades de floculação no nível superior, todavia para a remoção de cor um tempo maior favorece, o que não ocorre para a remoção de turbidez. Este fato pode ser ocasionado pela desagregação do floco, decorrente de um tempo maior de agitação e crescimento.

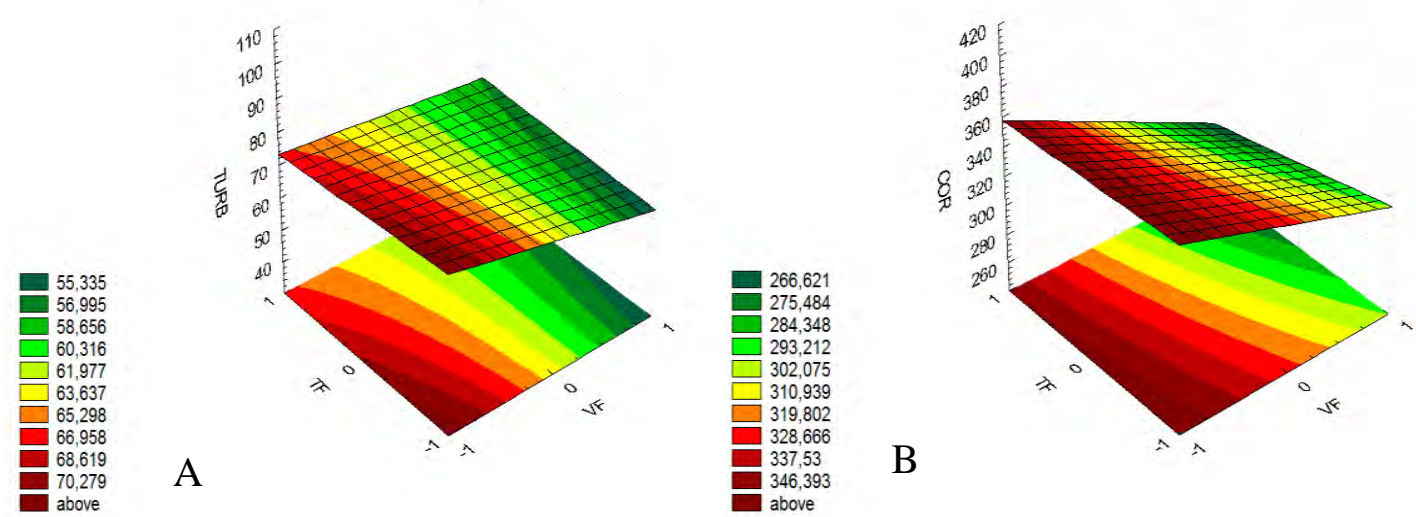

Figura 5. Efeito do tempo (TF) e da velocidade (VF) de floculação sobre a turbidez (A) e sobre a cor (x10) (B).

A partir das superfícies de resposta apresentadas na Figura 6, constatou-se que a diminuição do tempo de coagulação favoreceu de forma mais intensa a remoção de cor que a remoção da turbidez, este fato pode ser devido ao tempo do nível inferior já ser suficiente para a dispersão do coagulante.

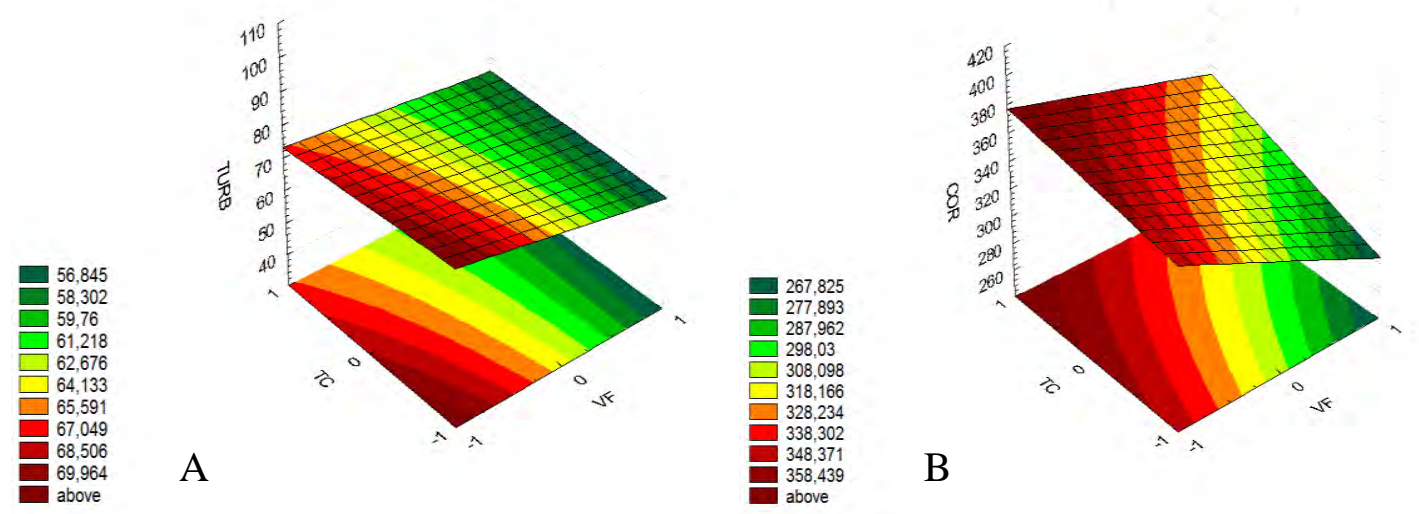

Figura 6. Efeito do tempo de coagulação (TC) e da velocidade de floculação (VF) sobre a turbidez (A) e sobre a cor (x10) (B).

Fazendo uso do planejamento fatorial para o tempo de floculação de 6 minutos e solução mãe de leite cal de concentração $200 \mathrm{~g} / \mathrm{L}$, obteve-se remoção de cor do lixiviado de mediana biodegradabilidade de $5.505 \mathrm{~Hz}$ para 2.660 , significando aproximadamente $52 \%$ de redução, resultados superiores ao de Lins (2011) que utilizando um tempo de floculação semelhante 
(5 min.) e um leite de cal à uma concentração de $150 \mathrm{~g} / \mathrm{L}$, conseguiu reduzir a cor de 6.410 para 5.370, significando cerca de $16 \%$ de remoção para o chorume de mediana biodegradabilidade.

Santana-Silva (2008), utilizando a cal hidratada sólida numa concentração de $35 \mathrm{~g} / \mathrm{L}$ dissolvida diretamente no lixiviado, obteve redução de 8435 para $2970 \mathrm{~Hz}$, significando cerca de $64 \%$ de remoção de cor.

Para turbidez, partiu-se de um valor de 33,10 NTU para 28 NTU demonstrando uma redução em torno de $9 \%$ estando dentro dos padrões estabelecidos na resolução CONAMA 357/2005 (Brasil, 2005), enquanto Lins (2011) conseguiu reduzir com tempo de floculação de 5 minutos de 172,3 para 103,4 aproximadamente $40 \%$ de remoção.

A Figura 7 mostra o lixiviado bruto (B) no centro da figura, o lixiviado após a coagulação/floculação com leite de cal $50 \mathrm{~g} / \mathrm{L}$ (A) e o lixiviado tratado com $200 \mathrm{~g} / \mathrm{L}$ (C) a $10 \%$ em volume.

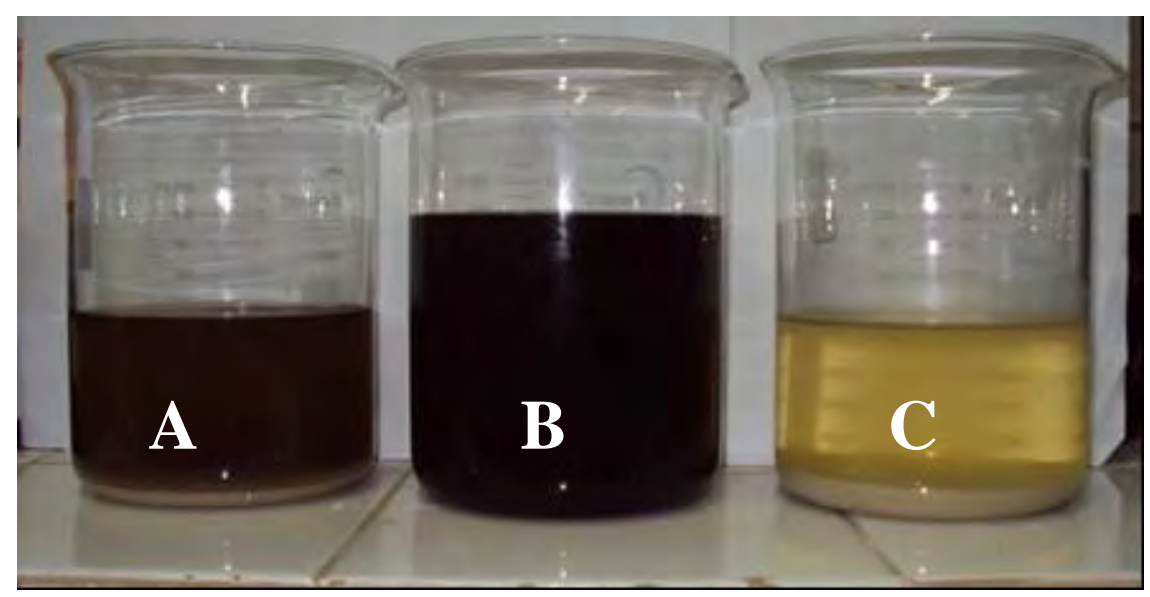

Figura 7. Foto do lixiviado bruto (B) e após tratamento com 5,55 g de cal por litro (lixiviado A) e 22,22 g de cal por litro (lixiviado C).

\section{CONCLUSÃO}

Empregando-se a técnica de planejamento experimental para tratamento de lixiviado por coagulação/floculação/decantação foi possível determinar as condições ótimas de tempo de coagulação, de floculação e de decantação, assim como velocidade de floculação e de coagulação e quantidade de leite de cal.

Constatou-se que as variáveis que exerceram maior influência significativa, dentro da faixa estudada, foram o tempo de coagulação, tempo de floculação, velocidade de floculação e tempo de decantação. A partir do planejamento fatorial completo $2^{4}$, percebeu-se que com valores superiores estudados da velocidade de floculação e valores inferiores para o tempo de coagulação é possível obter um bom nível de redução da turbidez e da cor. Estes fatos acarretam economia de energia e redução do TDH.

\section{AGRADECIMENTOS}

Agradecemos à CAPES e ao CNPq pelas bolsas concedidas e à FINEP (PROSAB 5) pelo suporte financeiro. 


\section{REFERENCIAS}

ALEGRIA, M. Déficit na destinação final de resíduos sólidos no Brasil: um dos desafios que preocupa os especialistas. Revista Meio Ambiente, 10 out. 2010. Disponível em: <http://www.revistameioambiente.com.br/2010/10/10/>. Acesso em: 13 abril 2012.

AMOKRANE, A.; COMEL, C.; VERON, J. Landfill leachates pretreatment by coagulationflocculation. Water Research, v. 31, n. 11, p. 2775-2782, 1997. http://dx.doi.org/10.1016/S0043-1354(97)00147-4

AMERICAN PUBLIC HEALTH ASSOCIATION -APHA; AMERICAN WATER WORKS ASSOCIATION - AWWA; WATER ENVIRONMENT FEDERATION - WEF. Standard methods for the examination of water and wastewater. 22. ed. Washington, DC, 2012. 1472p.

BIDONE, R. F. Tratamento de lixiviado de aterro sanitário por um sistema composto por filtros anaeróbios seguidos de banhados construídos: estudo de caso - Central de Resíduos do Recreio, em Minas do Leão/RS. 2007. 156f. Dissertação (Mestrado em Hidráulica e Saneamento) - Escola de Engenharia de São Carlos, Universidade de São Paulo, São Carlos, 2007.

BILA, D. M. Aplicação de processos combinados no tratamento de chorume. 2000. $108 \mathrm{f}$. Dissertação (Mestrado em Engenharia Química) - Programa de Engenharia Química, Universidade Federal do Rio de Janeiro, Rio de Janeiro, 2000.

BRAGA, B.; HESPANHOL, I.; CONEJO, J. G. L.; MIERZWA, J. C. Introdução à engenharia ambiental. São Paulo: Pearson Education do Brasil, 2010. 310 p.

BRASIL. Conselho Nacional do Meio Ambiente. Resolução no 357, de 17 de março de 2005. Disponível em: <www.mma.gov.br/port/conama/res/res05/res35705.pdf>. Acesso em: 14 mar. 2012.

BRASIL. Conselho Nacional do Meio Ambiente. Resolução n 430, de 13 de maio de 2011. Disponível em: <http://www.mma.gov.br/port/conama/res/res11/res43011.pdf>. Acesso em: 14 mar. 2012.

CALADO, V.; MONTGOMERY, D. C. Planejamento de experimentos usando o Statistica. Rio de Janeiro: E-papers, 2003. 260p.

GIORDANO, G. Análise e formulação de processos para tratamento dos chorumes gerados em aterros de resíduos sólidos urbanos. 2003. 257f. Tese (Doutorado) Departamento de Ciência dos Materiais e Metalurgia, Pontifícia Universidade Católica do Rio de Janeiro, Rio de Janeiro, 2003.

GOMES, L. P. (Org.). Tratamento, disposição e reciclagem de resíduos sólidos, com ênfase no tratamento do lixiviado e tendo em vista a proteção dos corpos d'água. Rio de Janeiro: PROSAB 5;FINEP;ABES, 2009. 362p.

HO, S.; BOYLE, C. W.; HAM, R. K. Chemical treatment of leachates from sanitary landfills. Water Pollution Control Federation, v. 46, n. 7, p. 1776-1791, 1974. Disponível em: <http://www.jstor.org/stable/25038828>. Acesso em: 17 ago. 2012.

HONG, S.; ELIMELECH, M. Chemical and physical aspects of natural organic matter (NOM) fouling of nanofiltration membranes. Journal of Membrane Science, v. 132, n. 2, p. 159-181, 1997. http://dx.doi.org/10.1016/S0376-7388(97)00060-4 
KEENAN, J. D.; STEINER, R. L.; FUNGAROLI, A. A. Chemical-physical leachate treatment. Journal of Environmental Engineering, v. 109, n. 6, p. 1371-1384, 1983. http://dx.doi.org/10.1061/(ASCE)0733-9372(1983)109:6(1371)

KURNIAWAN, T. A.; LO, W.; CHAN, G. Y. Physico-chemical treatments for removal of recalcitrant contaminants from landfill leachate. Journal of Hazardous Materials, v. 129, n. 1/3, p. 80-100. 2006. http://dx.doi.org/10.1016/j.jhazmat.2005.08.010

LINS, E. A. M. Proposição e avaliação de um sistema experimental de processos físicos e químicos para tratamento de lixiviado. 2011. 277f. Tese (Doutorado) - Programa de Pós-graduação em Engenharia Civil, Universidade Federal de Pernambuco, Recife, 2011.

MELLO, V. F. B. Otimização do tratamento de lixiviados e corantes por processos físicoquímicos. 2011. 106f. Dissertação (Mestrado) - Programa de Pós-graduação em Engenharia Civil, Universidade Federal de Pernambuco, Recife, 2011.

MORAIS, J. L. Estudo da potencialidade de processos oxidativos avançados isolados e integrados com processos biológicos tradicionais para tratamento de chorume de aterro sanitário. 2005. 207f. Tese (Doutorado) - Universidade Federal do Paraná, Curitiba, 2005.

MILLOT, N. Les Lixiviats de décharges contrôlées: caractérisation analytique - dtude es filiéres de traitement. 1986. 188f. Tese (Doutorado) - Instituto Nacional de Ciências Aplicadas de Lyon, Lyon, 1986.

RENOU, S.; GIVAUDAN, J. G; POULAIN, S.; DIRASSOUYAN, F.; MOULIN, P. Landfill leachate treatment: review and opportunity. Journal of Hazardous Materials, v. 150, n. 3, p. 468-493, 2008a. http://dx.doi.org/10.1016/j.jhazmat.2007.09.077

RENOU, S.; POULAIN, S.; GIVAUDAN, J. G.; MOULIN, P. Treatment process adapted to stabilized leachates: lime precipitation - prefiltration - reverse osmosis. Journal of Membrane Science, v. 313, n. 1/2, p. 9-22, 2008b. http://dx.doi.org/10.1016/j.memsci. 2007.11.023

RENOU, S.; POUlAIN, S.; GIVAUDAN, J. G.; SAHUT, C.; MOULIN, P. Lime treatment of stabilized leachates. Water Science \& Technology, v. 59, n. 4, p. 673 - 685, 2009. http://dx.doi.org/10.2166/wst.2009.014

SANTANA-SILVA, F. M. Avaliação do método de precipitação química aassociado ao stripping de amônia no tratamento do lixiviado do aterro de Muribeca-PE. 2008. 117f. Dissertação (Mestrado) - Programa de Pós-graduação em Engenharia Civil, Universidade Federal de Pernambuco, Recife, 2008

SILVA, M. P. Avaliação da tratabilidade do lixiviado de aterro industrial por processo de biorreator à membrana (MBR). 2011. 157f. Dissertação (Mestrado) - Programa de Pós-graduação em Engenharia de Recursos Hídricos e Ambiental, Universidade Federal do Paraná, Curitiba, 2011.

SLATER, C. S.; AHLERT, R. C.; UCHRIN C. G. Treatment of landfill leachates by reverse osmosis. Environmental Progress, v. 2, n. 4, p. 251-256, 1983. http://dx.doi.org/ 10.1002/ep.670020411

THORNTON, R. J.; BLANC, F. C. Leachate treatment by coagulation and precipitation. Journal of Environmental Engineering Division, v. 99, n. 4, p. 535-544, 1973. 
MELlO, V. F. B.; ABREU, J. P. G.; FERREIRA, J. M.; JUCÁ, J. F. T.; MOTTA SOBRINHO, M. A. Variáveis no processo de coagulação /floculação/decantação de lixiviados de aterros sanitários urbanos. Ambi-Agua, Taubaté, v. 7, n. 2, p. 88-100, 2012. (http://dx.doi.org/10.4136/ambi-agua.861)

TREBOUET, D.; SCHLUMPF, J. P.; JAOUEN, P.; QUÉMENÉOUR, F. Stabilized landfill leachate treatment by combined physic-chemical-nanofiltration process. Water Research, v. 35, n. 12, p. 2935-2942, 2001. http://dx.doi.org/10.1016/S00431354(01)00005-7 


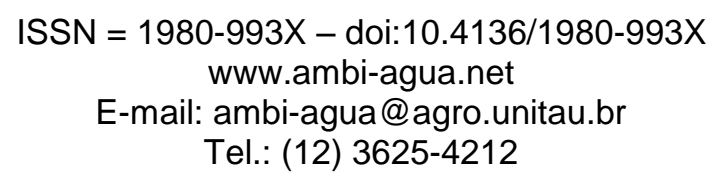

\title{
Influência da temperatura na remoção de fosfato por microalgas em biorreatores heterotróficos
}

\author{
(http://dx.doi.org/10.4136/ambi-agua.856)
}

\author{
Juliana Guerra Vieira ${ }^{1}$; Eduardo Jacob-Lopes ${ }^{2}$; Adriana Gonçalves da Silva Manetti ${ }^{1}$; \\ Maria Isabel Queiroz ${ }^{1}$ \\ ${ }^{1}$ Escola de Química e Alimentos, Universidade Federal do Rio Grande (FURG), \\ Rio Grande, RS, Brasil, \\ e-mails: juguerravieira@uol.com.br, didialimentos@yahoo.com.br; mariaisabel.queiroz@mailcity.com, \\ ${ }^{2}$ Departamento de Tecnologia e Ciência de Alimentos, \\ Universidade Federal de Santa Maria (UFSM), Santa Maria, RS, Brasil, \\ e-mail: jacoblopes@pq.cnpq.br
}

\section{RESUMO}

Neste trabalho, a eficiência da cianobactéria Aphanothece microscopica Nägeli em remover heterotroficamente fosfato total dissolvido do efluente do processamento de laticínios foi avaliada. Os experimentos foram conduzidos em biorreatores operados descontinuamente, alimentados com 4,5 L de efluente. As condições experimentais foram: concentração celular inicial de $0,2 \mathrm{~g} / \mathrm{L}, \mathrm{pH}$ ajustado a 7,6, reator isotérmico operando em temperaturas de 10,20 e $30^{\circ} \mathrm{C}$, ausência de luminosidade e aeração contínua de 1 VVM. Os resultados mostraram que a remoção de fosfato é fortemente dependente da temperatura do processo. A cianobactéria A. microscopica Nägeli foi efetiva na remoção de fosfato, alcançando taxas de remoção de $3,77 \mathrm{mg} / \mathrm{L} . \mathrm{h}$, que refletiram em conversões de $98,4 \% \mathrm{em}$ tempos de detenção hidráulica de $24 \mathrm{~h}$.

Palavras-chave: microalgas, biorreator heterotrófico, fosfato, efluente de laticínios.

\section{Influence of temperature in phosphate removal by microalgae in heterotrophic bioreactors}

\begin{abstract}
The removal of total dissolved phosphate by the cyanobacteria Aphanothece microscopica Nägeli cultivated heterotrophically in dairy processing wastewater was investigated in this work. The experiments were carried out in bioreactors operating in a batch mode, fed with $4.5 \mathrm{~L}$ of wastewater. The experimental conditions were as follows: initial cell concentration of $0.2 \mathrm{~g} / \mathrm{L}, \mathrm{pH}$ adjusted to 7.6, isothermal reactor operating at temperatures of 10,20 and $30^{\circ} \mathrm{C}$ with absence of light and continuous aeration of $1 \mathrm{VVM}$. The results showed that phosphate removal is strongly dependent on process temperature. $A$. microscopica Nägeli was effective in the removal phosphate achieving removal rates of $3.77 \mathrm{mg} / \mathrm{L} . \mathrm{h}$, which reflected in the conversion of $98.4 \%$ in hydraulic detention times of $24 \mathrm{~h}$.
\end{abstract}

Keywords: microalgae, heterotrophic bioreactor, phosphate, dairy processing wastewater. 
VIEIRA, J. G.; JACOB-LOPES, E.; MANETTI, A. G. S.; QUEIROZ, M. I. Influência da temperatura na remoção de fosfato por microalgas em biorreatores heterotróficos. Ambi-Agua, Taubaté, v. 7, n. 2, p. 101-109, 2012. (http://dx.doi.org/10.4136/ambi-agua.856)

\section{INTRODUÇÃO}

O desenvolvimento de células de microalgas em zonas afóticas, associado à manutenção destas estruturas celulares nos períodos de escuro, durante o fotoperíodo diário, indica a possibilidade de utilizar tecnologicamente rotas metabólicas heterotróficas para o cultivo microalgal (Perez-Garcia et al., 2011).

Todos os micro-organismos, incluindo as microalgas utilizam o mesmo metabolismo respiratório. Com algumas pequenas diferenças, as microalgas possuem grande similaridade deste metabolismo quando comparado às plantas superiores. É impossível, no entanto, especificar substratos específicos que podem ser preferencialmente utilizados por uma espécie particular de microalga (Smith, 1982).

Durante a respiração, ao contrário da fotossíntese, oxigênio é consumido, com paralela produção de $\mathrm{CO}_{2}$, sendo que a taxa respiratória dos substratos orgânicos está intimamente orientada para o crescimento e divisões celulares. $\mathrm{O}$ metabolismo respiratório em microalgas desempenha duas funções principais: serve como fonte exclusiva de energia para manutenção e biossíntese e fornece os blocos construtores de carbono para a biossíntese (Geider e Osborne, 1989; Jacob-Lopes et al., 2010).

O desenvolvimento do cultivo em completo escuro elimina diversas desvantagens dos biorreatores fotossintéticos, principalmente no que se refere ao aporte de energia luminosa, possibilitando o uso de reatores convencionais como os reatores agitados mecanicamente e coluna de bolhas (Queiroz et al., 2011).

Nestas condições as fontes orgânicas exógenas de carbono podem ser obtidas através de águas residuárias industriais. Nesse caso específico é possível direcionar a conversão de poluentes como matéria orgânica, nitrogênio e fósforo em biomoléculas de valor agregado. Por outro lado, se considerarmos apenas as características de tratamento de resíduos industriais, a principal vantagem do uso de biorreatores heterotróficos com microalgas está relacionada com a conversão simultânea de matéria orgânica, nitrogênio e fósforo, em uma única etapa, reduzindo custos capitais e operacionais comumente associados às formas convencionais de tratamento (Queiroz et al., 2007).

A remoção de fosfato por microalgas é uma tecnologia em potencial para a mitigação deste poluente eutrofizante. Diversos sistemas têm sido desenvolvidos considerando o metabolismo fotossintético destes organismos em lagoas de alta taxa (Phang et al., 2000; Powell et al., 2006, 2008, 2009), além de outras configurações de fotobiorreatores (Gonzales et al., 1997; Singh e Thomas, 2012). Estudos restritos, no entanto, têm sido direcionados para elucidar o potencial do metabolismo heterotrófico de microalgas para esta finalidade (Devi et al., 2012).

O crescimento de microalgas heterotroficamente consome fósforo como um elemento essencial requerido na constituição celular de fosfolipídeos, nucleotídeos e ácidos nucléicos. Tipicamente as células destes organismos contem aproximandamente $1 \%$ de fósforo em base seca, embora em certas condições, haja evidências que as estes organismos sejam capazes de retirar do meio quantidades excedentes de fósforo para posterior utilização. Este fósforo extra é estocado na forma de fosfato para uso como recurso interno quando as condições externas de fósforo são limitantes (Miyachi et al., 1964).

Entre as inúmeras variáveis que controlam esse processo, a temperatura parece ser o maior limitante, já que é uma variável geográfica que afeta a taxa metabólica de todos os processos biológicos (Sakamoto et al., 1997). Adicionalmente, as taxas de remoção biológica de fósforo estão relacionadas com a taxa de difusão através da camada limite que circunda a célula e com a especiação iônica do fosfato, já que o fosfato total dissolvido é 
resultado do somatório das espécies reativas, ácido-hidrolisáveis e orgânicas (Cembella et al., 1983; Spivakov et al., 1999).

Em face disto, este trabalho investiga o efeito da temperatura na remoção de fosfato por microalgas em biorreatores heterotróficos. Embora já exista um entendimento destas dinâmicas em sistemas fotossintéticos, este trabalho vai auxiliar a definir estas transformações em sistemas no completo escuro.

\section{MATERIAIS E MÉTODO}

\subsection{Micro-organismo e condições de cultivo}

Uma monocultura de Aphanothece microscopica Nägeli (RSMan92), originalmente isolada da Lagoa dos Patos, no estado do Rio Grande do Sul, Brasil ( $\left.32^{\circ} 01^{\prime} \mathrm{S}-52^{\circ} 05^{\prime} \mathrm{W}\right)$ foi utilizada. As culturas foram propagadas e mantidas em meio sintético BGN (Rippka et al., 1979). As condições de manutenção usadas foram $25^{\circ} \mathrm{C}$, intensidade luminosa de $15 \mu$ mol.m $\mathrm{m}^{-2} . \mathrm{s}^{-1}$ e fotoperíodo de $12 \mathrm{~h}$.

\section{2. Água residuária}

O efluente do processamento de laticínios foi coletado no tanque de equalização do sistema de tratamento de efluente de uma indústria localizada em Pelotas, RS. As amostras foram coletadas por um período de 12 meses, e caracterizadas quando ao $\mathrm{pH}$, demanda química de oxigênio (DQO), nitrogênio total (NTK), ácidos voláteis totais (AVT), alcalinidade (ALC), óleos e graxas (OG), sólidos totais (ST), sólidos fixos (SF), sólidos suspensos (SS), sólidos voláteis (SV) e fósforo total $\left(\mathrm{PO}_{4}{ }^{-3}\right)$, segundo metodologia proposta por APHA (2005). As razões $\mathrm{C} / \mathrm{N}$ e N/P foram determinadas a partir das concentrações de DQO, NTK e $\mathrm{PO}_{4}{ }^{-3}$. Os resultados da caracterização do efluente são apresentados na Tabela 1.

Tabela 1. Caracterização do efluente de laticínios em um período de 12 meses.

\begin{tabular}{c|rrr|l}
\hline Parâmetro & Mínimo & Máximo & Média & CV (\%) \\
\hline $\mathrm{pH}$ & 7,1 & 9,6 & 9,1 & 10,5 \\
$\mathrm{DQO}$ & 400,0 & 780,0 & 566,3 & 25,5 \\
$\mathrm{NTK}$ & 3,0 & 55,1 & 30,6 & 54,2 \\
$\mathrm{NH}_{4}{ }^{+}$ & 3,1 & 10,5 & 7,0 & 38,2 \\
$\mathrm{PO}_{4}{ }^{-3}$ & 16,3 & 23,9 & 21,9 & 12,8 \\
$\mathrm{AVT}$ & 20,0 & 444,0 & 213,3 & 83,0 \\
$\mathrm{ALC}$ & 30,0 & 1550,0 & 656,6 & 105,5 \\
$\mathrm{OG}$ & 31,1 & 1609,0 & 431,0 & 138,6 \\
$\mathrm{ST}$ & 2155,0 & 3725,0 & 2608,0 & 23,1 \\
$\mathrm{SF}$ & 595,0 & 2402,5 & 1290,4 & 56,7 \\
$\mathrm{SV}$ & 565,0 & 2120,0 & 1317,9 & 46,4 \\
$\mathrm{SS}$ & 322,5 & 1115,0 & 691,6 & 47,1 \\
$\mathrm{C} / \mathrm{N}$ & 9,6 & 23,6 & 16,8 & 32,6 \\
$\mathrm{~N} / \mathrm{P}$ & 1,2 & 2,4 & 1,6 & 28,7 \\
\hline
\end{tabular}




\subsection{Biorreator}

$\mathrm{O}$ aparato experimental (Figura 1) foi constituído de um biorreator do tipo coluna de bolhas, construído em PVC de $4 \mathrm{~mm}$ de espessura, diâmetro interno de $10 \mathrm{~cm}$, altura de $100 \mathrm{~cm}$ e 4,5 L de volume de trabalho. O sistema de dispersão de gases do reator consistiu em um difusor de ar de $1,5 \mathrm{~cm}$ localizado no centro da base da coluna.

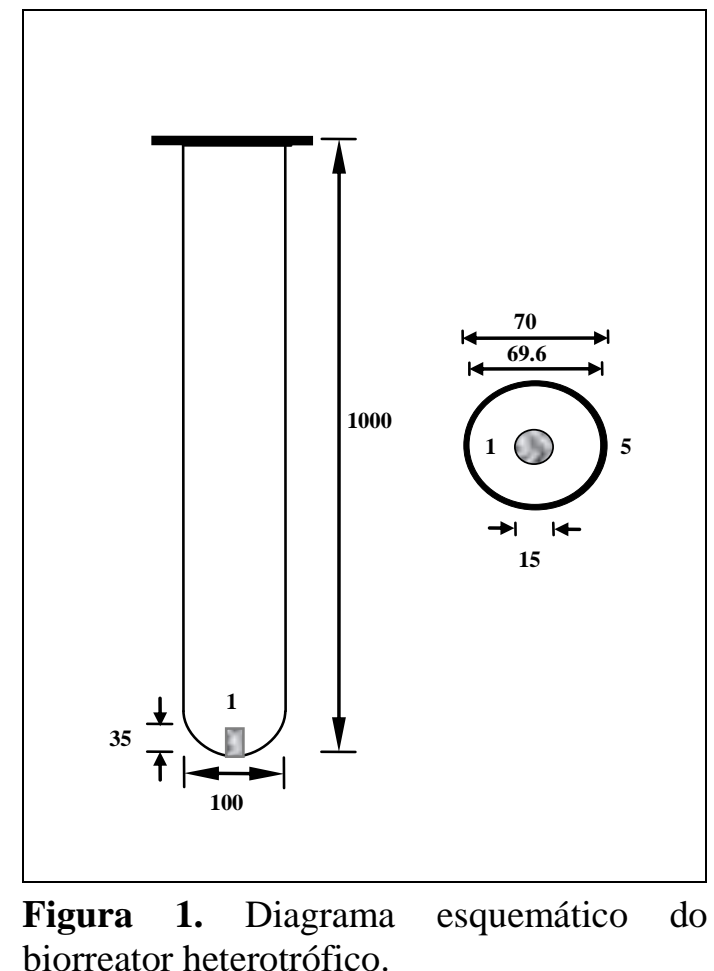

\subsection{Obtenção dos dados cinéticos}

Os experimentos foram conduzidos em um biorreator operando em batelada, alimentados com 4,5 L de efluente, $\mathrm{pH}$ ajustado a 7,6, 0,2 g/L de inóculo, temperaturas de 10,20 e $30^{\circ} \mathrm{C}$, ausência de luminosidade, e aeração contínua de 1VVM (volume de ar por volume de efluente por minuto). Os experimentos foram em triplicata e os dados cinéticos referem-se a uma média de 6 repetições.

\subsection{Parâmetros cinéticos}

Para cada temperatura avaliada um modelo cinético de ordem zero foi ajustado aos dados experimentais de fósforo total dissolvido (Equação 1).

$$
C=C_{0}-k . t
$$

em que:

$C_{0}$ é a concentração inicial de fosfato $(\mathrm{mg} / \mathrm{L}), C$ é a concentração final de fosfato $(\mathrm{mg} / \mathrm{L}), k$ é a constante da velocidade de reação $\left(\mathrm{h}^{-1}\right)$ e $t$ é o tempo de reação (h).

$\mathrm{O}$ efeito da temperatura sobre a constante da taxa de reação em relação a um padrão temperatura $(293 \mathrm{~K})$ pode ser expressa pela equação de Arrhenius modificada, conforme a Equação 2 (Sözen et al., 1996): 
VIEIRA, J. G.; JACOB-LOPES, E.; MANETTI, A. G. S.; QUEIROZ, M. I. Influência da temperatura na remoção de fosfato por microalgas em biorreatores heterotróficos. Ambi-Agua, Taubaté, v. 7, n. 2, p. 101-109, 2012. (http://dx.doi.org/10.4136/ambi-agua.856)

$$
r_{T}=r_{293} \times \theta^{(T-293)}
$$

em que:

o $r_{T}$ é a taxa de reação na temperatura $T=T(\mathrm{mg} / \mathrm{L} . \mathrm{h}), \mathrm{r}_{293}$ é a taxa de reação na temperatura de $293 \mathrm{~K}$ (mg/L.h), $\theta$ é o coeficiente de temperatura e $T$ é a temperatura da reação $(\mathrm{K})$.

A energia de ativação da reação foi determinada graficamente por meio do logaritmo natural da equação de Arrhenius, conforme indicado pela Equação 3:

$$
\ln _{r T}=\frac{-E_{\text {a }}}{R T}+\ln A
$$

em que:

$A$ é o fator de frequência para a reação, $R$ é a constante universal dos gases (kJ/mol.k), $T$ é a temperatura (K) e $E a$ é a energia de ativação $(\mathrm{kJ} / \mathrm{mol})$.

\subsection{Análise estatística}

Os dados cinéticos foram determinados mediante o auxílio de técnicas de estatística multivariada, expresso por análises de regressão. A diferenciação das condições testadas foi avaliada por análise de variância (ANOVA). Ambas as análises realizadas no software Statistica 7.0 (StatSoft Inc., 2004).

\section{RESULTADOS E DISCUSSÃO}

A temperatura é um dos mais importantes fatores para a seleção de condições operacionais de biorreações, já que os micro-organismos não possuem mecanismos para controlar sua temperatura interna. Desta forma, a temperatura interna da célula é determinada pela temperatura externa do ambiente (Tomaselli et al., 1988). A Tabela 2 apresenta as constantes cinéticas para o consumo de fosfato total em biorreatores heterotróficos por microalgas. Na faixa de temperatura avaliada, verificou-se que o consumo de fosfato está fortemente relacionado com a temperatura do biorreator, com máximas taxas de remoção na ordem de $3,77 \mathrm{mg} / \mathrm{L} . \mathrm{h}$ a $30^{\circ} \mathrm{C}$.

A aderência do modelo cinético de ordem zero aos dados experimentais, comprovada pelos elevados coeficientes de determinação, sugere que o consumo de fosfato por Aphanothece microscopica Nägeli em regime heterotrófico independe da concentração de fósforo no efluente. Em termos de eficiência de remoção, para um tempo de detenção hidráulica de 24h, observaram-se índices de 29,1, 89,1 e 98,4 \% para as temperaturas de 10, 20 e $30^{\circ} \mathrm{C}$, respectivamente. Comparativamente Gonzalez et al. (1997) reportaram máximas taxas de remoção de fosfato em efluente do processamento de laticínios de $0,30 \mathrm{mg} / \mathrm{L} . \mathrm{h}$ em biorreatores fotossintéticos de geometria cilíndrica com a microalga Chlorella vulgaris. Adicionalmente, Phang et al. (2000) verificaram máximas taxas de remoção de fosfato na ordem de $0,06 \mathrm{mg} / \mathrm{L} . \mathrm{h}$ em efluente de fecularia em lagoas de alta taxa com a cianobactéria Spirulina Platensis. Singh e Thomas (2012) obtiveram taxas de remoção de 0,03mg/L.h de fosfato de efluente doméstico em fotorreator de membranas com Chlorella vulgaris. Estes estudos consideraram exclusivamente rotas fotossintéticas para a remoção biológica de fosfato. Por outro lado, Devi et al. (2012) citam taxas de remoção de fosfato em efluente doméstico de 1,0 mg/L.h por um consórcio de microlgas em um biorreator heterotrófico. 
VIEIRA, J. G.; JACOB-LOPES, E.; MANETTI, A. G. S.; QUEIROZ, M. I. Influência da temperatura na remoção de fosfato por microalgas em biorreatores heterotróficos. Ambi-Agua, Taubaté, v. 7, n. 2, p. 101-109, 2012. (http://dx.doi.org/10.4136/ambi-agua.856)

Apesar da diversidade dos sistemas comparados, pode-se constatar que o uso de microalgas em biorreatores heterotróficos apresenta melhor desempenho na remoção biológica das diferentes formas de fósforo presente nas águas residuárias.

Tabela 2. Constantes cinéticas para consumo de fosfato em biorreatores heterotróficos.

\begin{tabular}{c|cccccc}
\hline $\begin{array}{c}\text { Temperatura } \\
\left({ }^{\mathbf{o}} \mathbf{C}\right)\end{array}$ & $\begin{array}{c}\mathbf{C}_{\mathbf{0}} \\
(\mathbf{m g} / \mathbf{L})\end{array}$ & $\begin{array}{c}\mathbf{C} \\
(\mathbf{m g} / \mathbf{L})\end{array}$ & $\mathbf{R}^{2}$ & $\begin{array}{c}\mathbf{k} \\
\left(\mathbf{h}^{-\mathbf{1}}\right)\end{array}$ & $\begin{array}{c}\mathbf{r} \\
(\mathbf{m g} / \mathbf{L} \cdot \mathbf{h})\end{array}$ & $\begin{array}{c}\mathbf{E R} \\
(\mathbf{\%})\end{array}$ \\
\hline 10 & $19,3 \pm 0,57$ & $13,7 \pm 0,41$ & $0,98 \pm 0,04$ & $1,09^{\mathrm{a}} \pm 0,05$ & $1,09^{\mathrm{a}} \pm 0,05$ & $29,1^{\mathrm{a}} \pm 1,45$ \\
20 & $20,5 \pm 0,51$ & $2,20 \pm 0,01$ & $0,96 \pm 0,02$ & $2,45^{\mathrm{b}} \pm 0,12$ & $2,45^{\mathrm{b}} \pm 0,12$ & $89,1^{\mathrm{b}} \pm 2,67$ \\
30 & $19,4 \pm 0,62$ & $0,31 \pm 0,01$ & $0,94 \pm 0,03$ & $3,77^{\mathrm{c}} \pm 0,22$ & $3,77^{\mathrm{c}} \pm 0,22$ & $98,4^{\mathrm{c}} \pm 1,47$
\end{tabular}

Nota: letras diferentes na mesma coluna indicam diferença significativa pelo teste de Tukey $(\alpha=0,05)$.

Em relação à temperatura, o critério de projeto mais utilizado no dimensionamento de biorreatores, considera a temperatura média do ar no mês mais frio. O uso deste parâmetro é um critério de segurança, já que a temperatura do fluído estará um pouco mais elevada. A seleção do período frio ocorre devido à velocidade das reações bioquímicas, que são críticas no funcionamento do biorreator (Tchobanoglous et al., 2003). Se considerarmos a região em análise, os dados climatológicos históricos de temperatura demonstram mínimas temperaturas médias de $10^{\circ} \mathrm{C}$. Se considerarmos os valores médios anuais, a temperatura média situa-se em $19,5^{\circ} \mathrm{C}$, com máximos valores médios de $30^{\circ} \mathrm{C}$ (INMET, 2011). Com base nestes valores de temperatura, o processo foi avaliado. O efeito da temperatura nas taxas de remoção de fosfato pode ser melhor elucidado através da aplicação da equação de Arrhenius aos dados experimentais. A Tabela 3 apresenta os coeficientes de temperatura e a energia de ativação para a remoção de fosfato por microalgas. Os coeficientes de temperatura obtidos foram de $\theta=1,08$ para a faixa de temperatura de $10-20^{\circ} \mathrm{C}$ e $\theta=1,04$ para a faixa $20-30^{\circ} \mathrm{C}$. Estes valores indicam que o efeito da temperatura é mais sensível na faixa de baixas temperaturas quando comparado à faixa mais elevada. Segundo Sawyer e McCarty (1978) os coeficientes de temperatura podem variar substancialmente dentro de uma faixa reduzida de temperatura. Segundo estes autores, os valores de $\theta$ são usualmente adotados para a correção das diversas reações envolvidas no tratamento de efluentes.

Adicionalmente, uma energia de ativação de $8,86 \mathrm{~kJ} / \mathrm{mol}$ foi determinada para a faixa de temperatura de 10 a $30^{\circ} \mathrm{C}$. Estes coeficientes são particularmente úteis no projeto de reatores, já que correlacionam a taxa de remoção com a temperatura de operação. Desta forma, a diminuição da temperatura implica na diminuição da constante da taxa de remoção (k), e consequentemente no aumento do tempo de detenção hidráulica do sistema, para que não haja alterações na eficiência do sistema. Além disso, deve-se considerar a possibilidade da redução considerável no volume do biorreator quando temperaturas otimizadas são empregadas. Segundo Healey (1982) a temperatura tem um efeito determinante na assimilação de fosfato por microalgas, com valores ótimos na faixa de 20 a $30^{\circ} \mathrm{C}$. A remoção dependente da temperatura e independente da concentração de fosfato indica que processos ativos e passivos estão envolvidos na remoção de fosfato por A. microscopica Nägeli em biorreatores heterotróficos. Segundo Lei et al. (2007) os processos passivos determinam atividades fisiológicas destes micro-organismos, como consumo de nutrientes e metabolismo respiratório, como resultado da dependência do tamanho e morfologia das células. 
Tabela 3. Coeficientes de temperatura e energia de ativação para o biorreator heterotrófico.

\begin{tabular}{c|cc}
\hline $\begin{array}{c}\text { Faixa de } \\
\text { Temperatura }\left({ }^{\circ} \mathbf{C}\right)\end{array}$ & $\boldsymbol{\theta}$ & Ea $(\mathbf{k J} / \mathbf{m o l})$ \\
\hline 10 a 20 & $1,08^{\mathrm{a}} \pm 0,03$ & - \\
20 a 30 & $1,04^{\mathrm{a}} \pm 0,02$ & - \\
10 a 30 & - & $8,86 \pm 0,44$ \\
\hline
\end{tabular}

Nota: letras diferentes na mesma coluna indicam diferença significativa pelo teste de Tukey $(\alpha=0,05)$.

\section{CONCLUSÃO}

Biorreatores heterotróficos com A. microscopica Nägeli foram efetivos na remoção de fosfato total dissolvido do efluente do processamento de laticínios, verificando-se taxas de remoção de 3,77 mg/L.h, que refletiram em conversões de 98,4\% em tempos de detenção hidráulica de $24 \mathrm{~h}$. Deve-se considerar, entretanto, que a remoção de fosfato é altamente sensível a temperatura, principalmente na faixa entre 10 a $20^{\circ} \mathrm{C}(\theta=1,08)$, e nestas condições, a operacionalidade do biorreator deverá ser ajustada para a manutenção da eficiência do sistema.

\section{AGRADECIMENTOS}

Ao Conselho Nacional de Desenvolvimento Científico e Tecnológico (CNPq), projeto CNPq: 564588 2008-3.

\section{REFERÊNCIAS}

AMERICAN PUBLIC HEALTH ASSOCIATION - APHA. Standard methods for the examination of water and wastewater. Washington, 2005.

CEMBELlA, A. D.; ANTIA, N. J.; HARRISON, P. J. The utilization of inorganic and organic phosphorous compounds as nutrients by eukaryotic microalgae: a multidisciplinary perspective. CRC Critical Reviews in Microbiology, v.10, n. 4, p. 317-391, 1983. http://dx.doi.org/10.3109/10408418209113567

DEVI, M. P.; SUBHASH, G. V.; MOHAN, S. V. Heterotrophic cultivation of mixed microalgae for lipid accumulation and wastewater treatment during sequential growth and starvation phases: effect of nutrient supplementation. Renewable Energy, v. 43, p. 276-283, 2012. http://dx.doi.org/10.1016/j.renene.2011.11.021

GEIDER, R. J.; OSBORNE, B. A. Respiration and microalgal growth: a review of the quantitative relationship between dark respiration and growth. New Phytologist Trust, v. 112, p. 327-341, 1989. http://dx.doi.org/10.1111/j.1469-8137.1989. tb00321.x

GONZALEZ, L. E.; CAÑIZARES, R. O.; BAENA, S. Efficiency of ammonia and phosphorus removal from a Colombian agroindustrial wastewater by the microalgae Chlorella vulgaris and Scenedesmus dimorphus. Bioresource Technology, v. 60, p. 259-262, 1997. http://dx.doi.org/10.1016/S0960-8524(97)00029-1 
HEALEY, F. P. Phosphate. In: CARR, N. G.; WHITTON, B. A. (Eds.). The biology of cyanobacteria. Berkeley: University of California Press, 1982.

INSTITUTO NACIONAL DE METEOROLOGIA - INMET (Brasil). Brasília, 2011. Disponível em: <http://www.inmet.gov.br/portal/>. Acesso em: 8 jun. 2011.

JACOB-LOPES, E.; SCOPARO, C.H.G.; QUEIROZ, M. I.; FRANCO, T. T. Biotransformations of carbon dioxide in photobioreactors. Energy Conversion and Management, v. 51, n. 5, p. 894-900, 2010. http://dx.doi.org/10.1016/j.enconman. 2009.11 .027

LEI, A. P.; HU, Z. L.; WONG, Y. S.; TAM, N. F. Y. Removal of fluoranthene and pyrene by different microalgal species. Bioresource Technology, v. 98, n. 2, p. 273-280, 2007. http://dx.doi.org/10.1016/j.biortech.2006.01.012.

MIYACHI, S.; KANAI, R.; MIHARA, S.; MIYACHI, S.; AOKI, S. Metabolic roles of inorganic polyphosphates in Chlorella cells. Biochimica et Biophysica Acta, v. 93, n. 3, p. 625-634, 1964. http://dx.doi.org/10.1016/0304-4165(64)90345-9

PEREZ-GARCIA, O.; ESCALANTE, F. M. E.; DE-BASHAN, L. E.; BASHAN, Y. Heterotrophic cultures of microalgae: metabolism and potential products. Water Research, v. 45, n. 1, p.11-36, 2011. http://dx.doi.org/10.1016/j.watres.2010.08.037

PHANG, S. M.; MIAH, M. S.; YEOH, B. G.; HASHIM, M. A. Spirulina cultivation in digested sago starch factory wastewater. Journal of Applied Phycology, v. 12, n. 3/5, p. 395-400, 2000. http://dx.doi.org/10.1023/A:1008157731731

POWELL, N.; SHILTON A.; CHISTI Y.; PRATT, S. Towards a luxury uptake process via microalgae - Defining the polyphosphate dynamics. Water Research, v. 43, n. 17, p. 4207 - 4213, 2009. http://dx.doi.org/10.1016/j.watres.2009.06.011

POWELL, N.; SHILTON, A. N.; PRATT, S.; CHISTI Y. Factors influencing luxury uptake of phosphorus by microalgae in waste stabilization ponds. Environmental Science \& Technology, v. 42, n. 16, p. 5958-5962, 2008. http://dx.doi.org/10.1021/es703118s

POWELL, N.; SHILTON, A.; PRATT, S.; CHISTI, Y. Luxury uptake of phosphorus by microalgae in waste stabilization ponds. In: Stuetz, R., Teik-Thye, L. (Eds.). Young researchers 2006. London: IWA Publishing, 2006. p. 249-256. (Water and Environment Management, n. 12).

QUEIROZ, M. I.; HORNES M. O.; SILVA-MANETTI, A. G.; JACOB-LOPES, E. Singlecell oil production by cyanobacterium Aphanothece microscopica Nägeli cultivated heterotrophically in fish processing wastewater. Applied Energy, v. 88, n. 10, p. 3438-3443, 2011. http://dx.doi.org/10.1016/j.apenergy.2010.12.047

QUEIROZ, M. I.; JACOB-LOPES, E.; ZEPKA, L. Q.; BASTOS, R. G.; GOLDBECK, R. The kinetics of the removal of nitrogen and organic matter from parboiled rice effluent by cyanobacteria in a stirred batch reactor. Bioresource Technology, v. 98, n. 11, p. 2163-2169, 2007. http://dx.doi.org/10.1016/j.biortech.2006.08.034

RIPPKA, R.; DERUELLES, J.; WATERBURY, J. B.; HERDMAN, M.; STANIER, R. Y. Generic assignments strain histories and properties of pure cultures of cyanobacteria. Microbiology, v. 111, n. 1, p. 01-61, 1979. http://dx.doi.org/10.1099/00221287-111-1-1 
SAKAMOTO, T.; SHEN, G.; HIGASHI, S.; MURATA, N.; BRYANT, D. A. Alteration of low-temperature susceptibility of the cyanobacterium Synechococcus sp. PCC 7002 by genetic manipulation of membrane lipid unsaturation. Archives of Microbiology, v.169, n. 1, p. 20-28, 1997. http://dx.doi.org/10.1007/s002030050536

SAWYER, C. N.; MCCARTY, P. L. Chemistry for environmental engineering. 3. ed. New York: McGraw-Hill, 1978.

SINGH, G.; THOMAS, P. B. Nutrient removal from membrane bioreactor permeate using microalgae and in a microalgae membrane photoreactor. Bioresource Technology, v. 117, p. 80-85, 2012. http://dx.doi.org/10.1016/j.biortech.2012.03.125

SMITH, A. J. Modes of cyanobacterial carbon metabolism. In: Carr, N. G.; Whitton, B. A. (Eds.). The biology of cyanobacteria. Berkeley: University of California Press, 1982.

SÖZEN, S.; ORHON, D.; SAN, H. A. A new approach for the evaluation of the maximum specific growth rate in nitrification. Water Research, v. 30, n. 7, p. 1661-1669, 1996. http://dx.doi.org/10.1016/0043-1354(96)00031-0

STATSOFT INC. STATISTICA - data analysis software system. Version 7.0. 2004. Disponível em: 〈http://www.statsoft.com>. Acesso em 17 ago. 2012.

SPIVAKOV, B. Y.; MARYUTINA, T. A.; MUNTAU, D. H. Phosphorus speciation in water and sediments. Pure Applied Chemistry, v. 71, n. 11, p. 2161-2176, 1999.

TCHOBANOGLOUS, G.; BURTON, F. L.; STENSEL, D. Wastewater engineering, treatment and reuse. 4th edition. New York: McGraw-Hill, 2003.

TOMASELLI, L.; GIOVANNETTI, L.; SACCHI, A.; BOCHI, F. Effects of temperature on growth and biochemical composition in Spirulina platensis strain M2. In: Stadler, T.; Mellion, J.; Verdus, M. C.; Karamanos, Y.; Morvan, H.; Christiaen, D. (Eds.). Algal biotechnology. London: Elsevier Applied Science, 1988. p. 303-314. 


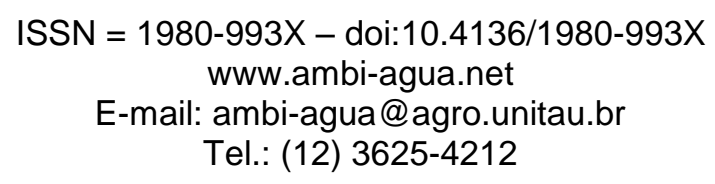

\title{
Avaliação da poluição doméstica fluvial na zona urbana do município de Piracicaba, SP, Brasil
}

(http://dx.doi.org/10.4136/ambi-agua.846)

\author{
Jefferson Mortatti ${ }^{1}$; Diego Vendramini ${ }^{1}$; Helder de Oliveira ${ }^{1}$ \\ ${ }^{1}$ Centro de Energia Nuclear na Agricultura, Universidade de São Paulo, Piracicaba-SP, \\ e-mails: jmortatt@cena.usp.br, dvendram@cena.usp.br, helder@cena.usp.br
}

\section{RESUMO}

A influência dos efluentes urbanos brutos na carga dissolvida do rio Piracicaba em termos de carga de poluição per capita das principais espécies químicas inorgânicas dissolvidas, foi estimada a partir de um modelo de aportes de efluentes pontuais sem tratamento prévio na zona urbana central do município de Piracicaba (SP). As cargas químicas inorgânicas, representadas pelos cátions e ânions principais e a sílica dissolvida foram determinadas nos efluentes brutos e no próprio rio, antes e depois da área urbana. $\mathrm{O}$ modelo utilizado permitiu estimar as contribuições dessas espécies químicas nas cargas totais dos efluentes para toda a bacia de drenagem e quantificar em termos mais específicos os respectivos aportes por habitante.

Palavras-chave: efluentes urbanos, carga dissolvida, poluição, rio Piracicaba.

\section{Evaluation of fluvial domestic pollution in the urban area of Piracicaba, SP, Brazil}

\begin{abstract}
The influence of urban raw sewage, in terms of per capita load pollution of major dissolved inorganic chemical species, in fluvial dissolved load was estimated using a model of punctual sewage contributions without previous treatment, in urban central area of Piracicaba city, SP. The inorganic loads represented by major cations, anions and dissolved silica, were determined in both raw sewage and in the river, before and after the river crossing the urban area. This model also allowed the contributions of these chemical species of total effluent loads to be estimated for the entire drainage basin, as well their respective contributions per capita.
\end{abstract}

Keywords: raw sewage, dissolved load, pollution, Piracicaba river.

\section{INTRODUÇÃO}

O descarte de efluentes urbanos brutos é um dos principais causadores de poluição e contaminação de rios e mananciais de água doce no mundo, em geral, e no Brasil, em particular, com efeitos sobre a qualidade das águas e impactos nesses ecossistemas (Rebouças et al., 1999). A poluição fluvial só é destacada para o grande público, ou seja, vira notícia, quando ocorrem acidentes graves de aportes pontuais de efluentes brutos, sem tratamento 
MORTATTI, J.; VENDRAMINI, D.; OLIVEIRA, H. Avaliação da poluição doméstica fluvial na zona urbana do município de Piracicaba (SP). Ambi-Agua, Taubaté, v. 7, n. 2, p. 110-119, 2012. (http://dx.doi.org/10.4136/ambi-agua.846)

prévio diretamente no rio, quer seja doméstico, industrial, agrícola ou criminoso, causando mortalidade de peixes e prejudicando o tratamento e distribuição de água temporariamente (Meybeck e Helmer, 1989; Mortatti et al., 2008).

De acordo com Thibert (1994), a influência antrópica é bem definida com respeito à escala de tempo, sendo diária e semanal (rejeitos urbanos domésticos e industriais), sazonal (atividades agrícolas) e episódica (canais pluviais).

A poluição crônica, que se apresenta muito mais danosa, tem várias origens (domésticas, agrícolas e industriais) e geralmente passa despercebida até o momento em que o sistema fluvial tem seu aspecto visual alterado em suas características originais (Meybeck, 1990). O aspecto dinâmico do rio, em termos das oscilações das vazões ao longo do tempo, segundo Mortatti e Probst (2010), colabora para camuflar o sinal da poluição, sendo percebido principalmente durante a estação mais seca, onde ocorrem as mais baixas vazões.

A avaliação da poluição fluvial urbana tem um papel muito importante no estudo hidrogeoquímico de bacias de drenagem, pois sem a sua correção, associada às contribuições totais atmosféricas, não seria possível identificar na carga dissolvida fluvial, as espécies químicas provenientes dos processos erosivos de alteração de rochas que ocorrem na bacia de drenagem (Stallard e Edmond, 1981; Probst et al., 1994; Tardy et al., 2005).

O impacto das atividades antrópicas nas águas do rio Piracicaba tem aumentado muito nestas últimas décadas em função do grande desenvolvimento industrial e demográfico ocorrido na região, desencadeando um processo de degradação global que parece ser irreversível, a não ser que as autoridades governamentais tomem drásticas atitudes no controle e tratamento dos efluentes domésticos, agrícolas e industriais para a preservação, recuperação e manutenção dos mananciais, visando diretamente a qualidade de vida da população.

$\mathrm{O}$ tratamento dos efluentes tem contribuído para amenizar o processo de degradação dos rios dessa bacia de drenagem, que é antigo, entretanto, o rio Piracicaba e seus afluentes continuam entre os mais poluídos do Estado de São Paulo.

É fundamental, portanto, caracterizar esses poluentes, sob todos os aspectos e avaliar seus efeitos, para dimensionar melhor o problema e gerar conhecimentos que possam subsidiar outros estudos, sejam hidrogeoquímicos, limnológicos e tecnológicos, vinculados ao tratamento de água, de esgotos, enfim, voltados à gestão dos recursos hídricos (Evangelista, 2003).

O lançamento de esgotos domésticos sem tratamento prévio em águas fluviais tem sido investigado nos últimos anos sem que haja, ainda, um conhecimento detalhado desse potencial de poluição. Nesse sentido, o presente trabalho tem como foco principal caracterizar e quantificar a influência dos efluentes urbanos brutos, principalmente os domésticos na carga dissolvida do rio Piracicaba, de acordo com suas principais espécies químicas, verificando o seu potencial de poluição em termos de fluxo per capita, com base em cinco pontos de lançamento de efluentes diretamente no rio e também com amostras fluviais coletadas antes e após a área urbana do município de Piracicaba (São Paulo, Brasil).

\section{DESENVOLVIMENTO METODOLÓGICO}

\section{1. Área de estudo}

O município de Piracicaba, considerado um importante pólo regional de desenvolvimento industrial e agrícola, situado em uma das regiões mais industrializadas e produtivas do estado de São Paulo, está localizado entre as coordenadas $22^{\circ} 43^{\prime} 31^{\prime \prime}$ de latitude sul e $47^{\circ} 38^{\prime} 57^{\prime}$ ' de longitude oeste, a uma altitude de 547 metros, com uma população estimada em 2009 de 368.843 habitantes (IBGE, 2010). A base econômica do município encontra-se alicerçada na indústria e na agroindústria da cana-de-açúcar, cultura que teve sua 
MORTATTI, J.; VENDRAMINI, D.; OLIVEIRA, H. Avaliação da poluição doméstica fluvial na zona urbana do município de Piracicaba (SP). Ambi-Agua, Taubaté, v. 7, n. 2, p. 110-119, 2012. (http://dx.doi.org/10.4136/ambi-agua.846)

expansão a partir da década de 1970 propiciada por incentivos governamentais e características físicas adequadas de declividade e aptidão agrícola (Barreto et al., 2006).

$\mathrm{O}$ presente estudo foi realizado na parte central da área urbana do município de Piracicaba, em uma área de $30 \mathrm{~km}^{2}$ que integra uma parte do rio Piracicaba, representativa de uma população de 170.000 habitantes. Nessa área central foram observados e selecionados cinco pontos principais de lançamento de efluentes urbanos diretamente no rio Piracicaba sem nenhum tratamento prévio e também dois pontos de controle para amostragem fluvial antes e depois da área estudada, conforme pode ser verificado na Figura 1.

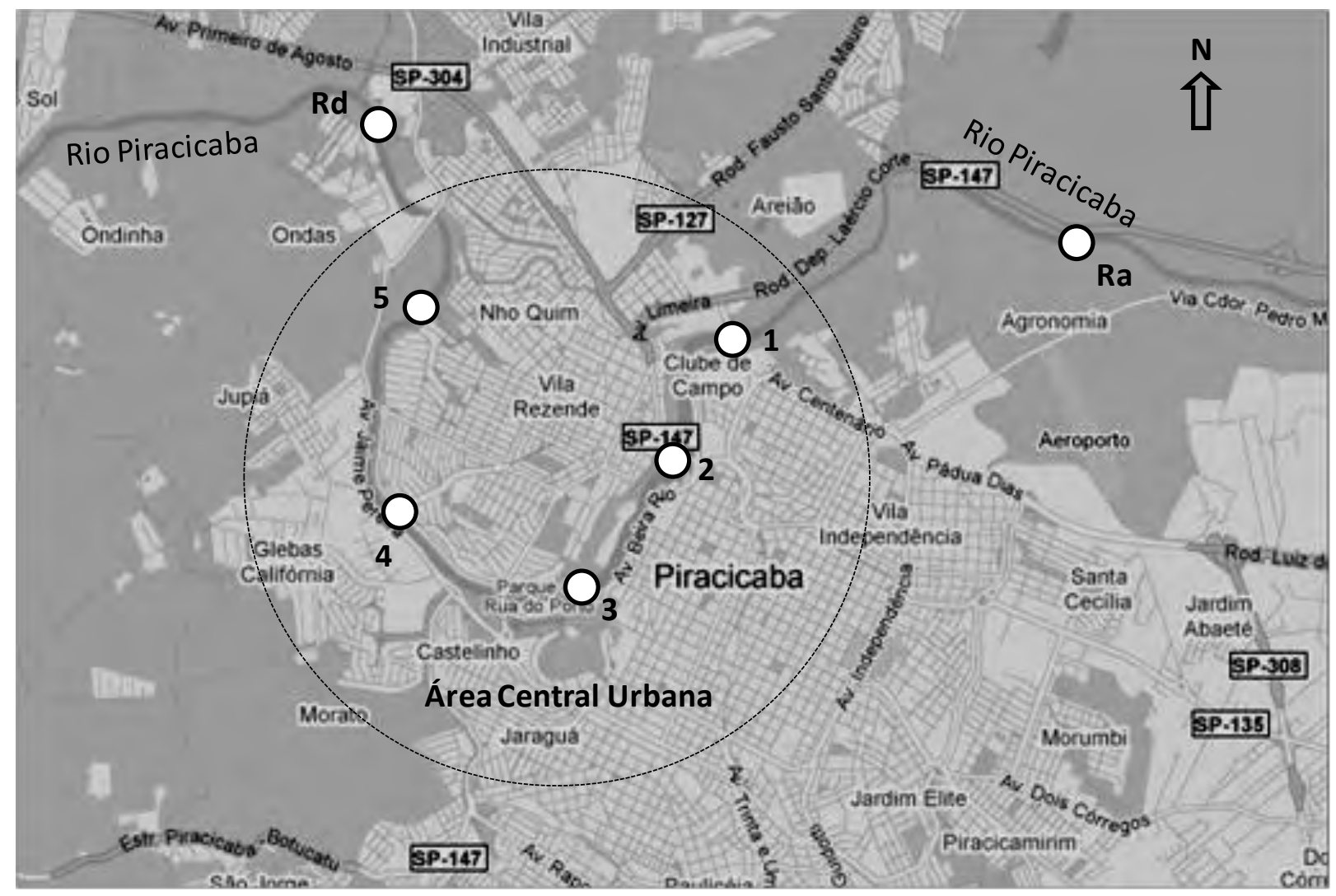

Figura 1. Área central urbana do município de Piracicaba (SP) evidenciando os cinco pontos de amostragem de efluentes urbanos ( 1 a 5 ) e os pontos de amostragem fluvial antes (Ra) e depois (Rd) da área estudada.

\subsection{Protocolo de amostragem}

Foram realizadas 13 excursões de amostragens nos pontos de lançamento direto de efluentes urbanos ( 1 a 5) e no próprio rio Piracicaba, antes ( $\mathrm{Ra})$ e depois ( $\mathrm{Rd}$ ) da zona urbana do município, conforme já observados na Figura 1. O período referente às amostragens realizadas foi de junho 2007 a outubro 2008, considerando a sazonalidade fluvial.

As amostragens nos pontos de 1 a 5 foram realizadas em triplicata usando baldes de polietileno, calibrados, sendo as amostras brutas e preservadas (razão $1 \mathrm{~mL} \mathrm{de} \mathrm{H}_{2} \mathrm{SO}_{4}$ conc. por litro de amostra), armazenadas em frascos plásticos de $1000 \mathrm{~mL}$, com etiquetas de identificação, sendo as mesmas mantidas sob refrigeração em torno de $4{ }^{\circ} \mathrm{C}$.

Para cada ponto de amostragem foi calculada a vazão dos efluentes, medindo-se o volume escoado em função do tempo (para os pontos tubulares) e profundidade, largura e velocidade para os pontos tipo galeria, até o estabelecimento de uma curva chave entre profundidade e vazão. 
MORTATTI, J.; VENDRAMINI, D.; OLIVEIRA, H. Avaliação da poluição doméstica fluvial na zona urbana do município de Piracicaba (SP). Ambi-Agua, Taubaté, v. 7, n. 2, p. 110-119, 2012. (http://dx.doi.org/10.4136/ambi-agua.846)

Os pontos Ra e Rd de coleta da água do rio Piracicaba, respectivamente antes e depois da zona urbana do município, foram amostrados também em triplicata no eixo da corrente do rio, utilizando um amostrador pontual a 1 metro de profundidade e seguiram o mesmo procedimento de armazenagem descrito. As vazões do rio Piracicaba nesses dois pontos de amostragens foram determinadas a partir da série histórica dos dados diários de vazão do SEMAE (Serviço Municipal de Águas e Esgotos de Piracicaba), para cada dia da coleta.

\subsection{Protocolo analítico}

As amostras oriundas das cargas dissolvidas dos efluentes urbanos e do rio antes e depois da zona urbana do município de Piracicaba (SP), após processo de filtração manual a vácuo (filtros millipore acetato, $0,45 \mu \mathrm{m}$ ), foram analisadas em triplicata para principais cátions $\left(\mathrm{Ca}^{2+}, \mathrm{Mg}^{2+}, \mathrm{Na}^{+}, \mathrm{K}^{+}\right.$e $\left.\mathrm{NH}_{4}{ }^{+}\right)$e ânions $\left(\mathrm{Cl}^{-}, \mathrm{SO}_{4}{ }^{2-}, \mathrm{NO}_{3}{ }^{-}\right.$e $\left.\mathrm{PO}_{4}{ }^{3-}\right)$ por cromatografia iônica usando um equipamento Dionex ICS-90. As concentrações de $\mathrm{HCO}_{3}{ }^{-}$foram determinadas em função da alcalinidade total pelo método da micro-titulação de Gran (Edmond, 1970). As análises de $\mathrm{Si}$ foram realizadas em termos de $\mathrm{SiO}_{2}$ por espectrometria de emissão atômica com plasma induzido de argônio (ICP/AES). Todas as análises químicas foram realizadas no Laboratório de Isótopos Estáveis do Centro de Energia Nuclear na Agricultura, CENA/USP.

\section{DISCUSSÃO DOS RESULTADOS}

\subsection{Caracterização química inorgânica dos efluentes urbanos}

Os resultados das análises das principais espécies químicas inorgânicas, cátions, ânions e sílica, presentes nos efluentes brutos lançados no rio Piracicaba, em sua parte central urbana, nos cinco pontos de amostragem selecionados e no rio Piracicaba, antes e depois da zona urbana, podem ser observados nas Tabelas 1 e 2 . Os resultados observados representaram as concentrações médias, obtidas em cada ponto de coleta para as 13 excursões de amostragem realizadas, incluindo os respectivos desvios-padrão. Cabe salientar que os erros analíticos foram sempre inferiores a $5 \%$.

Dentre os cátions principais o $\mathrm{Na}^{+}$e o $\mathrm{Ca}^{2+}$ foram os que apresentaram maior concentração nos efluentes lançados, com médias de 136,1 $\pm 8,1$ e $34,5 \pm 8,5 \mathrm{mg} \mathrm{L}^{-1}$, respectivamente. As concentrações de $\mathrm{Na}^{+}$verificadas no rio Piracicaba antes e depois da zona urbana, aumentaram de $39,2 \pm 10,7$ a $56,5 \pm 10,1 \mathrm{mg} \mathrm{L}^{-1}$. Em termos de $\mathrm{Ca}^{2+}$ os resultados foram similares, com concentrações de $17,6 \pm 2,9$ e $19,8 \pm 3,9 \mathrm{mg} \mathrm{L}^{-1}$ para Ra e $\mathrm{Rd}$, respectivamente. As concentrações de $\mathrm{SiO}_{2}$ se mostraram bastantes baixas nos efluentes urbanos, com um valor médio de $1,4 \pm 0,1 \mathrm{mg} \mathrm{L}^{-1}$, quase dez vezes menos do que a concentração verificada no rio Piracicaba, da ordem de $11,1 \pm 1,0 \mathrm{mg} \mathrm{L}^{-1}$.

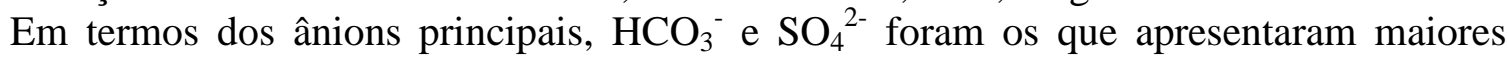
concentrações nos efluentes lançados, com concentrações médias de 176,0 \pm 45,9 e 128,4 \pm $20,2 \mathrm{mg} \mathrm{L}^{-1}$, respectivamente. Já no rio Piracicaba, as concentrações de $\mathrm{HCO}_{3}{ }^{-}$se apresentaram similares antes e depois da zona urbana, com 72,9 $\pm 14,7$ e 82,1 $\pm 19,5 \mathrm{mg} \mathrm{L}^{-1}$, respectivamente, o mesmo ocorrendo com o $\mathrm{SO}_{4}{ }^{2-}$, com concentrações de $27,1 \pm 1,9$ e 28,3 \pm $1,8 \mathrm{mg} \mathrm{L}^{-1}$, respectivamente.

Os elevados desvios-padrão observados principalmente para $\mathrm{HCO}_{3}{ }^{-}$e $\mathrm{SO}_{4}{ }^{2-}$, tanto para a média dos efluentes (MNQ) como em cada ponto de amostragem, representam uma significativa variabilidade desses aportes ao longo do período estudado, em função da sazonalidade e principalmente das taxas de produção no ambiente fluvial. No caso do íon $\mathrm{HCO}_{3}{ }^{-}$o mesmo é produzido à partir da oxidação da matéria orgânica via microorganismos, intermediada por íons $\mathrm{SO}_{4}{ }^{2-}$, conforme descrito por Haida et al. (1996). 
MORTATTI, J.; VENDRAMINI, D.; OLIVEIRA, H. Avaliação da poluição doméstica fluvial na zona urbana do município de Piracicaba (SP). Ambi-Agua, Taubaté, v. 7, n. 2, p. 110-119, 2012. (http://dx.doi.org/10.4136/ambi-agua.846)

Tabela 1. Concentração média dos cátions principais e sílica nos efluentes brutos lançados no rio Piracicaba, em sua parte central urbana, nos cinco pontos de amostragem selecionados, incluindo as respectivas vazões e as médias normalizadas pelas vazões (MNQ) no rio Piracicaba, antes e depois da zona urbana ( $\mathrm{Ra}$ e $\mathrm{Rd}$, respectivamente).

\begin{tabular}{|c|c|c|c|c|c|c|c|}
\hline \multirow{2}{*}{ Amostra } & $\mathbf{Q}_{\text {média }}$ & $\mathrm{Ca}^{2+}$ & $\mathrm{Mg}^{2+}$ & $\mathbf{N a}^{+}$ & $\mathbf{K}^{+}$ & $\mathrm{NH}_{4}^{+}$ & $\mathrm{SiO}_{2}$ \\
\hline & $\left(L . s^{-1}\right)$ & \multicolumn{6}{|c|}{$\left(m g \cdot L^{-1}\right)$} \\
\hline 1 & 1,5 & $18,6 \pm 2,9$ & $5,6 \pm 0,5$ & $149,7 \pm 48,6$ & $7,4 \pm 1,4$ & $18,8 \pm 11,1$ & $1,1 \pm 0,1$ \\
\hline 2 & 551,6 & $33,5 \pm 5,5$ & $9,1 \pm 1,8$ & $137,2 \pm 15,0$ & $11,6 \pm 2,6$ & $11,6 \pm 3,2$ & $1,4 \pm 0,1$ \\
\hline 3 & 84,5 & $41,3 \pm 10,5$ & $16,3 \pm 1,8$ & $129,2 \pm 13,8$ & $10,6 \pm 1,8$ & $7,9 \pm 2,0$ & $1,7 \pm 0,1$ \\
\hline 4 & 0,3 & $36,4 \pm 6,3$ & $7,0 \pm 4,3$ & $94,1 \pm 21,4$ & $5,8 \pm 2,0$ & $1,5 \pm 1,0$ & $0,4 \pm 0,0$ \\
\hline 5 & 3,4 & $31,5 \pm 7,8$ & $5,8 \pm 1,9$ & $119,1 \pm 15,9$ & $9,0 \pm 2,4$ & $6,3 \pm 3,2$ & $1,0 \pm 0,1$ \\
\hline MNQ & & $34,5 \pm 8,5$ & $10,1 \pm 4,5$ & $136,1 \pm 8,1$ & $11,4 \pm 2,4$ & $11,9 \pm 5,9$ & $1,4 \pm 0,1$ \\
\hline $\mathrm{Ra}$ & 80000,0 & $17,6 \pm 2,9$ & $4,7 \pm 1,2$ & $39,2 \pm 10,7$ & $11,5 \pm 3,1$ & $3,3 \pm 1,3$ & $10,6 \pm 0,5$ \\
\hline $\mathrm{Rd}$ & 80986,0 & $19,8 \pm 3,9$ & $4,0 \pm 1,1$ & $56,5 \pm 10,1$ & $9,7 \pm 1,1$ & $4,1 \pm 1,6$ & $11,1 \pm 1,0$ \\
\hline
\end{tabular}

Tabela 2. Concentração média dos ânions principais nos efluentes brutos lançados no rio Piracicaba, em sua parte central urbana, nos cinco pontos de amostragem selecionados, incluindo as respectivas vazões e as médias normalizadas pelas vazões (MNQ) no rio Piracicaba, antes e depois da zona urbana (Ra e $\mathrm{Rd}$, respectivamente).

\begin{tabular}{|c|c|c|c|c|c|c|}
\hline \multirow{2}{*}{ Amostra } & $\mathbf{Q}_{\text {média }}$ & $\mathrm{HCO}_{3}^{-}$ & $\mathrm{Cl}^{-}$ & $\mathrm{SO}_{4}{ }^{2-}$ & $\mathrm{NO}_{3}^{-}$ & $\mathrm{PO}_{4}{ }^{3-}$ \\
\hline & $\left(L . s^{-1}\right)$ & \multicolumn{5}{|c|}{$\left(m g . L^{-1}\right)$} \\
\hline 1 & 1,5 & $111,0 \pm 58,7$ & $64,3 \pm 5,1$ & $105,3 \pm 8,0$ & $4,8 \pm 1,1$ & $0,86 \pm 1,0$ \\
\hline 2 & 551,6 & $173,7 \pm 27,1$ & $58,3 \pm 3,8$ & $96,6 \pm 10,1$ & $1,3 \pm 0,4$ & $2,4 \pm 1,3$ \\
\hline 3 & 84,5 & $194,5 \pm 35,8$ & $54,9 \pm 4,2$ & $90,9 \pm 7,3$ & $6,8 \pm 1,1$ & $1,7 \pm 0,9$ \\
\hline 4 & 0,3 & $82,3 \pm 33,2$ & $40,0 \pm 4,0$ & $66,3 \pm 6,1$ & $4,1 \pm 0,4$ & $1,8 \pm 1,5$ \\
\hline 5 & 3,4 & $127,2 \pm 30,7$ & $50,6 \pm 3,2$ & $83,8 \pm 8,4$ & $2,3 \pm 0,5$ & $3,1 \pm 2,0$ \\
\hline MNQ & & $176,0 \pm 45,9$ & $57,8 \pm 9,1$ & $128,4 \pm 20,2$ & $2,1 \pm 2,1$ & $2,6 \pm 1,0$ \\
\hline $\mathrm{Ra}$ & 80000,0 & $72,9 \pm 14,7$ & $21,4 \pm 1,8$ & $27,1 \pm 1,9$ & $2,9 \pm 0,3$ & $0,6 \pm 0,2$ \\
\hline $\mathrm{Rd}$ & 80986,0 & $82,1 \pm 19,5$ & $22,1 \pm 1,7$ & $28,3 \pm 1,8$ & $4,0 \pm 0,3$ & $0,6 \pm 0,1$ \\
\hline
\end{tabular}

A partir dos resultados médios normalizados das concentrações das espécies químicas estudadas e das vazões médias para cada ponto de amostragem foi possível calcular, em termos químicos inorgânicos, os aportes e influências dos efluentes urbanos brutos na carga dissolvida do rio Piracicaba, primeiramente da parte central urbana, de acordo com o modelo de balanço de massa proposto, depois para o município e finalmente para a bacia do rio Piracicaba como um todo, conforme pode ser na Tabela 3. 
MORTATTI, J.; VENDRAMINI, D.; OLIVEIRA, H. Avaliação da poluição doméstica fluvial na zona urbana do município de Piracicaba (SP). Ambi-Agua, Taubaté, v. 7, n. 2, p. 110-119, 2012. (http://dx.doi.org/10.4136/ambi-agua.846)

Tabela 3. Resultados dos aportes dos efluentes brutos para a área central urbana, município e bacia do rio Piracicaba e suas influências porcentuais na carga dissolvida das principais espécies químicas no período estudado.

\begin{tabular}{|c|c|c|c|c|c|c|c|}
\hline \multirow{3}{*}{ Espécie } & \multirow{3}{*}{$\begin{array}{c}\text { Rio Piracicaba } \\
\left(t . d^{-1}\right)\end{array}$} & \multicolumn{6}{|c|}{ Efluente Bruto } \\
\hline & & \multicolumn{2}{|c|}{$\begin{array}{c}\text { Área central } \\
\text { urbana }\end{array}$} & \multicolumn{2}{|c|}{ Município } & \multicolumn{2}{|c|}{ Bacia } \\
\hline & & $\left(t . d^{-1}\right)$ & $(\%)$ & $\left(t \cdot d^{-1}\right)$ & $(\%)$ & $\left(t . d^{-1}\right)$ & $(\%)$ \\
\hline $\mathrm{Ca}^{2+}$ & 134,09 & 1,91 & 1,43 & 4,15 & 3,10 & 39,39 & 29,38 \\
\hline $\mathrm{Mg}^{2+}$ & 27,59 & 0,56 & 2,02 & 1,21 & 4,38 & 11,48 & 41,61 \\
\hline $\mathrm{Na}^{+}$ & 388,13 & 7,54 & 1,94 & 16,36 & 4,22 & 155,26 & 40,00 \\
\hline $\mathrm{K}^{+}$ & 67,94 & 0,63 & 0,93 & 1,38 & 2,03 & 13,06 & 19,22 \\
\hline $\mathrm{NH}_{4}^{+}$ & 28,77 & 0,62 & 2,15 & 1,33 & 4,62 & 12,71 & 44,16 \\
\hline $\mathrm{SiO}_{2}$ & 77,67 & 0,08 & 0,10 & 0,17 & 0,22 & 1,61 & 2,07 \\
\hline $\mathrm{HCO}_{3}^{-}$ & 574,24 & 9,75 & 1,70 & 21,16 & 3,69 & 200,83 & 34,97 \\
\hline $\mathrm{Cl}^{-}$ & 154,64 & 3,20 & 2,07 & 6,95 & 4,50 & 65,98 & 42,66 \\
\hline $\mathrm{SO}_{4}^{2-}$ & 198,02 & 5,31 & 2,68 & 11,52 & 5,82 & 109,31 & 55,20 \\
\hline $\mathrm{NO}_{3}^{-}$ & 27,68 & 0,11 & 0,41 & 0,25 & 0,89 & 2,35 & 8,49 \\
\hline $\mathrm{PO}_{4}^{3-}$ & 4,48 & 0,13 & 2,90 & 0,29 & 6,47 & 2,77 & 61,83 \\
\hline
\end{tabular}

Os cálculos realizados para a área central urbana levaram em consideração a carga total de efluentes brutos dos pontos amostrados, em toneladas por dia, em função da população representativa dessa área (170.000 habitantes), bem como para todo o município de Piracicaba, de acordo com a população estimada de 368.843 habitantes para o ano de 2010 (IBGE, 2010). Os dados relativos à bacia do rio Piracicaba foram calculados de acordo com as estimativas do total da população ao longo da bacia hidrográfica, de 3.500 .000 habitantes para 2008 (Beduschi, 2008; CBH/PCJ, 2007).

Pode ser verificado que as cargas totais dos efluentes brutos na área central urbana foram particularmente importantes para as seguintes espécies químicas inorgânicas, na ordem decrescente, $\mathrm{HCO}_{3}{ }^{-}>\mathrm{SO}_{4}{ }^{2-}>\mathrm{Cl}^{-}>\mathrm{Na}^{+}$, com aportes máximos de $9,75 \mathrm{t}$. d $\mathrm{d}^{-1}$ para $\mathrm{HCO}_{3}{ }^{-} \mathrm{e}$ 5,31 t. $\mathrm{d}^{-1}$ para $\mathrm{SO}_{4}{ }^{2-}$ entre as espécies dominantes. No entanto, as maiores contribuições porcentuais da área central urbana em termos de efluentes brutos em relação ao transporte fluvial do rio Piracicaba foram de $\mathrm{PO}_{4}{ }^{3-}, \mathrm{SO}_{4}{ }^{2-}$ e $\mathrm{NH}_{4}{ }^{+}$, com 3,00, 2,68, e 2,15\%, respectivamente.

As estimativas das contribuições das cargas totais dos efluentes brutos do município de Piracicaba para o transporte total fluvial do rio Piracicaba seguiram o mesmo modelo da área central urbana, supondo nenhum tratamento desses efluentes.

Não houve a necessidade de correção desses valores em função da porcentagem de esgoto tratado no município de Piracicaba (36\%) e nem na bacia de drenagem (37\%) devido ao fato do tipo de tratamento utilizado não ser eficiente para remoção dessas espécies químicas inorgânicas dissolvidas, ocorrendo até mesmo um aumento após o tratamento, casos particulares de $\mathrm{NH}_{4}{ }^{+}$e $\mathrm{HCO}_{3}{ }^{-}$, conforme descrito por Evangelista et al. (2002).

De acordo com a evolução dos resultados obtidos, os aportes de $\mathrm{HCO}_{3}{ }^{-}{\mathrm{e} \mathrm{SO}_{4}{ }^{2-} \text { devido }}^{-}$ aos efluentes brutos oriundos do município de Piracicaba na carga fluvial foram de 21,16 e 11,52 t. $\mathrm{d}^{-1}$ respectivamente, enquanto que para a bacia de drenagem esses aportes foram de 
MORTATTI, J.; VENDRAMINI, D.; OLIVEIRA, H. Avaliação da poluição doméstica fluvial na zona urbana do município de Piracicaba (SP). Ambi-Agua, Taubaté, v. 7, n. 2, p. 110-119, 2012. (http://dx.doi.org/10.4136/ambi-agua.846)

200,83 e 109,31 t. $\mathrm{d}^{-1}$ respectivamente. Tais cargas, aparentemente elevadas, representaram cerca de $35 \%$ para o caso do $\mathrm{HCO}_{3}^{-}$, ou seja, $35 \%$ do $\mathrm{HCO}_{3}{ }^{-}$que se encontra presente dissolvido nas águas do rio Piracicaba, ao longo de sua bacia de drenagem, vêm dos esgotos brutos lançados diretamente no canal fluvial, enquanto que para o $\mathrm{SO}_{4}{ }^{2-}$ essa contribuição foi da ordem de $55 \%$.

Os resultados obtidos para os aportes de efluentes brutos na parte central urbana do município de Piracicaba, de acordo com modelo utilizado, permitiram estimar as cargas dissolvidas per capita das principais espécies e comparar com o resultado de outras cidades onde o mesmo tipo de estudo foi realizado.

A Tabela 4 apresenta a comparação da carga dissolvida per capita dos efluentes urbanos brutos do município de Piracicaba, para as principais espécies químicas estudadas, com as cargas brutas urbanas das cidades de Paris, França (Thibert, 1994), Bruxelas, Bélgica (Verbanck et al., 1989) e Montreal, Canadá (Caille et al.,1973).

A escolha de tais cidades pode ser justificada sob vários aspectos: disponibilidade de dados referente ao objeto de estudo; tratamento de esgoto similar ao comumente realizado no Brasil; estudos sobre eficiência desses tratamentos, usando modelos de balanço de massa similares ao do presente trabalho.

Pode ser verificado que as cargas dos efluentes urbanos brutos das diferentes cidades foram bastante similares, variando em um ou outro elemento, conforme os diferentes hábitos alimentares e composição química de saponáceos e detergentes presentes normalmente nos efluentes domésticos urbanos.

$\mathrm{O} \mathrm{SiO}_{2}$, por exemplo, é parte integrante da maioria dos saponáceos, e sua carga em Piracicaba, de 0,46 g.d $\mathrm{d}^{-1} \cdot \mathrm{hab}^{-1}$, foi praticamente a mesma de Paris, sendo bastante diferente de Bruxelas, que apresentou um valor de $3,29 \mathrm{~g} \cdot \mathrm{d}^{-1} \cdot \mathrm{hab}^{-1}$. Já no caso de $\mathrm{K}^{+}$, o mesmo se mostrou associado essencialmente aos rejeitos domésticos e como pode ser observado, seu aporte, de $3,73 \mathrm{~g} \cdot \mathrm{d}^{-1} \cdot \mathrm{hab}^{-1}$ foi praticamente o mesmo em todas as cidades estudadas.

Caso interessante foi o do $\mathrm{SO}_{4}{ }^{2-}$, cuja presença nos detergentes como agente surfactante é bastante conhecida, apareceu em altas concentrações no efluente urbano bruto, com uma carga per capita bastante elevada no município de Piracicaba, com 31,23 g.d $\mathrm{d}^{-1} \cdot \mathrm{hab}^{-1}$, similar ao observado nas outras cidades comparadas, com exceção da cidade de Bruxelas, que apresentou um aporte de $15,89 \mathrm{~g} \cdot \mathrm{d}^{-1} \cdot \mathrm{hab}^{-1}$.

As cargas per capita de $\mathrm{HCO}_{3}{ }^{-}$e $\mathrm{Cl}^{-}$obtidas para Piracicaba, com 57,38 e 18,85 g.d ${ }^{-1}$.hab ${ }^{1}$ foram similares às verificadas para todas as cidades estudadas, enquanto as cargas de $\mathrm{Ca}^{2+}$ em Piracicaba, 11,25 g. $\mathrm{d}^{-1} \cdot \mathrm{hab}^{-1}$ foram superiores as verificadas nas outras cidades, sendo que Paris foi a que apresentou a menor carga per capita, com $3,30 \mathrm{~g} \cdot \mathrm{d}^{-1} \cdot \mathrm{hab}^{-1}$.

De acordo com Siegrist et al. (1976), as presenças de $\mathrm{NH}_{4}{ }^{+}$e $\mathrm{NO}_{3}{ }^{-}$nos efluentes brutos urbanos estão relacionados principalmente aos componentes fecais e não fecais dos rejeitos humanos, sendo em Piracicaba essas cargas da ordem de 3,63 e 0,67 g.d . $^{-1} \mathrm{hab}^{-1}$, respectivamente. Para o $\mathrm{PO}_{4}^{3-}$, cuja presença em saponáceos e detergentes é normalmente significante, a carga nos efluentes brutos de Piracicaba foi de 0,79 g.d $\mathrm{d}^{-1} \cdot \mathrm{hab}^{-1}$, valores muito próximos aos verificados em Paris e Bruxelas.

Parâmetros outros, complementares, poderiam ser também utilizados para ilustrar a caracterização dos efluentes brutos estudados, como DBO, DQO e Coliformes fecais. No entanto, o presente trabalho teve por foco a química inorgânica desses efluentes e seu comportamento no rio Piracicaba, uma vez que a eficácia das estações de tratamento de esgoto é bastante baixa ou nula com relação à esses compostos. 
MORTATTI, J.; VENDRAMINI, D.; OLIVEIRA, H. Avaliação da poluição doméstica fluvial na zona urbana do município de Piracicaba (SP). Ambi-Agua, Taubaté, v. 7, n. 2, p. 110-119, 2012. (http://dx.doi.org/10.4136/ambi-agua.846)

Tabela 4. Comparação das cargas dos efluentes urbanos brutos per capita estimados para o município de Piracicaba, para as principais espécies químicas estudadas, com aquelas verificadas para outras cidades em estudos correlatos.

\begin{tabular}{|c|c|c|c|c|}
\hline \multirow{2}{*}{ Carga Dissolvida } & Piracicaba & Paris $^{a}$ & Bruxelas $^{b}$ & Montreal \\
\hline & \multicolumn{4}{|c|}{$\left(g . d^{-1} \cdot h a b^{-1}\right)$} \\
\hline $\mathrm{Ca}^{2+}$ & 11,25 & 3,30 & 7,12 & 8,77 \\
\hline $\mathrm{Mg}^{2+}$ & 3,28 & 1,90 & $\mathrm{n} / \mathrm{d}$ & 1,78 \\
\hline $\mathrm{Na}^{+}$ & 44,36 & 17,50 & 26,02 & 18,08 \\
\hline $\mathrm{K}^{+}$ & 3,73 & 4,10 & 4,38 & 2,74 \\
\hline $\mathrm{NH}_{4}^{+}$ & 3,63 & 5,50 & 6,58 & $\mathrm{n} / \mathrm{d}$ \\
\hline $\mathrm{SiO}_{2}$ & 0,46 & 0,50 & 3,29 & $\mathrm{n} / \mathrm{d}$ \\
\hline $\mathrm{HCO}_{3}^{-}$ & 57,38 & 39,70 & 40,27 & 65,75 \\
\hline $\mathrm{Cl}^{-}$ & 18,85 & 17,00 & 23,01 & 22,47 \\
\hline $\mathrm{SO}_{4}^{2-}$ & 31,23 & 30,00 & 15,89 & 36,99 \\
\hline $\mathrm{NO}_{3}^{-}$ & 0,67 & 0,00 & $\mathrm{n} / \mathrm{d}$ & $\mathrm{n} / \mathrm{d}$ \\
\hline $\mathrm{PO}_{4}^{3-}$ & 0,79 & 1,20 & 1,11 & $\mathrm{n} / \mathrm{d}$ \\
\hline
\end{tabular}

\section{CONCLUSÕES}

As influências dos efluentes urbanos brutos na carga dissolvida do rio Piracicaba foram avaliadas para as principais espécies químicas e caracterizadas em termos de aportes per capita diários. O procedimento proposto permitiu estimar a carga química desses efluentes na parte central da zona urbana do município de Piracicaba tendo como parâmetros os pontos de amostragem fluvial antes e depois dos aportes pontuais.

As cargas totais dos efluentes brutos da área central urbana foram particularmente importantes não só nos períodos chuvosos, quando a carga transportada é maior, mas também ao longo do ano. Dentre os cátions principais o $\mathrm{Na}+\mathrm{Ca} 2+$ e $\mathrm{NH} 4+$ foram os que apresentaram maior aporte diário, mas foi o NH4+ quem apresentou a maior contribuição para o canal fluvial. Dentre os ânions principais, embora o HCO3- tenha tido o maior aporte diário foi o PO43- quem mais contribuiu para o rio, justificando a sua utilização como traçador de esgotos domésticos.

As cargas per capita das principais espécies químicas presentes nos efluentes urbanos brutos lançados no rio Piracicaba quando comparadas com as cargas brutas urbanas das cidades de Paris (França), Bruxelas (Bélgica) e Montreal (Canadá), mostraram ser similares apesar dos diferentes hábitos alimentares e composição química de saponáceos e detergentes presentes normalmente nos efluentes domésticos urbanos.

De uma forma geral, foi possível verificar a importância do tratamento de esgotos e efluentes, principalmente referente à composição química inorgânica, que normalmente passa desapercebida, sendo essas espécies químicas, quando em excesso, também prejudiciais a saúde. 
MORTATTI, J.; VENDRAMINI, D.; OLIVEIRA, H. Avaliação da poluição doméstica fluvial na zona urbana do município de Piracicaba (SP). Ambi-Agua, Taubaté, v. 7, n. 2, p. 110-119, 2012. (http://dx.doi.org/10.4136/ambi-agua.846)

\section{AGRADECIMENTOS}

Agradecemos à FAPESP (Fundação de Amparo à Pesquisa do Estado de São Paulo) e CNPq (Conselho Nacional de Desenvolvimento Científico e Tecnológico) pela concessão dos recursos para pesquisa e bolsas de estudo.

\section{REFERÊNCIAS}

BARRetto, A. G. O. P.; SPAROVEK, G.; GIANNOTTI, M. Atlas rural de Piracicaba. Piracicaba: IPEF, 2006. p. 76.

BEDUSCHI, C. E. Caracterização isotópica dos componentes do ciclo hidrológico em quatro sub-bacias pertencentes à bacia do rio Piracicaba (SP). 2008. 97f. Dissertação (Mestrado) - Escola Superior de Agricultura Luiz de Queiroz, Universidade de São Paulo, Piracicaba, 2008.

CAILlE, A.; CAMPBELl, P.; MEYBECK, M.; SASSEVILlE J. L. Etude du fleuve St Laurent: effluent urbains de l'agglomération de Montréal. Rapport Interne, INRS Eau. Québec: Université du Quèbec, 1973. 203p.

COMITÊ DAS BACIAS HIDROGRÁFICAS DOS RIOS PIRACICABA, CAPIVARI E JUNDIAÍ - CBH/PCJ. Relatório de situação dos recursos hídricos das bacias hidrográficas dos rios Piracicaba, Capivari e Jundiaí (2004/2006). [S.1.: s.n]: 2007. v. 2. p. 258-333.

EDMOND, J. M. High precision determination of tritation alkalinity and total carbon dioxide content of sea water by potentiometric tritation. Deep-Sea Research Part I: Oceanographic Research Papers, Oxford, v. 17, n. 4, p. 737-750, 1970.

EVANGELISTA, R. A. O.; BORTOLETTO JÚNIOR, M. J.; MORTATTI, J. Estudo da variabilidade temporal diurna de $15-\mathrm{N}$ e $13-\mathrm{C}$ em efluentes domésticos. Revista Brasileira de Pesquisa e Desenvolvimento, v. 4, n. 3, p. 681-686, 2002.

EVANGELISTA, R. A. Caracterização química e isotópica de carbono e nitrogênio no estudo hidrogeoquímico de efluentes urbanos. 2003. 139f. Tese (Doutorado) - Centro de Energia Nuclear na Agricultura, Universidade de São Paulo, Piracicaba, 2003.

HAIDA, S.; SNOUSSI, M.; LATOUCHE, C.; PROBST, J. L. Géodynamique actuelle dans le basin versant de l'oued Tensift (Maroc): erosion et bilan du transfert solide fluviatile. Sciences Géologiques, v. 49, p. 7-23, 1996.

INSTITUTO BRASILEIRO DE GEOGRAFIA E ESTATÍSTICA - IBGE. Cidades. Disponível em: <http://www.ibge.gov.br/cidadesat/default.php>. Acesso em: 20 set. 2010.

MEYBECK, M. La pollution des fleuves. La Recherche, v. 21, n. 221, p. 608-617, 1990.

MEYBECK, M.; HELMER, R. The quality of rivers: from pristine stage to global pollution. Global and Planetary Change, v. 1, n. 4, p. 283-309, 1989. http://dx.doi.org/10.1016/ 0921-8181(89)90007-6 
MORTATTI, J.; VENDRAMINI, D.; OLIVEIRA, H. Avaliação da poluição doméstica fluvial na zona urbana do município de Piracicaba (SP). Ambi-Agua, Taubaté, v. 7, n. 2, p. 110-119, 2012. (http://dx.doi.org/10.4136/ambi-agua.846)

MORTATTI, J.; PROBST, J. L.; FERNANDES, A. M.; MORTATTI, B. C.; OLIVEIRA, H. Influence of discharge on silicate weathering dynamics of the Tiete river basin: major cations and dissolved silica approach. Geochimica Brasiliensis, v. 22, n. 1, p. 15-26, 2008 .

MORTATTI, J.; PROBST, J. L. Characteristics of heavy metals and their evaluation in suspended sediments form Piracicaba river basin (São Paulo, Brazil). Revista Brasileira de Geociências, v. 40, n. 3, p. 375-379, 2010.

PROBST, J. L.; MORTATTI, J.; TARDY, Y. Carbon river fluxes and global weathering CO2 consumption in the Congo and Amazon river basins. Applied Geochemistry, v. 9, p. 113, 1994. http://dx.doi.org/10.1016/0883-2927(94)90047-7

REBOUÇAS, A. C.; BRAGA, B; TUNDISI, J. G. Águas doces no Brasil: capital ecológico, uso e conservação. São Paulo: Escrituras, 1999. 717p.

STALLARD, R. F.; EDMOND, J. M. Geochemistry of the Amazon 1. Precipitation chemistry and the marine contribution to the dissolved load at the time of peak discharge. Journal of Geophysical Research, Washington, v. 86, n. C10, p. 9844-9858, 1981. http://dx.doi.org/10.1029/JC086iC10p09844

SIEGRIST, R.; WITT, M.; BOYLE, W. C. Characteristics of rural household wastewater. Journal of the Environmental Engineering Division, ASCE, v. 102, p. 533-548, 1976.

TARDY, Y; BUSTILLO, V.; ROQUIN, C.; MORTATTI, J.; VICTORIA, R. The Amazon. Bio-geochemistry applied to river basin management: Part I. Hydro-climatology, hydrograph separation, mass transfer balances, stable isotopes, and modeling. Applied Geochemistry, v. 20, n. 9, p. 1746-1829, 2005. http://dx.doi.org/10.1016/j.apgeochem. 2005.06.001

THIBERT, S. Exportations naturelles et anthropiques des ions majeurs et des élements nutritifs dans le bassin de la Seine: approches méthodologiques. 1994. Thése (Doctorale) - Université Pierre et Marie Curie, Paris, 1994.

VERBANCK, M.; VANDERBORGHT, J. P.; WOLLAST, R. Major ion content of urban wastewater: an assessment of per capita loading. Research Journal of the Water Pollution Control Federation, v. 61, p. 1722-1728, 1989. 


ISSN = 1980-993X - doi:10.4136/1980-993X
www.ambi-agua.net
E-mail: ambi-agua@agro.unitau.br
Tel.: (12) 3625-4212

\title{
Urbanização e escoamento superficial na bacia hidrográfica do Igarapé Tucunduba, Belém, PA, Brasil
}

\author{
(http://dx.doi.org/10.4136/ambi-agua.905)
}

\author{
Marcelo dos Santos Targa ${ }^{1}$; Getulio Teixeira Batista ${ }^{1}$; Hélio Nóbile Diniz ${ }^{2}$ \\ Nelson Wellausen Dias ${ }^{3}$; Fernando Cardoso de Matos ${ }^{4}$ \\ ${ }^{1}$ Programa de Pós-Graduação em Ciências Ambientais, Universidade de Taubaté - UNITAU \\ e-mail: agenormicaeli@yahoo.com.br; mtarga@unitau.br; \\ e-mail: getulio@agro.unitau.br; \\ ${ }^{2}$ Instituto Geológico do Estado de São Paulo - IG/SMA, São Paulo, SP \\ e-mail: heliodiniz1@yahoo.com.br \\ ${ }^{3}$ Instituto Brasileiro de Geografia e Estatística - IBGE, Aracajú, SE \\ e-mail: nelson.dias@ibge.gov.br, nwdias@gmail.com \\ ${ }^{4}$ Instituto Federal de Educação, Ciência e Tecnologia do Pará, IFPA, Belém, PA \\ e-mail: matos2001@gmail.com
}

\section{RESUMO}

O presente trabalho teve por objetivo estudar o escoamento superficial decorrente da ocupação desordenada na área do Igarapé Tucunduba, em Belém do Pará, no período de 1972 a 2006. Caracterizada por um processo de urbanização iniciado na década de 60 por uma população de baixa renda e com carência de serviços de infraestrutura. A urbanização modifica a superfície do solo interferindo na fase terrestre do ciclo hidrológico, pois em geral reduz a área de infiltração, aumenta o escoamento superficial e o coeficiente de Escoamento. Foi utilizada uma base cartográfica de uso e ocupação do solo da bacia desenvolvida com o apoio de fotografias aéreas ortorretificadas dos anos de 1972, 1977 e 1998 e de uma imagem do satélite SPOT de 2006. A construção de mapas e avaliação dos processos de urbanização foram possibilitadas por meio de ferramentas do software ArcGis ${ }^{\mathrm{TM}}$. Para a estimativa da infiltração potencial (S) e da precipitação efetiva $(\mathrm{Pe})$ em função de chuvas máximas de duração igual ao tempo de concentração da bacia, foi utilizado a metodologia Curva Número do Natural Resources Conservation Service (NRCS). Foram utilizados os dados pluviométricos calculados a partir da equação de chuva máxima da cidade de Belém, adaptados para Tempos de retorno que variaram de 2, 5, 10, 15, 20, 25, 50, 100 e 200 anos. Os resultados mostraram um aumento da densidade populacional (classes urbanizadas elevada e média) e diminuição da área na classe de baixa densidade populacional (mata de capoeira) na análise temporal dos anos 1972, 1977, 1998 e 2006, e, como consequência, um valor de precipitação efetiva maior, assim como, um valor de coeficiente de escoamento (C) também maior.

Palavras-chave:, ciências ambientais, uso do solo, sistema de informação geográfica.

\section{Urbanization and runoff in the Tucunduba hydrographic basin, Belém, PA, Brazil}

\begin{abstract}
The present work investigated the runoff resulting from urban sprawl in the area of Tucunduba basin, in Belem, in the period between 1972 and 2006, which is characterized by a
\end{abstract}


TARGA, M. S.; BATISTA, G. T.; DINIZ, H. D.; DIAS, N. W.; MATOS, F. C. Urbanização e escoamento superficial na bacia hidrográfica do Igarapé Tucunduba, Belém, PA, Brasil. Ambi-Agua, Taubaté, v. 7, n. 2, p. 120-142, 2012. (http://dx.doi.org/10.4136/ambi-agua.905)

urbanization process started in the 1960 s by low income population without adequate infrastructure services. Urbanization modifies the soil surface interfering on the ground phase of the hydrological cycle, inasmuch as it reduces the area of infiltration, increases runoff, and the runoff coefficient. A geographic database with land use and land cover map layers extracted from orthophotos acquired in 1972, 1977, and 1998 and a SPOT satellite image acquired in 2006 were used. Digital maps and analysis of the urbanization processes were supported by tools available in ArcGISTM software package. To estimate the infiltration potential (S) and effective rainfall $(\mathrm{Pe})$, as a function of rainfall duration equal to the maximum time of concentration of the water in the basin, Curve Number methodology proposed by the Natural Resources Conservation Service (NRCS) was applied. Rainfall estimates were calculated using the maximum rain equation for the city of Belém, with return times specified at 2, 5, 10, 15, 20, 25, 50, 100, and 200 years. The results showed an increase in areas of high and medium population density (urban) and reduced area of low population density (secondary forest growth) for the years of 1972, 1977, 1998, and 2006, that generated a higher effective precipitation value and, therefore, a higher effective runoff coefficient value $(\mathrm{C})$.

Keywords: environmental sciences, land use, geographic information system.

\section{INTRODUÇÃO}

A necessidade de o homem ocupar novos espaços, seja para moradia ou para realização de atividades econômicas, tem-se tornado cada vez maior e esse fato tem provocado a ocupação, não planejada, principalmente de áreas marginais aos cursos d'água e, com isso, gerado impactos negativos e criado ambientes hostis à vida humana.

Em várias áreas urbanas do Brasil, em especial, os cursos d'água, em geral, são transformados em canais retificados onde se despeja tanto a água pluvial, quanto os efluentes domésticos não tratados. Nessa situação, se enquadra a bacia do Igarapé Tucunduba, em Belém, PA, que apresenta um cenário de ocupação com considerável degradação ambiental. Nas margens do igarapé Tucunduba, por exemplo, existe o comércio de madeiras, telhas, tijolos, carvão, açaí, além do lançamento dos efluentes do comércio e das residências diretamente no corpo hídrico, os quais alteram a qualidade da água.

Em condições naturais, os igarapés, nome regional para rios de pequena ordem, são componentes importantes da floresta (Lima e Gascon 1999), pois sustentam uma fauna diversa que depende principalmente do material orgânico proveniente das florestas adjacentes.

Por outro lado, no processo de escoamento de água proveniente de precipitações máximas, ocorre a interação entre fatores como o uso e cobertura do solo, a declividade e a forma da bacia hidrográfica. Nesse contexto, a maior alteração da superfície de uma bacia resulta da urbanização que causa a impermeabilização do solo, diminui a infiltração e aumenta o escoamento superficial ocasionando cheias e inundações.

Além dos aspectos já mencionados, a cidade de Belém possui um sistema de drenagem ineficiente para escoar toda a água pluvial quando das ocorrências de chuvas intensas rápidas, ou ainda de chuvas contínuas, quando combinadas com a maré alta. Isso devido ao fato da cidade de Belém ser circundada pelos Rios Guamá e Guajará e devido às águas subterrâneas e aos igarapés sofrerem forte influência das marés (Tavares, 1998 ).

O objetivo desse trabalho foi estimar a precipitação efetiva e os coeficientes de escoamento, em função das mudanças no uso e ocupação do solo no período de 1972 a 2006, 
TARGA, M. S.; BATISTA, G. T.; DINIZ, H. D.; DIAS, N. W.; MATOS, F. C. Urbanização e escoamento superficial na bacia hidrográfica do Igarapé Tucunduba, Belém, PA, Brasil. Ambi-Agua, Taubaté, v. 7, n. 2, p. 120-142, 2012. (http://dx.doi.org/10.4136/ambi-agua.905)

na bacia hidrográfica do igarapé Tucunduba, em Belém, PA por meio das técnicas de Curva Número e de geoprocessamento.

\subsection{Bacia Hidrográfica e Urbanização}

A bacia hidrográfica é definida como o conjunto de terras limitadas por divisores de águas contendo uma rede de drenagem que drena a água para um único ponto denominado exutório. O sistema de drenagem da bacia é composto de nascentes dos cursos de água, principais e secundários, denominados afluentes e subafluentes (Targa, 2008).

O tempo de viagem da água da chuva que cai na região mais remota da bacia até o exutório é chamado de Tempo de concentração da bacia (Tc). O uso do solo pode alterar as características naturais, modificando as quantidades de água que infiltram, que escoam e que evaporam, alterando o tempo de viagem da água e o comportamento hidrológico de uma bacia. Algumas das mais agressivas formas de modificação do uso e ocupação de uma bacia hidrográfica consistem no desmatamento e na urbanização.

De modo geral, a cobertura vegetal interfere nos mecanismos de transporte de águas superficiais e subterrâneo, reduz a erosão e aumenta o potencial de infiltração, sendo fundamental para a recarga dos aquíferos (Lima, 2008).

Segundo Tucci (2008), o crescimento urbano ocorrido nas últimas décadas transformou o Brasil num país essencialmente urbano ( $83 \%$ de população urbana). O município de Belém (PA), por exemplo, cresceu com taxas médias de aproximadamente 3,6\% ao ano entre 1980 e 2000 (Faure, 2002).

A Região Norte, com o maior potencial hídrico do país, em geral possui baixa densidade populacional (Rebouças, 2002), por outro lado, segundo Castro (2003), a cidade de Belém consistiu na experiência de maior aglomeração urbana em toda a região amazônica. $\mathrm{Na}$ região conhecida como Grande Belém tem sido registradas as taxas mais altas de ocupação humana na Amazônia, nos últimos 20 anos.

Para Tucci (1997), os principais impactos provocados pela urbanização nas redes de drenagem são o aumento do escoamento superficial, redução da evapotranspiração, redução do escoamento subterrâneo, rebaixamento do lençol freático, aumento da produção de material sólido proveniente de limpeza de ruas e da armazenagem inadequada do lixo pela população resultando na deterioração da qualidade das águas superficiais e subterrâneas. A qualidade da água da rede pluvial depende de vários fatores: limpeza urbana e sua frequência, intensidade da precipitação e sua distribuição no tempo e no espaço, bem como da época do ano e do tipo de uso da área urbana (Tucci, 2002).

\subsection{Geoprocessamento e uso do solo}

Sistemas de informação geográfica (SIG) constituem um poderoso conjunto de ferramentas que possibilita colecionar, armazenar, recuperar, transformar e exibir dados espaciais referenciados ao mundo real (Burrough, 1986). Esta tecnologia permitiu otimizar, de forma mais eficiente e ampla, as técnicas tradicionais que dependem da integração de dados cartográficos e tabulares, estabelecendo, não apenas correlações espaciais, mas também relações de causa e efeito e identificação de variações ao longo do tempo (Towshend, 1992). Uma das principais vantagens de um SIG direcionado para análise do espaço urbano é a possibilidade de integrar dados de diferentes fontes e formatos e, assim, gerar novas informações pelo cruzamento destes dados (Pereira e Silva, 2001). No Brasil, o uso do geoprocessamento no estudo de bacias hidrográficas é bastante difundido e diversificado. Machado et al. (2003) aplicaram um sistema de modelagem hidrológica para a geração de cenários alternativos de uso do solo para simular a produção de sedimentos em uma microbacia. Nascimento et al. (2005) analisaram os conflitos entre uso do solo com as áreas 
TARGA, M. S.; BATISTA, G. T.; DINIZ, H. D.; DIAS, N. W.; MATOS, F. C. Urbanização e escoamento superficial na bacia hidrográfica do Igarapé Tucunduba, Belém, PA, Brasil. Ambi-Agua, Taubaté, v. 7, n. 2, p. 120-142, 2012. (http://dx.doi.org/10.4136/ambi-agua.905)

de preservação permanente (APP) identificadas automaticamente em uma bacia hidrográfica pelo cruzamento de informações espaciais. Santos et al. (2007) integraram informações sobre o meio físico, qualidade da água e dados socioeconômicos para melhor compreender a organização social e o manejo do uso da terra das propriedades rurais de uma bacia hidrográfica.

A aplicação da técnica de geoprocessamento possibilita a determinação acurada da variação do uso e ocupação do solo de uma bacia hidrográfica no tempo e no espaço e assim permite maior precisão no cálculo do escoamento superficial na forma de precipitação efetiva.

O método Curva Número, considerado o método mais utilizado para a estimativa do escoamento superficial em bacias hidrográficas, pode fornecer melhor resultado quando se faz uso das técnicas de geoprocessamento. Aguiar et al. (2007), por exemplo, utilizaram o método Curva Número $(\mathrm{CN})$ e aplicaram técnicas de geoprocessamento para melhor definir as condições de infiltrabilidade pelas diferentes classes de uso da bacia do ribeirão Itaim no Vale do Paraíba Paulista. Machado et al. (2003) utilizaram o modelo SWAT para simular o escoamento superficial na bacia hidrográfica do ribeirão dos Marins, afluente do rio Piracicaba, e utilizaram o CN para calibração do modelo. As classes mais impermeáveis apresentam $\mathrm{CN}$ mais elevados e, portanto, indicam menor potencial de infiltração e maior escoamento superficial da água.

O NRCS (1997) distingue no método Curva Número os grupos hidrológicos de solos (A, $\mathrm{B}, \mathrm{C}$ e D) os quais apresentam as seguintes características:

Grupo A - Solos que produzem baixo escoamento superficial e alta infiltração (arenosos com baixo teor de argila total, inferior a $8 \%$ ).

Grupo B - Solos menos permeáveis que o anterior, arenosos menos profundos que os do Grupo A e com permeabilidade superior a média (teor de argila ainda inferior a $15 \%$ ).

Grupo C - Solos que geram escoamento superficial acima da média e com capacidade de infiltração abaixo da média, contendo considerável porcentagem de argila e pouco profundo (barrentos com teor total de argila de 20 a $30 \%$ mas sem camadas argilosas impermeáveis ou contendo pedras até profundidades de 1,2 m).

Grupo D - Solos contendo argilas expansivas e pouco profundos com muito baixa capacidade de infiltração e alta capacidade de escoamento (argilosos 30 - $40 \%$ de argila e ainda com camada densificada a uns $50 \mathrm{~cm}$ de profundidade.

$\mathrm{Na}$ medida em que uma bacia vai sendo urbanizada, também vai ocorrendo o aumento do escoamento superficial. Como resultado do aumento da impermeabilização, uma maior parcela da precipitação se transforma em escoamento na bacia e com isso aumenta o valor do coeficiente de escoamento superficial (C). Dessa forma, o coeficiente C é de grande importância na avaliação da capacidade de sistemas de drenagens.

Estudos de análise temporal da expansão urbana no entorno do Igarapé Tucunduba, Belém, PA, Brasil no período de 1972 a 2006, por meio de técnicas de geoprocessamento e visitas em campo, demonstraram que a área de vegetação nativa diminuiu e a urbanização aumentou no período (Matos et al., 2011).

\section{MATERIAL E MÉTODOS}

\subsection{Caracterização física da área de estudo}

O igarapé Tucunduba (Figura 1) tem sua nascente localizada nas coordenadas $1^{\mathrm{o}} 26^{\text {' }}$ 10,38" S e 48 27' 15,84" O, na Travessa Angustura, 3579, no bairro do Marco e seu exutório na margem direita do Rio Guamá nas coordenadas $1^{\circ} 28^{\prime} 35,95^{\prime}$ ' S e $48^{\circ} 27^{\prime} 13,11^{\prime \prime} \mathrm{O}$. Sua bacia possui aproximadamente 1.055 ha, dos quais 575 ha são áreas de "baixadas" que correspondem a $21 \%$ das áreas de várzea da área urbana de Belém (Belém, 2001). 


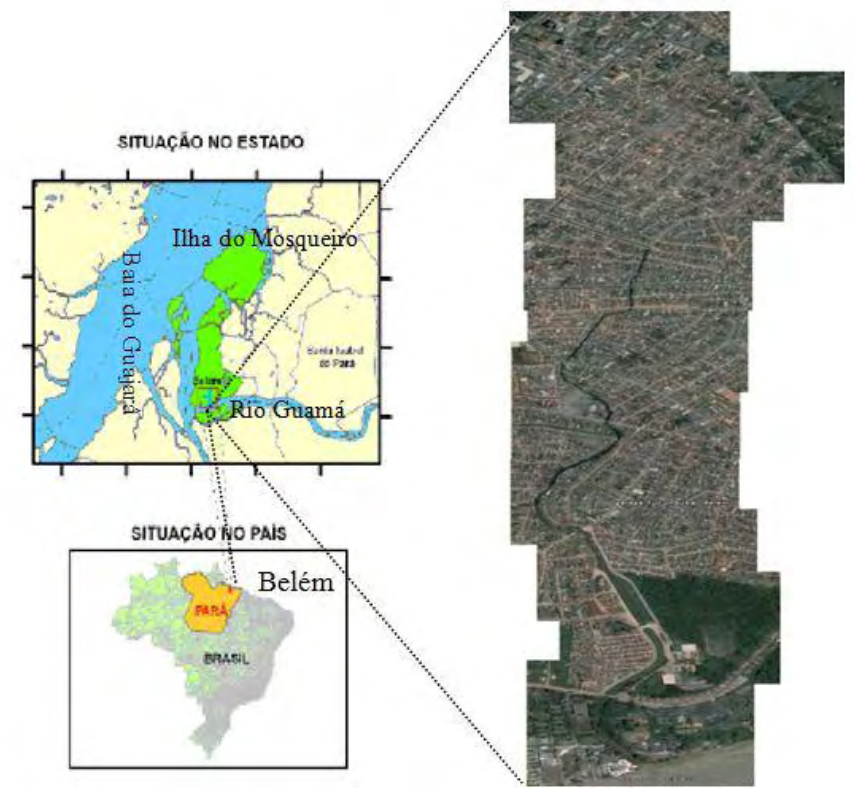

Figura 1. Localização da área de estudo, (Igarapé Tucunduba)

Fonte: Matos et al. (2011) .

\subsubsection{Topografia}

A área de estudo é uma bacia urbanizada que drena para o rio Guamá e este para a baia do Guajará. Esta baia está localizada numa região estuarina, ou seja, um ambiente fluvial com importante influência marinha, com oscilação típica de mesomaré com alcance médio de $3 \mathrm{~m}$. Os terrenos continentais adjascentes à baia, onde se situa a área de estudo, se dividem em duas unidades fisiográficas, Terra Firme e Várzeas (Pará, 2002). Nas Várzeas, as marés são o principal agente transportador de sedimentos e material orgânico em suspensão (Pinheiro, 1987). A porção de Terra Firme que ocorre na área de estudo não possui grande amplitude topográfia em função de sua proximidade à área do estuário.

Portanto, a bacia do Tucunduba possui baixa declividade com elevação variando de 0 a 3 metros na parte baixa da bacia e de 15 a $18 \mathrm{~m}$ na área de maior elevação (Cacela Filho et al., 2007). Essa baixa variação de altitude proporciona pequeno gradiente entre as áreas de nascente e o exutório e faz com que os escoamentos ocorram mais lentamente.

\subsubsection{Clima}

Pela classificação de Köppen, o clima de Belém é quente e úmido. A temperatura média varia entre 22 e $25^{\circ} \mathrm{C}$. A umidade relativa do ar chega a $91 \%$ nos meses mais chuvosos. Sem estações climáticas definidas, possui dois períodos sazonais: chuvoso (dezembro a maio) e menos chuvoso (julho a novembro). A precipitação média anual varia entre 2.500 a 3.000 mm, logo Belém é uma das cidades mais chuvosas do Brasil (Nascimento, 1995). A estação chuvosa de dezembro a maio é regionalmente chamada de Inverno e é quando ocorrem as chuvas mais intensas. A estação menos chuvosa é regionalmente chamada de Verão.

O balanço hídrico médio mensal no período de 1972 a 1990, pelo método de Thornthwaite-Mather, foi elaborado por Rolim et al. (1998) adotando uma capacidade de água disponível (CAD) de $100 \mathrm{~mm}$ e utilizando o programa "BHnorm" (Figura 2), demonstraram que o município de Belém apresenta excedente hídrico no solo em praticamente todos os meses do ano. 
TARGA, M. S.; BATISTA, G. T.; DINIZ, H. D.; DIAS, N. W.; MATOS, F. C. Urbanização e escoamento superficial na bacia hidrográfica do Igarapé Tucunduba, Belém, PA, Brasil. Ambi-Agua, Taubaté, v. 7, n. 2, p. 120-142, 2012. (http://dx.doi.org/10.4136/ambi-agua.905)

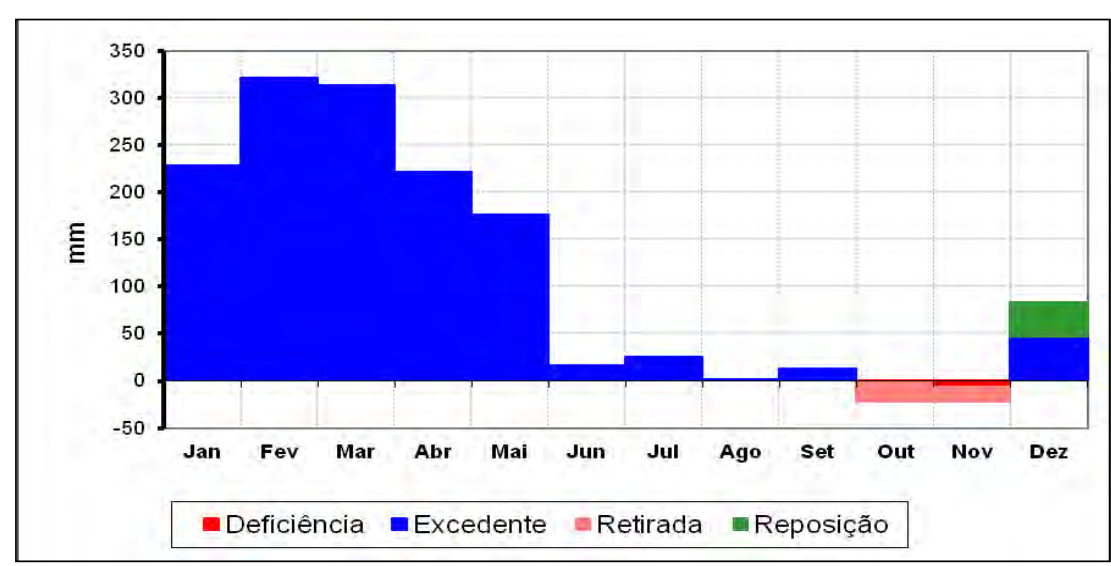

Figura 2. Balanço hídrico mensal do município de Belém, PA, no período de 1972 a 1990.

Fonte: Rolim et al. (1998).

Conforme Villela e Matos (1975), para utilização prática dos dados de chuva em sistemas de drenagem superficial faz-se necessário o conhecimento da intensidade, duração e frequência das chuvas. Uma das formas de relacionar essas características da chuva se dá por meio das chamadas equações de chuvas, dentre as quais, a mais amplamente utilizada é a expressa na Equação 1.

$$
I=\frac{K \operatorname{Tr}^{a}}{(t+b)^{c}}
$$

em que:

$I=$ Intensidade de precipitação média máxima $(\mathrm{mm} / \mathrm{h})$

$\operatorname{Tr}=$ Período de retorno (anos)

$t=$ tempo de duração da precipitação em (min)

$K, a, b, c=$ Parâmetros de ajuste da equação

Vários autores têm se preocupado com a definição de equações de chuvas intensas para os diversos estados do Brasil, o que significa que em curto espaço de tempo poderá se ter estruturas hidráulicas e planos de macro drenagem dimensionados em bases técnicas. Os principais autores são: Martinez Junior e Magni (1999), Genovez e Zuffo (2000), para o Estado de São Paulo, Oliveira et al. (2005) para o Estado de Goiás e Distrito Federal, Pinto (1995) para o Estado de Minas Gerais, Santos et al. (2009) para o Estado de Mato Grosso do Sul, Scaramussa et al. (2010) para o Estado do Pará, Pfastetter (1982) e Pruski et al. (2002) para o Brasil.

Com a finalidade de se calcular o escoamento máximo no exutório da bacia, adotou-se neste trabalho o tempo de duração da precipitação máxima igual ao Tempo de concentração (Tc), o qual é definido como o tempo necessário para que a água que caiu no ponto mais distante chegue até o exutório da bacia. Sua estimativa foi baseada na velocidade média do escoamento superficial que é a função do espaço a ser percorrido e da diferença de nível entre o ponto mais afastado na bacia e o ponto de controle considerado (exutório da bacia), sendo calculado pela equação de Kirpich (1940) (Equação 2).

$$
T c=57 *\left(\frac{L^{3}}{H}\right)^{0,385}
$$


TARGA, M. S.; BATISTA, G. T.; DINIZ, H. D.; DIAS, N. W.; MATOS, F. C. Urbanização e escoamento superficial na bacia hidrográfica do Igarapé Tucunduba, Belém, PA, Brasil. Ambi-Agua, Taubaté, v. 7, n. 2, p. 120-142, 2012. (http://dx.doi.org/10.4136/ambi-agua.905)

em que:

$T c=$ Tempo de Concentração (min)

$L=$ Comprimento do Talvegue $(\mathrm{Km})$

$H=$ Diferença de nível entre o ponto mais afastado e o ponto de controle considerado (m)

Considerando as características da bacia do Igarapé Tucunduba de 3,6 Km e uma diferença de nível de $18 \mathrm{~m}$ entre o ponto mais afastado e o ponto de controle considerado (exutório da bacia ), chega-se ao valor de Tempo de Concentração de 82 minutos.

Parâmetros da equação de chuvas intensas foram obtidos de estudos preliminares das relações I-D-F (Intensidade-Duração-Frequência) para a cidade de Belém, no estado do Pará (Scaramussa et al., 2010). Com base na Equação 1, é possível estabelecer Equação 3 de Intensidade de precipitação máxima para a cidade de Belém.

$$
I=\frac{1256,6 \operatorname{Tr}^{0,0944}}{(t+8,13)^{0,767}}
$$

A parcela da precipitação que causa o escoamento superficial é denominada precipitação efetiva (Pe) a qual é calculada pelo método Curva Número $(\mathrm{CN})$ utilizando-se as Equações 4 e 5. O coeficiente de escoamento $(\mathrm{C})$ indica a proporção da chuva de projeto que descarrega rapidamente no sistema de drenagem da bacia e que contribui para a descarga de pico. Seu valor é diretamente dependente das características de infiltração do solo e das características de detenção e retenção da bacia (Targa, 2011). Dessa forma, o coeficiente de escoamento "C" é o adimensional que reflete a relação entre a precipitação efetiva e a precipitação total e pode ser calculado pela Equação 6.

$$
\begin{aligned}
& P e=\frac{(P-0,2 S)^{2}}{(P+0,8 S)} \\
& S=\frac{25400}{C N}-254 \\
& C=\frac{(P-0,2 S)^{2}}{(P+0,8 S)} * \frac{1}{P}
\end{aligned}
$$

em que:

Pe: escoamento superficial ou precipitação efetiva $(\mathrm{mm})$

P: precipitação máxima em dado período de retorno $(\mathrm{mm})$

S: Infiltração potencial (mm)

CN: Número da Curva, adimensional

C: coeficiente de escoamento, adimensional

$\mathrm{O}$ valor adimensional do $\mathrm{CN}$ deve ser definido por meio de tabelas, contudo em situações onde existe variação do uso e cobertura, o estabelecimento de um valor de $\mathrm{CN}$ ponderado (Targa, 2011) para a bacia pode melhorar a estimativa do volume de escoamento, o que pode ser obtido pela Equação 7. 
TARGA, M. S.; BATISTA, G. T.; DINIZ, H. D.; DIAS, N. W.; MATOS, F. C. Urbanização e escoamento superficial na bacia hidrográfica do Igarapé Tucunduba, Belém, PA, Brasil. Ambi-Agua, Taubaté, v. 7, n. 2, p. 120-142, 2012. (http://dx.doi.org/10.4136/ambi-agua.905)

$$
\text { CNpond }=\frac{\sum\left(C N_{c}\left(A_{c}\right)\right)}{A_{t}}
$$

em que:

$\mathrm{CN}_{\text {pond }}=$ Valor do Número da Curva ponderado, adimensional

$\mathrm{CN}_{\mathrm{c}}=$ Valor do número da curva de cada classe de uso e cobertura do solo da bacia, adimensional

$\mathrm{A}_{\mathrm{c}}=$ Área de cada classe de uso e cobertura do solo da bacia em $\mathrm{km}^{2}$

$\mathrm{A}_{\mathrm{t}}=$ Área total da bacia em $\mathrm{km}^{2}$

\subsubsection{Uso e Ocupação}

Para a análise da evolução da ocupação urbana e da redução das áreas florestadas do igarapé do Tucunduba em Belém, PA, foram utilizadas imagens aerofotogramétricas dos anos de 1972 e 1977 (em preto e branco) e de 1998 (coloridas) na escala 1:2.000 e corrigidas cartograficamente para projeção ortogonal. Para o ano de 2006 foi utilizada uma imagem georreferenciada do satélite SPOT com resolução espacial de 5 metros, o que permite gerar informações na escala 1:5.000. Todas essas imagens foram armazenadas em um banco de dados geográfico (BDG) utlizando o programa ArcGIS, versão 9.0. Por meio da interpretação visual das imagens foram geradas informações sobre uso e ocupação do solo na bacia (Matos et al., 2011). No mesmo BDG foram empregadas técnicas de cruzamento de planos de informação geográfica disponíveis no programa ArcGIS para diagnosticar o avanço da urbanização na área do Igarapé do Tucunduba.

O uso e ocupação da área da bacia Tucunduba foram classificados segundo o grau de ocupação em alta, média e baixa conforme proposta de Ferreira (1995), da seguinte forma:

I - Classe Baixa Ocupação - adotada em situações de ocorrência de áreas em que há presença de árvores nas ruas, gramados nas áreas de passagem, casas com jardim e quintal, os recuos entre as edificações são mais amplos e estas não se unem umas às outras, permitindo uma maior ventilação e há uma menor concentração de pessoas.

II - Classe Média Ocupação - adotada quando a urbanização não é tão adensada, mas já se observa uma aproximação entre as moradias e uma diminuição das áreas verdes.

III - Classe Alta Ocupação - adotada quando se observa que as construções ficam encostadas umas as outras e praticamente não se tem área verde, as calçadas são estreitas, as ruas asfaltadas e existem estivas dando acesso à margem do igarapé. Além de uma maior concentração de pessoas na classe alta ocupação, em geral há pouca ventilação e o consequente aumento de temperatura.

Segundo Santos (1997), as vegetações de capoeira e de várzea apresentam características semelhantes e representam uma vegetação não muito exuberante, devido às condições físicoquímicas do solo, enquanto que a floresta de igapó é encontrada em níveis topográficos mais baixos e, portanto, em regiões alagadas, como a do Igarapé Tucunduba.

Os solos da várzea do Igarapé apresentam drenagem fraca e são argilosos e úmidos. Porém, ficam encharcados somente no inverno e apresentam $\mathrm{pH}$ neutro na sua parte superior, sendo estas várzeas do tipo "várzea de maré", pois se enriquecem continuamente com os depósitos deixados pelas marés (Moreira, 1966).

De acordo com a classificação de solo do NRCS (USDA, 1997), os solos da bacia Tucunduba são classificados nos Tipos A e D (Figura 3) sendo o tipo D o de maior grau, pois corresponde aos solos que contêm argilas expansivas, com muito baixa capacidade de infiltração e geralmente associados com escoamento superficial alto (Cacela Filho et al., 2007), além de ocuparem uma área maior na bacia. 
TARGA, M. S.; BATISTA, G. T.; DINIZ, H. D.; DIAS, N. W.; MATOS, F. C. Urbanização e escoamento superficial na bacia hidrográfica do Igarapé Tucunduba, Belém, PA, Brasil. Ambi-Agua, Taubaté, v. 7, n. 2, p. 120-142, 2012. (http://dx.doi.org/10.4136/ambi-agua.905)

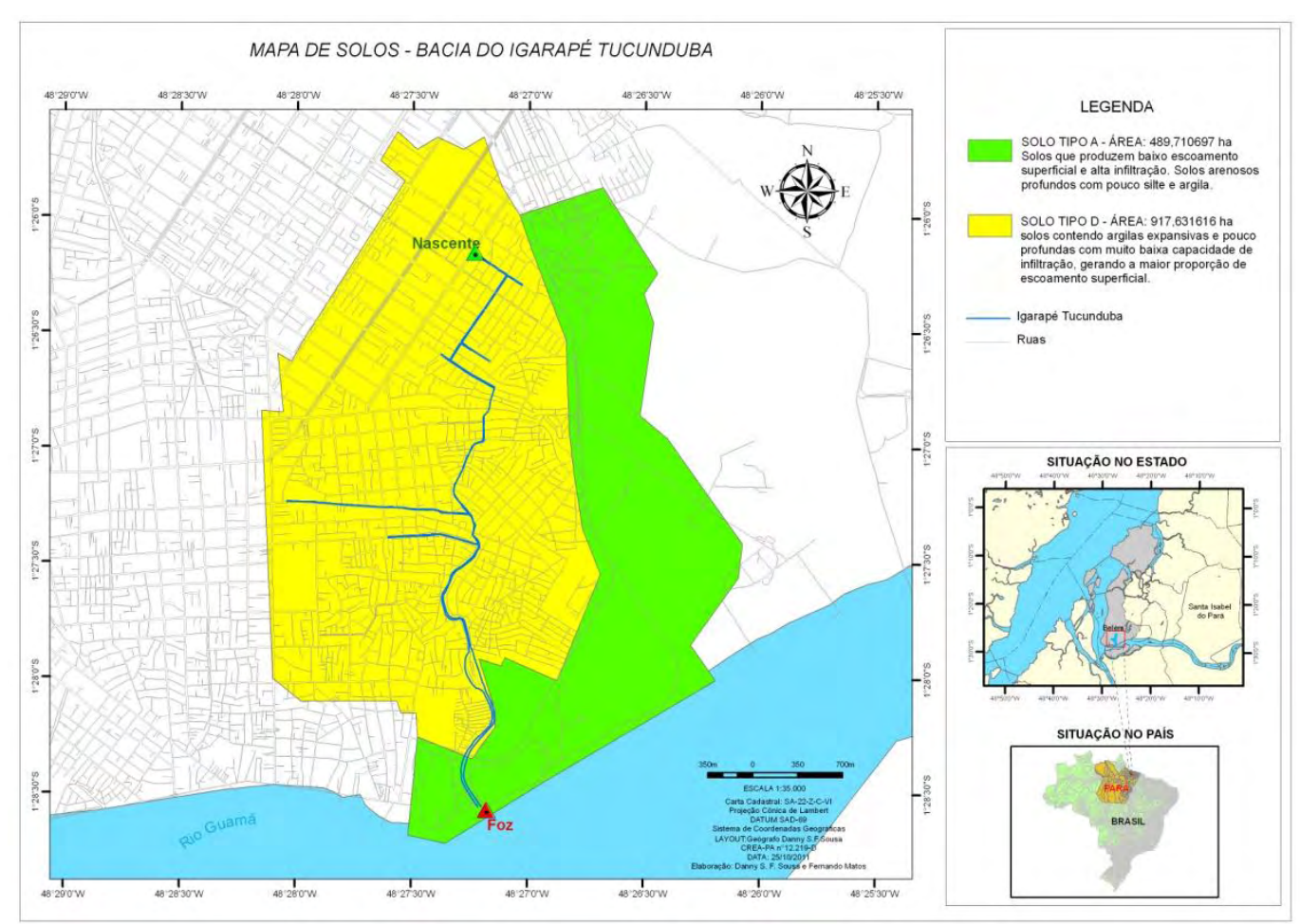

Figura 3. Bacia do Igarapé Tucunduba, com destaque para os solos em amarelo o tipo $\mathrm{D}$ e em verde tipo A.

Fonte:Adaptado de Cacela Filho et al. (2007).

\section{RESULTADOS E DISCUSSÃO}

\subsection{Evolução da ocupação urbana sobre a área do Igarapé Tucunduba}

Até a metade do século XX, o bairro do Guamá, em Belém do Pará, um dos bairros em que está localizado o igarapé do Tucunduba, era pouco habitado, mas já apresentava problemas de infraestrutura, com a maioria de suas casas de madeira e palha com imensos quintais, que mais pareciam sítios. As áreas de mata ofereciam muita caça e frutas para os poucos moradores (Ramos, 2002).

O processo de urbanização mais intenso no Brasil teve início a partir de 1940, como resultado da modernização econômica e do grande desenvolvimento industrial devido a injeção de capital estrangeiro no país. Contudo, a Amazônia só foi integrada ao restante do Brasil a partir de 1950 com a criação, pelo governo federal, do Programa de Integração Nacional (PIN), que pretendia ligar a Amazônia ao restante do país. A construção, da rodovia Belém-Brasília repercutiu de forma intensa e transformadora na capital do estado do Pará, por meio da migração e da entrada de produtos industrializados de outras regiões (Matos et al., 2011).

Na medida em que uma cidade se urbaniza, segundo Tucci (1997), em geral ocorre:

I - Aumento das vazões máximas devido ao aumento da capacidade de escoamento através do sistema de drenagem (condutos e canais) e da superfície impermeável;

II - Aumento da produção de sedimentos devido à desproteção da superfície e a produção de resíduos sólidos;

III - A deterioração da qualidade das águas superficiais, principalmente no início das chuvas que lavam as superfícies impermeáveis e carreiam material sólido. 
TARGA, M. S.; BATISTA, G. T.; DINIZ, H. D.; DIAS, N. W.; MATOS, F. C. Urbanização e escoamento superficial na bacia hidrográfica do Igarapé Tucunduba, Belém, PA, Brasil. Ambi-Agua, Taubaté, v. 7, n. 2, p. 120-142, 2012. (http://dx.doi.org/10.4136/ambi-agua.905)

Segundo Ferreira (1995), na cidade de Belém no estado do Pará, a construção de um grande dique na década de 1940, de $6 \mathrm{Km}$ de extensão, para a contenção das águas do rio Guamá e ensecamento das várzeas adjacentes, pelo Serviço Especial de Saúde Pública (SESP), propiciou uma valorização maior das áreas da referida orla e, principalmente, depois da construção, sobre o dique, na atual avenida Bernardo Sayão.

As áreas de várzea do igarapé Tucunduba ficaram à margem da expansão da malha urbana de Belém até o início da década de 1960, sendo urbanizada somente na década de 1970, ocasião em que houve grandes transformações no contexto político, econômico e social de Belém, devido à intensa ocupação das planícies pela população que migrava para a capital ou que se deslocava de setores mais valorizados da cidade. No processo de ocupação do Tucunduba, logo após o desmatamento da área, ocorreu a colocação das estivas de madeira para a construção de palafitas (Figura 4). Uma vez instalada, a população utilizou laterita ou piçarra, lixo e outros detritos, como caroços de açaí e serragem para constituir aterro para acesso às palafitas. Na sequência, o lixo ou a laterita depositados nas ruas foram aproveitados também para aterrar a frente das palafitas, provocando represamento ou estagnação de água sob as casas. As ruas aterradas, no lugar das estivas de madeira, propiciaram a retificação de canais de drenagem, a instalação de ruas laterais, e a substituição gradativa das palafitas de madeira por casas de alvenaria (Ferreira, 1995).

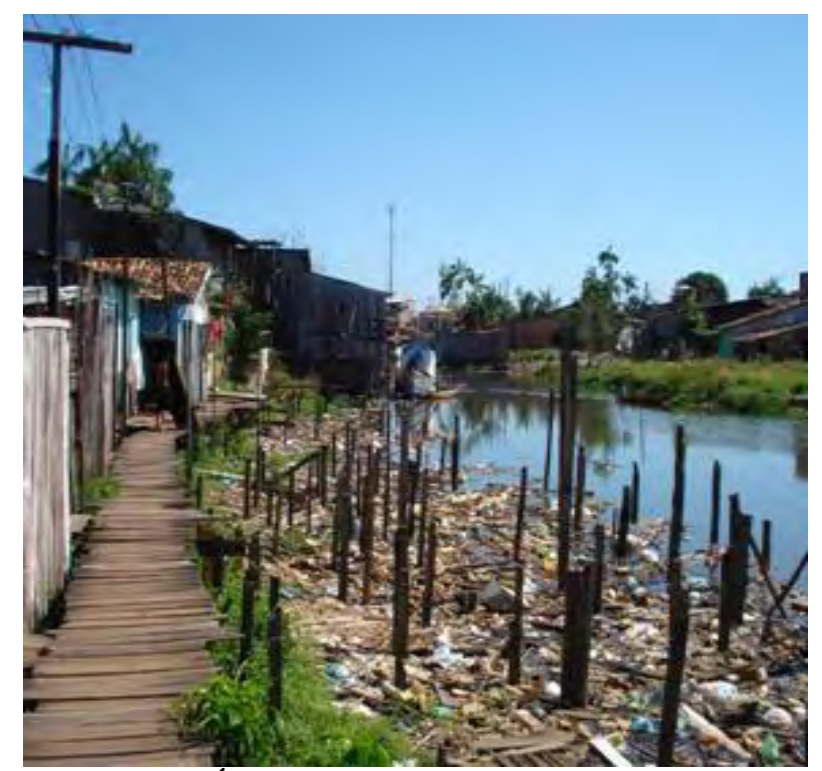

Figura 4. Área de ocupação do Igarapé com estivas de madeira

A análise auxiliada por técnicas de geoprocessamento permitiu avaliar a evolução do processo de urbanização da bacia Tucunduba na cidade de Belém nos anos de 1972, 1977, 1998 e 2006 (Matos et al., 2011). Em 1972, a maior parte da área era ocupada pela Classe Baixa Ocupação com mais de 4,3 $\mathrm{km}^{2}$, contudo, já se observava também uma área de mais de $1,8 \mathrm{~km}^{2}$ na Classe Média Ocupação.

Já em 1977, a área que representa a Alta ocupação aumentou em quase $2 \mathrm{~km}^{2}$ em relação a 1972, em detrimento das áreas de Média e Baixa ocupação.

Em 1998, passados 26 anos em relação a 1972, com uma área de mais de 7,5 km², a Alta ocupação predominava e existia apenas uma área de $0,2 \mathrm{~km}^{2}$ de Média Ocupação. A área definida como Baixa Ocupação, que predominava em 1972, reduziu de 4,3 km² para $1,1 \mathrm{~km}^{2}$. Contudo, a Classe Alta Ocupação, no período de 1998 a 2006, manteve-se praticamente igual. Isso pode ser atribuído à intervenção do poder público que a partir de 2000 implantou um 
TARGA, M. S.; BATISTA, G. T.; DINIZ, H. D.; DIAS, N. W.; MATOS, F. C. Urbanização e escoamento superficial na bacia hidrográfica do Igarapé Tucunduba, Belém, PA, Brasil. Ambi-Agua, Taubaté, v. 7, n. 2, p. 120-142, 2012. (http://dx.doi.org/10.4136/ambi-agua.905)

plano de macrodrenagem no igarapé. Observa-se também que nesse período a classe Média Ocupação era menor que no ano de 1972, porém maior que em 1977 e 1998.

$\mathrm{Na}$ Figura 5 apresentam-se imagens representativas da evolução da urbanização no período de 1972 a 2006 na bacia do igarapé Tucunduba, em Belém, PA. Ressalta-se no ano de 2006 a melhor definição do canal principal devido à implantação do plano de macrodrenagem iniciado em 2000.

A evolução do processo de urbanização ocasionou o adensamento populacional e a consequente redução de $755 \%$ na área de vegetação nativa do igarapé, no período de 1972 para 2006 (Matos et al., 2011).

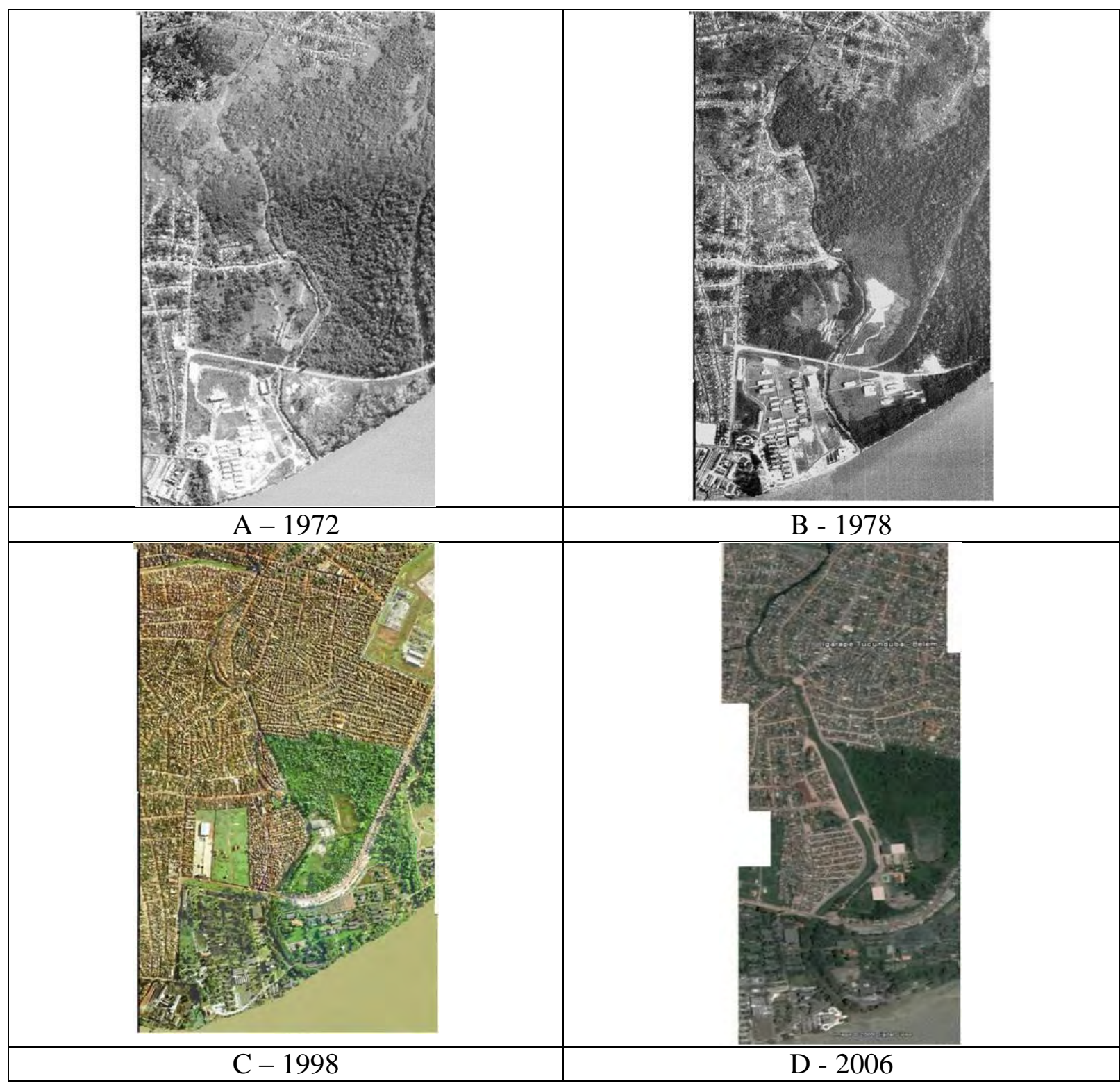

Figura 5. Imagens representativas da evolução da urbanização no período de 1972 a 2006 na bacia do igarapé Tucunduba, em Belém, PA.

Considerando os dados de Cacela Filho et al. (2007) e segundo a classificação de solo (USDA, 1997) com relação à capacidade de infiltração dos solos, a bacia é composta por solos do tipo A e D. Aproximadamente $35 \%$ da área do Tucunduba possui solo do Tipo A e $65 \%$ solo tipo D. Verificam-se nas Tabelas 1 e 2 a evolução da ocupação das áreas referentes aos solos A e D. 
TARGA, M. S.; BATISTA, G. T.; DINIZ, H. D.; DIAS, N. W.; MATOS, F. C. Urbanização e escoamento superficial na bacia hidrográfica do Igarapé Tucunduba, Belém, PA, Brasil. Ambi-Agua, Taubaté, v. 7, n. 2, p. 120-142, 2012. (http://dx.doi.org/10.4136/ambi-agua.905)

Tabela 1. Evolução da ocupação nas áreas de solo Tipo A no igarapé Tucunduba.

\begin{tabular}{c|cccc}
\hline \multicolumn{5}{c}{ Área $\left(\mathbf{K m}^{2}\right)$} \\
\hline Ocupação & 1972 & 1977 & 1998 & 2006 \\
\hline Alta & 1,43 & 2,54 & 4,45 & 4,49 \\
Média & 1,01 & 0,37 & 0,23 & 0,24 \\
Baixa & 2,45 & 1,98 & 0,22 & 0,16 \\
\hline
\end{tabular}

Tabela 2. Evolução da ocupação nas áreas de solo Tipo D no igarapé Tucunduba.

\begin{tabular}{c|cccc}
\hline \multicolumn{5}{c}{ Área $\left(\mathbf{K m}^{2}\right)$} \\
\hline Ocupação & 1972 & 1977 & 1998 & 2006 \\
\hline Alta & 2,68 & 4,77 & 8,33 & 8,42 \\
Média & 1,90 & 0,70 & 0,43 & 0,45 \\
Baixa & 4,60 & 3,72 & 0,41 & 0,30 \\
\hline
\end{tabular}

A Tabela 3 ilustra o percentual de modificação na urbanização na bacia. Pode-se observar que a Classe Alta Ocupação, em 1977, apresentou crescimento aproximadamente 78\% superior a 1972 e em 1998, cerca de 75\% superior a 1977. A Classe Média Ocupação perdeu pouco mais que 63\% de área em entre 1972 e 1977 e cerca de 37,5\% no período de 1977 a 1998. A Classe de Baixa Ocupação cerca de 19\% de área entre 1972 a 1977, quase $89 \%$ entre 1977 e 1998 e ainda, pouco mais de $26 \%$ entre 1998 e 2006.

Tabela 3. Evolução da ocupação para áreas de solos Tipo D+A em valores absolutos e percentuais na bacia do igarapé Tucunduba.

\begin{tabular}{|c|c|c|c|c|c|c|c|c|}
\hline & $\begin{array}{l}\text { Área } \\
\left(\mathbf{K m}^{2}\right)\end{array}$ & $(\%)$ & $\begin{array}{l}\text { Área } \\
\left(\mathbf{K m}^{2}\right)\end{array}$ & $(\%)$ & $\begin{array}{l}\text { Área } \\
\left(\mathbf{K m}^{2}\right)\end{array}$ & $(\%)$ & $\begin{array}{l}\text { Área } \\
\left(\mathbf{K m}^{2}\right)\end{array}$ & $(\%)$ \\
\hline Ocupação & \multicolumn{2}{|c|}{1972} & \multicolumn{2}{|c|}{1977} & \multicolumn{2}{|c|}{1998} & \multicolumn{2}{|c|}{2006} \\
\hline Alta & 4,11 & 100 & 7,31 & 77,83 & 12,78 & 74,83 & 12,91 & 1,06 \\
\hline Média & 2,91 & 100 & 1,07 & 63,37 & 0,67 & $-37,52$ & 0,70 & 4,50 \\
\hline Baixa & 7,05 & 100 & 5,70 & 19,21 & 0,63 & $-88,96$ & 0,46 & $-26,39$ \\
\hline
\end{tabular}

De acordo com a condição hidrológica dos solos descritas pelo NRCS (1997) pode-se definir os valores Curva Número $(\mathrm{CN})$ para as classes Alta, Média e Baixa ocupação em função do tipo de solo de acordo com o preconizado para as condições de solos do Brasil (Setzer e Porto, 1979). O solo do tipo A apresenta elevada capacidade de infiltração enquanto o solo tipo D apresenta baixa capacidade de infiltração. Dessa forma, para o solo tipo A definiram-se os valores de CN como 98, 61 e 45, respectivamente para as classes Alta, Média 
TARGA, M. S.; BATISTA, G. T.; DINIZ, H. D.; DIAS, N. W.; MATOS, F. C. Urbanização e escoamento superficial na bacia hidrográfica do Igarapé Tucunduba, Belém, PA, Brasil. Ambi-Agua, Taubaté, v. 7, n. 2, p. 120-142, 2012. (http://dx.doi.org/10.4136/ambi-agua.905)

e Baixa ocupação. Para o solo Tipo D definiram-se os valores de CN como 98, 95 e 92, respectivamente.

Em função da porcentagem de área de cada tipo de solo na bacia e dos valores $\mathrm{CN}$ definidos pode-se calcular por meio da equação 7 (Targa, 2011) os valores CN ponderados (Tabela 4) para a área total (solos tipo A + D) e para as parcelas da bacia com solo Tipo A e solo tipo D e calcular com base na Equação 5 (USDA, 1997) a Infiltração potencial (S) para o solo Tipo A e solo tipo D (Figura 6).

Tabela 4. Evolução dos valores de CN ponderado e Infiltração Potencial (S) para o igarapé Tucunduba, em função do tipo de solo.

\begin{tabular}{c|ccc}
\hline \multicolumn{4}{|c}{ Tipo de Solo } \\
\hline \multirow{2}{*}{ Ano } & A + D & A & D \\
\cline { 2 - 4 } & $\mathbf{C N}_{\text {pond }}$ & $\mathbf{C N}_{\text {pond }}$ & $\mathbf{C N}_{\text {pond }}$ \\
\hline \multirow{2}{*}{1972} & 77,04 & 63,88 & 90,20 \\
1977 & 83,04 & 73,85 & 92,24 \\
1998 & 95,56 & 94,02 & 97,09 \\
2006 & 95,90 & 94,57 & 97,23 \\
\hline
\end{tabular}

Conforme se pode observar (Figura 6) o solo do Tipo A apresenta maior capacidade de infiltração potencial $(\mathrm{S})$, contudo, na bacia esse valor diminui à medida que esse tipo de solo vai sendo impermeabilizado pelo processo de urbanização. O solo do Tipo D apresenta, já desde o início, uma menor capacidade de infiltração potencial (S), mas que também se reduz com o processo de urbanização.

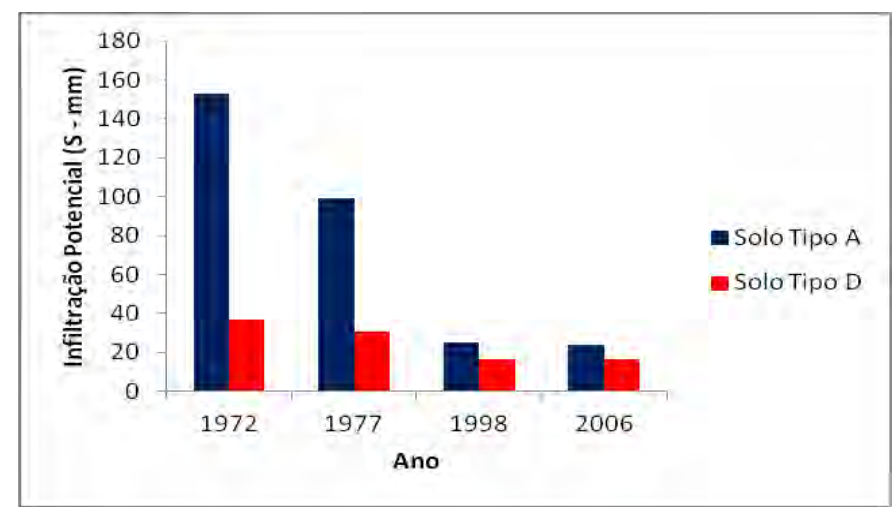

Figura 6. Variação da infiltração potencial (S) em função do Tipo de solo e do processo de impermeabilização devido à urbanização.

$\mathrm{Na}$ Tabela 5 são mostrados os valores de precipitação efetiva $(\mathrm{Pe})$ com base na precipitação máxima de Belém com duração (td) igual ao Tempo de concentração (Tc) e Tempos de retorno (Tr) variando de 2 a 200 anos.

Tabela 5. Evolução da precipitação efetiva $(\mathrm{Pe})$ para o Igarapé Tucunduba, em função do Tempo de retorno (Tr) e da precipitação máxima $(\mathrm{P})$. 
TARGA, M. S.; BATISTA, G. T.; DINIZ, H. D.; DIAS, N. W.; MATOS, F. C. Urbanização e escoamento superficial na bacia hidrográfica do Igarapé Tucunduba, Belém, PA, Brasil. Ambi-Agua, Taubaté, v. 7, n. 2, p. 120-142, 2012. (http://dx.doi.org/10.4136/ambi-agua.905)

\begin{tabular}{c|c|c|c|c|c}
\hline \multirow{2}{*}{$\begin{array}{c}\mathbf{T r} \\
\text { (anos) }\end{array}$} & $\mathbf{P}(\mathbf{m m})$ & \multicolumn{4}{|c}{ Precipitação efetiva - Pe (mm) } \\
\cline { 2 - 6 } & & 1972 & 1977 & 1998 & 2006 \\
\hline 2 & 58,06 & 10,20 & 19,73 & 38,88 & 39,56 \\
5 & 63,31 & 16,41 & 23,35 & 43,75 & 44,46 \\
10 & 67,59 & 18,96 & 26,41 & 47,75 & 48,48 \\
20 & 72,16 & 21,80 & 29,78 & 52,06 & 52,81 \\
25 & 73,70 & 22,77 & 30,93 & 53,51 & 54,27 \\
50 & 78,68 & 26,03 & 34,73 & 58,25 & 59,02 \\
100 & 84,00 & 29,64 & 38,88 & 63,33 & 64,11 \\
200 & 89,68 & 33,61 & 43,42 & 68,78 & 69,58 \\
\hline
\end{tabular}

Os resultados obtidos na Tabela 5 para a bacia do igarapé Tucunduba (solo do Tipo A+D) são expressos graficamente na Figura 7 em que fica notória a variação da precipitação efetiva em função da modificação da superfície pela urbanização. Os valores da Tabela 5 (Pe e Tr) foram ajustados a um modelo do tipo potencial.Nesse ajuste foram obtidas as equações para cada período, e os valores de $\mathrm{R}^{2}$ que variaram de 0,95 para o ano de 1972 a 0,99 para os demais.

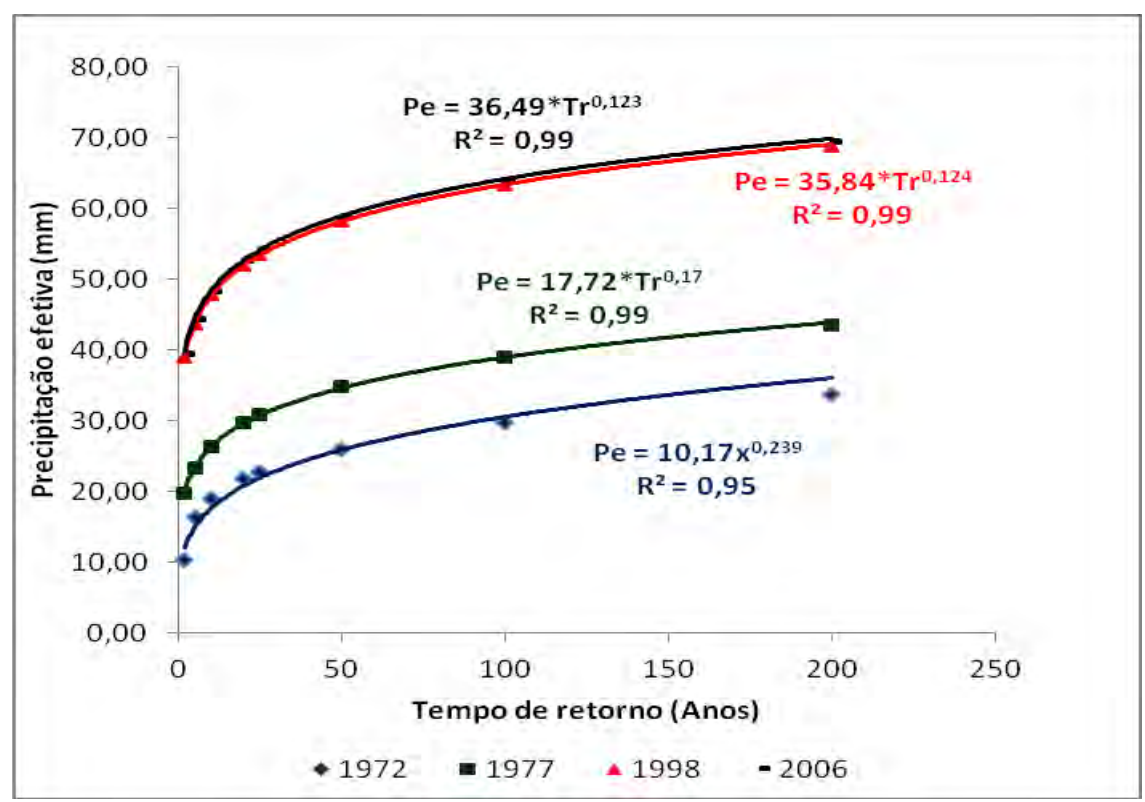

Figura 7. Aumento da precipitação efetiva $(\mathrm{Pe})$ para o igarapé Tucunduba (Solo A+D), em função do Tempo de retorno (Tr) para a precipitação máxima (P) no período de 1972 a 2006.

Em geral em cálculos de vazão máxima e escoamento em áreas urbanizadas, adota-se pelo menos 50 anos como o Tempo de retorno para o dimensionamento de sistemas de drenagem urbana (São Paulo, 1994).

Graficamente se visualiza na Figura 7 que Para o período que vai de 1972 para 1977 houve um acréscimo significativo no escoamento superficial que percentualmente pode-se inferir que esses aumentos foram da ordem de $33 \%$ para 50 anos de Tempo de retorno. Contudo, para o período de 1972 para 1998 houve, também, um acréscimo significativo no 
TARGA, M. S.; BATISTA, G. T.; DINIZ, H. D.; DIAS, N. W.; MATOS, F. C. Urbanização e escoamento superficial na bacia hidrográfica do Igarapé Tucunduba, Belém, PA, Brasil. Ambi-Agua, Taubaté, v. 7, n. 2, p. 120-142, 2012. (http://dx.doi.org/10.4136/ambi-agua.905)

escoamento superficial, e que percentualmente infere-se aumentos de cerca de $67 \%$ para 50 anos de Tempo de retorno.

Entre os anos de 1998 e 2006, praticamente não há diferença no escoamento superficial, pois a variação da precipitação efetiva é menor que 2\%. Contudo, de 1972 para 2006 (34 anos), o acréscimo na área urbanizada foi da ordem de $215 \%$ que foi suficiente para provocar aumentos no escoamento superficial é da ordem de $127 \%$ para chuvas com 50 anos de Tempo de retorno.

Na Figura 8 são mostrados os acréscimos na precipitação efetiva $(\mathrm{Pe})$ para as porções do solo tipo A e D na bacia do igarapé Tucunduba, em função do Tempo de retorno (Tr) para a precipitação máxima (P) no período de 1972 a 2006.

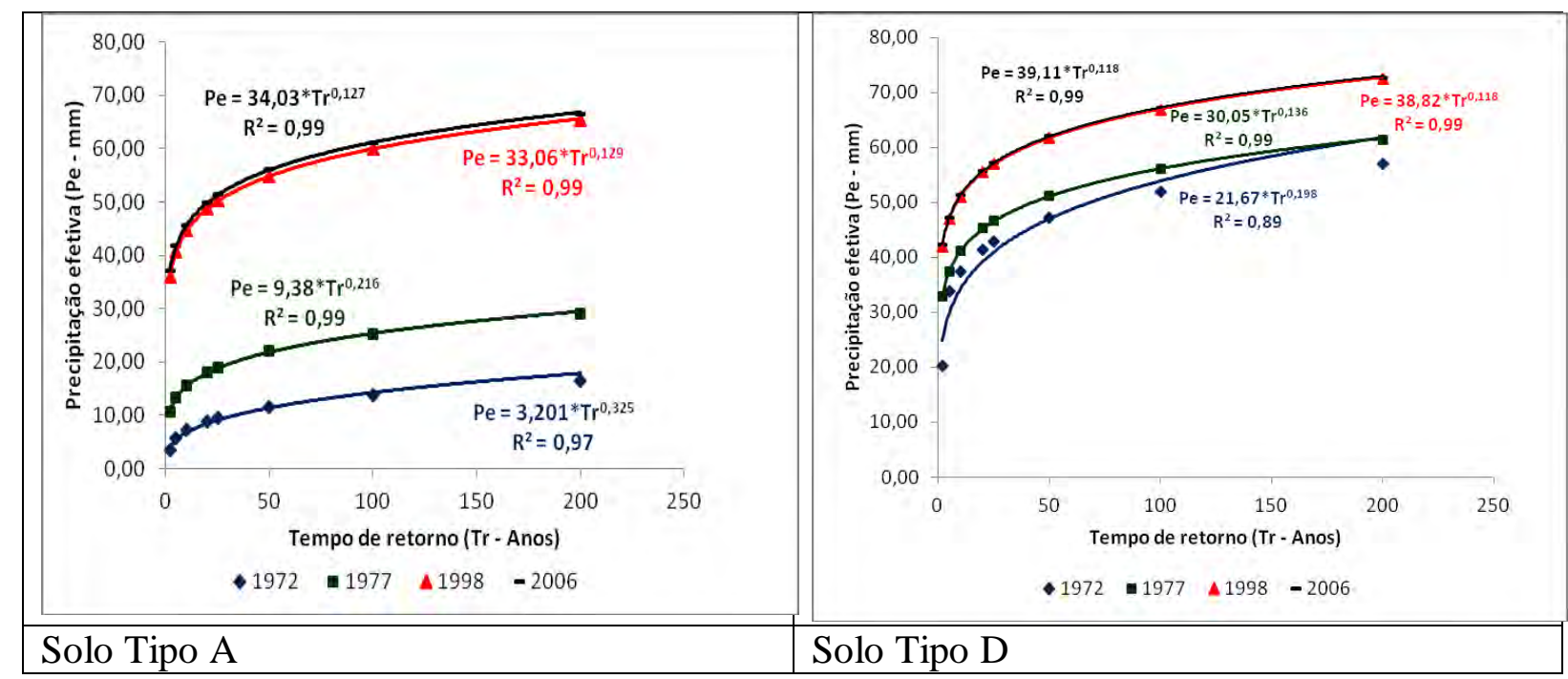

Figura 8. Aumento da precipitação efetiva $(\mathrm{Pe})$ para as porções do solo tipo A e D no igarapé Tucunduba, em função do Tempo de retorno (Tr) para a precipitação máxima (P) no período de 1972 a 2006.

Os resultados obtidos de Pe e Tr para os solos do Tipo A e Tipo D foram ajustados a um modelo do tipo potencial. Nesse ajuste foram obtidas as equações para cada período, e os valores de $\mathrm{R}^{2}$ que para solos Tipo A variaram de 0,97 para o ano de 1972 a 0,99 para os demais, enquanto para o solo Tipo D variaram de 0,89 para o ano de 1972 a 0,99 para os demais.

Na Figura 8, analisando somente as parcelas da bacia do igarapé Tucunduba com solo do Tipo A, observa-se que a partir do momento que a bacia sofreu urbanização entre 1972 e 1977, foi suficiente para promover decréscimo de $160 \mathrm{~mm}$ para $100 \mathrm{~mm}$ (Figura 6) na infiltração potencial (S) e com isso elevar no escoamento superficial para chuvas com Tempo de retorno de 50 anos na ordem de $90 \%$. Entre 1977 e 1998 a infiltração potencial cai de $100 \mathrm{~mm}$ para $25 \mathrm{~mm}$ fazendo o escoamento superficial aumentar em quase $150 \%$. Contudo, entre 1998 e 2006, o acréscimo em urbanização é pequeno e provoca aumento no escoamento superficial pouco superior a $2 \%$, mas, nesse período mesmo o solo Tipo A tendo maior capacidade de infiltrar água, o escoamento superficial dessa área praticamente se iguala ao escoamento que ocorre na parcela de solo do Tipo $\mathrm{D}$ isso se deve a impermeabilização de quase toda área A. Considerando o período todo de 1972 a 2006 (34 anos) o acréscimo no escoamento superficial para chuvas de 50 anos de Tempo de retorno é de quase $385 \%$.

Considerando a relação entre a precipitação efetiva $(\mathrm{Pe})$ e a precipitação máxima $(\mathrm{P})$ expressa na Equação 4, pode-se observar para a bacia do Igarapé Tucunduba (Figura 9) que o coeficiente de escoamento $(\mathrm{C})$ varia com a magnitude da precipitação $(\mathrm{P})$ para cada Tempo de 
TARGA, M. S.; BATISTA, G. T.; DINIZ, H. D.; DIAS, N. W.; MATOS, F. C. Urbanização e escoamento superficial na bacia hidrográfica do Igarapé Tucunduba, Belém, PA, Brasil. Ambi-Agua, Taubaté, v. 7, n. 2, p. 120-142, 2012. (http://dx.doi.org/10.4136/ambi-agua.905)

retorno $(\mathrm{Tr})$, pois à medida que aumenta a precipitação e as condições de perdas iniciais e infiltração são satisfeitas, a precipitação efetiva (Pe) aumenta e assim o escoamento aumenta.

Os resultados obtidos para os coeficientes de escoamento $\mathrm{C}$ foram ajustadas a um modelo potencial cujas equações do tipo potencial e coeficientes de determinação $\mathrm{R}^{2}$ também estão demonstradas na Figura 9. Em geral os ajustes foram bons pois os valores de $\mathrm{R}$ variaram de 0,87 para o ano 1972 e 0,99 para os demais anos.

As modificações no escoamento superficial e nos valores do coeficiente de escoamento superficial (C) se devem principalmente à evolução do processo de urbanização, pois conforme demonstraram Matos et al. (2011), a evolução da urbanização na bacia do Igarapé Tucunduba ocasionou o adensamento populacional e a consequente redução de $755 \%$ na área de vegetação do Igarapé, no período de 1972 para 2006. Os coeficientes de escoamento superficial variaram na média para a bacia do Igarapé do Tucunduba (Solos Tipo A+D) de 0,30; 0,41; 0,72 e 0,73, respectivamente, para os anos de 1972, 1977, 1998 e 2006. Basicamente os valores obtidos para o coeficiente de escoamento 1972 e 1977 apresentaram variação em função dos tempos de retorno entre 0,18 e 0,48 , o que denota uma resposta de áreas rurais, enquanto que para os anos 1998 e 2006 os valores variaram na ordem de 0,67 a 0,78 denotando uma resposta de áreas urbanas.

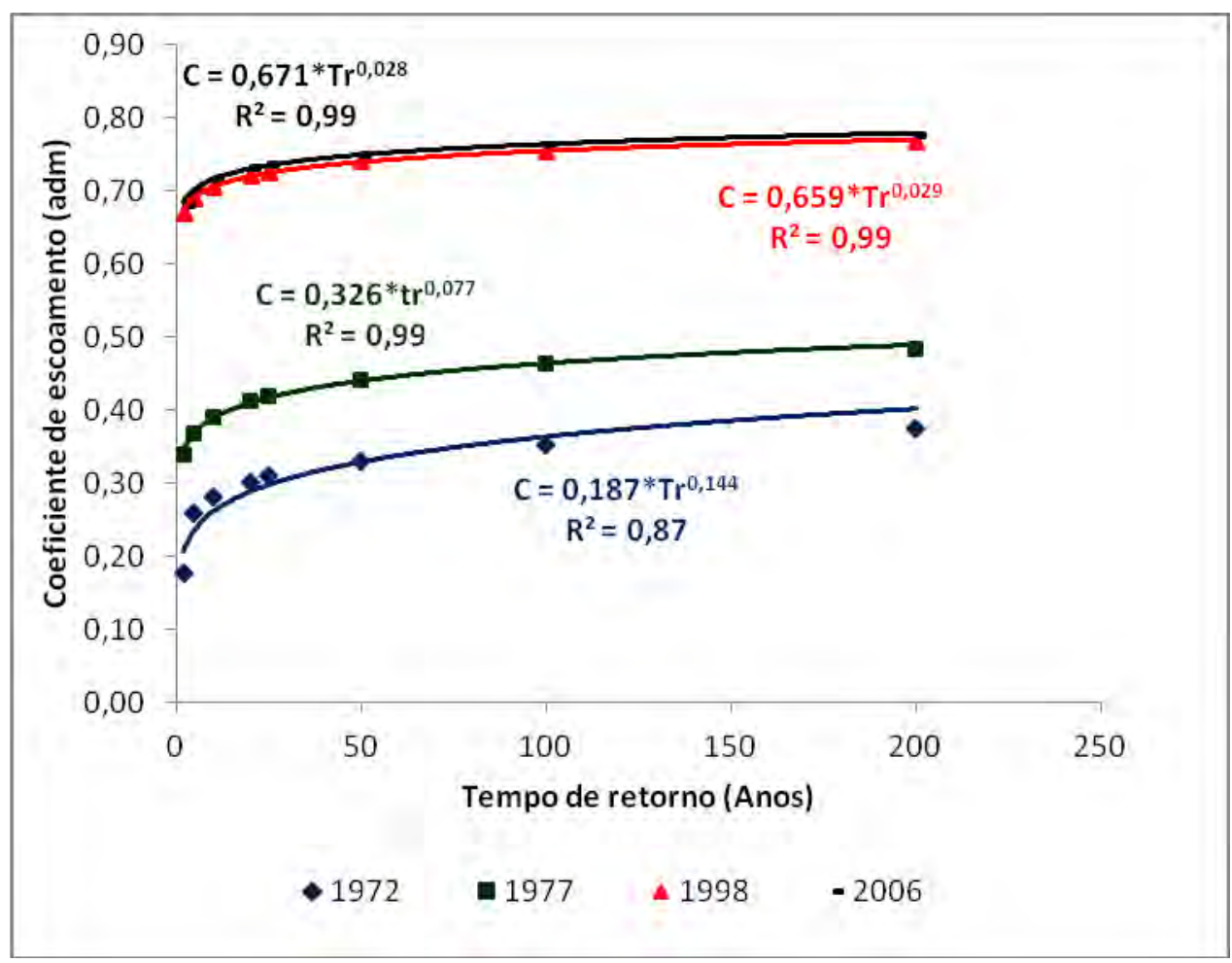

Figura 9. Variação do coeficiente de escoamento (C) para o igarapé Tucunduba (Solo A+D) em função do Tempo de retorno (Tr) no período de 1972 a 2006. 
TARGA, M. S.; BATISTA, G. T.; DINIZ, H. D.; DIAS, N. W.; MATOS, F. C. Urbanização e escoamento superficial na bacia hidrográfica do Igarapé Tucunduba, Belém, PA, Brasil. Ambi-Agua, Taubaté, v. 7, n. 2, p. 120-142, 2012. (http://dx.doi.org/10.4136/ambi-agua.905)

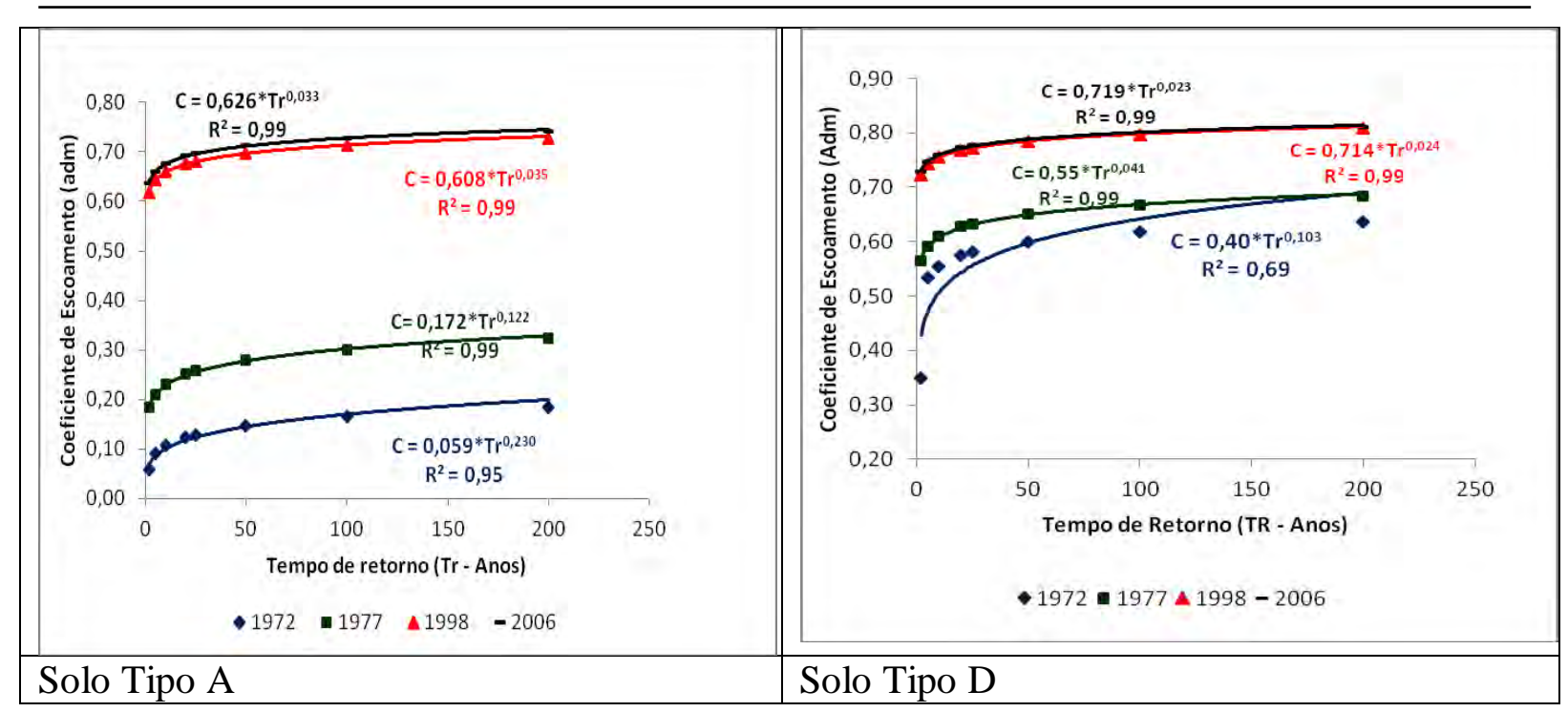

Figura 10. Variação do coeficiente de escoamento (C) para as porções do solo Tipo A e Tipo D no Igarapé Tucunduba, em função do tempo de retorno (Tr), no período de 1972 a 2006.

Os coeficientes de escoamento superficial para ambos os tipos de solos (A e D) em função do tempo de retorno foram ajustados a um modelo potencial e suas respectivas equações e valores de $\mathrm{R}^{2}$ podem ser observados na Figura 10. As equações tiveram melhor ajuste nos resultados obtidos para o solo Tipo A que apresentou valores de $\mathrm{R}^{2}$ de 0,95 para $\mathrm{O}$ ano de 1972 e 0,99 para os demais anos. Por outro lado o ajuste da equação aos pontos calculados do coeficiente de escoamento para a área de solo Tipo D no ano de 1972 apresentou um $\mathrm{R}^{2}$ de apenas 0,62 , enquanto que os demais anos apresentaram valores de $\mathrm{R}^{2}=$ 0,99 .

Pode se observar que na média, após a consolidação da urbanização da bacia do Igarapé Tucunduba, que ocorre efetivamente entre 1998 e 2006, praticamente não ocorre variação no valor médio do coeficiente de escoamento superficial (C), pois para a parcela da bacia com solo Tipo A é de 0,13 (1972), 0,25 (1977), 0,68 (1998) e 0,69 (2006) enquanto que para a parcela da bacia com solo Tipo D é de 0,56 (1972), 0,63 (1977), 0,77 (1998 e 2006).

Para a área com solo Tipo A no período de 1972 e 1977 os valores de coeficiente de escoamento(C) variaram de 0,06 a 0,32 em função dos tempos de retorno, denotando resposta de área florestal e rural, enquanto para o período de 1998 a 2006 esses valores variaram de 0,62 a 0,74 denotando resposta de área urbanizada.

Para a área com solo Tipo D no período de 1972 e 1977 os valores de coeficiente de escoamento(C) variaram de 0,35 a 0,68 em função dos tempos de retorno, denotando resposta de área rural e urbana, enquanto para o período de 1998 a 2006 esses valores variaram de 0,72 a 0,81 denotando resposta de área totalmente urbanizada.

A implantação do projeto de macro drenagem, iniciado em 2000, tem retirado as moradias e estabelecido um perfil melhorado para o canal do Igarapé Tucunduba com a finalidade de minimizar os problemas de cheias e garantir melhor condição de vida à população do entorno. Conforme Tucci (2002), a qualidade da água da rede pluvial depende, dentre outros fatores, da limpeza urbana e de sua frequência. De fato, as obras iniciadas em 2000 de certo modo melhoraram a qualidade da água. Os coliformes são importantes indicadores microbiológicos de poluição e segundo Lopes et al. (2007), valores da ordem de $10^{7}$ NPM ocorreram no ano de 1989 e permaneceram próximo a esse patamar durante dez anos. Em 2000, devido à desapropriação e remoção dos imóveis e comércios próximos à margem, bem como a periódica limpeza do leito, houve melhoria nos valores de Coliformes que caíram para $10^{3}$ a $10^{5}$ NPM. 
TARGA, M. S.; BATISTA, G. T.; DINIZ, H. D.; DIAS, N. W.; MATOS, F. C. Urbanização e escoamento superficial na bacia hidrográfica do Igarapé Tucunduba, Belém, PA, Brasil. Ambi-Agua, Taubaté, v. 7, n. 2, p. 120-142, 2012. (http://dx.doi.org/10.4136/ambi-agua.905)

O projeto de macrodrenagem (Belém, 2001) prevê a urbanização nas margens do canal do Tucunduba e o remanejamento de 1.300 famílias que residem no entorno. O deslocamento dessas famílias seria necessário para que fossem concluídas as obras de saneamento e urbanização em execução na área e que iriam beneficiar diretamente mais de 4 mil famílias que vivem naquele local (Figura 11).

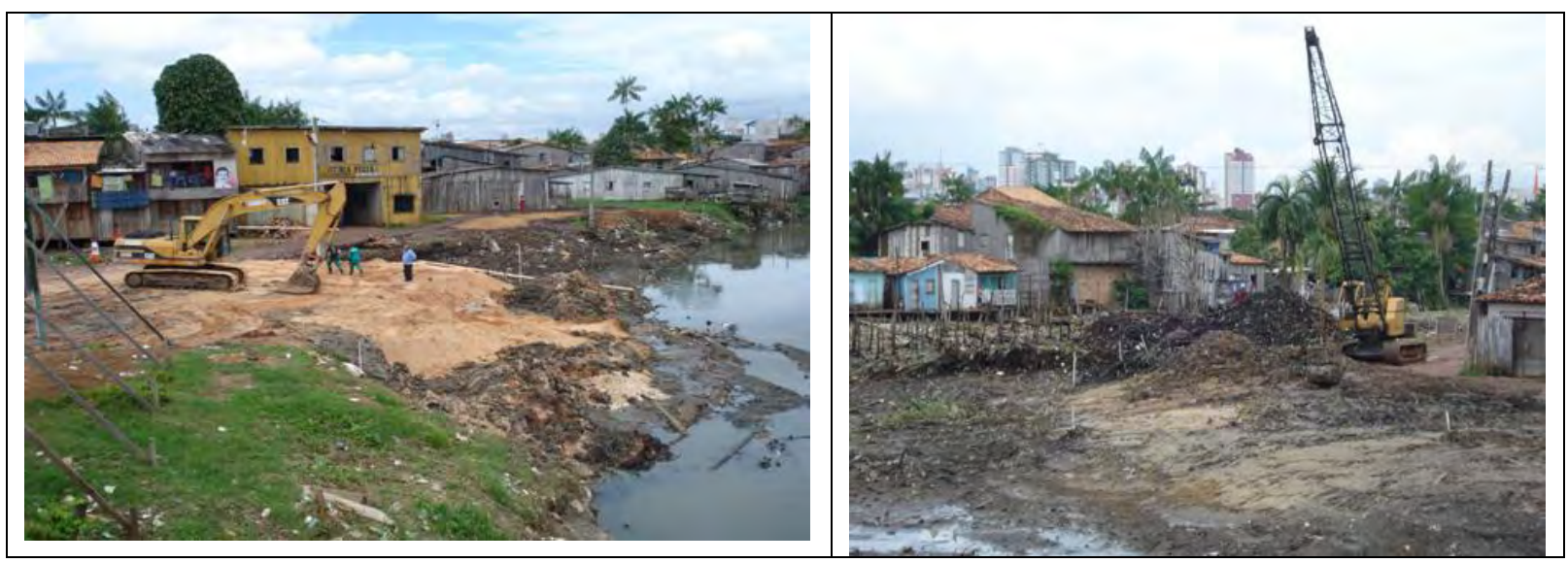

Figura 11. Imagens de início das obras no Igarapé Tucunduba após a remoção das casas.

Um conjunto residencial, denominado Liberdade, está sendo construído (Figura 12) para as famílias remanejadas das margens do Igarapé pela Companhia de Habitação do Estado do Pará - COHAB-PA em área cedida pela UFPA (Universidade Federal do Pará) entre a Avenida Perimetral e a marginal do Tucunduba, conforme se observa na Figura 13.

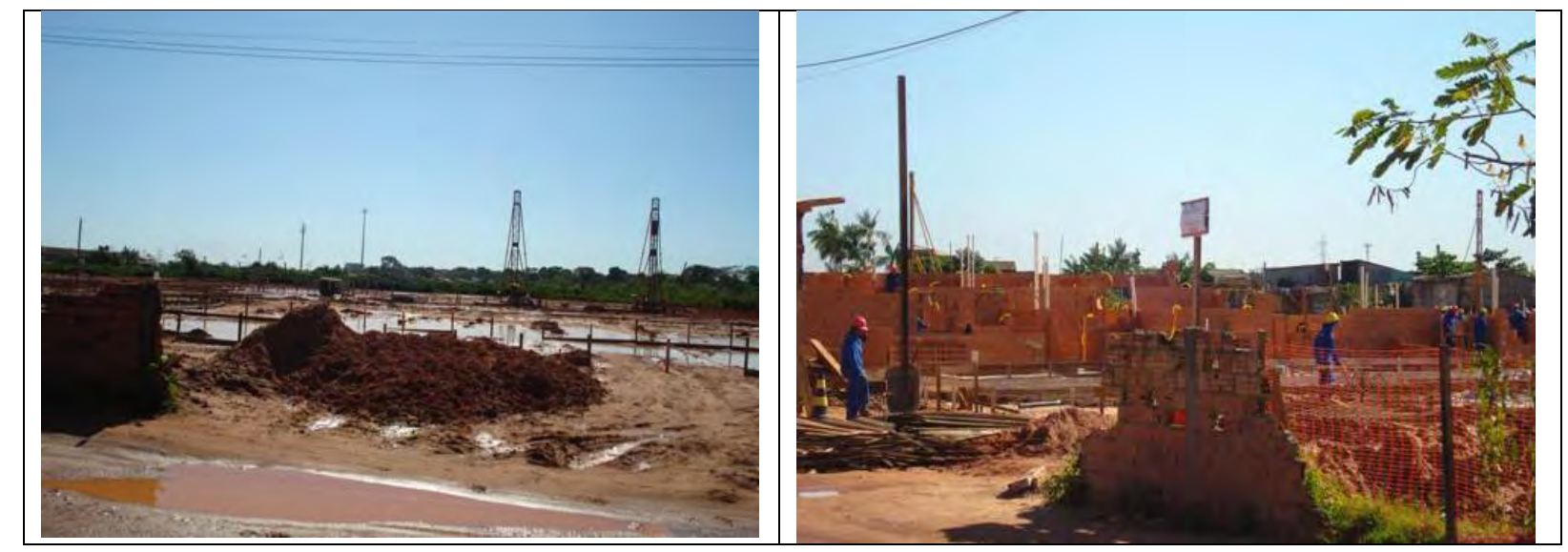

Figura 12. Início de construção pela $\mathrm{COHAB}$ do Conjunto Residencial Liberdade às margens do Igarapé Tucunduba.

$\mathrm{Na}$ área destinada à construção do Conjunto Residencial, a largura do Igarapé Tucunduba tem, aproximadamente, 20m e pelo Art $3^{\circ}$ da resolução do CONAMA (2002), a distância para se construir deveria ser de $50 \mathrm{~m}$. Na realidade a distância é de $46,27 \mathrm{~m}$ na margem esquerda do igarapé, portanto dentro de área de APP. Outro aspecto que chama a atenção é que praticamente essa era a única área que possuía concentração de vegetação nativa na bacia do Tucunduba. 


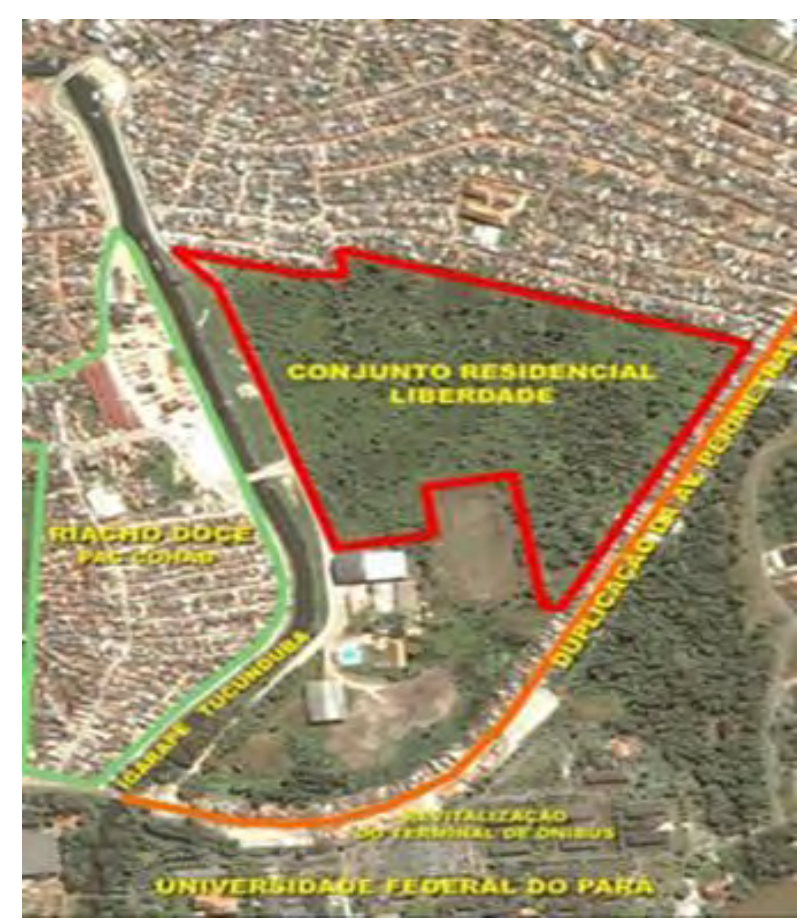

Figura 13. Área reservada para a construção do Conjunto Residencial Liberdade às margens do Igarapé Tucunduba.

A crescente urbanização implica em alterações da superfície e ocasiona desequilíbrio na fase terrestre do ciclo hidrológico, pois o aumento da impermeabilização provoca a diminuição das áreas de recarga e aumenta do escoamento superficial e, consequentemente, o valor do coeficiente de escoamento.

Com relação às inundações, principalmente pelo fato das áreas mais a jusante da bacia serem ocupadas pela população de baixa renda e de forma ilegal e, em geral, pelo fato das áreas a montante serem ocupadas pela população de média e alta renda, incluindo atividades de comércio e indústria estabelecidas de forma legal, o uso indiscriminado de tubulações e canalizações nas áreas mais elevadas pelo poder público transfere o escoamento superficial e agrava rapidamente os problemas da inundação nas áreas mais baixas. De fato, isso se deve, também, à erosão do solo e ao assoreamento de canais e galerias, diminuindo suas capacidades de condução do excesso de água.

\section{CONCLUSÕES}

Com base na análise auxiliada por técnicas de geoprocessamento da bacia do igarapé do Tucunduba, em Belém do Pará, ficou evidenciado que em função do aumento da urbanização nos anos de 1972, 1977, 1998 e 2006 a infiltração potencial (S) reduziu drasticamente e com isso a precipitação efetiva (escoamento) aumentou, resultando em valores médios de 22,43; 30,$90 ; 53,29$ e 54,04 mm para os diferentes anos.

Os coeficientes de escoamento superficial $\mathrm{C}$ variaram na média para a bacia do Igarapé do Tucunduba de 0,30; 0,41; 0,72 a 0,73, respectivamente, para os anos de 1972, 1977, 1998 e 2006, em função do crescimento da urbanização.

As áreas que apresentam boa infiltração na bacia após a consolidação do processo de urbanização perdem sua função de infiltrar água e respondem como solo de baixa infiltração tanto nos valores de escoamento quanto dos coeficientes de escoamento. 


\section{REFERÊNCIAS}

AGUIAR, L. S. G.; TARGA, M. S.; BATISTA, G. T. Escoamento superficial na bacia hidrográfica do Ribeirão Itaim. Ambi-Agua, Taubaté, v. 2, n. 1, p. 44-56, 2007. http://dx.doi.org/10.4136/ambi-agua.19

BELÉM. Prefeitura Municipal. Programa Habitar Brasil - BID. Sub-Programa Urbanização de Assentamentos Subnormais. Plano de desenvolvimento local Riacho Doce e Pantanal. Concepção Geral. Belém: Secretaria Municipal de Coordenação Geral do Planejamento e Gestão/Secretaria Municipal de Saneamento/Fundação PAPA João XXIII, 2001.v. 1.

BURROUGH, P. A. Principles of geographical information systems: methods and requirements for land use planning. Oxford : Clarendon Press, 1986.

CACELA FILHO, F. C. O.; SILVA, A. P. S.; BARP, A. R. B.; COSTA, L. E. C. Modelagem da bacia hidrográfica urbana utilizando o Watershed Modeling System (WMS). In: SIMPÓSIO BRASILEIRO DE SENSORIAMENTO REMOTO, 13., 21-26 abril 2007, Florianópolis. Anais ... São José dos Campos: INPE, 2007. p. 3303-3310.

CASTRO, E. Geopolítica da água e novos dilemas a propósito da Amazônia e seus recursos naturais. In: ARAGON, L. E.; CLÜSENER-GODT, M. (Orgs.). Problemática do uso local e global da água da Amazônia. Belém: NAEA, 2003. p. 334.

FAURE, J. F. Dinâmicas de urbanização em meio tropical úmido: uso do sensoriamento remoto para a construção de indicadores sócio-ambientais na Amazônia Oriental. 2002. 67f. Relatório (Pesquisa de Desenvolvimento Científico e Tecnológico Regional) Conselho Nacional de Desenvolvimento Científico e Tecnológico, 2002.

FERREIRA, C. F. Produção do espaço urbano e degradação ambiental: um estudo de caso sobre a várzea do Igarapé do Tucunduba Belém-Pará. 1995. 120f. Dissertação (Mestrado em Geografia Física) - Coordenadoria de Pós-Graduação em Geografia Física, Universidade de São Paulo, São Paulo, 1995.

GENOVEZ, A. M.; ZUFFO, A. C. Chuvas intensas no estado de São Paulo: estudos existentes e análise comparativa. Revista Brasileira de Recursos Hídricos, v. 5, n. 3, p. 45-58, 2000.

KIRPICH, Z. B. Time of concentration of small agricultural watersheds. Engineers Notebook, v. 10, n. 6, 1940.

LIMA, M. G.; GASCON, C. The conservation value of linear forest remmants in central Amazonia. Biological Conservation, v. 91, n. 2/3, p. 241-247, 1999. http://dx.doi.org/10.1016/S0006-3207(99)00084-1

LIMA, W. P. Hidrologia florestal aplicado ao manejo de bacias hidrográficas. 2. ed. Piracicaba: ESALQ/USP, 2008. 245p.

LOPES, D. F.; MACHADO, L. C. G. T.; LOPES, M. do S. B.; BRAZ, V. N. Situação temporal da contaminação dos canais de drenagem da cidade de Belém - caso do igarapé Tucunduba. In: CONGRESSO BRASILEIRO DE ENGENHARIA SANITÁRIA E AMBIENTAL, 24., 2007, Belo Horizonte. Anais... Belo Horizonte: ABES, 2007. 
MACHADO, R. E.; VETTORAZZI, C. A.; XAVIER, A. C. Simulação de cenários alternativos de uso da terra em uma microbacia utilizando técnicas de modelagem e geoprocessamento. Revista Brasileira de Ciência do Solo, Viçosa-MG, v. 27, n. 4, p. 727-733, 2003. http://dx.doi.org/10.1590/S0100-06832003000400017

MACHADO, R. E.; VETORAZZI, C. E.; CRUCIANI, D. E. Simulação de escoamento em uma microbacia hidrográfica utilizando técnicas de modelagem e geoprocessamento. Revista Brasileira de Recursos Hídricos, v. 8, n. 1, p. 147-155, 2003.

MARTINEZ JUNIOR, F.; MAGNI, N. L. G. Equações de chuvas intensas do Estado de São Paulo. São Paulo: DAEE/CTH, 1999. 141p.

MATOS, F. C.; TARGA, M. S.; BATISTA, G. T.; DIAS, N. W. Análise temporal da expansão urbana no entorno do Igarapé Tucunduba, Belém, PA, Brasil. Revista Biociências, v. 17, n. 1, p. 7-16, 2011.

MOREIRA, E. Belém e sua expressão geográfica. Belém: UFPA, 1966. (Cadernos NAEA, n. 2).

NASCIMENTO, C. C. Clima e morfologia urbana de Belém. Belém: Universidade Federal do Pará, 1995. 160p.

NASCIMENTO, M. C.; SOARES, V. P.; RIBEIRO, C. A. A.; SILVA, E. Uso de geoprocessamento na identificação de conflito de uso da terra em áreas de preservação permanente na bacia hidrográfica do rio Alegre, Espirito Santo. Ciência Florestal, Santa Maria, v. 15, n. 2, p. 207-220, 2005.

OLIVEIRA, L. F. C.; CORTÊS, F. C.; WEHR, T. R.; BORGES, L. B.; SARMENTO, P. H. P.; GRIEBELER, N. P. Intensidade-duração-frequência de chuvas intensas para algumas localidades no Estado de Goiás e Distrito Federal. Pesquisa Agropecuária Tropical, Goiânia, v. 35, n. 1, p. 13-18, 2005.

PARÁ. Governo do Estado. Plano diretor de mineração em áreas urbanas: região metropolitana de Belém. Belém: IBGE, 2002. 157 p.

PEREIRA, G. C.; SILVA, B. N. Geoprocessamento e urbanismo. In: GERARDI, L. H. O.; MENDES, I. A. (Orgs). Teoria, técnica, espaços e atividades: temas de geografia contemporânea. São Carlos: UNESP/AGETEO, 2001. 432 p.

PFASTETTER, O. Chuvas intensas no Brasil: relacão entre precipitação, duração e frequência de chuvas, registradas com pluviógrafos, em 98 postos meteorológicos. 2. ed. Rio de Janeiro: DNOS, 1982. 426p.

PINHEIRO, R. V. L. Estudo hidrodinâmico e sedimentológico do estuário Guajará Belém/PA. 1987. 164f. Dissertação (Mestrado em Geociências) - Universidade Federal do Pará, Belém, 1987.

PINTO, F. A. Chuvas intensas no estado de Minas Gerais: análises e modelos. 1995. 87f. Tese (Doutorado em ) - Universidade Federal de Viçosa, Viçosa, MG, 1995.

PRUSKI, F. F.; SILVA, D. D.; TEIXEIRA, A. F.; SILVA, J. M. A.; CECÍlIO, R. A.; SILVA, D. F. Chuvas intensas para o Brasil. In: CONGRESSO BRASILEIRO DE ENGENHARIA AGRÍCOLA, 31., 2002, Salvador. Anais... Salvador: Sociedade Brasileira de Engenharia agrícola, 2002. 1 CD-Rom. 
TARGA, M. S.; BATISTA, G. T.; DINIZ, H. D.; DIAS, N. W.; MATOS, F. C. Urbanização e escoamento superficial na bacia hidrográfica do Igarapé Tucunduba, Belém, PA, Brasil. Ambi-Agua, Taubaté, v. 7, n. 2, p. 120-142, 2012. (http://dx.doi.org/10.4136/ambi-agua.905)

RAMOS, J. M. T. Entre dois tempos: um estudo sobre o bairro do Guamá/Escola Frei Daniel/Patrono. Belém: [s.n.], 2002. 75p., il.

REBOUÇAS, A. C. A água doce no mundo e no Brasil. In: REBOUÇAS, A. C.; BRAGA, B.; TUNDISI, J.G. (Orgs.). Águas doces no Brasil: capital ecológico, uso e conservação. 2.ed. São Paulo: Escrituras, 2002. p. 1-37.

ROLIM, G. S.; SENTELHAS, P. C.; BARBIERI, V. Planilhas no ambiente EXCEL para os cálculos de balanços hídricos: normal, sequencial, de cultura e de produtividade real e potencial. Revista Brasileira de Agrometeorologia, Santa Maria, v. 6, n. 1, p. 133-137, 1998.

SANTOS, M. T. P. Avaliação ambiental da matéria orgânica degradada nos canais de drenagem da região metropolitana de Belém (PA). 1997. Dissertação (Mestrado em Geologia) - Pós-Graduação em Geologia e Geoquímica, Universidade Federal do Pará, Belém, 1997.

SANTOS, V. G.; DIAS, H. C. T.; SILVA, A. P. S.; MACEDO, M. N. C. Análise hidrológica e socioambiental da bacia hidrográfica do córrego Romão dos Reis, Viçosa-MG. Revista Árvore, v. 31, n. 5, p. 931-940, 2007. http://dx.doi.org/10.1590/S010067622007000500017

SANTOS, G. G.; FIGUEIREDO, C. C.; OLIVEIRA, L. F. C.; GRIEBELER, N. P. Intensidade-duração-frequência de chuvas para o estado de Mato Grosso do Sul. Revista Brasileira de Engenharia Agrícola e Ambiental, v. 13, (suplemento), p. 899-905, 2009.

SÃO PAULO (Estado). Departamento de Águas e Energia Elétrica. Manual de cálculos das vazões máximas, médias e mínimas nas bacias hidrográficas do Estado de São Paulo. São Paulo, 1994. 64p.

SCARAMUSSA, P. H. M.; SOUZA, R. O. R. M.; AMARAL, A. C. M.; PANTOJA, A. V.; PEREIRA NETO, J. A. Equações de chuvas intensas para localidades do Estado do Pará. In: CONGRESSO BRASILEIRO DE METEOROLOGIA, 16., 2010, Belém. Anais... A Amazônia e o clima global. Belém: SBMET, 2010.

SETZER, J.; PORTO, R. L. L. Tentativa de avaliação do escoamento superficial de acordo com o solo e seu recobrimento vegetal nas condições do Estado de São Paulo. Boletim Técnico do DAEE, São Paulo, v. 2, n. 2, p. 82-135, maio/ago. 1979.

TARGA, M. S. Hidrologia e manejo de bacias hidrográficas. Taubaté: UNITAU, 2008. 61f. 1 Apostila.

TARGA, M. S. Vazão de projeto em bacias hidrográficas rurais com áreas em declive. Taubaté: Programa de Pós-Graduacão em Ciências Ambientais, Universidade de Taubaté, 2011. p. 1-20. Disponível em: <http://www.agro.unitau.br/dspace>. Acesso em: ago. 2012.

TAVARES, J. P. N. Enchentes repentinas na cidade de Belém-PA: condições climáticas associadas e impactos sociais no ano de 1987. Caminhos de Geografia Uberlândia, v. 9, n. 28. p. $1-6,1998$.

TOWSHEND, J. R. G. Environmental database and GIS. In: MAGUIRE, D. J.; GOODCHILD, M. F.; RHIND, D. W. Geographical information systems: principles and applications. New York: Longman Scientific \& Technical, 1992, p. 201-205. 
TARGA, M. S.; BATISTA, G. T.; DINIZ, H. D.; DIAS, N. W.; MATOS, F. C. Urbanização e escoamento superficial na bacia hidrográfica do Igarapé Tucunduba, Belém, PA, Brasil. Ambi-Agua, Taubaté, v. 7, n. 2, p. 120-142, 2012. (http://dx.doi.org/10.4136/ambi-agua.905)

TUCCI, C. E. M. Plano diretor de drenagem urbana: princípios e concepção. Revista Brasileira de Recursos Hídricos, v. 2, n. 2, p. 5-12, jul./dez. 1997.

TUCCI, C. E. M. Gerenciamento da drenagem urbana. Revista Brasileira de Recursos Hídricos, v. 7, n. 1, p. 5-27, jan./mar. 2002.

TUCCI, C. E. M. Urban waters. Estudos Avançados, v. 22, n. 63, p. 97-112, 2008. http://dx.doi.org/10.1590/S0103-40142008000200007

UNITED STATES. Department of Agriculture. Natural Resources Conservation Service NRCS. Estimation of direct runoff from storm raifall. In: National engineering handbook hydrology chapters. Washington, DC, 1997. Part 630. Cap. 10. 79p. Disponível em: <www.nrcs.usda.gov>. Acesso em: abril de 2010.

VILLELA, S. M.; MATTOS, A. Hidrologia aplicada. São Paulo: Mc Graw-Hill do Brasil, 1975. 


ISSN = 1980-993X - doi:10.4136/1980-993X
www.ambi-agua.net
E-mail: ambi-agua@agro.unitau.br
Tel.: (12) 3625-4212

\title{
Caracterização hidrogeológica e hidroquímica do aquífero livre localizado no manto de alteração da Formação Serra Geral, na bacia hidrográfica Taquari-Antas, região nordeste do estado do Rio Grande do Sul
}

(http://dx.doi.org/10.4136/ambi-agua.903)

\author{
Pedro Antonio Roehe Reginato ${ }^{1}$; Siclério Ahlert ${ }^{2}$; \\ Karoline Chiaradia Gilioli ${ }^{3}$; Gisele Cemin ${ }^{4}$ \\ ${ }^{1}$ Universidade Federal do Rio Grande do Sul (UFRGS) - Instituto de Pesquisas Hidráulicas (IPH) - Porto Alegre, \\ ${ }^{2,3,4}$ Universidade de Caxias do Sul (UCS) - Caxias do Sul \\ e-mails: pedro.reginato@ufrgs.br, siclerio@yahoo.com.br, \\ e-mails: karolgilioli@hotmail.com,gcemin3@ucs.br
}

\section{RESUMO}

Este artigo apresenta a caracterização hidrogeológica e hidroquímica do aquífero livre localizado no manto de alteração das rochas vulcânicas da Formação Serra Geral, na região nordeste do estado do Rio Grande do Sul. Esse aquífero é condicionado pelo solo, topografia, litologia e clima, sendo caracterizado por uma espessura saturada menor que 1,7 m, níveis estáticos entre 0 e $1 \mathrm{~m}$ e vazões baixas $\left(<0,5 \mathrm{~m}^{3} / \mathrm{h}\right)$. Essas águas são do tipo bicarbonatadas cálcicas ou magnesianas, apresentam baixa alcalinidade e condutividade elétrica, menores concentrações de cálcio, magnésio, sódio, potássio e cloretos e, maior concentração de ferro e manganês. Adicionalmente, essas águas têm maior concentração de nitratos (média acima de $10 \mathrm{mg} / \mathrm{L}$ ) e presença de coliformes totais. Essas características evidenciam a existência de uma rápida circulação entre as zonas de recarga e descarga, neste aquífero.

Palavras-chave: aquífero livre, hidrogeologia, hidroquímica.

\section{Hydrogeological and hydrochemical characterization of unconfined aquifer located in the alteration mantle of the Serra Geral Formation, in the Taquari-Antas river basin, northeast of Rio Grande do Sul State}

\begin{abstract}
This paper presents the hydrogeological and hydrochemical characterization of the unconfined aquifer located in the alteration mantle in the volcanic rocks from Serra Geral Formation, in the northeast region of Rio Grande do Sul State. This aquifer is conditioned by the soil, topography, lithology and climate, being characterized by a saturated layer thinner than $1,7 \mathrm{~m}$, static levels between 0 and $1 \mathrm{~m}$ and low flow $\left(<0,5 \mathrm{~m}^{3} / \mathrm{h}\right)$. These waters are of calcium or magnesium bicarbonate type, and low alkalinity and electrical conductivity, low calcium, magnesium, sodium, potassium and chloride concentrations, and high iron and manganese concentrations. Additionally, these waters have high concentration of nitrates (mean above $10 \mathrm{mg} / \mathrm{L}$ ) and the presence of total coliforms. These characteristics evidence a quick circulation between the recharging and discharge zones in the aquifer.
\end{abstract}

Keywords: unconfined aquifer, hydrogeology, hydrochemical. 


\section{INTRODUÇÃO}

Na região nordeste do estado do Rio Grande do Sul há ocorrência de dois aquíferos principais: o livre ou freático e o fraturado (Reginato, 2003). O primeiro aquífero tem menor capacidade de produção (volumes reduzidos de água), sendo mais utilizado pela população rural, que capta suas águas através de poços escavados (tipo cacimba) ou nascentes naturais. O segundo aquífero possui maior capacidade de produção e água de melhor qualidade, sendo captado por meio de poços tubulares profundos. É utilizado para abastecimento da população urbana, bem como das comunidades rurais (poços comunitários), na maioria dos municípios.

$\mathrm{O}$ aquífero livre ou freático está localizado no manto de alteração existente sobre as rochas vulcânicas da Formação Serra Geral e possui como principais condicionantes os seguintes fatores: solo (tipo e espessura), topografia, litologia (tipo, composição e estruturação da rocha) e clima (Reginato e Strieder, 2005). Em função dos diferentes tipos de condicionantes, o aquífero livre, embora poroso, tem um comportamento heterogêneo, dimensões e continuidade lateral reduzidas (poucos metros) e circulação localizada.

O aquífero fraturado está localizado nas rochas vulcânicas, sendo seu principal condicionante as estruturas tectônicas. Os condicionantes secundários consistem nas estruturas de resfriamento das rochas vulcânicas (zonas de brechas vulcânicas, vesiculares a amigdalóides, disjunções e fraturas), o relevo e o solo desenvolvido sobre as rochas vulcânicas (tipo e espessura). Esse aquífero é caracterizado por uma forte anisotropia responsável por vazões (em média, inferiores $10 \mathrm{~m}^{3} / \mathrm{h}$ ) e capacidades específicas (entre 0,106 e $1,166 \mathrm{~m}^{3} / \mathrm{h} / \mathrm{m}$ ) variáveis (Reginato, 2003).

As águas subterrâneas que circulam por esses aquíferos apresentam características hidroquímicas e qualidades variadas (Reginato et al., 2010). Essa diferenciação depende do tipo de aquífero, da recarga, da vulnerabilidade natural à contaminação, do grau de confinamento e do uso e ocupação do solo (na área de recarga e junto ao ponto de captação). Em geral, as águas subterrâneas que circulam no aquífero livre apresentam padrões hidroquímicos que as diferenciam das águas subterrâneas que circulam no aquífero fraturado, sendo caracterizadas, por exemplo, por uma menor concentração de elementos químicos e uma mais baixa condutividade elétrica.

No mapa hidrogeológico do Rio Grande do Sul (Machado e Freitas, 2005) é representado somente o aquífero fraturado, denominado de Sistema Aquífero Serra Geral II. Esse sistema está associado aos derrames de rochas vulcânicas da Unidade Hidroestratigráfica Serra Geral e apresenta as seguintes características: capacidade específica inferior a $0,5 \mathrm{~m}^{3} / \mathrm{h} / \mathrm{m}$ (podendo chegar a $2 \mathrm{~m}^{3} / \mathrm{h} / \mathrm{m}$ em áreas com maior grau de fraturamento ou com arenitos da Formação Botucatu, na base) e baixa concentração de sólidos totais dissolvidos (inferiores a $250 \mathrm{mg} / \mathrm{L}$ ). Nas regiões onde há menor espessura de rochas vulcânicas as águas subterrâneas podem apresentar maiores valores de $\mathrm{pH}$, condutividade elétrica e sódio.

Neste trabalho é apresentada a caracterização hidrogeológica e hidroquímica do aquífero livre que está localizado no manto de alteração da Formação Serra Geral, na bacia hidrográfica Taquari-Antas, na região nordeste do estado do Rio Grande do Sul. O estudo desse aquífero é justificado, pois as águas subterrâneas que circulam nesse aquífero, possuem características hidroquímicas diferenciadas e problemas de qualidade (origem natural e antrópica), que afetam os padrões de potabilidade.

\section{MATERIAL E MÉTODOS}

A área de estudo está localizada na região nordeste do estado do Rio Grande do Sul, abrangendo o setor médio e superior da bacia hidrográfica Taquari-Antas (Figura 1). 
REGINATO, P .A. R.; AHLERT, S.; GILIOLI, K. C.; CEMIN, G. Caracterização hidrogeológica e hidroquímica do aquífero livre do manto de alteração da Formação Serra Geral, na bacia hidrográfica Taquari-Antas, região nordeste do estado do Rio Grande do Sul. Ambi-Agua, Taubaté, v. 7, n. 2, p. 143-162, 2012. (http://dx.doi.org/10.4136/ambi-agua.903)

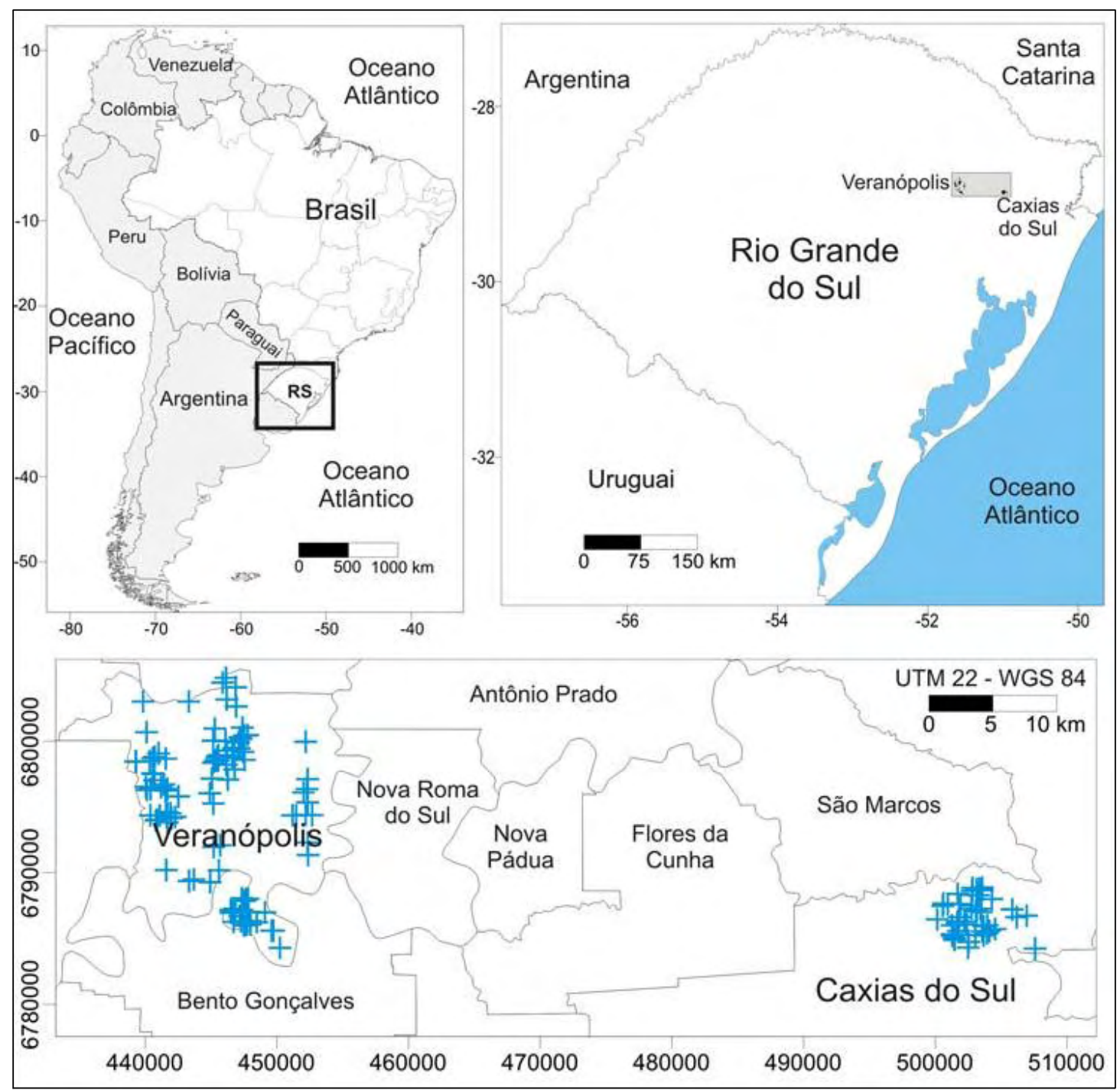

Figura 1. Localização da área de estudo.

A caracterização hidrogeológica e hidroquímica do aquífero livre foi realizada por meio do desenvolvimento das seguintes etapas: inventário e cadastramento de pontos de captação de água subterrânea; levantamento e interpretação de dados geológicos e hidrogeológicos; coleta, análise e interpretação de amostras de água subterrânea.

Essa caracterização foi detalhada em duas regiões (Figura 1), sendo uma no município de Veranópolis e outra, em Caxias do Sul. Essas regiões apresentam diferentes tipos de rochas vulcânicas (ácidas e básicas), variações do relevo (grau de dissecação) e diferentes tipos de solos.

A etapa de inventário e cadastramento de pontos de captação foi realizada, por meio de levantamento de informações disponíveis junto ao SIAGAS (Sistema de Informações de Águas Subterrâneas), às Companhias de Abastecimento e às prefeituras municipais (secretarias de agricultura e da saúde). Com isso, foi possível identificar as regiões que eram abastecidas por poços tubulares profundos (captam água dos aquíferos fraturados) e as que eram abastecidas por poços escavados (tipo cacimba) ou nascentes naturais (captam água do aquífero livre).

As etapas de levantamento e interpretação de dados geológicos e hidrogeológicos foram realizadas por meio da obtenção de informações disponíveis sobre a região, como mapas geológicos e pedológicos, cartas topográficas e relatórios. 
REGINATO, P .A. R.; AHLERT, S.; GILIOLI, K. C.; CEMIN, G. Caracterização hidrogeológica e hidroquímica do aquífero livre do manto de alteração da Formação Serra Geral, na bacia hidrográfica Taquari-Antas, região nordeste do estado do Rio Grande do Sul. Ambi-Agua, Taubaté, v. 7, n. 2, p. 143-162, 2012. (http://dx.doi.org/10.4136/ambi-agua.903)

Foram realizados trabalhos de campo para identificação, localização e caracterização dos diferentes pontos de captação de água subterrânea, na área de estudo. Sempre que possível, foram obtidas, informações sobre o nível estático, espessura da zona saturada e vazão dos poços. Ao todo foram cadastrados 78 pontos que captam água do aquífero livre e 88 pontos que captam água do aquífero fraturado. Para a caracterização hidrogeológica e hidroquímica do aquífero livre foram selecionados e analisados 30 pontos (Tabela 1 e Figuras 2 e 3).

Foram realizados levantamentos geológicos (litologias, estruturas e estratigrafia dos litotipos presentes na área de estudo) e pedológicos (tipos, espessura e características dos solos). Todos os dados foram interpretados com o objetivo de caracterizar o aquífero livre e avaliar a forma de circulação da água subterrânea.

A etapa de coleta, análise e interpretação de amostras de água subterrânea foi feita em alguns pontos de captação distribuídos ao longo das regiões de Veranópolis e Caxias do Sul. No município de Veranópolis foram realizadas análises de $\mathrm{pH}$, condutividade elétrica, ferro, manganês, nitrato, fluoretos e coliformes totais em 22 pontos (Tabela 1 e Figura 2). Em 4 pontos foi realizada a análise de parâmetros como alcalinidade, cloreto, sulfato, cálcio, magnésio, sódio e potássio. Na região de Caxias do Sul foram analisados, os parâmetros $\mathrm{pH}$ e condutividade elétrica em 18 pontos de captação. Em 8 pontos (Tabela 1 e Figura 3) foram feitas análises dos seguintes parâmetros: ferro, manganês, nitrato, fluoretos, coliformes totais, alcalinidade, cloreto, sulfato, cálcio, magnésio, sódio e potássio.

A coleta das amostras de água subterrânea foi feita de duas formas principais. Quando o ponto de captação não possuía equipamento de bombeamento a coleta foi feita com o emprego de Bailer. Já, quando o ponto de captação possuía sistema de bombeamento, a bomba era acionada e mantida ligada, por pelo menos 10 minutos. Após esse tempo, foi feita a coleta das amostras de água, na saída da tubulação ligada a bomba. Para cada ponto foram coletadas três amostras. Duas, foram acondicionadas em frascos plásticos (um contendo $\mathrm{HNO}_{3}$ ) e enviadas para analise dos parâmetros ferro, manganês, nitrato, fluoretos, alcalinidade, cloreto, sulfato, cálcio, magnésio, sódio e potássio. Uma amostra foi acondicionada em frasco do tipo borossilicato esterelizado e foi utilizada na avaliação dos coliformes totais. Todas as amostras foram acondicionadas em caixas de isopor, mantidas refrigeradas e transportadas, no mesmo dia da coleta, para os laboratórios onde foram feitas as análises.

As análises químicas e bacteriológicas foram realizadas na Central Analítica e Laboratório de Saneamento (LASAN) da Universidade de Caxias do Sul (Tabela 2). As análises de $\mathrm{pH}$ e condutividade foram realizadas, diretamente no campo, por meio do emprego de um medidor multiparâmetros HQ40D com sonda para CE (robusta, eletrodo de grafite e cabo de $5 \mathrm{~m}$ ) e sonda para $\mathrm{pH}$ (robusta, membrana de vidro e cabo de $5 \mathrm{~m}$ ).

A interpretação dos dados das análises de água subterrânea do aquífero livre, foi realizada por meio da utilização do programa Qualigraf (Mobus, 2002), sendo gerados diferentes diagramas (Piper e Stiff), para classificação e separação dos diferentes tipos de água subterrânea que circulam no aquífero livre.

Foi realizada uma comparação das características químicas das águas do aquífero livre com as águas do aquífero fraturado, visando com isso identificar diferenças ou semelhanças no padrão hidroquímico dessas águas. Para isso, foram utilizados relatórios disponíveis de análises físico-químicas e bacteriológicas de águas subterrâneas, provenientes de poços tubulares profundos que captam água dos aquíferos fraturados. 
REGINATO, P .A. R.; AHLERT, S.; GILIOLI, K. C.; CEMIN, G. Caracterização hidrogeológica e hidroquímica do aquífero livre do manto de alteração da Formação Serra Geral, na bacia hidrográfica Taquari-Antas, região nordeste do estado do Rio Grande do Sul. Ambi-Agua, Taubaté, v. 7, n. 2, p. 143-162, 2012. (http://dx.doi.org/10.4136/ambi-agua.903)

Tabela 1. Pontos selecionados e analisados para a caracterização hidrogeológica.

\begin{tabular}{|c|c|c|c|c|c|}
\hline Código & Latitude & Longitude & Captação & Aquífero & Região \\
\hline PALV6 & $-28,977579$ & $-51,604423$ & Poço Escavado & Livre & Veranópolis \\
\hline PALV23 & $-29,062436$ & $-51,516313$ & Poço Escavado & Livre & Veranópolis \\
\hline PALV60 & $-29,023515$ & $-51,565472$ & Poço Escavado & Livre & Veranópolis \\
\hline PALV2 & $-28,978688$ & $-51,59243$ & Poço Escavado & Livre & Veranópolis \\
\hline PALV18 & $-28,960023$ & $-51,614419$ & Poço Escavado & Livre & Veranópolis \\
\hline PALV22 & $-28,940706$ & $-51,62276$ & Poço Escavado & Livre & Veranópolis \\
\hline PALV40 & $-29,044026$ & $-51,547548$ & Poço Escavado & Livre & Veranópolis \\
\hline PALV31 & $-29,041909$ & $-51,5465$ & Poço Escavado & Livre & Veranópolis \\
\hline PALV54 & $-29,0688$ & $-51,511219$ & Poço Escavado & Livre & Veranópolis \\
\hline PALV3 & $-28,979406$ & $-51,59539$ & Nascente & Livre & Veranópolis \\
\hline PALV4 & $-28,976199$ & $-51,596121$ & Nascente & Livre & Veranópolis \\
\hline PALV13 & $-28,956292$ & $-51,6012$ & Nascente & Livre & Veranópolis \\
\hline PALV26 & $-28,935028$ & $-51,60513$ & Nascente & Livre & Veranópolis \\
\hline PALV24 & $-28,940277$ & $-51,612055$ & Nascente & Livre & Veranópolis \\
\hline PALV29 & $-28,938239$ & $-51,609601$ & Nascente & Livre & Veranópolis \\
\hline PALV38 & $-29,043443$ & $-51,546631$ & Nascente & Livre & Veranópolis \\
\hline PALV45 & $-29,050676$ & $-51,5414$ & Nascente & Livre & Veranópolis \\
\hline PALV39 & $-29,044047$ & $-51,535573$ & Nascente & Livre & Veranópolis \\
\hline PALV56 & $-29,035681$ & $-51,537717$ & Nascente & Livre & Veranópolis \\
\hline PALV49 & $-29,057006$ & $-51,517704$ & Nascente & Livre & Veranópolis \\
\hline PALV53 & $-29,044476$ & $-51,522859$ & Nascente & Livre & Veranópolis \\
\hline PALV59 & $-29,01541$ & $-51,558597$ & Nascente & Livre & Veranópolis \\
\hline PAFV13 & $-28,899408$ & $-51,581361$ & Poço Tubular & Fraturado & Veranópolis \\
\hline PAFV14 & $-28,899222$ & $-51,617083$ & Poço Tubular & Fraturado & Veranópolis \\
\hline PAFV15 & $-28,920344$ & $-51,614408$ & Poço Tubular & Fraturado & Veranópolis \\
\hline PAFV16 & $-28,927353$ & $-51,490556$ & Poço Tubular & Fraturado & Veranópolis \\
\hline PAFV17 & $-28,977906$ & $-51,498142$ & Poço Tubular & Fraturado & Veranópolis \\
\hline PAFV19 & $-28,925256$ & $-51,540664$ & Poço Tubular & Fraturado & Veranópolis \\
\hline PAFV34 & $-28,926939$ & $-51,553097$ & Poço Tubular & Fraturado & Veranópolis \\
\hline PAFV47 & $-29,005069$ & $-51,489014$ & Poço Tubular & Fraturado & Veranópolis \\
\hline PAFV49 & $-28,999286$ & $-51,562578$ & Poço Tubular & Fraturado & Veranópolis \\
\hline PE1 AL & $-29,039329$ & $-50,993786$ & Nascente & Livre & Caxias do Sul \\
\hline PE2 AL & $-29,051423$ & $-50,982692$ & Poço Escavado & Livre & Caxias do Sul \\
\hline PE3 AL & $-29,032785$ & $-50,982633$ & Nascente & Livre & Caxias do Sul \\
\hline PE4 AL & $-29,044705$ & $-50,968385$ & Nascente & Livre & Caxias do Sul \\
\hline PE5 AL & $-29,059848$ & $-50,95971$ & Nascente & Livre & Caxias do Sul \\
\hline PE6 AL & $-29,058456$ & $-50,96345$ & Nascente & Livre & Caxias do Sul \\
\hline PE7 AL & $-29,06097$ & $-50,968842$ & Nascente & Livre & Caxias do Sul \\
\hline PE8 AL & $-29,060477$ & $-50,986902$ & Poço Escavado & Livre & Caxias do Sul \\
\hline PT1 AF & $-29,063175$ & $-50,985022$ & Poço Tubular & Fraturado & Caxias do Sul \\
\hline PT2 AF & $-29,05275$ & $-50,98303$ & Poço Tubular & Fraturado & Caxias do Sul \\
\hline PT3 AF & $-29,033639$ & $-50,966344$ & Poço Tubular & Fraturado & Caxias do Sul \\
\hline PT4 AF & $-29,039743$ & $-50,980496$ & Poço Tubular & Fraturado & Caxias do Sul \\
\hline PT6 AF & $-29,045192$ & $-50,964163$ & Poço Tubular & Fraturado & Caxias do Sul \\
\hline PT7 AF & $-29,058196$ & $-50,957789$ & Poço Tubular & Fraturado & Caxias do Sul \\
\hline PT8 AF & $-29,048787$ & $-50,981542$ & Poço Tubular & Fraturado & Caxias do Sul \\
\hline
\end{tabular}


REGINATO, P .A. R.; AHLERT, S.; GILIOLI, K. C.; CEMIN, G. Caracterização hidrogeológica e hidroquímica do aquífero livre do manto de alteração da Formação Serra Geral, na bacia hidrográfica Taquari-Antas, região nordeste do estado do Rio Grande do Sul. Ambi-Agua, Taubaté, v. 7, n. 2, p. 143-162, 2012. (http://dx.doi.org/10.4136/ambi-agua.903)

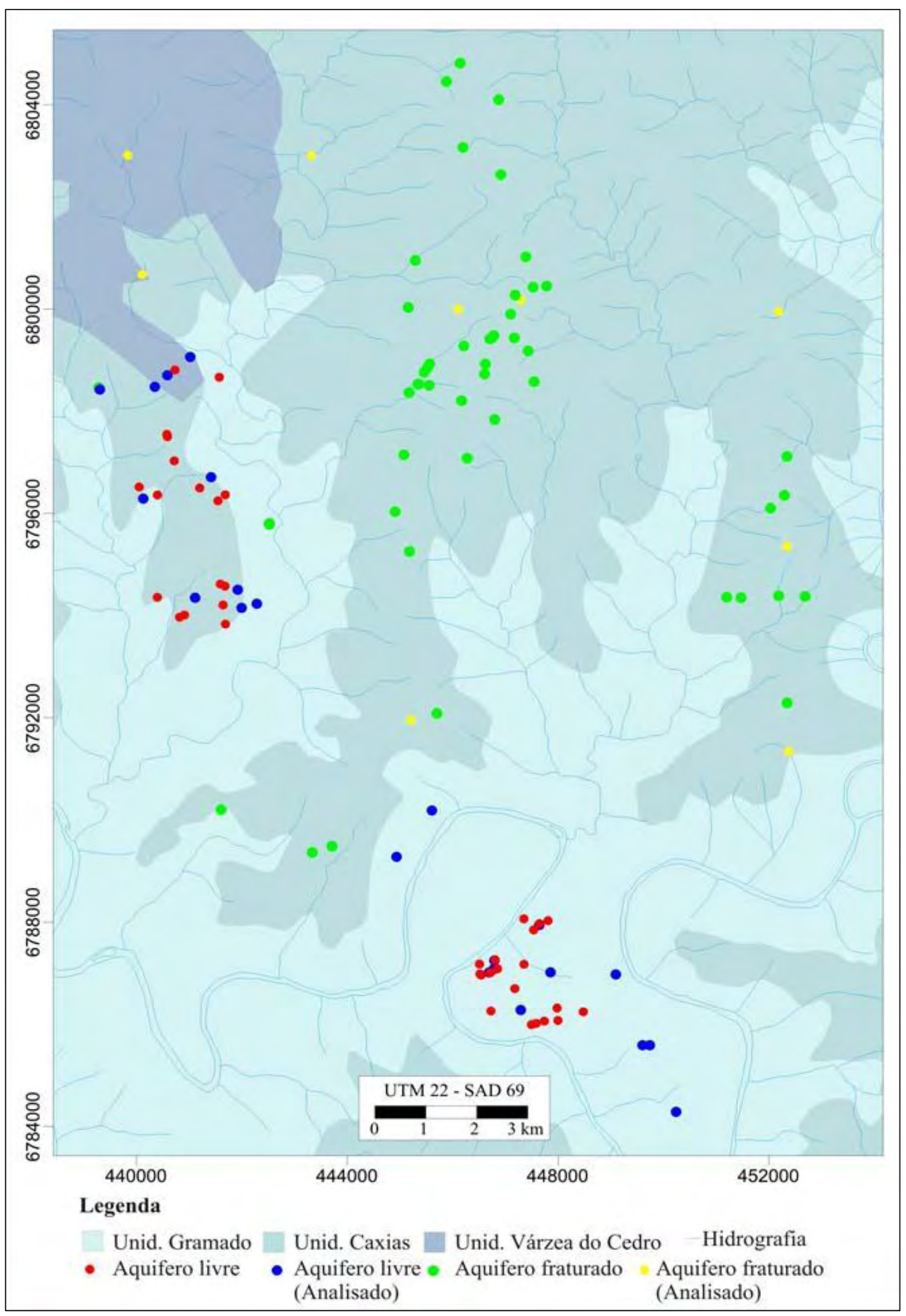

Figura 2. Localização dos pontos de captação dos aquíferos livre (poços escavados do tipo cacimba e nascentes) e fraturado (poços tubulares profundos) na região de Veranópolis. 
REGINATO, P .A. R.; AHLERT, S.; GILIOLI, K. C.; CEMIN, G. Caracterização hidrogeológica e hidroquímica do aquífero livre do manto de alteração da Formação Serra Geral, na bacia hidrográfica Taquari-Antas, região nordeste do estado do Rio Grande do Sul. Ambi-Agua, Taubaté, v. 7, n. 2, p. 143-162, 2012. (http://dx.doi.org/10.4136/ambi-agua.903)

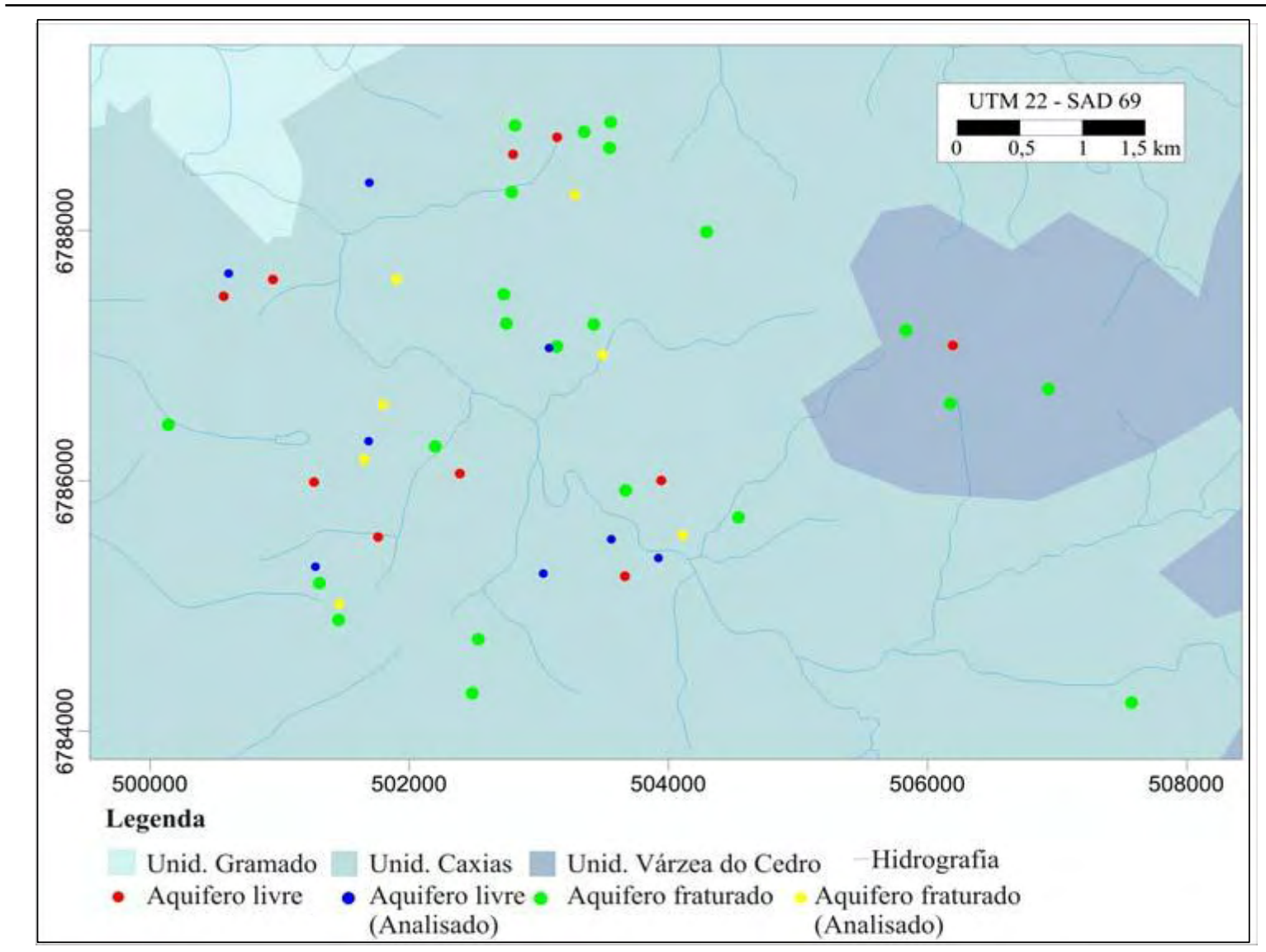

Figura 3. Localização dos pontos de captação dos aquíferos livre (poços escavados do tipo cacimba e nascentes) e fraturado (poços tubulares profundos) na região de Caxias do Sul.

Tabela 2. Parâmetros, limites de detecção e metodologias empregadas nos laboratórios responsáveis pelas análises químicas e bacteriológicas das amostras de água subterrânea do aquífero livre.

\begin{tabular}{|c|c|c|}
\hline Parâmetro & $\begin{array}{l}\text { Limite de } \\
\text { Detecção }\end{array}$ & Metodologia Utilizada \\
\hline Alcalinidade total $\left(\mathrm{mg} / \mathrm{L} \mathrm{CaCO}_{3}\right)$ & 0,50 & SM - Titulação Potenciométrica \\
\hline Cloreto $\left(\mathrm{mg} / \mathrm{L} \mathrm{Cl}^{-}\right)$ & 0,15 & SM - Método Argentimétrico \\
\hline Sulfato $\left(\mathrm{mg} / \mathrm{L} \mathrm{SO}_{4}^{--}\right)$ & 1,00 & SM - Turbidimetria \\
\hline Cálcio (mg/L Ca) & 0,01 & SM - Método 3030 E e 3111 D \\
\hline Magnésio (mg/L Mg) & 0,01 & SM - Método 3030 E e 3111 D \\
\hline Potássio (mg/L K) & 0,01 & SM - Método 3030 E e 3500 B \\
\hline Sódio (mg/L Na) & 0,01 & SM - Método 3030 E e 3500 B \\
\hline Nitrato (mg/L N-NO $\left.{ }_{3}\right)$ & 0,01 & Método Ácido Fenoldissulfônico \\
\hline Ferro $(\mathrm{mg} / \mathrm{L} \mathrm{Fe})$ & 0,04 & SM - Método 3030 E e 3111 B \\
\hline Manganês (mg/L Mn) & 0,01 & SM - Método 3030 E e 3111 B \\
\hline Fluoretos $\left(\mathrm{mg} / \mathrm{L} \mathrm{F}^{-}\right)$ & 0,20 & Colorimétrico - SPADNS \\
\hline Coliformes Totais (UFC/100 mL) & - & Tubos Múltiplos \\
\hline
\end{tabular}


REGINATO, P .A. R.; AHLERT, S.; GILIOLI, K. C.; CEMIN, G. Caracterização hidrogeológica e hidroquímica do aquífero livre do manto de alteração da Formação Serra Geral, na bacia hidrográfica Taquari-Antas, região nordeste do estado do Rio Grande do Sul. Ambi-Agua, Taubaté, v. 7, n. 2, p. 143-162, 2012. (http://dx.doi.org/10.4136/ambi-agua.903)

\section{RESULTADOS E DISCUSSÃO}

\subsection{Hidrogeologia do aquífero livre}

Na região de estudo, há ocorrência de rochas vulcânicas da Formação Serra Geral (Figura 4), que podem ser agrupadas em três unidades principais, denominadas de Gramado, Palmas/Caxias e Várzea do Cedro (CPRM, 1998). Segundo Reginato e Strieder (2006), as rochas vulcânicas nessa região estão associadas a duas sequências, uma ácida e outra básica, dispostas em nove derrames principais. As rochas básicas são representadas por basaltos e constituem seis derrames de lavas, enquanto que as rochas ácidas (ocorrem sobre as rochas básicas) são caracterizadas pela presença de riodacitos, dacitos, riolitos e vidros vulcânicos e formam três derrames principais. Associadas às rochas vulcânicas ácidas e básicas, ocorrem litologias representadas por brechas (mais comuns na sequência básica) e por níveis de vidro vulcânico (mais comuns na sequência ácida). Essas rochas apresentam estruturas tectônicas (fraturas, zonas de fraturas, veios e diques) e estruturas de resfriamento associados aos diferentes derrames (zonas maciças, de brecha, vesiculares a amigdalóides, disjunção ou diáclases horizontais e verticais).

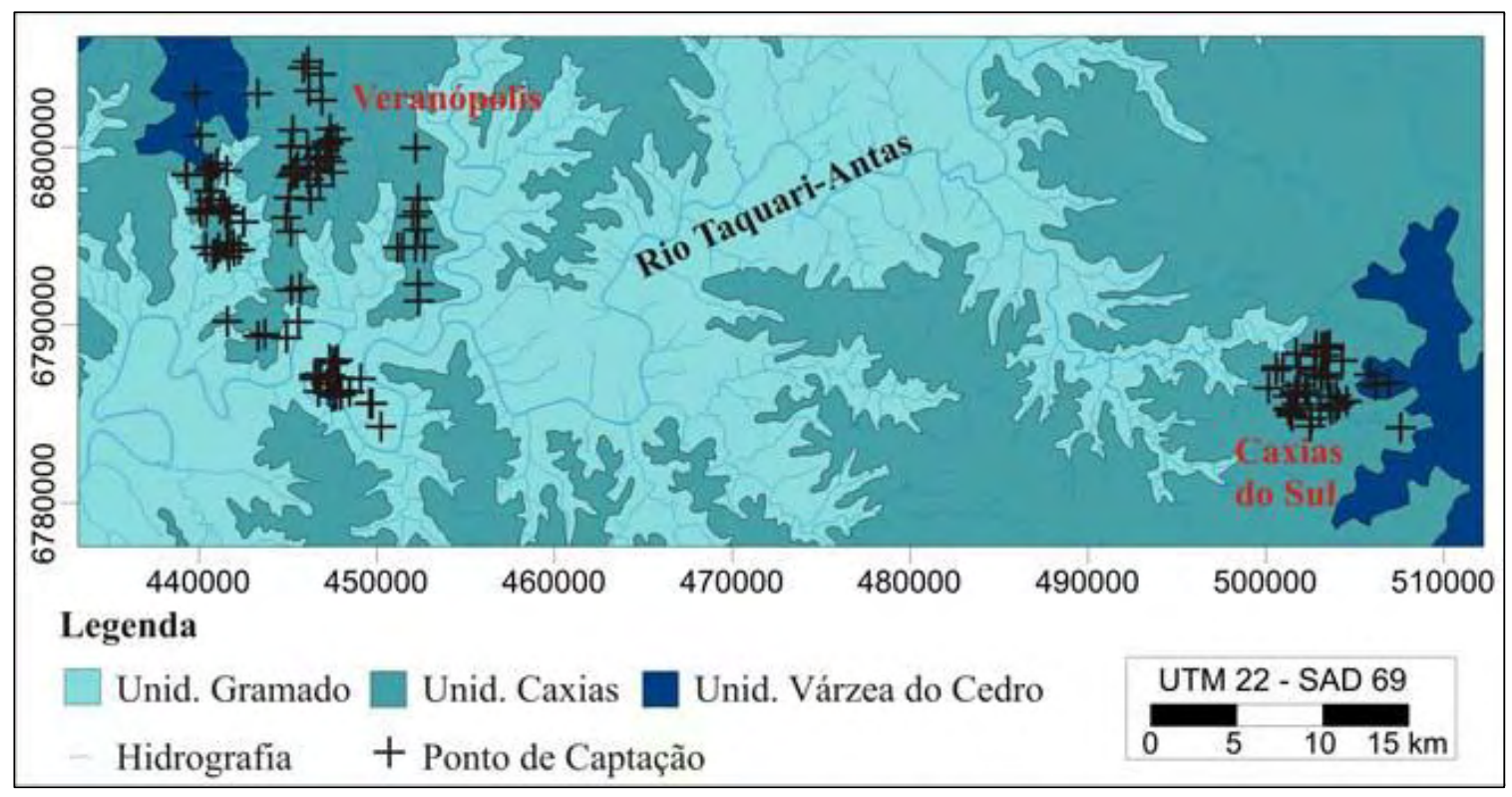

Figura 4. Mapa geológico regional com a localização das principais unidades da Formação Serra Geral e os pontos de captação de águas subterrâneas dos aquíferos livre e fraturado.

Sobre as rochas vulcânicas desenvolveram-se diferentes tipos de solos que apresentam propriedades físicas e espessuras variáveis. As principais classes de solos correspondem a Cambissolos, Neossolos, Chernossolos, Argissolos, Latossolos e Nitossolos (Flores et al., 2007). As duas primeiras classes são as que apresentam as menores espessuras de solos e, a menor chance de ocorrência do aquífero livre.

O aquífero livre ou freático está localizado no manto de alteração existente sobre as rochas vulcânicas da Formação Serra Geral, sendo captado através de poços escavados (tipo cacimba) ou de nascentes (ao longo das áreas de descarga). Os poços escavados têm diâmetros inferiores a $1 \mathrm{~m}$ e profundidades variáveis (média de $3,4 \mathrm{~m}$ ), mas inferiores a $10 \mathrm{~m}$ (Figura 5 e Tabela 3). Em geral apresentam revestimento por tijolos, mas em alguns locais foram identificados poços rasos (1 a 2 metros) sem revestimento. 
REGINATO, P .A. R.; AHLERT, S.; GILIOLI, K. C.; CEMIN, G. Caracterização hidrogeológica e hidroquímica do aquífero livre do manto de alteração da Formação Serra Geral, na bacia hidrográfica Taquari-Antas, região nordeste do estado do Rio Grande do Sul. Ambi-Agua, Taubaté, v. 7, n. 2, p. 143-162, 2012. (http://dx.doi.org/10.4136/ambi-agua.903)

As nascentes possuem caixas de coleta que podem encontrar-se abertas ou fechadas, tendo seu entorno, em geral, capões de mata ou campo. Na maioria, os poços escavados e as captações de nascentes não apresentam boas condições sanitárias ou de proteção às águas subterrâneas (Figura 6).

A formação, ocorrência e circulação de água no aquífero livre são condicionadas por fatores como o tipo e a espessura do solo, a topografia, a litologia e as condições climáticas.
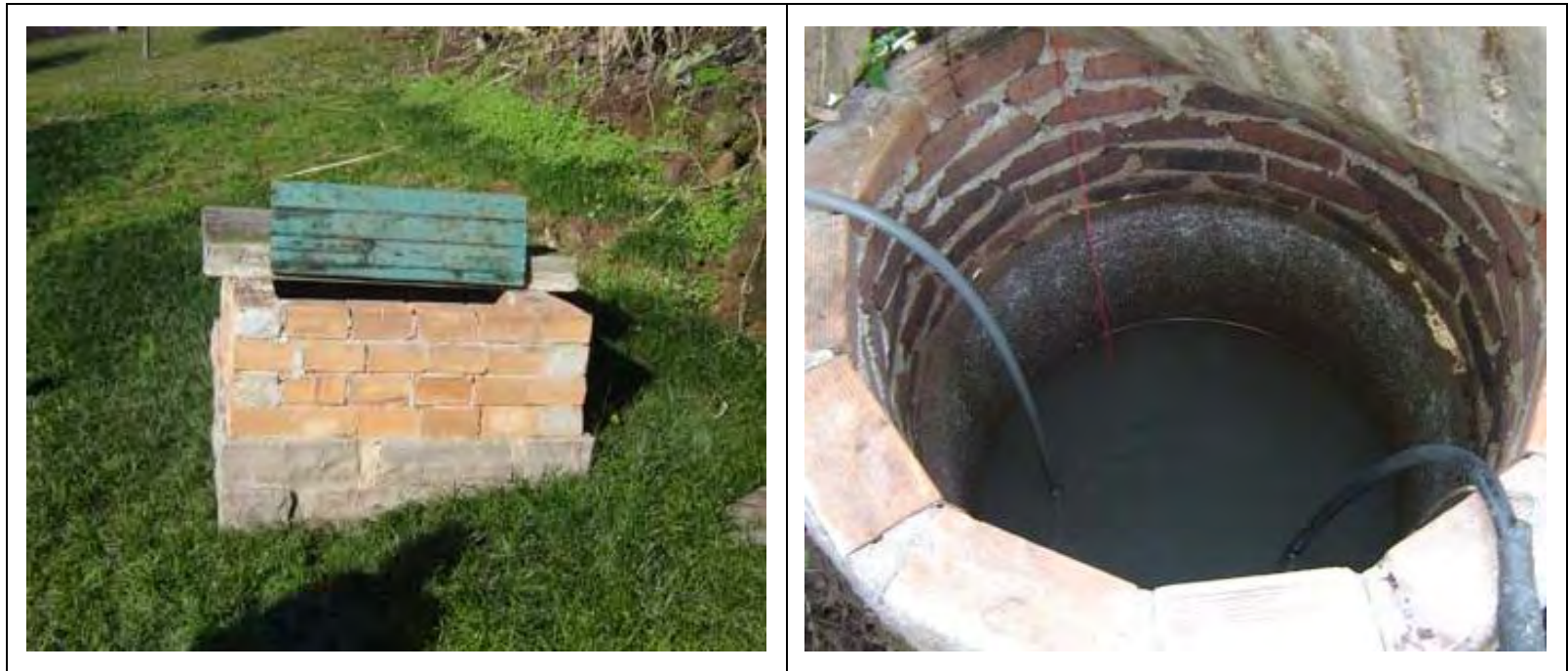

Figura 5. Poços escavados (tipo cacimba) cadastrados na área de estudo.

Tabela 3. Dados hidrogeológicos dos poços escavados cadastrados na área de estudo e utilizados para captação de água subterrânea, utilizada para abastecimento.

\begin{tabular}{c|c|c|c|c|c}
\hline Código & $\begin{array}{c}\text { Região } \\
\text { Estudada }\end{array}$ & $\begin{array}{c}\text { Profundidade } \\
(\mathbf{m})\end{array}$ & $\begin{array}{c}\mathbf{N E} \\
(\mathbf{m})\end{array}$ & $\begin{array}{c}\text { Vazão } \\
\left(\mathbf{m}^{\mathbf{3}} \mathbf{h}\right)\end{array}$ & $\begin{array}{c}\text { Espessura } \\
\text { Saturada }(\mathbf{m})\end{array}$ \\
\hline PALV6 & Veranópolis & 3,0 & 0,5 & 0,6 & 2,5 \\
PALV23 & Veranópolis & 1,5 & 0,6 & 1,0 & 0,9 \\
PALV60 & Veranópolis & 2,0 & 0,9 & 0,5 & 1,1 \\
PALV2 & Veranópolis & 6,4 & 3,7 & 1,0 & 2,7 \\
PALV18 & Veranópolis & 9,1 & 5,0 & 1,5 & 4,1 \\
PALV22 & Veranópolis & 2,5 & 0,8 & 0,5 & 1,7 \\
PALV40 & Veranópolis & 3,5 & 1,2 & 0,8 & 2,3 \\
PALV31 & Veranópolis & 1,2 & 0,9 & 0,2 & 0,3 \\
PALV54 & Veranópolis & 1,8 & 0,7 & 0,6 & 1,1 \\
PE2 AL & Caxias do Sul & 7,1 & 6,2 & 0,4 & 0,9 \\
PE8 AL & Caxias do Sul & 2,6 & 1,1 & 0,8 & 1,5 \\
\hline
\end{tabular}


REGINATO, P .A. R.; AHLERT, S.; GILIOLI, K. C.; CEMIN, G. Caracterização hidrogeológica e hidroquímica do aquífero livre do manto de alteração da Formação Serra Geral, na bacia hidrográfica Taquari-Antas, região nordeste do estado do Rio Grande do Sul. Ambi-Agua, Taubaté, v. 7, n. 2, p. 143-162, 2012. (http://dx.doi.org/10.4136/ambi-agua.903)

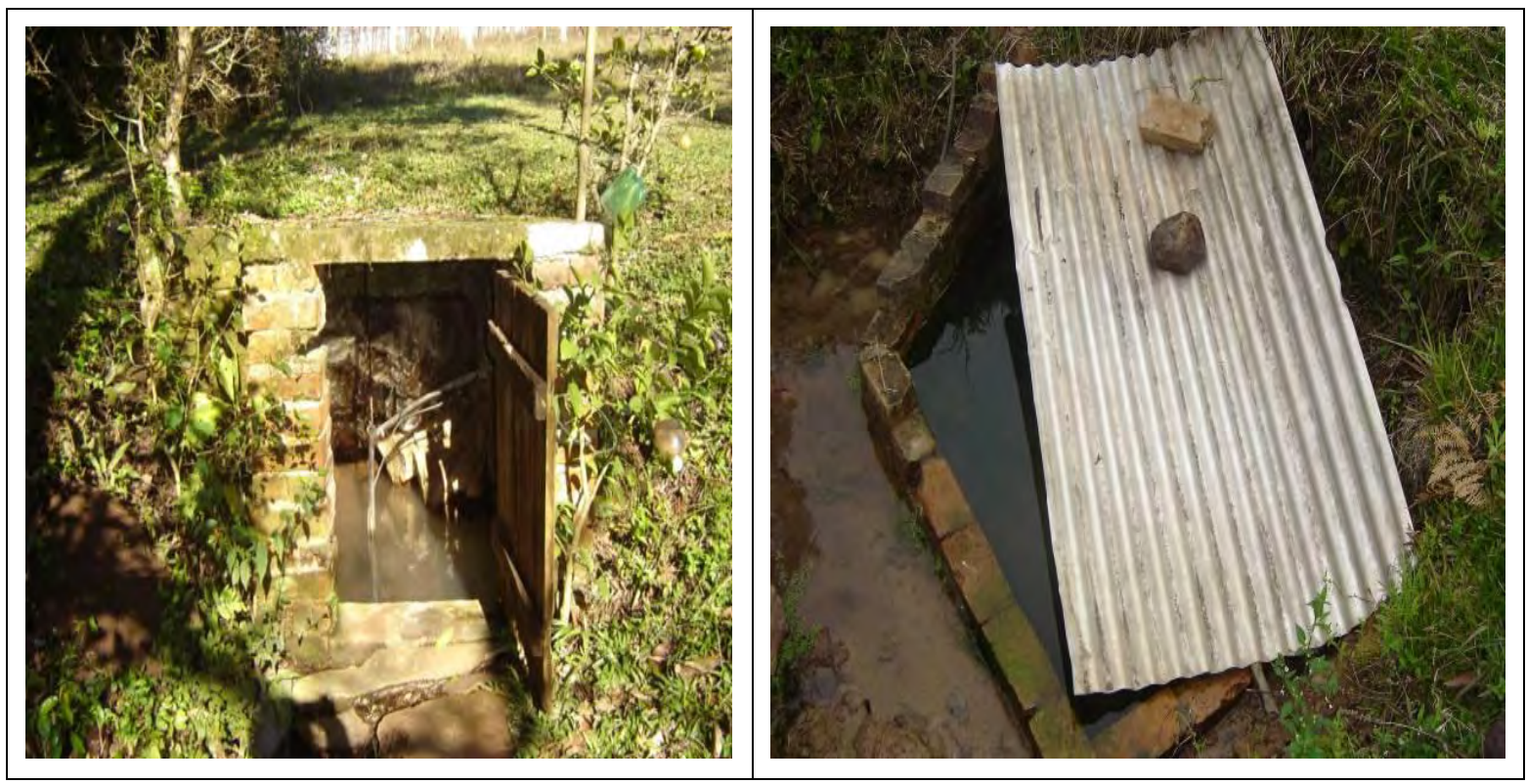

Figura 6. Nascentes cadastradas na área de estudo, utilizadas pelas comunidades como fonte de água para abastecimento.

Os solos que apresentam menores porcentagens de argilas (35 a 71\%) e maiores espessuras (maior que 1,5 m) possuem, em princípio, as melhores condições de armazenar e circular a água subterrânea. A topografia tem uma influência direta no processo de circulação da água, pois a mesma acompanha as inclinações naturais da superfície e do substrato rochoso. Assim, em regiões de declividade mais acentuada, onde há quebra de relevo haverá a tendência de formação de nascentes (denominadas de fontes de encosta). Quanto ao substrato rochoso, o principal fator corresponde à estruturação dos derrames de lavas, pois em zonas maciças, a circulação da água ocorrerá entre o contato da zona de alteração e da rocha sã. É o caso das áreas onde há ocorrência de vidro vulcânico, que possui um comportamento impermeável favorecendo assim, esse tipo de circulação.

O clima possui uma relação direta com o volume de água que circula no aquífero livre e também com a posição do nível estático. Dependendo do tamanho da área de recarga (microbacia) e da quantidade de precipitação sobre a mesma, haverá a formação e circulação de maiores ou menores quantidades de água subterrânea. Além disso, quando há variações significativas da precipitação, há mudanças na posição do nível estático, que em períodos de chuvas intensas acarreta num aumento da zona saturada que eleva o nível da água subterrânea, enquanto que, em períodos de estiagem há rebaixamento deste nível.

As zonas de recarga desses aquíferos correspondem a altos topográficos com baixa declividade e solos com maior espessura, que se caracterizam por áreas onde haverá uma maior tendência a infiltração da água. Já as áreas de descarga correspondem aos locais mais baixos ou onde há quebra de relevo, dando origem a nascentes e banhados. Essa situação é evidenciada na região de Caxias do Sul, onde há o predomínio de rochas ácidas associadas à ocorrência de camadas de vidros vulcânicos. Essas camadas são impermeáveis e respondem como aquífugos. Dessa forma a água que infiltra no solo, circula preferencialmente no contato entre o solo e as camadas vulcânicas mais impermeáveis e, quando há quebra do relevo, ocorrem nascentes que dão origem a banhados.

A análise dos dados hidrogeológicos obtidos no inventário e cadastramento dos pontos de captação de água subterrânea (Tabela 3) permitiu determinar algumas características do aquífero livre como: 
REGINATO, P .A. R.; AHLERT, S.; GILIOLI, K. C.; CEMIN, G. Caracterização hidrogeológica e hidroquímica do aquífero livre do manto de alteração da Formação Serra Geral, na bacia hidrográfica Taquari-Antas, região nordeste do estado do Rio Grande do Sul. Ambi-Agua, Taubaté, v. 7, n. 2, p. 143-162, 2012. (http://dx.doi.org/10.4136/ambi-agua.903)

- o nível estático (NE) ocorre em média, abaixo de $1 \mathrm{~m}$ de profundidade;

- a espessura da zona saturada, em media, é de $1,7 \mathrm{~m}$, variando entre 0,3 até $4,1 \mathrm{~m}$;

- as vazões são inferiores a $1,5 \mathrm{~m}^{3} / \mathrm{h}$, sendo mais comuns valores abaixo de $0,5 \mathrm{~m}^{3} / \mathrm{h}$;

- a transmissividade média é igual a $1,14.10^{-3} \mathrm{~m}^{2} / \mathrm{s}$, enquanto a condutividade média é da ordem de $2,72.10^{-4} \mathrm{~m} / \mathrm{s}$.

Segundo Hausman (1966), as vazões associadas ao aquífero existente na zona de alteração das rochas vulcânicas, na maior parte, são inferiores a $1 \mathrm{~m}^{3} / \mathrm{h}$, mas podem, em alguns locais, alcançar até $18 \mathrm{~m}^{3} / \mathrm{h}$. As vazões sofrem influência do clima, pois, em períodos de estiagem, ocorrem diminuições significativas (na maioria dos casos, essa diminuição chega em média a $50 \%$ ).

Em função dos diferentes tipos de condicionantes e das características hidrogeológicas, o aquífero livre, embora poroso, tem um comportamento heterogêneo, dimensões reduzidas, pequena continuidade lateral e circulação localizada.

\subsection{Caracterização hidroquímica do aquífero livre}

Conforme Hausman (1966), as águas subterrâneas do aquífero livre possuem pH variando entre 6 e 9,5, apresentam baixos teores de sólidos totais, alcalinidade não muito elevada e dureza abaixo de $100 \mathrm{mg} / \mathrm{L}$. Outra característica é a presença de ferro, que em boa parte dos casos, se apresenta em níveis acima do permitido (maiores que 0,3 mg/L), conforme Portaria MS no 2914 de 12/12/2011 (Brasil 2011).

Tedesco e Reginato (2004) realizaram um estudo sobre a contaminação bacteriológica das águas subterrâneas do sistema aquífero livre da região de Veranópolis, onde foram analisadas 50 amostras de água provenientes de poços escavados (tipo cacimba) e nascentes utilizadas pela comunidade rural para abastecimento. Os resultados encontrados evidenciam que o aquífero possui um grau de contaminação bacteriológica elevada, onde mais de $70 \%$ dos pontos de captação apresentaram índices de coliformes fecais que variavam entre $3000 \mathrm{a}$ $42000 \mathrm{UFC} / \mathrm{mL}$ (o limite permitido é a Ausência em $100 \mathrm{~mL}$ ), conforme Portaria MS n 294 de 12/12/2011 (Brasil, 2011). Segundo esses autores, a origem da contaminação das águas subterrâneas do aquífero livre está relacionada com as atividades agrícolas (em função das práticas de cultivo que dispensam resíduos orgânicos em toda a extensão da propriedade) e domésticas (pelo lançamento das águas residuárias sem tratamento prévio).

A caracterização hidroquímica do aquífero livre foi realizada, com base na interpretação dos resultados das análises físico-químicas e bacteriológicas (Tabelas 4, 5, 6 e 7) e dos diagramas Piper e Stiff, gerados com o emprego do programa Qualigraf (Mobus, 2002). Os resultados obtidos foram comparados com dados hidroquímicos de águas subterrâneas que circulam pelo aquífero fraturado (captada por poços tubulares profundos), visando avaliar semelhanças ou diferenças entre o padrão hidroquímico das águas dos dois aquíferos.

Nas Figuras 7 e 8 são apresentados as variações das concentrações de diferentes parâmetros (alcalinidade, cloreto, sulfato, cálcio, magnésio, potássio e sódio) das águas subterrâneas do aquífero livre (Figura 7) e do aquífero fraturado (Figura 8).

Comparando a distribuição da concentração dos diferentes parâmetros, representados nas Figuras 7 e 8 fica evidenciado que as águas do aquífero livre apresentam baixa alcalinidade e menor concentração para elementos como cloretos, cálcio, magnésio, potássio e sódio. Essa baixa concentração, pode estar relacionada com a rápida circulação da água subterrânea, entre a zona de recarga e descarga, resultando num baixo tempo de residência. Outra explicação pode estar relacionada à composição do solo e as interações hidrogeoquímicas que podem ocorrer nesse ambiente. No entanto, é evidente a existência de uma diferenciação hidroquímica entre as águas subterrâneas do aquífero livre e do fraturado. 
REGINATO, P .A. R.; AHLERT, S.; GILIOLI, K. C.; CEMIN, G. Caracterização hidrogeológica e hidroquímica do aquífero livre do manto de alteração da Formação Serra Geral, na bacia hidrográfica Taquari-Antas, região nordeste do estado do Rio Grande do Sul. Ambi-Agua, Taubaté, v. 7, n. 2, p. 143-162, 2012. (http://dx.doi.org/10.4136/ambi-agua.903)

Tabela 4. Resultados das análises realizadas em pontos de captação do aquífero livre.

\begin{tabular}{l|c|c|c|c|c|c|c}
\hline \multicolumn{1}{c}{ Código } & $\begin{array}{c}\text { Coliformes } \\
\text { (UFC/100mL) }\end{array}$ & $\begin{array}{c}\mathbf{N}-\mathbf{N O} \mathbf{3}_{\mathbf{3}} \\
(\mathbf{m g} / \mathbf{L})\end{array}$ & $\begin{array}{c}\mathbf{F e ~ T o t a l} \\
(\mathbf{m g} / \mathbf{L})\end{array}$ & $\begin{array}{c}\mathbf{M n} \\
(\mathbf{m g} / \mathbf{L})\end{array}$ & $\begin{array}{c}\mathbf{F} \\
(\mathbf{m g} / \mathbf{L})\end{array}$ & $\mathbf{p H}$ & $\begin{array}{c}\mathbf{C E} \\
(\mathbf{u S} / \mathbf{c m})\end{array}$ \\
\hline PALV6 & Ausência & 4,43 & 0,21 & 0,02 & n.d. & 5,85 & 26,2 \\
\hline PALV23 & Ausência & 8,86 & 0,24 & n.d. & n.d. & 5,64 & 48,4 \\
\hline PALV60 & 5000 & 25,25 & 0,78 & 0,01 & 0,11 & 6,08 & 44,9 \\
\hline PALV2 & 200 & 55,37 & 1,22 & 0,02 & n.d. & 6,36 & 97,7 \\
\hline PALV18 & 10000 & 38,54 & 0,10 & 0,02 & n.d. & 5,98 & 129,7 \\
\hline PALV22 & 100 & 10,63 & 0,22 & 0,02 & n.d. & 5,93 & 50,5 \\
\hline PALV40 & 4000 & 44,74 & 1,85 & 0,02 & 0,19 & 7,51 & 23,5 \\
\hline PALV31 & 200 & 29,68 & 0,19 & n.d. & n.d. & 6,71 & 147,4 \\
\hline PALV54 & Ausência & 7,97 & 0,06 & n.d. & n.d. & 5,60 & 35,1 \\
\hline PALV3 & Ausência & 12,84 & 0,29 & 0,02 & n.d. & 5,28 & 47,0 \\
\hline PALV4 & Ausência & 13,73 & 0,17 & 0,02 & n.d. & 5,65 & 51,1 \\
\hline PALV13 & 500 & 14,17 & 0,79 & 0,02 & n.d. & 6,32 & 55,0 \\
\hline PALV26 & 100 & 9,74 & 0,30 & 0,02 & n.d. & 6,47 & 30,5 \\
\hline PALV24 & 50 & 10,18 & 0,17 & 0,01 & n.d. & 6,30 & 57,5 \\
\hline PALV29 & Ausência & 10,18 & 0,29 & 0,02 & n.d. & 5,95 & 35,8 \\
\hline PALV38 & 2000 & 11,96 & 0,31 & n.d. & 0,10 & 7,09 & 209,0 \\
\hline PALV45 & 200 & 36,32 & 2,39 & 0,06 & n.d. & 6,50 & 27,1 \\
\hline PALV39 & 200 & 7,97 & 0,11 & n.d. & 0,10 & 6,66 & 28,7 \\
\hline PALV56 & Ausência & 4,43 & 0,09 & n.d. & 0,25 & 7,08 & 19,7 \\
\hline PALV49 & Ausência & 6,20 & 0,10 & n.d. & n.d. & 5,61 & 25,6 \\
\hline PALV53 & 50000 & 53,16 & 2,73 & 0,02 & n.d. & 5,95 & 49,1 \\
\hline PALV59 & 2000 & 15,06 & 0,41 & 0,01 & n.d. & 6,06 & 53,2 \\
\hline PE1 AL & 4 & 0,06 & 0,23 & n.d. & n.d. & 5,59 & 18,14 \\
\hline PE2 AL & 110 & 0,07 & 0,51 & 0,02 & n.d. & 5,91 & 28,5 \\
\hline PE3 AL & Ausência & 0,10 & 0,15 & n.d. & n.d. & 6,14 & 34,0 \\
\hline PE4 AL & 4 & 0,12 & 0,71 & n.d. & n.d. & 5,67 & 36,1 \\
\hline PE5 AL & 4 & n.d. & 0,26 & 0,02 & n.d. & 5,37 & 27,8 \\
\hline PE6 AL & 11 & 0,17 & 0,18 & 0,01 & n.d. & 5,43 & 21,9 \\
\hline PE7 AL & 13 & 0,32 & 0,16 & 0,01 & n.d. & 5,23 & 35,6 \\
\hline PE8 AL & 89 & 0,25 & 0,38 & 0,05 & n.d. & 5,08 & 42,5 \\
\hline & & & & & & \\
\hline
\end{tabular}

Tabela 5. Resultados das análises realizadas em pontos de captação do aquífero livre.

\begin{tabular}{l|c|c|c|c|c|c|c}
\hline \multicolumn{1}{c|}{ Ponto } & $\begin{array}{c}\text { Alcalinidade } \\
\mathrm{mg} / \mathrm{L} \mathrm{CaCO}_{3}\end{array}$ & $\begin{array}{c}\mathrm{Cl}^{-} \\
(\mathbf{m g} / \mathbf{L})\end{array}$ & $\begin{array}{c}\mathrm{SO}_{4}^{-} \\
(\mathbf{m g} / \mathbf{L})\end{array}$ & $\begin{array}{c}\mathbf{C a} \\
(\mathbf{m g} / \mathbf{L})\end{array}$ & $\begin{array}{c}\mathbf{M g} \\
(\mathbf{m g} / \mathbf{L})\end{array}$ & $\begin{array}{c}\mathbf{K} \\
(\mathbf{m g} / \mathbf{L})\end{array}$ & $\begin{array}{c}\mathbf{N a} \\
(\mathbf{m g} / \mathbf{L})\end{array}$ \\
\hline PALV6 & 18,5 & 0,70 & 2,00 & 3,05 & 0,42 & 0,50 & 1,61 \\
\hline PALV23 & 22,3 & 1,20 & 2,00 & 2,55 & 0,78 & 3,33 & 4,56 \\
\hline PALV60 & 27,7 & 0,50 & 8,00 & 3,27 & 1,28 & 1,01 & 3,16 \\
\hline PALV3 & 0,5 & 2,00 & 4,00 & 3,45 & 0,98 & 2,00 & 2,32 \\
\hline PE1 AL & 8,0 & n.d. & 2,56 & 1,12 & 1,78 & 1,21 & 1,53 \\
\hline PE2 AL & 9,0 & n.d. & 6,16 & 1,21 & 1,74 & 1,58 & 1,53 \\
\hline PE3 AL & 9,5 & n.d. & 1,11 & 1,29 & 1,67 & 2,12 & 1,94 \\
\hline PE4 AL & 9,8 & 0,79 & 2,56 & 1,25 & 2,01 & 1,39 & 2,36 \\
\hline PE5 AL & 8,0 & 1,31 & n.d. & 1,23 & 1,42 & 1,21 & 1,94 \\
\hline PE6 AL & 5,5 & n.d. & 1,80 & 1,14 & 1,16 & 1,03 & 1,11 \\
\hline PE7 AL & 4,0 & 2,10 & n.d. & 1,24 & 1,34 & 1,03 & 1,73 \\
\hline PE8 AL & 2,0 & 1,31 & n.d. & 1,33 & 1,99 & 0,67 & 2,36 \\
\hline
\end{tabular}


REGINATO, P .A. R.; AHLERT, S.; GILIOLI, K. C.; CEMIN, G. Caracterização hidrogeológica e hidroquímica do aquífero livre do manto de alteração da Formação Serra Geral, na bacia hidrográfica Taquari-Antas, região nordeste do estado do Rio Grande do Sul. Ambi-Agua, Taubaté, v. 7, n. 2, p. 143-162, 2012. (http://dx.doi.org/10.4136/ambi-agua.903)

Tabela 6. Dados de análises disponíveis de poços tubulares profundos que captam água do aquífero fraturado.

\begin{tabular}{|c|c|c|c|c|c|c|c|}
\hline Código & $\begin{array}{c}\text { Coliformes } \\
\text { (UFC/100mL) }\end{array}$ & $\begin{array}{l}\mathrm{N}-\mathrm{NO}_{3} \\
(\mathrm{mg} / \mathrm{L})\end{array}$ & $\begin{array}{c}\text { Fe Total } \\
(\mathrm{mg} / \mathrm{L})\end{array}$ & $\begin{array}{c}\text { Mn } \\
(\mathrm{mg} / \mathrm{L})\end{array}$ & $\begin{array}{c}\mathbf{F} \\
(\mathrm{mg} / \mathrm{L})\end{array}$ & pH & $\begin{array}{c}\text { CE } \\
(\mathbf{u S} / \mathbf{c m})\end{array}$ \\
\hline PAFV13 & Ausência & 0,43 & n.d. & n.d. & n.d. & 6,24 & 93,1 \\
\hline PAFV14 & Ausência & 0,53 & n.d. & n.d. & 0,26 & 7,17 & 185,0 \\
\hline PAFV15 & Ausência & 0,13 & n.d. & n.d. & 0,16 & 6,46 & 107,0 \\
\hline PAFV16 & Ausência & 0,15 & n.d. & n.d. & 0,25 & 7,14 & 153,0 \\
\hline PAFV17 & Ausência & 1,27 & n.d. & n.d. & 0,11 & 6,38 & 77,6 \\
\hline PAFV19 & Ausência & 2,20 & 0,1 & n.d. & 0,24 & 7,86 & 253,0 \\
\hline PAFV34 & Ausência & 0,12 & n.d. & n.d. & 0,17 & 6,37 & 145,0 \\
\hline PAFV47 & Ausência & 2,51 & 0,07 & 0,04 & 0,34 & 6,71 & 121,0 \\
\hline PAFV49 & Ausência & 0,79 & 0,60 & n.d. & 0,20 & 6,78 & 158,0 \\
\hline PT1 AF & Ausência & 1,16 & 0,18 & n.d. & 0,36 & 7,10 & 169,8 \\
\hline PT2 AF & Ausência & n.d. & 0,29 & n.d. & 0,30 & 7,29 & 148,2 \\
\hline PT3 AF & Ausência & 1,97 & 0,16 & 0,02 & n.d. & 6,84 & 129,2 \\
\hline PT4 AF & Ausência & 0,25 & 0,15 & 0,02 & 0,41 & 6,35 & 110,8 \\
\hline PT6 AF & Ausência & 1,26 & 0,10 & n.d. & 0,57 & 7,77 & 165,6 \\
\hline PT7 AF & Ausência & 0,36 & 0,18 & 0,02 & 0,25 & 6,72 & 105,4 \\
\hline PT8 AF & 30 & 0,06 & 0,17 & 0,02 & n.d. & 6,12 & 93,0 \\
\hline
\end{tabular}

Tabela 7. Dados de análises disponíveis de poços tubulares profundos que captam água do aquífero fraturado.

\begin{tabular}{l|c|c|c|c|c|c|c}
\hline Ponto & $\begin{array}{c}\text { Alcalinidade } \\
\mathrm{mg} / \mathrm{L} \mathrm{CaCO}_{3}\end{array}$ & $\begin{array}{c}\mathrm{Cl}^{-} \\
(\mathbf{m g} / \mathbf{L})\end{array}$ & $\begin{array}{c}\mathrm{SO}_{4}^{-} \\
(\mathbf{m g} / \mathbf{L})\end{array}$ & $\begin{array}{c}\mathbf{C a} \\
(\mathbf{m g} / \mathbf{L})\end{array}$ & $\begin{array}{c}\mathbf{M g} \\
(\mathbf{m g} / \mathbf{L})\end{array}$ & $\begin{array}{c}\mathbf{K} \\
(\mathbf{m g} / \mathbf{L})\end{array}$ & $\begin{array}{c}\mathbf{N a} \\
(\mathbf{m g} / \mathbf{L})\end{array}$ \\
\hline PAFV13 & 14,7 & 4,45 & 3,00 & 9,70 & 1,46 & 2,51 & 2,60 \\
\hline PAFV14 & 78,8 & 4,45 & 2,00 & 21,80 & 14,10 & 1,38 & 6,60 \\
\hline PAFV15 & 37,8 & 6,23 & n.d. & 9,70 & 2,67 & 2,15 & 3,40 \\
\hline PAFV16 & 67,2 & 8,01 & 2,00 & 17,80 & 4,86 & 0,59 & 8,20 \\
\hline PAFV17 & 23,1 & 5,34 & 2,00 & 6,46 & 1,94 & 2,00 & 2,60 \\
\hline PAFV19 & 133,0 & 2,60 & 3,00 & 6,87 & 4,37 & 0,98 & 42,00 \\
\hline PAFV34 & 48,4 & 3,50 & 2,00 & 15,30 & 5,35 & 4,71 & 5,70 \\
\hline PAFV47 & 40,7 & 3,11 & 4,00 & 9,29 & 4,86 & 1,43 & 6,10 \\
\hline PAFV49 & 62,0 & 11,10 & 1,00 & 17,80 & 4,13 & 1,20 & 6,70 \\
\hline PT1 AF & 58,5 & 0,26 & n.d. & 12,00 & 9,28 & 0,67 & 12,8 \\
\hline PT2 AF & 50,9 & 0,52 & n.d. & 11,60 & 9,87 & 1,03 & 13,00 \\
\hline PT3 AF & 43,0 & n.d. & 1,49 & 12,20 & 13,50 & 0,48 & 9,03 \\
\hline PT4 AF & 31,5 & n.d. & 1,30 & 10,10 & 12,20 & 1,58 & 9,44 \\
\hline PT6 AF & 54,5 & 0,79 & 1,80 & 10,90 & 13,70 & 0,85 & 20,9 \\
\hline PT7 AF & 53,5 & 1,31 & 2,37 & 10,80 & 12,30 & 1,03 & 9,86 \\
\hline PT8 AF & 24,0 & 4,46 & n.d. & 1,82 & 1,53 & 1,39 & 8,82 \\
\hline
\end{tabular}


REGINATO, P .A. R.; AHLERT, S.; GILIOLI, K. C.; CEMIN, G. Caracterização hidrogeológica e hidroquímica do aquífero livre do manto de alteração da Formação Serra Geral, na bacia hidrográfica Taquari-Antas, região nordeste do estado do Rio Grande do Sul. Ambi-Agua, Taubaté, v. 7, n. 2, p. 143-162, 2012. (http://dx.doi.org/10.4136/ambi-agua.903)

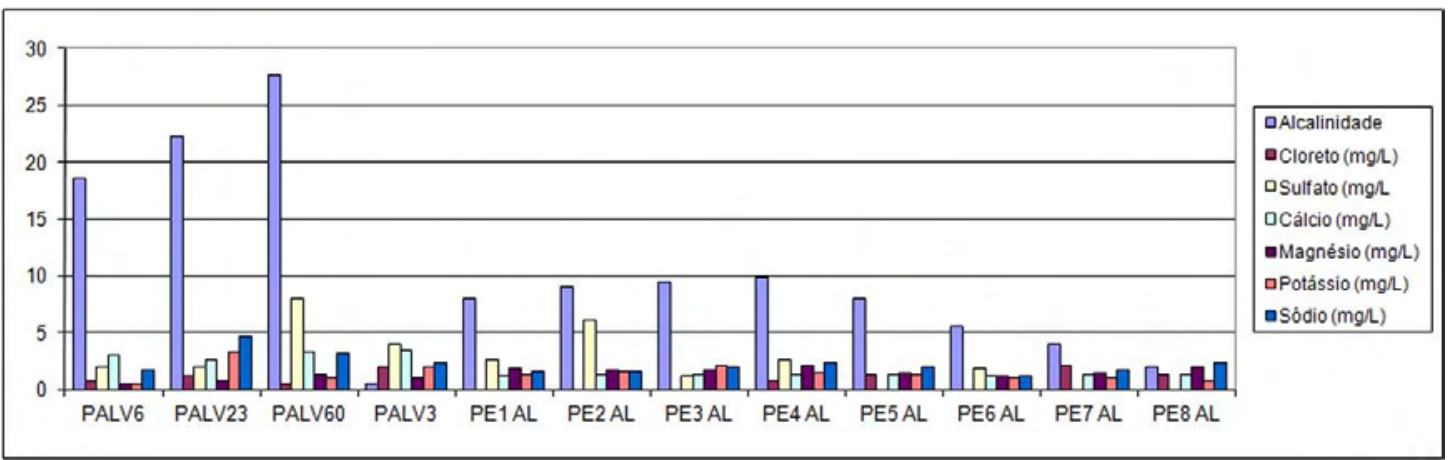

Figura 7. Parâmetros químicos obtidos das águas subterrâneas do aquífero livre.

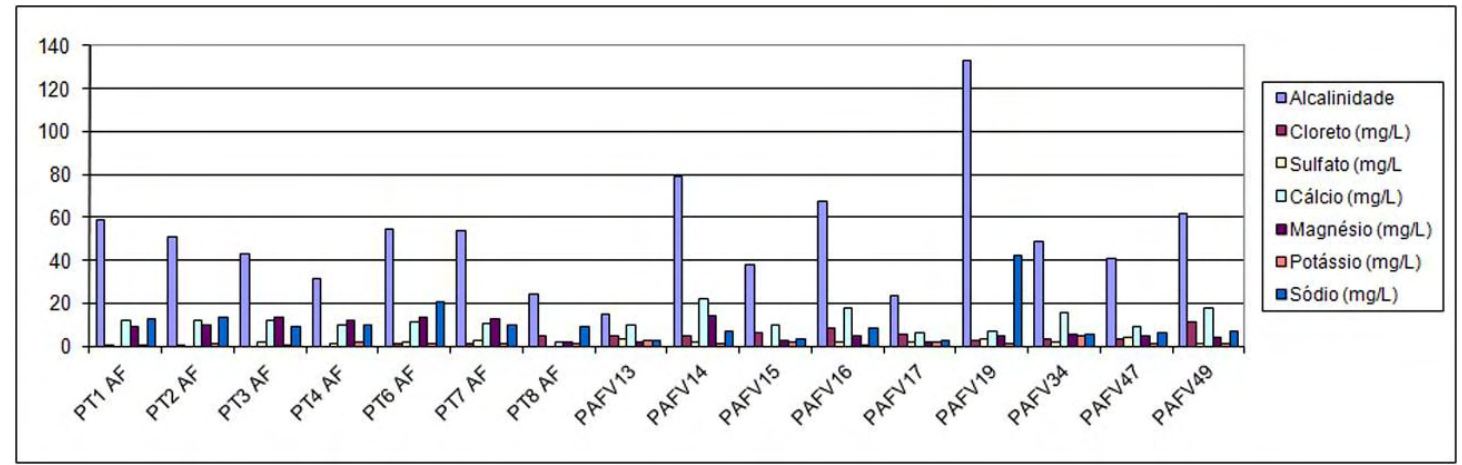

Figura 8. Parâmetros químicos obtidos das águas subterrâneas do aquífero fraturado.

Nas Figuras 9 e 10 é apresentada uma comparação entre os parâmetros condutividade elétrica (CE) e pH para as águas subterrâneas dos aquíferos livre e fraturado.

Analisando-se o parâmetro condutividade elétrica (Figura 9), observa-se que na maior parte dos casos, as águas do aquífero livre apresentam valores abaixo dos $100 \mathrm{uS} / \mathrm{cm}$ (a média geral é abaixo dos $50 \mathrm{uS} / \mathrm{cm}$ ). Já as águas do aquífero fraturado apresentam diferentes valores, sendo os mesmos em média, mais elevados (acima de $100 \mathrm{uS} / \mathrm{cm}$ ). Esse parâmetro evidencia que há diferenças entre as águas subterrâneas dos aquíferos livre e fraturado, sendo que uma das explicações, pode estar relacionada à circulação e tempo de residência das águas subterrâneas. Em geral, as águas subterrâneas do aquífero livre tendem a apresentar uma circulação mais rápida, entre a zona de recarga e descarga, implicando num menor tempo de residência e numa menor concentração de elementos. No entanto, essa circulação pode ser mais lenta, o que poderia explicar a ocorrência de pontos, onde foram identificados maiores valores de condutividade.

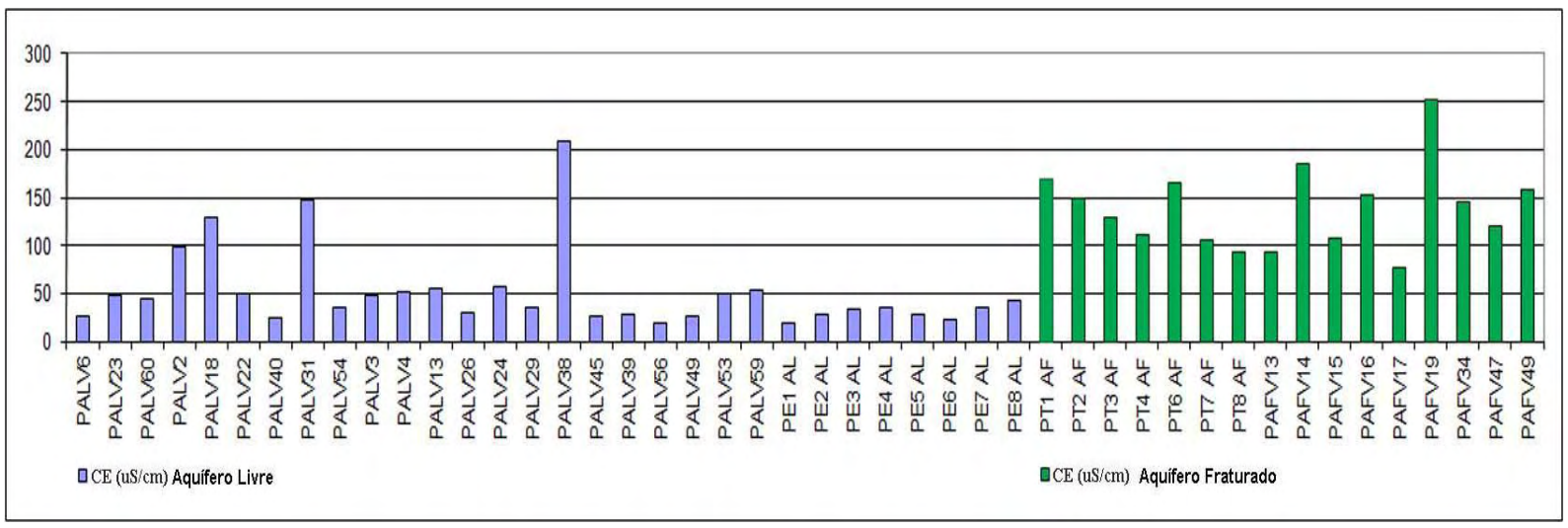

Figura 9. Valores de condutividade elétrica das águas do aquífero livre e fraturado. 
REGINATO, P .A. R.; AHLERT, S.; GILIOLI, K. C.; CEMIN, G. Caracterização hidrogeológica e hidroquímica do aquífero livre do manto de alteração da Formação Serra Geral, na bacia hidrográfica Taquari-Antas, região nordeste do estado do Rio Grande do Sul. Ambi-Agua, Taubaté, v. 7, n. 2, p. 143-162, 2012. (http://dx.doi.org/10.4136/ambi-agua.903)

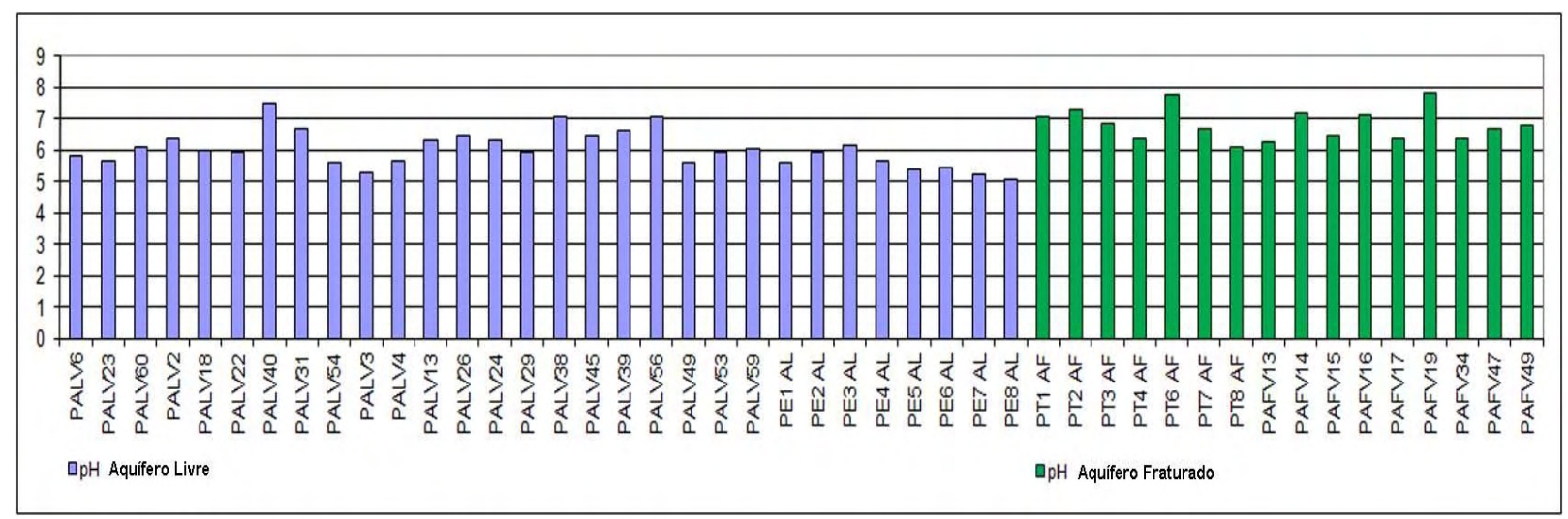

Figura 10. Valores de $\mathrm{pH}$ das águas do aquífero livre e fraturado.

O parâmetro $\mathrm{pH}$ (Figura 10) tem uma pequena diferenciação, sendo que as águas subterrâneas do aquífero livre tem uma tendência a apresentar um $\mathrm{pH}$ entre 5 e 6 , enquanto as águas subterrâneas do aquífero fraturado tendem a ter um $\mathrm{pH}$ entre 6 e 8 . A existência de $\mathrm{pH}$ mais baixo para as águas do aquífero livre é explicada, pois o mesmo é mais superficial e está localizado na zona de alteração das rochas vulcânicas, local onde ocorrem processos de decomposição da matéria orgânica, que dão origem a ácidos orgânicos, responsáveis pela diminuição do $\mathrm{pH}$. Outra explicação pode estar relacionada com as características dos solos, que em geral, são ácidos e mais pobres.

Analisando-se outros parâmetros, observa-se que a concentração de ferro total e manganês é maior nas águas subterrâneas que circulam pelo aquífero livre, do que as que circulam pelo aquífero fraturado (Figura 11). As concentrações de ferro total no aquífero livre variam entre 0,04 e $2,73 \mathrm{mg} / \mathrm{L}$. A explicação para essas altas concentrações está relacionada ao fato que, esses elementos são provenientes dos processos de alteração dos minerais ferromagnesianos, presentes nas rochas vulcânicas da Formação Serra Geral, que acabam se concentrando nos solos (Argissolos, Nitossolos, Latossolos e Cambissolos) encontrados na região. A ocorrência de ferro total, encontrado nas águas subterrâneas do aquífero fraturado é explicada por Reginato e Strieder (2007). Esses autores destacam que poços que captam água de aquíferos fraturados, localizados em regiões de ocorrência de solos do tipo Argissolos, Nitossolos e Latossolos, com entradas de água pouco profundas (em geral, localizadas abaixo dos 15 metros), tendem a apresentar concentrações de ferro total elevadas (acima de 0,3 $\mathrm{mg} / \mathrm{L})$.

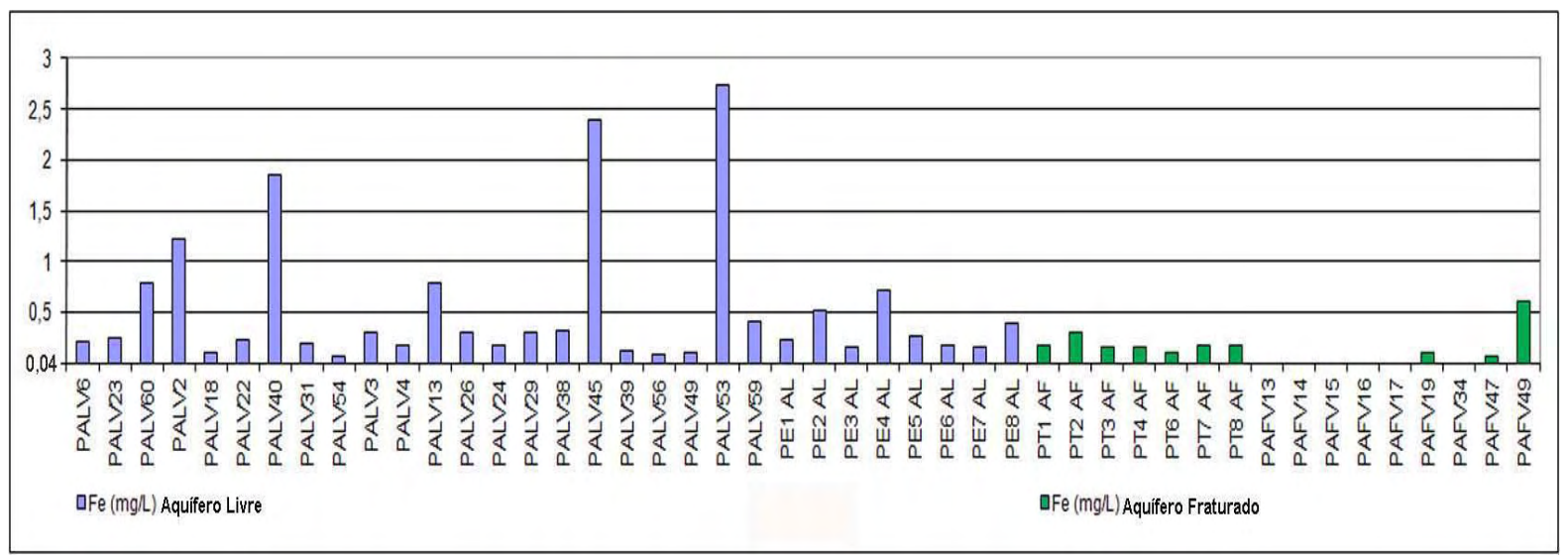

Figura 11. Valores da concentração de Ferro total obtidos em águas subterrâneas dos aquíferos livre e fraturado. 
REGINATO, P .A. R.; AHLERT, S.; GILIOLI, K. C.; CEMIN, G. Caracterização hidrogeológica e hidroquímica do aquífero livre do manto de alteração da Formação Serra Geral, na bacia hidrográfica Taquari-Antas, região nordeste do estado do Rio Grande do Sul. Ambi-Agua, Taubaté, v. 7, n. 2, p. 143-162, 2012. (http://dx.doi.org/10.4136/ambi-agua.903)

Com relação ao fluoreto (Tabelas 4 e 6), nas águas subterrâneas do aquífero livre não é comum a ocorrência desse elemento. No entanto, quando presente, as concentrações variaram entre 0,1 e $0,25 \mathrm{mg} / \mathrm{L}$. O fluoreto é mais facilmente encontrado nas águas subterrâneas que circulam pelos aquíferos fraturados, sendo sua origem, segundo Nanni et al. (2008), condicionada por estruturas tectônicas que promovem a conexão entre os sistemas aquíferos Serra Geral e Guaraní.

O parâmetro nitrato foi avaliado, pois tem grande importância na identificação de fontes de contaminação orgânica. Na figura 12 é apresentada a variação da concentração desse parâmetro para as águas subterrâneas do aquífero livre. Observa-se que os valores encontrados variaram entre 0,01 e $60 \mathrm{mg} / \mathrm{L}$, sendo comum a ocorrência de valores acima de $10 \mathrm{mg} / \mathrm{L}$. Esses valores já indicam a ocorrência de processos de contaminação por fontes orgânicas. As causas estariam relacionadas com o tipo de aquífero, tipo e proteção do ponto de captação e a ocupação do entorno (Reginato e Gilioli, 2010).

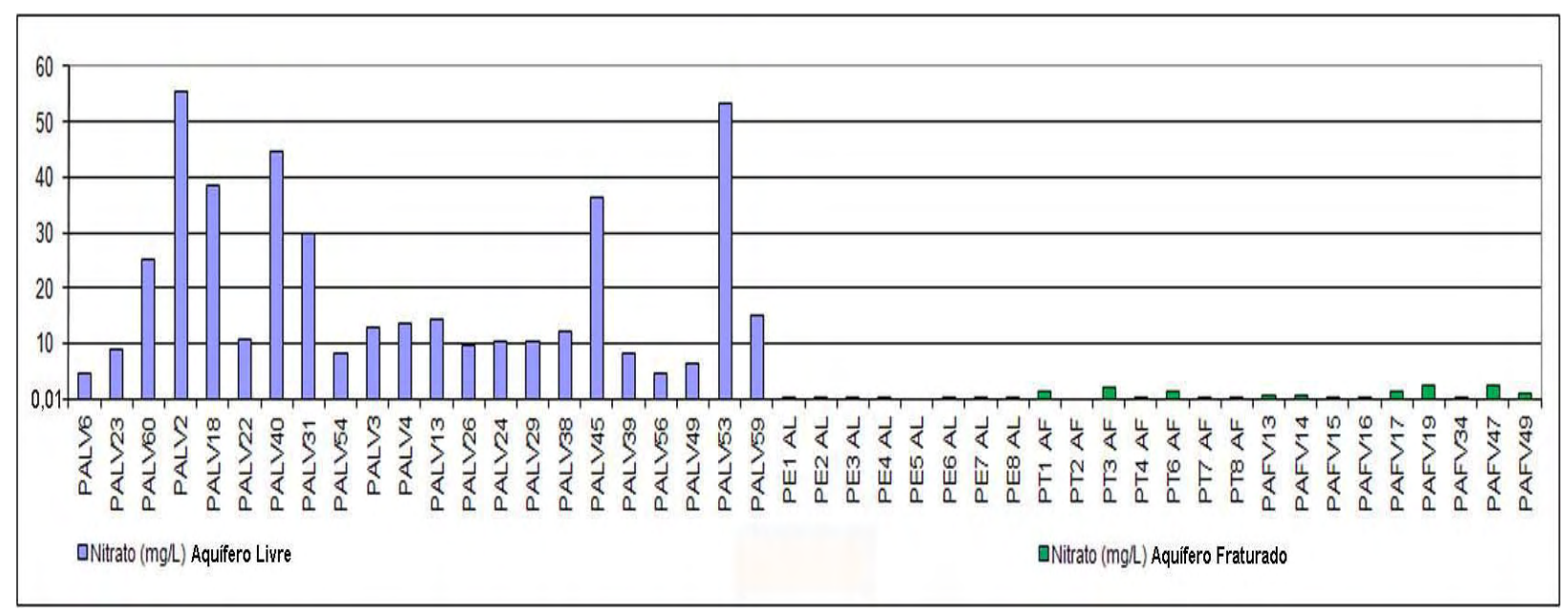

Figura 12. Valores de Nitrato encontrados nas águas do aquífero livre.

A contaminação do aquífero livre é evidenciada também pelas análises bacteriológicas (Tabela 4), sendo que na maior parte dos pontos analisados, foi identificada a presença de coliformes totais.

Ao se analisar a classificação das águas subterrâneas que circulam pelo aquífero livre, apresentada no diagrama Piper (Figura 13), observa-se que as amostras indicam a ocorrência de um único grupo que é o das águas bicarbonatadas cálcicas ou magnesianas. Com base nos cátions, observa-se que a maior parte das águas é considerada mista, enquanto poucas são do tipo cálcicas. Essa relação está de acordo com o ambiente de formação, pois o aquífero livre está associado ao manto de alteração das rochas vulcânicas da Formação Serra Geral, com minerais ferromagnesianos e sódicos, local onde é comum a ocorrência dos elementos cálcio, magnésio e sódio. Além disso, essa classificação corresponde ao padrão típico das águas que circulam pelo aquífero fraturado, pois em geral, quando há ausência de conexão com outros sistemas aquíferos ou um menor grau de confinamento, as águas subterrâneas, que circulam pelo aquífero fraturado, tendem a ser do tipo bicarbonatadas cálcicas ou magnesianas (Reginato et al., 2010). 
REGINATO, P .A. R.; AHLERT, S.; GILIOLI, K. C.; CEMIN, G. Caracterização hidrogeológica e hidroquímica do aquífero livre do manto de alteração da Formação Serra Geral, na bacia hidrográfica Taquari-Antas, região nordeste do estado do Rio Grande do Sul. Ambi-Agua, Taubaté, v. 7, n. 2, p. 143-162, 2012. (http://dx.doi.org/10.4136/ambi-agua.903)

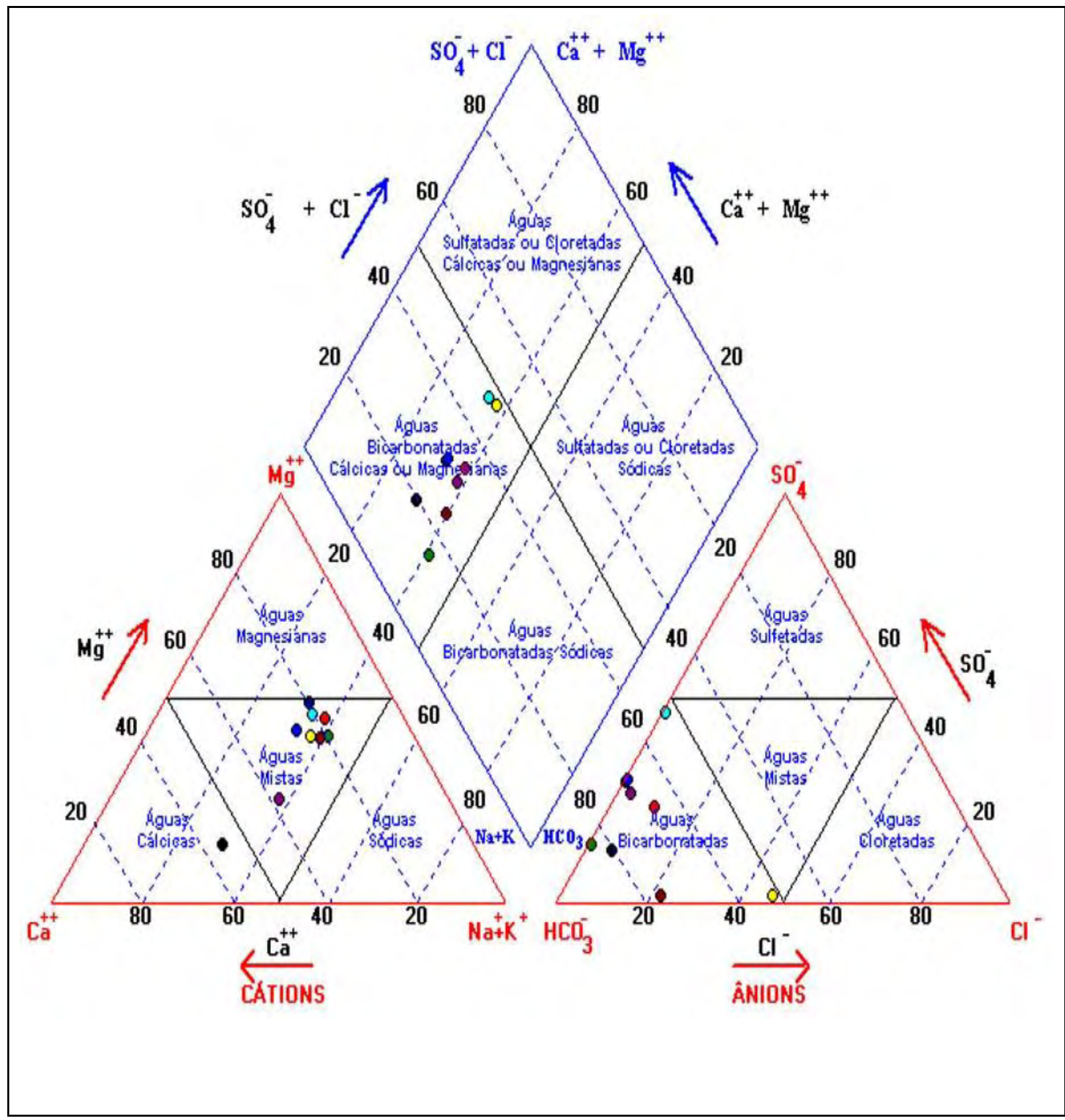

Figura 13. Diagrama de Piper com a classificação das águas subterrâneas coletadas do aquífero livre, em solos de alteração das rochas vulcânicas da Formação Serra Geral.

Com base na análise do diagrama de Stiff (Figura 14), pode-se identificar o padrão típico das águas que circulam pelo aquífero livre. A geometria apresentada no diagrama é típica de águas subterrâneas que apresentam pequenas concentrações de elementos, evidenciando uma rápida circulação e baixo tempo de residência. Além disso, fica claro que essas águas têm a mesma origem e o mesmo padrão químico. 
REGINATO, P .A. R.; AHLERT, S.; GILIOLI, K. C.; CEMIN, G. Caracterização hidrogeológica e hidroquímica do aquífero livre do manto de alteração da Formação Serra Geral, na bacia hidrográfica Taquari-Antas, região nordeste do estado do Rio Grande do Sul. Ambi-Agua, Taubaté, v. 7, n. 2, p. 143-162, 2012. (http://dx.doi.org/10.4136/ambi-agua.903)

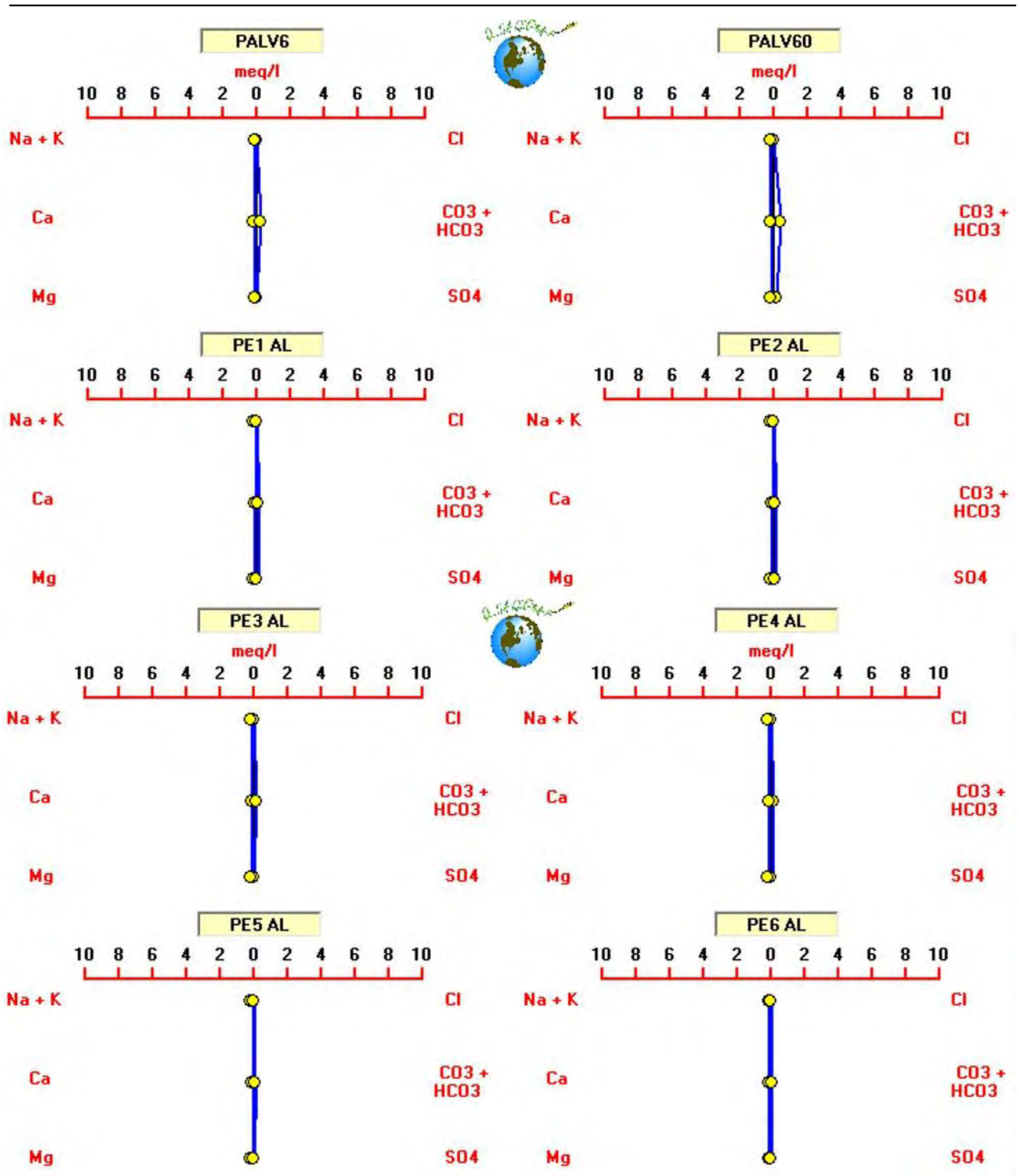

Figura 14. Diagrama de Stiff com as concentrações de águas subterrâneas coletadas no aquífero livre.

\section{CONCLUSÃO}

O aquífero livre está localizado no manto de alteração das rochas vulcânicas da Formação Serra Geral, sendo condicionado por fatores como o solo, a topografia, a litologia do substrato e o clima. A circulação da água ocorre no manto de alteração, junto ao substrato rochoso, dando origem a zonas saturadas com espessuras médias de 1,7 metros e níveis estáticos entre 0 e 1 metro. As zonas de recarga correspondem aos altos topográficos com baixas declividades e solos com maior espessura. As regiões de descarga são caracterizadas pela ocorrência de nascentes que aparecem na intersecção entre a água subterrânea e a 
topografia. As reservas de água subterrânea sofrem influência do clima, sendo que a capacidade de produção dos poços escavados (tipo cacimba) e nascentes, em geral, é inferior a $0,5 \mathrm{~m}^{3} / \mathrm{h}$. Em média, a transmissividade é $1,14.10^{-3} \mathrm{~m}^{2} / \mathrm{s}$ e a condutividade é $2,72.10^{-4} \mathrm{~m} / \mathrm{s}$.

As águas subterrâneas do aquífero livre são bicarbonatadas cálcicas ou magnesianas (predomínio de águas mistas) com baixa alcalinidade e menor concentração de elementos como cálcio, magnésio, sódio, potássio e cloretos. A condutividade é inferior a $100 \mathrm{uS} / \mathrm{cm}$ e o $\mathrm{pH}$ varia entre 5 e 6 . Além disso, as águas tendem a apresentar uma maior concentração de ferro total. Essas características são típicas de um aquífero localizado no manto de alteração, desenvolvido sobre rochas vulcânicas e, evidencia, a existência de uma rápida circulação entre as áreas de recarga e descarga.

Como esse aquífero é poroso, desenvolvido em sedimentos e localizado próximo a superfície, possui uma maior chance de ser contaminado e pode apresentar problemas na qualidade (potabilidade) das águas subterrâneas. Isso é evidenciado pelas concentrações obtidas para o parâmetro nitrato, cujos valores médios são superiores a $10 \mathrm{mg} / \mathrm{L}$ e pela presença de coliformes totais, indicando a existência de fontes de contaminação orgânica.

\section{REFERÊNCIAS}

BRASIL. Ministério da Saúde. Portaria $\mathbf{N}^{\mathbf{2}} 2914$ de 12.12.2011. Dispõe sobre os procedimentos de controle e de vigilância da qualidade da água para consumo humano e seu padrão de potabilidade. Disponível em: <bvsms.saude.gov.br/bvs/saudelegis/gm 12011/prt2914_12_12_2011.html>. Acesso em: 11 julho 2012.

COMPANHIA DE PESQUISAS DE RECURSOS NATURAIS - CPRM. Mapeamento geológico integrado da bacia hidrográfica do Guaíba: carta geológica. Folha SH22V-D-Caxias do Sul. Porto Alegre, 1998. 1 mapa. Escala 1:250.000.

FlORES, C. A. F.; PÖTTER, R. O.; FASOlO, P. J.; HASENACK, H.; WEBER. E. Levantamento semidetalhado de solos: região da serra gaúcha - estado do Rio Grande do Sul. Porto Alegre: UFRGS/Centro de Ecologia, 2007. 1 CD-ROM.

HAUSMAN, A. Comportamento do freático nas áreas basálticas do Rio Grande do Sul. Boletim Paranaense de Geografia, v 18, n. 20, p. 177-215, 1966.

MACHADO, J. L. F.; FREITAS, M. A. de. Projeto mapa hidrogeológico do Rio Grande do Sul: relatório final. Porto Alegre: CPRM, 2005. 65p. il. mapa.

MOBUS, G. Qualigraf: programa para análise da qualidade da água. Fortaleza: FUNCENE, 2002.

NANNI, A.; ROISENBERG, A; FACHEL, J. M. G.; MESQUITA, G.; DANIELI, C. Fluoride characterization by principal component analysis in the hydrochemical facies of Serra Geral aquifer system in southern Brazil. Anais da Acadêmia Brasileira de Ciências, Rio de Janeiro, v. 80, n. 4, p. 693-701, 2008. http://dx.doi.org/10.1590/S000137652008000400010

REGINATO, P. A. R. Integração de dados para prospecção de aquíferos fraturados em trecho da bacia hidrográfica Taquari-Antas (RS). 2003. 254f. Tese (Doutorado em Engenharia de Minas) - Escola de Engenharia, Programa de Pós-Graduação em Engenharia de Minas, Metalúrgica e dos Materiais, Universidade Federal do Rio Grande do Sul, Porto Alegre, 2003. 
REGINATO, P .A. R.; AHLERT, S.; GILIOLI, K. C.; CEMIN, G. Caracterização hidrogeológica e hidroquímica do aquífero livre do manto de alteração da Formação Serra Geral, na bacia hidrográfica Taquari-Antas, região nordeste do estado do Rio Grande do Sul. Ambi-Agua, Taubaté, v. 7, n. 2, p. 143-162, 2012. (http://dx.doi.org/10.4136/ambi-agua.903)

REGINATO, P. A. R.; GILIOLI, K. C. Qualidade dos recursos hídricos subterrâneos utilizados para abastecimento pelas comunidades rurais no município de Veranópolis. In: CONGRESSO INTERNACIONAL DE TECNOLOGIAS PARA O MEIO AMBIENTE, 2., 2010, Bento Gonçalves. Anais... Bento Gonçalves: FIEMA, 2010. 1 CD-ROM.

REGINATO, P. A. R.; STRIEDER, A. J. Caracterização hidrogeológica dos recursos hídricos subterrâneos da Formação Serra Geral na Região Nordeste do Estado do Rio Grande do Sul. In: SIMPÓSIO DE RECURSOS HÍDRICOS DO SUL, 1., 2005, Santa Maria. Anais... Porto Alegre: ABRH, 2005. 1 CD-ROM.

REGINATO, P. A. R.; STRIEDER, A. J. Caracterização estrutural dos aquíferos fraturados da Formação Serra Geral na região nordeste do estado do Rio Grande do Sul. Revista Brasileira de Geociências, v. 36, n. 1, p. 13-22, 2006.

REGINATO, P. A. R.; STRIEDER, A. J. Condicionantes geológicos da ocorrência de ferro e manganês em aquíferos fraturados da Formação Serra Geral. In: ENCONTRO NACIONAL DE PERFURADORES DE POÇOS, 15., E SIMPÓSIO DE HIDROGEOLOGIA SUL-SUDESTE, 1., 2007, Gramado. Anais... São Paulo: ABAS, 2007. 1 CD-ROM.

REGINATO, P. A. R.; AHLERT, S.; FINOTTI, A. R.; SCHNEIDER, V. E.; GILIOLI, K. C. Qualidade das águas subterrâneas de diferentes aquíferos associados à Formação Serra Geral na região nordeste do estado do Rio Grande do Sul. In: CONGRESSO BRASILEIRO DE ÁGUAS SUBTERRÂNEAS, 16., E ENCONTRO NACIONAL DE PERFURADORES DE POÇOS, 17., 2010, São Luis. Anais... São Paulo: ABAS, 2010. 1 CD-ROM.

TEDESCO, M.; REGINATO, P. A. R. A contaminação da água usada para abastecimento por compostos orgânicos e biológicos na zona rural do município de Veranópolis. In: CONGRESSO BRASILEIRO DE ÁGUAS SUBTERRÂNEAS, 13., 2004, Cuiabá. Anais... São Paulo: ABAS, 2004. 1 CD-ROM. 


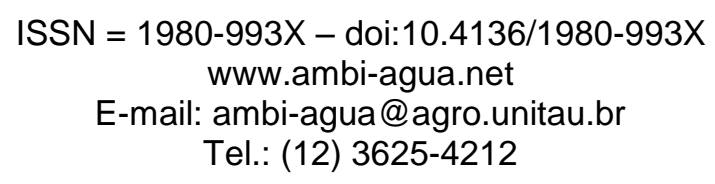

\title{
Modelagem do fluxo de contaminantes em aquífero freático na área do cemitério Bom Jardim, Fortaleza, CE, Brasil
}

\author{
(http://dx.doi.org/10.4136/ambi-agua.917) \\ Mauro César de Brito Sousa1; Marco Aurélio Holanda de Castro²; David Lopes de \\ Castro $^{3}$; Mariano da Franca Alencar Neto ${ }^{4}$; Bruno Leonardy Sousa Lopes ${ }^{1}$ \\ IInstituto Federal do Piauí, \\ e-mails: mauro.sousa@ifpi.edu.br, brunoleonardy@uol.com.br, \\ ${ }^{2}$ Universidade Federal do Ceará, e-mail: marco@ufc.br, \\ 3Programa de Pesquisa e Pós-Graduação em Geodinâmica e Geofísica (UFRN), \\ e-mail: david@geologia.ufrn.br, \\ ${ }^{4}$ Instituto Federal do Ceará, e-mail: mariano@ifce.edu.br
}

\section{RESUMO}

A contaminação de aquíferos freáticos pela decomposição de corpos em cemitérios configura-se como uma realidade comum no Brasil e no mundo. Na cidade de Fortaleza (CE), o cemitério Bom Jardim é um típico exemplo da ameaça de contaminação. O risco se deve, principalmente, pelo fato de que frequentemente a população utiliza-se das águas do aquífero freático para os mais diversos fins. Nesta investigação, analisou-se a possibilidade do cemitério Bom Jardim contribuir para a contaminação microbiológica do aquífero freático local. O software PMWIN PRO ${ }^{\circledR}$ foi utilizado para simular fluxo de águas subterrâneas e avaliar o transporte de microrganismos patogênicos presentes na pluma de contaminação. A simulação numérica foi obtida em regime permanente e admitiu-se o transporte advectivo dos microrganismos patogênicos. Os resultados mostraram a pequena possibilidade da contaminação microbiológica ultrapassar os limites do cemitério.

Palavras-chave: águas subterrâneas, modelagem computacional, pluma de contaminação, cemitérios.

\section{Computational modelling of contaminants flow in groundwater in the Bom Jardim cemetery, Fortaleza, CE, Brazil}

\begin{abstract}
The contamination of groundwater by degradation of buried corpses in cemeteries appears as a common reality in Brazil and worldwide. In the Fortaleza (CE), the Bom Jardim cemetery is a typical example of a contamination threat. The risk is mainly due to the fact that often the population utilizes the groundwater for different purposes. In this investigation, we analyzed the possibility of the Bom Jardim cemetery to contribute to microbiological contamination in the local aquifer. The software PMWIN PRO ${ }^{\circledR}$ was utilized to simulate the groundwater flow and to evaluate the transport of pathogenic microorganisms presented in a pollution plume. The numerical simulation of groundwater was achieved in steady state and was admitted the advective transport of pathogenic microorganisms. The results showed a slight possibility of microbiological contamination to exceed the boundaries of the cemetery.
\end{abstract}

Keywords: groundwater, computational modelling, contamination plume, cemeteries. 


\section{INTRODUÇÃO}

É fato, que a qualidade e a quantidade das águas subterrâneas são um ponto crítico na conservação ambiental, assim como, são responsáveis pela manutenção do bom status ecológico das águas de superfície (Rebouças, 2006).

Atualmente, porém, com o aumento da população, as modificações do uso do solo e a industrialização acelerada, a água subterrânea encontra-se em situação de extrema dificuldade de conservação e sustentabilidade. Sensível a esta questão, a comunidade científica tem aumentado os esforços na busca de soluções para evitar os efeitos mais nocivos de uma possível degradação das águas subterrâneas em escala global.

Dentre os diversos estudos para se dirimir os riscos de poluição dos mananciais subterrâneos, destacam-se aqueles que estão relacionados a derivados de petróleo, a derivados de práticas agrícolas, a contaminação por esgotos urbanos, a produção de lixiviado a partir de aterros sanitários, e, principalmente, relacionados a atividades industriais.

Igualmente, porém negligenciados, os cemitérios apresentam-se como um elemento com forte impacto ambiental e fonte de contaminação de mananciais subterrâneos. Sabe-se que a maioria das necrópoles foi locada sem planejamento adequado, em áreas urbanas, sobre aquíferos freáticos vulneráveis e muitas vezes às margens de corpos de água superficiais (Üçisik e Rushbrook, 1998).

Conforme o Conselho Nacional do Meio Ambiente, resolução n.335 (Brasil, 2003), os cemitérios precisam de uma regulamentação, devendo obedecer a diretrizes cuidadosamente traçadas como meio de garantir a integridade da água subterrânea, melhorar a gestão ambiental e contribuir para a manutenção de condições propícias à saúde pública.

Segundo a Associação Brasileira de Águas Subterrâneas, muitos dos cemitérios municipais brasileiros apresentam riscos ao meio ambiente e possibilidade eminente de contaminação dos aquíferos freáticos (ABAS, 2001).

A possibilidade de dispersão de doenças de veiculação hídrica via fluxo subterrâneo é uma realidade factível, atingindo principalmente as comunidades de baixa renda que costumam se servir de águas de poços rasos.

Conforme Dent (2005), a propagação do líquido gerado pela decomposição dos corpos sepultados apresenta-se como o principal impacto gerado pela prática de disposição de corpos humanos em cemitérios. Essa contaminação contém grande quantidade de matéria orgânica, sais minerais e uma infinidade de microrganismos patogênicos (Pacheco, 2000).

Pelo mundo, vários casos de contaminação do lençol freático foram relatados e relacionados com a presença de cemitérios em áreas inadequadas e próximas a comunidades urbanas. Como exemplos, citam-se os casos clássicos mencionados por Bouwer (1978): ocorrência de maior incidência de febre tifoide entre as pessoas que viviam perto de um cemitério em Berlim em meados de 1867; e também, a presença de um sabor adocicado e odor fétido em águas de poços nos arredores de cemitérios em Paris, especialmente em verões quentes (Bouwer, 1978).

As pesquisas brasileiras, sobre cemitérios, tiveram início com a criação do Centro de Pesquisas de Águas Subterrâneas (Cepas), no Instituto de Geociências da Universidade de São Paulo (USP) em meados de 1983. Nesses estudos, Martins et al. (1991), Pacheco (2000) e Matos (2001) caracterizaram os impactos de cemitérios em aquíferos freáticos a partir da identificação de microrganismos comumente encontrados no processo de decomposição dos corpos humanos ali presentes.

No nordeste brasileiro, destaca-se como pioneira a pesquisa de Marinho (1998) no cemitério São João Baptista em Fortaleza (CE), na qual, a partir de análises físico-químicas e bacteriológicas em poços de monitoramento, foi possível identificar a presença de contaminação no lençol freático. 
Na Austrália, na década de 90, foi realizado um dos maiores estudos relatados sobre a contaminação de águas subterrâneas por cemitérios (Dent e Knight, 1998). A pesquisa foi realizada com avaliação hidrogeoquímica e microbiológica das águas subterrâneas em aquíferos de nove cemitérios, em cinco estados, em uma ampla gama de configurações hidrogeológicas dos solos.

Em 2002, foi publicado no Reino Unido um dos mais completos guias para avaliação de contaminação das águas subterrâneas por cemitérios (Environment Agency, 2002). O trabalho contempla não somente os dados de qualidade das águas subterrâneas, mas vislumbra uma gestão mais ampla, integrada à análise de vulnerabilidade, estudo de proteção de fontes, análise de riscos para implantação de novos cemitérios e insere a necessidade de modelos numéricos para previsão de cenários de contaminação e transporte de microrganismos. Nesse cenário, evidencia-se a importância da modelagem numérica computacional para casos de contaminação e preservação de aquíferos impactados.

Os modelos numéricos computacionais trabalham na atenuação das incertezas por contemplarem a maior complexidade do fluxo subterrâneo em estudo. Ainda incipiente no Brasil, mas abundante ao redor do mundo, a modelagem computacional tem proporcionado melhores subsídios para o gerenciamento dos recursos hídricos, graças à possibilidade de obtenção de cenários que favorecem a tomada de decisão (Nobre, 2006).

No ano de 2005, Castro (2008) desenvolveu uma investigação para avaliar a possível contaminação do lençol freático sob o Cemitério Bom Jardim Fortaleza (CE) e os possíveis danos ambientais à comunidade local. A locação de poços de observação (piezômetros), levantamentos geofísicos para o reconhecimento do substrato rochoso e a coleta de água subterrânea para análises em termos hidroquímicos e bacteriológicos, compuseram a abordagem que procurou levantar o maior aporte de dados possíveis sobre o sistema aquífero e suas particularidades.

Terminada a parte de coleta de campo, e de posse dos resultados das análises, Castro (2008) determinou que existia uma contaminação generalizada nas amostras obtidas dos piezômetros, ocasionada principalmente por microrganismos. No entanto, segundo resultados apresentados naquele estudo, a possibilidade do nível de contaminação estar diretamente relacionada à inexistência de saneamento local (ausência de coleta por esgotos, sobretudo) revelou-se a hipótese mais provável.

Apesar disso, foram perceptíveis as dúvidas da comunidade local, que mesmo em vista dos fatos apresentados no estudo, continuaram propensas a acreditar na possível contaminação advinda dos limites do cemitério Bom Jardim.

Como forma de aprofundar as conclusões obtidas pelo estudo de campo relatado por Castro (2008), a presente investigação propôs a modelagem computacional do aquífero freático em questão, com o objetivo de estabelecer o avanço do fluxo subterrâneo no período de meia vida da contaminação microbiológica.

A partir do modelo gerado e calibrado, foi possível estimar a velocidade de fluxo, seu sentido preferencial e utilizar modelos de transportes de contaminantes para determinar os cenários indicativos do deslocamento de microrganismos. Os resultados apresentados produziram uma fonte de informações que possibilitou o conhecimento da área passível de contaminação oriunda especificamente do cemitério Bom Jardim.

\section{MATERIAIS E MÉTODO}

\subsection{Caracterização da área de estudo}

O cemitério Municipal Parque Bom Jardim encontra-se localizado na Rua Estrada Jatobá, 2.668, no bairro Bom Jardim, Fortaleza - CE, Brasil (Figura 1). Incrustado em plena área urbana, é considerado o maior cemitério público de Fortaleza, de pouco mais de 84 mil metros 
SOUSA, M. C. B.; CASTRO, M. A. H.; CASTRO, D. L.; AlENCAR NETO, M. F.; LOPES, B. L. S. Modelagem do fluxo de contaminantes em aquífero freático na área do cemitério Bom Jardim, Fortaleza, CE, Brasil. Ambi-Agua, Taubaté, v. 7, n. 2, p. 163-178, 2012. (http://dx.doi.org/10.4136/ambi-agua.917)

quadrados de área. Atende à demanda da população fortalezense e grande parcela da região metropolitana.

A inexistência de investigações prévias à sua instalação, como a falta de caracterização geoambiental do estrato rochoso, repercute na preocupação com o possível impacto ambiental gerado pelo cemitério na região circunvizinha e, por conseguinte, na necessidade de aprofundar o conhecimento sobre os intervenientes do aquífero em questão (Castro, 2008).

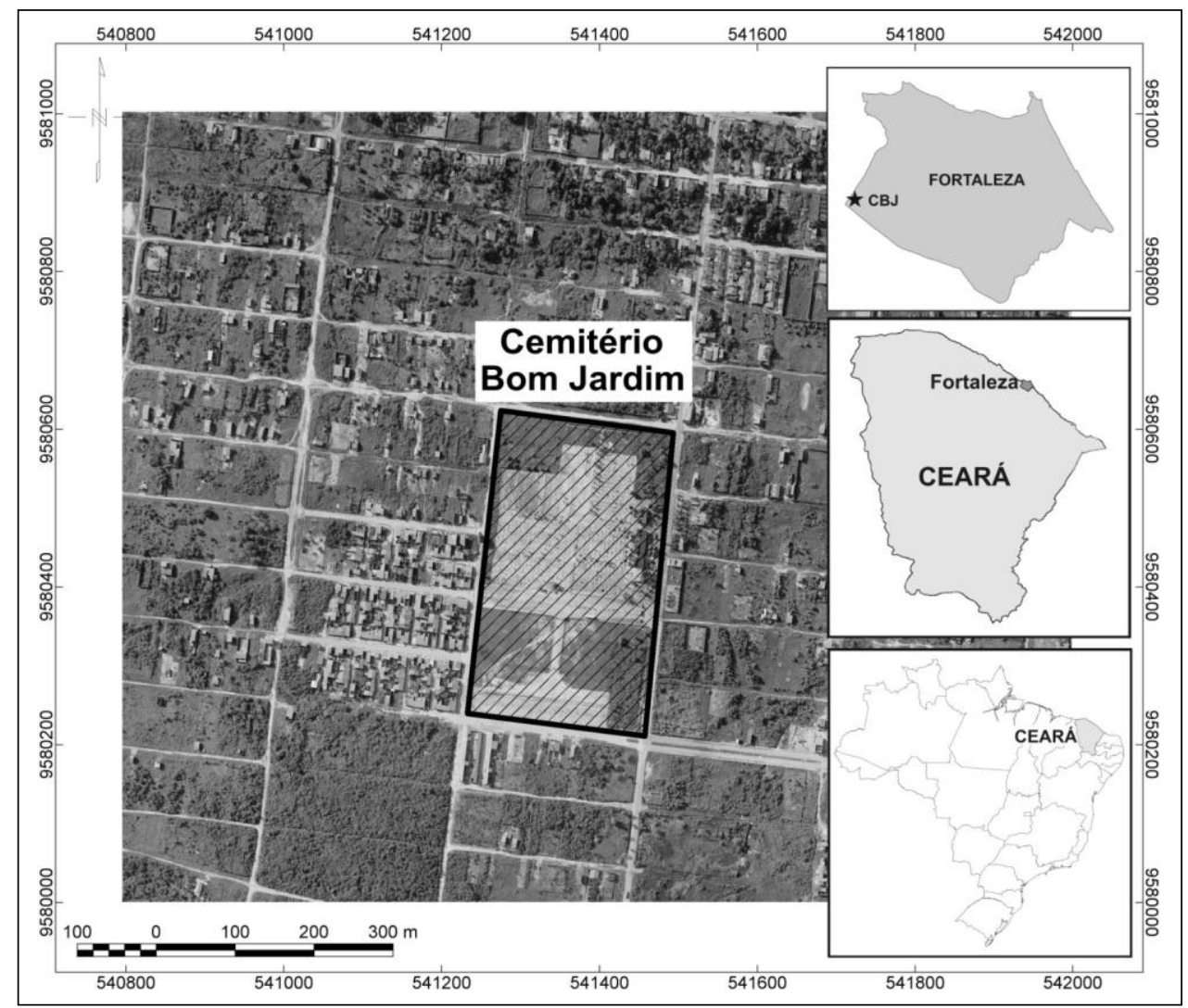

Figura 1. Localização do Cemitério Bom Jardim.

Fonte: Castro (2008).

\subsection{Aspectos Geoambientais da área de estudo}

O cemitério Bom Jardim encontra-se na região mais plana do topo de uma elevação topográfica moderada de $20 \mathrm{~m}$ em relação às áreas adjacentes (Figura 2). O solo do tipo solonetz sadolizado oriundo de rochas granito-gnaíssicas do embasamento cristalino subflorante é predominante na área. Este solo, com diferentes colorações (de cinza amarelada a avermelhada) é representado por intercalações de níveis arenosos e argilosos (Castro, 2008).

No contexto hidrológico, o aquífero sedimentar (Dunas/Paleodunas, Formação Barreiras, Aluviões e Coberturas Colúvio-eluviais) prevalece. Nesta formação, os mantos de intemperismo ou sedimentares da cobertura cólui-eluvial são úteis no armazenamento de volumes de água, dependendo da espessura local do aquífero (Castro, 2008).

O clima local é quente com chuvas tropicais alternado com períodos secos ao longo do ano. A precipitação média apresenta-se na faixa de 1200 a $1400 \mathrm{~mm}$, variando com anos escassos e de grande intensidade pluviométrica. A temperatura média anual fica em torno de 26 a $27^{\circ} \mathrm{C}$, com máximas variando entre 31 e $32^{\circ} \mathrm{C}$ e amplitude térmica de $1,44^{\circ} \mathrm{C}$ (Castro, 2008). 
SOUSA, M. C. B.; CASTRO, M. A. H.; CASTRO, D. L.; ALENCAR NETO, M. F.; LOPES, B. L. S. Modelagem do fluxo de contaminantes em aquífero freático na área do cemitério Bom Jardim, Fortaleza, CE, Brasil. Ambi-Agua, Taubaté, v. 7, n. 2, p. 163-178, 2012. (http://dx.doi.org/10.4136/ambi-agua.917)

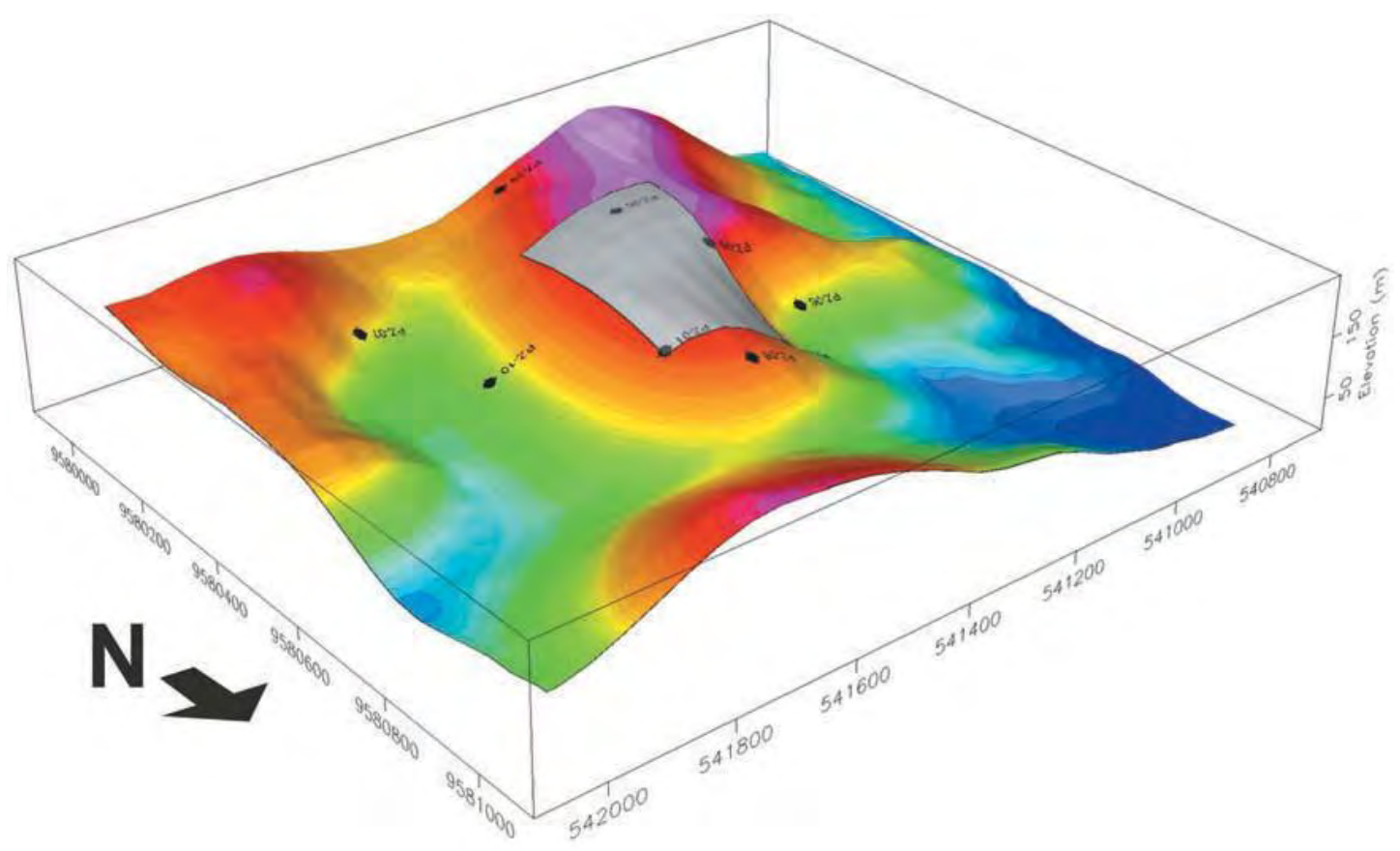

Figura 2. Modelo digital de terreno do cemitério Bom Jardim (área hachurada). Fonte: Castro (2008).

\subsection{Fontes de contaminação da área de estudo}

As concentrações de coliformes totais e fecais, estreptococos fecais, bactérias proteolíticas e clostrídios sulfitos redutores foram utilizadas como indicadores microbiológicos para a detecção da pluma contaminação no cemitério Bom Jardim (Castro, 2008).

Os indicadores bacteriológicos (Tabela 1) apresentam concentrações elevadas em praticamente todos os poços, seja dentro ou fora dos limites do cemitério. Em todos os poços, os coliformes totais e fecais superam valores de $3,6 \times 10^{2} \mathrm{NMP} / 100 \mathrm{~mL}$, o que torna a água subterrânea imprópria para o consumo humano (Castro, 2008). O posicionamento de cada poço pode ser verificado na Figura 3.

Tabela 1. Análise microbiológica nos piezômetros do cemitério Bom Jardim.

\begin{tabular}{l|ccccccccc}
\hline \multicolumn{1}{c|}{ Poços } & $\mathbf{0 1}^{*}$ & $\mathbf{0 3}^{*}$ & $\mathbf{0 4}^{*}$ & $\mathbf{0 5} *$ & $\mathbf{0 6}$ & $\mathbf{0 7}$ & $\mathbf{0 8}$ & $\mathbf{0 9}$ & $\mathbf{1 0}$ \\
\hline Coliformes a $35^{\circ} \mathrm{C}(\times 102 \mathrm{NMP} / 100 \mathrm{~mL})$ & 460 & 91 & 93 & 240 & 150 & 3,6 & 2400 & 240 & 23 \\
Coliformes a $45^{\circ} \mathrm{C}(\times 102 \mathrm{NMP} / 100 \mathrm{~mL})$ & 3,6 & 36 & 30 & 3,6 & 3,0 & 3,6 & 2400 & 230 & 9,1 \\
Estreptococos fecais $(\times 102 \mathrm{NMP} / 100 \mathrm{~mL})$ & 93 & 1,5 & 3,0 & 23 & 3,0 & 93 & 150 & 3,0 & 3,0 \\
Bactérias heterot. aeróbicas $(\times 105 \mathrm{UFC} / \mathrm{mL})$ & 60 & 39 & 11 & 24 & 2,2 & 1,7 & 55 & 7,8 & 4,0 \\
Bactérias heterot. anaeróbicas $(\times 103 \mathrm{UFC} / \mathrm{mL})$ & 120 & 1,3 & 1,7 & 150 & 63 & 18 & 28 & 37 & 70 \\
Bactérias proteolíticas $(\times 102 \mathrm{NMP} / 100 \mathrm{~mL})$ & 43 & 3,0 & 3,6 & 9,1 & 1100 & 15 & 240 & 93 & 460 \\
Clostrídios sulfitos redutores a $46^{\circ} \mathrm{C}(\mathrm{UFC} / \mathrm{mL})$ & $<10$ & $<10$ & $<10$ & $<10$ & $<10$ & $<10$ & $<10$ & $<10$ & $<10$ \\
\hline
\end{tabular}

Data da coleta: $14 / 11 / 2005$; NMP = Número mais provável;

UFC = Unidades formadoras de colônias;

* Poços no interior do cemitério.

Fonte: Castro (2008). 
SOUSA, M. C. B.; CASTRO, M. A. H.; CASTRO, D. L.; AlENCAR NETO, M. F.; LOPES, B. L. S. Modelagem do fluxo de contaminantes em aquífero freático na área do cemitério Bom Jardim, Fortaleza, CE, Brasil. Ambi-Agua, Taubaté, v. 7, n. 2, p. 163-178, 2012. (http://dx.doi.org/10.4136/ambi-agua.917)

\subsection{Premissas da modelagem de fluxo e transporte de microrganismos em águas subterrâneas}

De maneira geral, os mecanismos de transporte de bactérias na subsuperfície são afetados por processos relacionados às características do patógeno (tamanho, forma e atividade) e associados às particularidades do ambiente onde estão inseridos (granulometria do solo, temperatura, umidade e nível de adsorção) (Environment Agency, 1999).

Em vista da indeterminação do tempo de sobrevivência e imprecisão da atenuação do patógeno na zona insaturada ou saturada, é comum se fazer uso de modelos para proteger mananciais e fontes de captação de águas subterrâneas de um possível foco de contaminação microbiológica.

O modelo usualmente assumido por agências ambientais para o transporte de contaminantes microbiológicos em águas subterrâneas leva em consideração duas hipóteses fundamentais (USEPA, 1987 apud Anderson e Woessner, 1992; Taylor et al., 2004):

- A capacidade de sobrevivência dos patógenos (meia vida) no meio analisado (água subterrânea) é conhecida;

- Microrganismos são transportados na velocidade média linear do fluxo da água subterrânea (transporte advectivo).

Para a primeira hipótese, segundo os conhecimentos do meio e da capacidade de sobrevivência do microrganismo, é possível admitir que 50 dias de percurso no meio subterrâneo são suficientes para sua deterioração. Portanto, as chances de contaminação são pequenas para uma área que esteja além desse tempo de trajeto calculado (ARGOSS, 2001; Northern Ireland, 2001).

$\mathrm{Na}$ segunda hipótese, considerar o contaminante com características conservativas e o seu deslocamento na velocidade média linear do fluxo subterrâneo (transporte advectivo), configura-se como o mais usual e aceitável para fins de simplificação da modelagem (ARGOSS, 2001; Northern Ireland, 2001; Anderson e Woessner, 1992; Taylor et al., 2004).

Atualmente, o entendimento do fluxo de água e transporte de contaminantes no meio subterrâneo sofreu grandes avanços graças aos resultados fornecidos por modelos numéricos acoplados a pacotes computacionais (Chiang e Kinzelbach, 2001; Manoel Filho e Feitosa, 2000; Anderson e Woessner, 1992).

O MODFLOW ${ }^{\circledR}$ é um bom exemplo desse avanço. Neste pacote computacional, desenvolvido por McDonald e Harbaugh (1988), a equação geral que descreve o fluxo em meios porosos é resolvida numericamente pelo método das diferenças finitas, onde em cada nó da malha de discretização do problema, as equações diferenciais parciais que governam o fluxo são transformadas em equações algébricas. O modelo permite que se varie o nível estático até a convergência do sistema numérico, de forma que a resolução dos sistemas de equações possa ser facilmente desenvolvida por processos iterativos do próprio programa (Nobre, 2006; Anderson e Woessner, 1992; Manoel Filho e Feitosa, 2000).

Aliado ao MODFLOW ${ }^{\circledR}$ existe o PMPATH ${ }^{\circledR}$ (Chiang e Kinzelbach, 1994), pósprocessador utilizado para modelagem do transporte advectivo de contaminantes, onde um esquema semianalítico de deslocamento de partículas é usado para calcular trajetórias (paths) de fluxo e tempos de percurso.

As etapas da modelagem envolvem a seleção do modelo computacional, a formulação do modelo conceitual do aquífero e a calibração do modelo de escoamento. No que concerne à formulação do modelo conceitual do aquífero, os dados disponíveis devem ser preparados de acordo com as formas de entrada requeridas pelos modelos computacionais.

A calibração, por sua vez, envolve a reprodução aproximada da situação conhecida de distribuição de cargas hidráulicas, para que as condições simuladas se aproximem ao máximo das condições evidenciadas em campo. 
Nesta pesquisa, a modelagem computacional foi realizada com o uso do software PMWIN PRO ${ }^{\circledR}$, desenvolvido por Chiang (2005) e que oferece interface para simulação do fluxo da água subterrânea no pacote MODFLOW ${ }^{\circledR}$ (Mcdonald e Harbaugh, 1988) e simulação do transporte advectivo de partículas no pacote PMPATH ${ }^{\circledR}$ (Chiang e Kinzelbach, 1994). Os dados de entrada do modelo envolvem a obtenção da potenciometria observada, a estimativa inicial da condutividade hidráulica, determinação da espessura do aquífero, a recarga do aquífero e a definição das condições de contorno da área.

A calibração do modelo envolveu o procedimento desenvolvido por Schuster e Araújo (2004), denominado de Método Iterativo de Gradiente Hidráulico ou MIGHA. A formulação, os critérios de análise iterativa e convergência do método podem ser aprofundados nos trabalho publicados por Schuster e Araújo (2004) e Tavares (2010).

\subsection{Dados de entrada do modelo}

\subsubsection{Variação do nível estático (potenciometria)}

Foram executados dez furos de sondagem a trado e rotativa na região do cemitério Bom Jardim. Os furos, com diâmetro de 4", serviram para ensaios de granulometria e permeabilidade dos solos da região. Foram escolhidos nove dos dez furos (Figura 3) para a instalação dos piezômetros para o monitoramento da carga hidráulica do aquífero livre do local (Castro, 2008).

O monitoramento da variação do nível estático local aconteceu no período compreendido entre novembro de 2005 e novembro de 2006. Por conta da elevação do lençol freático a níveis mais próximos da superfície, o mês de julho de 2006 foi tido como o representativo para a potenciometria do modelo e para o período crítico de contaminação na localidade.

Nos piezômetros locados dentro do cemitério, considerando o mês de julho de 2006, identificou-se a profundidade do aquífero variando entre $7 \mathrm{~m}$ no piezômetro (P5) e 2,47 m no piezômetro (P4).

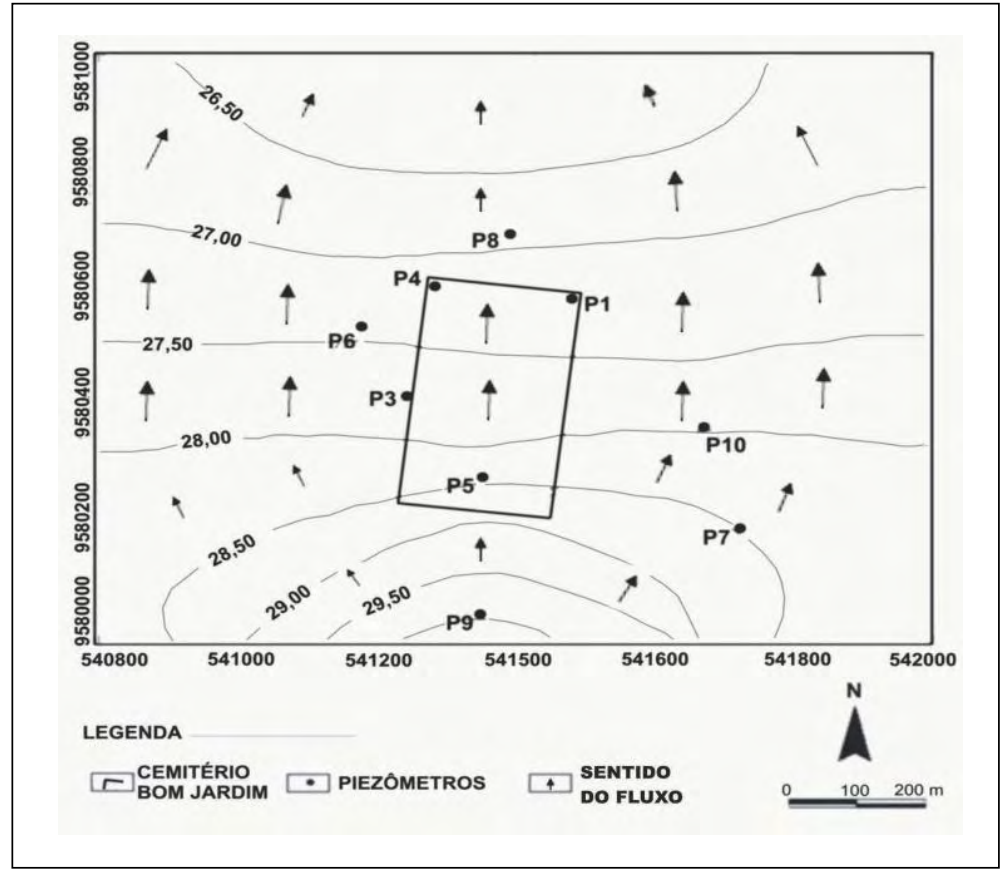

Figura 3. Mapa piezométrico (em metros) para a área de estudo. 
SOUSA, M. C. B.; CASTRO, M. A. H.; CASTRO, D. L.; ALENCAR NETO, M. F.; LOPES, B. L. S. Modelagem do fluxo de contaminantes em aquífero freático na área do cemitério Bom Jardim, Fortaleza, CE, Brasil. Ambi-Agua, Taubaté, v. 7, n. 2, p. 163-178, 2012. (http://dx.doi.org/10.4136/ambi-agua.917)

\subsubsection{Estimativa inicial da condutividade hidráulica da área}

Cerca de 66,6 m do regolito no local foram perfurados por sondagens com profundidade entre 2,5 a $15 \mathrm{~m}$, para realização dos ensaios de granulometria e permeabilidade; caracterização das camadas de solo; e profundidade do topo da rocha não alterada (Castro, 2008).

Segundo Castro (2008) o substrato da região é composto por três camadas de solo com teores de argila e areia, além de cascalho, conforme indicado nas colunas demonstradas nos furos (Figura 4). As camadas argilo-arenosas apresentam valores de permeabilidade variando entre $0,2 \times 10^{-6}$ a $8,4 \times 10^{-6} \mathrm{~cm} / \mathrm{s}$. E, nas camadas areno-argilosas, têm-se a variação em torno de $0,8 \times 10^{-6}$ a $5,8 \times 10^{-6} \mathrm{~cm} / \mathrm{s}$. Como percebe-se, os resultados indicam condições de baixa permeabilidade, com valor médio na ordem de $10^{-8} \mathrm{~m} . \mathrm{s}^{-1}$, para uma coluna de solo da região do cemitério.
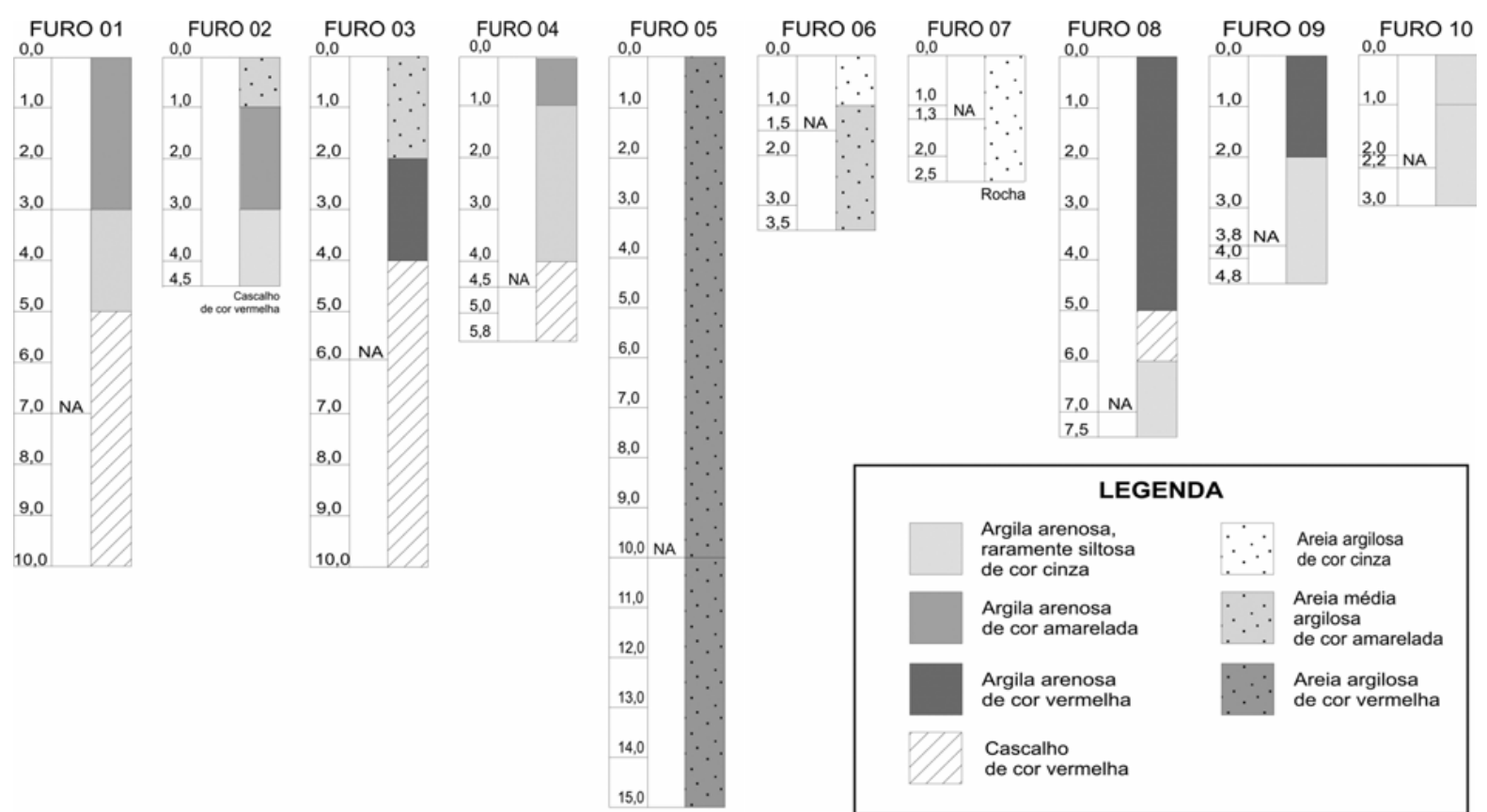

Figura 4. Colunas de solo dos furos de sondagem realizadas na região do cemitério.

Fonte: Castro (2008).

\subsubsection{Determinação da espessura do aquífero}

Para a determinação da espessura do aquífero, foram utilizados os dados publicados em Castro (2008). Segundo o estudo, foram realizados nove SEV's na região do cemitério, com arranjo Schlumber e abertura entre eletrodos de corrente máxima variando de 20 a $70 \mathrm{~m}$. As aberturas possibilitaram a investigação até $35 \mathrm{~m}$ de profundidade, englobando a totalidade da coluna de regolito e a porção superior da rocha não alterada (Castro, 2008).

As SEV's foram distribuídas de forma regular, tendo o cemitério como ponto central (Figura 5). A rocha não alterada segue de forma bastante irregular a morfologia do terreno (Figura 2), sendo o paleo-relevo do embasamento encontrado a $25 \mathrm{~m}$ de cota topográfica no limite sudeste e 17 m na porção noroeste da área (Figura 6). 
SOUSA, M. C. B.; CASTrO, M. A. H.; CASTRO, D. L.; AlENCAR NETO, M. F.; LOPES, B. L. S. Modelagem do fluxo de contaminantes em aquífero freático na área do cemitério Bom Jardim, Fortaleza, CE, Brasil. Ambi-Agua, Taubaté, v. 7, n. 2, p. 163-178, 2012. (http://dx.doi.org/10.4136/ambi-agua.917)

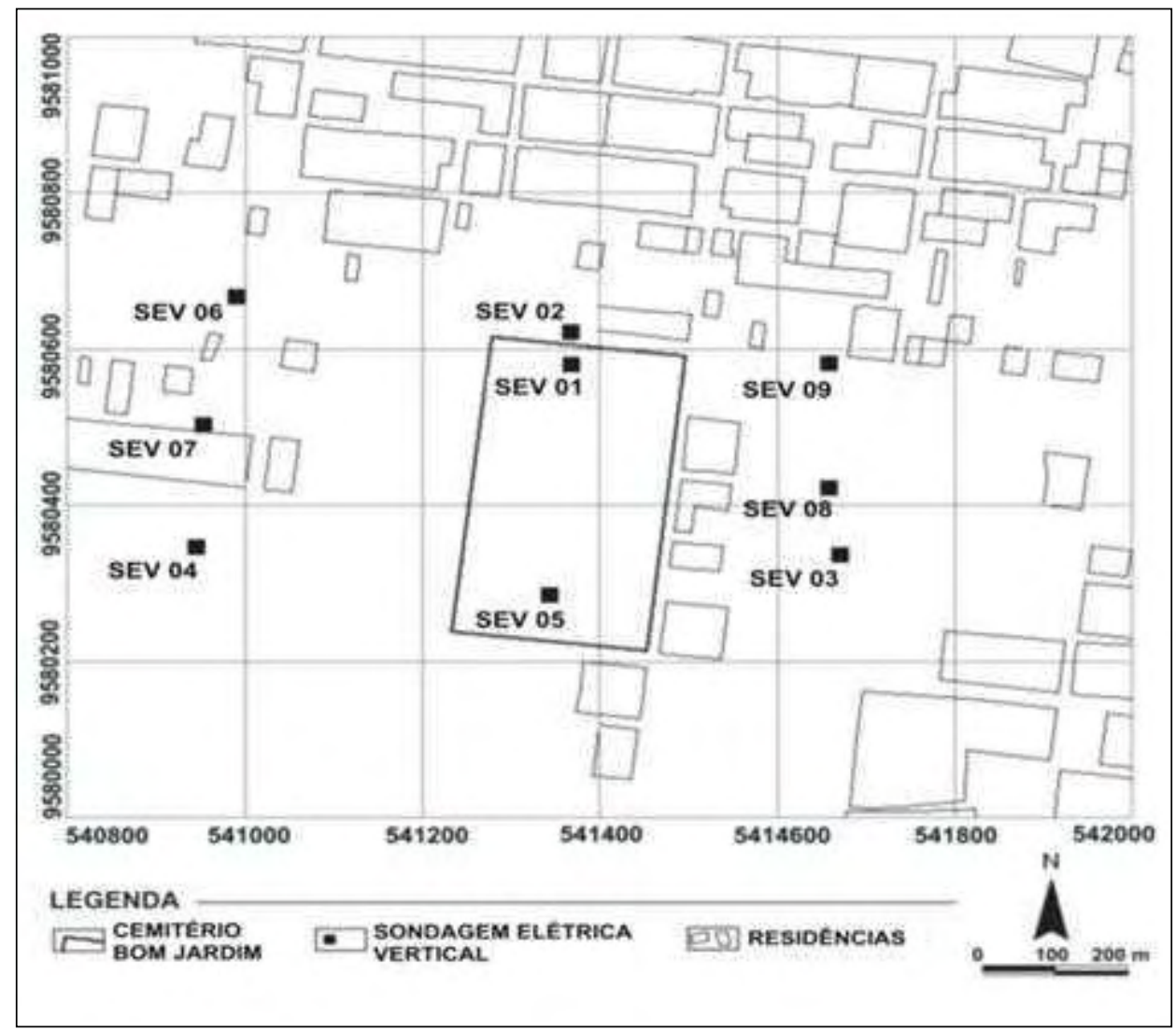

Figura 5. Localização das SEV's na área de estudo.

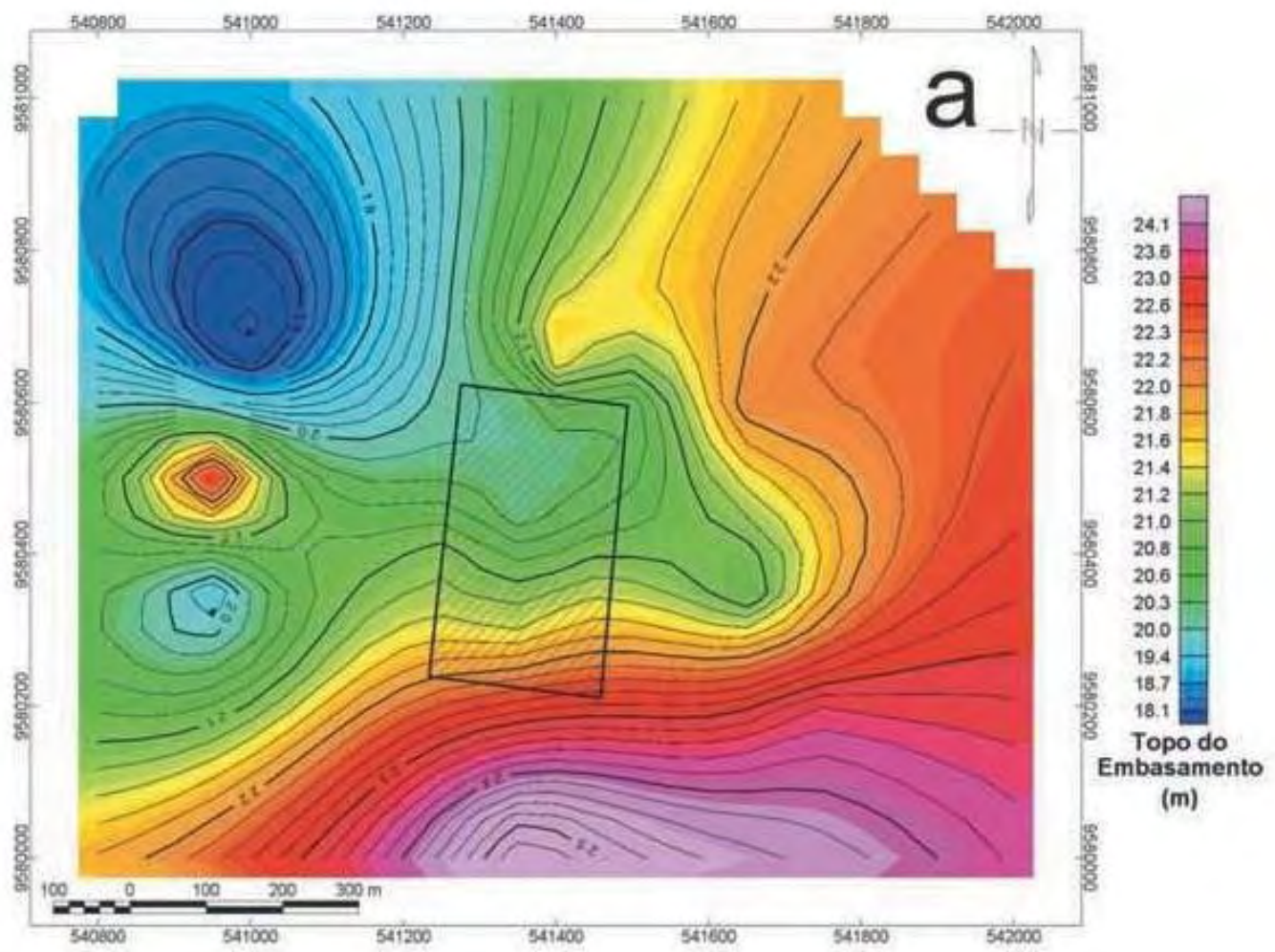

Figura 6. Profundidades do topo do embasamento.

Fonte: Castro (2008). 
SOUSA, M. C. B.; CASTRO, M. A. H.; CASTRO, D. L.; AlENCAR NETO, M. F.; LOPES, B. L. S. Modelagem do fluxo de contaminantes em aquífero freático na área do cemitério Bom Jardim, Fortaleza, CE, Brasil. Ambi-Agua, Taubaté, v. 7, n. 2, p. 163-178, 2012. (http://dx.doi.org/10.4136/ambi-agua.917)

\subsubsection{Recarga}

O balanço hídrico foi utilizado como alternativa para se avaliar a recarga de água no aquífero freático da região.

O Posto Pluviométrico Castelão, localizado no município de Fortaleza - CE, foi adotado como representativo para a área, abrangendo o Cemitério Bom Jardim. O período de informação é de 17 anos, de 1990 a 2006. Os dados da série histórica de precipitação e temperaturas médias mensais para o período analisado foram fornecidos pela FUNCEME e INMET, respectivamente. A partir do método de Thornthwaite (Tucci, 1997) e com base nas informações das séries históricas obtidas, pôde-se estimar a infiltração efetiva em 240,43 $\mathrm{mm} / \mathrm{ano}$.

\subsubsection{Definição do domínio do modelo e condições de contorno}

A modelagem computacional foi realizada com o uso do software PMWIN PRO ${ }^{\circledR}$. O domínio do modelo compreende uma área de $1,2 \mathrm{~km}^{2}$ e foi discretizado em uma malha de diferenças finitas de dimensões $1200 \mathrm{~m}$ ao longo da direção x (leste-oeste) e $1000 \mathrm{~m}$ ao longo da direção y (norte-sul), com células de dimensões 12 x 10 m (Figura 7). Sendo uma única camada definida por não confinada com espessura média adotada de $20 \mathrm{~m}$, homogênea e isotrópica.

O cenário simulado foi para o regime permanente, o contaminante transporta-se no meio por processos advectivos e está em contato direto com o lençol freático, desprezando a ação da camada insaturada do solo.

As condições de contorno foram delimitadas em conformidade com a adoção de sentido de fluxo sul-norte preferencial para o sistema. Onde se admitiu um contorno de carga hidráulica especificada fixa na fronteira de entrada de fluxo (a montante, limite sul), e um contorno de carga hidráulica especificada fixa na saída de fluxo (a jusante, limite norte).

E finalmente, aos limites laterais, partindo-se da concepção de que existam linhas de corrente que tornam o fluxo nulo na direção perpendicular a essas fronteiras, admitiu-se condições de contorno de fluxo nulo (Figura 7).

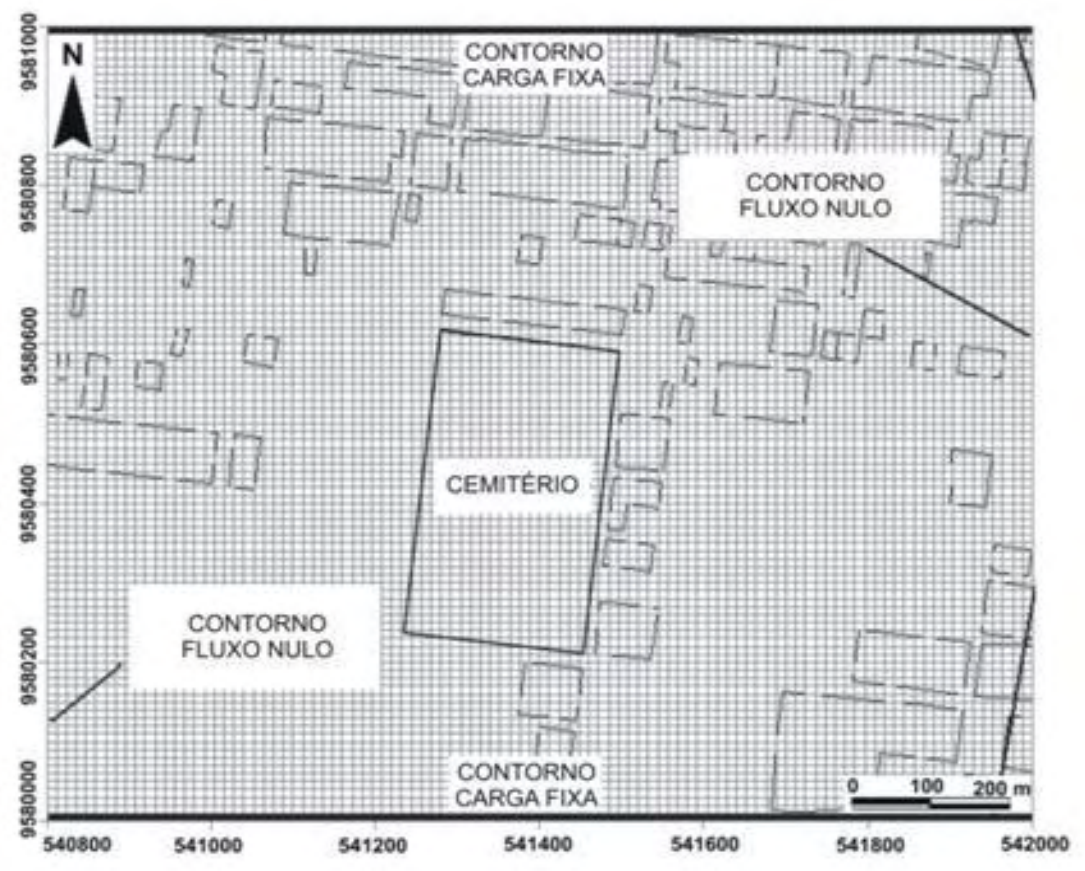

Figura 7. Definição do domínio do modelo e condições de contorno. 


\subsubsection{Calibração do modelo}

A calibração do modelo foi obtida pela minimização dos residuais verificados entre as cargas hidráulicas calculadas e as cargas hidráulicas observadas em campo. Para atingir tais resultados, o procedimento utilizado foi o desenvolvido por Schuster e Araújo (2004) denominado de Método Iterativo de Gradiente Hidráulico ou simplesmente MIGHA.

Este método consiste em um procedimento iterativo, em que a partir de uma matriz inicial de condutividades hidráulicas obtidas em campo, juntamente com a matriz das cargas hidráulicas observadas também em campo, e ainda, de posse da matriz de cargas hidráulicas calculadas fornecidas pela simulação do fluxo subterrâneo, seja possível gerar a cada ciclo iterativo no MIGHA, uma nova matriz otimizada de condutividades hidráulicas.

É feita então uma nova simulação no PMWIN $\mathrm{PRO}^{\circledR} \operatorname{com}$ os dados da nova condutividade hidráulica obtida, onde se observa as condições de convergência entre a potenciometria observada nas condições de campo e a potenciometria calculada na simulação.

Conforme haja convergência pode-se admitir que o modelo esteja calibrado. A formulação, os critérios de análise iterativa e convergência podem ser melhor compreendidos nos trabalho publicados por Schuster e Araújo (2004) e Tavares (2010).

\subsubsection{Fluxograma da modelagem computacional}

A Figura 8 descreve o fluxograma do processo de modelagem computacional aplicado à região do cemitério Bom Jardim.

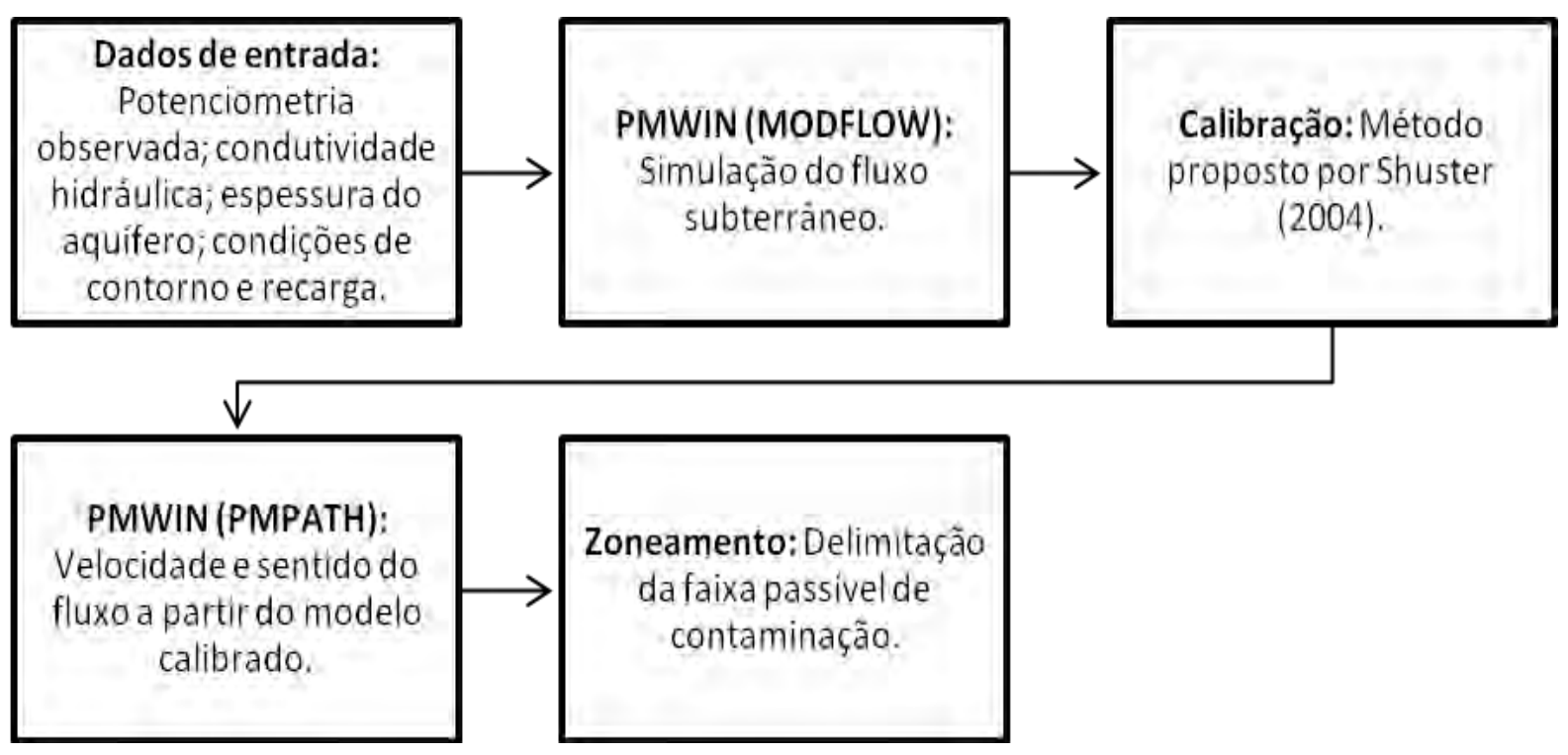

Figura 8. Simulação de fluxo de águas subterrâneas e transporte de contaminação.

\section{RESULTADOS E DISCUSSÃO}

Os resultados deste trabalho são apresentados seguindo-se a sequência do processo de modelagem computacional, onde, a partir da confrontação da potenciometria observada com a potenciometria calculada pela primeira simulação (Figura 9 à esquerda) evidenciou a necessidade da tomada do método de calibração para dirimir as diferenças encontradas entre o observado e o modelado. 
SOUSA, M. C. B.; CASTRO, M. A. H.; CASTRO, D. L.; ALENCAR NETO, M. F.; LOPES, B. L. S. Modelagem do fluxo de contaminantes em aquífero freático na área do cemitério Bom Jardim, Fortaleza, CE, Brasil. Ambi-Agua, Taubaté, v. 7, n. 2, p. 163-178, 2012. (http://dx.doi.org/10.4136/ambi-agua.917)
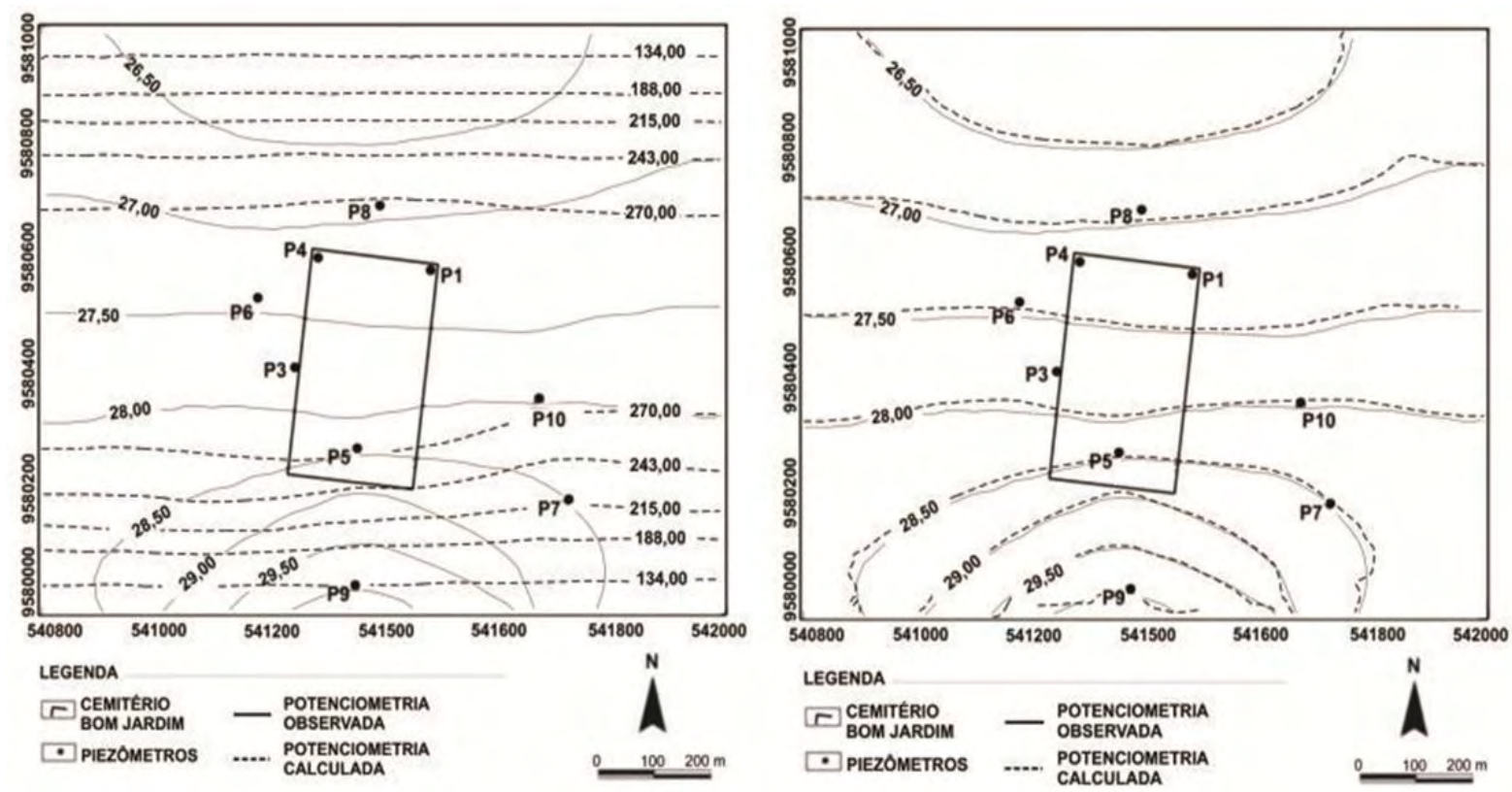

Figura 9. Carga hidráulica observada e calculada (em metros) antes da calibração (à esquerda) e depois da calibração (à direita).

Foram necessárias nove iterações no método proposto por Schuster (2004) para que houvesse a calibração. Em cada iteração no método, uma nova matriz de condutividades hidráulicas era formada e, a partir desta, uma nova simulação se sucedia no PMWIN PRO ${ }^{\circledR}$, gerando uma nova matriz de cargas hidráulicas calculadas.

A Figura 9 à direita apresenta o resultado final da calibração, com a potenciometria calculada convergindo para as condições observadas em campo. A proximidade entre potenciometrias (observadas e calculadas) demonstram o sucesso obtido pelo método, o que propiciou condições satisfatórias da representação do observado em campo. A velocidade média linear do fluxo subterrâneo foi estabelecida em $0,27 \mathrm{~m}^{-d i a^{-1}}$ após a simulação do fluxo calibrado no pacote PMPATH ${ }^{\circledR}$.

De acordo com a velocidade média de fluxo obtida, a faixa limitada em torno do limite norte do cemitério Bom Jardim abrangeria uma largura de 13,50 metros para um tempo de percurso do fluxo subterrâneo de 50 dias (Figura 10). O que, a partir da face exterior dessa faixa, seria possível admitir que não haja viabilidade da contaminação microbiológica (Tabela 1) ser advinda do interior do cemitério.

É perceptível, segundo o cenário apresentado, que a contaminação oriunda do cemitério não atinge os piezômetros, e algumas observações melhoram esta assertiva. Por exemplo, a condição de simulação admitiu que a pluma de microrganismos patogênicos estivesse, já na sua origem, em contato direto com o lençol freático (hipótese mais desfavorável), desprezando-se o caráter de atenuação da zona insaturada presente na área de estudo.

Sob essa condição específica pode-se afirmar que não corresponde à realidade de campo, visto que foi possível constatar nos dados colhidos, uma camada insaturada para a região no interior do cemitério (vide item 2.5.1). Sendo essa espessura insaturada referente ao mês onde se registrou a maior elevação do nível estático (julho de 2006).

Segundo ARGOSS (2001), a zona insaturada é a primeira linha de defesa natural que vai de encontro à poluição que se infiltra no manancial de água subterrânea, e não deve ser desconsiderada como um importante fator de atenuação da contaminação. 
SOUSA, M. C. B.; CASTRO, M. A. H.; CASTRO, D. L.; ALENCAR NETO, M. F.; LOPES, B. L. S. Modelagem do fluxo de contaminantes em aquífero freático na área do cemitério Bom Jardim, Fortaleza, CE, Brasil. Ambi-Agua, Taubaté, v. 7, n. 2, p. 163-178, 2012. (http://dx.doi.org/10.4136/ambi-agua.917)

Outro fator importante seria a composição mineralógica e granulométrica dos solos da região, onde se pôde constatar a indicação de solos argilosos. Segundo Dent (2005), Uçisik e Rushbrook (1998) e ARGOSS (2001), os solos argilosos são os melhores tipos de solo como primeira linha de defesa no combate à contaminação microbiológica, por conta do acentuado caráter de filtração, adsorção e dispersão para a maioria das partículas de vírus e bactérias.

Assim, em vista da faixa passível de contaminação, da presença de zona insaturada e presença de argilas nesta zona, pode-se propor que a má qualidade da água encontrada nos piezômetros (fora dos limites do cemitério) não tem o cemitério Bom Jardim como agente impactante. É razoável concluir que a contaminação seja proveniente do lançamento dos efluentes domésticos e fossas no solo na área analisada.

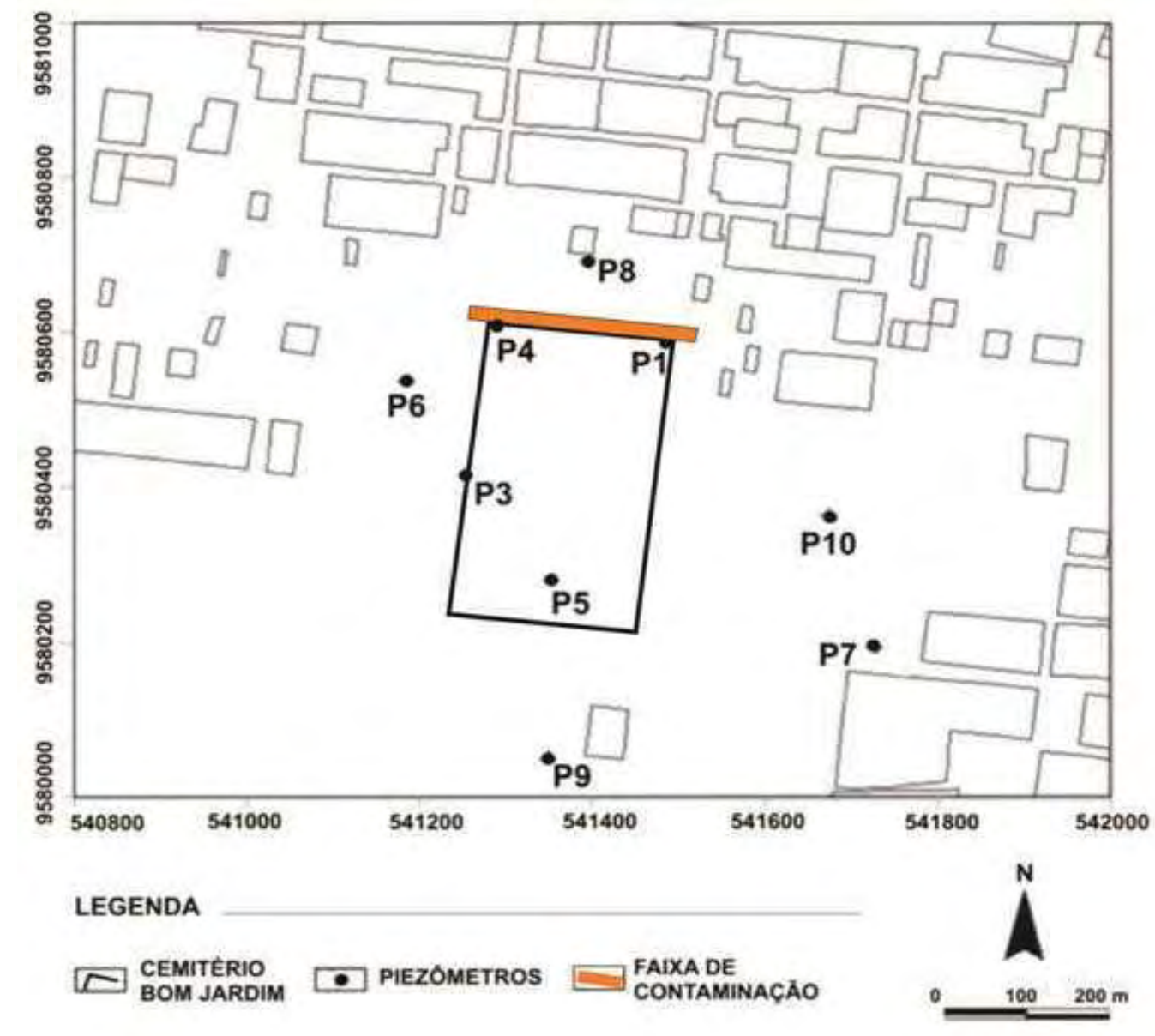

Figura 10. Indicação da faixa de contaminação microbiológica.

\section{CONCLUSÃO}

Os modelos matemáticos computacionais desempenham um papel de indispensável importância como ferramenta de previsão no controle de contaminação de mananciais subterrâneos. Nos últimos anos, a tomada de decisões no gerenciamento destes recursos delineação de zonas de proteção de poços, avaliação do transporte de contaminantes ou remediação de sítios contaminados - tem sido facilitada pelo aporte de dados gerados por estes modelos. Sabe-se, entretanto, que os modelos não são a última palavra na avaliação dos recursos hídricos modelados, mas são fundamentais na complementação dos estudos em escala de laboratório e do monitoramento em campo. 
No presente trabalho, a modelagem computacional atuando em parceria com o monitoramento dos dados de campo conseguiu fornecer subsídios que pudessem complementar o entendimento das peculiaridades do reservatório freático da região do cemitério Bom Jardim em Fortaleza - CE.

A proposta inicial, de se estabelecer um modelo que simulasse o que ocorre em escala real, como forma de se estimar a possível contaminação além dos limites do cemitério, correspondeu às expectativas de previsão do comportamento do fluxo subterrâneo e transporte do contaminante modelado. A velocidade do fluxo subterrâneo, estimada em torno de 0,27 m.dia ${ }^{-1}$, e a presença da camada insaturada argilosa compondo o substrato rochoso na região do cemitério, apontam para a percepção de que a pluma de contaminação estaria restrita a uma faixa de 13,50 metros dos limites norte do cemitério.

Essa faixa passível de contaminação, segundo o modelo, sugere que a má qualidade da água encontrada em todos os poços de observação não teria o cemitério como agente efetivo de degradação. A falta de saneamento seria, então, a causa mais razoável para assinalar o impacto na qualidade da água do aquífero local.

\section{AGRADECIMENTOS}

Agradecemos ao Professor Dr. David Lopes de Castro, bolsista de produtividade do CNPq, por ter disponibilizado os dados de sua pesquisa no cemitério Bom Jardim (financiada pelo CNPq, processo 480409/2004-8, Edital Universal 019/2004).

\section{REFERÊNCIAS}

ASSOCIAÇÃO BRASILEIRA DE ÁGUAS SUBTERRÂNEAS - ABAS. Cemitérios: risco potencial às águas subterrâneas. Boletim Informativo, n. 111, fev. 2001.

ANDERSON, M.; WOESSNER, W. Applied groundwater modeling: simulation of flow and advective transport. San Diego: Academic Press, 1992. 381 p.

ARGOSS. Guidelines for assessing the risk to groundwater from on-site sanitation. British Geological Survey Commissioned Report CR/01/142. Londres: BGS Keyworth, 2001. 104 p.

BOUWER, H. Groundwater hydrology. New York: McGraw-Hill Book, 1978. 480 p.

BRASIL. Conselho Nacional do Meio Ambiente. Resolução no 335, de 3 de abril de 2003. Dispõe sobre o licenciamento ambiental de cemitérios. Brasília, 2003. Disponível em: <http://www.mma.gov.br/port/conama/res/res03/res33503.xml>. Acesso em: jun. 2012.

CASTRO, D. L. Caracterização geofísica e hidrogeológica do cemitério Bom Jardim, Fortaleza - CE. Revista Brasileira de Geofísica, v. 26, n. 3, p. 251-271, 2008. http://dx.doi.org/10.1590/S0102-261X2008000300001

CHIANG W. H.; KINZELBACH, W. 3D-Groundwater Modeling with PMWIN. 1 ed. New York : Springer Berlin Heidelberg, 2001. 346 p.

CHIANG, W. H. 3D - Groundwater modeling with PMWIN: a simulation system for modeling groundwater flow and transport processes. 2. ed. New York: Springer Berlin Heidelberg, 2005. 397 p.

CHIANG, W. H; KINZELBACH, W. PMPATH for Windows: user's manual. Washington, DC: Scientific Software Group, 1994. 
DENT, B. B. Vulnerability and the unsaturated zone: the case for cemeteries. In: JOINT CONFERENCE, NEW ZEALAND HYDROLOGICAL SOCIETY, INTERNATIONAL ASSOCIATION OF HYDROGEOLOGISTS (AUSTRALIAN CHAPTER) AND NEW ZEALAND SOIL SCIENCE SOCIETY, 5., Nov. 30 - Dec. 2 2005, Auckland. Proceedings: where waters meet. Auckland: IAH, 2005.

DENT, B. B.; KNIGHT, M. J. Cemeteries: a special kind of landfill. In: INTERNATIONAL ASSOCIATION OF HYDROGEOLOGISTS SUSTAINABLE SOLUTIONS CONFERENCE, February 1998, Melbourne. Proceedings... Kenilworth: IAH, 1998.

ENVIRONMENT AGENCY (United Kingdom). Assessing the groundwater pollution potential of cemetery developments. Bristol, 2002. 20 p.

ENVIRONMENT AGENCY (United Kingdom). Microbiological contaminants in groundwater. Bristol: National Groundwater and Contaminated Land Centre, 1999. $8 \mathrm{p}$.

MANOEL FILHO, J.; FEITOSA, F. A. C. Hidrogeologia: conceitos e aplicações. 2. ed. Fortaleza: CPRM; LABHID, 2000. 391 p.

MARINHO, A. M. C. P. Contaminação de aquíferos por instalação de cemitérios: estudo de caso do cemitério São João Batista, Fortaleza - Ceará. 1998. 88f. Dissertação (Mestrado em Geologia) - Centro de Ciências, Universidade Federal do Ceará, Fortaleza,1998.

MARTINS, T.; PELlIZARI, V. H.; PACHECO, A.; MYAKI, D. M.; ADAMS, C.; BOSSOLAN, N. R. S. et al. Qualidade bacteriológica de águas subterrâneas em cemitérios. Revista Saúde Pública, São Paulo, v. 25, n. 1, p. 47-52, 1991.

MATOS, B. A. Avaliação da ocorrência e do transporte de microorganismo no aquiífero freático do cemitério de Vila Nova Cachoeirinha, município de São Paulo. 2001. 161f. Tese (Doutorado em Recursos Minerais e Hidrogeologia) - Instituto de Geociências, Universidade de São Paulo, São Paulo, 2001.

MCDONALD, M. G.; HARBAUGH, A. W. MODFLOW: a modular three-dimensional finite difference ground-water flow model. Washington: United States Government Printing Office, 1988. U. S. Geological Survey, Open-file report 83-875, Chapter A1. $523 \mathrm{p}$.

NOBRE, R. C. M. Avaliação de risco para o uso e proteção de aquíferos: estudo de caso: região metropolitana de Maceió - AL. 2006. 296f. Tese (Doutorado em Engenharia Civil) - Departamento de Engenharia Civil, Universidade Federal do Rio de Janeiro, Rio de Janeiro, 2006.

NORTHERN IRELAND. Department of the Environment. Environment and Heritage Service. Policy and practice for the protection of groundwater in Northern Ireland. Belfast, 2001. 40 p.

PACHECO, A. Cemitérios e meio ambiente. 2000. 102f. Tese (Livre Docência) Universidade de São Paulo, São Paulo, 2000.

REBOUÇAS, A. C. Águas doces no Brasil: capital ecológico, uso e conservação. São Paulo: Escrituras, 2006. 255 p. 
SOUSA, M. C. B.; CASTRO, M. A. H.; CASTRO, D. L.; AlENCAR NETO, M. F.; LOPES, B. L. S. Modelagem do fluxo de contaminantes em aquífero freático na área do cemitério Bom Jardim, Fortaleza, CE, Brasil. Ambi-Agua, Taubaté, v. 7, n. 2, p. 163-178, 2012. (http://dx.doi.org/10.4136/ambi-agua.917)

SCHUSTER, H. D. M.; ARAÚJO, H. D. B. Uma formulação alternativa do método iterativo de gradiente hidráulico no procedimento de calibração dos parâmetros hidrodinâmicos do Sistema Aquífero. RBRH - Revista Brasileira de Recursos Hídricos, v. 9, n. 2, p. 31-37, 2004.

TAVARES, P. R. L. Modelagem computacional e calibração da condutividade hidráulica horizontal em aquífero da bacia sedimentar do Araripe utilizando o método iterativo do gradiente hidráulico. 2010. 117f. Tese (Doutorado em Recursos Hídricos) Departamento de Engenharia Hidráulica e Ambiental, Universidade Federal do Ceará, Fortaleza, 2010.

TAYLOR, R.; CRONIN, A.; PEDLEY, S.; BARKER, J.; ATKINSON, T. The implications of groundwater velocity variations on microbial transport and wellhead protection - review of field evidence. FEMS Microbiology Ecology, v. 49, n. 1, p. 17-26, 2004. http://dx.doi.org/10.1016/j.femsec.2004.02.018

TUCCI, C. E. M. Hidrologia: ciência e aplicação. Porto Alegre: EDUSP;ABRH, 1997. 943p. (ABRH de Recursos Hídricos; v. 4).

ÜÇISIK, A. S.; RUSHBROOK, P. The impact of cemeteries on the environment and public health: an introductory briefing. Copenhagen: WHO, 1998. 15p. 


ISSN = 1980-993X - doi:10.4136/1980-993X
www.ambi-agua.net
E-mail: ambi-agua@agro.unitau.br
Tel.: (12) 3625-4212

\title{
Interpolação geoespacial da evapotranspiração de referência (ETo) em regiões com escassez de dados: estudo de caso no Sul de Minas Gerais, Brasil
}

\author{
(http://dx.doi.org/10.4136/ambi-agua.763)
}

\author{
Mateus Ricardo Nogueira Vilanova ${ }^{1}$; Silvio J. C. Simões ${ }^{2}$; Isabel C. B. Trannin ${ }^{2}$ \\ ${ }^{\mathbf{1}}$ Faculdade de Engenharia de Guaratinguetá-FEG, (UNESP), Programa de Pós-graduação em Engenharia \\ Mecânica (Transmissão e Conversão de Energia) \\ e-mail: mathidr@yahoo.com.br, \\ ${ }^{2}$ Faculdade de Engenharia de Guaratinguetá-FEG, (UNESP), Departamento de Engenharia Civil, \\ e-mails: silvio.jorge.simoes@gmail.com, isatrannin@uol.com.br
}

\section{RESUMO}

A evapotranspiração de referência é uma importante variável hidrometeorológica, cuja medição é escassa em grande parte do território brasileiro, exigindo a aplicação de métodos e técnicas alternativas para sua quantificação. Nesse sentido, o presente trabalho avalia o processo de espacialização da evapotranspiração de referência por meio do método geoestatístico de krigagem, em regiões com pouca disponibilidade de estações e dados hidrometeorológicos. A evapotranspiração de referência média mensal foi calculada pela equação de Penman-Monteith-FAO, a partir de dados de três estações meteorológicas localizadas no Sul de Minas Gerais (Itajubá, Lavras e Poços de Caldas) e, posteriormente, interpolada por krigagem ordinária pontual, utilizando a abordagem "calcular e interpolar". Os dados hidrometeorológicos de uma quarta estação (Três Corações), localizada dentro da área de interpolação, foram utilizados para validar as evapotranspirações de referência interpoladas espacialmente. Devido à reduzida quantidade de estações e conseqüente inviabilidade de se realizarem análises variográficas, a comparação entre as ETo calculadas e interpoladas para a estação Três Corações foi realizada por meio do coeficiente de correlação (r), índice de concordância (d), erro de viés médio (MBE), raiz do erro médio quadrático (RMSE) e t-test. Os resultados desta comparação indicam que o procedimento de espacialização por krigagem, mesmo dispondo de poucas estações, permite interpolar de forma satisfatória a evapotranspiração de referência, sendo uma importante ferramenta para aplicações agrícolas e hidrológicas em regiões pouco monitoradas.

Palavras-chave: hidrometeorologia, método de Penman-Monteith-FAO;krigagem, espacialização.

\section{Geospatial interpolation of reference evapotranspiration (ETo) in areas with scarce data: case study in the South of Minas Gerais, Brazil}

\begin{abstract}
The reference evapotranspiration is an important hydrometeorological variable; its measurement is scarce in large portions of the Brazilian territory, what demands the search for alternative methods and techniques for its quantification. In this sense, the present work investigated a method for the spatialization of the reference evapotranspiration using the geostatistical method of kriging, in regions with limited data and hydrometeorological stations. The monthly average reference evapotranspiration was calculated by the PenmanMonteith-FAO equation, based on data from three weather stations located in southern Minas
\end{abstract}


Gerais (Itajubá, Lavras and Poços de Caldas), and subsequently interpolated by ordinary point kriging using the approach "calculate and interpolate." The meteorological data for a fourth station (Três Corações) located within the area of interpolation were used to validate the reference evapotranspiration interpolated spatially. Due to the reduced number of stations and the consequent impossibility of carrying variographic analyzes, correlation coefficient (r), index of agreement (d), medium bias error (MBE), root mean square error (RMSE) and t-test were used for comparison between the calculated and interpolated reference evapotranspiration for the Três Corações station. The results of this comparison indicated that the spatial kriging procedure, even using a few stations, allows to interpolate satisfactorily the reference evapotranspiration, therefore, it is an important tool for agricultural and hydrological applications in regions with lack of data.

Keywords: hydrometeorology, Penman-Monteith-FAO, kriging;spatialization.

\section{INTRODUÇÃO}

A evapotranspiração de referência $\left(\mathrm{ET}_{\mathrm{o}}\right)$ é uma importante variável hidrometeorológica utilizada na agricultura e gerenciamento de recursos hídricos, sendo fundamental também para modelagem hidrológica distribuída (Zhang et al., 2010). Por definição, a $\mathrm{ET}_{\mathrm{o}}$ corresponde à evapotranspiração de uma cultura hipotética, cobrindo totalmente o solo, em crescimento ativo, sob condições ótimas de desenvolvimento (sem restrições hídricas e nutricionais), com altura média de $0,12 \mathrm{~m}$, albedo de 0,23 e resistência da superfície de 70 s.m ${ }^{-1}$ (Bernardo et al., 2008). Apesar da importância da $\mathrm{ET}_{\mathrm{o}}$ para a estudos e gestão de bacias hidrográficas, especialmente em áreas irrigadas e florestais, a medição da evapotranspiração é cara e escassa, demandando equipamentos e instrumentos específicos (Silva et al., 2010). Diante desse fato, várias pesquisas foram desenvolvidas, resultando em equações e métodos práticos para a determinação indireta da $\mathrm{ET}_{\mathrm{o}}$.

Dentre os métodos de estimativa da $\mathrm{ET}_{\mathrm{o}}$ amplamente utilizados na atualidade, destaca-se o Penman-Monteith-FAO, de base física, recomendado e difundido pela Organização das Nações Unidas para Agricultura e Alimentação (FAO) (Allen et al., 1998). Segundo Yin et al. (2008), o modelo Penman-Monteith-FAO, que incorpora aspectos termodinâmicos e aerodinâmicos em seu equacionamento, produz resultados satisfatoriamente precisos tanto em climas úmidos quanto áridos, sendo aceito e aplicado com êxito em todo mundo (Er-Raki et al., 2010).

As aplicações práticas dos dados de evapotranspiração - seja para o planejamento de irrigação, modelagem hidrológica e ambiental, dentre outras - exigem quase sempre que estes sejam avaliados de forma distribuída espacialmente (Mcvicar et al., 2007), residindo aí a importância da elaboração de mapas de $\mathrm{ET}_{\mathrm{o}}$.

A espacialização de dados hidrológicos, climáticos e ambientais pode ser feita a partir de métodos geoestatísticos, sendo a krigagem comumente utilizada (Mardikis et al., 2005; Bargaoui e Chebbi, 2009). A krigagem utiliza a "[...] dependência espacial entre amostras vizinhas, expressa no semivariograma, para estimar valores em qualquer posição dentro do espaço analisado ao qual o modelo do semivariograma foi ajustado, sem tendência e com variância mínima." (Motomiya et al., 2006). Utilizada em diversas áreas do conhecimento, a krigagem assume que a distância ou a diferença entre os pontos de amostragem refletem uma correlação espacial que pode ser utilizada para explicar sua variação em uma superfície (Childs, 2004). Trabalhos como os de Mello et al. (2003) e Alves et al. (2008) indicam desempenho superior da krigagem em relação a outros métodos geoestatísticos, como o do inverso da potência da distância. 
Zhang et al. (2010) e Mardikis et al. (2005) apresentam duas abordagens para o mapeamento da $\mathrm{ET}_{\mathrm{o}}$. Na primeira, denominada "calcular e interpolar", as $\mathrm{ET}_{\mathrm{o}}$ são calculadas para as estações meteorológicas de referência e, posteriormente,espacializadas. Na abordagem "interpolar e calcular", as variáveis meteorológicos utilizados no equacionamento da $\mathrm{ET}_{\mathrm{o}}$ são espacializados, e a $\mathrm{ET}_{\mathrm{o}}$ posteriormente calculada para as áreas de interesse, o que torna tal abordagem mais laboriosa que a "calcular e interpolar".

Diante do exposto, o trabalho tem por objetivo avaliar a qualidade dos valores de $\mathrm{ET}_{\mathrm{o}}$ médios mensais interpolados geospacialmente a partir do processo de krigagem, com pequena disponibilidade de dados/estações hidrometeorológicas - no caso estudado, foram consideradas apenas três estações, localizadas no sul de Minas Gerais. Uma quarta estação, localizada dentro da área de interpolação, foi utilizada como referência para validação da interpolação, por meio da comparação entre os valores de $\mathrm{ET}_{\mathrm{o}}$ calculados com dados dessa estação, e aqueles interpolados a partir das demais. A pequena quantidade de estações empregadas na interpolação inviabiliza a análise variográfica, tipicamente utilizada para se avaliar os resultados da krigagem, exigindo que a análise da qualidade da interpolação seja realizada por meio do coeficiente de correlação (r), índice de concordância (d), erro médio de viés (MBE), raiz do erro médio quadrático (RMSE) e t-test.

\section{MATERIAL E MÉTODOS}

O sul do Estado de Minas Gerais foi considerado como área de estudo, sendo selecionadas as estações meteorológicas dos municípios de Itajubá, Lavras, Poços de Caldas e Três Corações, cujos dados de temperatura mínima, temperatura máxima, umidade relativa do ar, velocidade média do vento, insolação e radiação foram obtidos na base do Grupo de Agrometeorologia da Organização das Nações Unidas para Agricultura e Alimentação (FAO). A Tabela 1 apresenta as coordenadas das estações selecionadas.

Tabela 1. Estações meteorológicas dos municípios do Sul de Minas Gerais empregadas no estudo

\begin{tabular}{l|lc|cc}
\hline \multicolumn{5}{c}{ Coordenadas aproximadas das estações utilizadas (WGS84) } \\
\hline \multirow{2}{*}{ Estação } & \multicolumn{2}{|c}{ Geográficas } & \multicolumn{2}{c}{ UTM (23 K) } \\
\cline { 2 - 5 } & ${\text { Latitude }\left[{ }^{\circ}\right]}^{\circ}$ & Longitude [ $\left.{ }^{\circ}\right]$ & E [m] & N [m] \\
\hline Três Corações (TC) & $21^{\circ} 42^{\prime} 04^{\prime \prime} \mathrm{S}$ & $45^{\circ} 14^{\prime} 59^{\prime \prime} \mathrm{O}$ & $474.169,73$ & $7.600 .234,43$ \\
Itajubá (IT) & $22^{\circ} 25^{\prime} 43 " \mathrm{~S}$ & $45^{\circ} 27^{\prime} 11^{\prime \prime} \mathrm{O}$ & $453.376,70$ & $7.519 .660,22$ \\
Lavras (LV) & $21^{\circ} 13^{\prime} 48 " \mathrm{~S}$ & $45^{\circ} 00^{\prime} 06^{\prime \prime} \mathrm{O}$ & $499.827,05$ & $7.652 .397,28$ \\
Poços de Caldas (PC) & $21^{\circ} 50^{\prime} 58^{\prime \prime} \mathrm{S}$ & $46^{\circ} 33^{\prime} 45^{\prime \prime} \mathrm{O}$ & $338.533,17$ & $7.583 .017,74$ \\
\hline
\end{tabular}

Fonte: FAO ( 2006).

Os critérios adotados para a seleção das estações foram a proximidade geográfica (distância inferior a $200 \mathrm{~km}$ ) e a inexistência de feições topográficas significativas entre elas, buscando obter uma maior homogeneidade dos parâmetros meteorológicos utilizados no cálculo da $\mathrm{ET}_{0}$, conforme recomenda o trabalho de McVicar et al. (2007). São consideradas significativas as feições topográficas que atuam sobre as condições hidrometeorológicas e hidroclimáticas regionais, ao contrário de pequenas unidades de relevo que influenciam tais condições de forma local (microclima). Um exemplo de feição significativa é a Serra da 
VILANOVA, M. R. N.; SIMÕES, S. J. C.; TRANNIN, I. C, B. Interpolação geoespacial da evapotranspiração de referência $\left(E_{\mathrm{o}}\right)$ em regiões com escassez de dados: estudo de caso no Sul de Minas Gerais. Ambi-Agua, Taubaté, v. 7, n. 2, p. 179-194, 2012. (http://dx.doi.org/10.4136/ambi-agua.763)

Mantiqueira, que tem papel fundamental no estabelecimento de condições meteorológicas distintas entre o Sul de Minas Gerais e o Vale do Rio Paraíba do Sul, apesar da proximidade geográfica das duas regiões. Todas as estações possuem dados históricos (médias mensais) de no mínimo 15 anos de observação (1975 a 2000), sendo estes obtidos com auxílio do aplicativo Climwat 2.0 (FAO, 2006), fornecido pela Organização das Nações Unidas para Agricultura e Alimentação (FAO). Posteriormente, as ET $_{0}$ médias mensais foram calculadas pelo método de Penman-Monteith-FAO, pela Equação [1].

$$
E T_{O}=\frac{0,408 \cdot \Delta \cdot(R n-G)+\gamma \cdot \frac{900}{T+273} \cdot U_{2} \cdot\left(e_{s}-e_{a}\right)}{\Delta+\gamma \cdot\left(1+0,34 \cdot U_{2}\right)}
$$

em que:

$\mathrm{ET}_{\mathrm{o}} \quad$ evapotranspiração de referência $\left[\mathrm{mm}_{\mathrm{d}} \mathrm{d}^{-1}\right]$

$\mathrm{Rn} \quad$ saldo de radiação à superfície $\left[\mathrm{MJ} \cdot \mathrm{m}^{-2} \cdot \mathrm{d}^{-1}\right]$;

$\mathrm{G} \quad$ fluxo de calor no solo $\left[\mathrm{MJ} \cdot \mathrm{m}^{-2} \cdot \mathrm{d}^{-1}\right]$;

$\mathrm{T}$ temperatura do ar $\left[{ }^{\circ} \mathrm{C}\right]$;

$\mathrm{U}_{2}$ velocidade do vento [m.s ${ }^{-1}$;

$\mathrm{e}_{\mathrm{s}} \quad$ pressão de saturação de vapor d'água no ar [kPa];

$\mathrm{e}_{\mathrm{a}} \quad$ pressão de vapor d'água no ar $[\mathrm{kPa}]$

$\left(\mathrm{e}_{\mathrm{s}}-\mathrm{e}_{\mathrm{a}}\right)$ déficit de pressão de vapor d'água no ar [kPa];

$\Delta \quad$ declividade da curva de pressão de saturação de vapor d'água no $\operatorname{ar}\left[\mathrm{kPa}^{\circ}{ }^{\circ} \mathrm{C}^{-1}\right]$;

$\gamma \quad$ constante psicrométrica $\left[\mathrm{kPa} .{ }^{0} \mathrm{C}^{-1}\right]$.

As Tabelas 2 a 5 apresentam os dados meteorológicos médios mensais de cada estação, bem como as $\mathrm{ET}_{\mathrm{o}}$ calculadas.

Tabela 2. Dados climatológicos para a localidade de Três Corações.

\begin{tabular}{|c|c|c|c|c|c|c|c|}
\hline \multicolumn{8}{|c|}{ TRÊS CORAÇÕES (TC) } \\
\hline Mês & $\begin{array}{c}\text { Temperatura } \\
\text { mínima } \\
{ }^{\circ} \mathbf{C}\end{array}$ & $\begin{array}{c}\text { Temperatura } \\
\text { máxima } \\
{ }^{\circ} \mathbf{C}\end{array}$ & $\begin{array}{c}\text { Umidade } \\
\text { do ar } \\
\%\end{array}$ & $\begin{array}{c}\text { Velocidade } \\
\text { do vento } \\
\text { km.d }\end{array}$ & $\begin{array}{c}\text { Insolação } \\
\mathbf{h}\end{array}$ & $\begin{array}{c}\text { Radiação } \\
\text { MJ.(m².d })^{-1}\end{array}$ & $\underset{\text { mm.d }}{\text { ETo }}$ \\
\hline Jan & 17,5 & 29,1 & 79,0 & 61,0 & 6,7 & 21,2 & 4,3 \\
\hline Fev & 17,6 & 29,1 & 81,0 & 78,0 & 5,9 & 19,2 & 4,0 \\
\hline Mar & 16,5 & 28,0 & 81,0 & 86,0 & 5,9 & 17,8 & 3,6 \\
\hline Abr & 14,0 & 26,7 & 80,0 & 86,0 & 6,3 & 16,0 & 3,1 \\
\hline Mai & 10,6 & 24,9 & 80,0 & 69,0 & 6,5 & 14,0 & 2,4 \\
\hline Jun & 8,0 & 23,8 & 77,0 & 69,0 & 6,4 & 12,8 & 2,1 \\
\hline Jul & 8,2 & 23,9 & 75,0 & 69,0 & 6,8 & 13,8 & 2,1 \\
\hline Ago & 9,5 & 26,5 & 69,0 & 86,0 & 7,2 & 16,2 & 2,9 \\
\hline Set & 12,3 & 27,5 & 71,0 & 104,0 & 5,6 & 16,5 & 3,3 \\
\hline Out & 14,6 & 27,5 & 73,0 & 112,0 & 5,3 & 17,8 & 3,7 \\
\hline Nov & 15,8 & 27,8 & 76,0 & 112,0 & 5,4 & 18,9 & 4,0 \\
\hline Dez & 16,9 & 27,8 & 80,0 & 104,0 & 4,8 & 18,2 & 3,8 \\
\hline
\end{tabular}

Fonte: FAO (2006). 
VILANOVA, M. R. N.; SIMÕES, S. J. C.; TRANNIN, I. C, B. Interpolação geoespacial da evapotranspiração de referência $\left(\mathrm{ET}_{\mathrm{o}}\right)$ em regiões com escassez de dados: estudo de caso no Sul de Minas Gerais. Ambi-Agua, Taubaté, v. 7, n. 2, p. 179-194, 2012. (http://dx.doi.org/10.4136/ambi-agua.763)

Tabela 3. Dados climatológicos para a localidadede Itajubá.

\begin{tabular}{|c|c|c|c|c|c|c|c|}
\hline \multicolumn{8}{|c|}{ Itajubá (IT) } \\
\hline Mês & $\begin{array}{c}\text { Temperatura } \\
\text { mínima } \\
{ }^{\circ} \mathbf{C}\end{array}$ & $\begin{array}{c}\text { Temperatura } \\
\text { máxima } \\
{ }^{\circ} \mathbf{C}\end{array}$ & $\begin{array}{c}\text { Umidade } \\
\text { do ar } \\
\%\end{array}$ & $\begin{array}{c}\text { Velocidade } \\
\text { do vento } \\
\text { km.d }\end{array}$ & $\begin{array}{c}\text { Insolação } \\
\text { H }\end{array}$ & 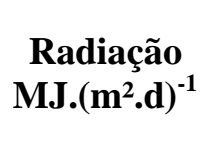 & $\begin{array}{c}\text { ETo } \\
\text { mm.d }^{-1}\end{array}$ \\
\hline Jan & 17,3 & 29,0 & 79,0 & 61,0 & 6,8 & 21,4 & 4,3 \\
\hline Fev & 17,3 & 29,0 & 80,0 & 78,0 & 5,8 & 19,0 & 3,9 \\
\hline Mar & 16,5 & 28,7 & 79,0 & 86,0 & 6,0 & 17,9 & 3,7 \\
\hline Abr & 14,0 & 27,1 & 78,0 & 86,0 & 6,3 & 15,9 & 3,1 \\
\hline Mai & 10,7 & 25,2 & 78,0 & 69,0 & 6,5 & 13,9 & 2,4 \\
\hline Jun & 8,8 & 24,2 & 76,0 & 69,0 & 6,5 & 12,8 & 2,1 \\
\hline Jul & 8,1 & 24,3 & 72,0 & 69,0 & 6,8 & 13,6 & 2,2 \\
\hline Ago & 9,5 & 26,5 & 68,0 & 86,0 & 7,1 & 16,0 & 2,9 \\
\hline Set & 12,1 & 27,3 & 68,0 & 104,0 & 5,7 & 16,5 & 3,4 \\
\hline Out & 14,5 & 27,8 & 71,0 & 112,0 & 5,3 & 17,7 & 3,8 \\
\hline Nov & 15,6 & 28,1 & 75,0 & 112,0 & 5,5 & 19,1 & 4,0 \\
\hline Dez & 16,7 & 28,2 & 78,0 & 104,0 & 4,9 & 18,4 & 3,9 \\
\hline
\end{tabular}

Fonte: FAO (2006).

Tabela 4. Dados climatológicos para a localidadede Lavras.

\begin{tabular}{|c|c|c|c|c|c|c|c|}
\hline \multicolumn{8}{|c|}{ Lavras (LV) } \\
\hline Mês & $\begin{array}{c}\text { Temperatura } \\
\text { mínima } \\
{ }^{\circ} \mathrm{C}\end{array}$ & $\begin{array}{c}\text { Temperatura } \\
\text { máxima } \\
{ }^{\circ} \mathbf{C}\end{array}$ & $\begin{array}{c}\text { Umidade } \\
\text { do ar } \\
\%\end{array}$ & $\begin{array}{c}\text { Velocidade } \\
\text { do vento } \\
\text { km.d }\end{array}$ & $\begin{array}{c}\text { Insolação } \\
\mathbf{h}\end{array}$ & 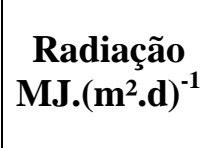 & $\underset{\text { mm.d }}{\text { ETo }}$ \\
\hline Jan & 17,7 & 27,8 & 84,0 & 61,0 & 5,6 & 19,4 & 3,9 \\
\hline Fev & 17,9 & 28,4 & 82,0 & 78,0 & 5,7 & 19,0 & 3,9 \\
\hline Mar & 17,3 & 27,0 & 84,0 & 86,0 & 6,0 & 18,0 & 3,6 \\
\hline Abr & 15,4 & 25,4 & 78,0 & 86,0 & 6,5 & 16,3 & 3,1 \\
\hline Mai & 12,7 & 24,7 & 77,0 & 69,0 & 6,5 & 14,1 & 2,4 \\
\hline Jun & 11,1 & 23,9 & 76,0 & 69,0 & 6,1 & 12,6 & 2,1 \\
\hline Jul & 10,4 & 23,7 & 73,0 & 69,0 & 6,6 & 13,6 & 2,2 \\
\hline Ago & 11,7 & 25,7 & 67,0 & 86,0 & 7,2 & 16,3 & 2,9 \\
\hline Set & 13,6 & 25,4 & 70,0 & 104,0 & 5,9 & 16,9 & 3,3 \\
\hline Out & 15,6 & 27,2 & 74,0 & 112,0 & 5,7 & 18,4 & 3,8 \\
\hline Nov & 16,6 & 27,2 & 77,0 & 112,0 & 5,5 & 19,1 & 3,9 \\
\hline Dez & 17,3 & 27,3 & 84,0 & 104,0 & 4,8 & 18,2 & 3,7 \\
\hline
\end{tabular}

Fonte: FAO (2006). 
VILANOVA, M. R. N.; SIMÕES, S. J. C.; TRANNIN, I. C, B. Interpolação geoespacial da evapotranspiração de referência $\left(\mathrm{ET}_{\mathrm{o}}\right)$ em regiões com escassez de dados: estudo de caso no Sul de Minas Gerais. Ambi-Agua, Taubaté, v. 7, n. 2, p. 179-194, 2012. (http://dx.doi.org/10.4136/ambi-agua.763)

Tabela 5. Dados climatológicos para a localidadede Poços de Caldas

\begin{tabular}{|c|c|c|c|c|c|c|c|}
\hline \multicolumn{8}{|c|}{ Poços de Caldas (PC) } \\
\hline Mês & $\begin{array}{c}\text { Temperatura } \\
\text { mínima } \\
{ }^{\circ} \mathbf{C}\end{array}$ & $\begin{array}{c}\text { Temperatura } \\
\text { máxima } \\
{ }^{\circ} \mathbf{C}\end{array}$ & $\begin{array}{c}\text { Umidade } \\
\text { do ar } \\
\%\end{array}$ & $\begin{array}{l}\text { Velocidade } \\
\text { do vento } \\
\text { km.d }^{-1}\end{array}$ & $\begin{array}{c}\text { Insolação } \\
\mathbf{h}\end{array}$ & 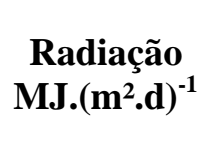 & $\begin{array}{c}\text { ETo } \\
\text { mm.d }^{-1}\end{array}$ \\
\hline Jan & 16,2 & 25,5 & 83,0 & 121,0 & 4,9 & 18,4 & 3,7 \\
\hline Fev & 16,2 & 25,9 & 82,0 & 121,0 & 5,1 & 18,0 & 3,6 \\
\hline Mar & 15,4 & 25,6 & 83,0 & 121,0 & 6,0 & 17,8 & 3,5 \\
\hline Abr & 12,7 & 24,3 & 81,0 & 95,0 & 6,7 & 16,5 & 3,0 \\
\hline Mai & 9,2 & 22,5 & 80,0 & 121,0 & 6,7 & 14,2 & 2,4 \\
\hline Jun & 7,5 & 21,4 & 78,0 & 112,0 & 6,8 & 13,2 & 2,1 \\
\hline Jul & 7,4 & 21,6 & 76,0 & 112,0 & 6,8 & 13,7 & 2,2 \\
\hline Ago & 8,9 & 23,8 & 70,0 & 130,0 & 7,3 & 16,3 & 2,9 \\
\hline Set & 11,4 & 24,8 & 71,0 & 130,0 & 6,2 & 17,3 & 3,4 \\
\hline Out & 13,7 & 25,3 & 75,0 & 130,0 & 6,0 & 18,9 & 3,7 \\
\hline Nov & 14,6 & 25,2 & 79,0 & 121,0 & 5,8 & 19,5 & 3,8 \\
\hline Dez & 15,6 & 25,2 & 82,0 & 121,0 & 5,3 & 19,1 & 3,8 \\
\hline
\end{tabular}

Fonte: FAO (2006).

A estação do município de Três Corações foi adotada para avaliação do método de interpolação geoespacial da $\mathrm{ET}_{0}$, devido ao fato desta se encontrar na região interior ao triângulo cujos vértices são posicionados, geograficamente, sobre as demais estações. Foi realizada uma análise de correlação, efetuando regressão linear entre os dados de $\mathrm{ET}_{\mathrm{o}}$ calculados para a estação de Três Corações e para as estações utilizadas na interpolação.

Realizou-se então o processo de espacialização das $\mathrm{ET}_{\mathrm{o}}$ médias mensais das estações Itajubá, Lavras e Poços de Caldas, por meio de krigagem ordinária pontual. As coordenadas das estações (Tabela 1) foram relacionadas com as respectivas $\mathrm{ET}_{\mathrm{o}}$ mensais (Tabelas 3 a 5). $\mathrm{As}_{\mathrm{ET}}$ foram interpoladas utilizando sistema de informação geográfica, dando origem aos 12 mapas de $\mathrm{ET}_{\mathrm{o}}$ médias mensais.

A krigagem é um método de interpolação semelhante ao da média móvel ponderada, diferindo deste no cálculo dos pesos, definidos a partir de uma análise espacial baseada no semivariograma experimental (Câmara e Medeiros, 1998).

Segundo Burrough e McDonnell (1998), o valor de uma variável espacializada Z é fornecido pela Equação [2]:

$$
Z(x)=m(x)+\varepsilon^{\prime}(x)+\varepsilon^{\prime \prime}
$$

em que: $\begin{array}{ll}Z(x) & \text { valor da variável Z, na posição x; } \\ X & \text { posição em uma, duas ou três dimensões; } \\ \mathrm{m}(\mathrm{x}) & \text { função determinística que descreve a componente estrutural de } \mathrm{Z} \text { em x; } \\ \varepsilon^{\prime} & \text { termo estocástico que varia localmente e depende espacialmente de m(x); } \\ \varepsilon^{\prime \prime} & \text { ruído aleatório não correlacionado, com distribuição normal, média zero e } \\ \text { variância } \square 2 .\end{array}$ 
Os variogramas e semivariogramas expressam a variação espacial de uma variável, sendo ferramentas fundamentais para a krigagem, segundo Câmara e Medeiros (1998) e Guedes (2008). O variograma de uma amostra pode ser expresso pela Equação [3]:

$$
\hat{2 \gamma(h)}=\frac{1}{N(h)} \cdot \sum_{i=1}^{N(h)}\left[z\left(x_{i}\right)-z\left(x_{i}+h\right)\right]^{2}
$$

em que:

$2 \hat{\gamma}(z h) \quad$ variograma estimado;

$\mathrm{h} \quad$ vetor distância entre dois pontos de amostragem;

$\mathrm{N}(\mathrm{h}) \quad$ número de pares de valores medidos separados por $\mathrm{h}, \mathrm{z}(\mathrm{xi}) \mathrm{e} \mathrm{z}(\mathrm{xi}+\mathrm{h})$;

$\mathrm{z}(\mathrm{xi})$ e $\mathrm{z}(\mathrm{xi}+\mathrm{h})$ valores da i-ésima observação da variável regionalizada, coletadas nos pontos xi e $(x i+h)$.

O estimador de krigagem ordinário, por sua vez, é dado pela Equação [4]:

$$
\mathrm{Z}_{\mathrm{x}_{\mathrm{o}}}^{*}=\sum_{\mathrm{i}=1}^{\mathrm{n}} \lambda_{\mathrm{i}} \cdot \mathrm{Z}\left(\mathrm{x}_{\mathrm{i}}\right)
$$

em que:

$\mathrm{Z}_{\mathrm{x}_{\mathrm{o}}}^{*} \quad$ estimador de krigagem ordinária para o ponto xo;

$\lambda_{\mathrm{i}} \quad$ i-ésimo peso;

Z(xi) valor da i-ésima observação da variável regionalizada, coletada nos pontos xi.

O equacionamento do estimador de krigagem ordinária pressupõe um estimador não tendencioso. Além disso, as Equações [5] e [6] devem ser atendidas (Câmara; Medeiros, 1998):

$$
\begin{aligned}
& \sum_{i=1}^{n} \lambda_{i}=1 \\
& \lambda_{0}=0
\end{aligned}
$$

O sistema de krigagem ordinária apresentado por Journel (1989) é representado pelo seguinte sistema de equações:

$$
\left\{\begin{array}{l}
\sum_{j=1}^{n} \lambda_{j} \cdot C\left(x_{i}, x_{j}\right)-\alpha=C\left(x_{i}, x_{0}\right) \quad \text { parai }=1, \ldots, n \\
\sum_{j=1}^{n} \lambda_{j}=1
\end{array}\right.
$$

em que:

$C\left(x_{i}, x_{j}\right)$ e $C\left(x_{i}, x_{0}\right)$ são semivariâncias entre os pontos $x_{i}$ e $x_{j}$ e entre os pontos $x_{i}$ e $x_{0}$, respectivamente;

$\alpha \quad$ multiplicador Lagrangeano necessário para a minimização da variância do erro. 
Ainda segundo Journel (1989), o sistema de krigagem ordinária é resolvido minimizando-se a variância do erro, ao mesmo tempo em que é atendida a Equação [5].

A comparação dos valores de ETO médias mensais calculados (a partir dos dados meteorológicos da estação) e interpolados por krigagem para a estação Três Corações foi efetuada por meio do t-test (Decoursey, 2003; Ross, 2004; Toutenburg, 2002), do coeficiente de correlação (r) e índice de concordância (d) propostos por Willmott (1981), além do erro médio de viés (MBE) e raiz do erro médio quadrático (RMSE) sugeridos por Jacovides e Kontoyiannis (1995). Tais indicadores são calculados pelas Equações [8] a [11].

$$
\begin{aligned}
& r=\frac{\sum_{i=1}^{n}\left(E T_{O O i}-\overline{E T_{O O i}}\right) \cdot\left(E T_{O E i}-\overline{E T_{O E i}}\right)}{\sqrt{\sum_{i=1}^{n}\left(E T_{O O i}-\overline{E T_{O O i}}\right)^{2} \cdot \sum_{i=1}^{n}\left(E T_{O E i}-\overline{E T_{O E i}}\right)^{2}}} \\
& \mathrm{~d}=1-\left[\frac{\sum_{\mathrm{i}=1}^{\mathrm{n}}\left(\mathrm{ET}_{\mathrm{OEi}}-\mathrm{ET}_{\mathrm{OOi}}\right)^{2}}{\sum_{\mathrm{i}=1}^{\mathrm{n}}\left(\left|\mathrm{ET}_{\mathrm{OEi}}-\overline{\mathrm{ET}_{\mathrm{OOi}}}\right|+\mid \mathrm{ET}_{\mathrm{OOi}}-\overline{\mathrm{ET}_{\mathrm{OOi}}}\right)^{2}}\right] \\
& \mathrm{MBE}=\frac{1}{\mathrm{n}} \cdot \sum_{\mathrm{i}=1}^{\mathrm{n}}\left(\mathrm{ET}_{\mathrm{OEi}}-\mathrm{ET}_{\mathrm{OOi}}\right) \\
& \mathrm{RMSE}=\sqrt{\frac{1}{\mathrm{n}} \cdot \sum_{\mathrm{i}=1}^{\mathrm{n}}\left(\mathrm{ET}_{\mathrm{OEi}}-\mathrm{ET}_{\mathrm{OOi}}\right)^{2}}
\end{aligned}
$$

em que:

r $\quad$ coeficiente de correlação [1];

d índice de concordância [1];

RMSE raiz do erro médio quadrático $\left[\mathrm{mm}^{-1} \mathrm{~d}^{-1}\right.$;

MBE erro médio de viés $\left[\mathrm{mm}^{-1} \mathrm{~d}^{-1}\right.$;

$\mathrm{ET}_{\mathrm{OEi}}$ evapotranspiração de referência estimada (interpolada) $\left[\mathrm{mm}_{\mathrm{d}} \mathrm{d}^{-1}\right]$;

$\mathrm{ET}_{\mathrm{OOi}}$ evapotranspiração de referência observada (calculada) $\left[\mathrm{mm}_{\mathrm{d}} \mathrm{d}^{-1}\right.$;

$\overline{\mathrm{ET}_{\mathrm{OEi}}}$ evapotranspiração de referência estimada (interpolada) média $\left[\mathrm{mm}_{\mathrm{d}} \mathrm{d}^{-1}\right]$;

$\overline{\mathrm{ET}_{\mathrm{OOi}}}$ evapotranspiração de referência observada (calculada) média $\left[\mathrm{mm} \mathrm{d}^{-1}\right]$.

\section{RESULTADOS E DISCUSSÃO}

As Figuras 1, 2 e 3 apresentam a regressão linear e os coeficientes de determinação $\left(\mathrm{R}^{2}\right)$ entre as ETo médias mensais calculadas da estação de referência (Três Corações) e das estações utilizadas na interpolação: 
VILANOVA, M. R. N.; SIMÕES, S. J. C.; TRANNIN, I. C, B. Interpolação geoespacial da evapotranspiração de referência $\left(\mathrm{ET}_{\mathrm{o}}\right)$ em regiões com escassez de dados: estudo de caso no Sul de Minas Gerais. Ambi-Agua, Taubaté, v. 7, n. 2, p. 179-194, 2012. (http://dx.doi.org/10.4136/ambi-agua.763)

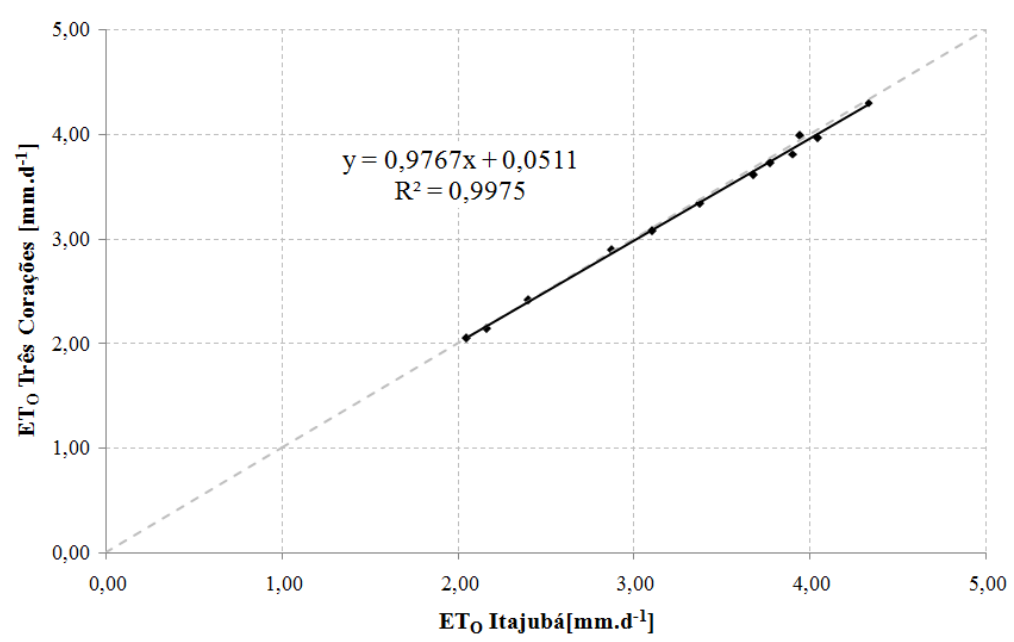

Figura 1. Regressão linear entre as evapotranspirações de referência médias mensais da estação Três Corações e a estação Itajubá.

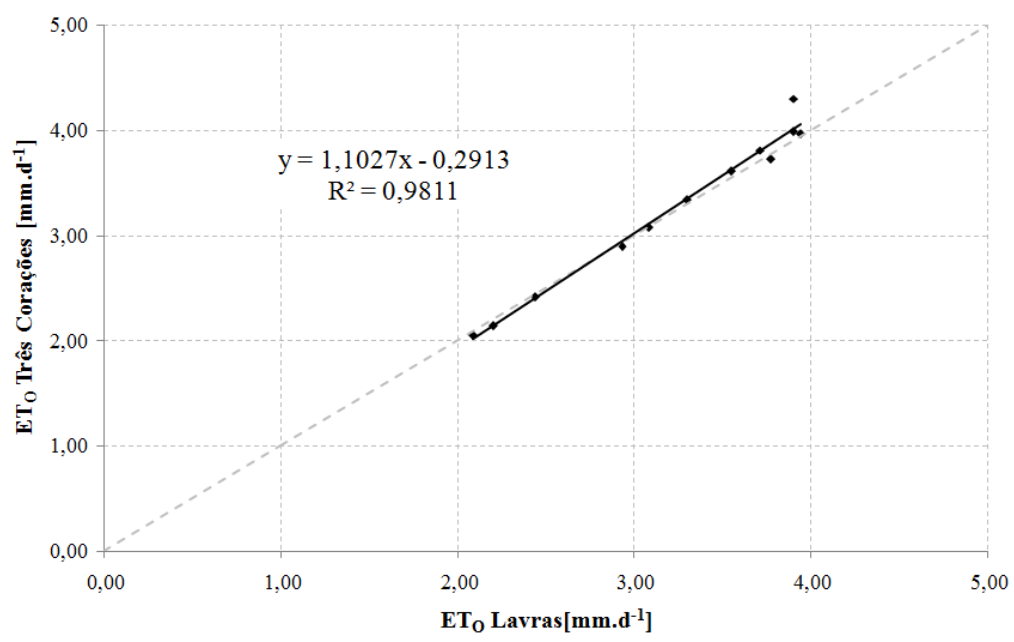

Figura 2. Regressão linear entre as evapotranspirações de referência médias mensais da estação Três Corações e a estação Lavras.

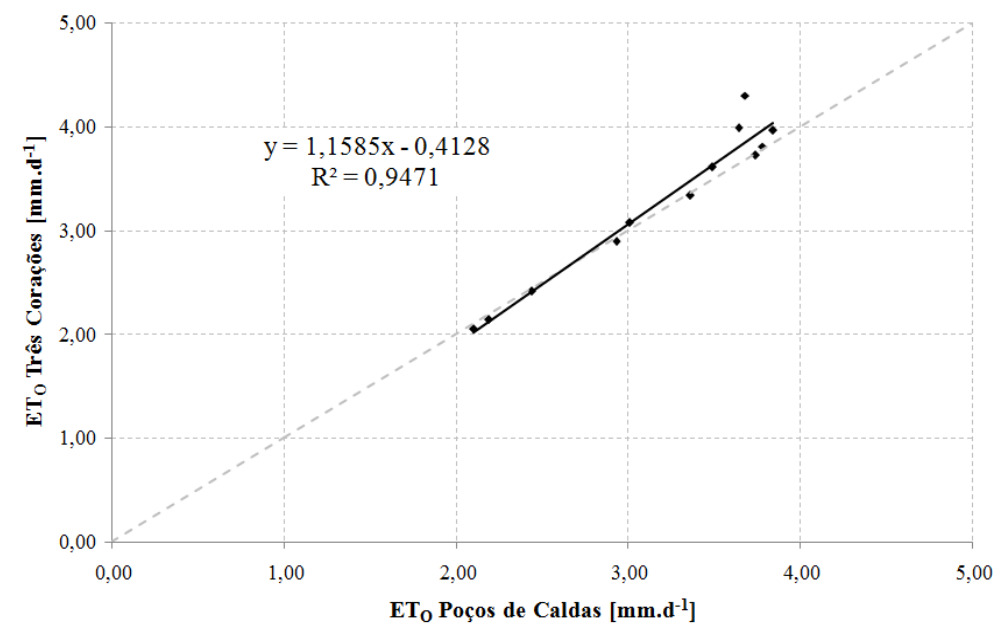

Figura 3. Regressão linear entre as evapotranspirações de referência médias mensais da estação Três Corações e a estação Poços de Caldas. 
Os $\mathrm{R}^{2}$ obtidos nas regressões das Figuras 1 a 3, superiores a 0,9000, demonstram que as ETo médias mensais calculadas para a estação de Três Corações variam de forma proporcional àquelas calculadas para as estações Itajubá, Lavras e Poços de Caldas, representando de forma satisfatória a variabilidade sazonal dos parâmetros meteorológicos utilizados no cálculo, o que corrobora os critérios utilizados na seleção destas estações para a krigagem.

As Figuras 4 e 5 apresentam os mapas de $\mathrm{ET}_{\mathrm{o}}$ médias mensais obtidos por krigagem.

Os mapas apresentados nas Figuras 4 e 5 ilustram a variabilidade espacial e temporal da $\mathrm{ET}_{\mathrm{o}}$ dentro da área de estudo, ao longo das estações do ano. Percebe-se que as menores $\mathrm{ET}_{\mathrm{o}}$, nos meses de janeiro a abril (verão e início de outono), ocorrem a noroeste. Entre maio e agosto (outono e inverno) ocorre uma clara inversão de padrão, com as menores $\mathrm{ET}_{\mathrm{o}}$ sendo identificadas a sudeste. Entre setembro e dezembro (primavera e início de verão), ocorre uma maior variabilidade da $\mathrm{ET}_{\mathrm{o}}$ média mensal, cujos menores valores oscilam entre nordeste e noroeste.

A Tabela 6 relaciona as ETo médias mensais calculadas e interpoladas para a estação do município de Três Corações:

Tabela 6. Evapotranspirações de referência (ETo) médias mensais calculadas e interpoladas para a estação Três Corações.

\begin{tabular}{l|cc|c}
\hline \multicolumn{1}{c|}{ Mês } & $\begin{array}{r}\text { ETo calculada } \\
\text { mm.d }^{-\mathbf{1}}\end{array}$ & $\begin{array}{c}\text { ETo interpolada } \\
\text { mm.d }^{-1}\end{array}$ & $\begin{array}{c}\text { Erro } \\
\text { mm.d }^{-1}\end{array}$ \\
\hline Janeiro & 4,30 & 4,03 & $-0,27$ \\
Fevereiro & 3,99 & 3,89 & $-0,10$ \\
Março & 3,61 & 3,59 & $-0,02$ \\
Abril & 3,08 & 3,08 & 0,00 \\
Maio & 2,41 & 2,42 & 0,01 \\
Junho & 2,05 & 2,07 & 0,02 \\
Julho & 2,14 & 2,18 & 0,04 \\
Agosto & 2,89 & 2,91 & 0,02 \\
Setembro & 3,34 & 3,33 & $-0,01$ \\
Outubro & 3,72 & 3,77 & 0,05 \\
Novembro & 3,96 & 3,98 & 0,02 \\
Dezembro & 3,81 & 3,78 & $-0,03$ \\
\hline
\end{tabular}


VILANOVA, M. R. N.; SIMÕES, S. J. C.; TRANNIN, I. C, B. Interpolação geoespacial da evapotranspiração de referência $\left(\mathrm{ET}_{\mathrm{o}}\right)$ em regiões com escassez de dados: estudo de caso no Sul de Minas Gerais. Ambi-Agua, Taubaté, v. 7, n. 2, p. 179-194, 2012. (http://dx.doi.org/10.4136/ambi-agua.763)
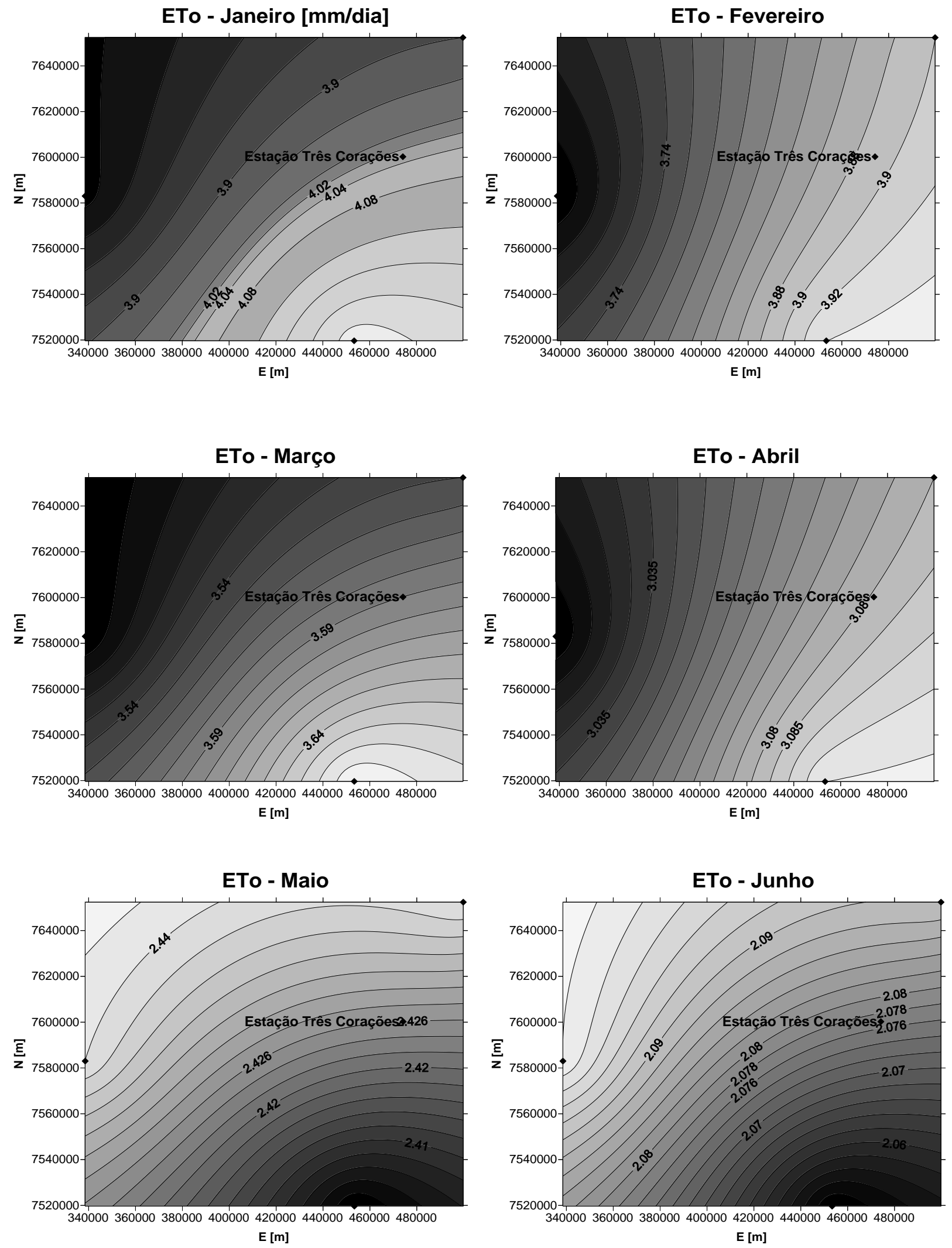

Figura 4. Evapotranspiração de referência média mensal interpolada por krigagem para os meses de janeiro a junho (1975 a 2000). 
VILANOVA, M. R. N.; SIMÕES, S. J. C.; TRANNIN, I. C, B. Interpolação geoespacial da evapotranspiração de referência $\left(\mathrm{ET}_{\mathrm{o}}\right)$ em regiões com escassez de dados: estudo de caso no Sul de Minas Gerais. Ambi-Agua, Taubaté, v. 7, n. 2, p. 179-194, 2012. (http://dx.doi.org/10.4136/ambi-agua.763)
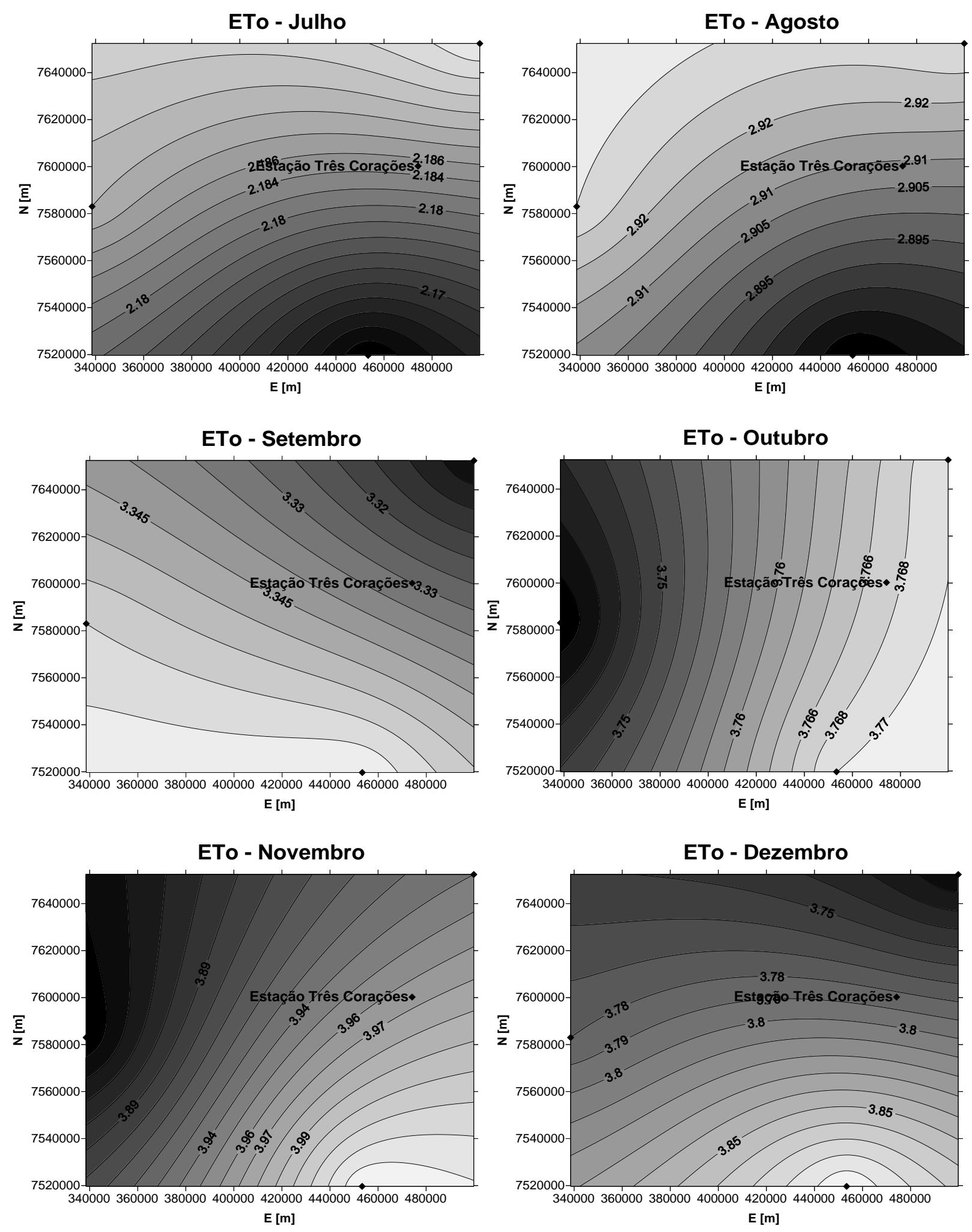

Figura 5. Evapotranspiração de referência média mensal interpolada por krigagem para os meses de julho a dezembro (1975 a 2000).

$\mathrm{Na}$ Tabela 6, percebe-se que os erros entre as $\mathrm{ET}_{\mathrm{o}}$ médias mensais calculadas e interpoladas foram pequenos, na sua maioria inferiores a $2 \%$, com exceção dos meses de janeiro e fevereiro (verão), que apresentaram, respectivamente, $6,28 \%$ e $2,51 \%$. Os menores erros, por sua vez, ocorreram em abril e setembro (outono e primavera). 
A Figura 6 correlaciona os dados calculados e interpolados para a estação de referência, e apresenta os valores dos coeficientes utilizados na análise:

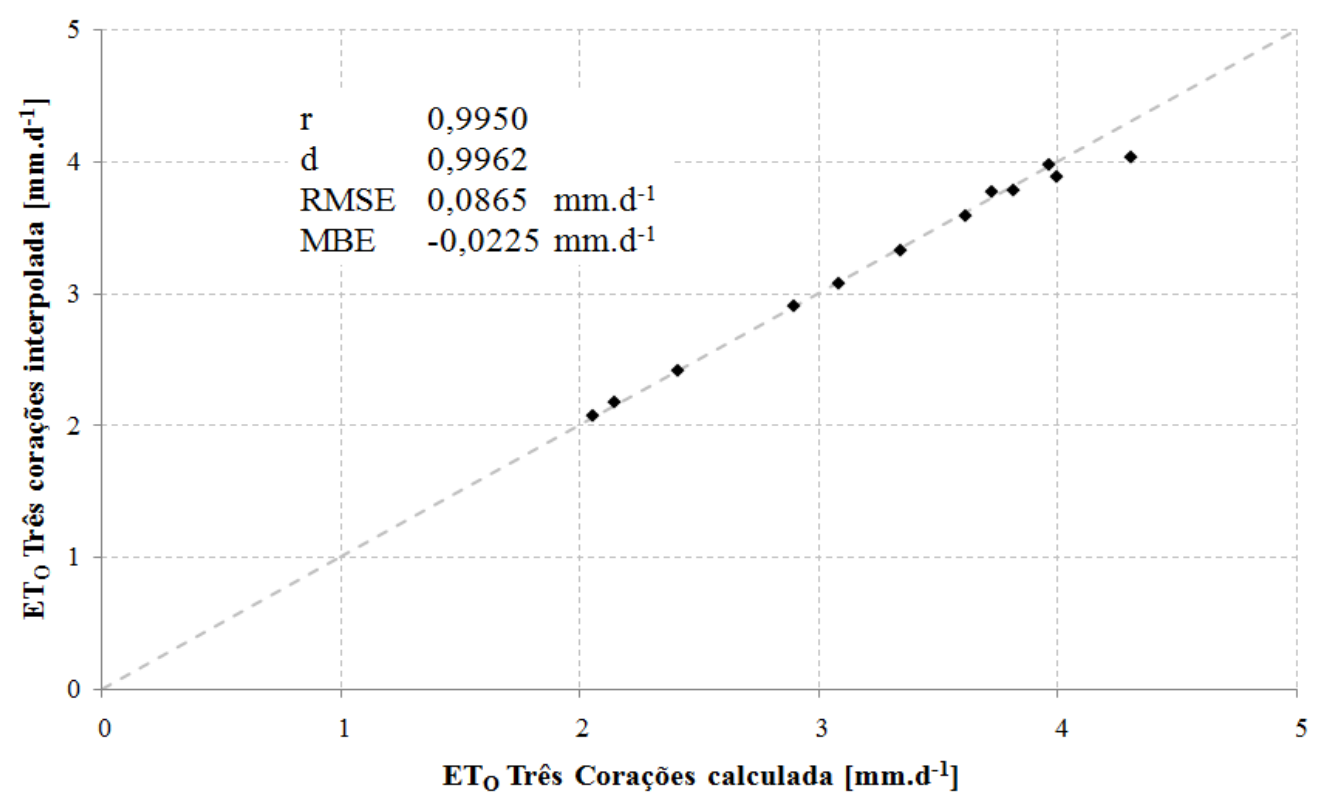

Figura 6. Evapotranspirações de referência médias mensais calculadas e interpoladas para a estação Três Corações.

$\mathrm{O}$ valor de $\mathrm{r}(0,9959)$ indica que o modelo de krigagem resultou em $\mathrm{ET}_{\mathrm{O}}$ interpoladas com alta correlação linear em relação aos valores calculados para a estação Três Corações. $\mathrm{O}$ elevado valor do índice d $(0,9962)$, próximo a 1,0000, indica que os valores de $\mathrm{ET}_{\mathrm{o}}$ calculados foram estimados com elevada exatidão pelos dados interpolados espacialmente.

O modelo de interpolação apresentou bom desempenho em relação aos erros de estimativa, como demonstra o RMSE de $0,0865 \mathrm{~mm} \cdot \mathrm{d}^{-1}$. O valor do MBE $\left(-0,0225 \mathrm{~mm} \cdot \mathrm{d}^{-1}\right)$ demonstra que as $\mathrm{ET}_{\mathrm{O}}$ interpoladas apresentam uma pequena sub-estimação em relação aos valores calculados.

A aplicação do $t$-test resultou em $\mathrm{t}=0,0748$ e $\mathrm{P}=0,941$, o que permite concluir que não há diferença estatística relevante entre as $\mathrm{ET}_{\mathrm{o}}$ calculadas e interpoladas para a estação Três Corações. A pequena diferença entre as médias dos dois grupos pode ser atribuída a aleatoriedades, por exemplo, no processo de amostragem dos parâmetros meteorológicos.

Os resultados indicam que a krigagem é uma técnica geoestatística válida para a espacialização da $\mathrm{ET}_{\mathrm{o}}$, o que condiz com os trabalhos de Mello et al. (2003), Markidis et al. (2005), Lemos Filho et al. (2010) e Sartori et al. (2010). A técnica produziu bons resultados durante a espacialização da evapotranspiração de referência, mesmo diante da pequena quantidade de dados (estações) utilizados, o que indica sua aplicabilidade para geração de mapas de $\mathrm{ET}_{\mathrm{o}}$ em regiões com poucas estações/dados hidrometeorológicos. Essa aplicação deve ser realizada de forma criteriosa, utilizando-se ferramentas para a validação dos resultados, como por exemplo, a consideração de uma estação base, conforme realizado nesse trabalho.

Os critérios de seleção das estações para interpolação por krigagem - pequena distância geográfica e inexistência de feições topográficas significativa - atingiram os objetivos esperados, resultando em boa correlação entre as $\mathrm{ET}_{\mathrm{o}}$ calculadas nas estações de interpolação e a estação de referência.

Os resultados também sugerem que a abordagem “calcular e interpolar", menos laboriosa que a "interpolar e calcular", pode ser priorizada em estudos e projetos que exijam a 
interpolação da $\mathrm{ET}_{\mathrm{O}}$, com exceção de casos que exijam, também, a espacialização das variáveis hidrometeorológicas utilizadas no cálculo da $\mathrm{ET}_{\mathrm{O}}$.

\section{CONCLUSÃO}

A krigagem pode ser aplicada para elaboração de mapas de $\mathrm{ET}_{\mathrm{O}}$ em regiões com escassez de dados hidrometeorológicos, desde que procedimentos para seleção das estações meteorológicas utilizadas e validação dos resultados sejam considerados.

\section{AGRADECIMENTOS} trabalho.

Os autores agradecem aos avaliadores do artigo pelas sugestões para aperfeiçoamento do

\section{REFERÊNCIAS}

ALLEN, R. G.; PEREIRA, L. S.; RAES, D.; SMITH, M. Crop evapotranspiration: Guidelines for computing crop water requirements. Roma: FAO, 1998. (FAO Irrigation and drainage paper, 56).

ALVES, M.; BOTELHO, S. A.; PINTO, L. V. A.; POZZA, E. A.; OllVEIRA, M. S.; FERREIRA, E.; ANDRADE, H. Variabilidade espacial de variáveis geobiofísicas nas nascentes da bacia hidrográfica do Ribeirão Santa Cruz. Revista Brasileira de Engenharia Agrícola e Ambiental, Campina Grande, v. 12, n. 5, p. 527-535, 2008. http://dx.doi.org/10.1590/S1415-43662008000500014

BARGAOUI, Z. K.; CHEBBI, A. Comparison of two kriging interpolation methods applied to spatiotemporal rainfall. Journal of Hydrology, Amsterdã, v. 365, n. 1/2, p. 56-73, 2009. http://dx.doi.org/10.1016/j.jhydrol.2008.11.025

BERnARDO, S.; SOARES, A. A.; MANTOVANI, E. C. Manual de irrigação. 8. ed. Viçosa: Editora UFV, 2008.

BURROUGH, P. A.; MCDONNELL, R. A. Principles of geographical information systems. Oxford: Oxford University Press, 1998.

CÂMARA, G.; MEDEIROS, J. S. (Org.). Geoprocessamento para projetos ambientais. 2. ed. São José dos Campos: INPE, 1998.

CHILDS, C. Interpolating surfaces in ArcGIS Spatial Analyst. ArcUser, Redlands, p. 32-35, jul./set. 2004.

DECOURSEY, W. J. Statistics and probability for engineering applications: with Microsoft ${ }^{\circledR}$ Excel. Woburn: Newness, 2003.

ER-RAKI, S.; CHEHBOUNI, A.; KHABBA, S.; SIMONNEAUZ, V.; JARLAN, L.; OULDBBA, A. et al. Assessment of reference evapotranspiration methods in semi-arid regions: can weather forecast data be used as alternate of ground meteorological parameters? Journal of Arid Environments, Amsterdã, v. 74, n. 12, p. 1587-1596, 2010. http://dx.doi.org/10.1016/j.jaridenv.2010.07.002

FOOD AND AGRICULTURE ORGANIZATION OF THE UNITED NATIONS - FAO. Climwat 2.0. Roma, 2006. 
GUEDES, L. P. C. Otimização de amostragem espacial. 2008. 143f. Tese (Doutorado em Agronomia) - Escola Superior de Agricultura Luiz de Queiroz, Universidade de São Paulo, Piracicaba, 2008.

JACOVIDES, C. P.; KONTOYIANNIS, H. Statistical procedures for the evaluation of evapotranspiration computing models. Agricultural Water Management, Amsterdã, v. 27, n. 3/4, p. 365-371, 1995. http://dx.doi.org/10.1016/0378-3774(95)01152-9

JOURNEL, A. G. Fundamentals of geostatistics in five lessons. Washington: American Geophysical Union, 1989. http://dx.doi.org/10.1029/SC008

LEMOS FILHO, L. C. A.; MELlO, C. R.; FARIA, M. A.; CARVALHO, L. G. Spatialtemporal analysis of water requirements of coffee crop in Minas Gerais State, Brazil. Revista Brasileira de Engenharia Agrícola e Ambiental, Campina Grande, v. 14, n. 2, fev. 2010. http://dx.doi.org/10.1590/S1415-43662010000200007

MARDIKIS, M. G.; KALIVAS, D. P.; KOLLIAS, V. J. Comparison of interpolation methods for the prediction of reference evapotranspiration - An application in Greece. Water Resources Management, [S. 1.], v. 19, n. 3, p. 251-278, 2005. http://dx.doi.org/ $10.1007 / \mathrm{s} 11269-005-3179-2$

MCVICAR, T. R.; VAN NIEL, T. G.; LI, L.; HUTCHINSON, M. F.; MU, X.; LIU, Z. Spatially distributing monthly reference evapotranspiration and pan evaporation considering topographic influences. Journal of Hydrology, Amsterdã, v. 338, p. 196220, 2007. http://dx.doi.org/10.1016/j.jhydrol.2007.02.018

MELlO, C. R.; LIMA, J. M.; SILVA, A. M.; MELlO, J. M.; OLIVEIRA, M. S. Krigagem e inverso do quadrado da distância para interpolação dos parâmetros da equação de chuvas intensas. Revista Brasileira de Ciência Solo, Viçosa, v. 27, n. 5, p. 925933, out. 2003. http://dx.doi.org/10.1590/S0100-06832003000500017

MOTOMIYA, A. V. A.; CORA, J. E.; PEREIRA, G. T. Uso da krigagem indicatriz na avaliação de indicadores de fertilidade do solo. Revista Brasileira de Ciência Solo, Viçosa, v. 30, n. 3, p. 485-496, 2006. http://dx.doi.org/10.1590/S010006832006000300010

ROSS, S. M. Introduction to probability and statistics for engineers and scientists. Burlington: Elsevier Academic Press, 2004.

SARTORI, A. A. C.; SILVA, A. F.; RAMOS, C. M. C.; ZIMBACK, C. R. L. Variabilidade temporal e mapeamento de dados climáticos de Botucatu-SP. Irriga, Botucatu, v. 15, n. 2, p. 131-139, abr. 2010.

SILVA, D.; MEZA, F. J.; VARAS, E. Estimating reference evapotranspiration $\left(\mathrm{ET}_{\mathrm{o}}\right)$ using numerical weather forecast data in central Chile. Journal of Hydrology, Amsterdã, v. 382, p. 64-71, 2010. http://dx.doi.org/10.1016/j.jhydrol.2009.12.018

TOUTENBURG, H. Statistical analysis of designed experiments. 2. ed. Nova Iorque: Springer, 2002.

WILLMOTT, C. J. On the validation of models. Physical Geography, v. 2, n. 2, p. 184-194, 1981. 
VILANOVA, M. R. N.; SIMÕES, S. J. C.; TRANNIN, I. C, B. Interpolação geoespacial da evapotranspiração de referência $\left(E_{\mathrm{o}}\right)$ em regiões com escassez de dados: estudo de caso no Sul de Minas Gerais. Ambi-Agua, Taubaté, v. 7, n. 2, p. 179-194, 2012. (http://dx.doi.org/10.4136/ambi-agua.763)

YIN, Y.; WU, S.; ZHENG, D.; YANG, Q. Radiation calibration of FAO56 Penman-Monteith model to estimate reference crop evapotranspiration in China. Agricultural Water Management, Amsterdã, v. 95, n. 1, p. 77-84, 2008. http://dx.doi.org/10.1016/j.agwat. 2007.09.002

ZHANG, X.; KANG, S.; ZHANG, L.; LIU, J. Spatial variation of climatology monthly crop reference evapotranspiration and sensitivity coefficients in Shiyang river basin of northwest China. Agricultural Water Management, Amsterdã, v. 97, n. 10, p. 15061516, 2010. http://dx.doi.org/10.1016/j.agwat.2010.05.004 


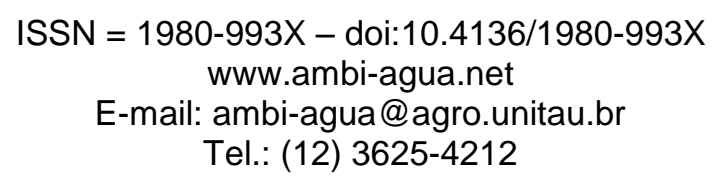

\title{
Modelagem para integração de dados sobre macrobentos em Infraestrutura de Dados Espaciais
}

\author{
(http://dx.doi.org/10.4136/ambi-agua.774)
}

\section{Gabriel Niero de Carvalho ${ }^{1}$; Mariana Abrantes Giannotti ${ }^{2}$; Silvia Sartor ${ }^{3}$;José Alberto Quintanilha ${ }^{4}$}

\author{
Escola Politécnica da Universidade de São Paulo - \\ Depto. Engenharia de Transportes - Laboratório de Geoprocessamento (LGP). \\ e-mails: ${ }^{1}$ gabrielncarvalho@ hotmail.com, ${ }^{2}$ mariana.giannotti@gmail.com, \\ ${ }^{3}$ ssartor@uol.com.br, ${ }^{4}$ jaquinta@usp.br
}

\section{RESUMO}

As Zonas Costeiras são áreas complexas que contemplam ambientes terrestres e marinhos que, além de possuírem enorme riqueza ambiental, também são áreas atrativas aos seres humanos por oferecer alimentos, lazer, negócios, transporte, entre outros. Algumas dificuldades de gerenciamento ocorrem pela complexidade, conflito de interesses e pelo fato de não haver padronização no levantamento de dados e disponibilização para a comunidade científica, órgãos públicos, etc. A organização, padronização e compartilhamento destas informações em Atlas Web são essenciais para auxiliar no planejamento e tomada de decisão pois agregam, em um único ambiente, diversos dados provenientes de fontes distintas. A construção de um modelo de dados espacial voltado à área ambiental, para ser utilizada em Infraestrutura de Dados Espaciais (IDE) é exemplificada a partir da modelagem de um bioindicador de qualidade de sedimentos. Este trabalho apresenta as etapas necessárias para a construção de modelo de dados espacial de Macrobentos e emprega a Região Metropolitana da Baixada Santista como referência. Conclui-se que a estruturação do conhecimento quando se trabalha com dados ambientais em um modelo é essencial para sua posterior integração em IDE. Constatou-se no processo de modelagem que questões metodológicas relativas ao processo de coleta podem dificultar ou inviabilizar a integração de dados provenientes de diferentes estudos em uma mesma área. A construção de um modelo de dados espacial, como o apresentado neste estudo poderá ser utilizado como referência para novas pesquisas com objetivos semelhantes.

Palavras-chave: IDE, Baixada Santista, SIG; biomonitoramento, Macrobentos, Modelo de Dados Espaciais.

\section{Database modeling to integrate macrobenthos data in Spatial Data Infrastructure}

\section{ABSTRACT}

Coastal zones are complex areas that include marine and terrestrial environments. Besides its huge environmental wealth, they also attracts humans because provides food, recreation, business, and transportation, among others. Some difficulties to manage these areas are related with their complexity, diversity of interests and the absence of standardization to collect and share data to scientific community, public agencies, among others. The idea to organize, standardize and share this information based on Web Atlas is 
essential to support planning and decision making issues. The construction of a spatial database integrating the environmental business, to be used on Spatial Data Infrastructure (SDI) is illustrated by a bioindicator that indicates the quality of the sediments. The models show the phases required to build Macrobenthos spatial database based on Santos Metropolitan Region as a reference. It is concluded that, when working with environmental data the structuring of knowledge in a conceptual model is essential for their subsequent integration into the SDI. During the modeling process it can be noticed that methodological issues related to the collection process may obstruct or prejudice the integration of data from different studies of the same area. The development of a database model, as presented in this study, can be used as a reference for further research with similar goals.

Keywords: SDI, GIS, Macrobenthos, biomonitoring, Spatial Database Model.

\section{INTRODUÇÃO}

A importância em zonas costeiras e marinhas aumenta significativamente pela concentração populacional, aspecto político, social e econômico envolvidos. Small e Cohen, (2004) descrevem sobre a distribuição espacial da população humana no mundo e ressaltam sua concentração em zonas costeiras.

A informação geográfica em zonas costeiras é essencial, pois agrega o contexto espacial, o que permite a realização de análises. Estas indicam distribuição, concentração e tendências de indicadores ambientais que facilitam o planejamento costeiro. Entretanto, para se fazer uso deste potencial é imprescindível que as fontes de dados sigam normas para que possam ser compartilhadas.

As iniciativas de organização e compartilhamento de informações costeiras, principalmente as internacionais (Estados Unidos, Canadá, Irlanda, Reino Unido e Austrália), estão em processo de desenvolvimento e cada vez mais buscam construir uma ferramenta que possa auxiliar na gestão e na tomada de decisão, por meio da integração de dados e a sua rápida disponibilização por meio, por exemplo, de portais.

No Brasil as iniciativas para construção de Infraestruturas de Dados Espaciais (IDEs) que contemplem as questões Costeiras e Marinhas ainda são incipientes. As Cartas de Sensibilidade Ambiental ao Óleo desenvolvidas pela Petrobras (Araujo et al., 2007) e pelo Ministério do Meio Ambiente Brasileiro (Ghehardi et al., 2008), avançaram na questão, mas não tratam de aspectos relativos à padronização no levantamento de dados ambientais e disponibilização ampla para facilitar o planejamento costeiro.

A proposta deste artigo é propor as etapas necessárias para a construção de um modelo de dados espacial com enfoque ambiental. $\mathrm{O}$ estudo focou no tema macrobentos, a partir de fontes de dados distintas e sem padrão de codificação dos levantamentos, para serem disponibilizadas e consumidas de forma padronizada por meio de um Atlas Web baseado em IDE. A área escolhida para a construção do modelo de dados foi a Região Metropolitana da Baixada Santista (RMBS), por ser relevante sob diversos aspectos ambientais e socioeconômicos (Sartor et al., 2007, 2009). Trata-se, portanto, de uma forma estruturada de representar os dados que, posteriormente, pode ser estendida para outras regiões e/ou temas ambientais.

Este trabalho está estruturado do seguinte modo: além desta Introdução, o item 2 apresenta uma revisão sobre IDEs para gerenciamento costeiro e marinho; o item 3 descreve a área de estudos e a importância dos macrobentos. No item 4 estão descritos os materiais e métodos utilizados, o quinto item apresenta os resultados e uma discussão e as conclusões são apresentadas no item 6. 


\section{Infraestrutura de dados espaciais para gerenciamento costeiro e marinho}

Strain et al. (2004), Rajabifard et al. (2008) e Bartlett e Smith (2005) ilustram dificuldades encontradas no gerenciamento de zonas costeiras:

- São governadas por complexas legislações e instituições;

- Agências governamentais em âmbito regional ou nacional são responsáveis por diferentes aspectos da mesma área física e uso da zona costeira, como por exemplo: meio ambiente, pesca, agricultura, transporte, planejamento urbano e cadastro;

- As mudanças do ambiente marinho são muito mais rápidas em relação ao ambiente terrestre;

- Há menos levantamento de dados e estudos que em ambiente terrestre.

Além dos aspectos apresentados há dificuldade na coleta, gerenciamento $\mathrm{e}$ disponibilização de dados nesses ambientes. Strain et al. (2004), Rajabifard et al. (2008) e Bartlett e Smith (2005) explicitam, os seguintes fatores a destacar:

- Os dados são dinâmicos e multidimensionais dificultando a delimitação da área de coleta e a atualização dos dados;

- Os dados são coletados para um projeto específico e raramente são compartilhados com outras organizações;

- Não há padronização no levantamento de dados, dificultando assim, a interoperabilidade (troca de informações sem necessidade de transformação);

- As diferenças entre ambientes marinhos e terrestres, além dos métodos de coleta e tecnologias utilizadas para o levantamento de dados, representam grande desafio para a interoperabilidade entre ambos;

- Os estudos sobre políticas para dados espaciais marinhos ainda são incipientes.

A complexa relação entre diferentes tipos de informações espaciais e a enorme dificuldade em gerenciar áreas costeiras incentiva, de certa forma, que cada país ou organização defina diferentes rotinas para a construção de uma arquitetura que possibilite a integração de dados entre os interessados (Bartlett e Smith, 2005).

Diante deste contexto, a implementação de soluções como a IDEs tem como principal objetivo facilitar e coordenar a troca e o compartilhamento de dados e serviços espaciais para melhor atingir as diversas necessidades em diferentes níveis político e administrativo. (Hjelmager et al., 2008; Rajabifard et al., 2006).

O Global Spatial Data Infrastructure Association (GSDI) é uma associação que promove a cooperação internacional e colabora com a criação de IDEs em diferentes escalas, sendo também responsável em produzir o chamado GSDI Cookbook, espécie de guia para a implementação de um IDE (GSDI, 2004):

"O termo Infraestrutura de Dados Espaciais (IDE), é frequentemente usado para designar a coleção de tecnologias, políticas e arranjos institucionais que facilitem a viabilidade e o acesso aos dados geográficos. A IDE fornece uma base para a descoberta de dados geográficos, avaliação e aplicação para os usuários e provedores em todos os níveis de governo, setor comercial, setor sem fins lucrativos, universidades e cidadãos em geral."

Uma IDE é muito mais do que simplesmente um conjunto de amostras ou banco de dados e vai além do levantamento e mapeamento de dados; na prática fornece um ambiente na qual organizações/ nações interagem, via tecnologia, para promover o uso, gerenciamento e produção de mecanismos para busca, acesso à dados, além de serviços ou softwares que dão suporte a toda esta comunicação (GSDI, 2004; Rajabifard et al., 2006).

Inicialmente, as IDEs contavam com uma metodologia de modelagem orientada aos produtos que visava um escopo temático amplo, em uma estratégia de concepção baseada na estrutura top-down (Rajabifard et al., 2006). A partir das experiências dessa primeira geração, 
percebeu-se que esse modelo não mais satisfazia às necessidades preconizadas para uma IDE. Com a evolução para a segunda geração de IDE, a modelagem passou a ser orientada a processos e sua constituição contava com uma visão bottom-up, partindo de estruturas locais para a posterior formação de uma estrutura nacional (Rajabifard et al., 2006). Crompvoets et al. (2004) analisam experiências em vários países, descrevendo cada componente do IDE sob a perspectiva de cada iniciativa estudada, e reforçam a ideia dessa mudança de estratégia da primeira geração de IDEs, orientada aos produtos e dados, para a segunda geração, mais orientadas às aplicações e seus usuários.

Iniciativas que privilegiam os conhecimentos locais são valorizadas pela riqueza de aplicações e diversidade de interesses impondo novos requisitos às IDEs. Diferentemente das questões relativas às propostas de IDE nacionais, as propostas locais requerem um maior detalhamento e, com isso, um maior acesso a diferentes fontes de dados, mantidas por diversos provedores (Davis e Alves, 2005).

A tendência de popularização da utilização de dados geográficos, decorrente das facilidades promovidas pelos serviços disponibilizados pela Web, tem feito com que, recentemente, haja uma demanda convergente por modelos de Infraestruturas de Dados Espaciais locais orientadas a serviços (Davis e Alves, 2005; Vaccari et al., 2008). Chan et al. (2001) ao analisarem as diversas definições de IDE, já mencionavam a falta de uma perspectiva de serviços nessas definições.

Masser et al. (2008) mencionam que o desenvolvimento de Infraestruturas de Dados Espaciais efetivas deve servir de forma transparente como suporte para a vasta maioria da sociedade que não é familiarizada com conceitos sobre consultas espaciais. Essas estruturas devem ser aprimoradas de tal forma que seja possível compartilhar, adicionalmente aos dados, estratégias, processos, operações, produtos de valor agregado, dentre outros.

Especificamente na questão de gerenciamento costeiro e marinho, as diversas atividades internacionais referentes ao assunto ajudaram e subsidiaram o desenvolvimento de soluções para suportar e compartilhar a dimensão espacial de dados marinhos e costeiros, conforme Strain (2008).

Como também lembra USCoOP (2002): "há a necessidade por uma melhor e mais compreensiva maneira para agregar trabalhos provenientes de diferentes disciplinas com o objetivo de oferecer um entendimento mais integrado do meio ambiente marinho e os processos que o controla (...) há a necessidade de se padronizar práticas e procedimentos".

Diante deste contexto, alguns IDEs estão sendo desenvolvidos com o enfoque principal no gerenciamento do ambiente costeiro e marinho. Como é possível notar, os casos explicitados a seguir, normalmente fazem parte de um IDE em maior escala, seja este regional ou nacional, que demonstra a preocupação de não serem desenvolvidos de maneira isolada e seguem as melhores práticas internacionais de padronização, troca de dados, etc.:

Inverti todos: nome depois sigla. É convenção.

- Coastal Spatial Data Infrastructure (CSDI): é gerenciado pelo Centro de Serviços Costeiros (The National Oceanic and Atmospheric Administration - NOAA), sendo desenvolvido como parte do IDE Americano (US NSDI), que permitiu o acesso e consumo de dados geoespaciais costeiros e marinhos (NOAA, 2011);

- Marine Geospatial Data Infrastructure (MGDI), iniciado no ano de 1999, como parte integrante do Canadian Geospatial Data Initiative (CGDI), agora denominado GeoConnections (CGDI, 2011);

- Marine Environmental Data and Information Network (MEDIN) desenvolvido na Inglaterra, o projeto iniciou no ano de 2003 com o nome de Marine Data and Information Partnership (MDIP) e em 2008, mudou-se o nome do Órgão que gerenciava tal projeto Marine Science Coordination Committee (MSCC) e consequentemente a solução sofreu uma restruturação para o nome atual (MEDIN, 2011); 
- Marine Irish Data Atlas (MIDA): Segundo Strain (2008), a Irlanda possui uma significativa quantidade de dados relacionados com o ambiente costeiro e marinho, pela integração de 18 diferentes agências em 6 departamentos distintos do governo. O projeto MIDA tem como intuito melhorar o acesso aos dados espaciais por meio do desenvolvimento de um Atlas Marinho (MIDA, 2011);

- Há diversas iniciativas na Austrália, sendo a Australian Marine Boundary Information System (AMBIS), desenvolvido pelo Geoscience Australia (GA) no ano de 2001 (AMSIS, 2011) e o Australian Ocean Data Centre Joint Facility (AODCJF), inaugurado em 2005 (AODCJF, 2011);

- African Marine Atlas (AMA): projeto desenvolvido pela Ocean Data and Information Network for Africa (ODINAFRICA), responsável por organizar mais de 40 institutos marinhos em 25 países na África, oficialmente lançado em 23 de Fevereiro de 2007, contendo grande quantidade de geo-informação marinha referente ao litoral e oceano africanos (ODINAFRICA, 2011);

- International Coastal Atlas Network (ICAN): é uma iniciativa formada por um grupo informal que contém mais de 35 organizações, com representações na Europa, América e África. Um dos principais objetivos do grupo é compartilhar experiências e soluções comuns para auxiliar no desenvolvimento de Portais Web (Atlas Ambiental - IDEs), levando em consideração padrões de armazenamento de metadados e troca de informações espaciais (ICAN, 2011).

Portanto, um dado proveniente de um estudo ou levantamento específico para ser consumido dentro de um Atlas Web, seguindo os conceitos de uma IDE, deve passar por uma série de etapas até que tal dado se transforme em uma informação realmente útil a um usuário final que fará uso para a tomada de decisão. É neste sentido que será ilustrado no tópico abaixo as etapas necessárias para inserir estudos distintos, realizados sobre diferentes perspectivas e contexto, referentes ao tema Macrobentos, em um modelo único de banco de dados, seguindo regras e padrões, para posterior disponibilização em IDE.

\section{3. Área de estudo e importância de macrobentos}

A Zona Costeira é "o espaço delimitado pela interface entre o oceano e a terra, ou seja, a faixa terrestre que recebe influência marítima e a faixa marítima que recebe influência terrestre", que na prática, trata-se de uma área de interface entre o ar, terra e mar (Rodríguez e Windevoxhel, 1998). Segundo o Atlas Universal do Oceano (UN Atlas, 2011), estima-se que dois terços da população vivem a 60 quilômetros da costa e que o crescimento da população humana nestas regiões seja cerca do dobro em relação à outras áreas do mundo.

Nos estuários concentram-se grandes centros urbanos, intensa atividade industrial, portuária e comercial (Nybakken, 1995). Essas atividades implicam em potenciais impactos ambientais (Kennish, 1997; Rivero et al., 2005). O aumento da industrialização na área estudada insere uma grande quantidade de agentes tóxicos que se acumulam no sedimento e influenciam diretamente nas populações faunísticas que vivem nestas áreas. O impacto em um elo da cadeia trófica, no caso, o macrobentos, interfere na atividade pesqueira, por exemplo.

Biologicamente, os estuários estão entre os ecossistemas mais produtivos do oceano. A Baixada Santista, região que compreende a área estudada no presente artigo, conforme ilustra a Figura 1, engloba o sistema estuarino de Santos e São Vicente. Localiza-se na faixa litorânea do Estado de São Paulo e apresenta complexa estrutura de ocupação da zona costeira que, frequentemente implica em conflito com o equilíbrio dos ecossistemas. Com relação à contaminação química industrial e orgânica, o estuário de Santos é considerado uma área crítica (CETESB, 2001, 2004, 20072008 e 2009; Sartor e Degaspari, 2000). 


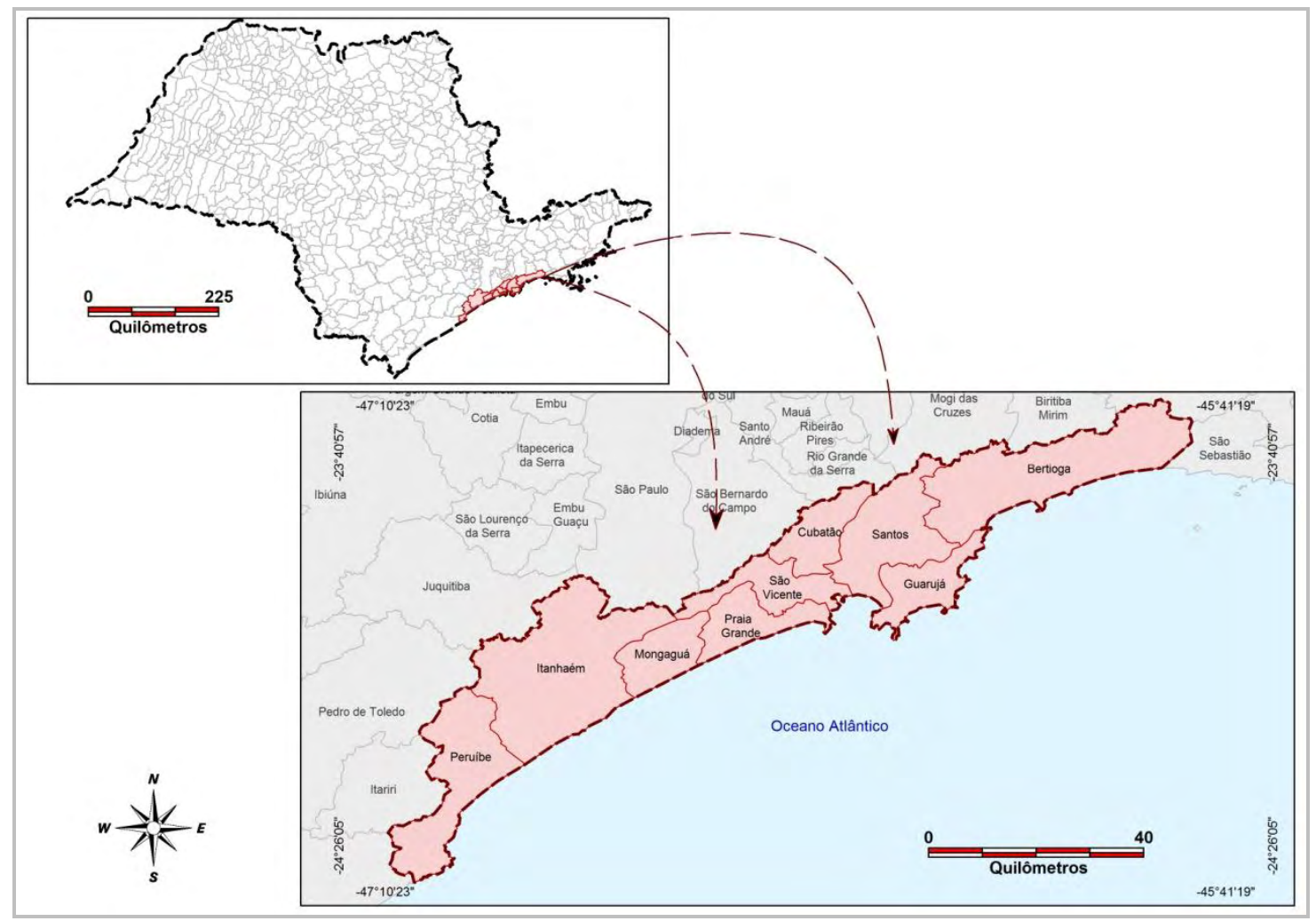

Figura 1. Contexto Espacial da Região Metropolitana da Baixada Santista no Estado de São Paulo composta pelos municípios: Bertioga, Cubatão, Guarujá, Itanhaém, Mongaguá, Peruíbe, Praia Grande, Santos e São Vicente.

Comunidades bentônicas têm sido amplamente utilizadas nos programas de monitoramento ambiental. A maioria dos organismos é séssil ou sedentária e podem indicar graus de poluição por alterar a composição da comunidade faunística. Além disso, incluem espécies com diferentes tolerâncias ao agente poluidor, como metais pesados, organoclorados, esgoto, entre outros. (Warwick, 1986; Bilyard, 1987; Ahn et al., 1995). A diversidade, abundância e dominância de espécies estão diretamente associadas às condições ambientais, tais como salinidade, temperatura, oxigênio dissolvido, variações de marés, ação de ondas, topografia, granulometria, entre outros (Snelgrove e Butman, 1994; McLachlan, 1996). A interação desses fatores é responsável pela estabilidade do sistema e alterações provocadas direta ou indiretamente pela ação do homem podendo desequilibrá-lo. Se as alterações forem frequentes, o desequilíbrio pode eliminar espécies sensíveis, substituindo-as por espécies oportunistas, provocando modificações nos níveis tróficos superiores da comunidade faunística (Bilyard, 1987).

Anelídeos poliquetas é o grupo dominante na região estudada e têm sido amplamente utilizados em programas de monitoramento ambiental, pois a diversidade e abundância relacionadas com os padrões de distribuição podem revelar se um determinado ambiente encontra-se ou não impactado (Pearson e Rosenberg, 1978; Choi e Koh, 1984; Pocklington e Wells, 1992; Rizzo e Amaral, 2000, 2001a, b). Dependendo dos fatores hidrodinâmicos e da heterogeneidade do substrato, os poliquetas podem dominar tanto em riqueza quanto em número de indivíduos, sendo representados por mais gêneros do que qualquer outro grupo animal (Brown e McLachlan, 1990; Amaral et al., 1995). Desempenham importante papel na cadeia trófica marinha, servindo como base alimentar para inúmeros organismos. Para algumas espécies de peixes e crustáceos, os poliquetas representam uma proporção superior a $80 \%$ do alimento ingerido (Amaral e Migotto, 1980). 


\section{MATERIAIS E MÉTODOS}

A Figura 2 ilustra a metodologia empregada no desenvolvimento deste estudo. A Modelagem Conceitual de Dados está intrinsicamente ligada às diversas Referências Bibliográficas existentes sobre o tema e as reais necessidades dos usuários do sistema, que em paralelo, subsidiam e refinam o modelo empregado. As referências utilizadas para este estudo foram: Codesp (2008, 2010), Embraport (2003), Tommasi (1979), Heitor (2002), Ferreira (2008).

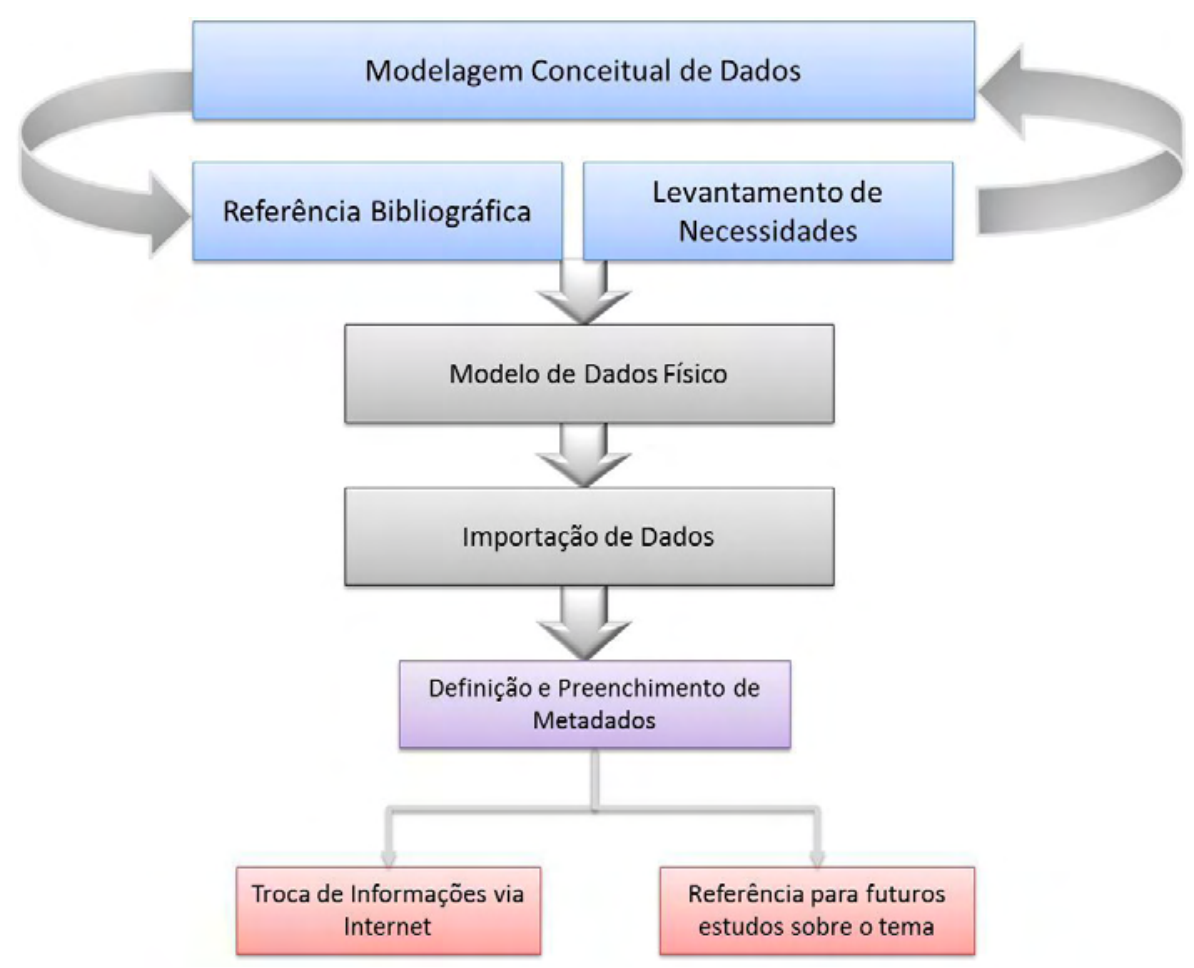

Figura 2. Resumo de metodologia aplicada.

Uma vez definido o Modelo Conceitual, adequado às fontes bibliográficas existentes, as necessidades dos usuários e ao tema em questão, os dados devem passar por um processo de Importação de Dados a um Modelo de Dados Físico que normalmente é representado em um Sistema Gerenciador de Banco de Dados tais como Oracle, Microsoft SQL Server, PostgreSQL, entre outros.

A Definição e o Preenchimento de Metadados são essenciais para que se possa documentar corretamente todos os passos realizados na definição das fontes e adequações nos dados, com o objetivo de facilitar a compreensão e o correto consumo destas informações em uma IDE. Os metadados ajudam a organizar e manter o investimento de uma organização, evitam duplicidade de esforços, além de facilitar e prover informações para consumo (GSDI, 2004).

Além disso, a correta parametrização de metadados também permite que tais dados, hoje armazenados em bibliotecas e documentos analógicos, possam ser consumidos por sistemas terceiros de maneira simples e direta por meio de Serviços Geoespaciais como WebMap Service (WMS), Web Feature Service (WFS), Catalog Service Web (CSW), segundo padrão definido pela Open Geospatial Consortium (OGC, 2011), que é exatamente o que representa a troca de informações via Internet e garante a interoperabilidade. 
Por fim, a expectativa é que o desenvolvimento de tal metodologia possa se tornar uma referência em futuros estudos sobre o tema ou similares, tanto em relação aos procedimentos realizados, quanto à agregação de levantamentos inéditos ao modelo existente, permitindo a troca de informações entre instituições, órgãos públicos, pesquisadores e a todos que destas informações necessitarem.

Especificamente neste artigo são discutidas as seguintes etapas da metodologia supracitada (Figura 2): Modelagem Conceitual de Dados, Referências Bibliográficas, Modelo de Dados Físico e Importação de Dados.

\section{Modelo de dados}

A evolução da tecnologia proporcionou acesso mais rápido e fácil aos dados espaciais, que permitiu apoiar a tomada de decisão por parte de gestores, uma vez que é possível inserir nas análises um conjunto de dados espaciais. Por outro lado, a produção de grande quantidade de dados pode também ser um problema, pois podem ter sido produzidos em diferentes padrões de software, escalas, propósitos, etc., e a falta de documentação (metadados), dificulta o consumo destas informações. Câmara e Lima Junior (2002) evidenciam suas preocupações com a busca por padrões no armazenamento e troca de informações espaciais entre os produtores: "Um dos desafios mais importantes no uso das geotecnologias é o intercâmbio de dados espaciais, impulsionado principalmente pelo alto custo de produção deste tipo de dado. A falta de modelos conceituais comuns acarreta problemas na troca de dados entre organizações utilizando Sistema de Informação Geográfica (SIGs) distintos, que incluem distorção de dados, comprometimento de qualidade da informação, perda de definições de atributos e georreferenciamento".

A busca pela interoperabilidade entre diferentes dados geoespaciais parte da adoção de um Modelo de Dados para a organização conceitual de dados e sua posterior disponibilização para diferentes organizações que utilizam padrões pré-definidos como Serviços Geoespaciais (Web Services), seguindo o padrão OGC. No Brasil, a crescente preocupação por padronização/ acessibilidade de dados geoespaciais fez com que fosse criada a Infraestrutura Nacional de Dados Espaciais (INDE-BR), sob tutela da Comissão Nacional de Cartografia (CONCAR). Dentre as atividades já realizadas, pode-se destacar a Especificação Técnica para a Aquisição de Dados Geoespaciais Vetoriais (ET-EDGV) que: "tem por objetivo padronizar e orientar todo o processo de aquisição da geometria dos vários tipos de dados geoespaciais vetoriais, presentes na Especificação Técnica para Estruturação de Dados Geoespaciais Vetoriais (ET-EDGV), da CONCAR, para qualquer que seja o insumo a ser utilizado (levantamento de campo, fotografias aéreas, imagens de sensores orbitais, etc.), visto que os processos de aquisição são similares." (Lunardi et al., 2009).

Diante deste cenário, torna-se cada vez mais necessário que haja uma padronização no levantamento, organização e documentação de dados espaciais, para que este possa ser utilizado por terceiros. Um modelo de dados, seja este com características geográficas ou não, é referente ao processo de abstração na qual apenas os elementos essenciais da realidade para um determinado estudo são considerados (Lisboa Filho e Iochpe, 1999).

O processo de abstração é parte fundamental na criação de sistemas de informações. Trata-se, portanto, da transposição de entidades do mundo real e suas interações para um banco de dados informatizado que realiza a descrição dos possíveis conteúdos dos dados, além de estruturas e regras das entidades escolhidas. Quando se considera o âmbito espacial, esta abstração ainda possui algumas especificidades referentes à localização espacial, o tempo de observação, a precisão de obtenção e representação das informações geográficas.

Para o processo de abstração específico para este artigo foi utilizado o modelo Object Modeling Technique for Geographic Applications (OMT-G), que é derivado do OMT convencional, baseado no método conceitual Orientado a Objeto (OO) e Diagrama de Classes 
UML (Unified Modeling Language), conforme destaca Borges et al. (2001) e: "provê primitivas para modelar a geometria e a topologia dos dados geográficos, oferecendo suporte a estruturas topológicas "todo-parte", estruturas de rede, múltiplas representações de objetos e relacionamentos espaciais. Além disso, o modelo permite a especificação de atributos alfanuméricos e métodos associados para cada classe. Os principais pontos do modelo são sua expressividade gráfica e sua capacidade de codificação, uma vez que anotações textuais são substituídas pelo desenho de relacionamentos explícitos, que denotam a dinâmica da interação entre os diversos objetos espaciais e não espaciais." (Câmara et al., 2005).

Além disso, trata-se do mesmo padrão adotado pela INDE, constituída em 2008 pelo Decreto $\mathrm{N}^{\circ}$ 6.666, de 27 de Novembro de 2008, que possui a missão de promover o adequado ordenamento na geração, armazenamento, acesso, compartilhamento, disseminação e uso dos dados geoespaciais (Lunardi et al., 2009). Para maiores detalhes sobre este e outros modelos analisar as seguintes bibliografias: Lisboa Filho e Iochpe (1999), Borges et al. (2001) e Câmara et al. (2005).

Uma vez realizado o levantamento das fontes de dados e a definição da metodologia a ser empregada, iniciou-se a construção do modelo de dados. Em se tratando especificamente do tema Macrobentos, percebe-se que há uma real dificuldade em, primeiramente, encontrar estudos semelhantes ao redor do mundo e em segundo, estarem vinculados e preocupados com a questão espacial. Assim, parte dos estudos existentes não possuem informações completas de levantamentos de amostras realizadas em campo (sistema de coordenadas, forma de armazenamento, processos e metodologia realizada) e, portanto, acabam por dificultar a agregação e consequentemente a modelagem conceitual dos estudos. Como já destacado por (Rajabifard et al., 2008), normalmente os levantamentos são feitos para um propósito específico e raramente são compartilhados com outras organizações.

\section{RESULTADOS E DISCUSSÃO}

O intuito da modelagem é exatamente para levantar os fenômenos intrínsecos ao tema em questão, entendê-los e organizá-los de maneira lógica com o objetivo de poder utilizá-los em futuros portais, atlas, entre outros. Para a construção do modelo foi utilizado o software Microsoft Visio 2010, com uma extensão específica aderente ao modelo OMT-G. Cada classe representada por um pictograma que contem as informações referentes ao tipo de representação espacial (linha, ponto, polígono, etc.) ou não espacial, atributos e operações seguindo o modelo OMT-G, como mostra a Figura 3.

\begin{tabular}{|c|c|c|c|c|c|c|c|c|}
\hline LINHA & PONTO & POLÍGONO & \multicolumn{2}{|c|}{$\begin{array}{c}\text { LINHA } \\
\text { UNI-DIRECIONADA }\end{array}$} & \multicolumn{2}{|c|}{$\begin{array}{c}\text { LINHA } \\
\text { BI-DIRECIONADA }\end{array}$} & \multicolumn{2}{|r|}{ Nó } \\
\hline \begin{tabular}{|l|l|}
- & Nome \\
da classe
\end{tabular} & \begin{tabular}{|l|l|}
\multirow{2}{*}{} & $\begin{array}{l}\text { Nome } \\
\text { da Classe }\end{array}$ \\
\end{tabular} & \begin{tabular}{|l|l|}
$\square$ & $\begin{array}{l}\text { Nome } \\
\text { da Classe }\end{array}$ \\
\end{tabular} & $\rightarrow$ & $\begin{array}{l}\text { Nome } \\
\text { da Classe }\end{array}$ & $\leftrightarrow$ & $\begin{array}{l}\text { Nome } \\
\text { da Classe }\end{array}$ & o & $\begin{array}{l}\text { Nome } \\
\text { da Classe }\end{array}$ \\
\hline Atributos Graficos & Atributos Granticos & Atrrbutos Grancos & \multicolumn{2}{|c|}{ Atributos Graficos } & \multicolumn{2}{|c|}{ Atrloutos Grancos } & \multicolumn{2}{|c|}{ Atributos Grancos } \\
\hline Atributos & Atributos & Atrioutos & & Atributos & & Atributos & & Atributos \\
\hline Operaçбes & Operaçбes & Operaçbles & & peraçбes & & Dperaçbes & & Operaçbles \\
\hline Ex: Muro & Ex: Árvore & Ex: Lote & Ex: & $\begin{array}{l}\text { recho rede } \\
\text { esgoto }\end{array}$ & Ex: & $\begin{array}{l}\text { Trecho rede } \\
\text { de água }\end{array}$ & Ex:P & oço de Visita \\
\hline
\end{tabular}

Figura 3. Exemplo de representação de classes.

Fonte: Adaptado de Borges et al. (2001). 
CARVAlHO, G. N.; GIANNOTTI, M. A.; SARTOR, S.; QUINTANILHA, J. A. Modelagem para integração de dados sobre macrobentos em Infraestrutura de Dados Espaciais. Ambi-Agua, Taubaté, v. 7, n. 2, p. 195-213, 2012. (http://dx.doi.org/10.4136/ambi-agua.774)

A Figura 4 apresenta o modelo desenvolvido para Macrobentos utilizando a metodologia proposta.

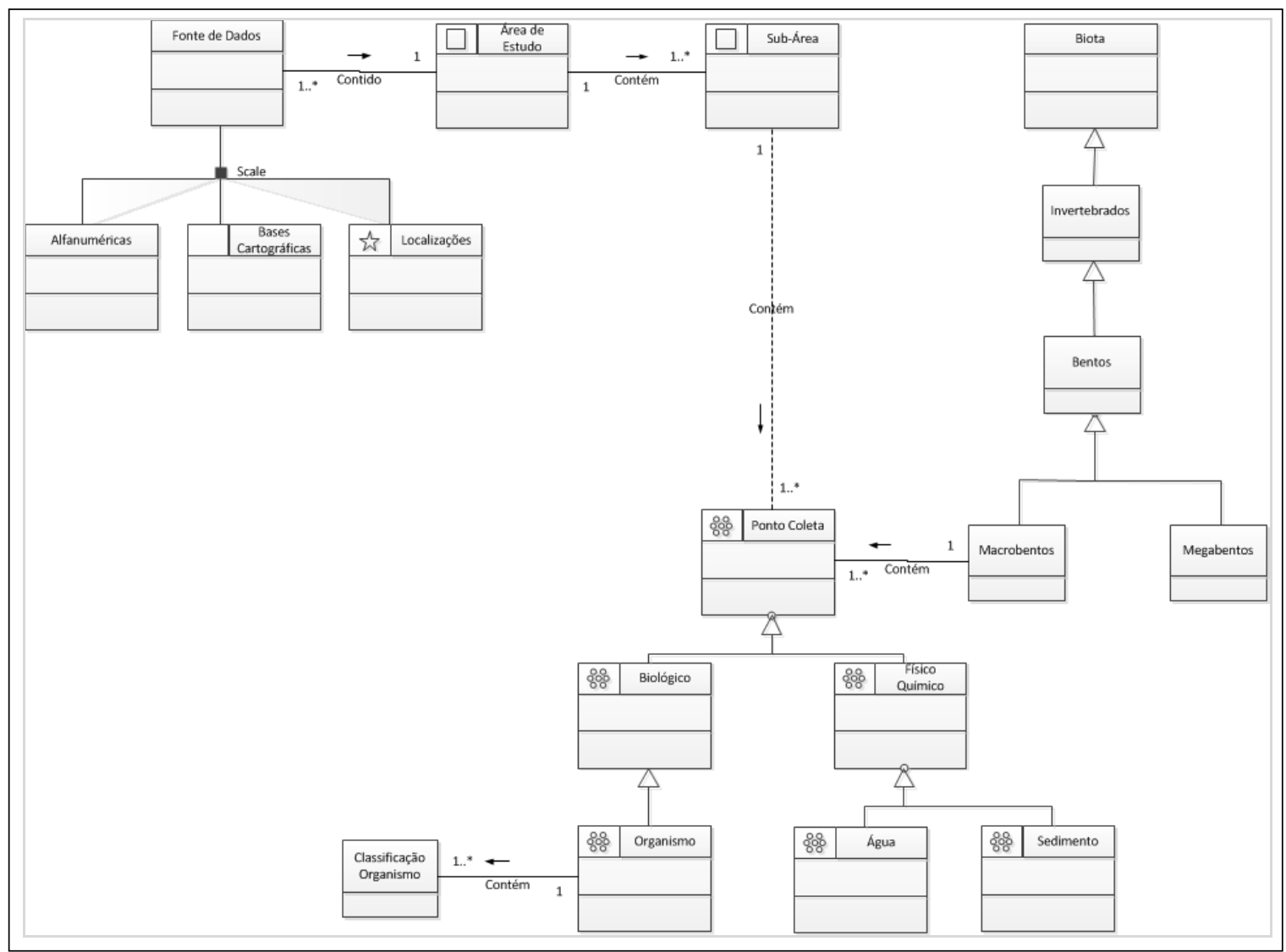

Figura 4. Modelagem de Dados Espaciais Teórico para o tema macrobentos.

A Tabela 1 ilustra com mais detalhes a composição do Modelo de Dados Espaciais Teórico seguindo o padrão OMT-G. Em cada etapa do processo é possível observar os diversos tipos de simbologia que compõem as classes, cada uma com seu significado intrínseco.

Tabela 1. Detalhamento do modelo teórico (abstrato) segundo OMT-G.

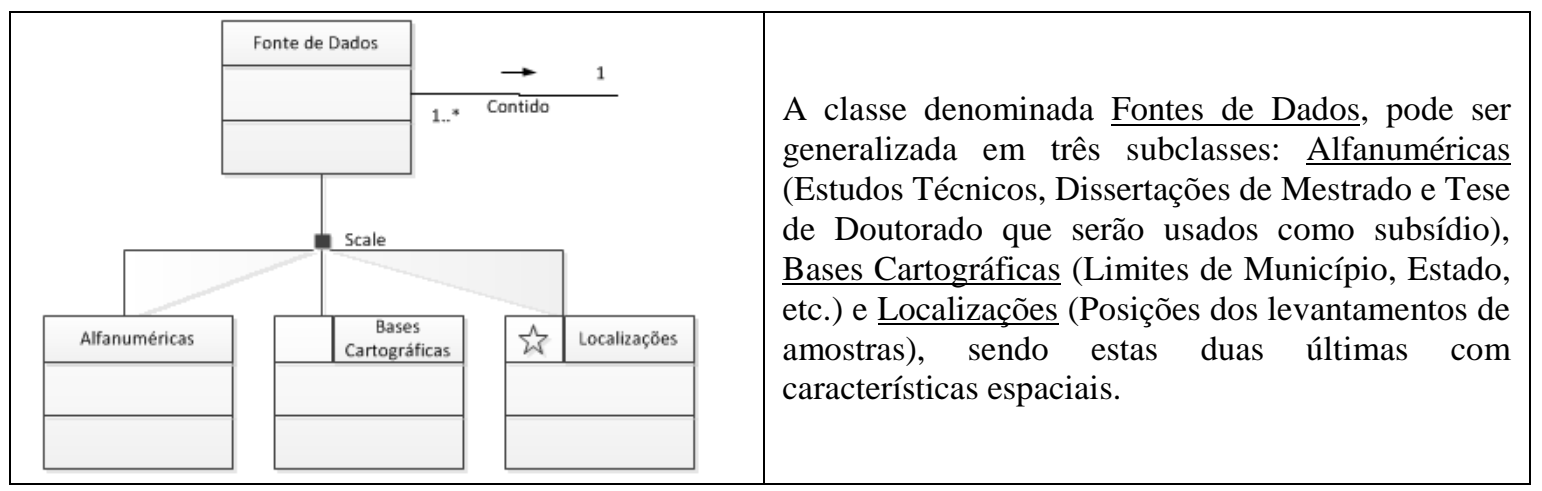


CARVAlHO, G. N.; GIANNOTTI, M. A.; SARTOR, S.; QUINTANILHA, J. A. Modelagem para integração de dados sobre macrobentos em Infraestrutura de Dados Espaciais. Ambi-Agua, Taubaté, v. 7, n. 2, p. 195-213, 2012. (http://dx.doi.org/10.4136/ambi-agua.774)

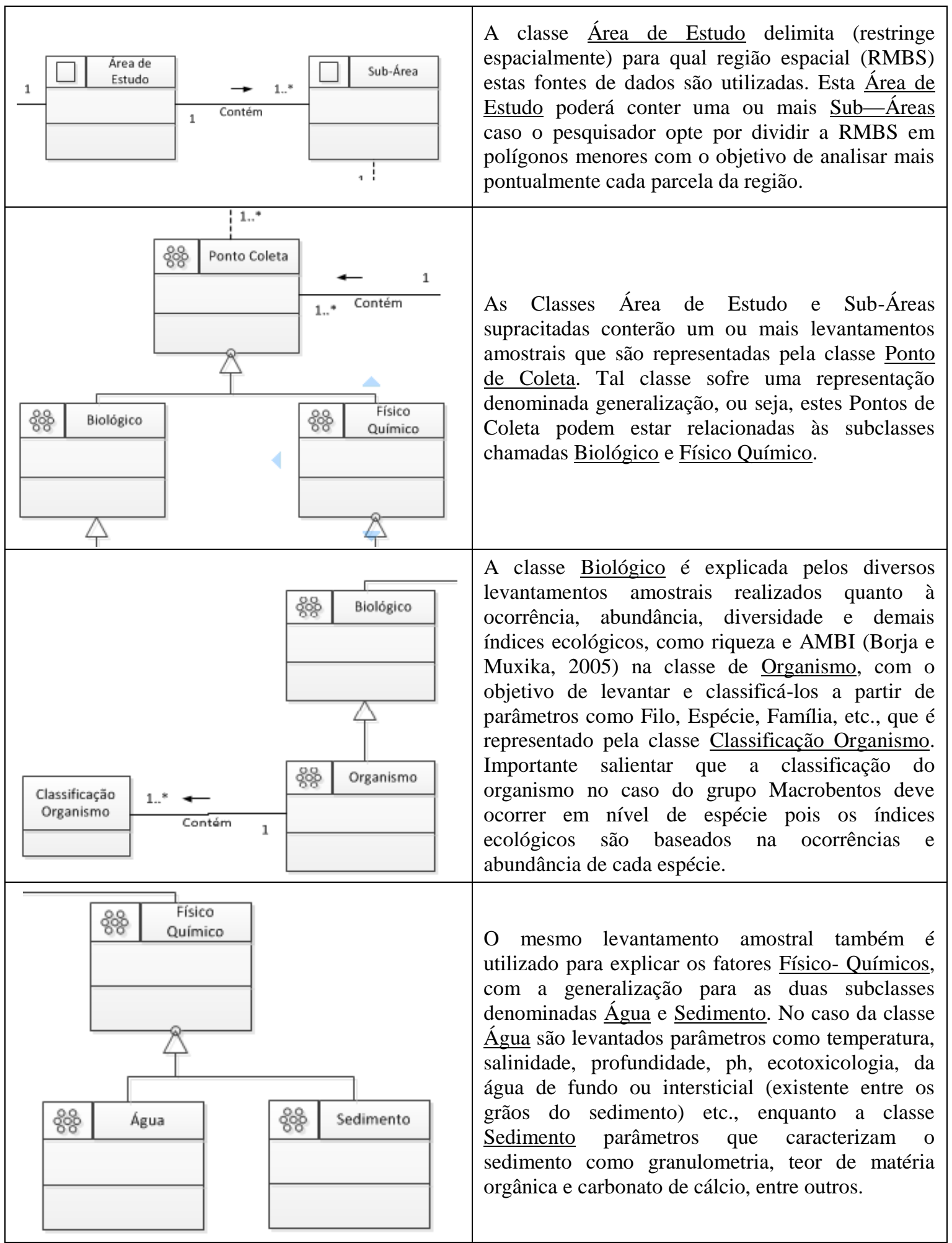




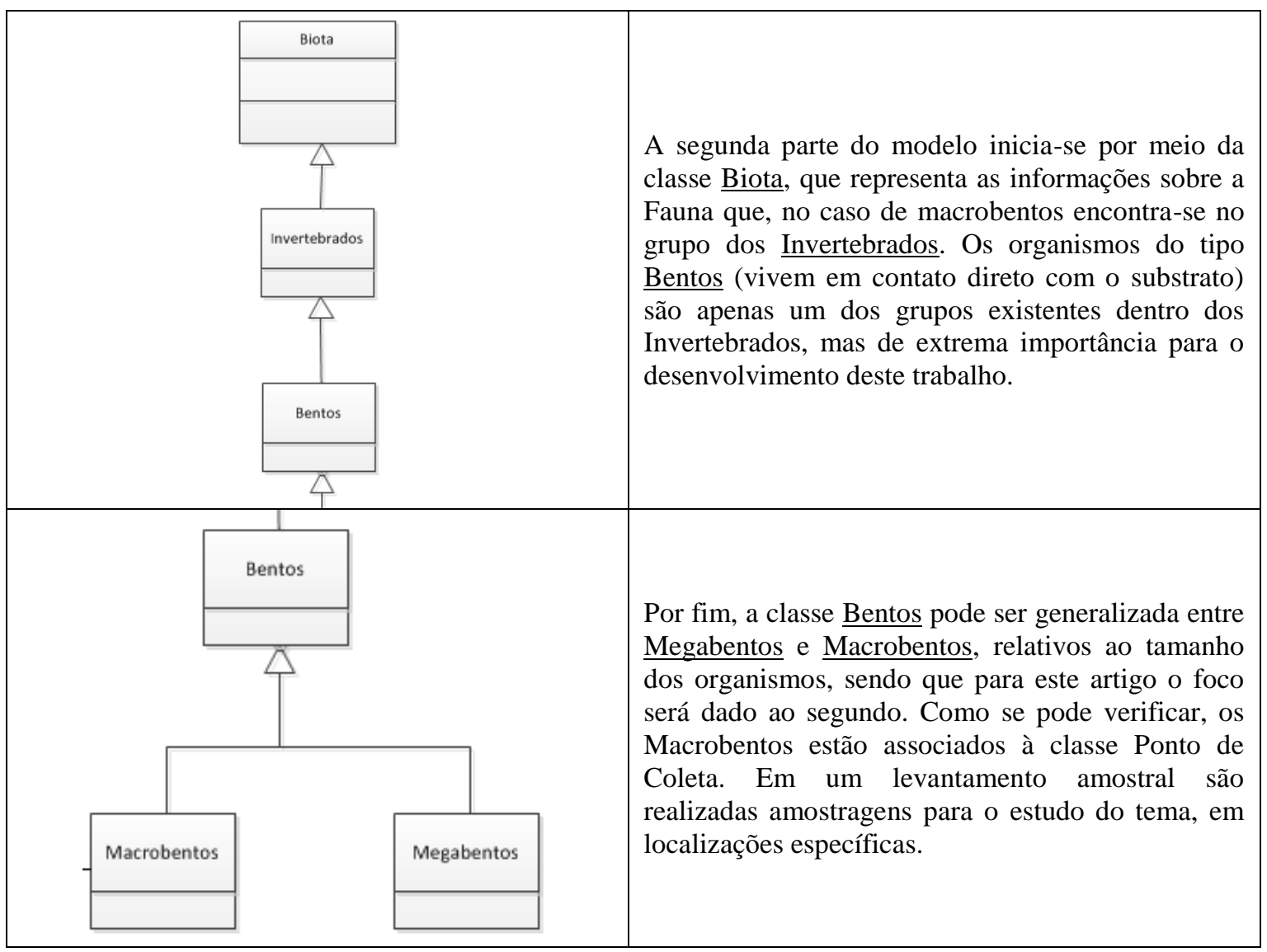

Com o modelo abstrato do banco de dados definido, este poderá servir como referência para a construção do modelo de implementação física e a posterior inserção das informações provenientes dos estudos supracitados. As classes bem definidas auxiliam o desenvolvedor a organizar e estruturar melhor a organização das tabelas e suas relações, tanto espaciais como alfanuméricas.

O modelo de implementação física apresentado na Figura 5, exemplifica a utilização do modelo abstrato do banco de dados baseado nas necessidades do projeto Atlas, como por exemplo determinar a quantidade de organismos existentes em uma área específica. Vale salientar que tal modelo pode também ser adaptado conforme existirem novas demandas.

Nesta primeira parte, representado pela (Figura 5), é explicitada apenas a relação entre a Área de Estudo e suas possíveis subáreas. Para a delimitação das áreas (zonas ecológicas) deverá ser levado em consideração os índices ecológicos indicados pelos Macrobentos. Os demais parâmetros como a contribuição dos recursos hídricos, da salinidade e hidrodinamismo (especialmente regime de marés), subsidiam o entendimento sobre as áreas impactadas ou conservadas.

A segunda parte do modelo de dados (Figura 6) transcreve a classe Biota na visão do tema Macrobentos. Uma característica específica para este tema condiz com o fato de que os estudos realizados nem sempre possuem as mesmas informações levantadas ou padronizadas. O pesquisador realiza o levantamento que utiliza um valor de medida de volume que não está padronizado e pode implicar em diferenças nos dados obtidos; isto novamente, porque cada estudo é realizado com enfoques diferentes e sem a preocupação no compartilhamento de dados. 


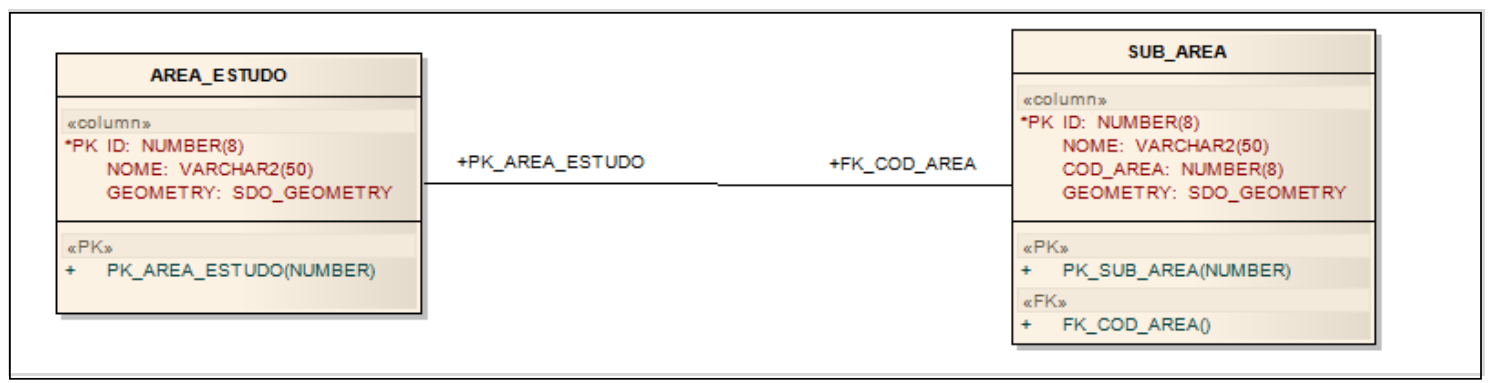

Figura 5. Parte 1 do Modelo físico de dados.

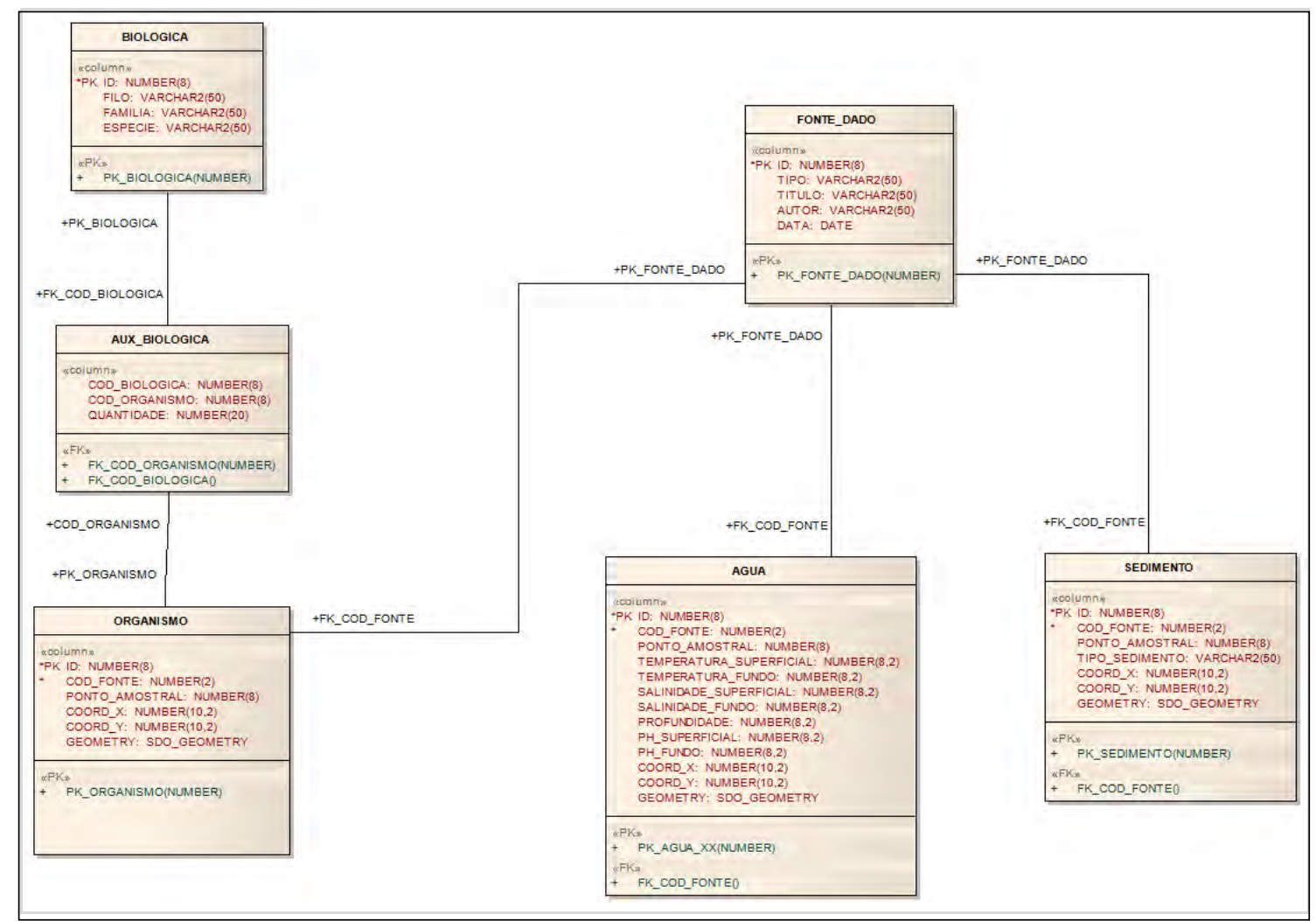

Figura 6. Parte 2 do modelo físico de dados.

\section{CONCLUSÃO}

Neste trabalho foi proposto um modelo conceitual sobre Macrobentos, idealizado para ser utilizado numa IDE. Além do modelo em si, foram indicadas as etapas necessárias para a sistematização e modelagem de dados ambientais, a exemplo do objeto estudado. Constatouse que a modelagem de dados ambientais, além de ser uma alternativa para a representação do conhecimento de uma forma estruturada, exerce um papel facilitador na integração de dados provenientes de diversas fontes, para que possam ser compartilhados de maneira padronizada em Atlas Web. A sequência metodológica da construção de um modelo de dados espaciais é descrita, levando em consideração a integração de conhecimento de especialistas sobre os temas abordados.

Especificamente para a área ambiental e o tema Macrobentos, quando da aquisição e coleta dos dados, foi possível concluir que grande parte dos dados existentes para a Região Metropolitana da Baixada Santista não se encontram na forma computacional. Estão dispersos em vários documentos, depositados em diferentes instituições. Não há a preocupação com a 
questão espacial e com a padronização no processo de constituição da informação, dificultando o acesso aos dados por parte dos pesquisadores, dos tomadores de decisão, entre outros. Essa realidade é a mesma encontrada para as demais regiões do Brasil, o que implica em constante retrabalho quando há a necessidade de estudar uma região.

Somado a isso, notou-se também que, quando se trabalha com dados ambientais coletados em pesquisas de campo, diferentes metodologias de coleta são utilizadas. Este fato dificulta ainda mais a integração dos dados, que podem apresentar incompatibilidade metodológica inviabilizando sua comparação ou integração. Verificou-se que um modelo conceitual para integração de dados, serve também como um sinalizador da importância dessas questões metodológicas de coleta, e da necessidade em se registrar certas informações, sem as quais o processo de integração pode ser inviabilizado. Dados provenientes de amostras coletadas em determinado estudo podem ser incompatíveis com outros dados coletados para a mesma área por diferenças metodológicas. Essa constatação alerta não apenas para as questões de padronização, como também, para a importância o levantamento dos metadados (dados sobre os dados) ou a sua criação para os dados já existentes.

$\mathrm{O}$ artigo mostra que, apesar das condições supracitadas, é possível conceber-se um modelo de dados que abrange um largo espectro de diferentes fontes de informação e que o uso das técnicas OMT-G e de outros procedimentos computacionais tidos como padrões em modelagem de dados, podem ajudar na elaboração de produtos mais úteis aos tomadores de decisão e aos demais usuários de dados ambientais.

O trabalho tem também o propósito de fomentar a discussão sobre a necessidade de padronização no levantamento, organização e disponibilização de dados, sejam estes vinculado à área ambiental, social ou econômica, para uso em portais baseados em IDEs. Tal discussão deve ser aprofundada em futuros estudos, especialmente neste momento, quando estão sendo cada vez mais discutidas a disponibilização e integração de dados por meio de serviços, metodologia de levantamentos, etc., como salienta a própria Infraestrutura Nacional de Dados Espaciais (CONCAR, 2011).

A construção de um modelo de dados espacial, como o apresentado neste estudo poderá ser utilizado como referência para novas pesquisas com objetivos semelhantes.

\section{AGRADECIMENTOS}

Os autores agradecem à Fundação de Amparo à Pesquisa do Estado de São Paulo (FAPESP 06/51780-2) pelo apoio financeiro na realização desta pesquisa, ao Conselho Nacional de Desenvolvimento Científico e Tecnológico $(\mathrm{CNPq})$ pelo apoio aos pesquisadores bolsistas, à Companhia Docas do Estado de São Paulo (CODESP) pelo fornecimento de dados, à empresa Imagem Sensoriamento Remoto S/C Ltda pelo fornecimento de softwares e a Escola Politécnica da Universidade de São Paulo (EPUSP), em particular ao Laboratório de Geoprocessamento, pela disponibilização da infraestrutura e apoio logístico.

\section{REFERÊNCIAS}

AHN, I. Y.; KANG, Y. C.; CHOI, J. The influence of industrial effluents on intertidal benthic communities in Panweol, Kyeonggi Bay (Yellow Sea) on the west coast of Korea. Marine Pollution Bulletin, v. 30, n. 3, p. 200-206, 1995. http://dx.doi.org/10.1016 /0025-326X(94)00125-S.

AMARAL, A. C. Z.; MIGOTTO, A. E. Importância dos anelídeos poliquetas na alimentação da macrofauna demersal e epibentônica da região de Ubatuba. Brazilian Journal of oceanography, São Paulo, v. 29, n. 2, p. 31-35, 1980. 
AMARAL, A. C. Z.; MORGADO, E. H.; PARDO, E. V.; REIS, M. O. Estrutura da comunidade de poliquetos da zona entre marés em praias da Ilha de São Sebastião (SP). Publicação Especial do Instituto de Oceanografia, São Paulo, v. 11, p. 229-237, 1995.

ARAUJO, S. I.; SILVA, G. H.; MUEHE, D. Mapas de sensibilidade ambiental a derrames de óleo: ambientes costeiros, estuarinos e fluviais. 2. ed. Rio de Janeiro: CENPES/Petrobras, 2007. 134 p.

AUSTRALIAN MARINE SPATIAL INFORMATION SYSTEM - AMSIS. 2011. Disponível em: <http://www.ga.gov.au/imf-amsis2>. Acesso em: 07 set. 2011.

AUSTRALIAN OCEAN DATA CENTRE JOINT FACILITY - AODCJF. 2011. Disponível em: <http://www.aodc.gov.au/index.php?id=19>. Acesso em: 07 set. 2011.

BARTLETT, D.; SMITH, J. GIS for coastal management. Boca Raton: CRC Press, 2005. $315 \mathrm{p}$.

BILYARD, G. R. The value of benthic infauna in marine pollution monitoring studies. Marine Pollution Bulletin, v. 18, n. 11, p. 581-585, 1987.

BORGES, K. A. V.; DAVIS, C. A.; LAENDER, A. H. F. OMT-G: an object-oriented data model for geographic applications. Geoinformatica, v. 5, n. 3, p. 221-260, 2001. http://dx.doi.org/10.1023/A:1011482030093

BORJA, A. MUXIKA, I. Guidelines for the use of AMBI (AZTI's marine biotic index) in the assessment of the benthic ecological quality. Marine Pollution Bulletin, v. 50, n. 7, p. 787-789, 2005. http://dx.doi.org/10.1016/j.marpolbul.2005.04.040.

BROWN, A. C.; MCLACHLAN, A. Ecology of sandy shores. Amsterdam: Elsevier, 1990. $327 \mathrm{p}$.

CÂMARA, G.; LIMA JR., P. O. GeoBR: intercâmbio sintático e semântico de dados espaciais. Informática Pública, Belo Horizonte, v. 4, n. 2, p. 251-281, 2002.

CÂMARA, G.; DAVIS, C. A.; VINHAS, L.; QUEIROZ, G. R.; CASANOVA, M. Bancos de dados geográficos. Curitiba: MundoGeo, 2005.

CANADIAN GEOSPATIAL DATA INFRASTRUCTURE - CGDI. Geoconnections. 2011. Disponível em: <http://www.geoconnections.org/en/index.html>. Acesso em: 23 mar. 2011.

CHAN, T. O.; FEENEY, M.; RAJABIFARD, A.; WILLIAMSON, I. The dynamic nature of spatial data infrastructures: a method of descriptive classification. Geomatica, v. 55 , n. 1, p. 451-462, 2001.

CHOI, J. W.; KOH, C. H. A study on the polychaete community in Kwangyang Bay, southern coast of Korea. J. Ocean. Soc. Korea, v. 15, n. 2, p. 153-162, 1984.

COMPANHIA DOCAS DO ESTADO DE SÃO PAULO - CODESP. Relatório técnico do estudo de impacto ambiental do aprofundamento do canal e bacias de evolução do Porto Organizado de Santos. [S.1.]: Fundação Ricardo Franco, 2008. 
COMPANHIA DOCAS DO ESTADO DE SÃO PAULO - CODESP. Relatório sobre monitoramento das atividades de dragagem na área de disposição oceânica do material dragado pela CODESP e suas regiões adjacentes (Município de Santos/SP): 2005 até 2010. [S.1.: s.n.], 2010.

COMPANHIA DE TECNOLOGIA DE SANEAMENTO BÁSICO - CETESB. Sistema estuarino de Santos e São Vicente. São Paulo, 2001.

COMPANHIA DE TECNOLOGIA DE SANEAMENTO BÁSICO - CETESB. Relatório de qualidade das águas interiores do Estado de São Paulo: balneabilidade das praias. São Paulo, 2004.

COMPANHIA DE TECNOLOGIA DE SANEAMENTO BÁSICO - CETESB. Relatório de qualidade das águas litorâneas do estado de São Paulo: balneabilidade das praias. São Paulo, 2007.

COMPANHIA DE TECNOLOGIA DE SANEAMENTO BÁSICO - CETESB. Relatório de qualidade das águas litorâneas do estado de São Paulo. São Paulo, 2008.

COMPANHIA DE TECNOLOGIA DE SANEAMENTO BÁSICO - CETESB. Relatório de qualidade das águas litorâneas do estado de São Paulo. São Paulo: CETESB, 2009.

COMISSÃO NACIONAL DE CARTOGRAFIA - CONCAR. Plano de ação para implantação da infraestrutura cacional de dados espaciais. 2011. Disponível em: <www.concar.ibge.gov.br>. Acesso em: 23 mar. 2011.

CROMPVOETS, J.; BREGT, A.; RAJABIFARD, A.; WILLIAMSON, I. Assessing the worldwide developments of national spatial data clearinghouses. International Journal of Geographical Information Science, v. 18, n. 7, p. 665-689, 2004. http://dx.doi.org/ 10.1080/13658810410001702030.

DAVIS JR. C. A.; ALVES, L. L. Local spatial data infrastructures based on a service oriented architecture. In: BRAZILIAN SYMPOSIUM ON GEOINFORMATICS, 7., 20-23 nov. 2005, Campos do Jordão. Proceedings... São José dos Campos: INPE, 2005. p. 30-45.

EMPRESA BRASILEIRA DE TERMINAIS PORTUARIOS - EMBRAPORT. EIA-RIMA sobre a construção do terminal portuário da Embraport. Santos, 2003. Vol. III.

GEHARDI, D. F. M.; CABRAL, A. P.; KLEIN, A. H. F.; MUEHE, D. C. E. H.; NOERBERG, M. A.; TESSLER, M. G. et al. Mapping the sensitivy to oil spill of the Santos basin coastline, Southeast Brazil. Brazilian Journal of Aquatic Science and Technology, Santos, v. 12, n. 2, p. 11-31, 2008. Disponível em: <https://www6.univali.br/seer/index.php/bjast/article/viewFile/659/533>. Acesso em: 20 ag. 2011.

FERREIRA, J. A. Estudos das associações de anelídeos Polychaeta da Baía de Santos e plataforma Continental Adjacente (SP, Brasil) e suas interrelações com parâmetros físicos e geoquímicos estruturadores. 2008. 204f. Tese (Doutorado em Oceanografia Básica) - Instituto Oceanográfico, Universidade de São Paulo, São Paulo, 2008 .

GLOBAL SPATIAL DATA INFRASTRUCTURE ASSOCIATION - GSDI. The SDI Cookbook. Version 2.0, 2004. Disponível em: <http://www.gsdi.org/ gsdicookbookindex>. Acesso em: 20 jan. 2011. 
HEITOR, S. R. Composição e distribuição da macrofauna bentônica em áreas sob a influência da disposição oceânica de esgotos municipais da Baixada Santista e no Canal de São Sebastião. 2002. 245f. Tese (Doutorado em Oceanografia Básica) Instituto Oceanográfico, Universidade de São Paulo, São Paulo, 2002.

HJELMAGER, J.; MOELlERING, H.; COPPER, A.; DELGADO, T.; RAJABIFARD, A.; RAPANT, P. et al. An initial formal model for spatial data infrastructures. International Journal of Geographic Information Science, v. 22, p. 1295-1309, 2008 .

INTERNATIONAL COASTAL ATLAS NETWORK - ICAN. 2011. Disponível em: <http://ican.science.oregonstate.edu/home>. Acesso em: 18 ago. 2011.

KENNISH, M. J. Practical handbook of estuarine and marine pollution. Boca Raton: CRC Press, 1997. 524 p.

LISBOA FILHO, J.; IOCHPE, C. Um estudo sobre modelos conceituais de dados para projeto de bancos de dados geográficos. Informática Pública, Belo Horizonte, v. 2, p. 67-90, 1999.

LUNARDI, O. A.; ISSMAEL, L. S.; ALVES, P. D. V.; CARVALHO, L. H. M. Aquisição da geometria de dados geoespaciais para a infra-estrutura nacional de dados espaciais (INDE). In: SIMPÓSIO BRASILEIRO DE SENSORIAMENTO REMOTO, 14., 25-30 abril 2009, Natal. Anais... Belo Horizonte: SBSR, 2009. p. 1795-1802.

MARINE ENVIRONMENTAL DATA \& INFORMATION NETWORK - MEDIN. Marine geoportal. 2011. Disponível em: <http://www.oceannet.org>. Acesso em: 02 set. 2011.

MARINE IRISH DIGITAL ATLAS. Digital Atlas. 2011. Disponível em: <http://mida.ucc.ie/pages/about.htm>. Acesso em 15 de outubro de 2011.

MASSER, I.; RAJABIFARD, A.; WILLIAMSON, I. Spatially enabling governments through SDI implementation. International Journal of Geographical Information Science, v. 22, n. 1, p. 5-20, 2008.

MCLACHLAN, A. Physical factors in benthic ecology: effects of changing sand size on beach fauna. Marine Ecology Progress Series, v. 131, p. 205-217, 1996.

NATIONAL OCEANIC AND ATMOSPHERIC ADMINISTRATION - NOAA. Digital Coast. 2011. Disponível em: <http://www.csc.noaa.gov/digitalcoast/data>. Acesso em 10 de outubro de 2011.

NYBAKKEN, J. W. Marine biology: an ecological approach. 5. ed. São Francisco: Benjamin Cummings, 1995. $516 \mathrm{p}$.

OCEAN DATA AND INFORMATION NETWORK FOR AFRICA - ODINAFRICA. African marine atlas. 2011. Disponível em: 〈http://193.191.134.9/odinafrica3/data.html>. Acesso em: 12 jul. 2011.

OPEN GEOSPATIAL CONSORTIUM - OGC. Reference model. 2011. Disponível em: <http://www.opengeospatial.org/standards/orm>. Acesso em: 04 fev. 2011.

PEARSON, T. H.; ROSENBERG, R. Macrobenthic succession in relation to organic enrichment and pollution of the marine environment. Oceanography and Marine Biology: an Annual Review, v. 16, p. 229-311, 1978. 
POCKLINGTON, P.; WELLS, P. G. Polychaetes: key taxa for marine environmental quality monitoring. Marine Pollution Bulletin, v. 24, n.12, p. 593-598, 1992.

RAJABIFARD, A.; VAEZ, S. S.; WILLIAMSON, I. P. Building Seamless SDI to Facilitate Land and Marine Environments. In: INTERNATIONAL CONFERENCE FOR SPATIAL DATA INFRASTRUCTURE, 10., 25-29 feb. 2008, St. Augustine. Proceedings... St. Augustine: GSDI, 2008.

RAJABIFARD, A.; BINNS, A.; MASSER, I.; WILLIANSON, I. The role of the sub-national government and the private sector in future spatial data infrastructure. International Journal of Geographical Information Science, v. 20, n. 7, p. 727-741, 2006. http://dx.doi.org/10.1080/13658810500432224.

RIZZO, A. E.; AMARAL, A. C. Z. Temporal variation of annelids in the intertidal zone of beaches of the São Sebastião Channel, southern Brazil. Journal of the Marine Biological Association of the United Kingdom, v. 80, n. 6, p. 1007-1017, 2000.

RIZZO, A. E.; AMARAL, A. C. Z. Spatial distribution of annelids in the intertidal zone in São Sebastião Channel, Brazil. Scientia Marina, v. 65, n. 4, p. 323-331, 2001 a.

RIZZO, A. E.; AMARAL, A. C. Z. Environmental variables and intertidal beach annelids of São Sebastião Channel (State of São Paulo, Brazil). Revista de Biologia Tropical, Costa Rica, v. 49, n. 3, p. 849-857, 2001 b.

RIVERO, M. S.; ELÍAS, R.; VALLARINO, E. A. First survey of macrofauna in the Mar del Plata Harbor (Argentina), and the use of polychaetes as pollution indicators. Revista de Biolígia Marina y Oceanografía, Valparaiso, v. 40, n. 2, p. 101-108, 2005.

RODRÍGUEZ, J. J.; WINDEVOXHEL, N. J. Análisis regional de la situación de la zona marina costera centroamericana. Washington, D.C.: BID, 1998. Env. 121. Disponível em: <http://www.infoiarna.org.gt/media/file/areas/marino/documentos/interna/(3)\%20 An\%C3\%A1lisis\%20de\%20la\%20situaci\%C3\%B3n\%20marina\%20costera.pdf $>$. Acesso em: 25 jun. 2012.

SARTOR, S. M.; DEGASPARI, F. A. A balneabilidade das praias de Santos: discussão dos critérios oficiais de avaliação. In: CONGRESSO INTERAMERICANO DE ENGENHARIA SANITÁRIA E AMBIENTAL, 27., 3-8 dez. 2000, Porto alegre. Anais... Porto Alegre: ABES, 2000.

SARTOR, S. M.; HANS, M. F. P.; PALMER, L.; SARTOR, L. M.; LEAO, A. L. Coastal marine mapping as an ecosystem based management: the case study of the Baixada Santista Region - São Paulo, Brazil. Journal of Coastal Research, Gold Coast, v. 50, p. 1178-1182, 2007.

SARTOR, S. M.; PALM, A. S.; PALM, L.; SHINOHARA, E. J.; QUINTANILHA, J. A. Tools for coastal marine ecosystem-based management and geographically referred data integration: the Santos Region case study. In: GLOBAL SPATIAL DATA INFRASCTUCTURE WORLD CONFERENCE, jun. 2009, Rotterdam. Proceedings... Rotterdam: GSDI Association, 2009.

SMALL, C.; COHEN, J. E. Continental physiography, climate, and the global distribution of human population. Current Anthropology, Palisales, v. 45, n. 2, 2004. Disponível em: <http://lab.rockefeller.edu/cohenje/PDFs/312SmallCohenCA2004ALLFIGURES.pdf>. Acesso em: 12 jun. 2011. 
SNELGROVE, P. V. R.; BUTMAN, C. A. Animal-sediment relationships revisited: cause versus effect. Oceanography and Marine Biology, v. 32, p. 111-177, 1994.

STRAIN, L. An SDI model to include the marine environment. 2008. 134f. Dissertação (Mestrado em Engenharia de Geomática) - Universidade de Melbourne, Melbourne, 2008.

STRAIN, L.; RAJABIFARD, A.; WILLIAMSON, I. P. Spatial data infrastructure to facilitate coastal zone management. In: COASTAL ZONE ASIA PACIFIC CONFERENCE. Proceedings... Brisbane: CZAP, 2004.

TOMMASI, L. R. Consideração ecológica sobre o sistema estuarino de Santos, Estado de São Paulo. 1979. 489f. Tese (Livre Docência) - Instituto Oceanográfico, Universidade de São Paulo, São Paulo, 1979.

UNITED NATIONS ATLAS OF OCEANS. Universal atlas of the oceans. 2011. Apresenta textos, mapas, bancos de dados, etc. referentes ao tema costeiro e oceânico. Disponível em: 〈http://www.oceansatlas.org>. Acesso em: 27 jan. 2011.

UNITED STATES COMMISSION ON OCEAN POLICY. Developing a national ocean policy: Mid-term report of the U. S. Commission on Ocean Policy. 2002. Disponível em: <http://www.oceancommission.gov/documents/midterm_report/midterm_report. html>. Acesso em: 18 ago. 2011.

VACCARI, L.; SHVAIKO P.; MARCHESE, M. An emergent semantics approach to semantic integration of geo-services and geo-metadata in Spatial Data Infrastructures. International Journal of Spatial Data Infrastructures Research, v. 3, 2008.

WARWICK, R. M. A new method for detecting pollution effects on marine macrobenthic communities. Marine Biology, v. 92, p. 557-562, 1986. http://dx.doi.org/10.1007 /BF00392515. 


ISSN = 1980-993X - doi:10.4136/1980-993X
www.ambi-agua.net
E-mail: ambi-agua@agro.unitau.br
Tel.: (12) 3625-4212

\title{
Ictiofauna de igarapés de pequenas bacias de drenagem em área agrícola do Nordeste Paraense, Amazônia Oriental
}

\author{
(http://dx.doi.org/10.4136/ambi-agua.739)
}

\author{
Jean Michel Corrêa ${ }^{1}$; Pedro Gerhard ${ }^{2}$; Ricardo de Oliveira Figueiredo ${ }^{3}$ \\ ${ }^{1}$ Instituto de Geociências, Universidade Federal do Pará, Belém, \\ e-mail: jeanoceano@yahoo.com.br, \\ ${ }^{2}$ Embrapa Amazônia Oriental, Belém, e-mail: pgerhard@cpatu.embrapa.br, \\ ${ }^{3}$ Embrapa Meio Ambiente, Jaguariúna, e-mail: ricfig@cnpma.embrapa.br
}

\section{RESUMO}

Comunidades de peixes podem se distribuir no espaço e no tempo de maneira organizada, seguindo um padrão que pode ser percebido pela associação ou agrupamento das espécies e pela relação de algumas espécies com determinados habitats. O número reduzido de estudos e o pouco conhecimento da fauna aquática na Amazônia resultam em subestimativas da diversidade da ictiofauna de igarapés (riachos amazônicos). No presente estudo, em três microbacias predominantemente ocupadas por agricultura familiar, foram coletados 2.117 peixes, distribuídos em sete ordens, 13 famílias, 27 gêneros e 43 espécies. A espécie mais abundante em todas as amostras coletadas foi Hyphessobrycon heterorhabdus, com 337 indivíduos, seguido por Bryconops melanurus, com 326 indivíduos. A riqueza de espécies foi maior num trecho do Igarapé Pachibá (IGPA-B), com 21 espécies. O Índice de Dominância de Simpson mostrou o valor mais alto no trecho B do Igarapé Cumaru, com valor 0,43, enquanto o Índice de Diversidade de Shannon revelou que o IGPA-B possuiu a maior diversidade, com valor 2,39. Iguanodectes rachovii foi a espécie amostrada com mais constância, e ocorreu em 50\% das amostras. Os resultados demonstraram que trechos médios dos igarapés apresentam maior diversidade de espécies, respondendo ao tamanho do habitat. Neste estudo foi possível observar que microbacias agrícolas dominadas por agricultura de pequeno porte pode suportar uma diversidade de peixes de igarapés razoável.

Palavras-chave: peixes de riachos, diversidade, agricultura familiar.

\section{Fish fauna of streams of small watersheds in agriculture area of northeastern Pará, Eastern Amazon}

\begin{abstract}
Stream fish communities can show spatial and temporal patterns, which can be revealed by species association or species groups as well as by species preference to certain habitats. The reduced number of studies and the scarce knowledge on the aquatic fauna in the Amazon results on an under-estimative upon stream fish fauna diversity. In this study, a survey at three small Amazonian catchments located in family agriculture areas, a total of 2,117 individuals were collected, belonging to seven orders, 13 families, 27 genera and 43 species. The most abundant species in all samples was Hyphessobrycon heterorhabdus, totaling 337 individuals, followed by Bryconops melanurus, with 326 individuals. The species richness was highest in a Pachibá stream reach, with 21 species. Simpson's diversity index in a Cumaru stream reach showed the highest species dominance with a value of 0.43 , while Shannon's diversity index showed that the Pachibá stream lowest reach, had the greatest diversity with a value of 2.39.
\end{abstract}


Iguanodectes rachovii was the most constant species, occurring in 50\% of samples. Therefore, as a response to habitat size, the intermediate stream reaches presented the highest species diversity. Our study showed that agricultural catchments dominated by smallholder farmers can bear a reasonable stream fish diversity.

Keywords: stream fishes, diversity, family agriculture.

\section{INTRODUÇÃO}

A conservação da biodiversidade em ecossistemas aquáticos é um dos desafios mais importantes e difíceis a serem enfrentados no mundo atual (Chernoff et al., 1996). Esse desafio não pode ser superado sem conhecimento detalhado da diversidade taxonômica e padrões de distribuição das espécies. Comunidades tropicais de animais são caracteristicamente muito diversificadas, com grande número de espécies e interações complexas, quando comparadas com comunidades localizadas em zonas temperadas. A fauna de peixes segue esta regra ecológica geral, tanto dentro de famílias quanto de ambientes (Lowe-McConnell, 1999). A fauna de peixes de água doce localizada na região Neotropical é mais diversificada e rica do planeta, com mais de 4.475 espécies descritas (Reis et al., 2003).

Os igarapés, denominação regional dada aos riachos amazônicos, são cursos d'água de pequeno porte, caracterizados pelo leito delimitado, correnteza relativamente acentuada e baixa temperatura da água. Sua porção média e superior é quase totalmente encobertas pelo dossel da floresta ripária, e seu leito tipicamente contém acúmulo de troncos e galhos caídos. Uma característica física dos igarapés é a subida abrupta do nível da água durante a ocorrência de fortes chuvas em suas bacias de drenagem. Nesses eventos meteorológicos extremos o nível da água alcança ou ultrapassa os limites das margens, disponibilizando aos peixes novos recursos alimentares. Em decorrência da redução da luz incidente produzido pela sombra das espécies florestais e a correnteza relativamente acentuada, os igarapés são sistemas aquáticos com baixa produtividade biológica e bastante dependentes da floresta. Esta atua como fonte de recursos alimentares para o sistema lótico, os quais são a base da cadeia trófica nestes ecossistemas (Santos e Ferreira, 1999).

As atividades agrícolas e pecuárias na bacia hidrográfica de um pequeno igarapé podem determinar uma série de alterações no ambiente aquático. A movimentação do solo nas vertentes da bacia para preparo de cultivos, a adição de corretivos, fertilizantes e agroquímicos, a compactação do solo pelo gado e a retirada de vegetação nativa na zona ripária são alguns destes determinantes. Os possíveis efeitos diretos incluem: aporte elevado de sedimentos no canal, alterações no regime de vazão do igarapé, na qualidade química e física da água, na entrada de energia solar direta e na entrada de resíduos de substâncias complexas potencialmente tóxicas. Indiretamente, esses efeitos determinam impactos negativos sobre a estrutura física e química do habitat dos peixes. Estes e outros aspectos foram estudados em trabalhos recentes, como Buss et al. (2002), Allan (2004), Ferreira e Casatti (2006), Casatti (2010), De Paula et al. (2011), Machado et al. (2011).

O objetivo desse trabalho foi analisar a composição e diversidade da ictiofauna em três pequenos igarapés (Cumaru, São João e Pachibá) situados no nordeste paraense, cujas bacias são ocupadas predominantemente pela agricultura familiar.

\section{MATERIAL E MÉTODOS}

\section{1. Área de estudo}

As três microbacias estudadas localizam-se no nordeste do Estado do Pará. As microbacias dos igarapés Cumaru e São João pertencem a bacia do Rio Maracanã, enquanto a 
CORRÊA, J. M.; GERHARD, P.; FIGUEIREDO, R. O. Ictiofauna de igarapés de pequenas bacias de drenagem em área agrícola do Nordeste Paraense, Amazônia Oriental. Ambi-Agua, Taubaté, v. 7, n. 2, p. 214-230, 2012. (http://dx.doi.org/10.4136/ambi-agua.739)

microbacia do igarapé Pachibá, afluente do igarapé Timboteua, pertence a bacia do Rio Marapanim (Figura 1). A agricultura familiar é muito expressiva nessa região, cujas principais culturas são o milho, o caupi, e a mandioca, além de cultivos industriais, como o maracujá e a pimenta-do-reino (Sommer et al., 2004). Além desta cobertura vegetal agrícola, existem importantes áreas de florestas secundárias em diferentes estágios sucessionais, as quais ocupam também os setores marginais aos cursos de água, constituindo floresta ripária. No entanto, essas florestas ripárias vêm sendo desmatadas no processo de expansão das áreas de cultivo e para retirada de madeira para as pequenas propriedades rurais da região (Watrin et al., 2009).

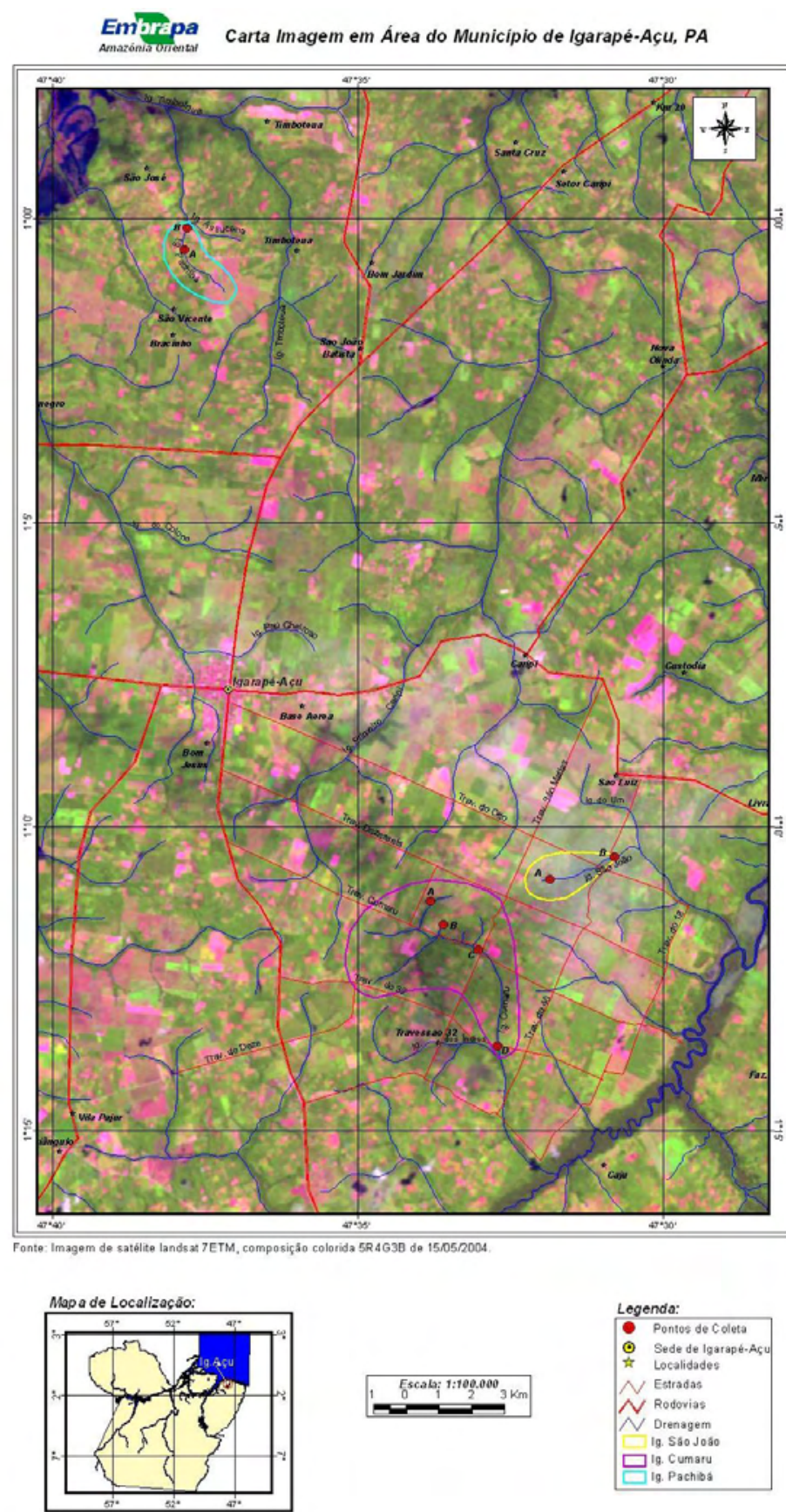

Figura 1. Localização das microbacias dos igarapés Cumaru, São João e Pachibá (A, B, C e D, representam estações de amostragem).

Fonte: Laboratório de Sensoriamento Remoto da EMBRAPA Amazônia Oriental. 
CORRÊA, J. M.; GERHARD, P.; FIGUEIREDO, R. O. Ictiofauna de igarapés de pequenas bacias de drenagem em área agrícola do Nordeste Paraense, Amazônia Oriental. Ambi-Agua, Taubaté, v. 7, n. 2, p. 214-230, 2012. (http://dx.doi.org/10.4136/ambi-agua.739)

Oito estações de amostragem foram definidas nas três microbacias estudadas pelo Projeto Agrobacias Amazônicas, desenvolvido pela Embrapa Amazônia Oriental, no qual uma série de outros estudos em temas como Biogeoquímica e Impactos Ambientais, por exemplo, foram abordados. Essas oito estações, localizadas em área de agricultura familiar, foram assim alocadas: quatro estações no igarapé Cumaru, sendo duas localizadas em áreas de nascentes e duas no trecho médio do canal principal; duas estações no igarapé São João, sendo uma em área de nascente e outra no trecho médio do canal principal; e duas estações localizadas no igarapé Pachibá, uma mais próxima à nascente e outra no trecho médio. A escolha de mais estações de amostragem na microbacia do Cumaru deve-se ao fato desta possuir uma área bem maior do que as demais microbacias avaliadas.

Gerhard (2007) realizou trabalho de classificação da paisagem das bacias aqui estudadas, utilizando imagens Landsat, dados do IBGE e vários programas computacionais em sensoriamento remoto, que proporcionaram inclusive as estimativas de áreas apresentadas na Tabela 1. Ressalta-se que os cursos d'água estudados são de primeira ordem (nascentes) a segunda e terceira ordens (trechos médios).

Tabela 1. Estações de amostragem, com localizações, microbacias, coordenadas geográficas e as áreas dos trechos amostrados.

\begin{tabular}{|c|c|c|c|c|}
\hline Estação & Microbacia & & Localização & Área (ha) \\
\hline IGCU-A & Cumaru & nascente & $01^{\circ} 11^{\prime} 25,0^{\prime \prime}$ S e $47^{\circ} 34^{\prime} 00,9^{\prime \prime} \mathrm{W}$ & 11,20 \\
\hline IGCU-B & Cumaru & nascente & $01^{\circ} 11^{\prime} 36,2^{\prime \prime}$ 'S e $47^{\circ} 33^{\prime} 39,8^{\prime \prime} \mathrm{W}$ & 8,62 \\
\hline IGCU-C & Cumaru & trecho médio & $01^{\circ} 12^{\prime} 00,8^{\prime \prime}$ S e $47^{\circ} 33^{\prime} 04,3^{\prime \prime} \mathrm{W}$ & 1180,28 \\
\hline IGCU-D & Cumaru & trecho médio & $01^{\circ} 13^{\prime} 31,0^{\prime \prime} \mathrm{S}$ e $47^{\circ} 32^{\prime} 46,3^{\prime \prime} \mathrm{W}$ & 1849,68 \\
\hline IGSJ-A & São João & nascente & $01^{\circ} 10^{\prime} 47,7^{\prime \prime}$ S e $47^{\circ} 32^{\prime} 35,5^{\prime \prime} \mathrm{W}$ & 181,73 \\
\hline IGSJ-B & São João & trecho médio & $01^{\circ} 10^{\prime} 30,0^{\prime \prime} \mathrm{S}$ e $47^{\circ} 30^{\prime} 56,1^{\prime \prime} \mathrm{W}$ & 570,51 \\
\hline IGPA-A & Pachibá & nascente & $01^{\circ} 00^{\prime} 24,2^{\prime \prime}$ S e $47^{\circ} 37^{\prime} 58,8^{\prime \prime} \mathrm{W}$ & 200,03 \\
\hline IGPA-B & Pachibá & trecho médio & $01^{\circ} 00^{\prime} 08,2^{\prime \prime}$ S e $47^{\circ} 37^{\prime} 53,3^{\prime \prime} \mathrm{W}$ & 322,60 \\
\hline
\end{tabular}

\subsection{Método de coleta}

As campanhas para estudo da ictiofauna foram realizadas em nove diferentes ocasiões com a finalidade de contemplar três condições diferentes, ajustando ao ciclo natural das chuvas e regimes hidrológicos da região Amazônica (Bastos e Pacheco, 2000; Pacheco e Bastos, 2007). Dessa maneira, foram realizadas: (A) três campanhas de campo realizadas no período de chuva, em maio e junho de 2006 e em março de 2007, (B) três amostragens no período de estiagem, em outubro e novembro de 2006 e em janeiro de 2007 e (C) três amostragens no período de transição entre os dois períodos citados, em julho, agosto e setembro de 2006. Os peixes foram coletados apenas no período diurno.

Em cada estação foi utilizado como apetrecho de pesca uma tarrafa com malha de $5 \mathrm{~mm}$, diâmetro de $3 \mathrm{~m}$ e uma rede de arrasto com comprimento de $6 \mathrm{~m}$, altura de $1,2 \mathrm{~m}$ e malha de $5 \mathrm{~mm}$. A captura foi feita por duas pessoas. Também foi utilizado puçá com malha de $2 \mathrm{~mm}$ para capturar peixes de menor porte. Para evitar a fuga dos cardumes durante a coleta, o trecho de coleta foi bloqueado por redes de espera com malha de $5 \mathrm{~mm}$ entre nós opostos, comprimento de $2 \mathrm{~m}$ e altura de $1,2 \mathrm{~m}$ em suas extremidades. Foram realizadas perturbações na água a fim de desalojar espécimes que ficam escondidas junto as margens. Foram utilizados covos feitos de garrafas de "pet" de dois litros de volume, que eram presos em pequenas estacas na margem do igarapé. Dentro dos covos foram colocadas pequenas 
quantidades de ração para facilitar a atração e captura dos peixes. A duração de cada coleta em cada ponto foi de uma hora, somando-se os apetrechos de pesca. Os indivíduos capturados foram colocados em sacos plásticos, etiquetados e acondicionados em caixas de isopor com gelo. No laboratório, o material resfriado foi colocado em frascos etiquetados para identificação, e conservados "in natura" em um freezer.

No momento da identificação das espécies, foram empregadas chaves de identificação dicotômicas pertinentes aos grandes grupos, como por exemplo, chaves de identificação para gênero e espécie contida em Ferreira et al. (1998), catálogos de espécies de importância comercial como o de Silvano et al. (2001), Santos et al. (2004) e na base de dados Fishbase (Froese e Pauly, 2007).

\subsection{Análise de dados}

Para comparar as assembléias de peixes em termos de atributos ecológicos (Krebs, 1999), utilizou-se o índice de constância (C) de espécies, usando a seguinte equação:

$$
C=\frac{c_{i}}{c}
$$

em que :

$c_{i}$ é o número de coletas contendo a espécie $i$ e $c$ é o número total de coletas efetuadas.

Uma espécie é considerada constante quando $C>50 \%$ das capturas. Se $50 \% \geq C \geq 25 \%$, é considerada acessória e acidental quando $\mathrm{C}<25 \%$.

A fim de verificar a dominância de espécies nas estações de amostragem, o índice de dominância $(D)$ para cada estação de amostragem foi calculado, utilizando-se a equação de Simpson:

$$
D=\Sigma\left(p_{i}\right)^{2}
$$

em que :

$p_{i}$ é a proporção de indivíduos da espécie $i$ em relação ao número total de indivíduos da amostra. Este índice atribui um peso maior às espécies abundantes.

O índice de diversidade de Shannon $\left(H^{\prime}\right)$ está relacionado com a riqueza de espécies, atribuindo um peso maior às espécies raras. Esse índice foi calculado para cada estação de amostragem usando a equação de Shannon:

$$
H^{\prime}=-\sum\left(p_{i}\right) x \ln \left(p_{i}\right)
$$

A eqüitabilidade de Shannon $(E q)$ revela uma uniformidade na distribuição das espécies, ou seja, se os indivíduos das espécies da amostra distribuem-se em proporções mais ou menos similares. Este índice foi calculado conforme a equação:

$$
E q=\frac{H^{\prime}}{H_{\max }^{\prime}}
$$

em que:

H'é o índice de diversidade de Shannon e H'max é a diversidade máxima de Shannon, calculada por:

$$
H^{\prime} \max =\ln S
$$

em que:

$S$ é o número de espécies da amostra. 
A fim de compreender a similaridade entre as comunidades de peixes amostradas nas oito estações, foi calculada a similaridade percentual (ou medida de Renkonen) (Krebs, 1999). Os valores resultantes entre os pares de amostras das estações foram dispostos em uma matriz de dissimilaridade, calculada como a recíproca da similaridade. Esta matriz de dissimilaridades foi submetida a uma análise de agrupamento, utilizando como método de ligação o algoritmo UPGMA (Unweighted Pair Group Method of Arithmetic Means).

$\mathrm{O}$ número de espécies que são encontradas durante um programa de amostragem depende, entre outros fatores, do tamanho da amostra. A fim de verificar se o esforço amostral empregado está próximo a um número máximo de espécies, uma curva de acumulação de espécies ou do coletor foi plotada para cada estação de amostragem, considerando os nove meses de coletas.

A relação entre as variáveis ecológicas e as variáveis relacionadas ao uso da terra foram submetidos a uma análise de regressão linear simples. É importante ressaltar que nem todas as variáveis ecológicas foram utilizadas e que foi preciso fazer uma matriz de correlação de Pearson para selecionar as variáveis a serem utilizadas. As análises estatísticas foram feitas utilizando-se o aplicativo STATISTICA 5.0 ${ }^{\mathrm{TM}}$.

\title{
3. RESULTADOS E DISCUSSÃO
}

\subsection{Composição ictiofaunística}

O número total de indivíduos coletados neste trabalho foi de 2.117. Ao todo foram identificados 43 táxons, pertencentes a 27 gêneros, 13 famílias e sete ordens. A lista taxonômica para as espécies do local de estudo foi elaborada com base na classificação sistemática proposta em Buckup e Menezes (2003), como segue:

\author{
Classe ACTINOPTERYGII \\ Ordem CHARACIFORMES \\ Família ANOSTOMIDAE \\ Leporinus sp. \\ Família CHARACIDAE \\ Astyanax bimaculatus (Linnaeus, 1758) \\ Astyanax sp. 1 \\ Astyanax sp. 2 \\ Astyanax sp. 3 \\ Astyanax sp. 4 \\ Bryconops melanurus (Bloch, 1795) \\ Bryconops sp. 1 \\ Bryconops sp. 2 \\ Hemigrammus sp. 1 \\ Hemigrammus sp. 2 \\ Hyphessobrycon cf. bentosi Durbin, 1908 \\ Hyphessobrycon heterorhabdus (Ulrey, 1894) \\ Hyphessobrycon sp. \\ Iguanodectes rachovii Regan, 1912 \\ Metynnis sp. \\ Moenkhausia chrysargyrea (Günther, 1864) \\ Moenkhausia collettii (Steindachner, 1882) \\ Poptella sp.
}


CORRÊA, J. M.; GERHARD, P.; FIGUEIREDO, R. O. Ictiofauna de igarapés de pequenas bacias de drenagem em área agrícola do Nordeste Paraense, Amazônia Oriental. Ambi-Agua, Taubaté, v. 7, n. 2, p. 214-230, 2012. (http://dx.doi.org/10.4136/ambi-agua.739)

Família CURIMATIDAE

Curimatopsis crypticus Vari, 1982

Curimatopsis sp.

Família ERYTHRINIDAE

Hoplias malabaricus (Bloch, 1794)

Família LEBIASINIDAE

Copella cf. arnoldi (Regan, 1912)

Copella cf. eigenmanni (Regan, 1912)

Nannostomus beckfordi Günther, 1872

Nannostomus eques Steindachner, 1876

Nannostomus trifasciatus Steindachner, 1876

Nannostomus sp.

Pyrrhulina cf. laeta (Cope, 1872)

Pyrrhulina sp.

Ordem GYMNOTIFORMES

Família APTERONOTIDAE

Apteronotus sp.

Ordem SILURIFORMES

Família HEPTAPTERIDAE

Mastiglanis asopos Bockmann, 1994

Família CALLICHTHYIDAE

Corydoras sp.

Família LORICARIIDAE

Farlowella sp.

Ordem BELONIFORMES

Família BELONIDAE

Potamorrhaphis guianensis (Jardine, 1843)

Ordem CYPRINODONTIFORMES

Família RIVULIDAE

Rivulus sp.

Ordem SYNBRANCHIFORMES

Família SYNBRANCHIDAE

Synbranchus marmoratus Bloch, 1795

Ordem PERCIFORMES

Família CICHLIDAE

Acaronia nassa (Heckel, 1840)

Aequidens sp.

Apistogramma caetei Kullander, 1980

Crenicara punctulatum (Günther, 1863)

Crenicichla sp.

Satanoperca jurupari (Heckel, 1840)

A ordem Characiformes foi a responsável pela maior parte dos exemplares capturados, com 1.920 indivíduos. Essa ordem apresentou a maior quantidade de espécies coletadas, 30 no total, sendo distribuídas em cinco famílias. A segunda ordem com maior representatividade foi Perciformes, que apresentou 121 exemplares com seis espécies, sendo todos da família Cichlidae, perfazendo um total de 5,72\% do total capturado (Tabela 2). 
CORRÊA, J. M.; GERHARD, P.; FIGUEIREDO, R. O. Ictiofauna de igarapés de pequenas bacias de drenagem em área agrícola do Nordeste Paraense, Amazônia Oriental. Ambi-Agua, Taubaté, v. 7, n. 2, p. 214-230, 2012. (http://dx.doi.org/10.4136/ambi-agua.739)

Tabela 2. Ordem, número de indivíduos $(\mathrm{N})$ e contribuição de cada ordem $(\mathrm{N} \%)$.

\begin{tabular}{l|rc}
\hline \multicolumn{1}{c|}{ Ordem } & $\mathbf{N}$ & $\mathbf{N}(\boldsymbol{\%})$ \\
\hline Characiformes & 1920 & 90,69 \\
Perciformes & 121 & 5,72 \\
Siluriformes & 49 & 2,31 \\
Beloniformes & 12 & 0,57 \\
Cyprinodontiformes & 12 & 0,57 \\
Gymnotiformes & 2 & 0,09 \\
Synbranchiformes & 1 & 0,05 \\
\hline Total & $\mathbf{2 1 1 7}$ & $\mathbf{1 0 0 , 0 0}$ \\
\hline
\end{tabular}

As espécies de peixes que foram capturadas não seguem o padrão Neotropical de distribuição de espécies em ordens, com maior predomínio de peixes Characiformes, seguido de Siluriformes, Gymnotiformes e Perciformes (Lowe-McConnell, 1999). Verificou-se que a ordem Characiformes foi bem capturada, seguida pela ordem Perciformes. Porém as ordens Siluriformes e Gymnotiformes foram pouco representadas. É possível que elas tenham sido subamostradas devido, provavelmente, à intensidade com que cada estação foi amostrada, à quantidade de apetrechos de pesca e sua seletividade e horário das amostragens. Por exemplo, o fato das coletas terem sido realizadas somente no período diurno contribui para que os Siluriformes fossem pouco representados.

Verificou-se que a ordem Characiformes foi predominante, sendo 30 espécies, num total de 1920 indivíduos $(90,69 \%$ da amostra) pertencentes a cinco famílias: Anostomidae, Characidae, Curimatidae, Erythrinidae e Lebiasinidae. Barbosa et al. (2003) realizando um estudo em um igarapé de terra firme situado na Amazônia Central, verificaram a presença de 10 espécies, distribuídos em 10 gêneros, sete famílias e quatro ordens. Os mesmos constataram que Characiformes foi a ordem predominante, com quatro espécies pertencentes a duas famílias.

\subsection{Constância de espécies}

Levando em consideração todas as 72 amostras realizadas, a espécie Iguanodectes rachovii ocorreu em 50\% das amostras, seguido da espécie Hyphessobrycon sp. com 45,8\% das amostras. A terceira maior ocorrência foi da espécie Pyrrhulina cf. laeta, em 40,3\% das amostras, seguido de Hyphessobrycon heterorhabdus e Bryconops melanurus, com 33,3\% das ocorrências. Oito espécies ocorreram em apenas uma das coletas efetuadas, contribuindo com $1,4 \%$ cada (Figura 2).

No presente estudo, das oito estações de amostragem, seis são ambientes característicos de poços, onde foi observada menor constância das espécies. É importante ressaltar que, embora não haja bibliografia de peixes amazônicos para comparar, a distribuição e constância de captura em diferentes habitats pode estar relacionadas com características hidrodinâmicas (vazão e corrente), aparato e horário de captura, características ambientais (vegetação aquática, disponibilidade de alimento, etc. 


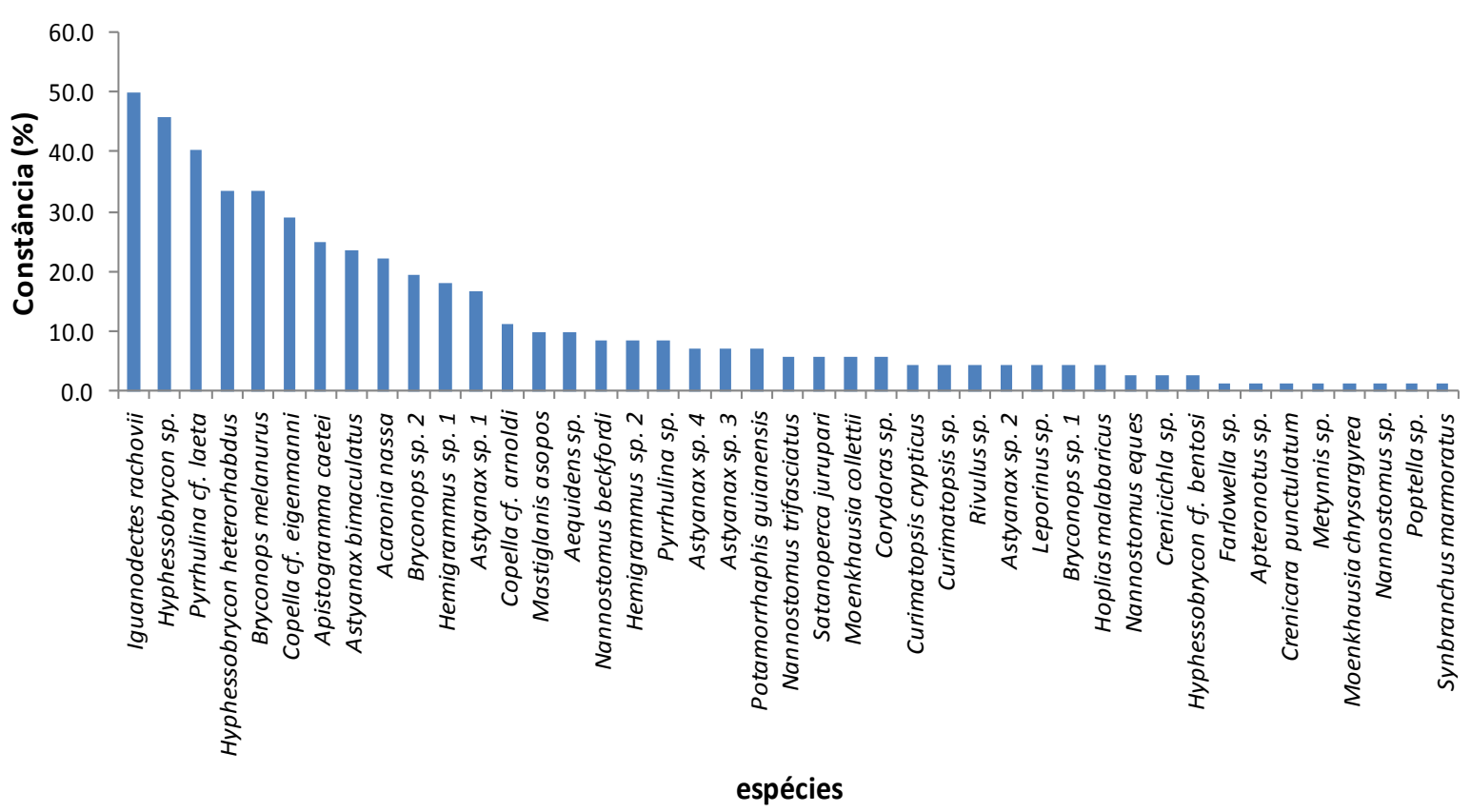

Figura 2. Constância das espécies em todas as oito estações de amostragem nos igarapés Cumaru, São João e Pachibá.

\subsection{Riqueza de espécies}

O Igarapé Pachibá, na estação de amostragem IGPA-B, apresentou a maior riqueza, com 21 espécies, sendo cinco espécies capturadas apenas nesse local: Curimatopsis crypticus, Curimatopsis sp., Nannostomus eques, Nannostomus sp. e Apteronotus sp. O Igarapé Cumaru, na estação IGCU-C apresentou 20, sendo Moenkhausia chrysargyrea apenas encontrada nesse ponto. O Igarapé Cumaru, na estação IGCU-D, apresentou 19 espécies e três capturadas neste lugar: Crenicara punctulatum, Farlowella sp. e Poptella sp. No Igarapé São João, na estação IGSJ-B, foram capturadas 18 espécies, sendo duas encontradas nesse ponto: Metynnis sp. e Rivulus sp. Os outros pontos de coleta que contribuíram com pouca riqueza de espécies foram: São João (IGSJ-A), com 13 espécies; Pachibá (IGPA-A), com 10 espécies, sendo Synbranchus marmoratus encontrado apenas nesse ponto; Cumaru (IGCU-A) com nove espécies. O Cumaru, no ponto IGCU-B, apresentou a menor riqueza, com apenas oito espécies, sendo Hoplias malabaricus encontrado somente nesse local de amostragem (Figura 3).

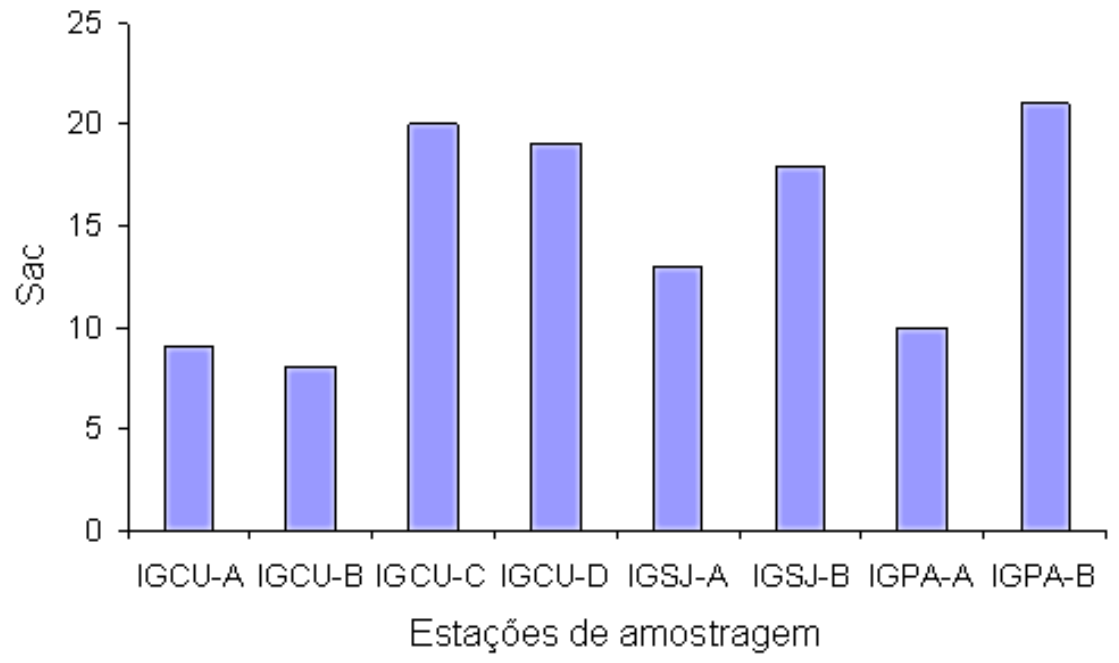

Figura 3. Número de espécies acumuladas $\left(S_{a c}\right)$ registradas em cada estação de amostragem. 


\subsection{Abundância das espécies}

Considerando todas as amostragens, a espécie Hyphessobrycon heterorhabdus foi a mais abundante, com 337 indivíduos, seguido da espécie Bryconops melanurus, com 326 espécimes, Pyrrhulina cf. laeta com 283 indivíduos e Iguanodectes rachovii, com 241 espécimes. Essas espécies corresponderam a $56 \%$ do total de indivíduos capturados. Seis espécies foram registradas com apenas um indivíduo: Crenicara punctulatum, Metynnis sp., Moenkhausia chrysargyrea, Nannostomus sp., Poptella sp. e Synbranchus marmoratus (Figura 4).

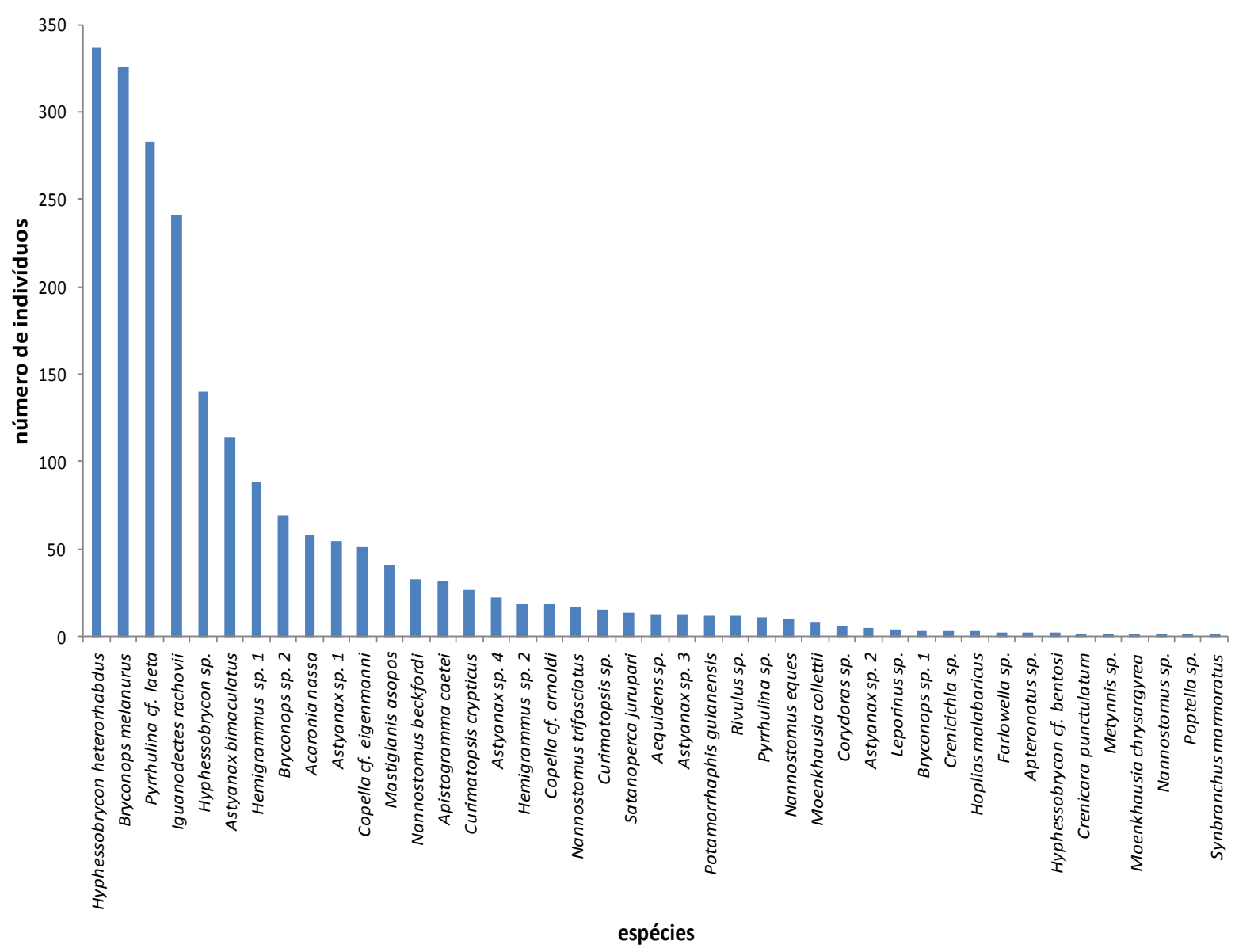

Figura 4. Ordenação de espécies por abundância de indivíduos nas oito estações de amostragem dos igarapés Cumaru, São João e Pachibá.

A abundância ou densidade relativa das espécies é um dos atributos ecológicos ou caracteres mais importantes nos estudos de comunidades de peixes, uma vez que mede a quantidade de peixes existentes, ou, na melhor das hipóteses, faz uma estimativa. Contudo, é também um dos parâmetros mais difíceis de se determinar na região Neotropical, principalmente em virtude da grande diversidade de formas e hábitos apresentados pelos peixes, o que faz com que as amostragens sejam viciadas, isto é, apresentem distorções causadas pelos métodos ou aparelhos usados nas capturas (Santos e Ferreira, 1999). Na maior parte de nossas amostragens, utilizou-se rede de arrasto e covos e, como estes apetrechos de pesca são bastante seletivos, geralmente selecionando as espécies de pequeno tamanho, outras espécies de peixes de tamanho médio não foram capturadas. A tarrafa também foi outro apetrecho de pesca seletivo, porém, neste caso foram capturadas indivíduos de médio porte. 
CORRÊA, J. M.; GERHARD, P.; FIGUEIREDO, R. O. Ictiofauna de igarapés de pequenas bacias de drenagem em área agrícola do Nordeste Paraense, Amazônia Oriental. Ambi-Agua, Taubaté, v. 7, n. 2, p. 214-230, 2012. (http://dx.doi.org/10.4136/ambi-agua.739)

\subsection{Medidas de diversidade}

A Tabela 3 apresenta as cinco diversas métricas (Número de espécies e indivíduos acumulados, Dominância, Diversidade e Equitabilidade) das comunidades de peixes estudadas. Dentre os pontos amostrados verificou-se que o IGCU-B apresentou uma comunidade de peixes com maior dominância $(D=0,43)$ e, consequientemente o menor valor de diversidade $\left(H^{\prime}=1,22\right)$, enquanto o IGPA-B apresentou o maior valor de diversidade $\left(H^{\prime}=2,39\right)$ e eqüitabilidade $(E q=0,78)$ e o menor valor de dominância $(D=0,12)$.

Tabela 3. Número de espécies acumuladas $\left(S_{a c}\right)$, número de indivíduos acumulados $\left(N_{a c}\right)$, Dominância de Simpson $(D)$, Diversidade de Shannon $\left(H^{\prime}\right)$ e Equitabilidade de Shannon $(E q)$ para os nove meses de coleta.

\begin{tabular}{l|ccccc}
\hline \multicolumn{1}{c|}{ Estações } & $\boldsymbol{S}_{\boldsymbol{a c}}$ & $\boldsymbol{N}_{\boldsymbol{a c}}$ & $\boldsymbol{D}$ & $\boldsymbol{H}^{\prime}$ & $\boldsymbol{E q}$ \\
\hline IGCU-A & 9 & 201 & 0,35 & 1,34 & 0,61 \\
IGCU-B & 8 & 397 & 0,43 & 1,22 & 0,59 \\
IGCU-C & 20 & 267 & 0,21 & 1,93 & 0,65 \\
IGCU-D & 19 & 294 & 0,39 & 1,62 & 0,55 \\
IGSJ-A & 13 & 328 & 0,20 & 1,92 & 0,75 \\
IGSJ-B & 18 & 163 & 0,16 & 2,18 & 0,75 \\
IGPA-A & 10 & 153 & 0,38 & 1,29 & 0,56 \\
IGPA-B & 21 & 314 & 0,12 & 2,39 & 0,78 \\
\hline Total & $\mathbf{4 3}$ & $\mathbf{2 1 1 7}$ & $\mathbf{0 , 0 9}$ & $\mathbf{2 , 7 7}$ & $\mathbf{0 , 7 4}$ \\
\hline
\end{tabular}

O Índice de Dominância de Simpson e a ordenação das espécies por abundância indicaram que o ponto B do igarapé Cumaru apresentou maior dominância, devido a maior abundância de Hyphessobrycon heterorhabdus sobre as demais espécies. Também nesse ponto de amostragem forma-se um ambiente de poço relativamente assoreado, com pouca cobertura e abrigo, sendo comum encontrar poucas espécies nesse local. Santos e Ferreira (1999) afirmam que a dominância relativamente alta de uma determinada espécie é devida à presença de cardumes ou de áreas muito modificadas pela atividade humana, como em igarapés e rios represados.

O Índice de Diversidade de Shannon revelou que o ponto IGPA-B do igarapé Pachibá possuiu maior diversidade do que os outros pontos de coleta. Isto se deve ao fato de que nessa estação de amostragem foi capturado o maior número de espécies acumuladas. Tal fato está associado à mudança no mesohabitat, pois, as três primeiras coletas nessa estação foram feitas a jusante do lago, sendo capturadas poucas espécies e que as coletas seguintes foram realizadas no próprio lago, sendo capturadas mais espécies.

Na microbacia do Igarapé Pachibá, a maior diversidade no trecho médio corrobora o Conceito de Rio como Contínuo ("River Continuum Concept"), de Vannote et al. (1980). Estes autores propuseram que a diversidade biológica em ambientes lóticos é máxima nos trechos médios destes sistemas. Barbosa et al. (2003), acharam maior índice de diversidade nas porções intermediárias do que nas nascentes. Os autores sugerem a existência de um gradiente longitudinal entre os ambientes, a qual pode estar relacionado com as barreiras físicas naturais, corredeiras e cachoeiras existentes ao longo do igarapé.

\subsection{Similaridade entre as comunidades}

A análise de agrupamento apresentou dois grupos no nível de 0,8 de dissimilaridade, denominados A e B (Figura 5). Este nível de corte corresponde exatamente aos grupos das 
amostras tomadas nas estações dos trechos médios (grupo A) e nascentes (grupo B). Estes grupos diferenciaram-se por um conjunto de espécies exclusivas, sendo Hemigrammus sp. 1 e Bryconops sp. 2 as espécies exclusivas do grupo A e Copella cf. eigenmanni, Copella cf. arnoldi e Pyrrhulina sp. as espécies exclusivas do grupo B. Em relação à dominância por espécies, Bryconops melanurus foi a mais representativa no grupo A, enquanto Pyrrhulina cf. laeta obteve maior representatividade no grupo B.

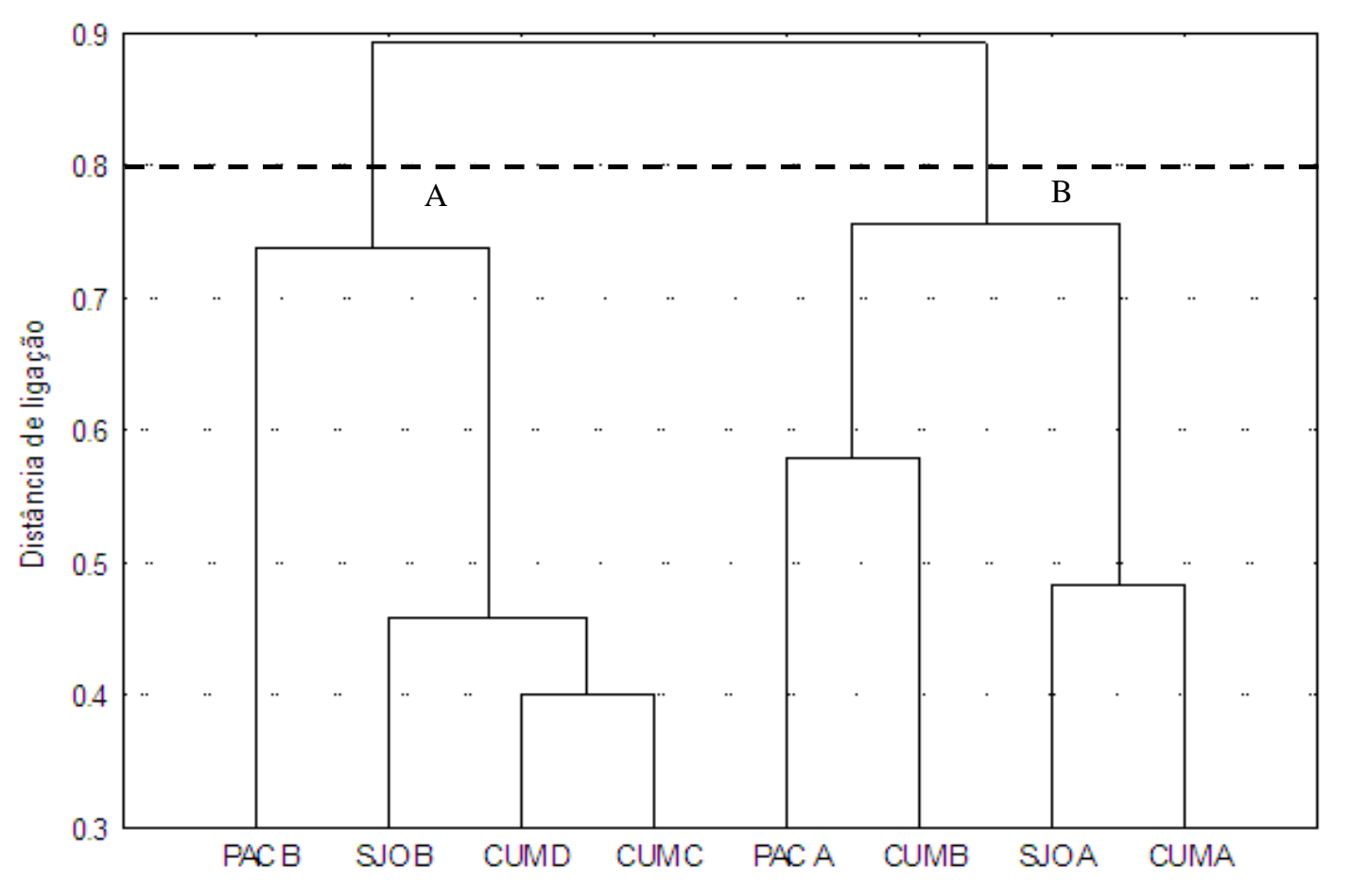

Figura 5. Resultado da análise de agrupamento entre as estações de amostragem. Corte ao nível de 0,8 de dissimilaridade.

Assim verificou-se que a distribuição das espécies nos igarapés seguiu um padrão longitudinal ao invés de um padrão geográfico (referente à bacia hidrográfica a que pertencem as microbacias), ou seja, independente do igarapé, a maioria das espécies que ocorreram nas nascentes não ocorreram nas porções intermediárias desses igarapés e vice-versa (Figura 5). Suarez e Petrere Júnior (2003) estudando associações de espécies de peixes em ambientes lóticos da bacia do rio Iguatemi, sugeriram que existe uma diferenciação no uso dos habitats pelas espécies de peixes que leva a uma formação de diferentes grupos de espécies coocorrentes e que esses grupos são representados por espécies característicos de riachos e por espécies característicos de trechos de rios.

No grupo A, a espécie Bryconops melanurus, além de ter sido uma espécie dominante, também foi uma das espécies exclusivas desse local. Isto se deve ao fato de que esse animal tem uma preferência por águas com leve correnteza e com substrato rochoso (Froese e Pauly, 2007). O gênero Copella, em especial a espécie Copella cf. eigenmanni destacou-se no grupo B. Isto se deve provavelmente a estes indivíduos serem encontrados próximos às margens das nascentes, onde há uma redução considerável da correnteza e acúmulo de folhiços no substrato. As estações amostradas tinham predomínio total de ambientes represados, tendendo ao lêntico. 
CORRÊA, J. M.; GERHARD, P.; FIGUEIREDO, R. O. Ictiofauna de igarapés de pequenas bacias de drenagem em área agrícola do Nordeste Paraense, Amazônia Oriental. Ambi-Agua, Taubaté, v. 7, n. 2, p. 214-230, 2012. (http://dx.doi.org/10.4136/ambi-agua.739)

\subsection{Análise de regressão linear}

Não houve diferença significativa entre o número de espécies acumuladas com o uso da terra (Tabela 4).

Tabela 4. Valores da regressão linear entre o número de espécies acumuladas $\left(\mathrm{S}_{\mathrm{ac}}\right)$ e as variáveis do uso da terra.

\begin{tabular}{l|cc}
\hline & $\mathbf{r}^{2}$ & $\mathbf{p}$ \\
\hline $\mathrm{S}_{\mathrm{ac}}$ X Agricultura & 0,289 & 0,1677 \\
$\mathrm{~S}_{\mathrm{ac}}$ X Pasto & 0,328 & 0,1359 \\
$\mathrm{~S}_{\mathrm{ac}}$ X Capoeira & 0,217 & 0,2444 \\
$\mathrm{~S}_{\mathrm{ac}}$ X Floresta & 0,313 & 0,1480 \\
$\mathrm{~S}_{\mathrm{ac}}$ X Agricultura (\%) & 0,369 & 0,1083 \\
$\mathrm{~S}_{\mathrm{ac}}$ X Pasto (\%) & 0,149 & 0,3465 \\
$\mathrm{~S}_{\mathrm{ac}}$ X Capoeira $(\%)$ & 0,268 & 0,1866 \\
$\mathrm{~S}_{\mathrm{ac}}$ X Floresta $(\%)$ & 0,351 & 0,1195 \\
\hline
\end{tabular}

Não foi observada uma diferença significativa entre o número de indivíduos acumulados e índice de dominância de Simpson com as variáveis do uso da terra (Tabelas 5 e 6).

Tabela 5. Valores da regressão linear entre o número de indivíduos acumulados $\left(\mathrm{N}_{\mathrm{ac}}\right)$ e as variáveis do uso da terra.

\begin{tabular}{l|cc}
\hline & $\mathbf{r}^{2}$ & $\mathbf{p}$ \\
\hline $\mathrm{N}_{\mathrm{ac}}$ X Agricultura & 0,002 & 0,9107 \\
$\mathrm{~N}_{\mathrm{ac}}$ X Pasto & 0,018 & 0,7466 \\
$\mathrm{~N}_{\mathrm{ac}}$ X Capoeira & 0,000 & 0,9478 \\
$\mathrm{~N}_{\mathrm{ac}}$ X Floresta & 0,001 & 0,9331 \\
$\mathrm{~N}_{\mathrm{ac}}$ X Agricultura (\%) & 0,007 & 0,8378 \\
$\mathrm{~N}_{\mathrm{ac}}$ X Pasto $(\%)$ & 0,087 & 0,5184 \\
$\mathrm{~N}_{\mathrm{ac}}$ X Capoeira (\%) & 0,071 & 0,5260 \\
$\mathrm{~N}_{\mathrm{ac}}$ X Floresta (\%) & 0,088 & 0,5212 \\
\hline
\end{tabular}

Tabela 6. Valores da regressão linear entre o Índice de Dominância de Simpson (D) e as variáveis do uso da terra.

\begin{tabular}{l|cc}
\hline & $\mathbf{r}^{2}$ & $\mathbf{p}$ \\
\hline D X Agricultura & 0,029 & 0,6880 \\
D X Pasto & 0,011 & 0,7996 \\
D X Capoeira & 0,235 & 0,2221 \\
D X Floresta & 0,016 & 0,7610 \\
D X Agricultura (\%) & 0,099 & 0,5483 \\
D X Pasto (\%) & 0,077 & 0,5106 \\
D X Capoeira (\%) & 0,093 & 0,5327 \\
D X Floresta (\%) & 0,031 & 0,6743 \\
\hline
\end{tabular}


O número acumulado de espécies, o número acumulado de indivíduos e o Índice de Dominância de Simpson não foram influenciados pelas variáveis relacionadas ao uso da terra, ou seja, valores absolutos e percentuais de agricultura, pasto, capoeira e floresta. Assim sendo, apesar de algumas das estações de amostragem apresentarem processo inicial de assoreamento, o uso da terra predominante, a agricultura familiar, na abrangência espacial e intensidade que vem sendo praticada nas microbacias estudadas, ainda propicia que as maiores áreas das pequenas propriedades rurais mantenham-se cobertas por floresta secundária de diferentes idades, principalmente nas zonas ripárias, possibilitando assim que o ecossistema aquático seja habitado por diversas espécies de peixes característicos de igarapés.

No entanto, em outras regiões, como por exemplo, no sudeste brasileiro, a utilização da terra provocou um desequilíbrio nas comunidades de peixes. Casatti (2004) estudando a ictiofauna de dois riachos no alto rio Paraná, sendo um deles assoreado em área de pastagem e sem a vegetação ripária e o outro de referência, com a vegetação ripária, verificou a presença de 21 espécies de peixes no córrego assoreado. Destacou que a espécie Pyrrhulina cf. laeta foi uma das espécies dominantes favorecidas por habitats relacionados ao assoreamento, com ocorrência de 50\% nesse ambiente.

\subsection{Curva de acumulação}

Considerando todas as amostragens, verificou-se que a curva de acumulação não apresentou tendência à estabilização (Figura 6). Isto indica que o número total de espécies que ocorrem nesses ambientes ainda não foi alcançado. É importante que esse tipo de estudo tenha continuidade.

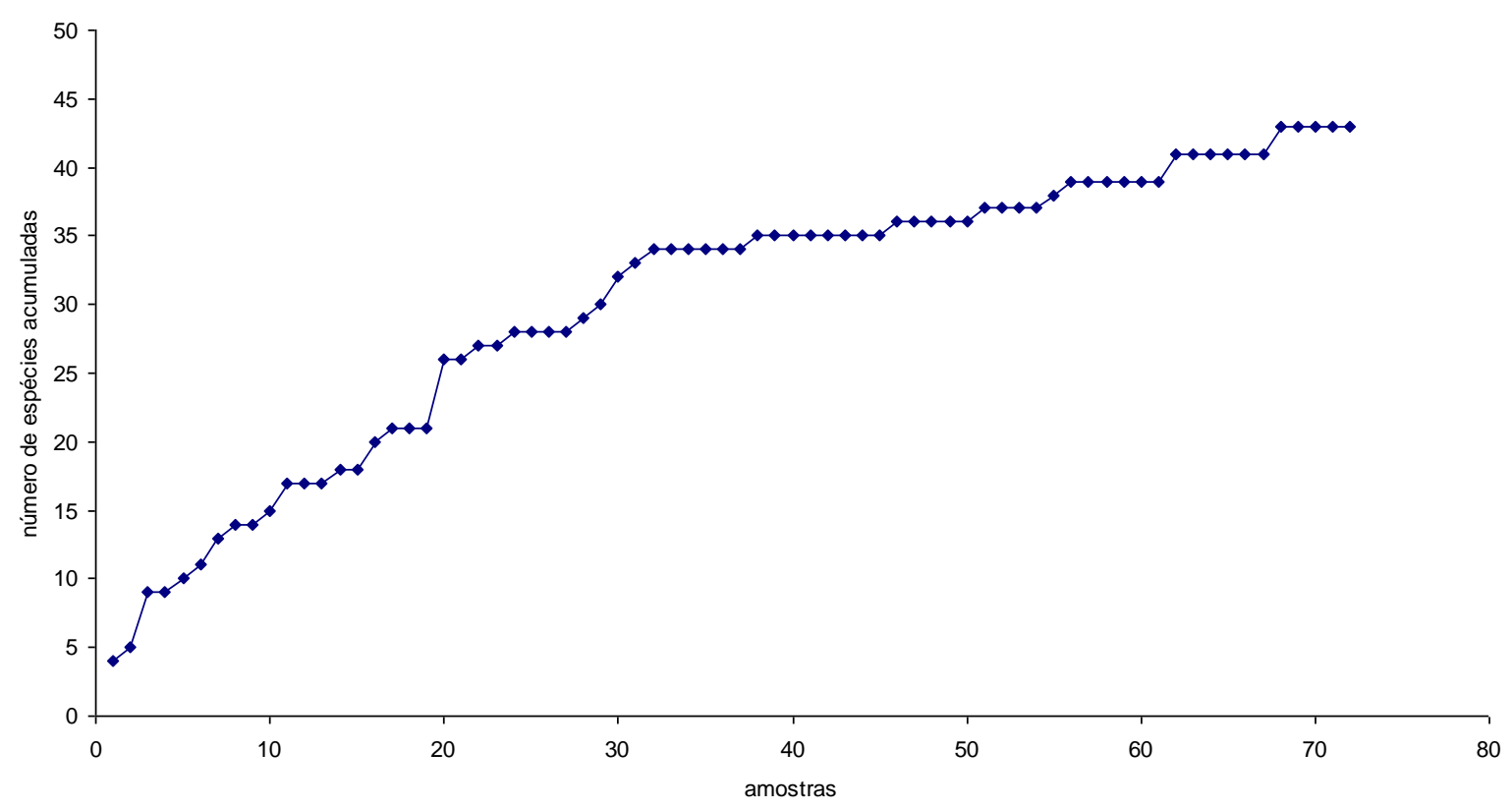

Figura 6. Curva de acumulação de espécies para todas as estações de amostragem nos igarapés Cumaru, São João e Pachibá.

\section{CONCLUSÃO}

Os trechos médios, com base nos índices de diversidade calculados, apresentaram uma ictiofauna com maior diversidade de espécies, mostrando que a diversidade aumenta de acordo com o tamanho do habitat ao longo dos igarapés.

A distribuição dos peixes seguiu um padrão longitudinal ao invés de um padrão geográfico, com predominância de espécies exclusivas tanto nas nascentes quanto nas porções 
CORRÊA, J. M.; GERHARD, P.; FIGUEIREDO, R. O. Ictiofauna de igarapés de pequenas bacias de drenagem em área agrícola do Nordeste Paraense, Amazônia Oriental. Ambi-Agua, Taubaté, v. 7, n. 2, p. 214-230, 2012. (http://dx.doi.org/10.4136/ambi-agua.739)

intermediárias. A agricultura familiar, da maneira como se processa atualmente na região, pareceu não influenciar grandemente na estrutura das comunidades de peixes, já que a intensidade com que essa atividade vem sendo executada ainda possibilita que o ecossistema aquático seja habitado por diversas espécies de peixes.

\section{AGRADECIMENTOS}

Aos projetos Agrobacias Amazônicas (EMBRAPA, 02.02.5.32), Rede Tipitamba (EMBRAPA, 02.03.1.10), Aguamor (CT-Hidro/CNPq, 502626/2003-8), e Milênio LBA2 (Institutos do Milênio/CNPq, 420199/2005-5), e respectivas equipes, pelo apoio na execução desse trabalho. A Universidade Federal Rural da Amazônia, por ter concedido espaço físico para as análises de identificação. Aos funcionários e estagiários da Embrapa Amazônia Oriental, em especial ao técnico Sr. Reginaldo Ramos Frazão, pelo apoio no trabalho de campo.

\section{REFERÊNCIAS}

ALLAN, J. D. Landscapes and riverscapes: the influence of land use on stream ecosystems. Annual Review of Ecology, Evolution and Systematics, v. 35, p .257-284, 2004. http://dx.doi.org/10.1146/annurev.ecolsys.35.120202.110122

BARBOSA, R. P.; FREITAS, C. E. C.; SANTOS, S. M. The fish community of an upland stream in the Central Amazon (Presidente Figueiredo - Amazonas - Brazil). Acta Limnologica Brasiliensia, Rio Claro, v. 15, n. 2, p. 37-41, 2003.

BASTOS, T.; PACHECO, N. A. Rainfall distribution and water balance for day periods in Igarapé-Açu, Eastern Amazonia, Brazil. In: GERMAN-BRAZILIAN WORKSHOP ON NEOTROPICAL ECOSYSTEMS - ACHIEVEMENTS AND PROSPECTS OF COOPERATIVE RESEARCH, 2000, Hamburg. Abstracts... Hamburg: Universität Hamburg, 2000. p. 213.

BUCKUP, P. A.; MENEZES, N. A. (Eds.). Catálogo dos peixes marinhos e de água doce do Brasil. 2. ed. 2003. Disponível em: <http://www.mnrj.ufrj.br/catalogo>. Acesso em: 01 jul. 2007.

BUSS, D. F.; BAPTISTA, D. F.; SILVEIRA, M. P.; NESSIMIAN, J. L.; DORVILLÉ, L. F. $M$. Influence of water chemistry and environmental degradation on macroinvertebrate assemblages in a river basin in south-east Brazil. Hydrobiologia, v. 481, n. 1-3, p. 125136, 2002. http://dx.doi.org/10.1023/A:1021281508709

CASATTI, L. Ichthyofauna of two streams (silted and reference) in the upper Paraná river basin, southeastern Brazil. Brazilian Journal of Biology, São Carlos, v. 64, n. 4, p. 757-765, 2004. http://dx.doi.org/10.1590/S1519-69842004000500004

CASATTI, L. Alterações no Código Florestal Brasileiro: impactos potenciais sobre a ictiofauna. Biota Neotropica, Campinas, v. 10, n. 4, p. 31-34, 2010. Disponível em: <http://www.biotaneotropica.org.br/v10n4/en/abstract?article+bn00310042010>. Acesso em: 03 abr. 2012.

CHERNOFF, B. A.; MACHADO-ALLISON, A.; SAUL, W. La conservación de los ambientes acuáticos: una necesidad impostergable. Acta Biologica Venezuelica, Caracas, v. 16, n. 2, p. 1-3, 1996. 
DE PAULA, F. R.; FERRAZ, S. F. B.; GERHARD, P.; VETTORAZZI, C. A.; FERREIRA, A. Large woody debris input and its influence on channel structure in agricultural lands of southeast Brazil. Environmental Management, v. 48, n. 4, p. 750-763, 2011. http://dx.doi.org/10.1007/s00267-011-9730-4

FERREIRA, C. P.; CASATTI, L. Integridade biótica de um córrego na bacia do Alto Rio Paraná avaliada por meio da comunidade de peixes. Biota Neotropica, Campinas, v. 6, n. 3, 2006. Disponível em: <http://www.biotaneotropica.org.br/v6n3/pt/abstract? article+bn00306032006ISSN1676-0603>. Acesso em: 03 abr. 2012.

FERREIRA, E. J. G.; ZUANON, J. A. S.; SANTOS, G. M. Peixes comerciais do médio amazonas: região de Santarém, Pará. Brasília: IBAMA, 1998. 214 p.

FROESE, R.; PAULY, D. (Eds.). Fishbase. Version 08/2007. World Wide Web electronic publication. Disponível em: 〈http://www.fishbase.org/search.php>. Acesso em: 15 set. 2007.

GERHARD, P. Definição de Índices de Integridade Biótica no meio aquático em bacias hidrográficas da microrregião Bragantina (PA), como subsídio para aferição da sustentabilidade de sistemas de produção na agricultura familiar. Belém: Embrapa Amazônia Oriental, 2007. 53 p.

KREBS, C. J. Ecological methodology. New York: Benjamin/Cummings, 1999. 620 p.

LOWE-McCONNELL, R. H. Estudos ecológicos de comunidades de peixes tropicais. São Paulo: EDUSP, 1999. 536 p.

MACHADO, N. G.; VENTICINQUE, E. M.; PENHA, J. Effect of environmental quality and mesohabitat structure on a Biotic Integrity Index based on fish assemblages of cerrado streams from Rio Cuiabá basin, Brazil. Brazilian Journal of Biology, São Carlos, v. 71, n. 3, p. 577-586, 2011. http://dx.doi.org/10.1590/S1519-69842011000400002

PACHÊCO, N. A.; BASTOS, T. X. Boletim agrometeorológico 2006 Igarapé-Açu. Belém: Embrapa Amazônia Oriental, 2007. 32 p.

REIS, R. E.; KULLANDER, S. O.; FERRARIS, C. J. The check list of the freshwater fishes of South and Central America. Porto Alegre: EDIPUCRS, 2003. 944 p.

SANTOS, G. M.; FERREIRA, E. J. G. Peixes da Bacia Amazônica. In: LOWEMcCONNELL, R. H. Estudos ecológicos de comunidades de peixes tropicais. São Paulo: EDUSP, 1999. p. 345-373.

SANTOS, G. M.; MERONA, B.; JURAS, A. A.; JEGU, M. Peixes do baixo rio Tocantins: 20 anos depois da usina hidrelétrica Tucuruí. Brasília: ELETRONORTE, 2004. 216 p.

SILVANO, R.; OYAKAWA, O.; AMARAL, B.; BEGOSSI, A. Peixes do alto rio Juruá (Amazonas, Brasil). São Paulo: EDUSP, 2001. 302 p.

SOMMER, R.; VLEK, P. L. G.; SÁ, T. D. A.; VIELHAUER, K.; COELHO, R. F. R.; FÖLSTER, H. 2004. Nutrient balance of shifting cultivation by burning or mulching in the Eastern Amazon - evidence for subsoil nutrient accumulation. Nutrient Cycling in Agroecosystems, v. 68, n. 3, p. 257-271, 2004. http://dx.doi.org/10.1023/B:FRES.0000019470.93637.54 
SUAREZ, Y. R.; PETRERE JÚNIOR, M. Associações de espécies de peixes em ambientes lóticos da bacia do rio Iguatemi, Estado do Mato Grosso do Sul. Acta Scientiarum, Maringá, v. 25, n. 2, p. 361-367, 2003. http://dx.doi.org/10.4025/actascibiolsci.v25i2.2024

VANNOTE, R. L.; MINSHALL, K. W.; CUMMINS, K. W.; SEDELL, J. R.; CUSHING, C. E. The river continuum concept. Canadian Journal of Fisheries and Aquatic Sciences, v. 37, p. 130-137, 1980. http://dx.doi.org/10.1139/f80-017

WATRIN, O. S.; GERHARD, P.; MACIEL, M. N. M. Dinâmica do uso da terra e configuração da paisagem em antigas áreas de colonização de base econômica familiar, no Nordeste do Estado do Pará. Geografia, Rio Claro, v. 34, p. 455-472, 2009. 


ISSN = 1980-993X - doi:10.4136/1980-993X
www.ambi-agua.net
E-mail: ambi-agua@agro.unitau.br
Tel.: (12) 3625-4212

\title{
Adequação e avaliação da aplicabilidade de um Protocolo de Avaliação Rápida na bacia do rio Gualaxo do Norte, Leste-Sudeste do Quadrilátero Ferrífero, MG, Brasil
}

(http://dx.doi.org/10.4136/ambi-agua.872)

\author{
Aline Sueli de Lima Rodrigues ${ }^{1}$; Guilherme Malafaia ${ }^{2}$; \\ Adivane Terezinha Costa ${ }^{3}$; Hermínio Arias Nalini Júnior ${ }^{4}$ \\ 1Departamento de Gestão Ambiental do Instituto Federal Goiano - Urutaí, GO, \\ e-mail: rodriguesasl@yahoo.com.br, \\ ${ }^{2}$ Departamento de Ciências Biológicas do Instituto Federal Goiano - Urutaí, GO, \\ e-mail: guilhermeifgoiano@gmail.com, \\ ${ }^{3,4}$ Departamento de Geologia da Universidade Federal de Ouro Preto - Ouro Preto, MG, \\ e-mails: adivane.costa@ hotmail.com, herminio.nalini@gmail.com
}

\section{RESUMO}

No presente estudo, adaptou-se um PAR para avaliar as condições ambientais do rio Gualaxo do Norte, Leste-Sudeste do Quadrilátero Ferrífero, MG, Brasil. Em seguida o PAR foi aplicado em 31 trechos ao longo do seu curso e, posteriormente, avaliou-se a aplicabilidade/viabilidade do instrumento adaptado utilizando-se informações científicas sobre o histórico e o atual uso e ocupação da bacia do rio Gualaxo do Norte. Os resultados demonstraram que o PAR adaptado foi eficiente na avaliação das condições ambientais do rio sob investigação. Contudo, foi evidenciada a necessidade de se ater para avaliação de parâmetros, que podem ter sua visibilidade influenciada pelo período do ano (estiagem ou cheia) ou pela própria localização na bacia. Essa constatação permitiu concluir que a construção/adaptação dos PARs deve ser um processo contínuo de ajustes e aprimoramentos para que o seu emprego possa cobrir uma gama diversificada de tipologias fluviais, bacias hidrográficas e ecorregiões.

Palavras-chave: avaliação ambiental, monitoramento, aspectos físicos, recursos hídricos.

\section{Adaptation and applicability assessment of the of a Rapid Assessment Protocol for the Gualaxo do Norte river basin, East-Southeast of the Quadrilátero Ferrífero, MG, Brazil}

\begin{abstract}
In this study, we adapted a Rapid Assessment Protocol methodology (RAP) to assess the environmental conditions of the Gualaxo do Norte River, East-Southeast of the Quadrilátero Ferrífero, MG, Minas Gerais, Brazil. Then the RAP was applied to 31 sections along its course and the applicability/viability of the adapted instrument using scientific information on the history and current use and occupation of the Gualaxo do Norte River basin was evaluated. The results showed that RAP was effectively adjusted to evaluate environmental conditions of river under investigation. However, it was observed the need to evaluate parameters that can have their appearance appraisal influenced by the season of the year (dry or wet) or by their location in the basin. It was concluded that the implementation/adaptation
\end{abstract}


RODRIGUES, A. S. L.; MALAFAIA, G.; COSTA, A. T.; NALINI-JÚNIOR, H. A. Adequação e avaliação da aplicabilidade de um Protocolo de Avaliação Rápida na bacia do rio Gualaxo do Norte, Leste-Sudeste do Quadrilátero Ferrífero (MG, Brasil). Ambi-Agua, Taubaté, v. 7, n. 2, p. 231-244, 2012. (http://dx.doi.org/10.4136/ambi-agua.872)

of RAPs should be a continuous process of adjustments and improvements to the extent that their employment may cover a diverse range of rivers, watersheds and ecoregions.

Keywords: environmental assessment, monitoring, physic aspects, water resources.

\section{INTRODUÇÃO}

Caracterizados por uma grande variabilidade e complexidade de parâmetros bióticos e abióticos, essencialmente dinâmicos, os rios possuem papel fundamental para a manutenção da qualidade de vida. A história do homem está intimamente ligada aos sistemas fluviais, pois é no entorno destes que o ser humano se instala e continuamente explora os recursos daí advindos. Estes sistemas têm sido destinados a uma infinidade de usos ao longo do tempo, como a obtenção de água para fins domésticos, industriais e transporte, além da geração de energia elétrica pelo represamento de suas águas (Barrella et al., 2001; Primack e Rodrigues, 2002).

Qualquer atividade humana que altere os fatores básicos que determinam o balanço hídrico influencia a disponibilidade dos recursos hídricos de uma bacia hidrográfica podendo afetar diretamente o equilíbrio ecológico dos sistemas lóticos (Rebouças, 2002). No Brasil, existem casos em que a atividade humana melhora a oferta de recursos hídricos, alterando o tempo de residência das águas na superfície terrestre. Isso pode ser observado na construção de açudes no Nordeste brasileiro e do sistema de represamento nos complexos hidrelétricos do rio Tietê, rio Grande e rio Paraná. Por outro lado, a expansão de áreas para a agricultura resultou em grandes desmatamentos, principalmente em áreas de mata ciliar, as quais exercem grande influência sobre a qualidade dos corpos d'água e sobre a comunidade biológica nela existente (Vogel et al., 2009). O uso da terra, com remoção da cobertura vegetal e implementação da agricultura, normalmente degrada os recursos hídricos (Minatti-Ferreira e Beaumord, 2004). De acordo com Traina e Laperche (1999), a otimização da produção agrícola, realizada por meio do incremento de fertilizantes industriais, provoca distúrbios ecológicos que afetam diretamente o equilíbrio do ecossistema fluvial, principalmente quando estes fertilizantes são carreados para os cursos d'água.

Diante disto, tem se observado a crescente necessidade de monitorar as alterações ambientais e avaliar seus efeitos sobre os ecossistemas fluviais. A avaliação ambiental dos rios, como ferramenta de monitoramento destes ecossistemas, tem fornecido subsídios importantes para uma análise integrada da qualidade dos mesmos.

Nesse sentido, entender as características e a dinâmica dos corpos hídricos é fundamental para a determinação das condições ambientais dos ecossistemas fluviais, principalmente quando se parte do princípio de que as condições ambientais de um rio estão relacionadas aos aspectos físicos do habitat. Nesse contexto, uma ferramenta possível de ser utilizada para tais fins, são os Protocolos de Avaliação Rápida de Rios (PARs), os quais têm a proposta de avaliar, de forma integrada, parâmetros físicos que determinam a qualidade do meio. Dessa forma, os PARs podem permitir a obtenção de informações que possibilitem o planejamento do uso e conservação dos recursos fluviais.

Por definição, os PARs são documentos de referência que reúnem procedimentos metodológicos aplicáveis à avaliação rápida, qualitativa e semi-quantitativa, de um conjunto de variáveis representativas dos principais componentes e fatores que condicionam e controlam os processos e funções ecológicas dos sistemas fluviais (Callisto et al., 2002; Rodrigues e Castro (2008a).

Nos PARs é estabelecido, em princípio, um limite considerado normal baseado em valores obtidos de locais minimamente perturbados, tidos como locais "referência" (Plafkin et 
RODRIGUES, A. S. L.; MALAFAIA, G.; COSTA, A. T.; NALINI-JÚNIOR, H. A. Adequação e avaliação da aplicabilidade de um Protocolo de Avaliação Rápida na bacia do rio Gualaxo do Norte, Leste-Sudeste do Quadrilátero Ferrífero (MG, Brasil). Ambi-Agua, Taubaté, v. 7, n. 2, p. 231-244, 2012. (http://dx.doi.org/10.4136/ambi-agua.872)

al., 1989), partindo da premissa de que os cursos d'água pouco afetados pela ação humana exibem melhores condições biológicas (Minatti-Ferreira e Beaumord, 2006). O gradiente de estresse ambiental é definido a partir da observação destes locais e de locais com vários graus de alterações, desde os pouco alterados até os muito degradados.

No Brasil, vários estudos têm utilizado os PARs como instrumentos de avaliação da estrutura e do funcionamento dos ecossistemas fluviais, como pode ser observado nos trabalhos de Xavier \& Teixeira (2007), Dillenburg (2007), Padovesi-Fonseca et al. (2010); Krupek (2010), Firmino et al. (2011) e Lobo et al. (2011). Contudo, devido à inerente subjetividade do método, à simplicidade de sua aplicação e devido ao fato dos PARs não serem uma ferramenta robusta, torna-se necessário avaliar a sua aplicabilidade em contextos específicos, até mesmo no sentido de testar a sua real viabilidade enquanto instrumentos de monitoramento ambiental. Nesse sentido, objetivou-se com o presente estudo, adaptar um PAR, usá-lo para determinar as condições ambientais do rio principal da bacia do rio Gualaxo do Norte (contribuinte da bacia do rio Doce, MG) e, mais especificamente, auto-avaliar a adaptação realizada e sua aplicabilidade/viabilidade enquanto instrumento de avaliação de um rio de porte médio.

\section{MATERIAIS E MÉTODO}

\section{1. Área de estudo}

O presente estudo foi desenvolvido na bacia do rio Gualaxo do Norte, a qual possui uma área de aproximadamente $250 \mathrm{~km}^{2}$ e apresenta um padrão de drenagem do tipo treliça e ocasionalmente dendrítico. A referida bacia tem suas cabeceiras localizadas nas proximidades do distrito de Antônio Pereira (Ouro Preto-MG) e Bento Rodrigues (Mariana-MG) (Figura 1) (Souza et al., 2005). O rio principal segue seu médio curso em direção a leste e deságua no rio do Carmo, no município de Barra Longa-MG (Costa, 2001). O rio do Carmo, após a confluência com o rio Piranga, segue em direção à Ponte Nova, com a designação de rio Doce.

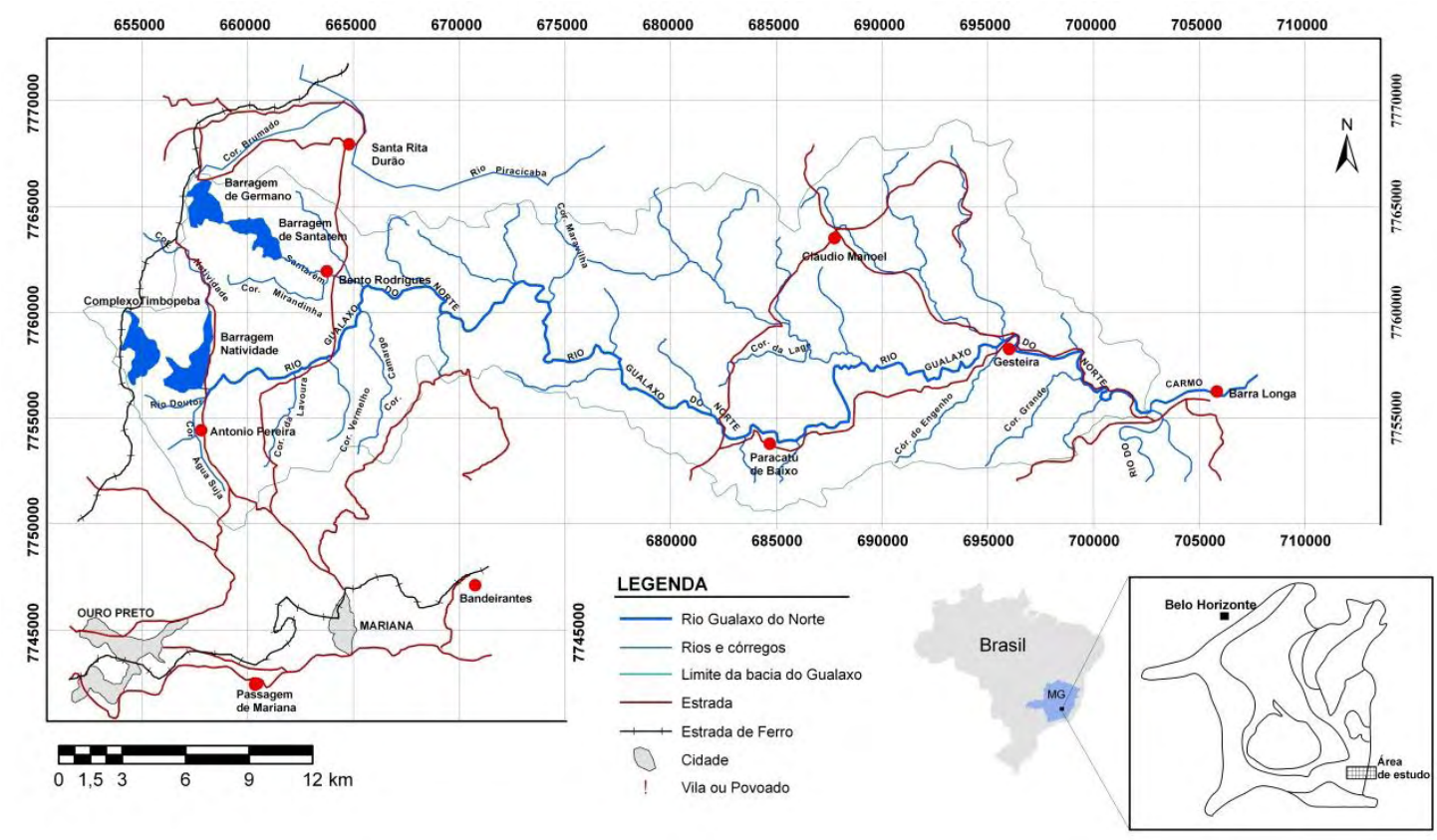

Figura 1. Mapa de localização da área de estudo. Os pontos vermelhos do mapa referem-se às distritos dos municípios de Ouro Preto ou Mariana. 
RODRIGUES, A. S. L.; MALAFAIA, G.; COSTA, A. T.; NALINI-JÚNIOR, H. A. Adequação e avaliação da aplicabilidade de um Protocolo de Avaliação Rápida na bacia do rio Gualaxo do Norte, Leste-Sudeste do Quadrilátero Ferrífero (MG, Brasil). Ambi-Agua, Taubaté, v. 7, n. 2, p. 231-244, 2012. (http://dx.doi.org/10.4136/ambi-agua.872)

Geologicamente, o alto curso do rio Gualaxo do Norte situa-se nos domínios de rochas supracrustais do QF, principalmente quartzitos, itabiritos e filitos do Supergrupo Minas. Seu médio curso drena rochas arqueanas predominando gnaisses e metabásicas, litotipos característicos dos complexos metamórficos granito-gnáissicos, além de xistos e quartzitos do Supergrupo Rio das Velhas (greenstone belt). Já seu baixo curso drena gnaisses e granitos do Complexo Santa Bárbara (Costa et al., 2003).

\subsection{Adaptação do protocolo utilizado}

Inicialmente foi adaptado um PAR para avaliação das condições ambientais do rio Gualaxo do Norte. Para tanto, considerou-se como documento referência o protocolo proposto Rodrigues e Castro (2008b), específico para a avaliação de riachos inseridos em campos rupestres do bioma Cerrado. O PAR adaptado foi constituído por cinco parâmetros (deposição de sedimentos, alterações no canal, estabilidade das margens, proteção das margens pela vegetação, estado de conservação da vegetação do entorno), cujas descrições e gradientes de estresse ambiental podem ser observados no Quadro 1.

Quadro 1: Adaptação do protocolo de avaliação rápida de rios*

\begin{tabular}{|c|c|c|c|}
\hline ÓTIMA & BOA & REGULAR & PÉSSIMA \\
\hline \multicolumn{4}{|c|}{ Parâmetro 1: "Deposição de sedimentos" } \\
\hline $\begin{array}{l}\text { Ausência ou pequeno alargamento } \\
\text { de ilhas ou barras de pontal. }\end{array}$ & $\begin{array}{l}\text { Alguns acréscimos recentes na } \\
\text { formação de barras, predomínio de } \\
\text { cascalho, areia ou sedimento fino. }\end{array}$ & $\begin{array}{l}\text { Deposição moderada de cascalhos } \\
\text { novos, areia ou sedimento fino } \\
\text { em barras recentes e antigas. } \\
\text { Sobretudo, de origem antrópica. }\end{array}$ & $\begin{array}{l}\text { Elevada deposição de } \\
\text { material fino ou cascalho e } \\
\text { aumento no desenvolvimento } \\
\text { de barras devido, } \\
\text { principalmente, às atividades } \\
\text { antrópicas. }\end{array}$ \\
\hline 4 & 3 & 2 & 1 \\
\hline \multicolumn{4}{|c|}{ Parâmetro 2: "Alterações no canal" } \\
\hline $\begin{array}{l}\text { Ausência de canalizações e } \\
\text { dragagens ou qualquer outra forma } \\
\text { de interferência que possa afetar o } \\
\text { curso d'água. Nesse caso, o curso } \\
\text { d'água segue com padrão natural. }\end{array}$ & $\begin{array}{l}\text { Presença de pequenas canalizações, } \\
\text { em geral em área para apoio de } \\
\text { pontes ou evidência de canalizações } \\
\text { antigas e de dragagem, mas com } \\
\text { ausência de canalizações recentes. } \\
\text { Não há evidências de que o leito } \\
\text { tenha sido explorado por atividades } \\
\text { antrópicas. }\end{array}$ & $\begin{array}{l}\text { Presença de diques, } \\
\text { terraplanagens, aterros, barragens } \\
\text { ou estruturas de escoramentos em } \\
\text { ambas as margens. Há evidências } \\
\text { antigas de que o leito já foi } \\
\text { explorado pela atividade } \\
\text { garimpeira ou ainda por } \\
\text { dragagem para retirada de } \\
\text { areia/cascalho. }\end{array}$ & $\begin{array}{l}\text { Margens revestidas com } \\
\text { gabiões ou cimento e o curso } \\
\text { d'água encontra-se canalizado } \\
\text { ou pode ser observado forte } \\
\text { evidência de revolvimento } \\
\text { das margens para exploração } \\
\text { recente pelas atividades } \\
\text { garimpeiras. }\end{array}$ \\
\hline 4 & $\mathbf{3}$ & 2 & 1 \\
\hline \multicolumn{4}{|c|}{ Parâmetro 3: "Estabilidade das margens" } \\
\hline $\begin{array}{l}\text { Margens estáveis, ausência ou } \\
\text { mínima evidência de erosão ou } \\
\text { falhas nas margens; pouco } \\
\text { potencial para problemas futuros. }\end{array}$ & $\begin{array}{l}\text { Margens moderadamente estáveis, } \\
\text { com presença de áreas com erosões } \\
\text { cicatrizadas. }\end{array}$ & $\begin{array}{l}\text { Margens moderadamente } \\
\text { instáveis. As margens } \\
\text { apresentam-se erodidas e o } \\
\text { potencial à erosão é alto durante } \\
\text { as cheias. }\end{array}$ & $\begin{array}{l}\text { Margens instáveis e muitas } \\
\text { áreas erodidas. A erosão é } \\
\text { frequente ao longo da seção } \\
\text { reta e nas curvas. }\end{array}$ \\
\hline 4 & 3 & 2 & 1 \\
\hline \multicolumn{4}{|c|}{ Parâmetro 4: "Proteção das margens pela vegetação" } \\
\hline $\begin{array}{l}\text { Mais de } 90 \% \text { da superfície das } \\
\text { margens e imediata zona ripária é } \\
\text { coberta por vegetação nativa. A } \\
\text { maioria das plantas pode crescer } \\
\text { naturalmente. }\end{array}$ & $\begin{array}{l}\text { De } 70 \text { a } 90 \% \text { da superfície marginal } \\
\text { é coberta por vegetação nativa; não } \\
\text { sendo observadas grandes } \\
\text { descontinuidades. }\end{array}$ & $\begin{array}{l}\text { De } 50 \text { a } 70 \% \text { da superfície das } \\
\text { margens está coberta pela } \\
\text { vegetação, havendo uma mistura } \\
\text { de locais onde o solo está coberto } \\
\text { e locais onde não há presença de } \\
\text { vegetação nativa. }\end{array}$ & $\begin{array}{l}\text { Menos de } 50 \% \text { da superfície } \\
\text { das margens está coberta por } \\
\text { vegetação nativa. É evidente a } \\
\text { descontinuidade da vegetação } \\
\text { do entorno sendo esta } \\
\text { praticamente inexistente. }\end{array}$ \\
\hline 4 & 3 & 2 & 1 \\
\hline \multicolumn{4}{|c|}{ Parâmetro 5: "Estado de conservação da vegetação do entorno" } \\
\hline $\begin{array}{l}\text { A vegetação do entorno é } \\
\text { composta por espécies nativas em } \\
\text { bom estado de conversação e não } \\
\text { apresenta sinais de degradação } \\
\text { causada por atividades humanas, } \\
\text { como pastagens ou áreas de } \\
\text { cultivo. }\end{array}$ & $\begin{array}{l}\text { A vegetação é composta não só por } \\
\text { espécies nativas, mas também por } \\
\text { exóticas, contudo está bem } \\
\text { preservada. Mínima evidência de } \\
\text { impactos causados por atividades } \\
\text { humanas. }\end{array}$ & $\begin{array}{l}\text { A vegetação presente é } \\
\text { constituída por espécies exóticas } \\
\text { e há pouca vegetação nativa. É } \\
\text { possível perceber impactos de } \\
\text { atividades humanas sobre a } \\
\text { vegetação do entorno. }\end{array}$ & $\begin{array}{l}\text { A vegetação nativa do } \\
\text { entorno é praticamente } \\
\text { inexistente e as atividades } \\
\text { humanas, tais como pastagens } \\
\text { e áreas de cultivo são } \\
\text { intensas. Além disso, o solo } \\
\text { pode estar exposto às } \\
\text { intempéries naturais. }\end{array}$ \\
\hline 4 & 3 & 2 & 1 \\
\hline
\end{tabular}

*Fonte: Adaptado de Rodrigues e Castro (2008b). 
RODRIGUES, A. S. L.; MALAFAIA, G.; COSTA, A. T.; NALINI-JÚNIOR, H. A. Adequação e avaliação da aplicabilidade de um Protocolo de Avaliação Rápida na bacia do rio Gualaxo do Norte, Leste-Sudeste do Quadrilátero Ferrífero (MG, Brasil). Ambi-Agua, Taubaté, v. 7, n. 2, p. 231-244, 2012. (http://dx.doi.org/10.4136/ambi-agua.872)

A adaptação constituiu-se de ajustes e aprimoramentos no que diz respeito aos parâmetros a serem avaliados, as pontuações a serem atribuídas a cada um deles (que levam a uma classificação da condição ambiental) e à descrição desses parâmetros, muito úteis no momento da avaliação do trecho in situ. Para a realização dessa etapa, várias visitas a campo foram realizadas (no período de chuva e de estiagem da região) com o intuito de determinar a tipologia fluvial que melhor se enquadrava o rio a ser avaliado, bem como as características fitofisionômicas encontradas na bacia.

Além disso, buscou-se identificar, por meio de observações direta dos pesquisadores, as principais atividades antrópicas desenvolvidas nos trechos visitados. Essas observações referem-se principalmente aos impactos ambientais na área, bem como ao uso e ocupação da paisagem. Vale salientar que os parâmetros substratos e/ou habitats disponíveis, soterramento, regimes de velocidade e profundidade, frequência de corredeiras, substratos em poços, diversidade de poços e sinuosidade do canal, considerados no PAR proposto por Rodrigues e Castro (2008b), não foram incluídos no PAR utilizado no presente estudo. Isso se deve à diferença entre as características e classificação dos rios considerados no trabalho de Rodrigues e Castro (2008b) e as características regionais da área foco do presente estudo.

No PAR adaptado, para cada um dos parâmetros avaliados, foi atribuído um valor correspondente à situação verificada no local da avaliação, podendo variar de uma situação péssima (pontuação de 0 a 1), regular (de 1,1 a 2), boa (de 2,1 a 3) até uma situação ótima (de 3,1 a 4). Para os parâmetros cuja avaliação envolveu as margens do canal (esquerda e direita) a pontuação foi atribuída a cada margem separadamente, sendo o resultado obtido por meio da média das pontuações de cada uma das margens.

Ao final da aplicação do PAR nos trechos selecionados, os resultados foram obtidos por meio da média dos valores atribuídos a cada parâmetro do protocolo. Estes resultados foram totalizados, analisados e comparados a uma condição referência, sendo posteriormente expressos graficamente.

\subsection{Aplicação do protocolo adaptado}

Após a adaptação do PAR, o mesmo foi aplicado (no período de estiagem da região) em 31 diferentes trechos ao longo do rio Gualaxo do Norte, os quais apresentavam diferentes níveis de impacto ambiental. Os critérios utilizados para seleção dos trechos analisados basearam-se nas características ecomorfológicas dos cursos d'água, as quais incluem geologia local, vegetação e relevo, condizentes com os parâmetros propostos no PAR utilizado, bem como pela facilidade de acesso aos trechos. Em cada trecho estudado, o PAR foi aplicado conjuntamente por dois avaliadores previamente treinados. A localização geográfica dos trechos avaliados pode ser observada na Figura 2 (Seção "Resultados e Discussão"). Vale salientar que essa etapa foi útil não apenas para avaliação/reconhecimento das condições ambientais atuais do rio Gualaxo do Norte, por meio do PAR, mas também para testar a aplicabilidade/viabilidade da ferramenta utilizada.

\subsection{Avaliação da aplicabilidade/viabilidade do protocolo proposto}

Após a aplicação do PAR adaptado, avaliou-se a aplicabilidade/viabilidade do protocolo proposto enquanto instrumento capaz de detectar com eficiência pequenos ou grandes impactos ambientais no rio avaliado. Essa avaliação foi realizada utilizando-se de informações de variada natureza, obtidas por meio da literatura científica, as quais incluíram, sobretudo, o histórico e o atual uso e ocupação da bacia do rio Gualaxo do Norte. Buscou-se nesse momento adotar um olhar crítico sobre o próprio método de avaliação e evitar vieses que pudessem influenciar essa etapa do estudo, como por exemplo, o grau de conhecimento dos pesquisadores sobre a região estudada. 
RODRIGUES, A. S. L.; MALAFAIA, G.; COSTA, A. T.; NALINI-JÚNIOR, H. A. Adequação e avaliação da aplicabilidade de um Protocolo de Avaliação Rápida na bacia do rio Gualaxo do Norte, Leste-Sudeste do Quadrilátero Ferrífero (MG, Brasil). Ambi-Agua, Taubaté, v. 7, n. 2, p. 231-244, 2012. (http://dx.doi.org/10.4136/ambi-agua.872)

\section{RESULTADOS E DISCUSSÃO}

Conforme pode ser observado na Figura 2, a avaliação do rio Gualaxo do Norte, apresentou resultados negativos, haja vista a obtenção de elevado percentual de ambientes classificados como regular e ruim, os quais juntos corresponderam a 77,4\% dos trechos analisados, sendo observada uma maior degradação ambiental na foz do referido rio. $\mathrm{O}$ Quadro 2 apresenta sumariamente as principais características registradas in situ que justificaram as notas atribuídas a cada trecho avaliado e, consequentemente, a classificação de suas condições ambientais.

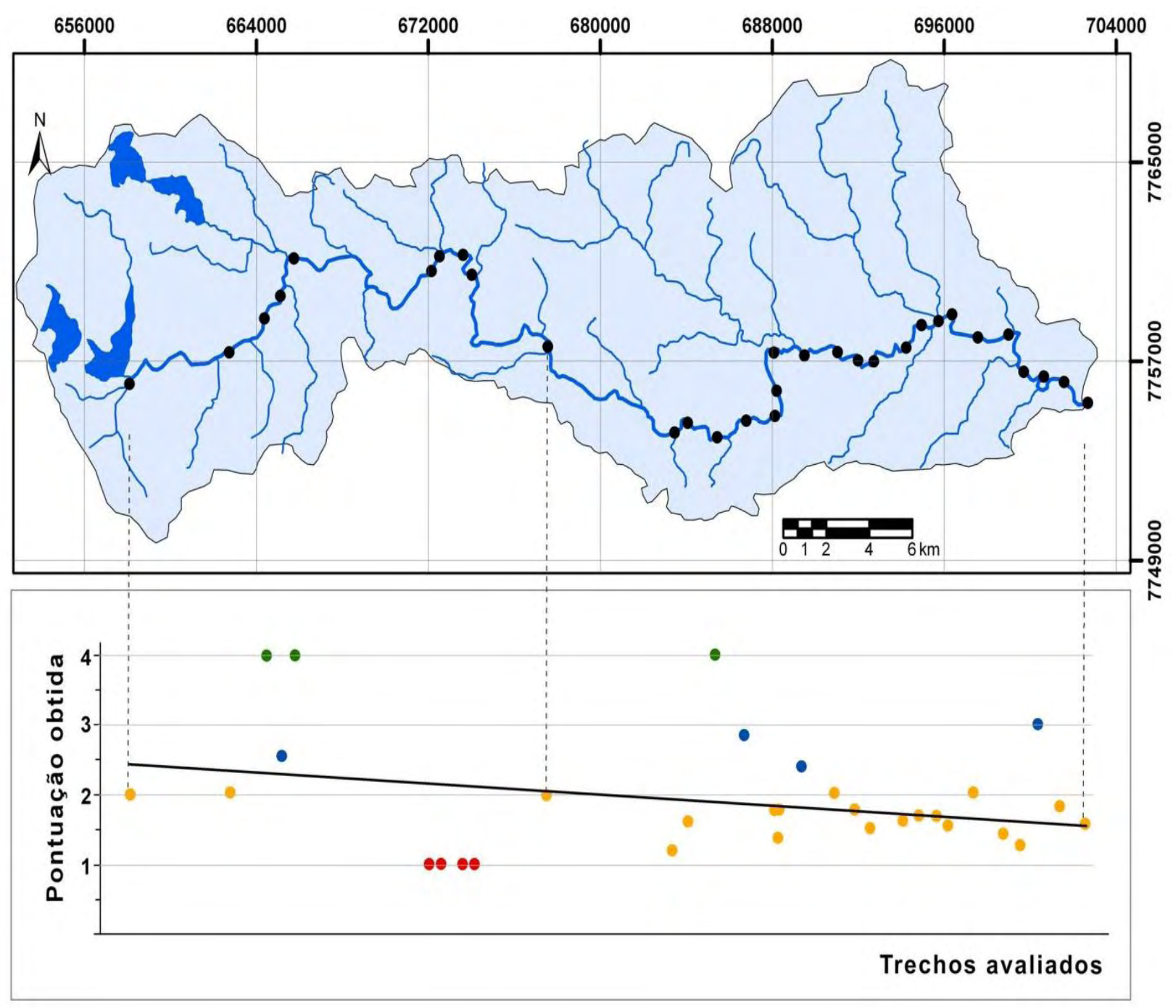

\section{LEGENDA DO MAPA}

- Trechos avaliados Rio Gualaxo do Norte

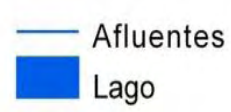

\section{LEGENDA DO GRÁFICO}

- Condição ruim - Condição boa

- Condição regular • Condição ótima

Figura 2. Localização dos trechos avaliados no rio Gualaxo do Norte e as respectivas pontuações obtidas por meio da aplicação do protocolo de avaliação rápida. As linhas tracejadas mostram a correspondência entre a localização do trecho avaliado e a sua pontuação. A linha contínua no gráfico representa a linha de tendência linear. 
RODRIGUES, A. S. L.; MALAFAIA, G.; COSTA, A. T.; NALINI-JÚNIOR, H. A. Adequação e avaliação da aplicabilidade de um Protocolo de Avaliação Rápida na bacia do rio Gualaxo do Norte, Leste-Sudeste do Quadrilátero Ferrífero (MG, Brasil). Ambi-Agua, Taubaté, v. 7, n. 2, p. 231-244, 2012. (http://dx.doi.org/10.4136/ambi-agua.872)

Quadro 2-Trechos avaliados, condições e suas principais características

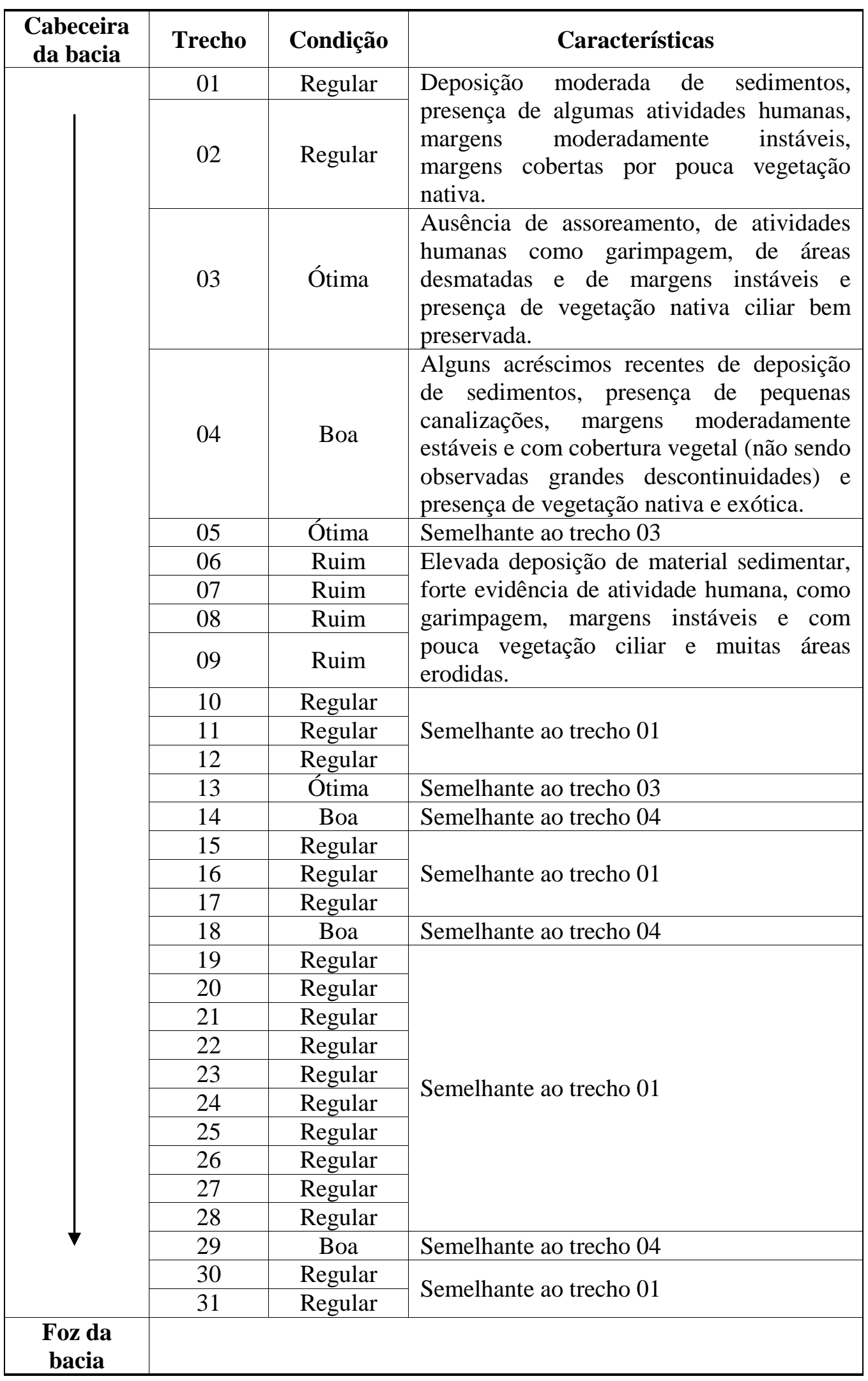

Os resultados específicos das avaliações dos parâmetros "deposição de sedimentos", "estabilidade das margens", "proteção das margens pela vegetação" e "estado de 
RODRIGUES, A. S. L.; MALAFAIA, G.; COSTA, A. T.; NALINI-JÚNIOR, H. A. Adequação e avaliação da aplicabilidade de um Protocolo de Avaliação Rápida na bacia do rio Gualaxo do Norte, Leste-Sudeste do Quadrilátero Ferrífero (MG, Brasil). Ambi-Agua, Taubaté, v. 7, n. 2, p. 231-244, 2012. (http://dx.doi.org/10.4136/ambi-agua.872)

conservação da vegetação do entorno", mostraram que os mesmos foram os que apresentaram as piores condições ambientais, quando comparados à condição referência, todos classificados em uma condição "regular" (médias de 1,97, 1,80, 1,71 e 1,71, respectivamente). Já os resultados da avaliação do parâmetro "alterações do canal" mostraram que este foi o único que apresentou uma condição classificada como "boa" (média de 2,61).

Em relação às atividades antrópicas observadas ao longo do rio Gualaxo do Norte, as mais comuns foram o desmatamento da vegetação do entorno para a criação de áreas de pastagens (observada em 76,2\% dos segmentos avaliados), os efeitos negativos no rio por atividades garimpeiras para a extração de ouro $(61,9 \%)$ e a substituição das áreas de mata nativa por áreas de cultivo $(52,4 \%)$. Poucos foram os trechos observados, nos quais havia presença de mata ciliar nativa e bem preservada. Construções de residências próximas às encostas, bem como lançamento de esgotos domésticos e presença de lixo nas margens e no leito do rio foram também observados. A Figura 3 ilustra de maneira esquemática as principais atividades antrópicas observadas ao longo do rio Gualaxo do Norte.

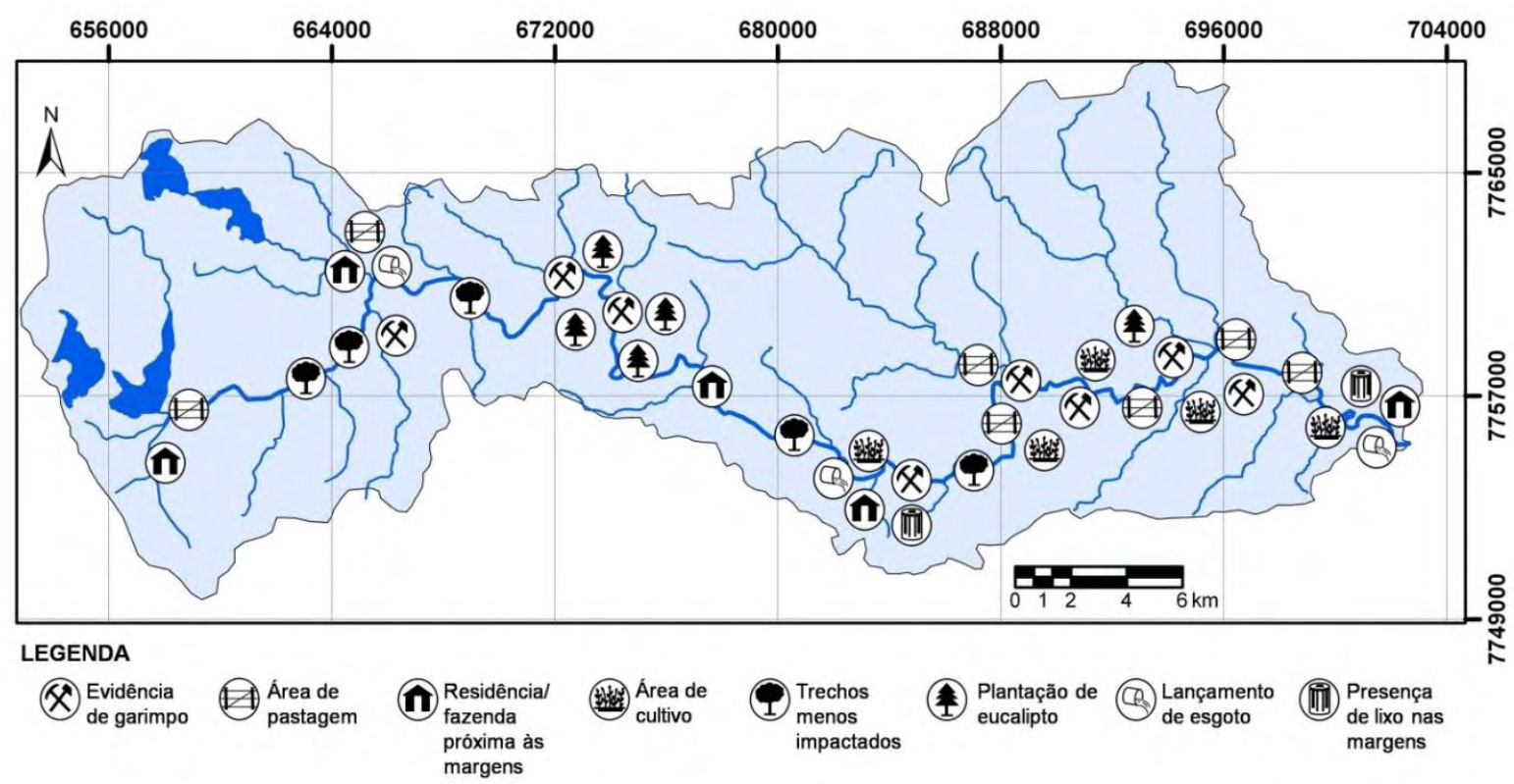

Figura 3. Principais atividades antrópicas observadas ao longo do rio Gualaxo do Norte, MG, Brasil.

A realização de avaliações ambientais ou de monitoramento contínuo de cursos d'água em diferentes contextos, certamente contribuem para identificação precoce de impactos que podem causar sérios e irreversíveis danos a esses ecossistemas. Contudo, é imprescindível que os instrumentos utilizados nessas avaliações ou nesses monitoramentos sejam sensíveis a ponto de detectar pequenas mudanças nas condições naturais desses ecossistemas e que sejam confiáveis e legítimos. Se porventura, esses instrumentos forem capazes de detectar apenas impactos fortemente evidenciados ou em estágios de degradação avançada, sua utilização pode ser considerada sem efeito.

Ao analisarmos especificamente os resultados da avaliação de cada parâmetro avaliado, alguns aspectos merecem destaque. Para o parâmetro "deposição de sedimentos", o PAR evidenciou uma pontuação que converge para uma condição "regular" (média de 1,97 pontos). De fato, em vários trechos avaliados foi possível observar claramente intensa deposição de sedimentos, como pode ser observado na Figura 4A e 4B, a qual pode estar 
RODRIGUES, A. S. L.; MALAFAIA, G.; COSTA, A. T.; NALINI-JÚNIOR, H. A. Adequação e avaliação da aplicabilidade de um Protocolo de Avaliação Rápida na bacia do rio Gualaxo do Norte, Leste-Sudeste do Quadrilátero Ferrífero (MG, Brasil). Ambi-Agua, Taubaté, v. 7, n. 2, p. 231-244, 2012. (http://dx.doi.org/10.4136/ambi-agua.872)

relacionada a processos de erosão observados em outros tantos trechos do rio principal e ao processo de exploração mineral histórico e atual na região da bacia estudada. Estudos desenvolvidos na área, sobretudo aqueles que enfocam análise da geoquímica de sedimentos fluviais, corroboram as evidências detectadas pelo PAR (Eleutério, 1997; Costa, 2001; Costa et al., 2003; Windmöller et al., 2007; Costa et al., 2010). Ressalta-se que a expansão das explorações do minério de ferro no alto curso da bacia tem contribuído para o aumento de sólidos em suspensão que se depositam no médio e baixo curso, principalmente durante o período chuvoso, conforme evidenciado recentemente por Rodrigues (2012).

Contudo, deve-se ressaltar que a avaliação da deposição de sedimentos no rio em questão foi prejudicada algumas vezes pela impossibilidade de visualização do leito do rio. Por se tratar de um rio de médio porte, o qual pode apresentar, naturalmente, trechos com maior profundidade, sobretudo, em remansos ou poços, a determinação do grau de deposição de sedimentos no fundo do rio foi impossibilitada (Figura 4B e 4C).

Outro problema refere-se à época em que o PAR deve ser aplicado. Se considerarmos sua aplicação em períodos de chuvas, mesmo naqueles trechos onde a profundidade é menor e que o leito do rio é evidente, a visibilidade do leito do rio será prejudicada, dada ao aumento da turbidez da água, inerente a essas épocas do ano. Nesses casos, tais constatações indicam que é necessário que uma avaliação cuidadosa desse parâmetro seja realizada, a fim de impedir a criação de vieses tendenciosos que mascarem as reais condições do rio sob avaliação. Sugerese, portanto, que a avaliação desse parâmetro seja realizara apenas em trechos de rios nos quais é visível o seu leito (e nesse caso, as notas dos trechos cuja visualização do leito é prejudicada não seria computada) ou apenas em épocas favoráveis a essa visualização (i.e.: estiagem).
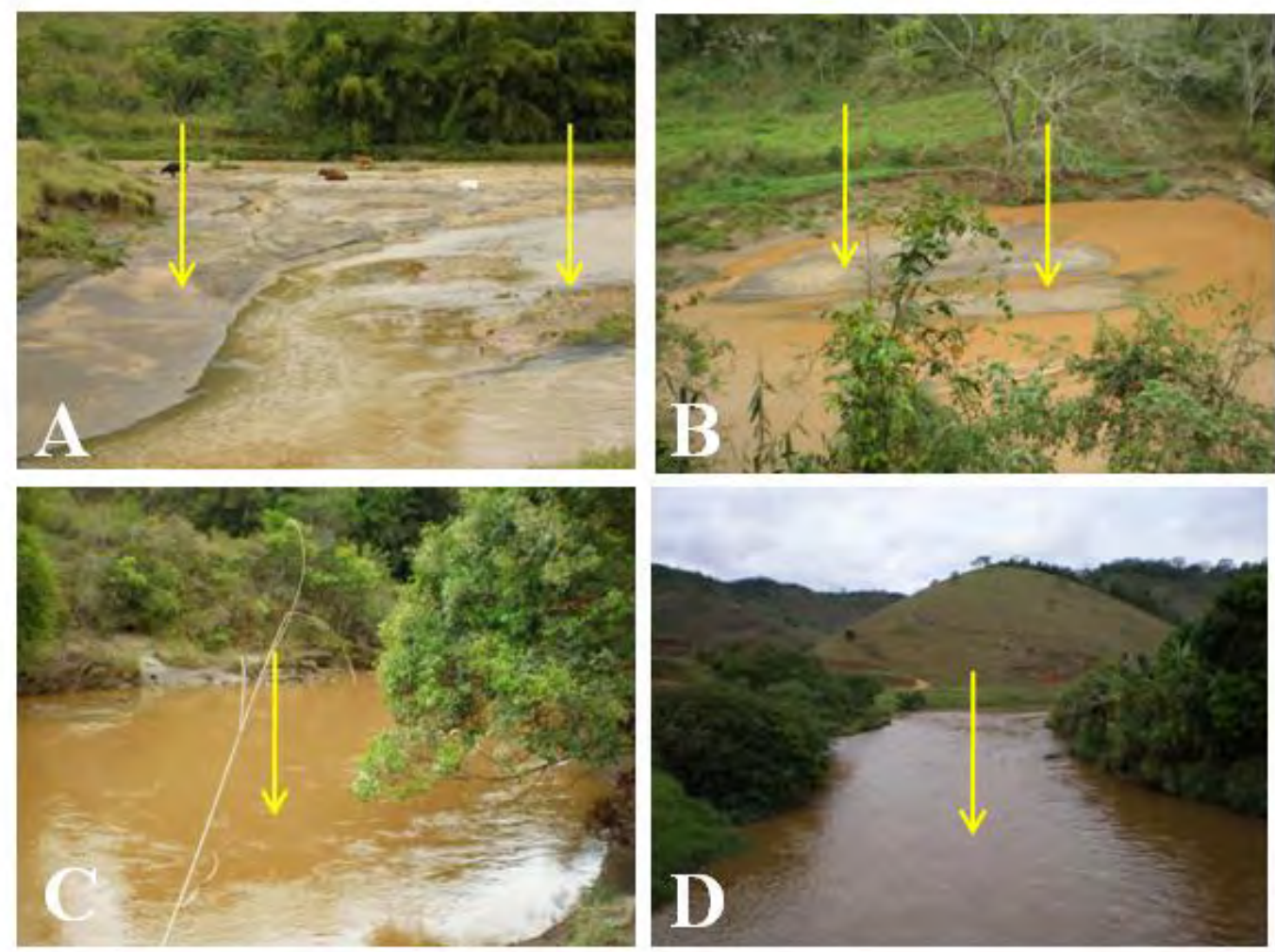

Figura 4. (A e B) Trechos do rio Gualaxo do Norte nos quais foi possível visualizar e avaliar o grau de deposição de sedimentos no seu leito (A e B) e trechos nos quais essa visualização/avaliação não foi possível (C e D). 
RODRIGUES, A. S. L.; MALAFAIA, G.; COSTA, A. T.; NALINI-JÚNIOR, H. A. Adequação e avaliação da aplicabilidade de um Protocolo de Avaliação Rápida na bacia do rio Gualaxo do Norte, Leste-Sudeste do Quadrilátero Ferrífero (MG, Brasil). Ambi-Agua, Taubaté, v. 7, n. 2, p. 231-244, 2012. (http://dx.doi.org/10.4136/ambi-agua.872)

Em relação ao parâmetro "alterações no canal", pode-se dizer que os resultados obtidos pelo PAR foram condizentes com a realidade observada. Embora se observe um crescimento populacional dos distritos e vilarejos localizados no entorno do rio Gualaxo do Norte, assim como a expansão das atividades relacionadas à agricultura e agropecuária na região (conforme discutido em Souza et al. (2005)), em geral, alterações drásticas no canal fluvial que têm como consequências, por exemplo, mudanças do curso do rio não, foram observadas.

As exceções englobam alguns poucos trechos com intensa atividade de exploração mineral recente, como por exemplo, aquela observada no garimpo do Engenho Podre no distrito de Monsenhor Horta (Mariana, MG) (Figura 5) e constatada também pelo trabalho de Amade e Lima (2009). De todo modo, estudos na área com enfoque em diagnóstico ambiental, ainda não foram conduzidos de forma sistemática, o que dificulta uma comparação dos dados obtidos neste estudo a trabalhos de natureza semelhante. Porém, considerando que não foram identificadas incoerências metodológicas, acredita-se que o PAR proposto tenha sido eficiente na avaliação desse parâmetro.
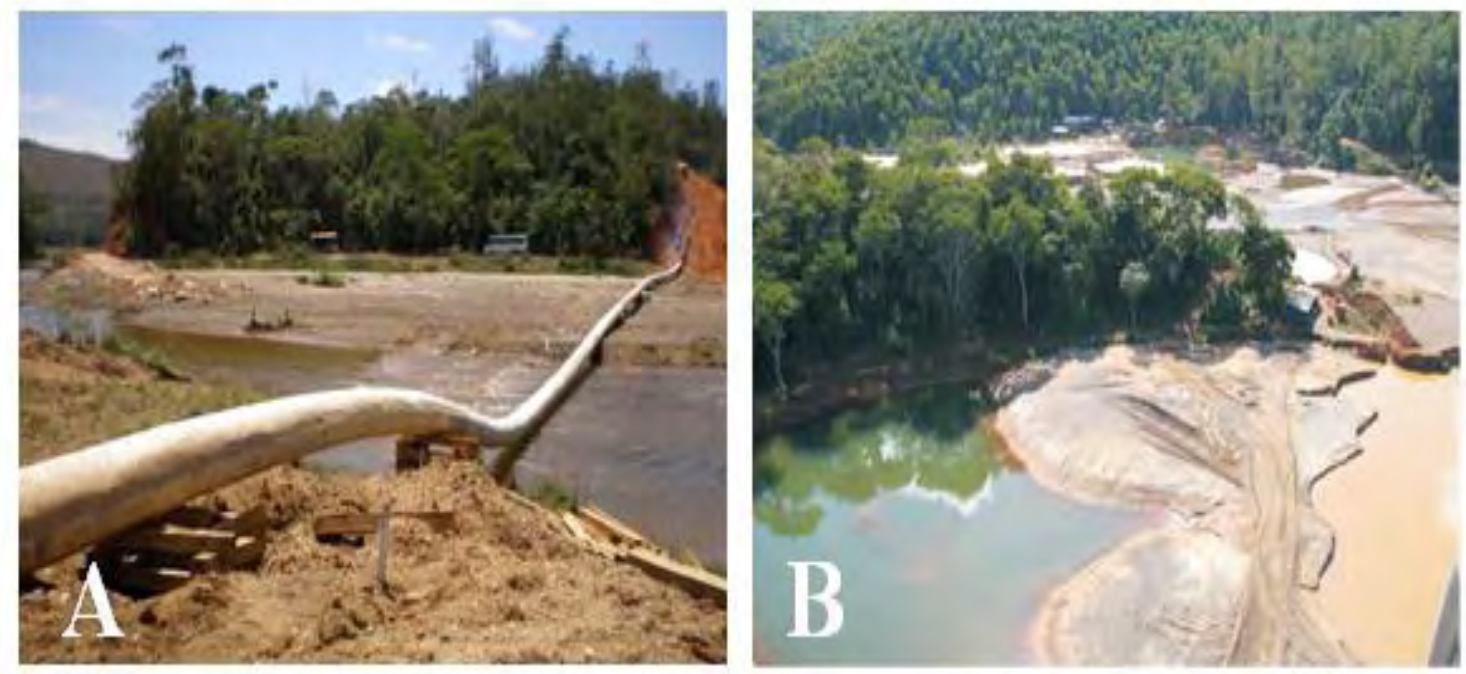

Figura 5. Fotos do Engenho Podre em Monsenhor Horta (Mariana, MG), as quais ilustram a influência do garimpo de ouro sobre o canal do rio Gualaxo do Norte. A foto em (B) foi extraída do estudo de Amade e Lima (2009).

Sobre o parâmetro "estabilidade das margens", o PAR evidenciou condições ruins ou regulares e de baixa qualidade ambiental em diversos trechos avaliados. De fato, as observações in situ aliadas a estudos realizados na bacia do rio Gualaxo do Norte que indiretamente mostram resultados semelhantes, dão sustentação aos resultados obtidos por meio da aplicação do PAR. É comum na área estudada a observação de margens erodidas próximas a áreas de pastagens ou agricultura, conforme pode ser observado na Figura 6. Um aspecto positivo do PAR utilizado refere-se à possibilidade de identificação de trechos com diferentes graus de erosão (que indicam um gradiente crescente de instabilidade das margens). Isso é importante, pois permite a identificação de trechos nos quais o processo erosivo é incipiente, sendo possível a adoção de medidas relativamente simples para o controle e estabilização das margens. 
RODRIGUES, A. S. L.; MALAFAIA, G.; COSTA, A. T.; NALINI-JÚNIOR, H. A. Adequação e avaliação da aplicabilidade de um Protocolo de Avaliação Rápida na bacia do rio Gualaxo do Norte, Leste-Sudeste do Quadrilátero Ferrífero (MG, Brasil). Ambi-Agua, Taubaté, v. 7, n. 2, p. 231-244, 2012. (http://dx.doi.org/10.4136/ambi-agua.872)

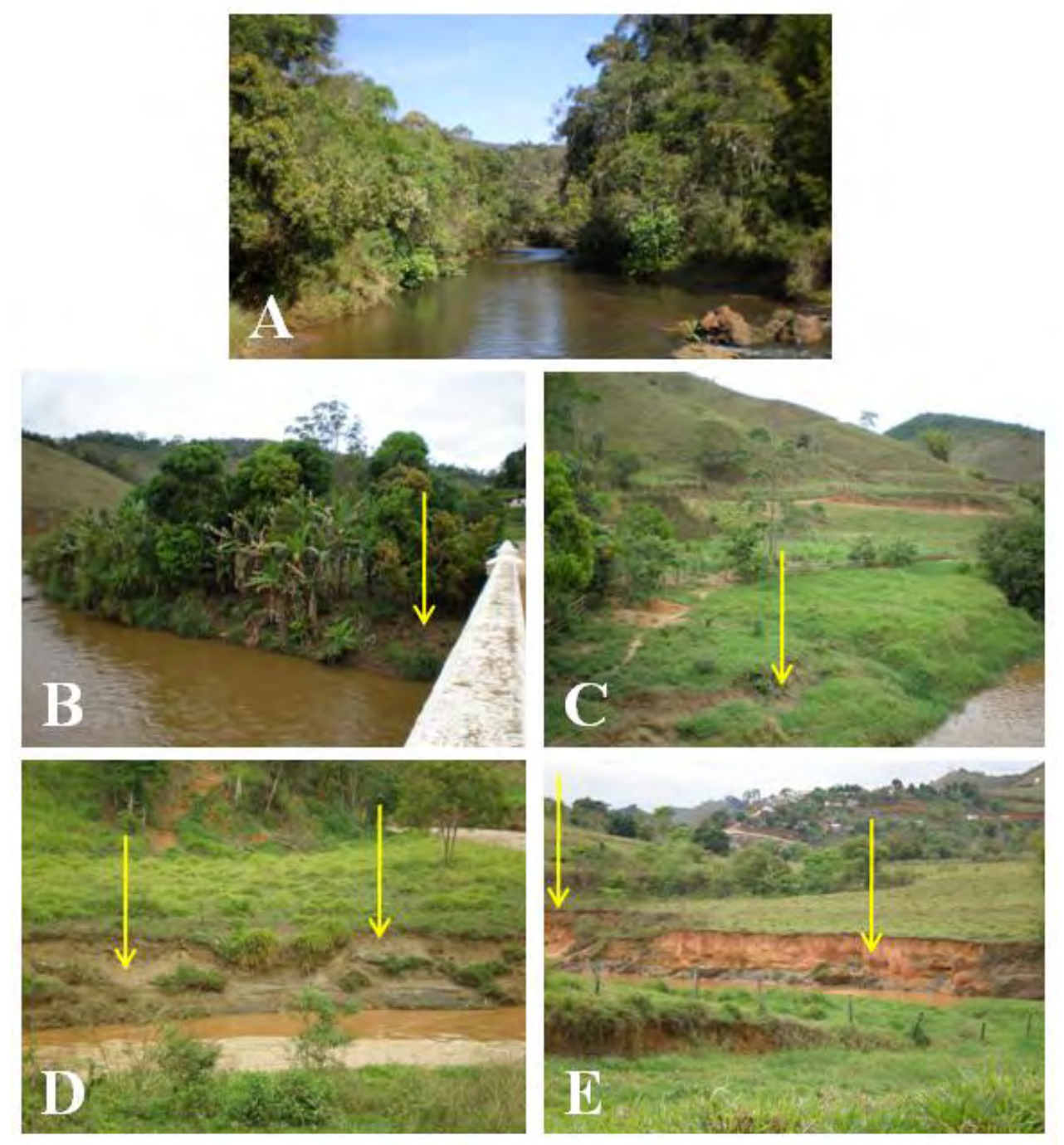

Figura 6. A) Exemplo de trecho cujas margens estão preservadas e sem sinal de erosão - condição "referência" e (B, C, D e E) exemplos de trechos que apresentam gradiente crescente, respectivamente, de erosão nas margens. As setas indicam margens em processo de erosão.

No que tange aos parâmetros "proteção das margens pela vegetação" e "estado de conservação da vegetação do entorno", os resultados obtidos pelo PAR também indicaram baixa qualidade ambiental para os mesmos. Outros estudos desenvolvidos na bacia do rio Gualaxo do Norte de fato demonstram, ainda que indiretamente, que em vários trechos não é possível observar vegetação ripária com características naturais ou vegetação do entorno com ausência total de interferência antrópica (Costa et al., 2007; Gazel et al., 2009; Oliveira et al., 2009; Gonçalves, 2009).

Isso pode ser explicado pelo uso intensivo das planícies de inundação e áreas adjacentes para criação de gado ou áreas de cultivo. Souza et al. (2005), em estudo sobre cartografia e diagnóstico geoambiental aplicados ao ordenamento territorial de Mariana, MG, destacaram que os sub-distritos de Paracatu e Pedras ao longo do rio Gualaxo do Norte estão entre as áreas da bacia cujas ocupações dessa natureza são mais representativas. Esses dados coincidem com os trechos evidenciados pelo PAR como aqueles que receberam baixas pontuações para o parâmetro "proteção das margens pela vegetação". Sendo assim, considerou-se eficiente a utilização do PAR para a avaliação desse parâmetro. 
RODRIGUES, A. S. L.; MALAFAIA, G.; COSTA, A. T.; NALINI-JÚNIOR, H. A. Adequação e avaliação da aplicabilidade de um Protocolo de Avaliação Rápida na bacia do rio Gualaxo do Norte, Leste-Sudeste do Quadrilátero Ferrífero (MG, Brasil). Ambi-Agua, Taubaté, v. 7, n. 2, p. 231-244, 2012. (http://dx.doi.org/10.4136/ambi-agua.872)

\section{CONCLUSÕES}

De acordo com os resultados, pôde-se concluir que o PAR adaptado se mostrou eficiente na avaliação das condições ambientais do rio sob investigação. As adaptações realizadas agregaram atributos básicos da ecomorfologia de ambientes fluviais, tanto presentes em áreas naturais ou pouco impactadas, quanto em áreas fortemente antropisadas. Contudo, evidenciou-se a necessidade de se ater para avaliação de parâmetros, pelo PAR, que podem ter sua visibilidade influenciada pelo período do ano (estiagem ou cheia) ou pela própria localização na bacia.

Em relação às avaliações realizadas no rio Gualaxo do Norte, pela aplicação do PAR, essas permitiram detectar prejuízos na condição ambiental de vários segmentos do rio Gualaxo do Norte.

\section{REFERÊNCIAS}

AMADE, P.; LIMA, H. M. Desenvolvimento sustentável e garimpo - O caso do garimpo do Engenho Podre em Mariana, Minas Gerais. REM: Revista da Escola de Minas, Ouro Preto, v. $62, \quad$ n. $2, \quad$ p. 237-242, 2009. http://dx.doi.org/10.1590/S037044672009000200016.

BARRELlA, W.; PETRERE JR., M.; SMITH, W. S.; MONTAG, L. F. A. As relações entre as matas ciliares, os rios e os peixes. In: RODRIGUES, R. M.; LEITÃ FILHO, H. F. Matas ciliares: conservação e recuperação. São Paulo: EDUSP; Fapesp, 2001. p. $187-$ 208.

CALliSTO, M.; FERREIRA, W.; MORENO, P.; GOULART, M. D. C.; PETRUCIO, M. Aplicação de um protocolo de avaliação rápida da diversidade de habitats em atividades de ensino e pesquisa (MG-RJ). Acta Limnologica Brasiliensia, Sorocaba, v. 14, n. 1, p. 91-98, 2002.

COSTA, A. A.; GONÇALVES, I. S.; DIAS, H. C. T. Avaliação da revegetação das margens do rio Gualaxo do Norte após a extração de ouro por draga em Mariana/MG. In: SEMINÁRIO DE RECURSOS HÍDRICOS DA BACIA HIDROGRÁFICA DO PARAÍBA DO SUL, 1., 2007, Taubaté. O eucalipto e o ciclo hidrológico. Anais... Taubaté: IPABHi, 2007. p. 275-278.

COSTA, A. T. Geoquímica das águas e dos sedimentos da Bacia do Rio Gualaxo do Norte, leste - sudeste do Quadrilátero Ferrífero (MG): estudo de uma área afetada por atividade de extração mineral. 2001. 146f. Dissertação (Mestrado em Evolução Crustal e Recursos Naturais) - Universidade Federal de Ouro Preto, Ouro Preto, 2001.

COSTA A. T.; NALINI JR., H. A.; LENA, J. C.; FRIESE, K.; MAGES, M. Surface water quality and sediment geochemistry in the Gualaxo do Norte basin, eastern Quadrilátero Ferrífero, Minas Gerais, Brazil. Environmental Geology, Alabama, v. 45, n. 2, p. 226235, 2003. http://dx.doi.org/10.1007/s00254-003-0870-6

COSTA, A. T.; NAlini JR., H. A.; CASTRO, P. T. A.; TATUMI, S. H. Análise estratigráfica e distribuição do arsênio em depósitos sedimentares quaternários da porção sudeste do Quadrilátero Ferrífero, bacia do Ribeirão do Carmo, MG. REM: Revista Escola de Minas, Ouro Preto, v. 63, n. 4, p. 703-714, 2010. 
RODRIGUES, A. S. L.; MALAFAIA, G.; COSTA, A. T.; NALINI-JÚNIOR, H. A. Adequação e avaliação da aplicabilidade de um Protocolo de Avaliação Rápida na bacia do rio Gualaxo do Norte, Leste-Sudeste do Quadrilátero Ferrífero (MG, Brasil). Ambi-Agua, Taubaté, v. 7, n. 2, p. 231-244, 2012. (http://dx.doi.org/10.4136/ambi-agua.872)

DILLENBURG, A. K. A importância do monitoramento ambiental na avaliação da qualidade de um rio - estudo de caso - Mercedes, PR. Revista Urutágua - Revista Acadêmica Multidisciplinar, Maringá, n. 12, p. 1-10, 2007.

ELEUTÉRIO, L. Diagnóstico da situação ambiental da cabeceira da bacia do rio Doce, MG, no âmbito das contaminações por metais pesados em sedimentos de fundo. 1997. 154f. Tese (Doutorado em Ciências Naturais) - Universidade Federal de Ouro Preto, Ouro Preto, 1997.

FIRMINO, P. F.; MALAFAIA, G.; RODRIGUES, A. S. L. Diagnóstico da integridade ambiental de trechos de rios localizados no município de Ipameri, Sudeste do Estado de Goiás, através de um protocolo de avaliação rápida. Brazilian Journal of Aquatic Science and Technology, Itajaí, v. 15, n. 2, p. 1-12, 2011.

GAZEL, D. L. T.; TAMOS, D. C.; DIAS, H. C. T. Revegetação das áreas mineiradas pela extração de ouro por draga nas margens do Rio Gualaxo do Norte, Mariana-MG. In: SEMINÁRIO DE RECURSOS HİDRICOS DA BACIA HIDROGRÁFICA DO PARAÍBA DO SUL, 2., 2009, Taubaté. Recuperação de áreas degradadas, serviços ambientais e sustentabilidade. Anais... Taubaté: IPABHi, 2009. p. 297-304.

GONÇALVES, I. S. Relação solo-vegetação em mata ciliar do Rio Gualaxo do Norte, município de Mariana, Minas Gerais. 2009. 90f. Dissertação (Mestrado em Ciência Florestal) - Universidade Federal de Viçosa, Viçosa, MG, 2009.

KRUPEK, R. A. Análise comparativa entre duas bacias hidrográficas utilizando um protocolo de avaliação rápida da diversidade de habitats. Ambiência, Guarapuava, v. 6, n. 1, p. 147-158, 2010.

LOBO, E. A.; VOOS, J. G.; ABREU JR., E. F. Utilização de um protocolo de avaliação rápida de impacto ambiental em sistemas lóticos do Sul do Brasil. Caderno de Pesquisa série Biologia, Santa Cruz, v. 23, n. 1, p. 18-33, 2011.

MINATTI-FERREIRA, D. D.; BEAUMORD, A. C. Avaliação rápida de integridade ambiental das sub-bacias do rio Itajaí-Mirim no Município de Brusque, SC. Revista Saúde e Ambiente, Joinville, v. 5, n. 2, p. 21-27, 2004.

MINATTI-FERREIRA, D. D.; BEAUMORD, A. C. Adequação de um protocolo de avaliação rápida de integridade ambiental para ecossistemas de rios e riachos: aspectos físicos. Revista Saúde e Ambiente, Joinville, v. 7, n. 1, p. 39-47, 2006.

OLIVEIRA, G. C.; DIAS, H. C. T.; MELO, F. O.; GONÇALVES, I. S. Identificação da zona ripária no rio Gualaxo do Norte através da fenologia da vegetação local. In: SEMINÁRIO DE RECURSOS HÍDRICOS DA BACIA HIDROGRÁFICA DO PARAÍBA DO SUL, 2., 2009, Taubaté. Recuperação de áreas degradadas, serviços ambientais e sustentabilidade. Anais... Taubaté: IPABHi, 2009. p. 601-608.

PADOVESI-FONSECA, C.; CORRÊA, A. C. G.; LEITE, G. F. M.; JOVELI, J. C.; COSTA, L. S.; PEREIRA, S. T. Diagnóstico da sub-bacia do reibeirão Mestre d'Armas por meio de dois métodos de avaliação ambiental rápida, Distrito Federal, Brasil Central. Revista Ambiente \& Água, Taubaté, v. 5, n. 1, p. 43-56, 2010. http://dx.doi.org/10.4136/ambiagua.118. 
RODRIGUES, A. S. L.; MALAFAIA, G.; COSTA, A. T.; NALINI-JÚNIOR, H. A. Adequação e avaliação da aplicabilidade de um Protocolo de Avaliação Rápida na bacia do rio Gualaxo do Norte, Leste-Sudeste do Quadrilátero Ferrífero (MG, Brasil). Ambi-Agua, Taubaté, v. 7, n. 2, p. 231-244, 2012. (http://dx.doi.org/10.4136/ambi-agua.872)

PLAFKIN, J. L.; BARBOUR, M. T.; PORTER, K. D.; GROSS, S. K.; HUGHES, R. M. Rapid bioassessment protocols for use in streams and rivers: benthic macroinvertebrates and fish. Washington: EPA, 1989. 339 p.

PRIMACK, R. B.; RODRIGUES, E. Biologia da conservação. Londrina: Vida, 2002. 328 p.

REBOUÇAS, A. C. Água doce no mundo e no Brasil. In: REBOUÇAS, A. C.; BRAGA, B.; TUNDISI, J. G. (Orgs.). Águas doces no Brasil: capital ecológico, uso e conservação. São Paulo: Escrituras, 2002. p. 1-37.

RODRIGUES, A. S. L. Caracterização da bacia do rio Gualaxo do Norte, MG, Brasil: avaliação geoquímica ambiental e proposição de valores de background. 2012. 184f. Tese (Doutorado em Ciências Naturais) - Universidade Federal de Ouro Preto, Ouro Preto, 2012.

RODRIGUES, A. S. L.; CASTRO, P. T. A. Protocolos de avaliação rápida: instrumentos complementares no monitoramento dos recursos hídricos. Revista Brasileira de Recursos Hídricos, Porto Alegre, v. 13, n. 1, p. 161-170, 2008a.

RODRIGUES, A. S. L.; CASTRO, P. T. A. Adaptation of a rapid assessment protocol for rivers on rocky meadows. Acta Limnologica Brasiliense, Sorocaba, v. 20, n. 4, p. 291 303, 2008b.

SOUZA, L. A.; SOBREIRA, F. G.; PRADO-FILHO, J. F. Cartografia e diagnóstico geoambiental aplicados ao ordenamento territorial do município de Mariana-MG. Revista Brasileira de Cartografia, Rio de Janeiro, v. 57, n. 3, p. 189-204, 2005.

TRAINA, S. J.; LAPERCHE, V. Contaminant bioavailability in soils, sediments, and aquatic environments. Proceedings of the National Academy of Sciences, Washington, v. 96, n. 7, p. 3365-3371, 1999. http://dx.doi.org/10.1073/pnas.96.7.3365.

VOGEL, H. F.; ZAWADZKI, C. H.; METRI, R. Florestas ripárias: importância e principais ameaças. Sabios: Revista de Saúde e Biologia, Campo Mourão, v. 4, n. 1, p. 24-30, 2009.

XAVIER, A. L.; TEIXEIRA, D. A. Diagnóstico das nascentes da sub-bacia hidrográfica do rio São João em Itaúna, MG. In: CONGRESSO DE ECOLOGIA DO BRASIL, 7., 2007, Caxambu. Anais... Caxambu: SEB, 2007. p. 1-2.

WINDMÖLLER, C. C.; SANTOS, R. C.; ATHAYDE, M.; PALMIERI, H. E. L. Distribuição e especiação de mercúrio em sedimentos de áreas de garimpo de ouro do Quadrilátero Ferrífero (MG). Química Nova, São Paulo, v. 30, n. 5, p. 1088-1094, 2007. http://dx.doi.org/10.1590/S0100-40422007000500007. 


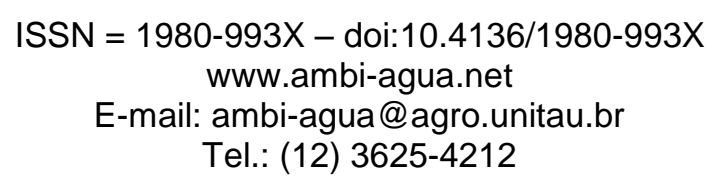

\title{
Qualidade da água de uma represa localizada em área agrícola (Campo Verde, MT, Brasil)
}

(http://dx.doi.org/10.4136/ambi-agua.904)

\section{Carolina Hortêncio Malheiros ${ }^{1}$; Edna Lopes Hardoim ${ }^{1}$; Zoraidy Marques de Lima ${ }^{1}$; Ricardo Santos Silva Amorim ${ }^{1}$}

\author{
${ }^{1}$ Programa de Pós-Graduação em Recursos Hídricos, \\ Universidade Federal de Mato Grosso, Cuiabá, Mato Grosso, Brasil, \\ e-mails: chmalheiros@gmail.com, ehardoim@terra.com.br, \\ zoraidy@terra.com.br, rsamorim@ufmt.br
}

\section{RESUMO}

No presente estudo avaliaram-se as mudanças espacial e temporal de algumas variáveis limnológicas de uma represa formada em uma das nascentes do Rio São Lourenço (Campo Verde, MT). A área de entorno da represa é utilizada para cultivo de soja, milho, algodão e pasto. Foram determinadas variáveis bióticas (bactérias heterotróficas e clorofila- $a$ ) e abióticas (precipitação, temperatura da água e do ar, condutividade elétrica, oxigênio dissolvido, $\mathrm{pH}$, turbidez, fósforo total, nitrito, nitrato e nitrogênio amoniacal) em três pontos amostrais na represa (entrada, meio e saída) e em três profundidades (superficial, Secchi e interface sedimento-água) da coluna d'água, bimestralmente, durante o ano de 2010. Para verificar a correlação entre as variáveis bióticas e abióticas e quais explicam melhor as variações dos dados entre os diferentes pontos de amostragem, profundidade da represa e períodos de observação. Foram analisadas a correlação de Spearman, componentes principais e de cluster. As análises mostraram uma forte correlação entre fatores como precipitação, bactérias heterotróficas, condutividade elétrica, turbidez e fósforo, indicando a influência da sazonalidade em áreas de cultivo. Observou-se que as variações entre os pontos de amostragem são mais significativas $(\mathrm{p}<0,01)$ do que na coluna d'água para a maioria das variáveis analisadas, provavelmente devido às características particulares de cada ponto de amostragem e por se tratar de uma represa com pouca profundidade.

Palavras-chave: atividades agrícolas, recursos hídricos, estatística multivariada.

\section{Quality of water of a dam located in an agricultural area (Campo Verde, MT, Brazil)}

\begin{abstract}
In this study spatial and temporal variations in limnological characteristics of a dam located in one of the headwaters of the São Lourenço River (Campo Verde, MT) were evaluated. The surrounding area is used for soybeans cultivation, corn, cotton, and pasture. We examined biotic (heterotrophic bacteria and chlorophyll a) and abiotic factors (precipitation, air and water temperature, electrical conductivity, dissolved oxygen, $\mathrm{pH}$, turbidity, total phosphorus, nitrite, nitrate, and ammonia nitrogen) at three sampling sites along the longitudinal axis of the water body, and at three depths (at the surface, the Secchi depth, and at the sediment-water interface). Samples were taken bimonthly during 2010. Spearman correlation analysis was used to examine the relationship between biotic and
\end{abstract}


MALHEIROS, C. H.; HARDOIM, E. L.; LIMA, Z. M.; AMORIM, R. S. S. Qualidade da água de uma represa localizada em área agrícola (Campo Verde, MT, Brasil) Ambi-Agua, Taubaté, v. 7, n. 2, p. xx-xxx, 2012. (http://dx.doi.org/10.4136/ambi-agua.904)

abiotic variables, and then principal components and cluster analyses were used to study the relationship between these factors and the variability observed among the various sampling sites, dam depths, and periods of observation. The analyses showed a strong correlation between factors such as rainfall, heterotrophic bacteria, conductivity, turbidity, and phosphorus, indicating the influence of seasonality in cultivated areas. It was observed that the variations between the sampling sites were more significant $(p<0.01)$ than in the water column for most of the variables, probably due to the particular characteristics of each sample point and its shallow water column.

Keywords: agricultural activities, water resources, multivariate statistics.

\section{INTRODUÇÃO}

A qualidade das águas de um ecossistema aquático é o reflexo do uso e ocupação do solo ao seu entorno (Shrestha e Kazama, 2007), que afeta a qualidade e quantidade da água dos rios, em particular e podendo modificar as características geomorfológicas e intensificar as fontes de poluição dos sistemas fluviais (Zhou et al., 2012).

Os rios acabam se tornando destinatários de poluentes das paisagens adjacentes, atuando como integradores das interações terra-água. Assim, suas condições, como a quantidade e qualidade da água não são apenas indicativos da saúde dos ecossistemas em si, mas também das paisagens circundantes. A qualidade da água do rio também é influenciada por ambos os fatores biofísicos e socioeconômicos adjacentes (Zhou et al., 2012).

O desenvolvimento econômico e social de qualquer país está fundamentado na disponibilidade de água de boa qualidade e na sua capacidade de conservação e proteção dos mananciais. Deste ponto de vista, aspectos relacionados com qualidade apresentam-se tão ou mais importantes que aqueles envolvendo apenas questões relacionadas com a quantidade de água disponível (Zimmermann et al., 2008).

O Estado de Mato Grosso, como o restante do país, tem tido grandes mudanças em seu aspecto socioeconômico. Isso é resultante do acelerado crescimento populacional, industrial e agropecuário, que têm proporcionado impactos principalmente sobre os recursos hídricos, tendo em vista o caráter eminentemente agrícola do Estado, o qual ocupa o $2^{\circ}$ lugar $(19,3 \%)$ na produção nacional de grãos (IBGE, 2011).

Esforços devem ser empregados para evitar a degradação de corpos hídricos que ainda estão preservados e para melhorar aqueles que já estão com problemas de degradação. Sendo necessário o desenvolvimento de pesquisas para se entender os processos físicos, químicos e biológicos que atuam nesses ambientes para, assim, serem elaboradas medidas mitigadoras que possam conter o avanço da degradação (Nascimento et al., 2011). Os estudos limnológicos são fundamentais para a compreensão dos impactos das atividades humanas sobre os recursos hídricos. Além de prognosticarem tendências e características de ecossistemas aquáticos ao longo do tempo, estes estudos auxiliam no controle de processos como a eutrofização (Tundisi e Matsumura-Tundisi, 2008).

$\mathrm{Na}$ avaliação de dados de monitoramento ambiental, técnicas de estatística multivariada, como Análise da Componente Principal (PCA), vem sendo empregada com muita frequência (Andrade et al., 2005; Meireles et al., 2005; Andrade et al., 2007), uma vez que representa uma forma exploratória de conhecer o comportamento dos dados no ambiente estudado. Esta técnica permite selecionar as variáveis mais representativas do corpo hídrico, favorecendo a definição de indicadores mais sensíveis, tanto para adoção de um programa de monitoramento como para avaliação das alterações ocorridas nos recursos hídricos (Toledo e Nicolella, 2002). 
MALHEIROS, C. H.; HARDOIM, E. L.; LIMA, Z. M.; AMORIM, R. S. S. Qualidade da água de uma represa localizada em área agrícola (Campo Verde, MT, Brasil) Ambi-Agua, Taubaté, v. 7, n. 2, p. xx-xxx, 2012. (http://dx.doi.org/10.4136/ambi-agua.904)

As análises de cluster e de PCA podem indicar associações entre amostras e variáveis. Essas associações, baseadas na magnitude similar ou nas variações dos constituintes físicos e químicos, podem indicar a presença de influências sazonais ou antrópicas, como a agrícola.

Dessa forma, percebe-se a importância de estudos que contemplem aspectos bióticos e abióticos dos ecossistemas aquáticos do Estado de Mato Grosso, que detém importantes bacias fluviais. Muitos desses ecossistemas estão alterados, principalmente com referência as suas características abióticas, uma vez que a produção agrícola é um dos principais fatores que acarretam prejuízos à biodiversidade, qualidade e quantidade dos recursos hídricos.

Nesse sentido, objetivou-se com o presente estudo avaliar a variabilidade espacial e temporal das características bióticas e abióticas da água de uma represa localizada em área agrícola, no município de Campo Verde, Mato Grosso, com vistas a identificar possíveis mudanças espaço-temporal na qualidade da água, bem como a influência dos fatores abióticos sobre a distribuição e abundância de bactérias heterotróficas. No município de Campo VerdeMT, os possíveis impactos ambientais causados pelo predomínio da agricultura e sua consequente adoção de insumos agrícolas e pesticidas, justificam o desenvolvimento de estudos sobre a abundância e diversidade de bactérias em uma represa localizada numa das nascentes do Rio São Lourenço.

\section{MATERIAL E MÉTODOS}

\subsection{Caracterização da área de estudo}

Campo Verde situa-se na Latitude S 15³7'19,4” e Longitude W 55¹0’29,6”' (Figura 1), com altitude de $735 \mathrm{~m}$, localizada a $127 \mathrm{~km}$ da capital do Estado de Mato Grosso, possui área de $4.782 \mathrm{Km}^{2}$ e uma população de 31.612 habitantes. O clima é tropical quente e sub-úmido, com temperatura variando entre $18{ }^{\circ} \mathrm{C}$ a $24{ }^{\circ} \mathrm{C}$, com máxima de $34{ }^{\circ} \mathrm{C}$, sendo quatro meses de seca, de maio a agosto. Precipitação anual de $1.750 \mathrm{~mm}$, com intensidade máxima em dezembro, janeiro e fevereiro (IBGE, 2011).

A área de estudo compreende uma das nascentes do Rio São Loureço em Campo Verde,

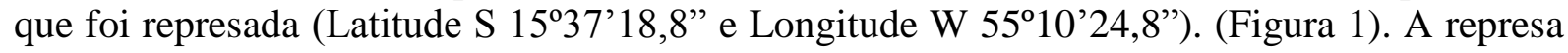
possui aproximadamente $232 \mathrm{~m}$ de comprimento e é caracterizada pela elevada quantidade de macrófitas aquáticas submersas por toda sua extensão. $\mathrm{O}$ solo predominante na área é Latossolo Vermelho-Amarelo e a cobertura vegetal é de mata nativa em recuperação e em suas adjacências há grandes áreas cultivadas com algodão, soja e milho, o que favorece a entrada de elementos químicos na represa devido a aplicação de pesticidas e insumos agrícolas.

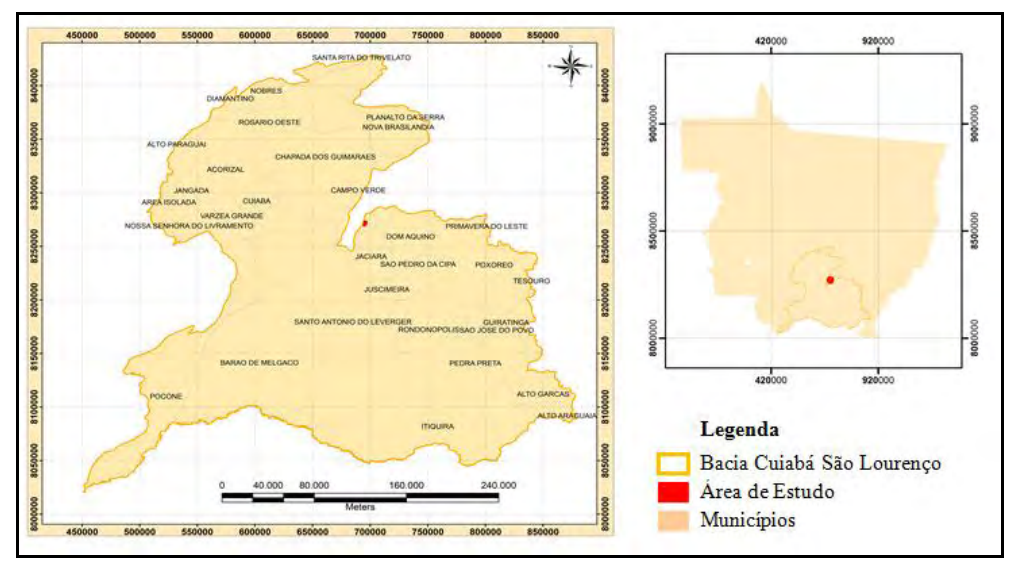

Figura 1. Mapa de localização da área de estudo inserida na nascente do Rio São Lourenço no Município de Campo Verde, Mato Grosso.

Fonte: SEPLAN (Mato Grosso, 2000); Araújo e Zeilhofer (2011). 
Uma das grandes preocupações com a qualidade da água de nascentes da bacia hidrográfica do Rio São Lourenço (coordenadas $16^{\circ} 08^{\prime} 15^{\prime \prime}$ e $17^{\circ} 11^{\prime} 22^{\prime \prime S}$ e 5348'16”, 03 e 54¹9'3,6”W) (Araujo e Zeilhofer, 2011) está relacionada principalmente ao uso e ocupação do solo nessa região, sendo o Rio São Lourenço um dos principais afluentes da planície inundável do Pantanal Mato-Grossense. Dessa forma, uma parte do sedimento introduzido em cursos d'água no planalto e dos compostos químicos utilizados nessas áreas de nascente podem ser carreados para o Pantanal, uma das maiores extensões úmidas contínuas do planeta, considerado Patrimônio Nacional pela Constituição Federal de 1988 e Reserva da Biosfera pela UNESCO no ano de 2000, bioma esse que possui grande diversidade biológica. Ressalta-se que as bacias hidrográficas são unidades de planejamento de uso da terra, ocorrendo ali uma grande interação dos produtores rurais, e de outras pessoas que ali vivem com os recursos naturais.

\subsection{Pontos de amostragem}

Os pontos de amostragem foram definidos de maneira a representar aquele ecossistema aquático e identificar possíveis influências antrópicas e sazonais na qualidade da água da represa. Dessa forma foram coletadas amostras na coluna d'água em três pontos amostrais, sendo a distância entre os pontos amostrais de aproximadamente $100 \mathrm{~m}$ (Figura 2).

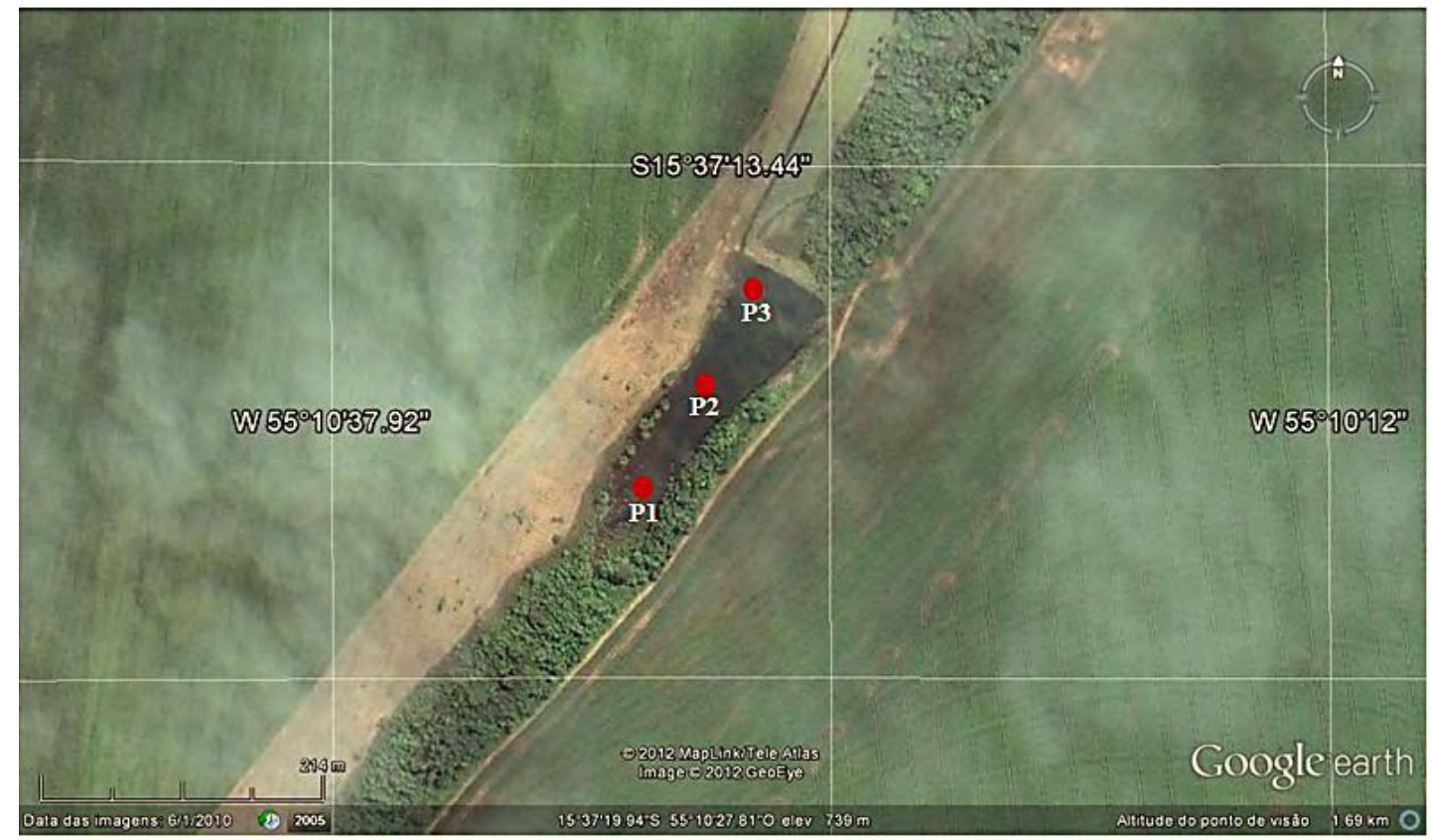

Figura 2. Estações de amostragem de água da represa inserida na nascente do Rio São Lourenço no Município de Campo Verde, Mato Grosso.

Fonte: Google Earth (2010).

As amostras de água sub-superficiais (10 $\mathrm{cm}$ abaixo da superfície) foram coletadas em tréplicas, sendo: $\mathrm{P} 1$ - entrada da represa, que possui mata ciliar, pois é próximo à nascente, e tem grande quantidade de troncos e restos de vegetação provenientes do represamento; P2 zona limnética e mais profunda; e P3 - saída da represa, uma área mais aberta, com pouca vegetação e ausência de mata ciliar. As amostras da coluna d'água foram coletadas em tréplicas com auxílio da garrafa de Van Dorn (APHA, 1998). As coletas foram feitas bimestralmente durante o período de janeiro a novembro de 2010, compreendendo dois períodos sazonais (seco e chuvoso), dessa forma a profundidade da represa foi mensurada nos três pontos amostrais em todos os meses de coleta.

\subsection{Variáveis bióticas e abióticas analisadas}


MALHEIROS, C. H.; HARDOIM, E. L.; LIMA, Z. M.; AMORIM, R. S. S. Qualidade da água de uma represa localizada em área agrícola (Campo Verde, MT, Brasil) Ambi-Agua, Taubaté, v. 7, n. 2, p. xx-xxx, 2012. (http://dx.doi.org/10.4136/ambi-agua.904)

As variáveis oxigênio dissolvido, $\mathrm{pH}$, condutividade elétrica e temperatura da água foram obtidas in loco com auxílio de medidor multiparamétrico (Hach Hq40d). A temperatura do ar, por sua vez, foi obtida com auxílio de um termômetro com bulbo de mercúrio. A determinação da turbidez, cor aparente, fósforo total, nitrogênio amoniacal, nitrato e nitrito seguiu o Standart Methods (APHA, 1998). Para avaliar as características físicas e químicas do ambiente aquático e as relações com a dinâmica da comunidade bacteriana utilizou-se como referência os parâmetros estabelecidos na Resolução CONAMA 357/05 para corpos d'água de Classe II (Brasil, 2005). Os dados secundários de pluviometria foram disponibilizados pelo administrador da fazenda onde foi realizado o presente estudo, sendo considerado o acúmulo mensal de precipitação. As análises microbiológicas foram feitas por meio da contagem geral de bactérias heterotróficas cultiváveis, sendo as amostras de água diluídas dentro das potências $10^{-1}$ a $10^{-4}$ e plaqueadas pelo método de pour plate em triplicatas no meio Ágar Nutriente (AN). A diluição tem a função de facilitar a contagem de colônias em placa, pois as amostras podem se encontrar concentradas, o que prejudicaria a análise. A determinação do pigmento fotossintetizante clorofila- $a$ foi feita conforme CETESB (1990).

\subsection{Análises estatísticas}

A análise da componente principal (ACP) foi aplicada aos dados para avaliar as associações entre as variáveis, evidenciando a participação individual dos elementos físicos, químicos e biológicos na qualidade das águas. Nas análises estatísticas utilizou-se o software Microsoft Office Excel ${ }^{\circledR}$ para transformar os dados microbiológicos em escala logarítmica e também na padronização e escalonamento dos dados de diversas ordens de grandeza e unidades específicas de medida, em valores compatíveis, passíveis de comparação (Moita Neto e Moita, 1998). Utilizou-se o pacote estatístico SPSS 15.0 no coeficiente de correlação, nas análises de componentes principais e análise de agrupamento.

Calculou-se o coeficiente de correlação de Spearman (r) entre as variáveis bióticas e abióticas analisadas durante o período de amostragem, sendo os coeficientes de correlação analisados ao nível de significância de 5 e $1 \%$ de probabilidade.

Fez-se uma análise de componentes principais (ACP) para verificar quais variáveis bióticas e abióticas mais explicam as variações dos dados entre os diferentes pontos de amostragem, profundidade da represa e períodos de observação, permitindo visualizar as variações na composição das comunidades avaliadas no espaço e no tempo. Bengraine e Marhaba (2003) definem a ACP como um método indicado para a análise de variações espaciais e temporais da qualidade de água como também para o estudo das possíveis relações entre uso e ocupação do solo e qualidade de água. O método das componentes principais consiste essencialmente em reescrever as coordenadas das variáveis em outro sistema de eixo mais conveniente para a análise dos dados. Em outras palavras, as n-variáveis originais geram, por meio de suas combinações lineares, n-componentes principais, cuja principal característica, além da ortogonalidade, é que são obtidas em ordem decrescente de máxima variância (Andrade et al., 2007)

Após a realização da ACP, fez-se a análise de cluster utilizando as variáveis que explicavam $60 \%$ dos resultados obtidos na análise de componentes principais. Na análise de agrupamentos (cluster analysis) a similaridade entre duas amostras pode ser expressa com uma função da distância entre os dois pontos representativos destas amostras no espaço ndimensional (Moita Neto e Moita, 1998; Vega et al., 1998). A técnica de agrupamento interliga as amostras por suas associações, produzindo um dendrograma onde as amostras semelhantes, segundo as variáveis escolhidas, são agrupadas entre si, sendo que quanto menor a distância entre os pontos, maior a semelhança entre as mesmas (Moita Neto e Moita, 1998). 
MALHEIROS, C. H.; HARDOIM, E. L.; LIMA, Z. M.; AMORIM, R. S. S. Qualidade da água de uma represa localizada em área agrícola (Campo Verde, MT, Brasil) Ambi-Agua, Taubaté, v. 7, n. 2, p. xx-xxx, 2012. (http://dx.doi.org/10.4136/ambi-agua.904)

\section{RESULTADOS E DISCUSSÃO}

O conjunto de dados da profundidade da represa mensurada em todas as coletas, considerando as variações sazonais no nível d'água, em cada um dos três pontos amostrais, é apresentado na Tabela 1, onde se observa maior profundidade em P2, devido a esse ponto amostral localizar-se na região limnética da represa, com profundidade maior. Já P1 e P3, região litorânea, apresentaram profundidade máxima de 1,55 e 1,60 m, respectivamente. A transparência da água nesses pontos amostrais foi de $100 \%$.

Tabela 1. Profundidade (m) dos pontos amostrais.

\begin{tabular}{c|cccccc}
\hline Pontos & Jan/10 & Mar/10 & Mai/10 & Jul/10 & Set/10 & Nov/10 \\
\hline P1 & 1,20 & 0,72 & 1,50 & 1,43 & 1,55 & 1,40 \\
P2 & 2,94 & 1,85 & 2,95 & 2,83 & 2,80 & 2,70 \\
P3 & 1,20 & 1,10 & 1,20 & 1,10 & 1,60 & 1,29 \\
\hline
\end{tabular}

Legenda: P1 - ponto amostral 1 (entrada da represa); P2 - ponto amostral 2 (centro da represa); P3 - ponto amostral 3 (saída da represa).

Na Tabela 2 são apresentadas as médias, os valores mínimos e máximos e desvio padrão das variáveis analisadas que permitiram verificar a qualidade da água em cada ponto amostral da represa estudada. Nota-se, para a temperatura do ar, valores mais elevados em P1 em todos os meses de coleta, sendo as coletas nesse ponto amostral feitas sempre no final da manhã, período de grande incidência solar. Este fato deve ter influenciado, também, nos valores mais elevados da temperatura da água superficial nos meses de coleta, com exceção no mês de novembro, nesse mesmo ponto amostral. A temperatura do ar também esteve mais elevada nos meses de maio, julho e setembro, que foram os meses de seca indicando que a temperatura é a variável mais influenciada pela sazonalidade.

Como esperado, a temperatura da água diminuiu com o aumento da profundidade, resultado semelhante foi encontrado por Bambi et al. (2008) na Baía das Pedras, MT, sendo os maiores valores obtidos na superfície e os menores nas camadas inferiores da Baía. No presente estudo esse comportamento foi observado em todos os pontos de coleta, embora essa diferença de temperatura da água não tenha sido tão acentuada com a profundidade.

As concentrações de oxigênio dissolvido variaram de $0,42 \mathrm{mg} \mathrm{L}^{-1}$ em P2 SEC e P2 SED a 8,25 mg L ${ }^{-1}$ em P1 SUP (Tabela 2). Com exceção do mês de novembro em P1 SED, P2 SEC e P2 SED, todos os valores estiveram dentro do estabelecido pela Resolução CONAMA 357/05 (Brasil, 2005), que define $5 \mathrm{mg} \mathrm{L}^{-1}$ como valor de OD mínimo. Ao longo do período da pesquisa foi observado apenas um processo de estratificação, em P2, região mais profunda da represa. Este ponto amostral apresentou, ainda, característica de alta produção primária, com concentrações elevadas de clorofila- $a$ e grande quantidade de macrófitas submersas.

A Resolução CONAMA 357/05 (Brasil, 2005), estabelece para corpos hídricos de água doce $\mathrm{pH}$ na faixa de 6,0 a 9,0. Valores abaixo de 6,0 foram registrados em todos os pontos amostrais (Tabela 2). $\mathrm{O} \mathrm{pH}$ medido neste estudo mostrou-se predominantemente ácido, cabendo ressaltar que a grande maioria das águas superficiais do cerrado tem seu $\mathrm{pH}$ influenciado pelo solo dessa região, provavelmente devido aos altos teores de ferro e a acidez trocável de solos. Os valores de fósforo total estiveram dentro de permitido pela legislação apenas em P2 SEC (Tabela 2). A Resolução CONAMA 357/05 (Brasil, 2005) estabelece valores de fósforo total, para ambientes intermediários, de até $0,050 \mathrm{mg} \mathrm{L}^{-1}$. As demais variáveis analisadas apresentaram valores dentro do estabelecido pela Resolução CONAMA 357/05 (Brasil, 2005). 
MALHEIROS, C. H.; HARDOIM, E. L.; LIMA, Z. M.; AMORIM, R. S. S. Qualidade da água de uma represa localizada em área agrícola (Campo Verde, MT, Brasil) Ambi-Agua, Taubaté, v. 7, n. 2, p. xx-xxx, 2012. (http://dx.doi.org/10.4136/ambi-agua.904)

Tabela 2. Médias, valores mínimos e máximos e desvio padrão das variáveis analisadas.

\begin{tabular}{|c|c|c|c|c|c|c|c|c|}
\hline Variáveis & Valores & P1 SUP & P1 SED & P2 SUP & P2 SEC & P2 SED & P3 SUP & P3 SED \\
\hline \multirow{4}{*}{$\ddot{\Xi}$} & Média & 29,7 & 29,7 & 28,1 & 28,1 & 28,1 & 26,5 & 26,5 \\
\hline & Mínimo & 25,9 & 25,9 & 24,0 & 24,0 & 24,0 & 24,0 & 24,0 \\
\hline & Máximo & 38,0 & 38,0 & 36,0 & 36,0 & 36,0 & 31,0 & 31,0 \\
\hline & Desvio padrão & 4,4 & 4,4 & 4,1 & 4,1 & 4,1 & 3,2 & 3,2 \\
\hline \multirow{4}{*}{ 常 } & Média & 25,4 & 24,0 & 24,8 & 24,5 & 24,4 & 24,6 & 24,1 \\
\hline & Mínimo & 24,2 & 22,4 & 23,0 & 22,0 & 22,0 & 22,4 & 21,9 \\
\hline & Máximo & 28,0 & 25,5 & 26,3 & 26,2 & 25,7 & 26,2 & 26,0 \\
\hline & Desvio padrão & 1,47 & 1,13 & 1,25 & 1,55 & 1,42 & 1,45 & 1,47 \\
\hline \multirow{4}{*}{ อิ } & Média & 6,46 & 5,74 & 7,24 & 6,14 & 5,82 & 7,48 & 7,38 \\
\hline & Mínimo & 5,70 & 3,47 & 6,47 & 0,42 & 0,42 & 6,51 & 6,48 \\
\hline & Máximo & 8,25 & 8,17 & 7,89 & 7,99 & 7,90 & 8,22 & 8,04 \\
\hline & Desvio padrão & 1,01 & 1,50 & 0,62 & 2,87 & 2,77 & 0,65 & 0,55 \\
\hline \multirow{4}{*}{ 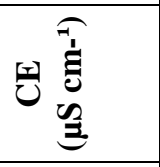 } & Média & 5,08 & 11,67 & 4,76 & 7,01 & 10,81 & 4,86 & 4,85 \\
\hline & Mínimo & 4,14 & 4,38 & 2,43 & 2,56 & 2,61 & 2,24 & 2,40 \\
\hline & Máximo & 7,44 & 34,10 & 11,05 & 13,38 & 37,80 & 10,71 & 10,77 \\
\hline & Desvio padrão & 1,28 & 11,43 & 3,30 & 5,07 & 13,62 & 3,39 & 3,26 \\
\hline \multirow{4}{*}{ 풀 } & Média & 4,88 & 4,78 & 4,98 & 5,34 & 5,23 & 5,98 & 5,84 \\
\hline & Mínimo & 4,75 & 4,41 & 4,57 & 5,01 & 4,70 & 5,15 & 5,00 \\
\hline & Máximo & 5,15 & 5,21 & 5,33 & 5,98 & 5,61 & 7,54 & 7,49 \\
\hline & Desvio padrão & 0,14 & 0,32 & 0,34 & 0,37 & 0,35 & 0,95 & 1,04 \\
\hline \multirow{4}{*}{ 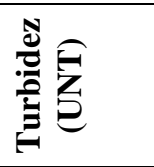 } & Média & 2,47 & 19,37 & 1,91 & 3,45 & 13,76 & 1,95 & 7,28 \\
\hline & Mínimo & 1,99 & 2,90 & 1,42 & 1,86 & 8,05 & 1,47 & 2,68 \\
\hline & Máximo & 3,43 & 38,56 & 2,50 & 3,58 & 25,10 & 2,49 & 11,04 \\
\hline & Desvio padrão & 0,54 & 15,15 & 0,44 & 1,37 & 7,53 & 0,44 & 5,09 \\
\hline \multirow{4}{*}{$\ddot{\theta}$} & Média & 20 & 55 & 20 & 30 & 60 & 20 & 30 \\
\hline & Mínimo & 5 & 20 & 5 & 10 & 10 & 10 & 10 \\
\hline & Máximo & 40 & 100 & 40 & 40 & 100 & 40 & 70 \\
\hline & Desvio padrão & 14 & 30 & 16 & 12 & 32 & 13 & 24 \\
\hline \multirow{4}{*}{ 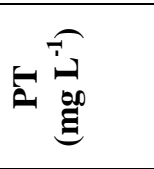 } & Média & 0,04 & 0,13 & 0,04 & 0,04 & 0,09 & 0,04 & 0,08 \\
\hline & Mínimo & 0,02 & 0,02 & 0,02 & 0,03 & 0,05 & 0,06 & 0,02 \\
\hline & Máximo & 0,06 & 0,27 & 0,07 & 0,05 & 0,12 & 0,04 & 0,17 \\
\hline & Desvio padrão & 0,02 & 0,09 & 0,02 & 0,01 & 0,03 & 0,02 & 0,06 \\
\hline \multirow{4}{*}{ ' } & Média & 0,15 & 0,15 & 0,15 & 0,15 & 0,15 & 0,13 & 0,18 \\
\hline & Mínimo & 0,01 & 0,01 & 0,01 & 0,01 & 0,01 & 0,01 & 0,01 \\
\hline & Máximo & 0,32 & 0,33 & 0,32 & 0,33 & 0,31 & 0,32 & 0,32 \\
\hline & Desvio padrão & 0,14 & 0,15 & 0,15 & 0,14 & 0,14 & 0,13 & 0,19 \\
\hline \multirow{4}{*}{ ' } & Média & 0,03 & 0,03 & 0,04 & 0,04 & 0,04 & 0,04 & 0,03 \\
\hline & Mínimo & 0,01 & 0,01 & 0,01 & 0,01 & 0,01 & 0,01 & 0,01 \\
\hline & Máximo & 0,08 & 0,08 & 0,12 & 0,11 & 0,12 & 0,12 & 0,07 \\
\hline & Desvio padrão & 0,03 & 0,03 & 0,04 & 0,05 & 0,05 & 0,05 & 0,03 \\
\hline \multirow{4}{*}{ 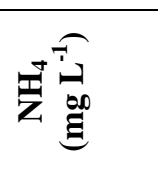 } & Média & 0,05 & 0,09 & 0,06 & 0,10 & 0,10 & 0,07 & 0,08 \\
\hline & Mínimo & 0,02 & 0,02 & 0,02 & 0,02 & 0,02 & 0,02 & 0,02 \\
\hline & Máximo & 0,14 & 0,33 & 0,15 & 0,19 & 0,28 & 0,12 & 0,24 \\
\hline & Desvio padrão & 0,05 & 0,12 & 0,05 & 0,09 & 0,11 & 0,05 & 0,09 \\
\hline \multirow{4}{*}{ 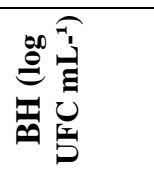 } & Média & 4,17 & 5,03 & 3,24 & 3,65 & 4,38 & 3,76 & 4,74 \\
\hline & Mínimo & 1,87 & 1,96 & 1,54 & 1,86 & 1,90 & 1,48 & 1,94 \\
\hline & Máximo & 7,45 & 8,58 & 3,98 & 5,40 & 6,77 & 7,29 & 7,73 \\
\hline & Desvio padrão & 2,04 & 2,41 & 1,05 & 1,30 & 1,76 & 2,02 & 2,19 \\
\hline \multirow{4}{*}{$\underset{\widetilde{v}}{\widetilde{\sigma}}$} & Média & 2,81 & 6,04 & 3,11 & 3,55 & 4,82 & 2,00 & 7,39 \\
\hline & Mínimo & 0,00 & 1,18 & 0,00 & 0,80 & 0,95 & 0,00 & 1,71 \\
\hline & Máximo & 3,94 & 16,25 & 9,17 & 7,70 & 8,66 & 4,70 & 15,33 \\
\hline & Desvio padrão & 2,36 & 5,37 & 3,78 & 2,87 & 2,74 & 2,15 & 4,95 \\
\hline
\end{tabular}

Legenda: bactérias heterotróficas $(\mathrm{BH})$, clorofila-a $(\mathrm{Cl} a)$, temperatura da água $\left(\mathrm{TH}_{2} \mathrm{O}\right)$, temperatura do ar (Tar), potencial hidrogeniônico $(\mathrm{pH})$, condutividade elétrica, (CE), cor aparente (Cor), turbidez (Turb), oxigênio dissolvido (OD), fósforo total (PT), nitrogênio amoniacal $\left(\mathrm{NH}_{4}\right)$, nitrito $\left(\mathrm{NO}_{2}^{-}\right)$, nitrato $\left(\mathrm{NO}_{3}{ }^{-}\right)$. 
MALHEIROS, C. H.; HARDOIM, E. L.; LIMA, Z. M.; AMORIM, R. S. S. Qualidade da água de uma represa localizada em área agrícola (Campo Verde, MT, Brasil) Ambi-Agua, Taubaté, v. 7, n. 2, p. xx-xxx, 2012. (http://dx.doi.org/10.4136/ambi-agua.904)

Os coeficientes de correlação entre as variáveis bióticas e abióticas e suas significâncias são apresentados na Tabela 3. Pode-se observar correlação significativa da variável precipitação com as variáveis bactérias heterotróficas $(\mathrm{r}=0,85)$, temperatura da água $(\mathrm{r}=0,76)$, condutividade elétrica $(\mathrm{r}=0,66)$, cor aparente $(\mathrm{r}=0,60)$ e nitrato $(\mathrm{r}=0,58)$. Durante o período chuvoso chegam aos corpos d'água, via escoamento superficial, íons (nitrato, entre outros) presentes nos insumos agrícolas, que proporcionam nesses ecossistemas aquáticos elevação expressiva da condutividade elétrica, das populações de microrganismos, de material dissolvido e particulado em suspensão, turbidez e, por consequência, a cor da água (Esteves, 2011). O escoamento da água sobre a superfície do solo, durante os eventos de chuva, consiste em uma das principais fontes difusas de poluição dos corpos d'água (Vasco et al., 2011).

Verificou-se correlação significativa $(\mathrm{p}=0,01)$ e positiva $(\mathrm{r}=0,55)$ entre a condutividade elétrica e a temperatura da água. Resultado semelhante ao observado por Carvalho et al. (2000) em uma microbacia localizada no oeste do Estado de São Paulo, que também recebe influência de atividades agrícolas $(\mathrm{r}=0,74)$. A variável temperatura da água também se correlacionou com bactérias heterotróficas $(r=0,63)$, o que pode ser explicado pelo fato da temperatura da água ser um fator limitante para o crescimento e desenvolvimento de microrganismos.

As bactérias heterotróficas também se correlacionaram com condutividade elétrica $(\mathrm{r}=0,65)$ e cor aparente $(\mathrm{r}=0,59)$. Alguns íons estão relacionados com o potencial de membrana dos canais de transporte e implicados nos mecanismos de osmorregulação, ou de pressão osmótica, para manter o turgor dentro dos limites e, por conseguinte, a viabilidade da célula (Moat et al., 2002). A cor da água está relacionada com o aumento na concentração de compostos orgânicos dissolvidos resultantes, entre outros, de atividades microbiológicas, como a decomposição (Martinac et al., 2008).

Correlações significativas foram observadas entre condutividade elétrica e as variáveis cor aparente $(r=0,65)$, nitrato $(r=0,56)$ e OD $(r=-0,61)$. Toledo e Nicolella (2002), também encontraram correlação negativa entre OD e condutividade elétrica em uma microbacia de uso agrícola e urbano.

A variável nitrato também se correlacionou com nitrito $(r=0,64)$, e $\mathrm{OD}$ com $\mathrm{pH}$ $(\mathrm{r}=0,57)$. Houve correlação entre turbidez e fósforo total $(\mathrm{r}=0,52)$, sendo que esta segunda variável se correlacionou com a cor aparente $(r=0,61)$. Esse fato pode ser explicado pela falta de mata ciliar e pelos processos erosivos que contribuem para a entrada de partículas de solo na represa que trazem consigo elementos químicos, como o fósforo, aumentando a turbidez e a cor da água, além de ocasionar um aumento no teor de íons (Neto et al., 1993).

Morais et al. (2012), ao determinar indicadores microbiológicos, metais e IQA na microbacia do Rio Cabeça, SP, observou correlação positiva entre turbidez e cor aparente $(\mathrm{r}=$ 0,99). O autor ressaltou que esta correlação era esperada, pois cor e turbidez são definidas pela reflexão e pela refração da luz sobre materiais dissolvidos ou em suspensão. O mesmo resultado pôde ser observado no presente estudo, com correlação significativa $(r=0,64)$ entre essas variáveis.

Diferentes usos do solo ao longo do eixo hídrico provocam alterações nas relações entre as variáveis, como observado por Toledo e Nicolella (2002) no trecho superior de uma microbacia em Guaíra, São Paulo, onde a agricultura predomina e influencia significativamente a turbidez, devido à ocorrência de processos erosivos. Essa constatação pode consistir em uma explicação para a correlação encontrada entre turbidez e fósforo total $(r=0,52)$, observada no presente estudo. 
MALHEIROS, C. H.; HARDOIM, E. L.; LIMA, Z. M.; AMORIM, R. S. S. Qualidade da água de uma represa localizada em área agrícola (Campo Verde, MT, Brasil). AmbiAgua, Taubaté, v. 7, n. 2, p. xx-xxx, 2012. (http://dx.doi.org/10.4136/ambi-agua.904)

Tabela 3. Matriz de correlação de Spearman (r) para as variáveis analisadas.

\begin{tabular}{|c|c|c|c|c|c|c|c|c|c|c|c|c|c|c|}
\hline & BH & Cla & $\mathbf{T}_{\mathbf{H} 2 \mathrm{O}}$ & $\mathbf{T}_{\mathrm{ar}}$ & pH & CE & Cor & Turb & OD & PT & $\mathbf{N H}_{4}$ & $\mathrm{NO}_{2}^{-}$ & $\mathrm{NO}_{3}^{-}$ & PPT \\
\hline BH & 1,00 & & & & & & & & & & & & & \\
\hline Cla & 0,050 & 1,00 & & & & & & & & & & & & \\
\hline $\mathrm{TH}_{2} \mathrm{O}$ & $0,62 * *$ & $-0,09$ & 1,00 & & & & & & & & & & & \\
\hline Tar & $-0,30 * *$ & $0,44 * *$ & $-0,23 * *$ & 1,00 & & & & & & & & & & \\
\hline pH & 0,05 & 0,44 & $-0,05$ & $-0,31$ & 1,00 & & & & & & & & & \\
\hline CE & $0,65 * *$ & $-0,13$ & $0,55^{* *}$ & $-0,44 * *$ & $-0,35$ & 1,00 & & & & & & & & \\
\hline Cor & $0,59 * *$ & $0,23^{*}$ & $0,40 * *$ & $-0,29 * *$ & 0,06 & $0,65^{* *}$ & 1,00 & & & & & & & \\
\hline Turb & $0,26^{* *}$ & $0,55^{* *}$ & 0,01 & 0,09 & 0,01 & $0,36^{* *}$ & $0,64 * *$ & 1,00 & & & & & & \\
\hline OD & $-0,13$ & 0,06 & $-0,30 * *$ & $-0,02$ & $0,57 * *$ & $-0,61 * *$ & $-0,23 * *$ & $-0,25^{* *}$ & 1,00 & & & & & \\
\hline PT & $0,42 * *$ & $0,33 * *$ & 0,15 & $-0,12$ & 0,04 & $0,29 * *$ & $0,61 * *$ & $0,52 * *$ & $-0,01$ & 1,00 & & & & \\
\hline $\mathbf{N H}_{4}$ & $-0,37 * *$ & 0,01 & $-0,19 *$ & $-0,10$ & 0,04 & $-0,07$ & 0,18 & 0,14 & 0,09 & 0,05 & 1,00 & & & \\
\hline $\mathrm{NO}_{2}^{-}$ & $0,22 *$ & $-0,11$ & 0,09 & $-0,70 * *$ & $-0,01$ & $0,27 * *$ & $0,24 * *$ & $-0,04$ & $0,27 * *$ & 0,16 & $0,27 * *$ & 1,00 & & \\
\hline $\mathrm{NO}_{3}^{-}$ & $0,48 * *$ & $-0,23 *$ & $0,36 * *$ & $-0,62 * *$ & $-0,05$ & $0,56^{* *}$ & $0,44 * *$ & 0,04 & $-0,08$ & $0,29 * *$ & $0,20^{*}$ & $0,64 * *$ & 1,00 & \\
\hline PPT & $0,85^{* *}$ & $-0,04$ & $0,76^{* *}$ & $-0,44 * *$ & 0,14 & $0,66^{* *}$ & $0,60 * *$ & 0,17 & $-0,10$ & $0,32 * *$ & $-0,12$ & $0,38 * *$ & $0,58 * *$ & 1,00 \\
\hline
\end{tabular}

*Correlações significativas a 0,05 .

**Correlações significativas a 0,01 .

Legenda: bactérias heterotróficas $(\mathrm{BH})$, clorofila-a $(\mathrm{Cl} a)$, temperatura da água $\left(\mathrm{TH}_{2} \mathrm{O}\right)$, temperatura do ar (Tar), potencial hidrogeniônico (pH), condutividade elétrica, $(\mathrm{CE})$,

cor aparente (Cor), turbidez (Turb), oxigênio dissolvido (OD), fósforo total (PT), nitrogênio amoniacal $\left(\mathrm{NH}_{4}\right)$, nitrito $\left(\mathrm{NO}_{2}^{-}\right)$, nitrato $\left(\mathrm{NO}_{3}^{-}\right)$e PPT (precipitação). 
A turbidez é um dos principais fatores físicos da água afetados pelo excesso de sedimentos, e pode influenciar o consumo de gases como o oxigênio dissolvido e o $\mathrm{CO}_{2}$ (Tundisi, 2005). Na área de estudo, apesar de alguns pontos de amostragem ter elevada turbidez na interface sedimento água, essa variável apresentou, nesse compartimento, maior correlação positiva $(\mathrm{r}=0,55)$ com a clorofila- $a$. Esse resultado pode ser atribuído à profundidade da represa, que tem penetração total de luz, com exceção do P2, zona limnética, um pouco mais profunda.

Com base na análise multivariada, três componentes principais $(\mathrm{CP})$ foram obtidos, os quais explicam $60 \%$ da variância total (Tabela 4). A primeira componente (CP1) explicou 29 \% da variância total dos dados, a segunda componente (CP2) 18 \% e, a terceira componente (CP3) $13 \%$. O escalonamento dos dados brutos contribuiu para que não ocorressem erros decorrentes das diferentes ordens de grandeza, existentes entre as variáveis analisadas. Com a matriz de correlação rotacionada foi possível reduzir a contribuição das variáveis menos significativas, tendo as variáveis $\mathrm{NO}_{2}, \mathrm{~T}_{\text {ar }}$ e $\mathrm{NO}_{3}$ correlacionadas com o primeiro componente $(\mathrm{r}>0,60)$; as variáveis Turb, PT, Cor e Cla correlacionadas com o segundo componente $(r>0,60)$; enquanto as variáveis TH2o, PPT e $\mathrm{BH}$ foram correlacionadas com o terceiro componente $(\mathrm{r}>0,60)$.

A Figura 3 apresenta no fator 1 e 2, as variáveis que compõem as CP1 e CP2, respectivamente, demonstrando a influência das atividades agrícolas, uma vez que a CP1 compreende uma relação inversa entre $\mathrm{NO}_{2}{ }^{-}$e $\mathrm{NO}_{3}{ }^{-}$com temperatura do ar, reafirmando a relação entre essas variáveis, também obtidas na correlação de Spearman. Destaca-se que nos meses de setembro e novembro observou-se elevada temperatura do ar e menor concentração de $\mathrm{NO}_{2}{ }^{-}$e $\mathrm{NO}_{3}{ }^{-}$, provavelmente devido às culturas de soja, realizadas nesse período, e que requererem maiores quantidades de insumos agrícolas fosfatados, evidenciando a relação entre as variáveis da CP2 (turbidez, PT, cor aparente e clorofila- $a$ ), e os teores mais elevados nesses meses. Esta relação negativa entre temperatura do ar e as concentrações de $\mathrm{NO}_{2}{ }^{-}$e $\mathrm{NO}_{3}{ }^{-}$, demonstra que o aumento da temperatura tem um efeito bactericida em função da maior radiação ultravioleta, o que reduz a presença de bactérias nitrificadoras dentro do ambiente aquático afetando, consequentemente, o processo de transformação do $\mathrm{N}$-amoniacal para as forma de nitrito e nitrato. A água, por meio do alto calor específico, tem a capacidade de absorver calor do ambiente para o corpo d'água. A temperatura, derivada diretamente da radiação solar, tem um papel fundamental na regulação de numerosos processos físicos, químicos e biológicos que ocorrem nos ecossistemas aquáticos (Pérez e Restrepo, 2008).

Na CP2 é demostrada a ligação entre essas variáveis e a importância de cada uma na dinâmica do ecossistema aquático, por serem variáveis relacionadas.

Nos pontos de amostragem que apresentaram a turbidez mais elevada verificou-se uma relação positiva com a cor aparente, registrando-se valores mais elevados dessas variáveis nas amostras da interface sedimento-água, o que era esperado, devido à influência do sedimento de fundo e pelo fato da decomposição ser maior nesse compartimento onde, além desses fatores, as maiores concentrações de clorofila- $a$ foram observadas e se relacionaram aos maiores valores de fósforo total.

Os fatores sazonais podem ser observados na Figura 4, onde se verifica a influência dos mesmos nos teores das variáveis analisadas que compõem as CP1 e CP3. Observa-se que ocorreu a separação dos meses de coleta conforme os mais chuvosos, acima da linha horizontal, e os secos, abaixo da linha horizontal. A relação entre as variáveis (temperatura da água, precipitação e bactérias heterotróficas) da CP3, indica a influência da sazonalidade. 
MALHEIROS, C. H.; HARDOIM, E. L.; LIMA, Z. M.; AMORIM, R. S. S. Qualidade da água de uma represa localizada em área agrícola (Campo Verde, MT, Brasil). Ambi-Agua, Taubaté, v. 7, n. 2, p. 245-262, 2012. (http://dx.doi.org/10.4136/ambi-agua.904)

Tabela 4. Componentes da matriz de correlação rotacionada.

\begin{tabular}{l|ccc}
\hline \multirow{2}{*}{ Variáveis } & \multicolumn{3}{c}{ Componentes } \\
\cline { 2 - 4 } & $\mathbf{1}$ & $\mathbf{2}$ & $\mathbf{3}$ \\
\hline $\mathrm{NO}_{2}{ }^{-}$ & 0,86 & $-0,30$ & 0,30 \\
$\mathrm{~T}_{\mathrm{ar}}{ }^{-}$ & $-0,82$ & 0,22 & $-0,10$ \\
$\mathrm{NO}_{3}$, & 0,66 & 0,09 & 0,52 \\
$\mathrm{Turb}$ & $-0,20$ & 0,80 & $-0,11$ \\
$\mathrm{PT}$ & 0,05 & 0,77 & 0,03 \\
$\mathrm{Cor}$ & 0,21 & 0,73 & 0,41 \\
$\mathrm{Cl} a$ & $-0,19$ & 0,66 & 0,03 \\
$\mathrm{~T}_{\mathrm{H} 20}$ & 0,07 & $-0,07$ & 0,89 \\
$\mathrm{PPT}$ & 0,42 & 0,10 & 0,77 \\
$\mathrm{BH}$ & 0,28 & 0,30 & 0,65 \\
$\mathrm{OD}$ & 0,26 & $-0,05$ & $-0,10$ \\
$\mathrm{CE}$ & $-0,01$ & 0,20 & 0,20 \\
$\mathrm{pH}$ & $-0,27$ & 0,05 & $-0,02$ \\
$\mathrm{NH}_{4}$ & 0,02 & 0,21 & $-0,16$ \\
Var. Exp. \% & 28,9 & 17,9 & 13,5 \\
Var. Acu. \% & 28,9 & 46,8 & 60,4 \\
\hline
\end{tabular}

Legenda: bactérias heterotróficas $(\mathrm{BH})$, clorofila-a $(\mathrm{Cl} a)$, temperatura da água $\left(\mathrm{TH}_{2} \mathrm{O}\right)$, temperatura do ar (Tar), potencial hidrogeniônico $(\mathrm{pH})$, condutividade elétrica, (CE), cor aparente (Cor), turbidez (Turb), oxigênio dissolvido (OD), fósforo total (PT), nitrogênio amoniacal $\left(\mathrm{NH}_{4}\right)$, nitrito $\left(\mathrm{NO}_{2}^{-}\right)$, nitrato $\left(\mathrm{NO}_{3}^{-}\right)$e PPT (precipitação).

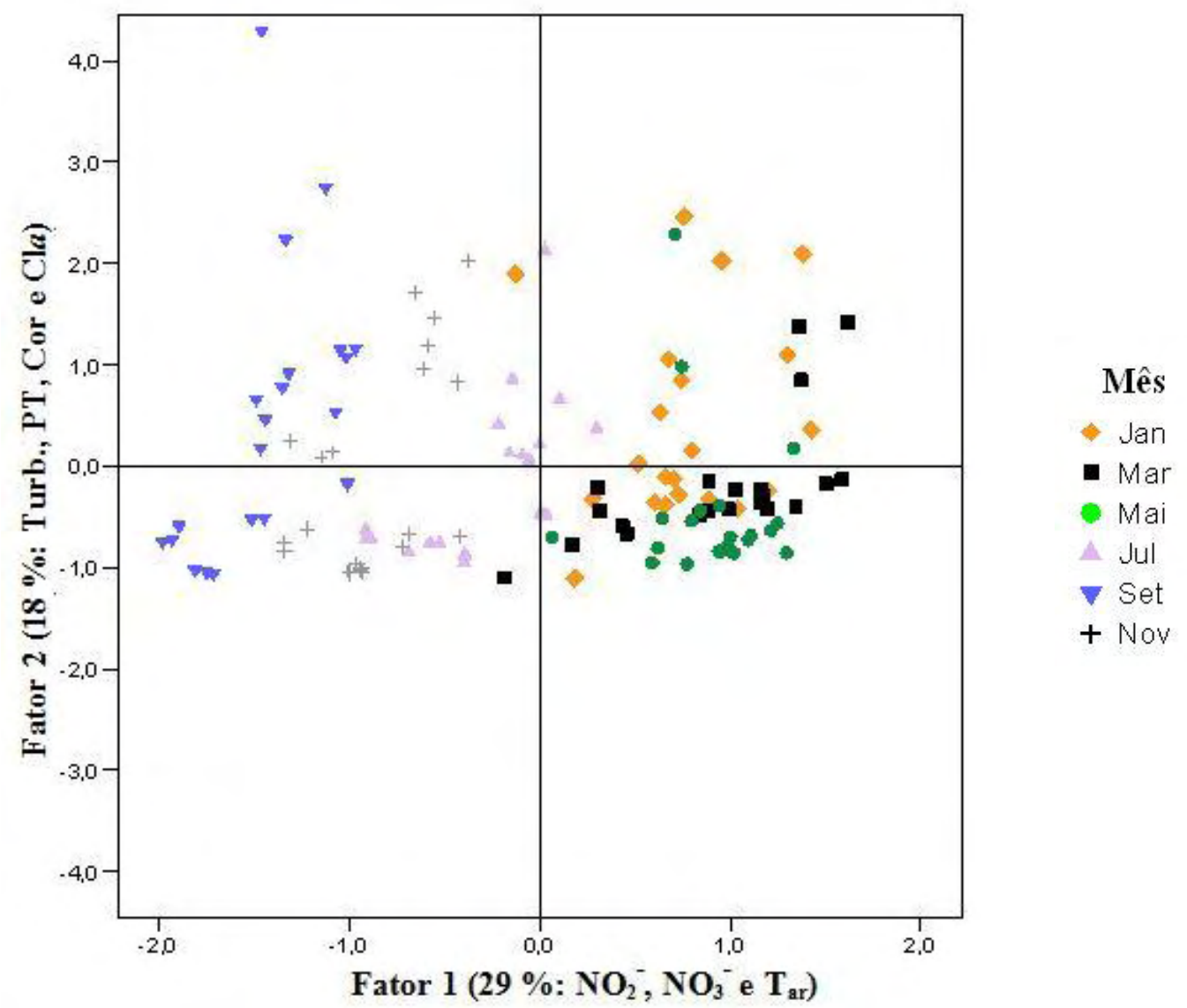

Figura 3. Comportamento das variáveis conforme mês de coleta em relação às componentes 1 e 2 . 
O material particulado, que chega ao corpo d'água por meio do escoamento superficial, também pode influenciar na temperatura da água, pois quando em elevada concentração absorve grande quantidade de calor. Com o aumento da temperatura, ocorre intensa reprodução do fitoplâncton devido ao aumento da taxa das reações químicas e biológicas, sendo a temperatura um fator limitante para os microrganismos. Percebe-se uma menor densidade de bactérias heterotróficas $(\mathrm{BH})$ em maio, julho e setembro, caracterizando meses com menor precipitação na área de estudo. Essa densidade de BH foi bem menor em maio, podendo estar relacionada à adaptação desses organismos a novas condições hidrológicas, pela redução da precipitação mensal de $80 \mathrm{~mm}$ (abril) a $2 \mathrm{~mm}$ (maio), o que também influenciou no material carreado para a represa, demonstrando a influência da precipitação sobre a comunidade microbiana.

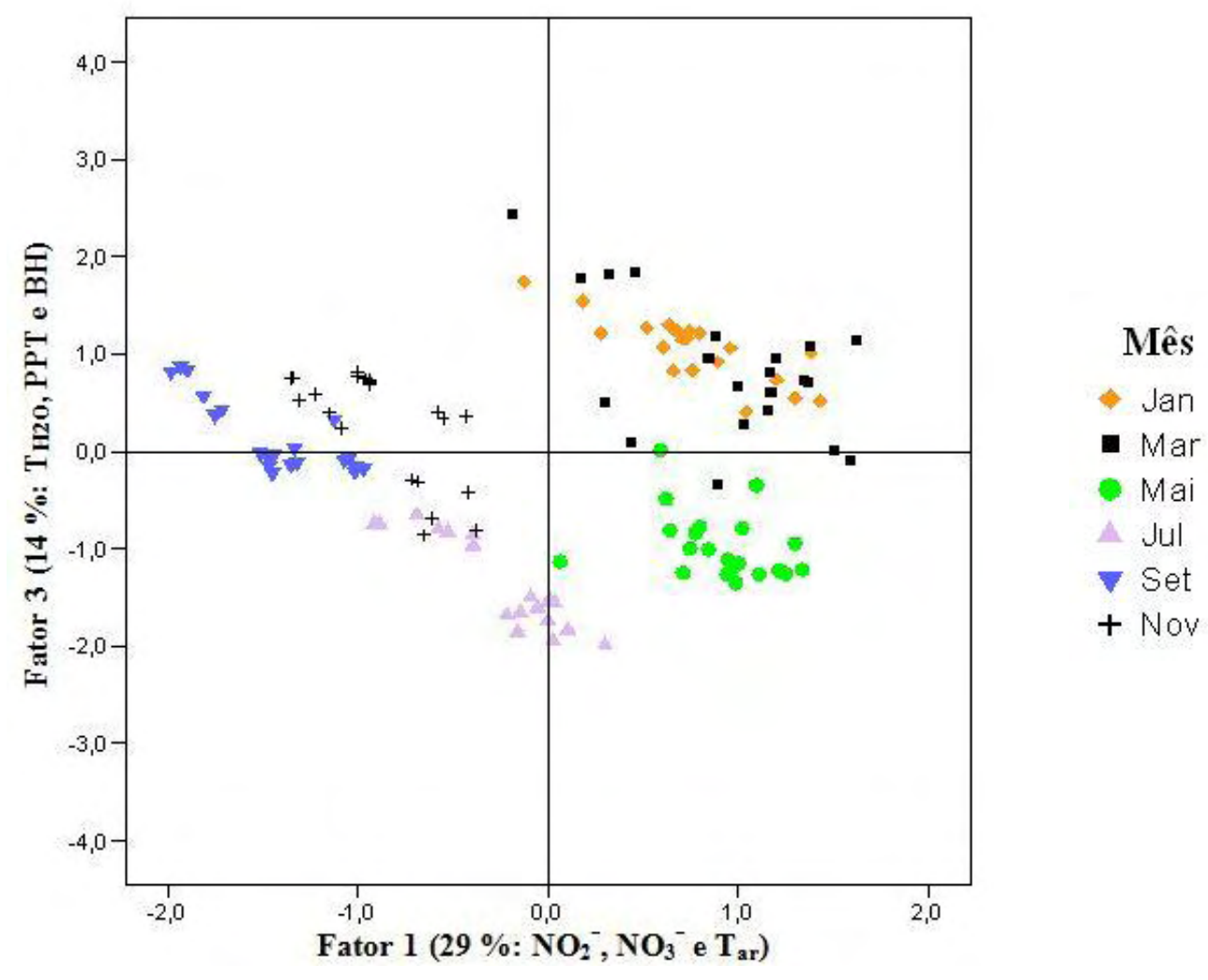

Figura 4. Comportamento das variáveis conforme mês de coleta em relação às componentes 1 e 3 .

Apesar da profundidade da represa não ser tão acentuada, algumas variáveis, principalmente da $\mathrm{CP} 2$, tiveram concentrações mais elevadas com o aumento da coluna d'água (Figura 5). A turbidez, cor aparente, clorofila- $a, \mathrm{PT}^{-} \mathrm{NO}_{2}^{-}$e $\mathrm{NO}_{3}{ }^{-}$, apresentaram valores mais elevados na interface sedimento-água, acima da linha horizontal. A variação negativa da temperatura do ar abaixo da linha horizontal influencia diretamente a temperatura da água, que diminui conforme a profundidade da coluna d'água. A elevada temperatura da água na camada superficial também proporciona a emigração vertical da comunidade do fitoplâncton (fotoinibição) que, como consequência, reduz a eficiência fotossintética na camada superficial da água com a produtividade, registrando os maiores valores entre 15 e $1 \%$ de luminosidade ao invés de $100 \%$. A produção primária é limitada a $100 \%$ de penetração de luz e a distribuição da biomassa (clorofila- $a$ ) aumenta a $1 \%$ de penetração (Bambi et al., 2008). Além desses fatores, no presente estudo, a maior 
MALHEIROS, C. H.; HARDOIM, E. L.; LIMA, Z. M.; AMORIM, R. S. S. Qualidade da água de uma represa localizada em área agrícola (Campo Verde, MT, Brasil). Ambi-Agua, Taubaté, v. 7, n. 2, p. 245-262, 2012. (http://dx.doi.org/10.4136/ambi-agua.904)

concentração de clorofila- $a$ com o aumento da profundidade, também pode estar relacionada às maiores concentrações de fósforo total na interface sedimento-água.

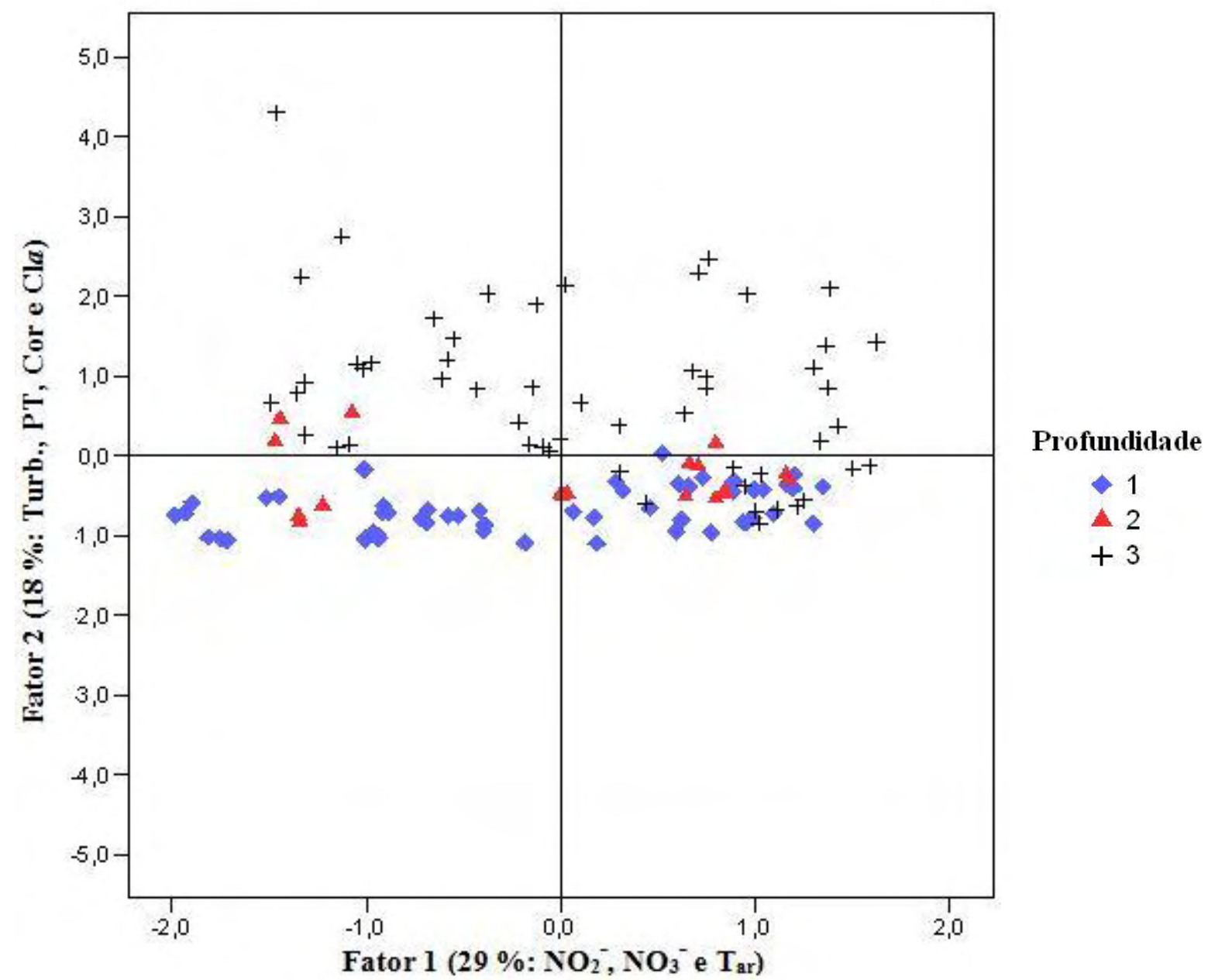

Figura 5. Comportamento das variáveis conforme profundidade de coleta em relação às componentes 1 e 2. Legenda: 1 - sub-superficial, 2 - profundidade Secchi, 3 - interface sedimento-água.

A dinâmica de fósforo é principalmente influenciada pela mobilização a partir do sedimento de fundo, do assoreamento e erosão, da decomposição de restos vegetais remanescentes, do intemperismo das rochas e minerais, tipo de solo, e, de forma mais intensa, pela ação antrópica difusa proveniente das atividades agrícolas (Bollmann et al., 2005). Essas características podem ser observadas na represa em estudo, que além de estar localizada em área agrícola possui grande quantidade de macrófitas e restos de vegetais, conferindo maiores concentrações de fósforo total na interface sedimento-água. Esteves (2011) ressalta que a proliferação de macrófitas aquáticas está relacionada a altas concentrações de nutrientes como fósforo e nitrogênio. Em áreas agrícolas a principal forma de perda de fósforo ocorre por efeito da erosão, por meio da lixiviação do fósforo do solo para o ambiente aquático (Cassol et al., 2007).

Assim como os valores de turbidez nas amostras da interface sedimento-água são mais elevados, causados principalmente pela ressuspensão do sedimento e maiores concentrações de clorofila, os valores de condutividade elétrica acompanham a mesma tendência. Barbosa (2002), no açude Taperoá II, PA, observou maiores valores de condutividade elétrica, maiores concentrações de nitrato e fósforo total no fundo, 
MALHEIROS, C. H.; HARDOIM, E. L.; LIMA, Z. M.; AMORIM, R. S. S. Qualidade da água de uma represa localizada em área agrícola (Campo Verde, MT, Brasil). Ambi-Agua, Taubaté, v. 7, n. 2, p. 245-262, 2012. (http://dx.doi.org/10.4136/ambi-agua.904)

indicando, segundo o autor, ocorrência de processos de decomposição nesse estrato do açude. Situação semelhante pôde ser observada no presente estudo para as mesmas variáveis. Estes processos podem originar detritos orgânicos e inorgânicos que são, juntamente com as bactérias, os principais responsáveis pela turbidez da água (Esteves, 2011).

A turbidez e cor aparente são variáveis relacionadas, pois nos pontos de amostragem que apresentaram turbidez mais elevada, a cor aparente também o foi. Dessa forma, a turbidez interfere diretamente na medida da cor aparente; além dos valores dessas variáveis serem mais elevados nas amostras da interface sedimento-água, como esperado, por receber influência do sedimento de fundo e pela decomposição ser maior com o aumento da profundidade.

Com base nas variáveis que representaram $60 \%$ dos dados obtidos na ACP, explicados pelas componentes 1, 2 e 3, foi gerado um dendrograma (Figura 6), onde notase a separação de três grupos distintos (G1, G2 e G3), representados pelos meses de coleta, que ligaram-se a um nível de distância de 25 .

Nota-se, na Figura 6, que a separação desses grupos foi diretamente influenciada pela precipitação, uma vez que G1 é composto pelos meses mais secos, G2 pelos meses mais chuvosos e G3, que representa o início do período chuvoso, sendo esses três grupos ligados a um nível de distância de 1, 3 e 8, respectivamente, conforme esperado. Dessa forma, constata-se que os padrões de sazonalidade e o uso e ocupação do solo estão diretamente relacionados às variáveis analisadas, considerando que elas estão agrupadas de acordo com características sazonais.

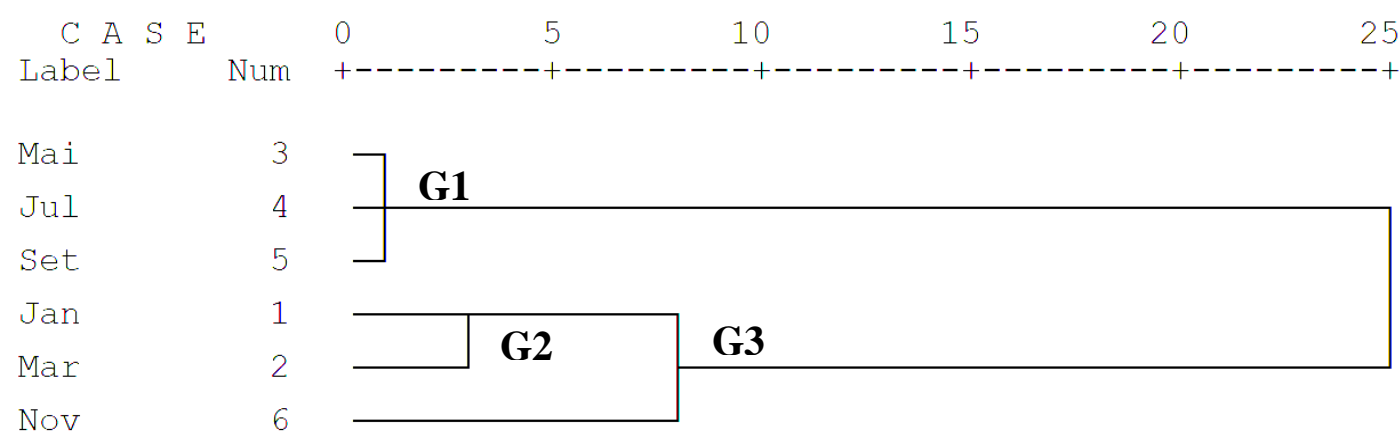

Figura 6. Dendrograma de análise de cluster abordando a variação sazonal entre as variáveis significativas obtidas na análise de componentes principais e os meses de coleta.

Alterações da qualidade da água, resultantes de atividades agrícolas que fazem uso de pesticidas, adubos, fertilizantes fosfatados e nitrogenados vêm sendo registradas por diversos autores, que chegam a resultados semelhantes da poluição difusa proveniente da agricultura, principalmente nas áreas com processos erosivos e durante o período chuvoso (Shrestha e Kazama, 2007; Wang et al., 2007; Vega et al., 1998).

Os parâmetros responsáveis pelas variações na qualidade da água estão relacionados principalmente à alta temperatura, poluição orgânica (fontes pontuais: as águas residuais domésticas e indústrias) e nutrientes (fontes difusas: agricultura) (Shrestha e Kazama, 2007), que acarretam prejuízos aos ecossistemas aquáticos.

Nogueira et al. (2012) ao avaliarem a presença de pesticidas em Campo Verde, na mesma área de estudo do presente trabalho, e em Lucas do Rio Verde, MT, concluíram a vulnerabilidade dos recursos hídricos nessas áreas e apontam para o risco de contaminação de áreas de nascentes de importantes córregos por pesticidas, como a nascente do Rio São 
Lourenço que encontra-se vulnerável devido, principalmente, à ausência de mata ciliar e uso indiscriminado de produtos químicos. Outros estudos estão sendo feitos nessa mesma área visando contribuir com os já existentes.

\section{CONCLUSÃO}

Os resultados indicam que as variações na coluna d'água não são significativas $(\mathrm{p} \leq 0,01)$ para a maioria das variáveis analisadas, provavelmente devido a características particulares de cada ponto de amostragem e por se tratar de uma represa com pouca profundidade. A densidade de bactérias heterotróficas $(\mathrm{BH})$ foi maior nas amostras da interface sedimento-água, devido a maior decomposição da matéria orgânica por parte desses microrganismos nesse compartimento, favorecendo o desenvolvimento dos mesmos. $\mathrm{O}$ fator sazonalidade também teve grande influência na densidade de $\mathrm{BH}$, sendo detectada maior abundância desses microrganismos no período chuvoso, comprovada pela forte correlação entre BH e PPT $(r=0,85)$. A correlação de Spearman, a análise de cluster e a ACP permitiram observar forte correlação entre algumas variáveis (nitrito, nitrato, temperatura da água e do ar, turbidez, cor aparente, fósforo total, clorofila- $a$, precipitação e bactérias heterotróficas) e sua importância na estrutura da represa e, principalmente, demonstrar que as variações sazonais e espaciais têm influência direta sobre as variáveis bióticas e abióticas analisadas, além de serem ferramentas eficazes na gestão e monitoramento da qualidade da água. Os resultados também evidenciam que a influência antrópica, resultante da atividade agrícola presente na área de estudo, em conjunto com a falta de mata ciliar e a precipitação, resultam em modificações gradativas na qualidade da água da represa, além de contribuir para o assoreamento do ecossistema aquático.

\section{AGRADECIMENTOS}

Os autores agradecem ao CNPq e FAPEMAT pelo auxílio financeiro e à CAPES, pela bolsa de mestrado.

\section{REFERÊNCIAS BIBLIOGRÁFICAS}

\section{AMERICAN PUBLIC HEALTH ASSOCIATION - APHA. Standard methods for examination of water and wastewater. 20. ed. Washington, 1998.}

ANDRADE, E. M.; PALÁCIO, H. A. Q.; CRISÓSTOMO, L. A.; SOUZA, I. H.; TEIXEIRA, A. S. Índice de qualidade de água, uma proposta para o vale do rio Trussu, Ceará. Revista Ciência Agronômica, Fortaleza, v. 36, n. 2, p. 135-42, 2005.

ANDRADE, E. M.; ARAÚJO, L. F. P.; ROSA, M. F.; DISNEY, W.; ALVES, A. B. Seleção dos indicadores da qualidade das águas superficiais pelo emprego da análise multivariada. Engenharia Agrícola, Jaboticabal, v. 27, n. 3, p. 683-690, 2007. http://dx.doi.org/10.1590/S0100-69162007000400011

ARAÚJO, G. C.; ZEILHOFER, P. Padrões espaciais da qualidade da água na Bacia do Rio Cuiabá e Rio São Lourenço - Mato Grosso. Hygeia, Uberlândia, v. 7, n. 13, p. 55-70, 2011. 
BAMBI, P.; DIAS, C. A. A.; PINTO-SILVA, V. Produção primária do fitoplâncton e as suas relações com as principais variáveis limnológicas na baía das pedras, Pirizal Nossa Senhora do Livramento, Pantanal de Poconé MT. UNICiências, Cuiabá, v. 12, p. 47-64, 2008.

BARBOSA, J. E. L. Dinâmica do fitoplâncton e condicionantes limnológicos na escala de tempo (nictimeral/sazonal) e de espaço (horizontal/vertical) no açude Taperoá II: trópico semi-árido nordestino. 2002. 201f. Tese (Doutorado em Ciências Biológicas) - Universidade Federal de São Carlos, São Carlos, 2002.

BENGRAINE, K.; MARHABA, T. F. Using principal component analysis to monitor spatial and temporal changes in water quality. Journal of Hazardous Materials, $v$. 100, n. 1/3, p. 179-195, 2003. http://dx.doi.org/10.1016/S0304-3894(03)00104-3

BOLLMANN, H. A.; CARNEIRO, C.; PEGORINI, E. Qualidade da água e dinâmica de nutrientes. In: ANDREOLI, C. V.; CARNEIRO, C. Gestão integrada de mananciais de abastecimento eutrofizados. Curitiba: SANEPAR, 2005. p. 213270.

BRASIL. Ministério do Meio Ambiente. Resolução no 357, de 17 março 2005. Dispõe sobre a classificação dos corpos de água e diretrizes ambientais para o seu enquadramento, bem como estabelece as condições e padrões de lançamento de efluentes, e dá outras providências. Brasília, 2005. 23 p.

CARVALHO, A. R.; SCHLITTLER, F. H. M.; TORNISIELO, V. L. Relações da atividade agropecuária com parâmetros físicos químicos da água. Química Nova, São Paulo, v. 23, n. 5, p. 618-622, 2000. http://dx.doi.org/10.1590/S0100-40422000000500009

CASSOL, E. A.; DENARDINI, J. E.; KOCHMANN, R. A. Sistema plantio direto: evolução e implicações sobre a conservação do solo e da água. In: SOCIEDADE BRASILEIRA DE CIÊNCIA DO SOLO. Tópicos em ciência do solo. Viçosa, 2007. p. 333-370.

COMPANHIA E TECNOLOGIA E SANEAMENTO AMBIENTAL - CETESB. Norma Técnica L5.306: determinação de pigmentos fotossintetizantes: Clorofila-a, b, c e Feofitina-a. São Paulo, 1990. 22 p.

ESTEVES, F. Fundamentos da limnologia. Rio de Janeiro: Interciência/FINEP, 2011. $771 \mathrm{p}$.

INSTITUTO BRASILEIRO DE GEOGRAFIA E ESTATÍSTICA - IBGE. 2011. Disponível em: 〈www.ibge.gov.br〉. Acesso em: 05 junho 2011.

MARTINAC, B.; SAIMI, Y.; KUNG, C. Ion channels in microbes. Physiological Reviews, Bethesda, v. 88, n. 4, p. 1449-1490, 2008. http://dx.doi.org/10.1152/ physrev.00005.2008

MATO GROSSO. Secretaria de Estado de Planejamento e Coordenação Geral - SEPLAN. Zoneamento sócio-econômico-ecológico do estado de Mato Grosso. Cuiabá, 2000.

MEIRELES, A. C. M.; ANDRADE, E. M.; FRISCHKORN, H.; CHAVES, L. C. G.; CRISÓSTOMO, L. A. Identificação dos principais constituintes da salinidade da água no Rio Acaraú. In: CONGRESSO BRASILEIRO DE RECURSOS HIDRICOS, 16., 2005, João Pessoa. Anais... João Pessoa: ABRH, 2005. 1 CD-ROM. 
MALHEIROS, C. H.; HARDOIM, E. L.; LIMA, Z. M.; AMORIM, R. S. S. Qualidade da água de uma represa localizada em área agrícola (Campo Verde, MT, Brasil). Ambi-Agua, Taubaté, v. 7, n. 2, p. 245-262, 2012. (http://dx.doi.org/10.4136/ambi-agua.904)

MOAT, A. G.; FOSTER, J. W.; SPECTOR, M. P. Microbial physiology. New York: Wiley-Liss Publication, 2002. 714 p.

MOITA NETO, J. M.; MOITA, G. C. Uma introdução à análise exploratória de dados multivariados. Química Nova, São Paulo, v. 21, n. 4, p. 467-469, 1998. http://dx.doi.org/10.1590/S0100-40421998000400016

MORAIS, E. B.; TAUK-TORNISIELO, S. M.; VENTORINI, S. H. Impacto de atividades agropecuárias na qualidade das águas do rio Cabeça, na bacia do rio Corumbataí. Holos Environment, Rio Claro, v. 12, n. 1, p. 45-57, 2012.

NASCIMENTO, R. F. F.; ALCÂNTARA, E; KAMPEL, M.; STECH, J. L. Caracterização limnológica do reservatório hidrelétrico de Itumbiara, Goiás, Brasil. Revista Ambiente \& Água, Taubaté, v. 6, n. 2, p. 143-156, 2011. http://dx.doi.org/10.4136/ambi-agua.191

NETO, M. S. S.; ALVEZ, R.; FIGUEIREDO, A. C.; HINO, K. Caracterização hidrogeoquímica da bacia do rio Manso-Cuiabá, Mato Grosso. Acta Limnológica Brasiliensia, Rio Claro, v. 6, p. 230-44, 1993.

NOGUEIRA, E. N.; DORES, E. F. G. C.; PINTO, A. A.; AMORIM, R. S. S.; RIBEIRO, M. L.; LOURENCETTI, C. Currently used pesticides in water matrices in centralwestern Brazil. Journal of the Brazilian Chemical Society, ahead of print Epub Aug 07, 2012. http://dx.doi.org/10.1590/S0103-50532012005000008

PÉREZ, G. A. R.; RESTREPO, J. J. R. Fundamentos de limnología neotropical. 2. ed. Medellín: Editora da Universidade de Antioquia, 2008. 413 p.

SHRESTHA, S.; KAZAMA, F. Assessment of surface water quality using multivariate statistical techniques: a case study of the Fuji river basin, Japan. Environmental Modelling \& Software, Maryland Heights, v. 22, n. 4, p. 464-475, 2007. http://dx.doi.org/10.1016/j.envsoft.2006.02.001

TUNDISI, J. G. Água no século XXI: enfrentando a escassez. São Carlos: RIMA/IIE. 2005. 248 p.

TUNDISI, J. G; MATSUMURA-TUNDISI, T. Limnologia. São Paulo: Oficina de Textos, 2008. 631p.

TOLEDO, L. G.; NICOLELLA, G. Índice de qualidade de água em microbacia sob uso agrícola e urbano. Scientia Agrícola, Piracicaba, v. 59, n. 1, p. 181-186, 2002. http://dx.doi.org/10.1590/S0103-90162002000100026

VASCO, A. N.; BRITTO, F. B.; PEREIRA, A. P. S.; MÉllO JÚNIOR, A. V. M.; GARCIA, C. A. B.; NOGUEIRA, L. C. Avaliação espacial e temporal da qualidade da água na sub-bacia do rio Poxim, Sergipe, Brasil. Revista Ambiente \& Água, Taubaté, v. 6, n. 1, p. 118-130, 2011. http://dx.doi.org/10.4136/ambi-agua.178

VEGA, M.; PARDO, R.; BARRADO, E.; DEBAN, L. Assessment of seasonal and polluting effects on the quality of river water by exploratory data analysis. Water Research, Maryland Heights, v. 32, n. 12 p. 3581-3592, 1998. http://dx.doi.org/10.1016/S0043-1354(98)00138-9 
MALHEIROS, C. H.; HARDOIM, E. L.; LIMA, Z. M.; AMORIM, R. S. S. Qualidade da água de uma represa localizada em área agrícola (Campo Verde, MT, Brasil). Ambi-Agua, Taubaté, v. 7, n. 2, p. 245-262, 2012. (http://dx.doi.org/10.4136/ambi-agua.904)

WANG, X. L.; LU, Y. L.; HAN, J.Y.; HE, G. Z.; WANG, T. Y. Identification of anthropogenic influences on water quality of rivers in Taihu watershed. Journal of Environmental Science, Maryland Heights, v. 19, n. 4, p. 475-481, 2007. http://dx.doi.org/10.1016/S1001-0742(07)60080-1

ZHOU, T.; WU, J.; PENG, S. Assessing the effects of landscape pattern on river water quality at multiple scales: a case study of the Dongjiang River watershed, China. Ecological Indicators, Maryland Heights, v. 23, p. 166-175, 2012. http://dx.doi.org/10.1016/ j.ecolind.2012.03.013

ZIMMERMANN, C. M.; GUIMARÃES, O. M.; PERALTA-ZAMORA, P. G. Avaliação da qualidade do corpo hídrico do rio Tibagi na região de Ponta Grossa utilizando análise de componentes principais (PCA). Química Nova, v. 31, n. 7, p. 1727-1732, 2008. http://dx.doi.org/10.1590/S0100-40422008000700025 


ISSN = 1980-993X - doi:10.4136/1980-993X
www.ambi-agua.net
E-mail: ambi-agua@agro.unitau.br
Tel.: (12) 3625-4212

\title{
Pantanal de Cáceres: composição granulométrica dos sedimentos de fundo no rio Paraguai entre a foz do rio Cabaçal e a cidade de Cáceres, Mato Grosso, Brasil
}

\author{
(http://dx.doi.org/10.4136/ambi-agua.876)
}

\section{Gustavo Roberto dos Santos Leandro', Célia Alves de Souza²}

\author{
${ }^{1}$ Graduando em Geografia e Bolsista de Iniciação Científica do Laboratório de Pesquisa e Estudos em \\ Geomorfologia Fluvial - LAPEGEOF da Universidade do Estado de Mato Grosso - UNEMAT. Cáceres - MT, \\ e-mail: gustavogeociencias@hotmail.com, \\ 2Professora adjunta do Departamento de Geografia e Mestrado em Ciências Ambientais da Universidade do \\ Estado de Mato Grosso - UNEMAT. Cáceres - MT \\ e-mail: celiaalvesgeo@globo.com
}

\section{RESUMO}

O estudo teve como objetivo verificar a composição granulométrica dos sedimentos de fundo ao longo do perfil longitudinal no rio Paraguai entre a foz do rio Cabaçal e a cidade de

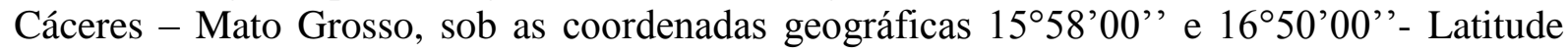

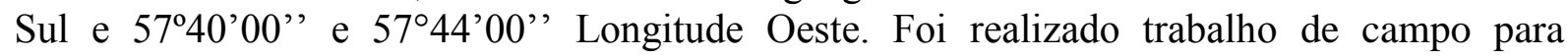
caracterização dos pontos e coleta dos sedimentos de fundo com o amostrador de mandíbulas tipo Van Veen (sete amostras); análise granulométrica com os métodos de pipeta e peneiramento (o método utiliza uma combinação de peneiração e sedimentação). $O$ rio Paraguai apresenta estilo sinuoso com dois períodos distintos (inundações periódicas e de estiagem) que, associado à dinâmica fluvial, alterna os processos de erosão, transporte e deposição de forma perceptível a partir das mudanças no complexo paisagístico. Desta maneira, a concentração de areia na carga de leito transportada no canal (cinco amostras) está relacionada aos elementos ambientais e uso da terra. Os sedimentos finos são transferidos para as feições (baías e lagoas) e planície de inundação; a intensa dinâmica fluvial bem como o curso (área de deposição aluvial) contribui para mudanças no canal e feições morfológicas (capacidade de transporte e deposição de sedimentos).

Palavras-chave: dinâmica e fragilidade fluvial, questões ambientais, carga de fundo, análise textural.

\section{Pantanal of Cáceres: granulometric composition of bottom sediments in the Paraguay River between the outfall of the Cabaçal River and the city of Cáceres, Mato Grosso, Brazil}

\begin{abstract}
The objective of the study was to verify the granulometric composition of bottom sediments along the longitudinal profile of the Paraguay River between the outfall of the Cabaçal River and the city of Cáceres, Mato Grosso, comprised by the geographic coordinates

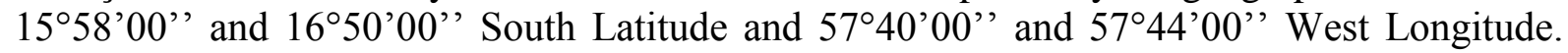
Work activity was conducted to characterize the sites and sediments collection with Van Veen sediment sampler (seven samples); textural analysis of the sediments by the pipetting and sieving method (the method uses a combination of sieving and sedimentation). The Paraguay River exhibits a meandering style with two distinct periods (periodic flooding regime and
\end{abstract}


LEANDRO, G. R. S.; SOUZA, C. A. Pantanal de Cáceres: composição granulométrica dos sedimentos de fundo no rio Paraguai entre a foz do rio Cabaçal e a cidade de Cáceres, Mato Grosso, Brasil. Ambi-Agua, Taubaté, v. 7, n. 2, p. 263-276, 2012. (http://dx.doi.org/10.4136/ambi-agua.876)

drought) that associated with of bottom sediments alternate processes of erosion, transport and deposition from the discernible changes in the complex landscaping. Thus, the concentration of sand in the bed load transported in the channel (five samples) is related to environmental elements and land use. The fine sediments are transferred to the features (bays and ponds) and flood plain; the intense fluvial dynamics and the course (alluvial deposition areas) contribute to changes in channel and morphologic features (capacity transport and sediment depositions).

Keywords: fluvial dynamics and fragility, environmental questions, bed load, particle size distribution.

\section{INTRODUÇÃO}

Carvalho (1994) define sedimento como a partícula depositada ao longo do leito do rio, derivada da rocha ou de materiais biológicos, e que pode ser transportada por fluido, por meio da fragmentação das rochas, por processo físico, químico ou de dissolução. A partícula derivada da rocha passa pelos processos de erosão, deslocamento, transporte do sedimento, deposição e compactação.

De acordo com Riccomini et al. (2003), os rios são cursos de água doce, com canais definidos e fluxo permanente ou sazonal que escoa para um oceano, lago ou outro rio. Dada a sua capacidade de erosão, transporte e deposição, os rios são os principais agentes de transformação da paisagem.

Os processos de sedimentação, que acontecem no canal ou na planície de inundação, provenientes da atividade do canal, compreendem os depósitos residuais do canal, barras de meandros, barra de canais e do preenchimento de canais (Suguio e Bigarella, 1990).

Vários trabalhos sobre a remobilização e composição granulométrica de sedimentos de fundo têm sido desenvolvidos em rios brasileiros para compreensão de mudanças na dinâmica do canal e no sistema de drenagem em termos de migração lateral, capacidade de transporte, armazenagem e deposição de sedimentos e magnitude da erosão marginal. Bayer (2002) diagnosticou os processos de erosão/assoreamento na planície do Araguaia; Souza (2004) analisou a dinâmica do rio Paraguai em três compartimentos; Franco (2007) associou a dinâmica e estrutura de fluxo a morfologia na confluência dos rios Ivaí-Paraná; Carvalho (2009) abordou o transporte de sedimentos no médio Araguaia; Bühler (2011) verificou os tipos de sedimentos transportados pelo rio Paraguai no perímetro urbano de Cáceres - MT.

A dinâmica fluvial e suas características enquanto campo de pesquisa possuem grande importância na geomorfologia e hidráulica. As informações geradas por esses trabalhos fornecem subsídios para elucidar questões relacionadas a problemas ambientais existentes em redes de drenagem e os resultados gerados podem ser utilizados como importantes instrumentos de planejamento e gestão de bacias hidrográficas (Kuerten et al., 2009).

Sendo assim o presente trabalho objetivou verificar a composição granulométrica do material de fundo e identificar as geoformas deposicionais ao longo do perfil longitudinal do rio Paraguai, pois as partículas sedimentares apresentam dimensões com variabilidade muito elevada nos ambientes fluviais, onde são encontrados depósitos arenosos a silto-argilosos. A análise das dimensões do material de fundo é um importante indicador da capacidade de transporte dos canais e segmentos deposicionais, bem como, de mudanças na dinâmica e morfologia fluvial. 
LEANDRO, G. R. S.; SOUZA, C. A. Pantanal de Cáceres: composição granulométrica dos sedimentos de fundo no rio Paraguai entre a foz do rio Cabaçal e a cidade de Cáceres, Mato Grosso, Brasil. Ambi-Agua, Taubaté, v. 7, n. 2, p. 263-276, 2012. (http://dx.doi.org/10.4136/ambi-agua.876)

\section{MATERIAL E MÉTODOS}

\section{1. Área de estudo}

O rio Paraguai nasce na Chapada dos Parecis, escoando de Norte para Sul em área de planície no Pantanal Corixo Grande-Jauru-Paraguai (Pantanal de Cáceres). Têm como principais afluentes os rios Sepotuba, Cabaçal e Jauru no estado de Mato Grosso. O segmento analisado está inserido no corredor fluvial definido por Souza (2004) como perfil que se estende do canal até a planície de inundação.

A área de estudo corresponde ao segmento do rio Paraguai entre a foz do rio Cabaçal (margem direita) e o perímetro urbano de Cáceres (margem esquerda) em Mato Grosso. Encontra-se entre as coordenadas geográficas $15^{\circ} 58^{\prime} 00^{\prime \prime}$ e 16 $10^{\circ} 50^{\prime} 00^{\prime \prime}$ - Latitude Sul e $57^{\circ} 40^{\prime}$ $00^{\prime \prime}$ e $57^{\circ} 44^{\prime} 00^{\prime \prime}$ Longitude Oeste (Figura 1).

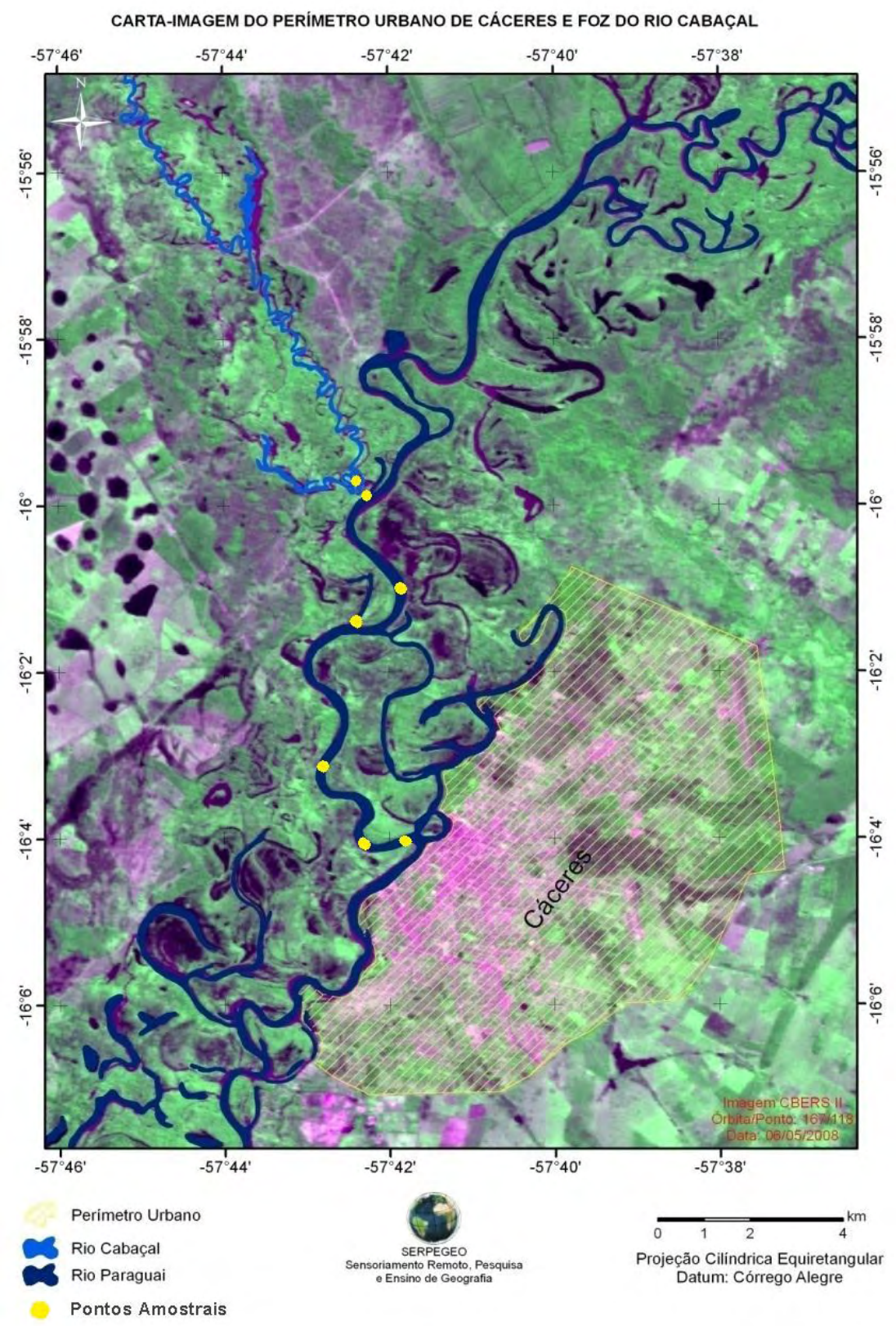

Figura 1. Carta imagem do segmento do corredor fluvial entre a foz do rio Cabaçal e a cidade de Cáceres - Mato Grosso. 
LEANDRO, G. R. S.; SOUZA, C. A. Pantanal de Cáceres: composição granulométrica dos sedimentos de fundo no rio Paraguai entre a foz do rio Cabaçal e a cidade de Cáceres, Mato Grosso, Brasil. Ambi-Agua, Taubaté, v. 7, n. 2, p. 263-276, 2012. (http://dx.doi.org/10.4136/ambi-agua.876)

O alto rio Paraguai, conforme Souza (2004), é uma área de sedimentação, pois possui forma de anfiteatro o que resulta em uma imensa bacia de recepção de água e sedimentos produzidos no Planalto Cristalino, Chapada dos Parecis, que a circunda sendo o canal principal um dos rios de planície mais importantes do Brasil.

A área está embasada nos sedimentos da Formação Pantanal e o sistema fluvial drena Aluviões atuais caracterizados por depósitos recentes de areias, siltes, argilas e cascalhos. Geomorfologicamente encontra-se na Depressão do Alto rio Paraguai e em áreas de planícies. Conforme Camargo (2011) a Morfoestrutura refere-se a dos sedimentos da bacia do rio Paraguai com Morfoescultura das Planícies Fluviais do rio Paraguai ou Planície Aluvionar Meandriforme. A precipitação média anual varia em torno de 1000 a $1500 \mathrm{~mm}$, sendo que, em dezembro-janeiro, ocorrem os maiores índices pluviométricos (Brasil, 1982; Souza, 2004; Camargo, 2011).

O tipo de solo ao longo do segmento é o Gleissolo Háplico Tb Eutrófico. São caracterizados como solos de áreas úmidas de textura arenosa em relevo plano. São ambientes de drenagem que, por ocasião das cheias, sempre recebem material, formando solos em camadas, onde os fatores de formação não tiveram tempo suficiente para promover o desenvolvimento de horizontes, como a sequência do tipo A, B e C. A condição incipiente em sua formação tem grande influência sobre sua instabilidade aos processos erosivos (Brasil, 1982; Souza, 2004; Camargo, 2011).

As características da planície contribuem para a ocorrência de inundação de forma diferenciada devido à altura do nível da água e o tempo (meses) em que a planície permanece alagada, possibilitando, assim, o desenvolvimento de vários tipos de formação vegetal: Contato Floresta Estacional/Savana, Floresta Aluvial e Savana Arborizada com Floresta Galeria (Brasil, 1982; Camargo, 2011).

O Pantanal foi dividido em onze sub-pantanais. Na divisão Silva e Abdon (1998) consideraram as diferenças em termos de material de origem, tipo de solo, drenagem, altimetria e vegetação, associados às bacias hidrográficas, possibilitando diagnosticar onze sub-bacias hidrográficas ou sub-regiões tais como: Corixo Grande-Jauru-Paraguai (Pantanal de Cáceres); Cuiabá-Bento Gomes-Paraguaizinho (Pantanal de Poconé); Itiquira-São Lourenço-Cuiabá (Pantanal de Barão de Melgaço); Taquari (Pantanal do Paiaguás e Pantanal de Nhecolândia); Negro (Pantanal do Abobral); Miranda-Aquidauana (Pantanal do Miranda e Pantanal de Aquidauana); Nabileque (Pantanal do Nabileque); Jacadigo e de Paiaguás (Pantanal do Paiaguás); e a confluência do rio Nabileque com o Paraguai (Pantanal de Porto Murtinho).

No segmento entre a foz do rio Cabaçal e a cidade de Cáceres, Pantanal Corixo GrandeJauru-Paraguai (Pantanal de Cáceres), o rio Paraguai apresenta padrão meandrante, com margens côncavas e convexas. Nas margens côncavas, o canal é mais profundo, com intensa erosão por corrosão, corrasão e cavitação gerando queda de grandes blocos por solapamento basal, enquanto que, nas margens convexas, os sedimentos são depositados.

A morfologia da calha do rio Paraguai é formada pelo movimento da água e dos sedimentos em relação aos materiais disponíveis no leito e nos bancos onde os canais mudam de forma em função dos processos de erosão e sedimentação. O escoamento superficial e a carga de sedimentos podem variar, em resposta às mudanças ocorridas no uso da terra, assim, um canal considerado estável pode, naturalmente, erodir o leito e bancos, sendo os processos de erosão mais expressivos após o maior pico de descarga.

\subsection{Procedimentos metodológicos}

\subsubsection{Levantamento de obras relacionadas à temática e área de estudo}

Os fatores ambientais como clima, geologia, geomorfologia, vegetação e solo podem refletir as características e o comportamento dos sistemas fluviais, definindo o tipo e 
LEANDRO, G. R. S.; SOUZA, C. A. Pantanal de Cáceres: composição granulométrica dos sedimentos de fundo no rio Paraguai entre a foz do rio Cabaçal e a cidade de Cáceres, Mato Grosso, Brasil. Ambi-Agua, Taubaté, v. 7, n. 2, p. 263-276, 2012. (http://dx.doi.org/10.4136/ambi-agua.876)

distribuição do sistema fluvial, além de contribuir para mudança no regime das águas e na produção de sedimentos nos canais fluviais e planície de inundação (Souza, 2004). Nessa perspectiva utilizou os relatórios e os mapas temáticos Escala 1: 1.000.000 e 1: 250.000 para levantamento dos elementos ambientais (Brasil, 1982; Camargo, 2011).

\subsubsection{Trabalho de campo}

Para caracterização das condições ambientais e coleta de amostras de sedimentos de fundo foi realizada atividade a campo. Ross e Fierz (2009) salientam que a pesquisa de campo pode ser dividida em três momentos: o primeiro pela observação e caracterização dos fatos com a maior precisão possível; o segundo é a interpretação de fotos, imagens de radar e satélite; e o terceiro refere-se à produção de ensaios de campo e experimentos. $\mathrm{O}$ trabalho de campo para caracterização do trecho e coleta de material de fundo em sete pontos do canal fluvial ocorreu no período de cheia (Quadro 1).

Quadro 1. Localização geográfica dos pontos de coleta de sedimentos de fundo ao longo do corredor fluvial.

\begin{tabular}{c|c|c|c}
\hline \multirow{2}{*}{$\begin{array}{c}\text { PONTO DE } \\
\text { COLETA }\end{array}$} & \multirow{2}{*}{ LOCAL } & \multicolumn{2}{c}{$\begin{array}{c}\text { COORDENADAS } \\
\text { GEOGRÁFICAS }\end{array}$} \\
\cline { 3 - 4 } & Latitude Sul & $\begin{array}{c}\text { Longitude } \\
\text { Oeste }\end{array}$ \\
\hline I & Rio Cabaçal (margem direita) & $15^{\circ} 59^{\prime} 57^{\prime}$, & $57^{\circ} 42^{\prime} 45^{\prime}$, \\
II & Foz do rio Cabaçal (margem direita) & $15^{\circ} 60^{\prime} 27^{\prime}$, & $57^{\circ} 42^{\prime} 34^{\prime}$, \\
III & Rio Paraguai (margem direita) & $16^{\circ} 01^{\prime} 14^{\prime}$, & $57^{\circ} 41^{\prime} 58^{\prime}$, \\
IV & Baía do Quati (margem direita) & $16^{\circ} 01^{\prime} 30^{\prime}$, & $57^{\circ} 42^{\prime} 41^{\prime}$, \\
V & Rio Paraguai & $16^{\circ} 033^{\prime} 32^{\prime}$, & $57^{\circ} 43^{\prime} 25^{\prime}$, \\
VI & Rio Paraguai & $16^{\circ} 04^{\prime} 07^{\prime}$, & $57^{\circ} 42^{\prime} 46^{\prime}$, \\
VII & Rio Paraguai, próximo à área central da cidade & $16^{\circ} 04^{\prime} 26^{\prime}$, & $57^{\circ} 41^{\prime} 52^{\prime}$, \\
\hline
\end{tabular}

\subsubsection{Coleta do material de fundo}

Para a coleta de sedimentos utilizou-se a draga do tipo Van Veen (amostrador de mandíbulas). O aparelho foi lançado no rio até alcançar o fundo do canal retendo carga sólida em suas mandíbulas (Figura 2). As amostras foram armazenadas em sacolas plásticas devidamente identificadas.

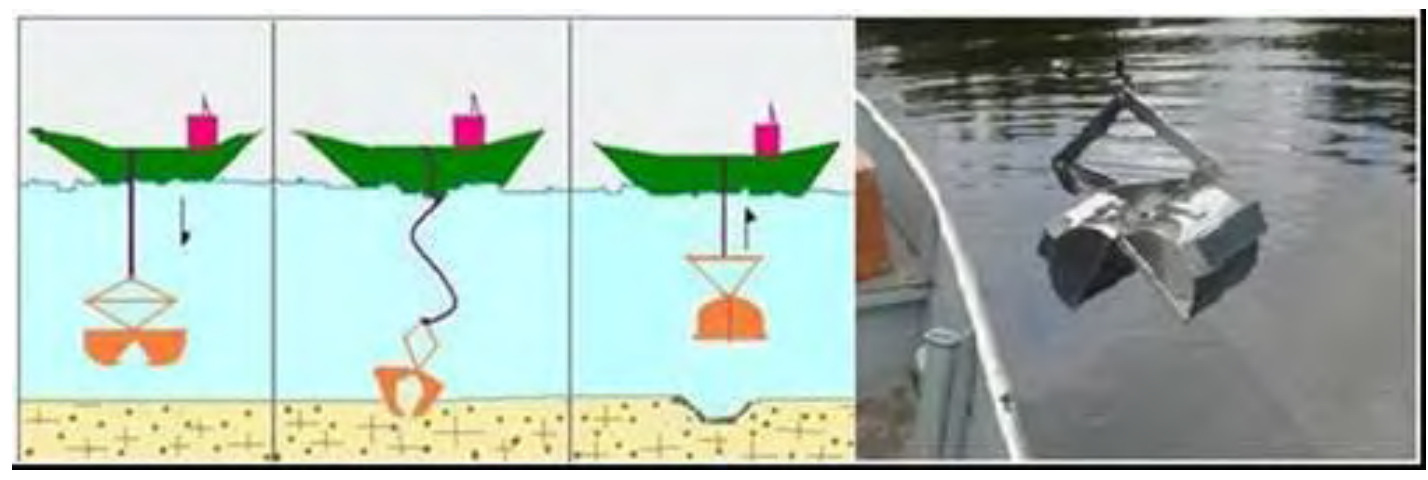

Figura 2. Ilustração do procedimento de coleta.

Fonte: Franco (2007). 
LEANDRO, G. R. S.; SOUZA, C. A. Pantanal de Cáceres: composição granulométrica dos sedimentos de fundo no rio Paraguai entre a foz do rio Cabaçal e a cidade de Cáceres, Mato Grosso, Brasil. Ambi-Agua, Taubaté, v. 7, n. 2, p. 263-276, 2012. (http://dx.doi.org/10.4136/ambi-agua.876)

\subsubsection{Análise granulométrica}

\subsubsection{Método de pipetagem (dispersão total) e peneiramento}

Para fracionamento do material de fundo em areia, silte e argila, utilizou-se o método de pipetagem - dispersão total (EMBRAPA, 1997).

Os procedimentos constaram das seguintes etapas:

- Após secagem a $100{ }^{\circ} \mathrm{C}$ em estufa, $20 \mathrm{~g}$ de amostra de cada ponto de coleta foram condicionadas em béqueres contendo $10 \mathrm{ml}$ de solução dispersante $\left(\mathrm{NaOH} 0,1 \mathrm{M} . \mathrm{L}^{-1}\right) \mathrm{e}$ água destilada $(100 \mathrm{ml})$. Em seguida, o conteúdo dos béqueres foi agitado com um bastão de vidro, tampado com um vidro de relógio e deixado em repouso por uma noite.

- Transcorrido o período de repouso, as amostras foram novamente agitadas, durante 15 minutos mecanicamente no Agitador de Wagner (TE-160).

- Na sequência o material foi lavado numa peneira de $20 \mathrm{~cm}$ de diâmetro e malha de $0,053 \mathrm{~mm}\left(\mathrm{n}^{\mathrm{o}} 270\right)$ apoiada sobre um funil que tinha logo abaixo uma proveta de 1000 ml. O silte e a argila passaram para a proveta de $1000 \mathrm{ml}$ e a areia ficou retida na peneira.

- O material da proveta foi agitado com um bastão de vidro por 30 segundos e deixado em repouso conforme tabela de temperatura e tempo de sedimentação.

- Transcorrido o tempo de sedimentação, foi introduzida uma pipeta no interior da proveta até a profundidade de $5 \mathrm{~cm}$, sendo em seguida aspirada a suspensão (fração argila).

- Ao fim do processo, tanto o material da pipeta (suspensão coletada) quanto da peneira, foram transferidos para béqueres identificados de acordo com o ponto de coleta $\mathrm{e}$ levados à estufa modelo TE-394/2 a $120^{\circ} \mathrm{C}$.

- Concluída a secagem, foi realizada pesagem com balança analítica e calculado os percentuais de areia, silte e argila para cada amostra, a fração silte equivale à diferença da soma areia/argila dos $20 \mathrm{~g}$ iniciais.

- Foram realizados três ensaios por ponto de coleta para obtenção da composição média do material de fundo.

\section{RESULTADO E DISCUSSÃO}

\subsection{Transporte de sedimentos de fundo e deposição no rio Paraguai}

O rio Paraguai, no trecho em estudo, possui sedimentos característicos da Formação Pantanal, oriundos do período Quaternário, constituídos basicamente por textura argilosa e intercalações com textura mais grosseira (arenoso, síltico-argiloso, argilosoarenoso e arenosoconglomerático). Esses sedimentos são removidos com facilidade, principalmente no período das cheias, acumulando-se em outros segmentos da planície e do canal, contribuindo para mudanças no sistema fluvial (Souza, 2004).

As características da calha, ao longo do perfil longitudinal do rio Paraguai são influenciadas pelos elementos ambientais; volume de água, que, varia de acordo com a sazonalidade (cheias ou estiagem); tamanho e peso dos sedimentos transportados e depositados, declividade e velocidade de fluxo do rio; e atividades antrópicas.

Os rios têm capacidade de transportar sedimentos de textura arenosa que são depositados no período de estiagem, o que origina as geoformas positivas por acresção na planície de inundação e na própria calha do canal. Bayer e Carvalho (2008) constataram que, com relação à granulometria do material de fundo, o rio Araguaia transporta basicamente, no trecho entre 
LEANDRO, G. R. S.; SOUZA, C. A. Pantanal de Cáceres: composição granulométrica dos sedimentos de fundo no rio Paraguai entre a foz do rio Cabaçal e a cidade de Cáceres, Mato Grosso, Brasil. Ambi-Agua, Taubaté, v. 7, n. 2, p. 263-276, 2012. (http://dx.doi.org/10.4136/ambi-agua.876)

o rio Crixás-Açu e a bifurcação Araguaia-Javaés, material arenoso de textura média. Nas margens, o rio apresenta, ao longo deste trecho, material muito fino (silte e argila).

\subsubsection{Ponto I}

O rio Cabaçal é afluente da margem direita do rio Paraguai desaguando acima da cidade de Cáceres em área de planície. As margens encontram-se preservadas onde foram identificadas espécies flutuantes, de médio porte, cipós e arbustos (Figura 3).

No baixo curso o canal perde capacidade de transportar sedimentos grosseiros. $\mathrm{O}$ percentual de areia encontrado na seção transversal apresenta textura fina característico de unidade de sedimentação. A composição granulométrica predominante no material de fundo foi a fração silte com $73,8 \%$, registrou-se a fração areia com $19 \%$ e, argila com $7,2 \%$ do total da amostra analisada (Tabela 1).

Bayer e Carvalho (2008) caracterizam como unidade de sedimentação segmentos onde há material arenoso de textura fina, muito fina e finos (material de fundo depositado, o qual se apresenta com características compactadas, material silte/argiloso, indicando estabilidade do fluxo e margens coesas).

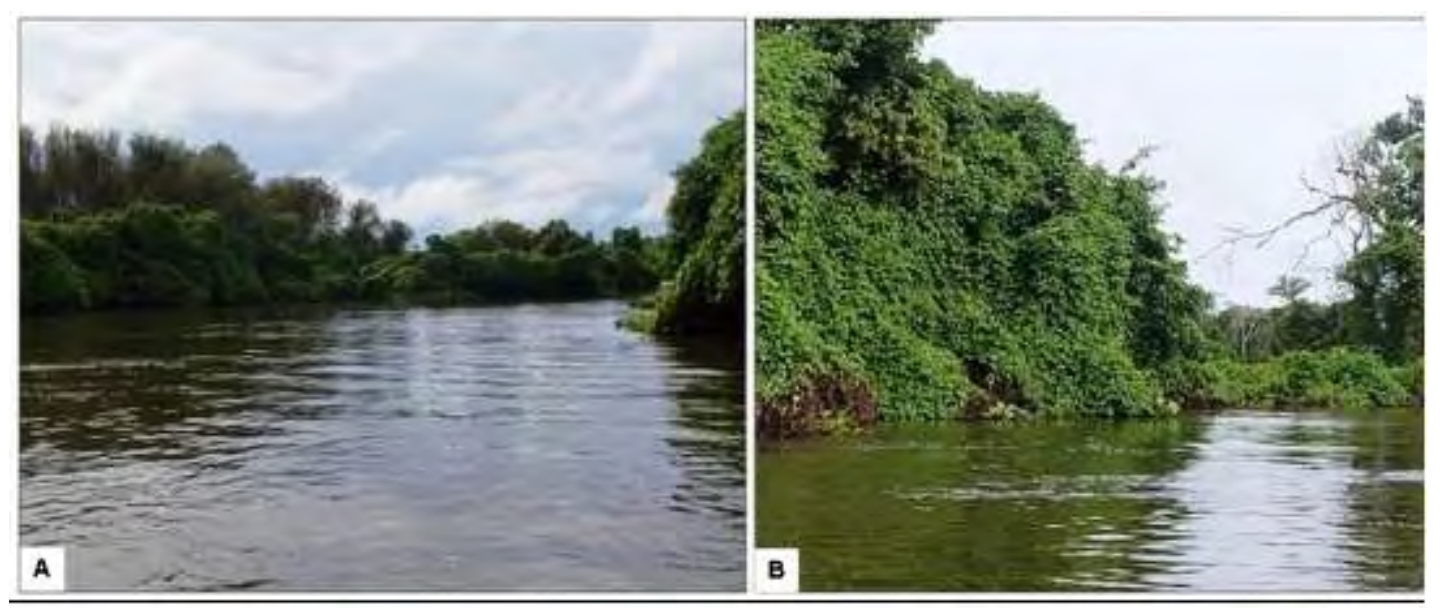

Figura 3. A) Canal fluvial do rio Cabaçal, tributário do rio Paraguai; B) Vegetação arbórea de médio porte e transbordamento para a planície de inundação.

Os resultados da composição granulométrica dos sedimentos de fundo nos Pontos I e II podem ser inferidos pelas características das margens do rio Cabaçal que, conforme Justiniano e Souza (2010) mostram maior coesão, com predominância de argila, o que indica processo de sedimentação no baixo curso do afluente com sedimentos finos (argila e silte).

Tabela 1. Composição granulométrica dos sedimentos transportados no fundo do canal, período de cheia (2010).

\begin{tabular}{c|c|c|c|c}
\hline \multicolumn{5}{c}{ Sedimentos de fundo (\%) } \\
\hline PONTO DE COLETA & LOCAL & Areia & Silte & Argila \\
\hline I & Rio Cabaçal & 19,0 & 73,8 & 7,2 \\
II & Foz do rio Cabaçal & 21,15 & 74,15 & 4,7 \\
III & Rio Paraguai & 95,15 & 4,3 & 0,55 \\
IV & Baía Quati & 89,75 & 8,95 & 1,3 \\
V & Rio Paraguai & 99,9 & 0,1 & ------- \\
VI & Rio Paraguai & 66,3 & 31,45 & 2,25 \\
VII & Rio Paraguai & 93,0 & 6,9 & 0,1 \\
\hline
\end{tabular}




\subsubsection{Ponto II}

As confluências fluviais caracterizam-se como ambientes bastante complexos, pois nestes locais ocorre a combinação de matéria (água, sedimentos) e energia (forças exercidas pelos fluxos) oriundas de diferentes fontes. As interações entre estes elementos resultam em uma variabilidade processual e morfológica, moldando o canal fluvial em função das flutuações sazonais das contribuições de cada curso d'água (Paes et al., 2008).

A foz do rio Cabaçal apresenta bifurcação com margens preservadas, observa-se vegetação de médio porte, flutuante, cipós e arbustos (Figura 4). Os sedimentos finos (silte e argila) estão concentrados no segundo canal e extensa planície de inundação. A análise granulométrica resultou em $21,15 \%$ de fração areia, $74,15 \%$ de fração silte e $4,7 \%$ de fração argila predominando material fino. A composição da amostra coletada pode ser explicada pela diminuição do gradiente do leito e da velocidade do fluxo.

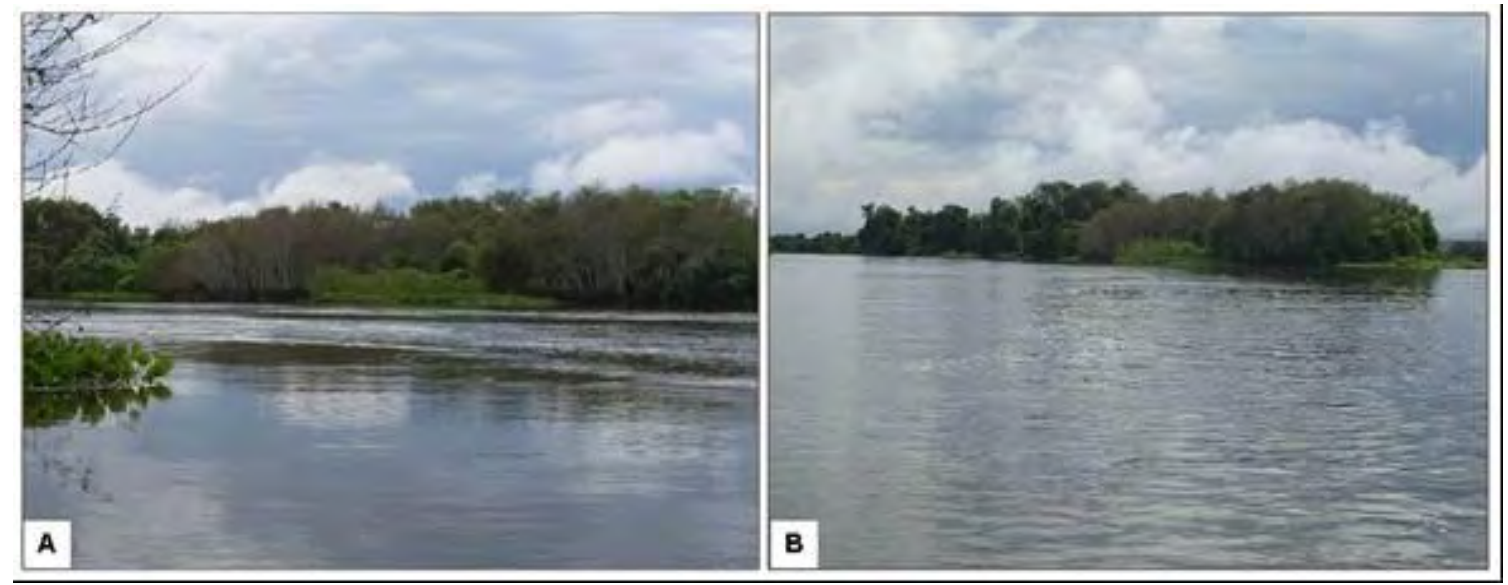

Figura 4. A) Desembocadura do rio Cabaçal à margem direita do rio Paraguai; B) Vista panorâmica do ponto de confluência da drenagem Cabaçal - Paraguai em segundo plano no período de cheia.

A fração areia encontrada na confluência aumenta com o processo de sedimentação promovido por refluxo exercido pelo rio Paraguai associado às baixas declividades deste com os afluentes, característico de área de planície. No período de estiagem o volume de água diminui gradualmente, o que, contribui para obstrução do segundo canal do rio Cabaçal onde cordões arenosos de granulometria fina são formados por acresção lateral e depósitos de fundo na foz do afluente.

Paes et al. (2008) reforçam que alguns estudos sobre áreas de confluência demonstraram que a morfologia do fundo dos canais desempenha um importante papel na organização dos fluxos e na dinâmica da carga sedimentar.

\subsubsection{Ponto III}

Nesse ponto constatou-se vegetação flutuante, arbórea de médio porte e cipós. Na área foram identificadas atividades antrópicas, tais como, navegação com embarcações de pequeno porte a motor e construções na margem.

O material de fundo analisado apresentou $95,15 \%$ de fração areia, $4,3 \%$ de fração silte e $0,55 \%$ de fração argila, contudo a carga de fundo caracteriza-se como textura fina. A deposição do material origina feições morfológicas no segmento do canal, tais como, barras laterais e diques marginais. O material depositado nesse ponto tem sua origem na remoção de partículas das margens côncavas e no transporte de material de pontos à montante. 
LEANDRO, G. R. S.; SOUZA, C. A. Pantanal de Cáceres: composição granulométrica dos sedimentos de fundo no rio Paraguai entre a foz do rio Cabaçal e a cidade de Cáceres, Mato Grosso, Brasil. Ambi-Agua, Taubaté, v. 7, n. 2, p. 263-276, 2012. (http://dx.doi.org/10.4136/ambi-agua.876)

O estudo de Rocha (2002) sobre o rio Paraná mostra que as formas são provenientes de processos deposicionais e ajuste fluvial dos rios ao longo de seu curso. Assim como grandes barras podem se formar e estabilizar por algum tempo, durante um evento de cheia podem ser totalmente mobilizadas. Portanto, são geoformas que ora passam por um estágio deposicional, ora pelo processo de erosão dada a grande mobilidade do talvegue em leito móvel. As mobilizações das formas arenosas no rio Paraguai são similares aos processos do rio Paraná, onde no período de estiagem o material de fundo é depositado e, no período de cheia, é transportado para seções à jusante dos depósitos.

\subsubsection{Ponto IV}

As feições peculiares, registradas no Pantanal, possuem uma terminologia tipicamente regional, ou seja, baías, braços, corixos, furados e vazantes. As baías constituem áreas deprimidas, contendo água, delineando formas circulares, semicirculares ou irregulares (Souza et al., 2009).

O quarto ponto corresponde a um canal secundário (feição alongada) denominado baía do Quati. No local foram identificados arbustos, cipós e principalmente espécies flutuantes típicas de área alagada como a vitória-régia (Euryle amazonica) e aguapés (Eichornia crassipes), também conhecidos como baronesa, orelha-de-jegue e jacinto-d'água (Figura 5).

Souza et al. (2009) destacam que a vitória-régia (Euryle amazonica) pertencente à família das Ninfeáceas é encontrada no Pantanal nos rios de águas calmas, principalmente próximo às margens, nas lagoas e baías.
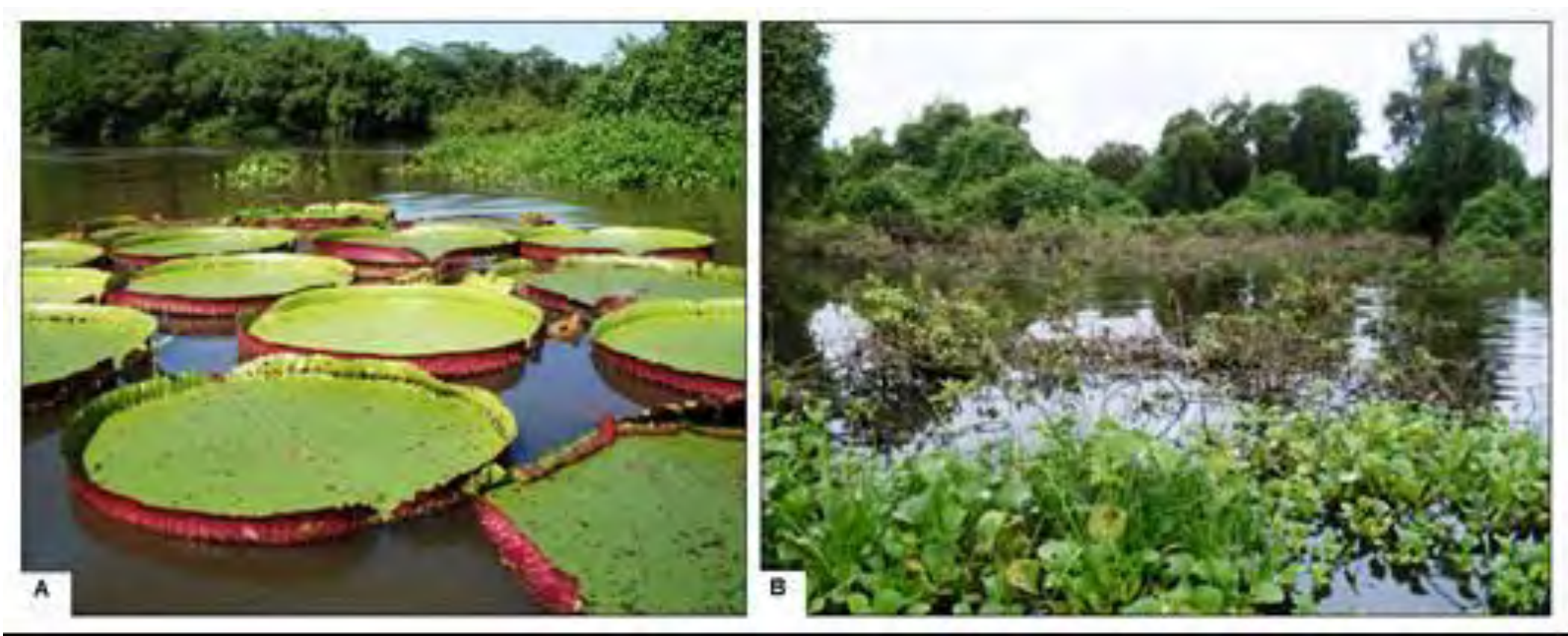

Figura 5. A) Campo de vitória-régia (Euryle amazonica) no período de cheia; B) Planície de inundação com vegetação flutuante.

A transferência de água e sedimentos do canal principal para a feição morfológica, baía do Quati e extensa planície de inundação, ocorre no período de cheia. A remobilização de sedimentos pela dinâmica fluvial é responsável pela manutenção das características do ambiente fluvial. A baía apresenta bifurcações, lagoas e canais secundários. Observa-se processo de erosão nas margens e deposição de sedimentos na calha (barras laterais, barras centrais e barras submersas) e na planície de inundação (diques marginais) (Figura 6). 


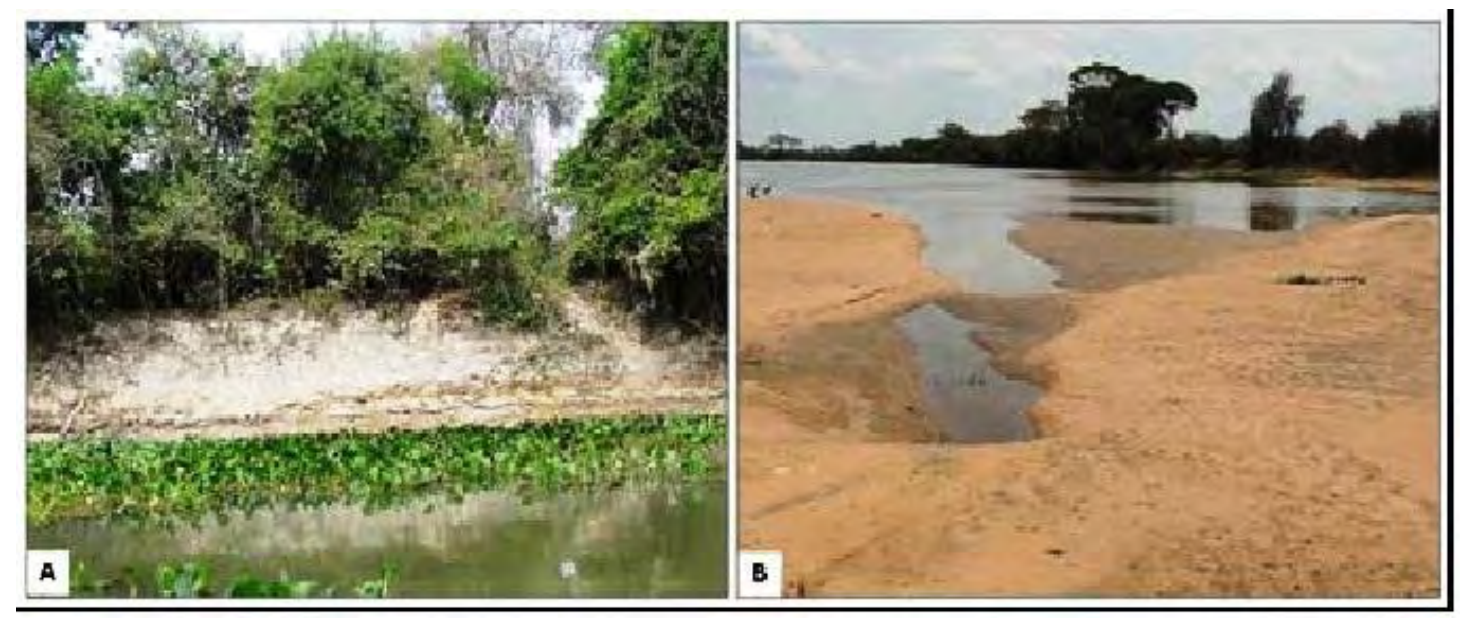

Figura 6. A) Margem da feição morfológica, baía do Quati, com deposição em camadas e processo erosivo; B) Em primeiro plano depósito central (barra central) de sedimentos na confluência da baía do Quati com o rio Paraguai, em segundo plano.

Por meio de análise foi registrada maior concentração de areia fina com $89,75 \%$ do total. As frações silte e argila também compõem a carga sedimentológica depositada com $8,95 \%$ e $1,3 \%$, respectivamente. A presença de material fino à jusante do ponto III resulta da própria erosão marginal da feição (margens com intercalações de materiais finos) e do transporte/deposição de matéria em suspensão, pois o fluxo no local apresentou baixa velocidade.

\subsubsection{Ponto V}

A amostra mesmo caracterizando-se com granulometria fina apresentou 99,9\% de fração areia e $0,1 \%$ de fração silte. A fração argila não foi registrada. Conforme Moraes (2002), o tipo e o volume de sedimentos fornecidos ao sistema têm uma importante influência na morfologia, no padrão e na forma de armazenamento de sedimentos no canal. A areia carreada de áreas à montante do perfil longitudinal é estocada no período de estiagem com a construção de cordões laterais, barras centrais e diques marginais.

A proporção, relativamente alta de sedimentos de fundo (areia) pode ser atribuída aos elementos ambientais do corredor fluvial do rio Paraguai embasado em Aluviões Atuais sem controle estrutural com leito móvel. A cada ciclo de cheia e estiagem os sedimentos podem ser acrescidos ou remobilizados para pontos à jusante a depender da capacidade do fluxo e do próprio padrão meandrante. Cada ambiente reflete não só a ação fluvial, mas também a interferência condicionante exercida por outros fatores, como o climático, o geológico, o topográfico e o antrópico com o uso da terra.

Souza (2004) destaca ainda que, a deposição no rio Paraguai ocorre, quando há diminuição na competência, o que pode ser causado pela redução da declividade que leva a menor velocidade de fluxo, consequentemente há formação de depósitos no próprio rio e planície de inundação. Embora menos estudadas pelos geomorfólogos, as formas construídas pela sedimentação fluvial possuem uma grande variedade de aspectos de depósitos.

\subsubsection{Ponto VI}

Por meio de análise granulométrica constatou-se que a amostra do local é composta de 66,3\% de areia, 31,45\% de silte (deposição de material em suspensão) e 2,25\% de argila.

Vale ressaltar que o rio Paraguai e seus afluentes, à montante da área em estudo, percorrem principalmente trechos rurais, sendo que a contribuição de sedimentos para os 
LEANDRO, G. R. S.; SOUZA, C. A. Pantanal de Cáceres: composição granulométrica dos sedimentos de fundo no rio Paraguai entre a foz do rio Cabaçal e a cidade de Cáceres, Mato Grosso, Brasil. Ambi-Agua, Taubaté, v. 7, n. 2, p. 263-276, 2012. (http://dx.doi.org/10.4136/ambi-agua.876)

canais ocorre pelo escoamento superficial, geralmente, no período chuvoso, na época que o solo está exposto para plantio.

O processo de ocupação humana de vertentes e várzeas para desenvolvimento de práticas antrópicas, agropecuária e industrial, somadas à retirada da vegetação são elementos que contribuem para o desencadeamento de processos erosivos provocados pela ação da água, assim diminui a infiltração e aumenta o escoamento superficial, carreando sedimentos produzidos nas vertentes, o que causa o assoreamento no canal (Queiroz e Rocha, 2010).

\subsubsection{Ponto VII}

As margens no entorno encontram-se parcialmente preservadas, pois no período de estiagem ocorre pesca de barranco, o que contribui para a retirada da cobertura vegetal e aumento da erosão, processo natural em margem côncava, por compactação do solo e desmoronamento de blocos. Bem como instalação de acampamentos em praias formadas pela deposição de sedimentos em margem convexa. A vegetação predominante é de árvores de médio porte (Figura 7).

A análise granulométrica do material de fundo da seção transversal apresentou $93 \%$ de areia, $6,9 \%$ de silte e $0,1 \%$ de argila. No entorno de ilha fluvial ocorre obstrução da baía do Malheiros e canal secundário que banha a área central da cidade. A cada ciclo de cheiaestiagem se percebe acrescimento arenoso na feição morfológica (Figura 7).
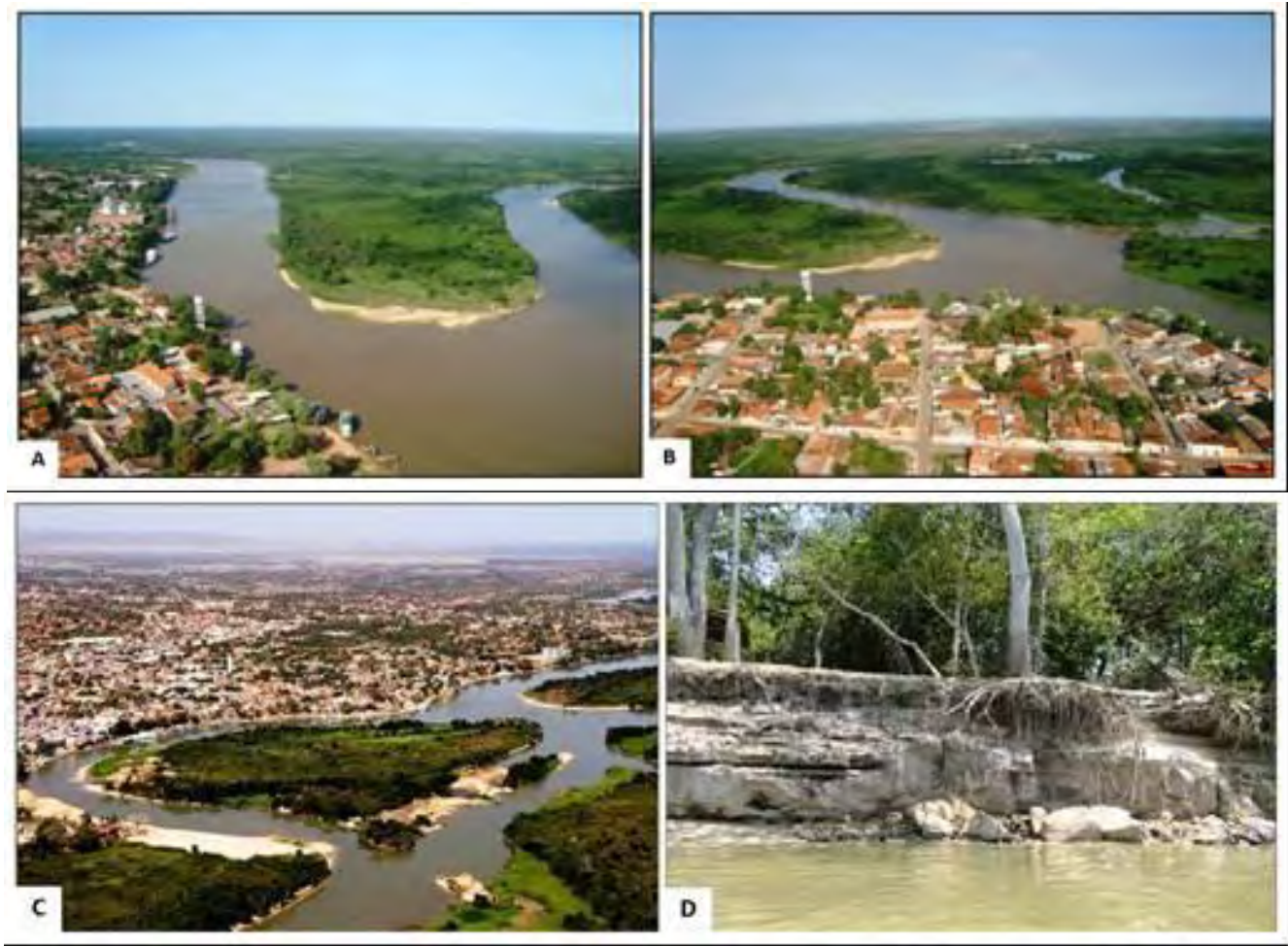

Figura 7. A) Vista aérea do canal principal do rio Paraguai e em segundo plano margem de erosão utilizada como ponto de pesca; B) Em primeiro plano, área central de Cáceres e rio Paraguai sentido Norte-Sul com barra em pontal; C) Ambiente de sedimentação por acresção na ilha fluvial, em segundo plano centro de Cáceres e em terceiro plano Província Serrana; D) Processos erosivos e ao fundo acampamento de pesca. 
Os bancos de areia, juntamente com as ilhas constituem os elementos morfológicos mais importantes no canal. Estas geoformas fluviais atingem diferentes dimensões que podem variar de período em período, sobretudo em ambiente de sedimentação. Originam-se a partir de processos deposicionais dos materiais transportados pelo rio, o que se deve à diminuição da capacidade de transporte dos fluxos nos períodos de estiagem (Morais, 2002).

O rio Paraguai possui uma dinâmica própria quanto ao escoamento do fluxo, reflexo do gradiente suave, com declividade de $6 \mathrm{~cm} / \mathrm{km}$. A planície de inundação armazena água no período de cheias anuais, além de abastecer baías e lagoas, sendo que os braços do rio também desvia parte do volume de água e sedimentos (Souza, 2004).

Ao longo do perfil longitudinal do segmento estudado ocorre o rompimento da conectividade do canal principal com as feições peculiares do Pantanal de Cáceres, tais como baías e canais secundários. Com a deposição dos sedimentos no período de estiagem, surgem as feições positivas de barramentos arenosos, o que prejudica a navegabilidade nos canais paralelos ao canal principal do rio Paraguai (braços), que, são utilizados no período da cheia como desvios, principalmente por pescadores e embarcações turísticas.

\section{CONCLUSÕES}

O corredor fluvial do rio Paraguai caracteriza-se com distintos ambientes de sedimentação. As feições morfológicas são representadas por pequenas lagoas, baías ou por antigos leitos de rio com conexão perene ou intermitente. Com relação às elevações do terreno, destacam-se barras laterais e em eixo central, diques marginais e ilhas fluviais; associadas aos sedimentos de fundo depositados no canal principal e entrada das feições morfológicas.

A análise granulométrica dos sedimentos conforme observado nos pontos amostrais indicou maior quantidade de fração areia, associada aos elementos ambientais e a capacidade de remobilização de sedimentos pelo fluxo do rio Paraguai no período de cheia. Nessa perspectiva o estudo serviu de indicador preliminar da capacidade de transporte dos rios Cabaçal e Paraguai.

Em decorrência da intensa dinâmica do rio Paraguai e afluentes, novos estudos com ênfase hidrogeomorfológica tornam-se necessários, tendo em vista as condições aluvionares e a planície fluvial aplanada, periódica ou permanentemente alagada, que resulta em mudanças na morfologia do sistema de drenagem com migração lateral, condicionada, pelo fluxo e processos de erosão/sedimentação.

\section{AGRADECIMENTOS}

Ao Conselho Nacional de Desenvolvimento Científico e Tecnológico - CNPq pelo apoio financeiro e concessão de Bolsa de Iniciação Científica - PIBIC/CNPq, que possibilitou os trabalhos de campo e laboratório dos quais decorrem este artigo. A Fundação de Amparo à Pesquisa do Estado de Mato Grosso - FAPEMAT pelo apoio financeiro. A Rede Pró-CentroOeste MCT/CNPq/FAPEMAT/Rede ASA pelo apoio financeiro. Também a Universidade do Estado de Mato Grosso - UNEMAT pelo apoio logístico por meio do Laboratório de Pesquisa e Estudos em Geomorfologia Fluvial - LAPEGEOF coordenado pela professora Dra. Célia Alves de Souza. 


\section{REFERÊNCIAS}

BAYER, M. Diagnóstico dos processos de erosão/assoreamento na planície aluvial do rio Araguaia, entre Registro do Araguaia (GO) e Cocalinho (MT). 2002. 126f. Dissertação (Mestrado em Geografia) - Universidade Federal de Goiás, Goiânia - GO, 2002.

BAYER, M.; CARVALHO, T. M. Processos morfológicos e sedimentos no canal do rio Araguaia. Revista de Estudos Ambientais, v. 10, n. 2, p. 24-31, 2008.

BRASIL. Ministério de Minas e Energia. Secretaria Geral. Projeto RADAMBRASIL. Levantamentos dos recursos naturais, Folha SD 21 - Cuiabá. Rio de Janeiro, 1982. $448 \mathrm{p}$.

BÜHLER, B. F. Qualidade da água e aspectos sedimentares da bacia hidrográfica do rio Paraguai no trecho situado entre a baía do Iate e a região do Sadao, município de Cáceres (MT), sob os enfoques quantitativos e perceptivos. 2011. 140f. Dissertação (Mestrado em Ciências Ambientais) - Instituto de Ciências Naturais e Tecnológicas, Universidade do Estado de Mato Grosso, Cáceres, 2011.

CAMARGO, L. (Org.). Atlas de Mato Grosso: abordagem socioeconômico-ecológica. Cuiabá: Entrelinhas, 2011.96 p.

CARVALHO, N. O. Hidrossedimentologia prática. Rio de Janeiro: CPRM, 1994. 372 p.

CARVAlHO, T. M. Avaliação do transporte de carga sedimentar no médio rio Araguaia. Revista Geosul, v. 24. n. 47, p. 147-160, jan./jun. 2009.

EMPRESA BRASILEIRA DE PESQUISA AGROPECUÁRIA - EMBRAPA. Manual de métodos de análises de solos. 2.ed. Rio de Janeiro: EMBRAPA solos, 1997. 212 p.

FRANCO, A. L. A. Análise da dinâmica e estrutura de fluxo e da morfologia da confluência dos rios Ivaí e Paraná - PR/MS. 2007. 98f. Dissertação (Mestrado em Análise Geoambiental) - Universidade de Guarulhos, Guarulhos, 2007.

JUSTINIANO, L. A. A.; SOUZA, C. A. Evolução das margens e transporte de sedimentos no rio Paraguai entre a foz do rio Sepotuba e a foz do rio Cabaçal. In: SANTOS, J. E.; GALBIATI, C.; MOSCHINI, L. E. (Orgs.). Gestão e educação ambiental: água, biodiversidade e cultura. Vol. 3. São Carlos: Rima Editora, 2010. p. 62-89.

KUERTEN, S.; SANTOS, M. L.; SILVA, A. Variação das características hidrossedimentares e geomorfologia do leito do rio Ivaí - PR, em seu curso inferior. Revista Geociências, São Paulo, v. 28. n. 2, p. 143-151, 2009.

MORAIS, R. P. Mudanças históricas na morfologia do canal do rio Araguaia no trecho entre a cidade de Barra do Garças (MT) e a foz do rio Cristalino na ilha do Bananal no período entre as décadas de 60 e 90. 2002. 189f. Dissertação (Mestrado em Geografia) - Universidade Federal de Goiás, Goiânia 2002.

PAES, R. J.; STEVAUX, J. C.; ETCHEBEHERE, M. L.; LELI, I. T. Dinâmica e morfologia do canal de confluência dos rios Paraná e Paranapanema pelo método do mapeamento temporal. Geografia, Londrina, v. 17. n. 2, p. 37-47, jul./dez. 2008. 
QUEIROZ, F. L. L.; ROCHA, P. C. Avaliação de sedimentos do leito no canal Curutuba / planície fluvial do alto rio Paraná, Mato Grosso do Sul - Brasil. Revista AGB/TL, n. 11, p. 147-164, maio 2010.

RICCOMINI, C.; GIANNINI, P. C.; MANCINI, F. Rios e processos aluviais. In: TEIXEIRA, W.; TOLEDO, M. C. M.; FAIRCHILD, T. R.; TAIOLI, F. (Orgs.). Decifrando a Terra. São Paulo: Oficinas de textos, 2003. p. 191-210.

ROCHA, P. C. Dinâmica dos canais no sistema rio-planície fluvial do Alto rio Paraná, nas proximidades de Porto Rico - PR. 2002. 169f. Tese (Doutorado em Ecologia de Ambientes Aquáticos Continentais) - Universidade Estadual de Maringá, Maringá, 2002.

ROSS, J. L. S.; FIERZ, M. S. M. Algumas técnicas de pesquisa em Geomorfologia. In: VENTURI, L. A. B. (Org.). Praticando geografia: técnicas de campo e laboratório. São Paulo: Oficina de Textos, 2009. p. 69-84.

SILVA, J. S. V.; ABDON, M. M. Delimitação do Pantanal brasileiro e suas sub-regiões. Revista PAB, v. 33, n. esp., p. 1703-1711, 1998.

SOUZA, C. A. Dinâmica do corredor fluvial do rio Paraguai entre a cidade de Cáceres e a Estação Ecológica da ilha de Taiamã-MT. 2004. 173f. Tese (Doutorado em Geografia) - Centro de Ciências Matemáticas e da Natureza, Universidade Federal do Rio de Janeiro, Rio de Janeiro, 2004.

SOUZA, C. A.; LANI, J. L.; SOUSA, J. B. Questões ambientais: Pantanal mato-grossense. Cáceres: Unemat, 2009. 118 p.

SUGUIO, K.; BIGARELLA, J. J. Ambientes fluviais. 2. ed. Florianópolis: Ed.UFSC/ UFPR, 1990. 183 p. 


\title{
Vulnerabilidade natural e ambiental do município de Ponta Porã, Mato Grosso do Sul, Brasil
}

\author{
(http://dx.doi.org/10.4136/ambi-agua.786)
}

\author{
Thalita Beatriz Antunes Klais ${ }^{1,2}$; Fabrício Bau Dalmas ${ }^{3}$, Renata Porto Morais ${ }^{1,2}$; \\ Gabriela Atique $^{4}$; Giancarlo Lastoria ${ }^{5}$ Antonio Conceição Paranhos Filho ${ }^{1,2}$ \\ 1,2,5 Universidade Federal de Mato Grosso do Sul, Campo Grande, MS. \\ e-mail: thaliklais@yahoo.com.br, eng.renataporto@gmail.com, \\ antonio.paranhos@pq.cnpq.br, g.lastoria@ufms.br \\ ${ }^{3}$ Universidade de São Paulo, São Paulo, SP. e-mail: fbdalmas@usp.br \\ ${ }^{4}$ Universidade Estadual de Campinas, SP. e-mail: gabrielaatique@yahoo.com.br.
}

\section{RESUMO}

A vulnerabilidade natural mostra a pré-disposição do ambiente frente a fatores naturais como: geomorfologia, geologia, solos e a sua estabilidade em relação à morfogênese e à pedogênese. Já a vulnerabilidade ambiental é definida como qualquer susceptibilidade do ambiente a um impacto potencial provocado por um uso antrópico qualquer. Os objetivos deste trabalho foram avaliar o uso e a ocupação do solo do município de Ponta Porã, situado na divisa do Mato Grosso do Sul com o Paraguai, bem como determinar a sua vulnerabilidade Natural e Ambiental. Para tal, foram utilizados mapas de geologia, aptidão agrícola, declividade, cartas topográficas e imagens de satélite Landsat TM. A vulnerabilidade Natural foi média em $62,8 \%$ da área do estudo, baixa em $20,7 \%$, alta em $12,8 \%$ e muito alta em $3,7 \%$. Os altos valores de vulnerabilidade Natural refletiram em elevadas porcentagens de vulnerabilidade Ambiental. Sendo assim, foi constatado que 75,2 \% do município, ou cerca de 400.704 ha, possui vulnerabilidade Ambiental alta a muito alta. Esses números foram encontrados principalmente em áreas onde o uso do solo é caracterizado por pastagens ou agricultura.

Palavras-chave: Cerrado, geotecnologias, vulnerabilidade natural e ambiental.

\section{Natural and environmental vulnerability of Ponta Porã municipality, Mato Grosso do Sul State, Brazil}

\section{ABSTRACT}

The natural vulnerability of the environment is prone to natural agents like geomorphology, geology, soils and its stability in relation to morphogenesis and pedogenesis. The environmental vulnerability is defined as the susceptibility of the environment to any potential impact caused by human actions. The objectives of this work were the evaluation of the land use at Ponta Porã municipality, located on the border between Mato Grosso do Sul (Brazil) and Paraguay, as well as the determination of its natural and environmental vulnerability. For this purpose, maps of geology, agricultural suitability, slope, topographic sheets and Landsat TM satellite images were used. The natural vulnerability had average values in $62.8 \%$ of the study area, low values in $20.7 \%$, high in $12.8 \%$ and very high values in $3.7 \%$. The high values of natural vulnerability corresponded to high values of environmental vulnerability as well. So it has been observed that $75.2 \%$ of the municipality, corresponding 
KLAIS, T. B. A.; DALMAS, F. B.; MORAIS, R. P.; ATIQUE, G.; LASTORIA, G.; PARANHOS FILHO, A. C. Vulnerabilidade natural e ambiental do município de Ponta Porã, Mato Grosso do Sul, Brasil. Ambi-Agua, Taubaté, v. 7, n. 2, p. 277-290, 2012. (http://dx.doi.org/10.4136/ambi-agua.786)

to about 400,704 ha has high to very high environmental vulnerability. These numbers have been found mainly in areas occupied by pasture and crop lands.

Keywords: Cerrado, geo-technologies, natural and environmental vulnerability.

\section{INTRODUÇÃO}

O município de Ponta Porã, no sul do Estado de Mato Grosso do Sul, representa uma área de importância geopolítica, pois está localizado na fronteira com a República Federativa do Paraguai. Sua sede municipal possui conurbação internacional com Pedro Juan Caballero, o que lhe confere vantagens de localização e condições para o desenvolvimento de suas potencialidades econômicas: criação de gado, plantação de soja e milho (Mato Grosso do Sul, 1990).

Os municípios que se encontram em áreas de fronteira devem ter ferramentas para controle de seus territórios e assim promover estudos que integrem informações de interesse para essas áreas. Sendo assim, por meio do uso de geotecnologias podem-se elaborar estratégias de conservação ambiental, planos de manejo mais adequados e de baixo custo (Paranhos Filho et al., 2008).

Toda ação que modifique o estado natural do meio, como alguns tipos de uso do solo (desmatamento, corte de barrancos e disposição inadequada de resíduos sólidos no solo), pode resultar, de acordo com as características locais aliadas à intensidade desta ação, numa grandeza de efeitos adversos, ao que chamamos de vulnerabilidade. Este trabalho segue o conceito de vulnerabilidade descrito pelo Ministério do Meio Ambiente (Brasil, 2007).

A vulnerabilidade natural mostra a predisposição do ambiente frente a fatores ambientais (Grigio, 2008). Já a vulnerabilidade ambiental, segundo Tagliani (2003), é definida como qualquer suscetibilidade de um ambiente a um impacto potencial provocado por um uso antrópico qualquer.

Uma vez que é necessário ampliar a base de informações sobre os distúrbios ocorridos nos ecossistemas, devem-se buscar técnicas e instrumentos que reduzam custos e tempo para identificação de pontos vulneráveis (Carrijo, 2005). O sensoriamento remoto e os Sistemas de Informação Geográfica (SIG) têm sido importantes ferramentas para o monitoramento ambiental, pois elas permitem analisar a dinâmica da cobertura vegetal e do uso do solo e associar essas transformações às condições físicas do meio, aos mecanismos de produção agropecuários e à qualidade de vida das populações locais (Lorena et al., 2001).

Assim, neste trabalho foram criadas as cartas de vulnerabilidade natural e ambiental, a partir de técnicas de geoprocessamento, com a finalidade de promover o planejamento ambiental e ações de gestão territorial adequadas ao município de Ponta Porã.

\section{MATERIAIS E MÉTODO}

\section{1. Área de estudo}

A área de estudo é o município de Ponta Porã, localizado na porção sul do Estado de Mato Grosso do Sul, entre as coordenadas, UTM 591.732/708.400E, 7.607.260/7.481.883N, Fuso 21, datum Córrego Alegre (Figura 1).

A vegetação possui predominância de campos limpos formados por áreas extensas de gramínea e vegetação herbácea constituindo amplas pastagens naturais, com alternância de vegetação arbustiva e arbórea (mata ciliar). Os solos são principalmente Latossolos Vermelhos escuros com predominância de Latossolos Roxos (Maldonado et al., 2009). O 
clima da região, segundo a classificação de Köeppen é do tipo Aw (Mato Grosso do Sul, 2002).

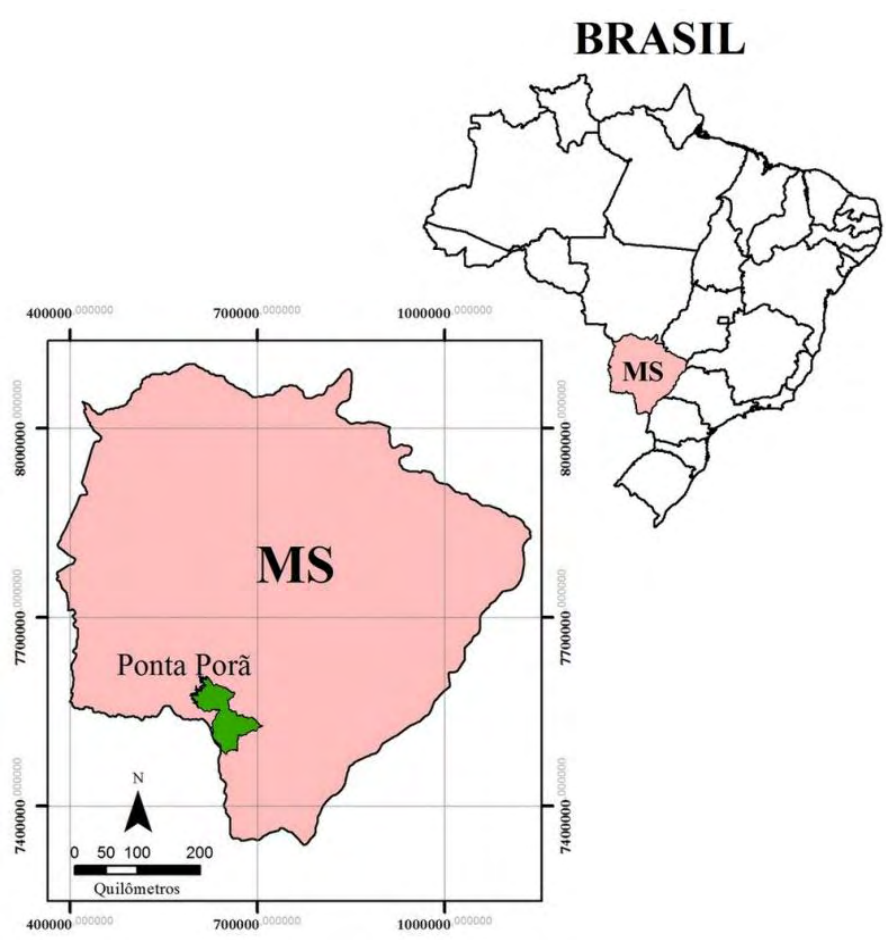

Figura 1. Localização do município de Ponta Porã, Mato Grosso do Sul, Brasil.

\subsection{Metodologia}

A carta de vulnerabilidade natural visa mostrar a predisposição do ambiente frente a fatores ambientais naturais como: geomorfologia; geologia; solos; estabilidade em relação à morfogênese e à pedogênese; e, para o fator vegetação, a estrutura das redes e teias alimentares, o estágio de fitossucessão e a biodiversidade. A carta de vulnerabilidade ambiental refere-se à susceptibilidade do ambiente a pressões antrópicas (Grigio, 2003).

Assim, a metodologia adotada neste trabalho baseou-se naquelas propostas por Grigio (2003) e Carrijo (2005), conforme destacado a seguir:

A) Carta de vulnerabilidade natural:

Atualização dos limites/contatos da carta temática de Geologia dos projetos RADAM (Brasil, 1982), com apoio da fotointerpretação de uma Banda PAN do sensor Landsat 7 ETM+ do ano de 2000.

Utilização do Mapa de Aptidão do Solo do Atlas Multirreferencial do Estado de Mato Grosso do Sul (Mato Grosso do Sul, 1990).

Declividade do município de Ponta Porã, obtida por meio do processamento dos dados altimétricos da SRTM - Shuttle Radar Topography Mission.

B) Carta de vulnerabilidade ambiental:

Cruzamento da vulnerabilidade natural com o mapa de solo de 2006. O mapa de uso do solo de 2006 foi elaborado a partir de classificação automática supervisionada das bandas 1 , 2, 3, 4, 5 e 7 da imagem do sensor Landsat 5-TM do ano de 2006, segundo a legenda do projeto Coordination of Information on the Environment (CORINE), utilizando o programa Erdas Imagine (Erdas Inc., 1997). 


\subsubsection{Elaboração dos mapas temáticos}

\subsubsection{Geologia}

De acordo com Santos et al. (2003), a geologia é um fator pouco abordado em estudos de vulnerabilidade. Dessa forma, neste estudo, utilizou-se o conceito onde a geologia não é considerada apenas substrato de suporte da paisagem, mas também como um dos componentes que interagem com os demais temas.

Os contatos geológicos existentes no projeto RADAM (Brasil, 1982) foram atualizados por meio de fotointerpretação de uma banda pancromática Landsat $\mathrm{ETM}^{+}$de 2006 (Barros et al., 2005), com a utilização do Macromedia FreeHand (Macromedia Inc., 2000). A geologia aflorante na área de estudo é constituída em 19,7\% pela Formação Serra Geral e em 80,3\% pela Formação Ponta Porã (Figura 2).

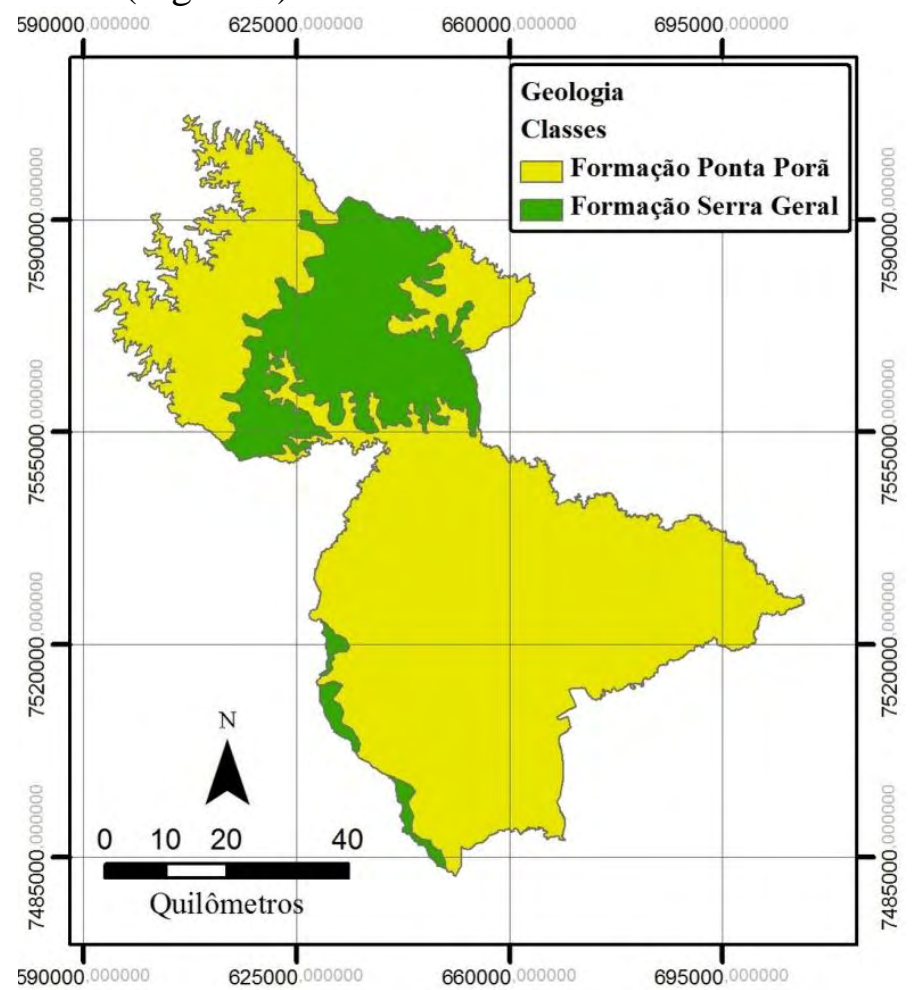

Figura 2. Mapa litológico do município de Ponta Porã.

Na Tabela 1 são observados os valores de vulnerabilidade atribuídos às classes de geologia do município de Ponta Porã.

Tabela 1. Valores de vulnerabilidade da geologia no município de Ponta Porã.

\begin{tabular}{c|c}
\hline Geologia & Valores de vulnerabilidade \\
\hline Serra Geral & 1,5 \\
Ponta Porã & 3,0 \\
\hline
\end{tabular}

\subsubsection{Aptidão dos Solos}

A aptidão agrícola dos solos é um elemento importante para o planejamento criterioso. Esse planejamento determina a capacidade produtiva das terras, por meio da interação entre o tipo de solo e de relevo, para a indicação de áreas aptas para lavouras, pastagens e silvicultura, além de áreas que são desaconselháveis ao processo produtivo. A aptidão agrícola dos solos 
KLAIS, T. B. A.; DALMAS, F. B.; MORAIS, R. P.; ATIQUE, G.; LASTORIA, G.; PARANHOS FILHO, A. C. Vulnerabilidade natural e ambiental do município de Ponta Porã, Mato Grosso do Sul, Brasil. Ambi-Agua, Taubaté, v. 7, n. 2, p. 277-290, 2012. (http://dx.doi.org/10.4136/ambi-agua.786)

foi definida a partir do Mapa de Aptidão dos Solos do Atlas Multirreferencial do Estado de Mato Grosso do Sul (Mato Grosso do Sul, 1990) e pode ser visualizada na Figura 3.

São cinco fatores de limitações que podem dificultar ou até mesmo impedir a utilização das terras: deficiência de fertilidade, deficiência de água, excesso de água ou deficiência de oxigênio, susceptibilidade à erosão, e impedimentos à mecanização. Esses fatores podem atuar de forma integrada ou separadamente e são analisados para se determinar os grupos, as classe de aptidão agrícola, os subgrupos e/ou unidades de mapeamento.

Na Tabela 2 estão descritos as aptidões agrícolas encontradas no município de Ponta Porã e a participação de cada classe na área de Ponta Porã, de acordo com o ZEE do Mato Grosso do Sul (Mato Grosso do Sul, 2002).

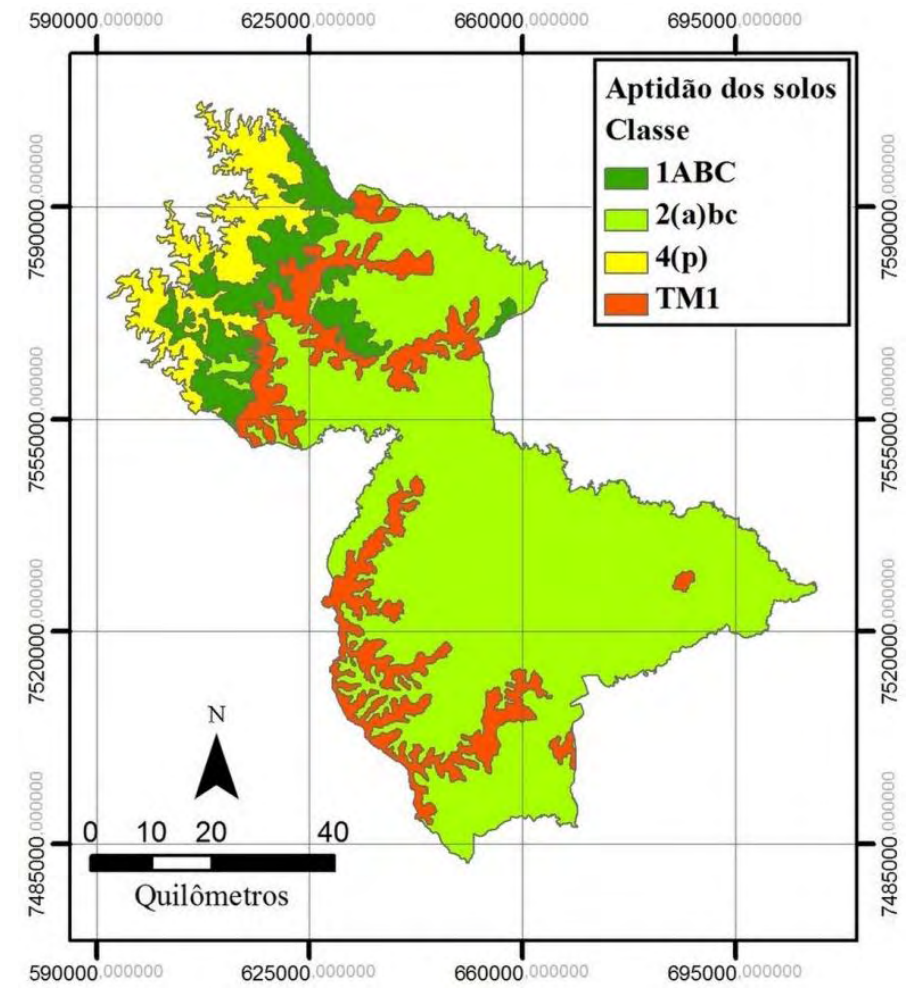

Figura 3. Mapa de aptidão dos solos de Ponta Porã.

Tabela 2. Subgrupos de aptidão agrícola encontrados no município de Ponta Porã.

\begin{tabular}{c|l|c}
\hline CLASSE & \multicolumn{1}{|c}{ DEFINIÇÃO } & ÁREA \\
\hline 1ABC & Aptidão BOA para lavoura, nos níveis de manejo A, B e C. & $8,18 \%$ \\
\hline 2(a)bc & $\begin{array}{l}\text { Aptidão REGULAR para lavouras; RESTRITA no alto nível } \\
\text { tecnológico - A, e para cultivos com lavouras em condições naturais } \\
\text { das terras, nos níveis B e C. }\end{array}$ & $68,80 \%$ \\
\hline TM1 & $\begin{array}{l}\text { Aptidão INTERMEDIÁRIA. A utilização dessas terras requer } \\
\text { pesquisas em lavouras, pastagem adaptadas e silvicultura. A } \\
\text { utilização com pastagem plantada oferece menores riscos. }\end{array}$ & $14,57 \%$ \\
\hline 4(p) & $\begin{array}{l}\text { Aptidão RESTRITA à pastagem plantada. O impedimento ao uso de } \\
\text { implementos agrícolas e a susceptibilidade à erosão são fatores mais } \\
\text { limitantes. }\end{array}$ & $8,45 \%$ \\
\hline
\end{tabular}




\subsubsection{Declividade}

A declividade do município foi obtida por meio do processamento dos dados altimétricos da SRTM (Shuttle Radar Topography Mission). A SRTM fornece arquivos MDE (modelos digitais de elevação), gerados a partir de imagens de radar, com resolução $90 \mathrm{~m}$ (distribuídos gratuitamente na $w e b$ ). A Carta de Declividade foi obtida pela aplicação de um algoritmo para a geração de vetores a partir do programa Geomatica (PCI Geomatics, 2003).

Para a geração da Carta de Declividade (Figura 4) foram empregados os critérios de Nascimento et al. (INCRA, 2006), que estabelecem uma relação entre as formas de relevo e as classes de declividade e define a estabilidade para o relevo do município de Ponta Porã. A partir das classes de relevo e de declividade, considerando a estabilidade dos solos, foram estabelecidos os valores de vulnerabilidade. Foi determinado o valor de vulnerabilidade 1,0 para as áreas com até $5 \%$ de declividade. Para áreas onde o relevo possui de 5 a $29 \%$ de declividade foi adotado o valor 3,0 de vulnerabilidade.

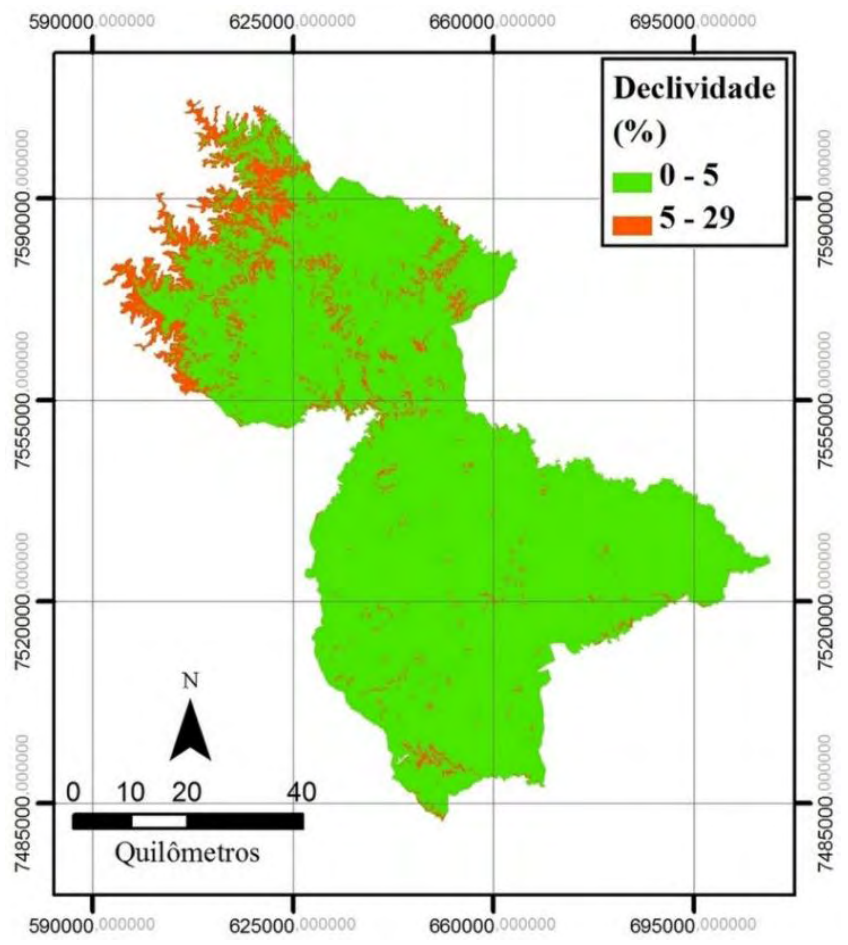

Figura 4. Mapa de declividade de Ponta Porã.

Para estabelecer valores de estabilidade ao se tratar o item declividade, foram empregados primeiramente os níveis utilizados pelo Instituto Nacional de Colonização e Reforma Agrária (INCRA, 2006), descritos na Tabela 3.

Tabela 3. Classes de relevo estabelecidas pelo INCRA.

\begin{tabular}{l|cc}
\hline \multicolumn{1}{c|}{ RELEVO } & \% & Graus \\
\hline Plano & $0-5$ & $0-2,9$ \\
Suave Ondulado & $5-10$ & $2,9-5,7$ \\
Ondulado & $10-15$ & $5,7-8,5$ \\
Muito Ondulado & $15-25$ & $8,5-14$ \\
Forte Ondulado & $25-47$ & $14-25$ \\
Áreas de Uso Restrito & $47-100$ & $25-45$ \\
Áreas de Preservação Permanente & $>100$ & $>45$ \\
\hline
\end{tabular}


Pode-se constatar na Carta de Declividade que o município é composto por $93 \%$ de áreas planas a suave onduladas (entre zero e 5\%); enquanto 7\% vão de ondulado a forte ondulado (entre 5\% e 29\%). A partir destes valores foi estabelecido o peso 1,0 para as áreas plana e suave ondulada; e 3,0 para áreas onde o relevo apresenta-se como ondulado a forte ondulado, portanto potencialmente mais suscetíveis à erosão.

\subsubsection{Uso e Ocupação do Solo}

O uso e ocupação do solo é um parâmetro importante por considerar o fator antrópico como atuante no processo de modelação da paisagem, ao alterar a configuração original da área de estudo. A caracterização do uso do solo no município de Ponta Porã foi elaborada por meio da classificação das bandas 1, 2, 3, 4, 5 e 7 da imagem do sensor Landsat 5-TM do ano de 2006, no programa Erdas Imagine (Erdas Inc., 1997).

Quanto ao uso do solo em Ponta Porã, em 2006, 46\% do território é utilizado para pastagens, $13 \%$ são constituídas por áreas de Cerrado, as áreas de assentamentos, matas e agricultura ocupam igualmente $6 \%$ do território. A área urbana corresponde a $1 \%$ do território, enquanto rios e lagos são responsáveis por 0,06\% (Figura 5).

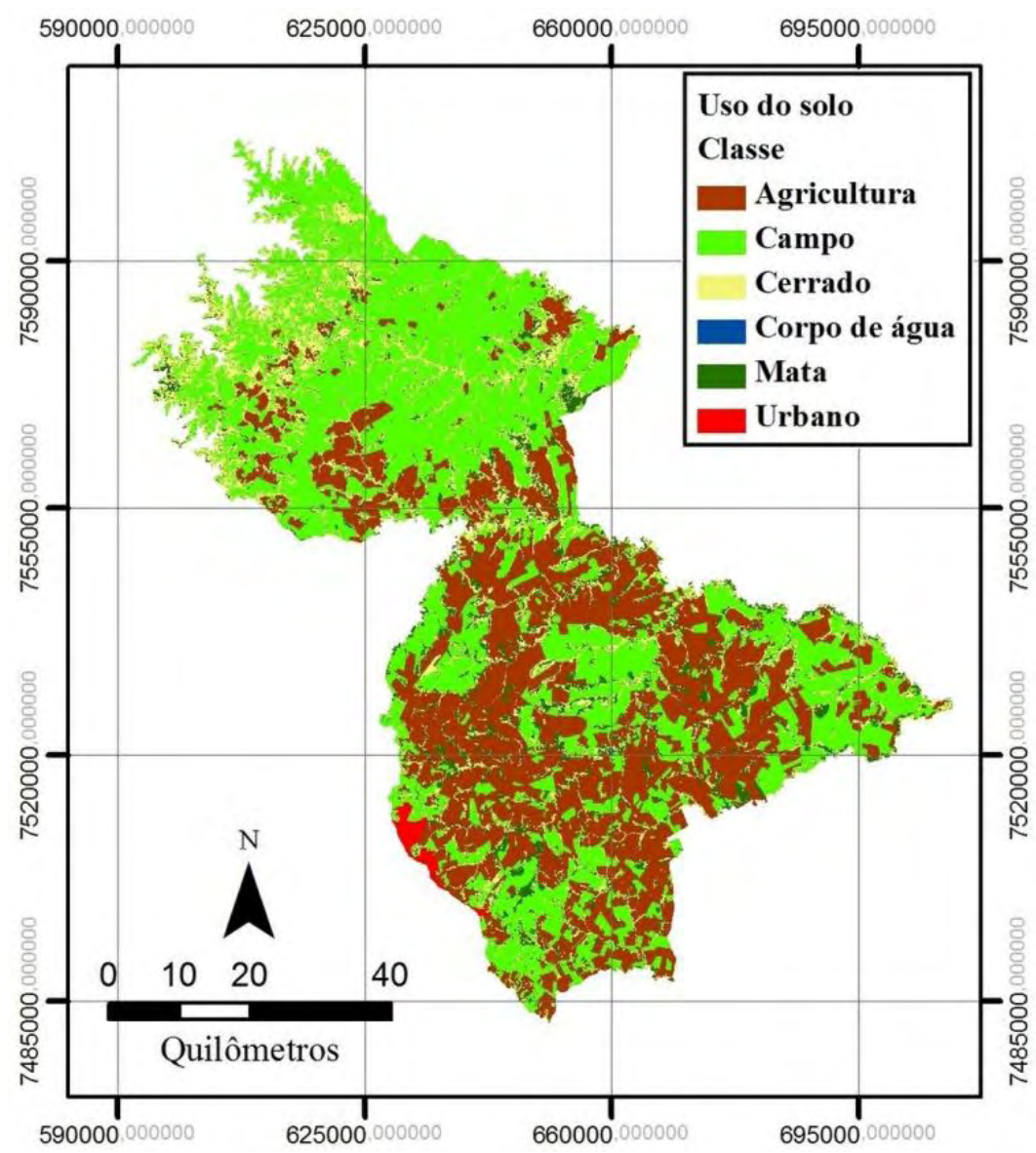

Figura 5. Mapa de uso e ocupação do solo, referente a 2006, do município de Ponta Porã.

Na Tabela 4 estão descritos os tipos de cobertura do solo encontrados no município de Ponta Porã e seus respectivos valores de vulnerabilidades. 
Tabela 4. Valores de vulnerabilidade para os diferentes tipos de cobertura do solo encontrados no município de Ponta Porã.

\begin{tabular}{l|c}
\hline COBERTURA DO SOLO & $\begin{array}{c}\text { VALORES DE } \\
\text { VULNERABILIDADE }\end{array}$ \\
\hline Urbano & 2,5 \\
Pastagem & 2,5 \\
Agricultura & 3,0 \\
Matas & 1,0 \\
Cerrado & 1,5 \\
Corpos de água & 2,0 \\
\hline
\end{tabular}

\subsection{2. Álgebra de mapas}

Para a obtenção dos mapas de vulnerabilidade natural (VN) e vulnerabilidade ambiental (VA) do município de Ponta Porã foi utilizada a álgebra de mapas, que pode ser definida como um conjunto de técnicas para análise da informação geográfica. Esse conjunto inclui a reclassificação, a intersecção (overlay), bem como operações matemáticas entre mapas e as consultas a bancos de dados (Câmara e Daves, 2001).

O Uso da álgebra de mapas é utilizado no cruzamento de atributos bióticos e abióticos para o estudo de vulnerabilidade, não havendo uma metodologia consagrada ou modelos prontos aplicáveis que leve em consideração as particularidades de cada região (Carrijo, 2005).

A VN e VA foram elaboradas conforme a metodologia proposta por Grigio (2003), sendo que a VN é obtida por meio do cruzamento dos mapas temáticos de geologia, aptidão dos solos e declividade. Já a VA é obtida do cruzamento do mapa de VN, com uma carta de uso e ocupação de solo. Tais cruzamentos foram realizados com álgebra de mapas tradicional, no modo tabular (diretamente nas tabelas), com a utilização da extensão Avenza MaPublisher (Avenza Systems Inc., 2001), que proporciona as potencialidades de um SIG ao Macromedia FreeHand (Macromedia Inc., 2000).

\subsubsection{Cruzamento dos Mapas Temáticos}

Optou-se utilizar a metodologia ecodinâmica de Tricart (1997), em que a estabilidade de cada unidade é classificada conforme a Tabela 5.

Tabela 5. Valores de estabilidade de unidades de paisagem.

\begin{tabular}{l|l|c}
\hline UNIDADE & RELAÇÃO PEDOGÊNESE/MORFOGÊNESE & VALOR ADOTADO \\
\hline Estável & Prevalece a pedogênese & 1 \\
Intermediário & Equilíbrio entre pedogênese e morfogênese & 2 \\
Instável & Prevalece a morfogênese & 3 \\
\hline
\end{tabular}

Fonte: (Grigio, 2003).

O grau de vulnerabilidade estipulado para cada classe foi distribuído em uma escala de um a 3,0 com intervalo de 0,5. Para valores próximos a um prevalece à pedogênese; próximos a 2,0 existe um equilíbrio entre a pedogênese e a morfogênese; e próximos a 3,0 prevalece a morfogênese. Esse critério foi utilizado para os mapas de geologia, aptidão dos solos, declividade e uso do solo. 
KLAIS, T. B. A.; DALMAS, F. B.; MORAIS, R. P.; ATIQUE, G.; LASTORIA, G.; PARANHOS FILHO, A. C. Vulnerabilidade natural e ambiental do município de Ponta Porã, Mato Grosso do Sul, Brasil. Ambi-Agua, Taubaté, v. 7, n. 2, p. 277-290, 2012. (http://dx.doi.org/10.4136/ambi-agua.786)

Os pesos atribuídos para cada mapa temático obtido para o município de Ponta Porã podem ser vistos na Tabela 6.

Tabela 6. Pesos atribuídos à vulnerabilidade das classes de cada mapa temático.

\begin{tabular}{c|l|c}
\hline \multicolumn{1}{c|}{ MAPA } & CLASSES & PESO \\
\hline \multirow{2}{*}{ Geologia } & JKsg- Serra Geral & 1,5 \\
& Kb-Grupo Bauru & 3,0 \\
\hline \multirow{3}{*}{ Aptidão do Solo } & $1 \mathrm{ABC}$ & 3,0 \\
& TM1 & 2,0 \\
& $2(\mathrm{a}) \mathrm{bc}$ & 2,0 \\
& $4 \mathrm{p}$ & 1,0 \\
\hline \multirow{2}{*}{ Declividade } & $0-5$ & 1,0 \\
& $5-29$ & 3,0 \\
\hline \multirow{3}{*}{ Uso do solo } & Agricultura & 3,0 \\
& Área Urbana & 2,5 \\
& Pastagem & 2,5 \\
& Rios & 2,0 \\
& Lagoas & 2,0 \\
& Cerrado & 1,5 \\
& Mata & 1,0 \\
\hline
\end{tabular}

Estabelecidos os valores de cada classe nos mapas citados, procedeu-se o cruzamento entre os mesmos, o que resultou na carta de vulnerabilidade natural.

A VN é a média aritmética dos valores de vulnerabilidade de cada classe. O resultado da média aritmética foi distribuído em seis classes, conforme proposto por Grigio (2003):

- Sem classificação (menor ou igual a 0,9 ).

- Muito baixa (de 1,0 a 1,3 de vulnerabilidade).

- Baixa (de 1,4 a 1,7 de vulnerabilidade).

- Média (de 1,8 a 2,2 de vulnerabilidade).

- Alta (de 2,3 a 2,5 de vulnerabilidade).

- Muito alta (maior ou igual a 2,6 de vulnerabilidade).

Para a obtenção da carta de vulnerabilidade ambiental foi aplicado o método de ponderação dos fatores, que permite a compensação entre os fatores analisados por meio de um conjunto de pesos relativos à importância de cada fator. Foram feitos vários cruzamentos com os diferentes pesos compensatórios (Tabela 7). O resultado foi distribuído em seis classes de VA, semelhante às classes utilizadas na carta de vulnerabilidade natural, conforme proposto por Grigio (2003).

Tabela 7. Os diferentes pesos compensatórios utilizados na vulnerabilidade natural e no uso do solo para a obtenção da vulnerabilidade ambiental final.

\begin{tabular}{r|ccc}
\hline \multirow{2}{*}{ Teste } & \multicolumn{3}{|c}{ Fator } \\
\cline { 2 - 4 } & Vulnerabilidade natural & Uso do Solo \\
\hline T1 & $20 \%$ & & $80 \%$ \\
T2 & $30 \%$ & & $70 \%$ \\
T3 & $40 \%$ & & $60 \%$ \\
T4 & $50 \%$ & & $50 \%$ \\
T5 & $60 \%$ & & $40 \%$ \\
T6 & $70 \%$ & Declividade & Uso e Ocupação do Solo \\
\hline T7 & Geologia & Aptidão dos Solos & $60 \%$ \\
& 10\% & $20 \%$ & \\
\hline
\end{tabular}




\section{RESULTADOS}

\subsection{Vulnerabilidade natural (VN)}

$\mathrm{Na}$ região com maior $\mathrm{VN}$ ocorre influência direta pelos maiores valores de vulnerabilidade de declividade. Nesta área a litologia é a Formação Bauru e o solo tem boa aptidão para pastagem (região nordeste do município).

A VN média se concentra onde há a junção da Formação Bauru com a aptidão do solo regular. Nestes lugares já existe uma alta erodibilidade pela geologia presente e a aptidão dos solos tem restrições quanto ao manejo na agricultura.

A vulnerabilidade baixa se concentra onde há a Formação Serra Geral e com aptidão com restrição à agricultura. O município se encontra em sua maioria classificado entre intermediário a estável, considerado equilibrado entre a pedogênese e a morfogênese.

Assim, quanto às classes de VN observadas, foi classificada como média vulnerabilidade $62,8 \%$ da área, baixa em 20,7\%, alta em 12,8\%, e muito alta em 3,7\% (Figura 6). Quanto ao uso e dos solos, $46 \%$ do território é utilizado para pastagens, $13 \%$ são constituídos por áreas de Cerrado, enquanto as áreas de matas e agricultura ocupam igualmente $6 \%$ do território. A área urbana corresponde a $1 \%$ do território, enquanto rios e lagos são responsáveis por $0,06 \%$.

\subsection{Vulnerabilidade ambiental (VA)}

De acordo com a carta de VA, 75,2\% do território (cerca de 400.704 ha) variou de alta a muito alta vulnerabilidade, seguida de média vulnerabilidade em $11,00 \%$, baixa em $13,10 \%$ e muito baixa em $0,7 \%$ (Figura 7). A VA é baixa onde não há ocupação antrópica, como as áreas de matas e lagoas. Já os locais onde a VA é média (sua maior parte), as áreas são ocupadas por pastagem.

Pode-se observar também que a área que está sendo utilizada para a agricultura é encontrada na carta de Aptidão dos Solos com um VA elevado, com algumas restrições para a agricultura. Sugere-se nestes casos um maior cuidado nas práticas de manejo.

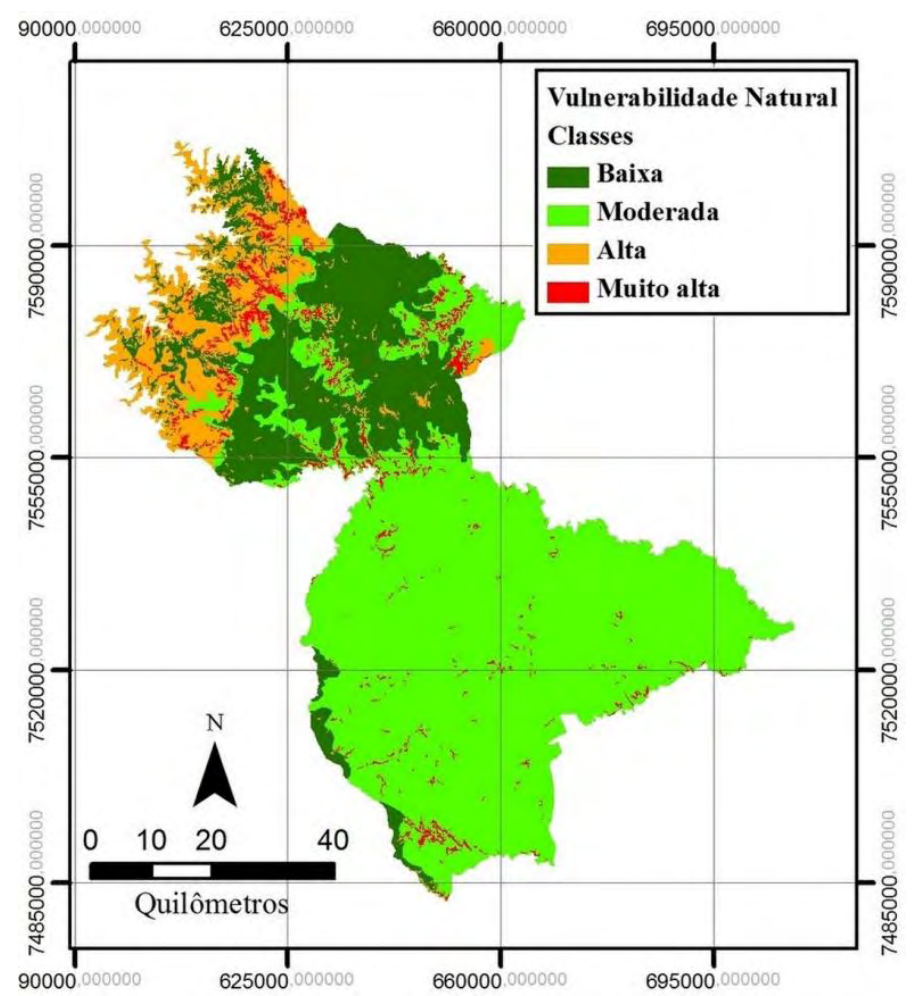

Figura 6. Mapa de VN do município de Ponta Porã. 


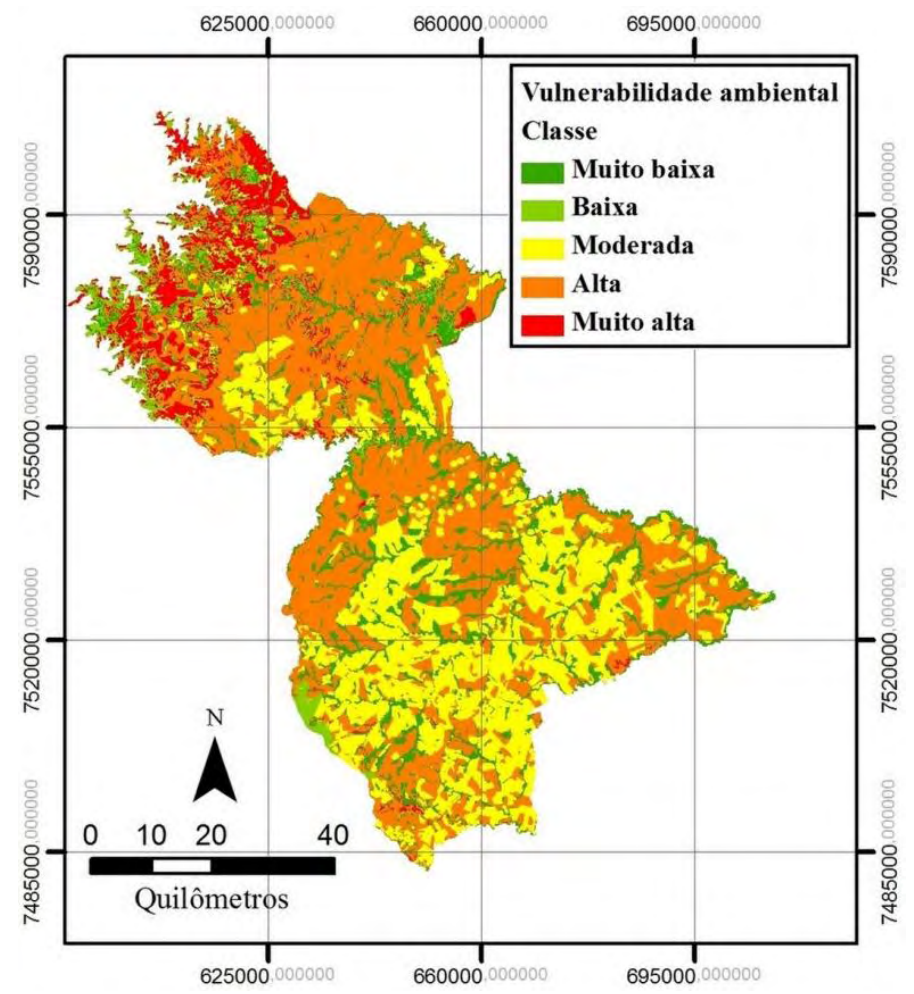

Figura 7. Mapa de VA do município de Ponta Porã.

$\mathrm{Na}$ Tabela 8 é possível visualizar os valores em área e porcentagem relativos às vulnerabilidades natural e ambiental.

Tabela 8. Valores de VA em área (ha) e em porcentagem do município de Ponta Porã.

\begin{tabular}{l|c|c|c|c}
\hline \multirow{2}{*}{ CLASSES } & \multicolumn{2}{|c|}{ VN } & \multicolumn{2}{c}{ VA } \\
\cline { 2 - 5 } & (ha) & \% & (ha) & \% \\
\hline Muito Baixa & - & - & 3730,0 & 0,7 \\
Baixa & 110300,4 & 20,7 & 69803,6 & 13,1 \\
Média & 334631,1 & 62,8 & 58613,7 & 11,0 \\
Alta & 68205,1 & 12,8 & 254170,5 & 47,7 \\
Muito Alta & 19715,5 & 3,7 & 146534,3 & 27,5 \\
\hline
\end{tabular}

\section{DISCUSSÃO}

A vulnerabilidade natural média em $62,8 \%$ da área de estudo pode ser explicada pelo conjunto de características que constituem a própria paisagem. Nessa área grande parte do relevo varia entre suave ondulado a plano, a litologia é a Formação Serra Geral e a aptidão do solo é regular. A VN alta e muito alta ocorre em algumas regiões devido à influência direta dos maiores valores de vulnerabilidade para a declividade. Estes locais são constituídos pela Formação Serra Geral e aptidão dos solos restrita para as pastagens. Essas características em conjunto são responsáveis por mais de $16,5 \%$ do território do município ser naturalmente composto por áreas de alta a muito alta vulnerabilidade. As áreas de $\mathrm{VN}$ média, alta e muito alta estão em locais de alto potencial à erosão pela geologia existente na região, sendo que nessas os solos são naturalmente mais rasos. Além disso, estas áreas apresentam aptidão dos 
solos restrita quanto ao manejo na agricultura. Já nos locais de VN baixa, os solos são mais profundos e garantem maior estabilidade quanto ao seu uso.

Quanto à vulnerabilidade ambiental, os altos valores encontrados são devidos à intensa ocupação do solo, por pastagens e agricultura. A conversão das áreas florestadas, resultado da ação humana, para cultivo de terras, construção de estradas e criação e expansão dos centros urbanos tem ocasionado acentuada modificação na paisagem natural, atingindo, muitas vezes, áreas de grande sensibilidade ambiental (Cemin et al., 2009). Isso corrobora os baixos índices de VA encontrados em locais do município que ainda não foram alterados pelo uso antrópico, como por exemplo, as áreas de matas, cerrados e lagoas.

Além disso, a área que atualmente é utilizada em Ponta Porã para a agricultura é classificada na carta de Aptidão dos Solos com restrições para este fim. Áreas com aptidão dos solos restrita são caracterizadas pelo impedimento quanto ao uso de implementos agrícolas, além de serem locais com alta susceptibilidade à erosão (Mato Grosso do Sul, 1990).

\section{CONCLUSÃO}

O método utilizado na elaboração das cartas de vulnerabilidade apresentou resultados que podem ser utilizados para estudos de planejamento relativos à questão espacial e ambiental de Ponta Porã. A utilização de um Sistema de Informação Geográfica nesse caso foi fundamental, principalmente porque se constitui em uma ferramenta com recursos para a integração de diferentes informações cartográficas, por meio da álgebra de mapas.

A análise da vulnerabilidade natural permitiu verificar que o município encontra-se, em sua maior parte, em situação intermediária a estável. Por outro lado, as áreas de pastagens e agricultura estão inseridas nos locais de maior vulnerabilidade ambiental, principalmente em locais de maior declividade, que representam $7 \%$ da área total do município.

Por fim, as cartas de vulnerabilidade natural e ambiental devem ser empregadas pela administração municipal de Ponta Porã no planejamento do uso e ocupação do solo, visando à regularização do manejo agrícola nas áreas de maior vulnerabilidade.

\section{REFERÊNCIAS}

AVENZA SYSTEMS INC. MaPublisher. Version 4.0. Toronto, 2001. 1CD-ROM.

BARROS, R. S. de; CRUZ, C. B. M.; REIS, R. B.; COSTA JR., N. de A. Avaliação do modelo digital de elevação do SRTM na ortorretificação de imagens Landsat 7 - área de aplicação: Angra dos Reis, RJ. In: SIMPÓSIO BRASILEIRO DE SENSORIAMENTO REMOTO (SBSR), 12., Goiânia, 2005. Proceedings... São José dos Campos: INPE, 2005. p. 3997-4004.

BRASIL. Ministério de Minas e Energia. Projeto RADAMBRASIL. Levantamento de Recursos Naturais, Geologia. Levantamento de recursos naturais, Campo Grande Folha SF 21. Rio de Janeiro, 1982.

BRASIL. Ministério do Meio Ambiente. Vulnerabilidade ambiental: desastres naturais ou fenômenos induzidos? Brasília, 2007. 192 p.

CÂMARA, G.; DAVES, C. Arquitetura de sistemas de informação geográfica. In: CÂMARA, G.; DAVIS, C.; MONTEIRO, A. M. V. (Org.). Introdução à ciência da geoinformação. São José dos Campos: INPE, 2001. p. 42 - 76. 
CARRIJO, M. G. G. Vulnerabilidade ambiental: o caso do Parque Estadual das Nascentes do Rio Taquari. 2005. Dissertação (Mestrado em Saneamento Ambiental e Recursos Hídricos) - Programa de Pós-Graduação em Tecnologias Ambientais, Universidade Federal do Mato Grosso do Sul, Campo Grande, 2005.

CEMIN, G.; PERICO, E.; REMPEL, C. Composição e configuração da paisagem da subbacia do arroio jacaré, Vale do Taquari, RS, com ênfase nas áreas de florestas. Revista Árvore, Viçosa, MG, v. 33, n. 4, p. 705-711, 2009. http://dx.doi.org/10.1590/S010067622009000400013

ERDAS INC. Erdas Imagine. Version 8.3.1. Atlanta, 1997. 1 CD ROM.

GRIGIO, A. M. Aplicação do sensoriamento remoto e sistemas de informação geográfica na determinação da vulnerabilidade natural e ambiental do município de Guaramé (RN): simulação de risco às atividades da indústria petrolífera. 2003. 230f. Dissertação (Mestrado em Geodinâmica) - Programa de Pós-Graduação em Geodinâmica e Geofísica, Universidade Federa do Rio Grande do Norte, Natal, 2003.

GRIGIO, A. M. Evolução da paisagem do baixo custo do Rio Piranhas-Assu (1988-2024): Uso de autômatos celulares em modelo dinâmico espacial para simulação de cenários futuros. 2008. 205f. Tese (Doutorado em Geodinâmica) - Programa de Pós-Graduação em Geodinâmica e Geofísica, Universidade Federal do Rio Grande do Norte, Natal, 2008 .

INSTITUTO NACIONAL DE COLONIZAÇÃO E REFORMA AGRÁRIA - INCRA (Brasil). Manual de obtenção de terras e perícia judicial: módulo II - levantamento de dados e informações de imóveis rurais. 2006. Disponível em: <http://www.incra.gov.br/index.php/servicos/publicacoes/manuais-eprocedimentos/file/652-manual-de-obtencao>. Acesso em: 11 jun. 2012.

LORENA, R. B.; SANTOS, J. R.; SHIMABUKURO, Y. E.; SANT'ANNA, H. M.; SANT'ANNA, H. S. S.; MENEZES, R. S. Dados multitemporais de sensoriamento remoto para análise da dinâmica do solo e da cobertura da terra na região do Peixoto (AC). In: SIMPÓSIO BRASILEIRO DE SENSORIAMENTO REMOTO, 10., 2001, FOZ DO IGUAÇU. Proceedings... São José dos Campos: INPE, 2001. p. 1653-1656.

MACROMEDIA INC. FreeHand. Version 9. Hackensack, 2000. 1 CD ROM.

MALDONADO, F. D.; SESTINI, M. F.; VALlES, G. F.; SANTOS, C. P. F. Detecção de mudanças com técnica de Rotação Radiométrica, RCEN, inovações para uma abordagem prática usando SPRING. In: SIMPÓSIO BRASILEIRO DE SENSORIAMENTO REMOTO, 14., 2009, Natal. Proceedings... São José dos Campos: INPE, 2009. p. 1433-1440.

MATO GROSSO DO SUL. Secretaria de Planejamento e Coordenação Geral. Atlas multirreferencial do Estado do Mato Grosso do Sul. Campo Grande: Governo Estadual; Fundação IBGE, 1990.

MATO GROSSO DO SUL. Zoneamento ecológico-econômico do Mato Grosso do Sul: contribuições técnicas, teóricas, jurídicas e metodológicas. Campo Grande, 2002. Vol. 1. $128 \mathrm{p}$. 
KLAIS, T. B. A.; DALMAS, F. B.; MORAIS, R. P.; ATIQUE, G.; LASTORIA, G.; PARANHOS FILHO, A. C. Vulnerabilidade natural e ambiental do município de Ponta Porã, Mato Grosso do Sul, Brasil. Ambi-Agua, Taubaté, v. 7, n. 2, p. 277-290, 2012. (http://dx.doi.org/10.4136/ambi-agua.786)

PARANHOS FILHO, A. C.; LASTORIA, G.; TORRES, T. G. Sensoriamento remoto ambiental aplicado: introdução as geotecnologias. Campo Grande: Editora UFMS, 2008. 198 p.

PCI GEOMATICS. Geomatica. Versão 9.1 for Windows. Toronto, 2003. 1 CD-ROM.

SANTOS, R. F.; ABDON, M. M.; SILVA, J. S. V.; POTT, A. A construção de cenários e a mudança temporal da cobertura vegetal na Bacia Hidrográfica do Rio Taquari (MS/MT). In: CONGRESSO DE ECOLOGIA DO BRASIL, 6., 2003, Fortaleza. Anais... Fortaleza: SEB, 2003.

TAGLIANI, C. R. A. Técnica para avaliação da vulnerabilidade ambiental de ambientes costeiros utilizando um sistema geográfico de informação. In: SEMINÁRIO BRASILEIRO DE SENSORIAMENTO REMOTO, 11., 2003, Belo Horizonte. Anais... São José dos Campos: INPE, 2003. p. 1657-1664.

TRICART, J. Ecodinâmica. Rio de Janeiro: SUPREN/IBGE, 1977. 91p. 